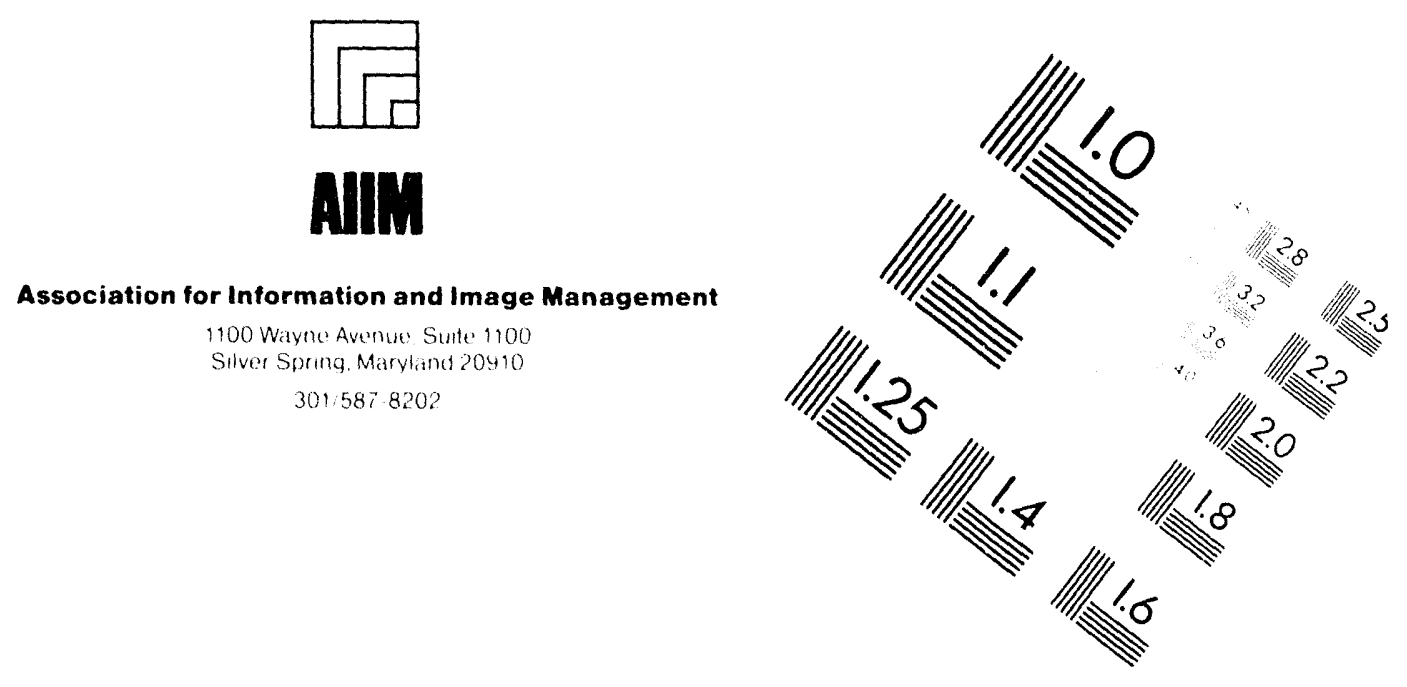

Centimeter

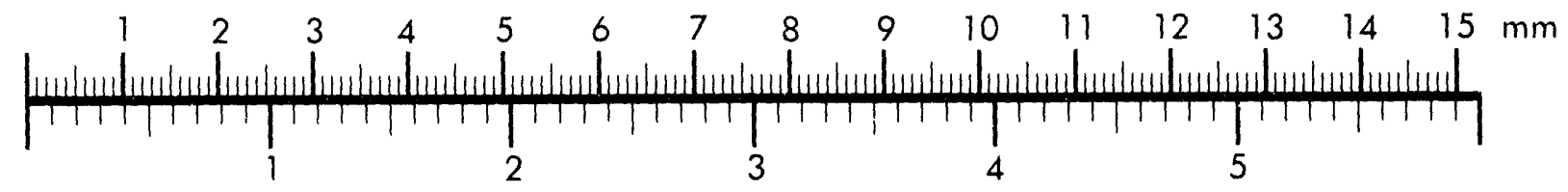
Inches
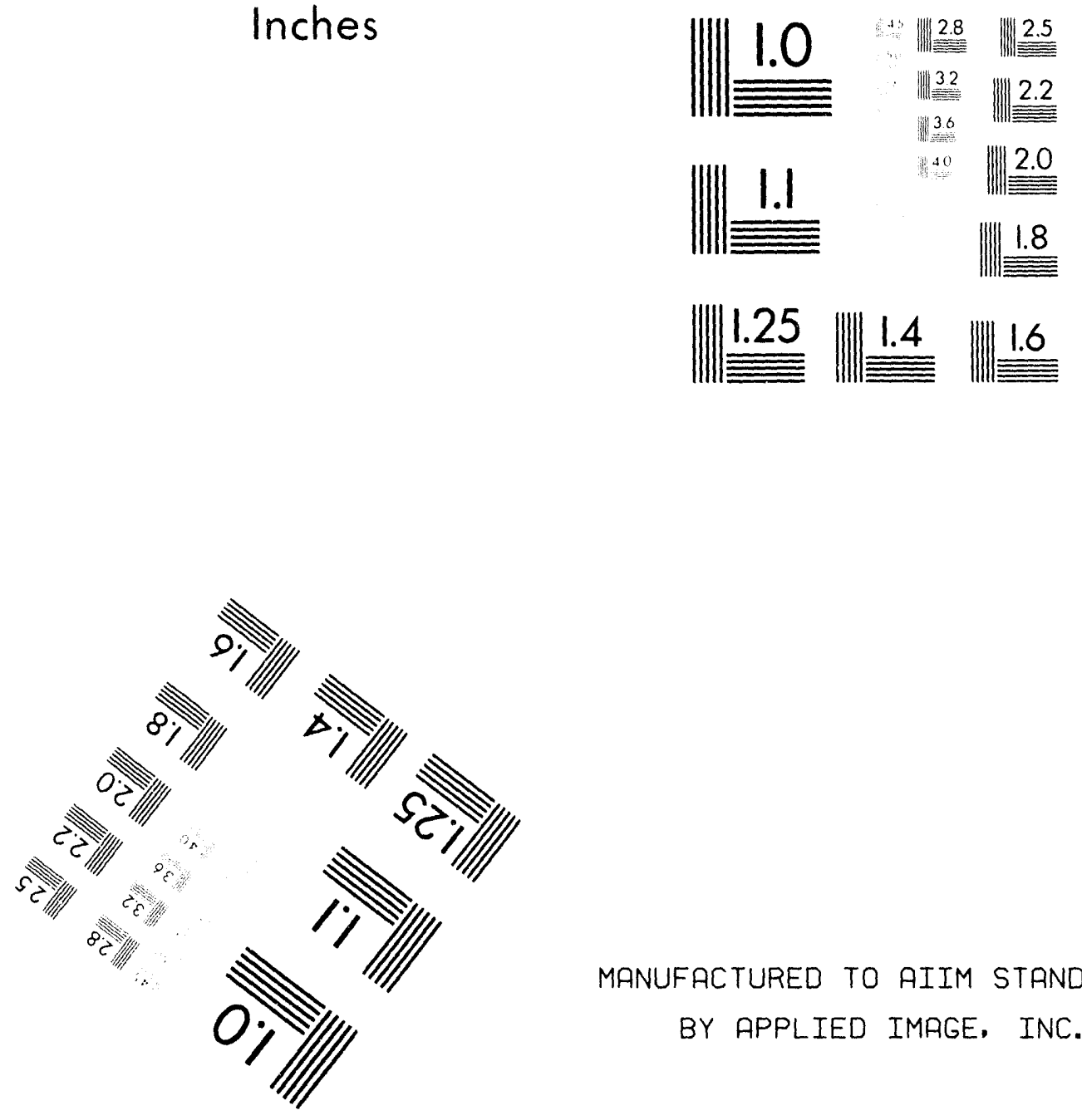

MANUFACTURED TO AIIM STANDARDS BY APPLIED IMAGE, INC.

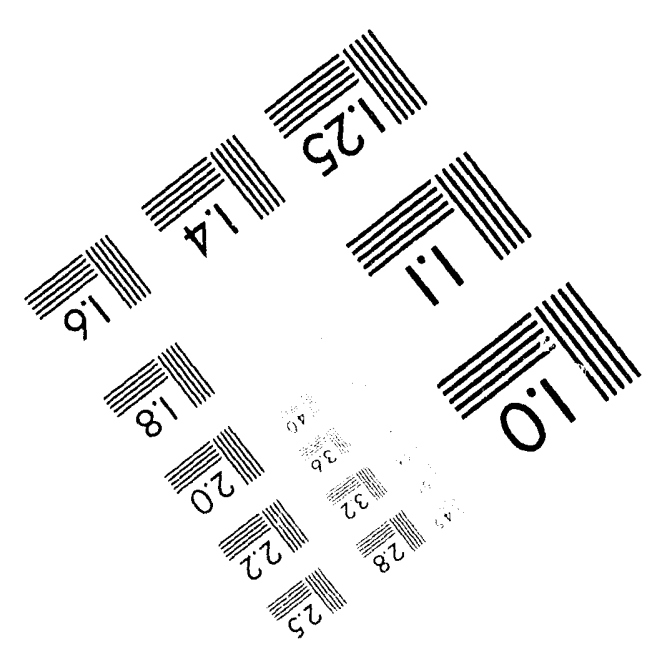



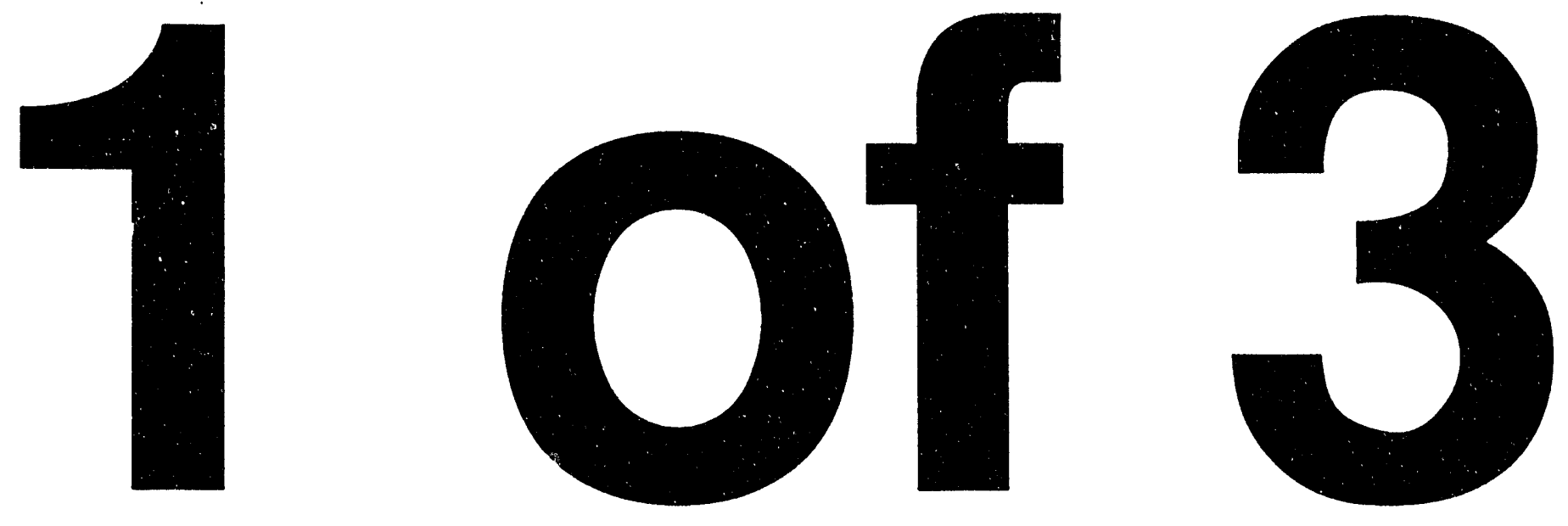

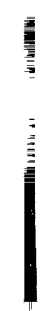


SAND94-(0308

Distribution

TTC-1294

Category UC-722

Unlimited Release

Printed May 1994

\title{
Impact Testing of the H1224A Shipping/Storage Container
}

\author{
D. C. Harding, J. G. Bobbe, D. R. Stenberg, and M. Arr'iso \\ Transportation Systems Technology and Development Departments 6642 and 6643 \\ Sandia National Laboratories ${ }^{* *}$ \\ Albuquerque, NM 87185
}

\begin{abstract}
H1224A weapons containers have been used for years by the Departments of Energy and Defense to transport and store W78 warhead midsections. Although designed to protect these midsections only in low-energy handling drop and impact accidents, a recent transportation risk assessment effort has identified a need to evaluate the container's ability to protect weapons in higher-energy environments. Four impact tests were performed on H1224A containers with W78 Mod $6 \mathrm{c}$ mass mockup midsections inside, onto an essentially unyielding target. Dynamic acceleration and strain levels were recorded during the side-on and end-on impacts, each at $12.2 \mathrm{~m} / \mathrm{s}$ (40 $\mathrm{ft} / \mathrm{s})$ and $38.1 \mathrm{~m} / \mathrm{s}(125 \mathrm{ft} / \mathrm{s})$. Measured peak accelerations experienced by the midsections during lower velocity impacts ranged from 250 to $600 \mathrm{Gs}$ for the end-on impact and 350 to 600 Gs for the side-on impact. Measured peak accelerations of the midsections during the higher velocity impacts ranged from 3,000 to 10,000 Gs for the end-on impact and 8,000 to 10,000 Gs for the sideon impact. Deformations in the H1224A container ranged from minimal to severe buckling and weld tearing. At higher impact velocities, the H1224A container may not provide significant energy absorption for the re-entry vehicle midsection but can provide some confinement of potentially damaged components.
\end{abstract}

* This work was performed at Sandia National Laboratories, Albuquerque, New Mexico, and sponsored by the Defense Nuclear Agency under DNA MIPR \#93-837 Work Unit \#()(165.

** A U.S. Department of Energy Facility

1 


\section{Acknowledgments}

Thanks to J. Calderone and L. A. Abeyta (2761) for test support. W. L. Uncapher (6642) and M. Hankinson (6642) provided data aquisition and reduction support, and Glenn Hohnstreiter (6642) provided management support throughout this investigation. Program management was provided by P. E. D’Antonio (12324), C. G. Shirley (12333) and J. D. Pierce (6642). C. L. Carrington (7432) assisted with security issues. Thanks also to D. J. Ammerman (6642) and P. E. McConnell (6643) for their draft document review. 


\section{Table of Contents}

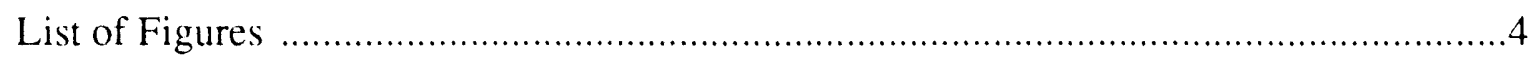

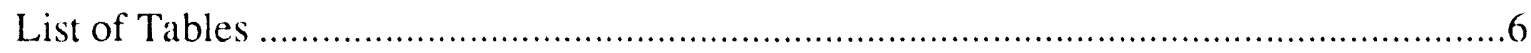

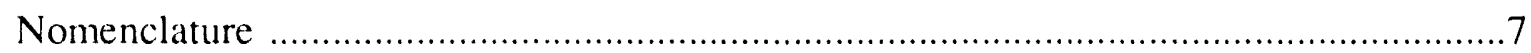

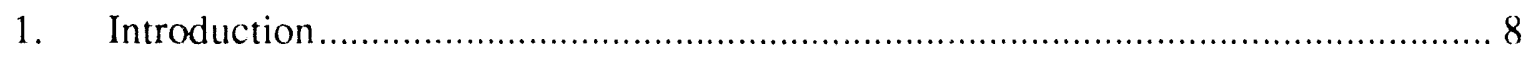

2. Impact Test Parameters .................................................................................. 10

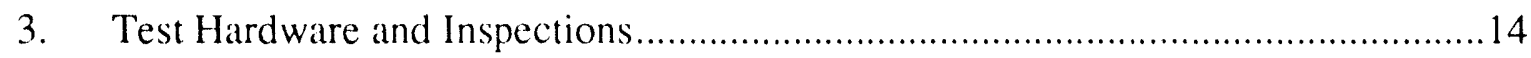

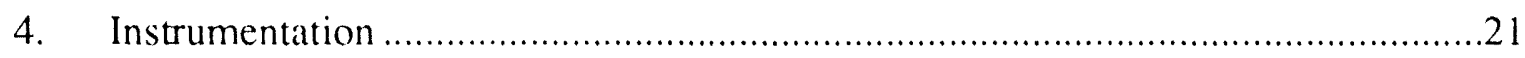

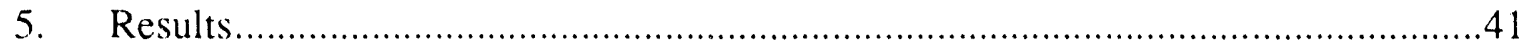

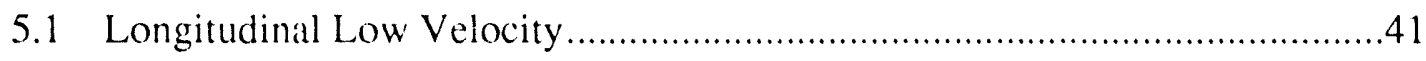

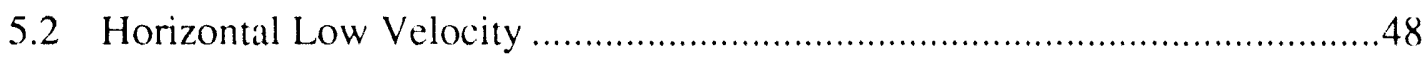

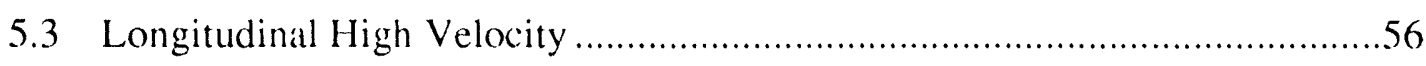

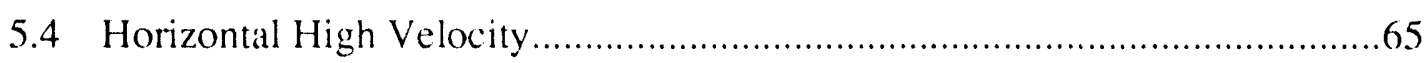

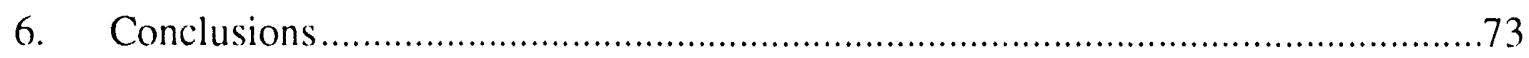

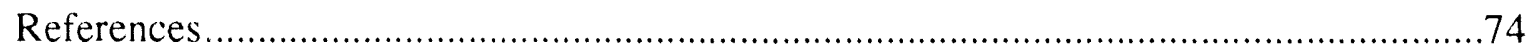

Appendix A. LLV Accelerometer and Strain Gage Data: Raw, Filtered, and Reduced...76 Appendix B. HLV Accelerometer and Strain Gage Data: Raw, Filtered, and Reduced 109 Appendix C. LHV Accelerometer and Strain Gage Data: Raw, Filtered, and Reduced 139 Appendix D. HHV Accelerometer and Strain Gage Data: Raw, Filtered, and Reduced 172

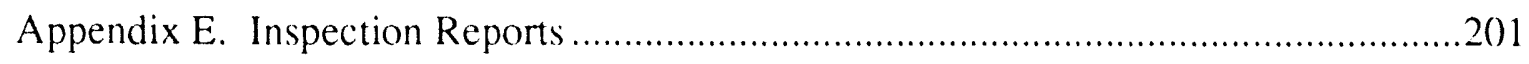

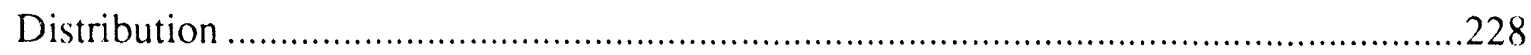




\section{List of Figures}

1.1 W78 midsection inside H1224A shipping/storage container..........................

$2.1 \quad$ Longitudinal (end-on) container impact test set-up ..................................11

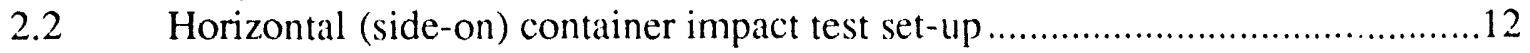

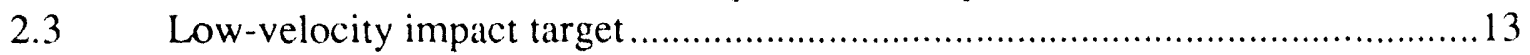

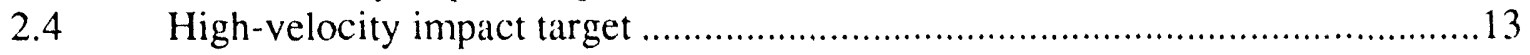

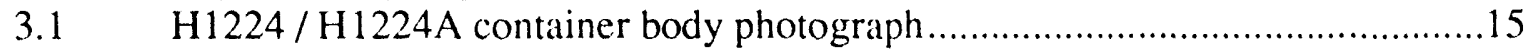

3.2 H1224A lower flexible foam insert and plywood load spreader .....................16

3.3 RV midsection with threaded fore plate and aft cover ................................16

3.4 RV midsection inside inner container and foam and H1224A outer shell .........17

3.5 Mk12a Mod6c schematic with internal weight plates ...................................17

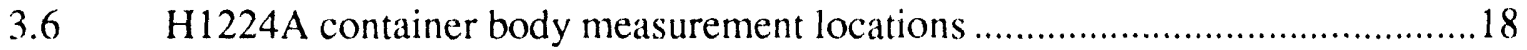

3.7 H1224A inner container measurement locations ...........................................19

3.8 Mk12A midsection and fore and aft cover measurement locations...................20

4.1 Strain gage locations for longitudinal impact tests .......................................23

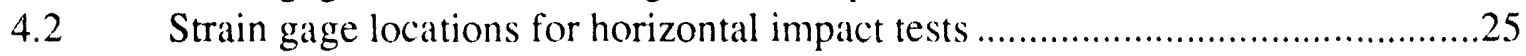

4.3 Accelerometer locations for longitudinal impact tests.................................27

4.4 Accelerometer locations for horizontal impact tests ..................................30

4.5 LLV mounting locations for A1, A2, S1, S15, S16, and terminal strips ............33

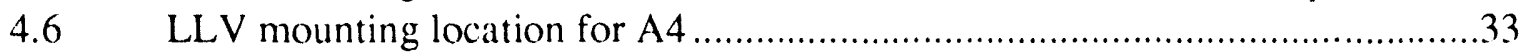

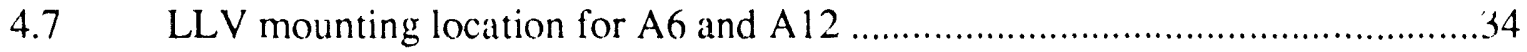

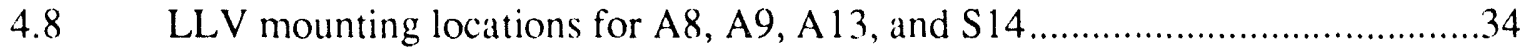

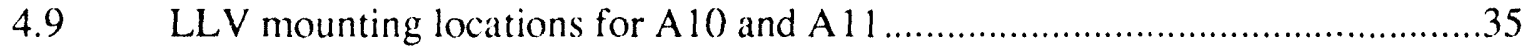

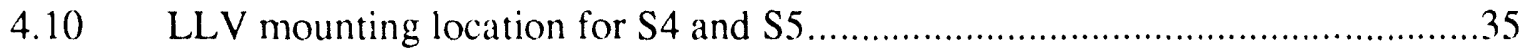

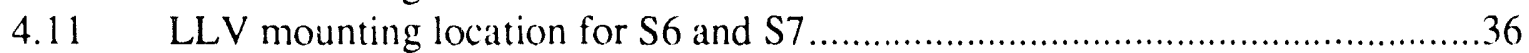

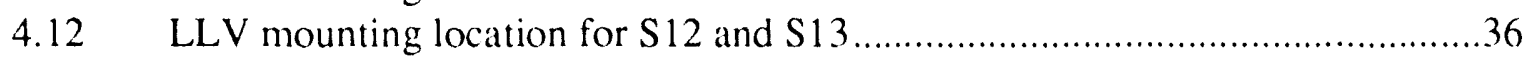

4.13 HLV mounting locations for A1, A2, A3, and some terminal strips ..................37

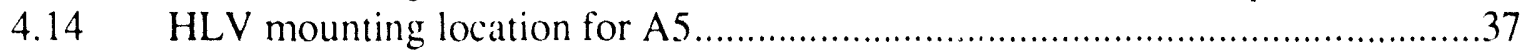

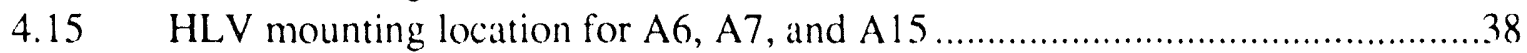

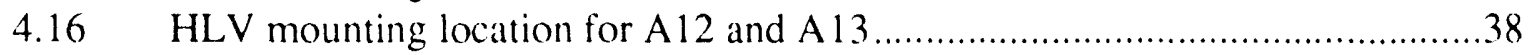

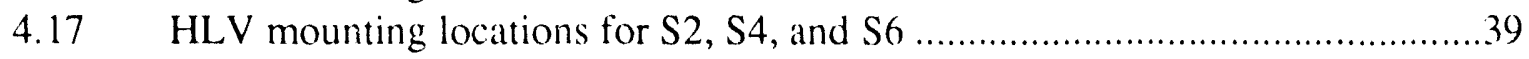

4.18 HLV mounting location for more terminal strips .......................................40

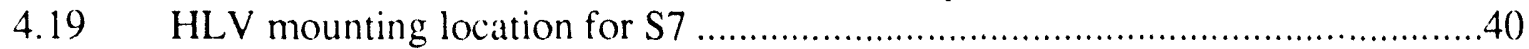

5.1.1 LLV impact test pre-drop...............................................................42

5.1.2 LLV H1224A post-test deformation .....................................................43

5.1 .3 LLV H1224A weld crack....................................................................44

5.1.4 LLV upper foam insert joint separation .................................................45

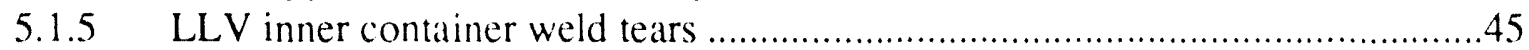

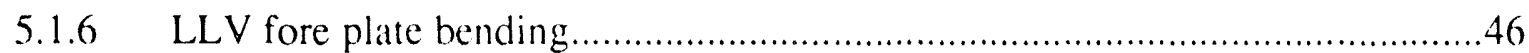

5.1.7 LLV H1224A bottom pan deformatior. ................................................46

5.1.8 LLV fore plate (nose end, RV) accelerations ...........................................47

5.1.9 LLV aft cover (tail end, RV) accele ations...........................................47 


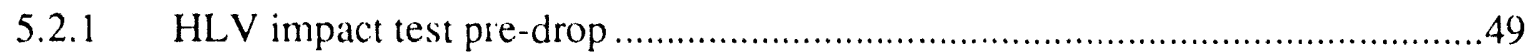

5.2.2 HLV H1224A top-end post-test deformation .................................................50

5.2.3 HLV H1224A bottom-end post-test deformation .........................................51

5.2.4 HLV inner container bending ................................................................52

5.2.5 HLV H1224A outer shell mid-body bending ............................................52

5.2.6a HLV Mk12a Mod6c cracking .......................................................................53

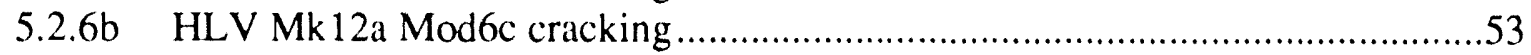

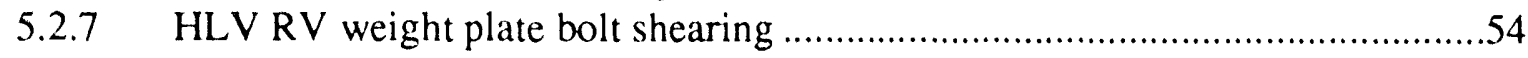

5.2.8 HLV aft cover (tail end, RV) accelerations ( $2 \mathrm{kHz}$ filter) ..............................55

5.2.9 HLV fore plate (nose end, RV) accelerations ( $2 \mathrm{kHz}$ filter) ............................55

5.3.1 LHV impact test pre-drop .........................................................................57

5.3.2a LHV H1224A post-test deformation ..........................................................58

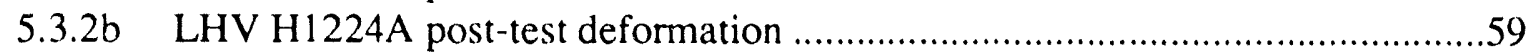

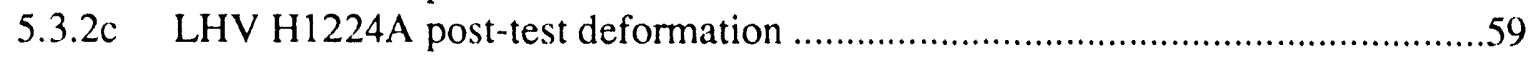

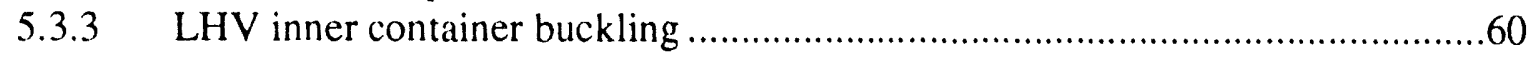

5.3.4 LHV aft cover below top level of inner container .......................................60

5.3.5 LHV Mk12a Mod6c aeroshell fracture and weight plate detachment ...............61

5.3.6 LHV RV carbon phenolic aeroshell fracture ...............................................62

5.3.7 LHV RV aeroshell nose-end fracture and impact onto accelerometers..............63

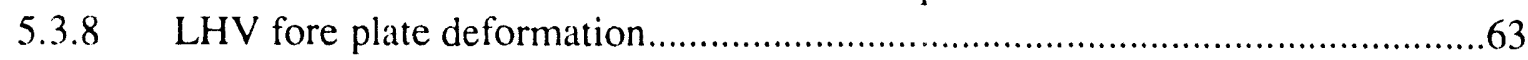

5.3.9 LHV fore plate (nose end, RV) accelerations ..........................................64

5.3.10 LHV aft cover (tail end, RV) accelerations ..............................................64

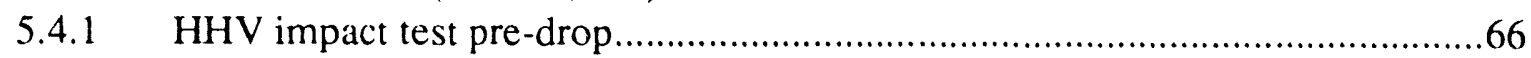

5.4.2a HHV H1224A post-test deformation ..........................................................67

$5.4 .2 \mathrm{~b}$ HHV H1224A post-test deformation ..........................................................67

$5.4 .2 \mathrm{c}$ HHV H1224A post-test deformation ........................................................68

5.4.3 HHV fore plate deformation and bolt shearing...........................................69

5.4.4 HHV inner container and aft cover deformation ........................................69

5.4.5 HHV H1224A outer shell deformation ........................................................70

5.4.6 HHV Mk12a Mod6c aeroshell fracture and detached weight plates ...................70

5.4.7 HHV RV carbon phenolic aeroshell fracture ...............................................71

5.4.8 HHV fore plate (nose end, RV) accelerations ...........................................72

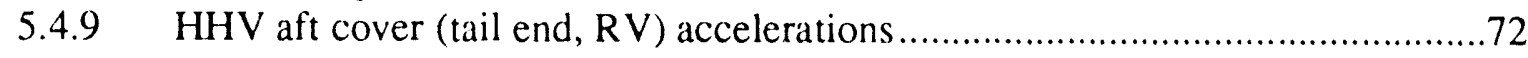




\section{List of Tables}

2.1 Test Matrix for H1224A Impact Testing ……..............................................

4.1 Longitudinal Impact Instrumentation Requirements--Strain Gages ...................24

4.2 Horizontal Impact Instrumentation Requirements--Strain Gages.....................26

4.3a Longitudinal $40 \mathrm{ft} / \mathrm{s}$ Impact Instrumentation Requirements--Accelerometers ....28

$4.3 \mathrm{~b} \quad$ Longitudinal $125 \mathrm{ft} / \mathrm{sImpact}$ Instrumentation Requirements-Accelerometers ..29

4.4a Horizontal $40 \mathrm{ft} / \mathrm{sImpact}$ Instrumentation Requirements--Accelerometers.........31

4.4b Horizontal $125 \mathrm{ft} / \mathrm{sImpact}$ Instrumentation Requirements--Accelerometers .......32

E 1.1 LLV H1224A Container Body Inspection Data ...........................................201

E 1.2 LLV Inner Container Inspection Data ....................................................205

E 1.3 LLV RV, Fore, and Aft Cover Inspection Data..........................................206

E 2.1 HLV H1224A Container Body Inspection Data ..........................................207

E 2.2 HLV Inner Container Inspection Data .....................................................211

E 2.3 HLV RV, Fore, and Aft Cover Inspection Data ..........................................212

E 3.1 LHV H1224A Container Body Inspection Data ...........................................214

E 3.2 LHV Inner Container Inspection Data ........................................................217

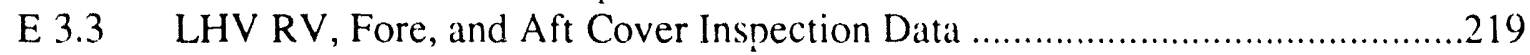

E 4.1 HHV H1224A Container Body Inspection Data ........................................220

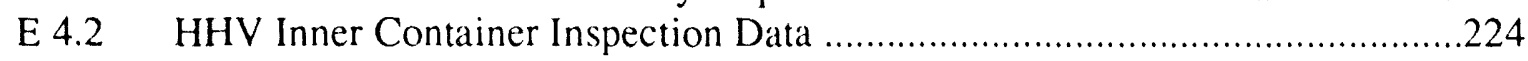

E 4.3 HHV RV, Fore, and Aft Cover Inspection Data ...........................................225 


\section{Nomenclature}

LLV Longitudinal Low-Velocity impact test

HLV Horizontal Low-Velocity impact test

LHV Longitudinal High-Velocity impact test

HHV Horizontal High-Velocity impact test

RV Re-entry Vehicle midsection mass mock-up

WR War Reserve

STS Stockpile-to-Target Sequence

$\mathrm{G}$ Acceleration of Gravity

ms milliseconds

m Mass

V Velocity 


\section{Impact Testing of the H1224A Shipping/Storage Container}

\section{Introduction}

Based on the results of recent Congressional and Department of Defense studies [1-3], the Defense Nuclear Agency (DNA) has commenced a program to assess the safety of the Minuteman III/W78/W87 weapon system in the form of a probabilistic risk assessment. The Minuteman III Weapon System Safety Assessment (WSSA) requires determination of the potential physical environments surrounding the W78 and W87 re-entry vehicles caused by credible accidents during air and ground transportation. Impact testing of the H1224A storage/shipping container is necessary to quantify the impact mitigation provided by the structure and determine boundary conditions for analytical modelling of weapon response during potential C-141 aircraft and ground transportation accident scenarios associated with the W78's Stockpile-to-Target Sequence (STS) [4].

The aluminum H1224A storage/shipping container is approximately $1.4 \mathrm{~m} \mathrm{(54} \mathrm{in.)} \mathrm{high} \mathrm{and}$ $0.82 \mathrm{~m}$ (33 in.) in diameter with a flexible polyurethane foam lining for cushioning (see Figure 1.1). The H1223B consists of an internal container and fore and aft threaded covers for the re-entry vehicle (RV) midsection. The H1224A container's original design intent was to protect W78 RV midsections from relatively light loadings associated with vibrations during shipping and handling, as well as providing protection against weather during storage. Previous testing of H1224A containers encompassed only vibration and minor handling drops [5-14]. Although not designed to provide significant RV impact mitigation during higher-speed accidents, the WSSA requires quantification of load levels during extreme accident conditions. Specifically, Weidlinger Associates (a contractor to DNA for this study) required RV and H1224A container acceleration histories during four different impact conditions to validate analytical predictions they were tasked to perform.

A series of four container impact tests (two impact orientations, each at low and high velocities) onto an essentially unyielding surface have been conducted to determine warhead midsection loadings during postulated severe accident conditions and to validate finite element model predictions. Accelerometers, strain gages, and photometric instrumentation were used to record container deformations and loads transmitted to the container and re-entry vehicle during impact testing. Computer modelling will be used to predict weapon response throughout the range of accident conditions, including impact, puncture, and crush environments.

Test results are described in terms of measured container and RV deceleration histories for each of the four impact tests and subsequent structural deformations. Raw and reduced acceleration and strain data are included with deformation measurements in the appendices. 


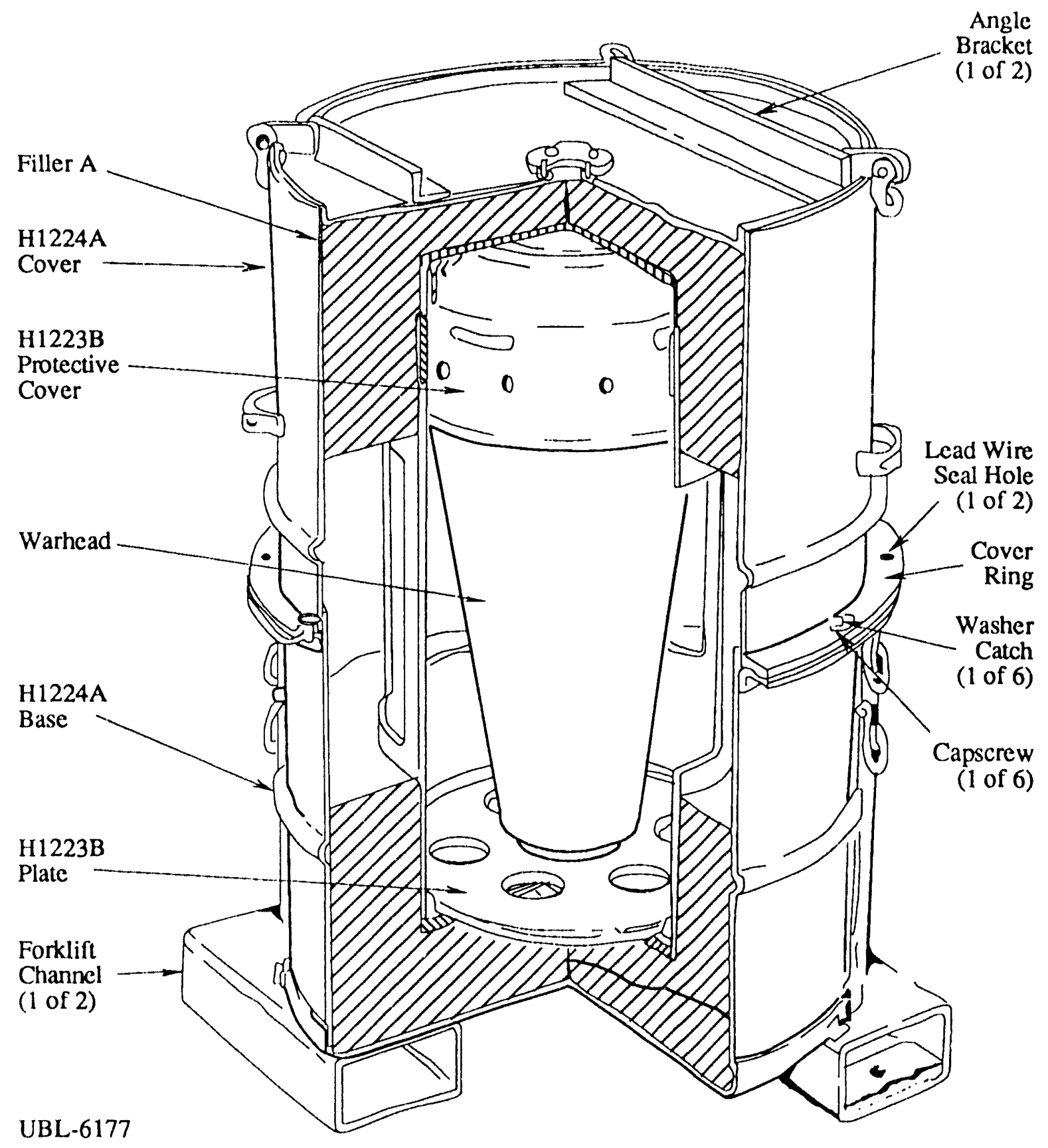

Figure 1.1 W78 midsection inside H1224A shipping/storage container 


\section{Impact Test Parameters}

Impact test velocities were determined jointly with Weidlinger Associates (Los Altos, California), to encompass a wide range of impact energies and validate analytical model predictions. Impacts at $12.2 \mathrm{~m} / \mathrm{s}(40 \mathrm{ft} / \mathrm{s})$ and $38.1 \mathrm{~m} / \mathrm{s}(125 \mathrm{ft} / \mathrm{s})$ in both end-on and side-on orientations onto an essentially unyielding target were selected. To ensure flat impacts in these two orientations, two parallel cables were used to guide the container to a point just above the target surface, where the container was released to continue freely toward impact, as shown schematically in Figures 2.1 and 2.2. The four impact tests are outlined below in Table 2.1.

\section{Table 2.1 Test Matrix for H1224A Impact Testing}

$\begin{array}{cccc}\text { Test } & \text { Container Orientation } & \text { Impact Velocity } & \text { Drop Height } \\ 1 & \text { Longitudinal (end-on) (LLV) } & 12.2 \mathrm{~m} / \mathrm{s}(40 \mathrm{ft} / \mathrm{s}) & 8.2 \mathrm{~m}(27 \mathrm{ft}) \\ 2 & \text { Horizontal (side-on) (HLV) } & 12.2 \mathrm{~m} / \mathrm{s}(40 \mathrm{ft} / \mathrm{s}) & 7.9 \mathrm{~m}(26 \mathrm{ft}) \\ 3 & \text { Longitudinal (end-on) (LHV) } & 38.1 \mathrm{~m} / \mathrm{s}(125 \mathrm{ft} / \mathrm{s}) & 86 \mathrm{~m}(283 \mathrm{ft}) \\ 4 & \text { Horizontal (side-on) (HHV) } & 38.1 \mathrm{~m} / \mathrm{s}(125 \mathrm{ft} / \mathrm{s}) & 88 \mathrm{~m}(288 \mathrm{ft})\end{array}$

Two different targets were used to conduct container impact tests, each essentially unyielding. The two lower-velocity drop tests were conducted at the 185 - $\mathrm{ft}$ drop tower of Sandia National Laboratories, consisting of a steel plate grouted to two concrete blocks, as shown in Figure 2.3. The steel is $91 \mathrm{~cm} \times 244 \mathrm{~cm} \times 13 \mathrm{~cm}$ ( $3 \mathrm{ft} \times 8 \mathrm{ft} \times 5 \mathrm{in})$ and provides the smooth target surface. The bottom concrete block is $168 \mathrm{~cm} \times 332 \mathrm{~cm} \times 61 \mathrm{~cm}(5.5 \mathrm{ft} \times 11 \mathrm{ft} \times 2 \mathrm{ft})$ of 5000$) \mathrm{lb} / \mathrm{in}^{2}$ reinforced concrete. The top concrete block is the same material but only $30.5 \mathrm{~cm}(12 \mathrm{in})$ thick. The overall mass of the target is over $10,000 \mathrm{~kg}(22,000 \mathrm{lb})$.

The two higher-velocity drop tests were conducted at Sandia's Aerial Cable Facility in Co:ote Test Field, consisting of a $1520 \mathrm{~m}(5000 \mathrm{ft})$ long wire rope suspended across a mountain canyon. The target consists of $910,000 \mathrm{~kg}(2,000,000 \mathrm{lb})$ of reinforced concrete and steel, partially resting on bedrock. A battleship armor plate $3 \mathrm{~m} \times 8.5 \mathrm{~m}$ and $10 \mathrm{~cm}$ to $20 \mathrm{~cm}$ thick is welded to the concrete reinforcing members and coupled to the concrete by a high-strength grout. The dimensions and construction of this target are shown in Figure 2.4. 


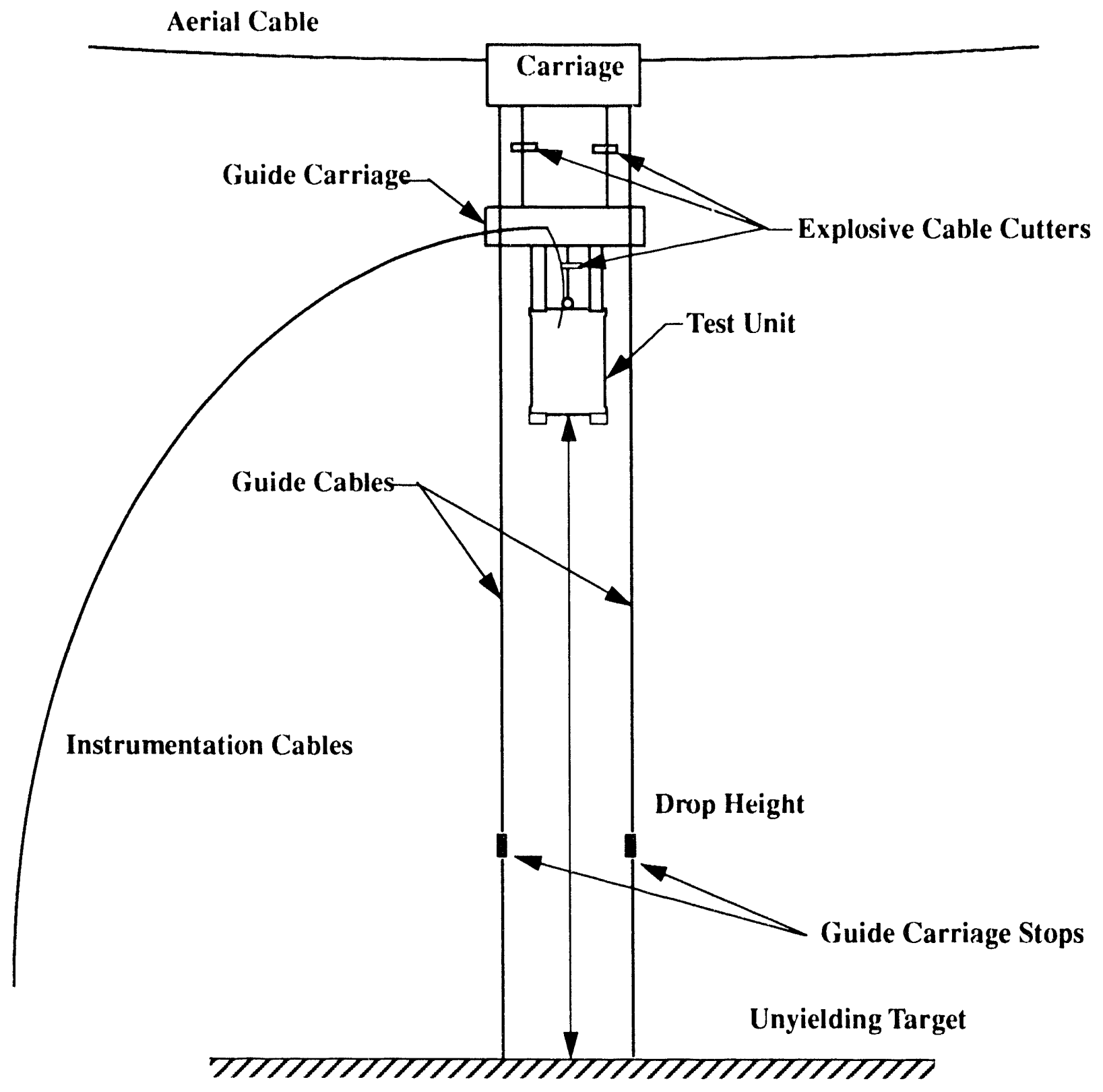

Figure 2.1 Longitudinal (end-on) container impact test set-up 


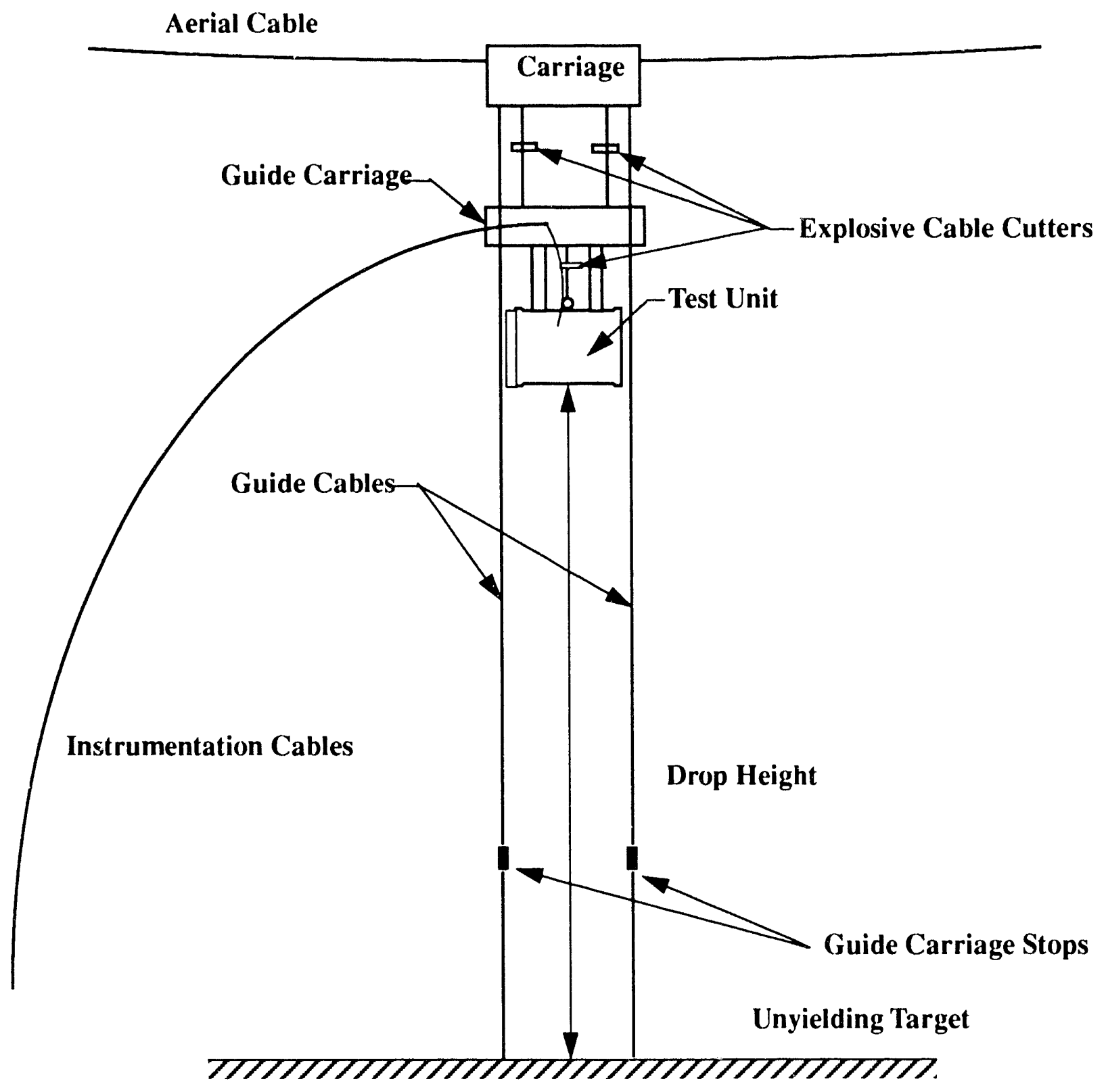

Figure 2.2 Horizontal (side-on) container impact test set-up 


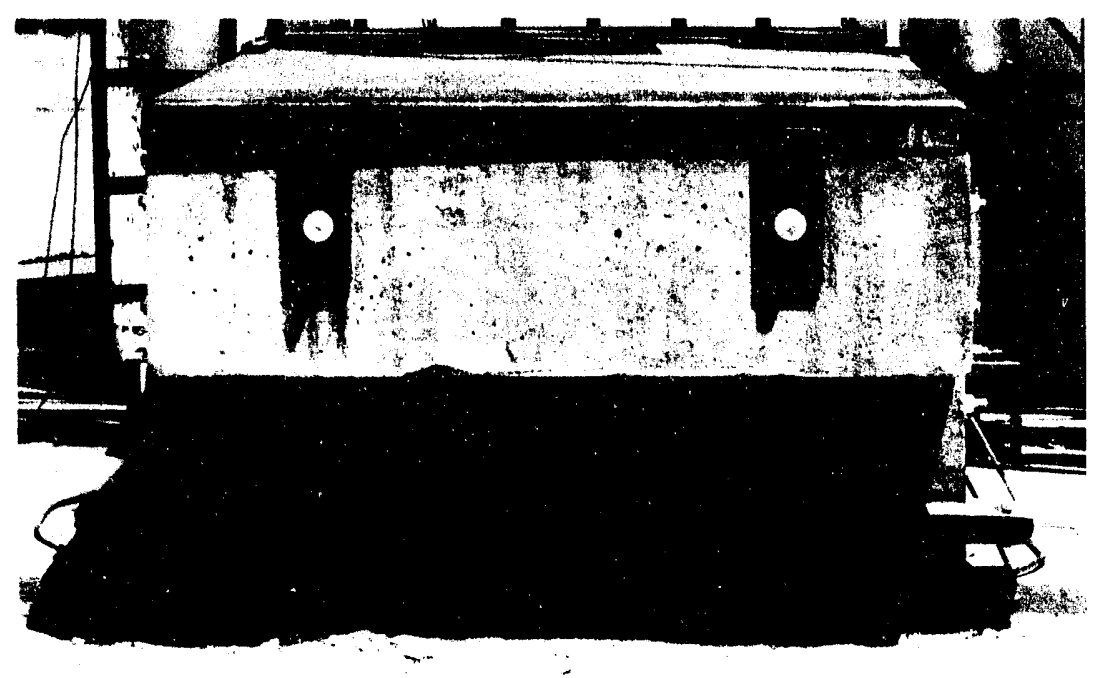

Figure 2.3 Low-velocity impact target

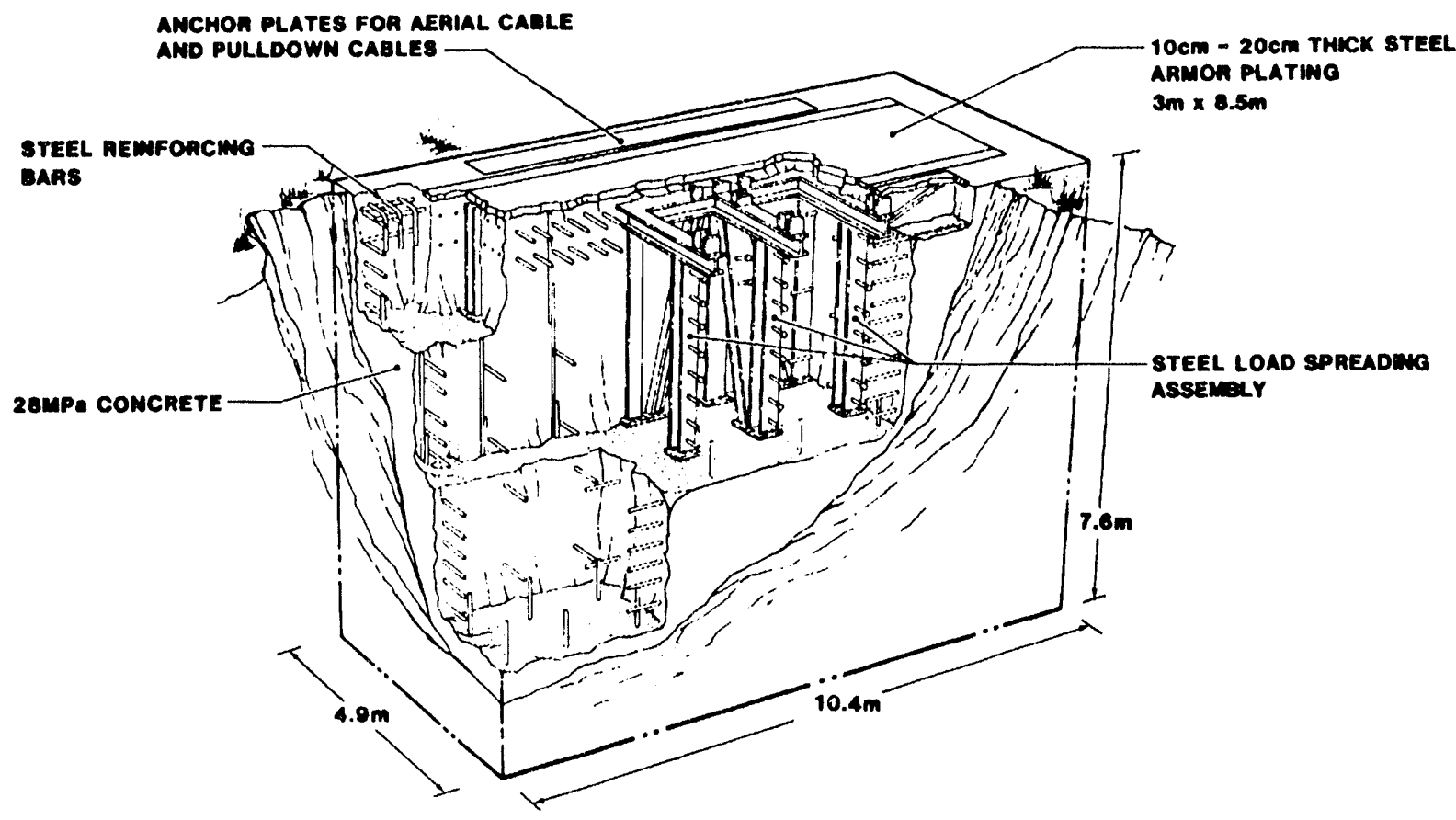

Figure 2.4 High-velocity impact target 


\section{Test Hardware and Inspections}

The H1224A shipping/storage container basically consists of a $2.3 \mathrm{~mm}(0.091 \mathrm{in}$.) thick 6061-T4 aluminum cylindrical outer shell approximately $1.4 \mathrm{~m}$ (54 in.) high and $0.82 \mathrm{~m}(33 \mathrm{in}$.) in diameter with a flexible polyurethane foam lining for RV cushioning [15] (see Figures 1.1 and 3.1). Fork lift channels are welded to the base for ease of handling. Its weight is approximately $145 \mathrm{~kg}(320 \mathrm{lb})$ without the RV inside. Flexible polyurethane foam vibration and light shock isolation is provided by the approximately $0.12 \mathrm{~m}$ (4.8 in.) thick General Plastics Last-a-Foam TF5070 inserts, which can deform and "bounce back" elastically.

The H1224A's cylindrical outer container shell is assembled in two halves, the base and the cover, by tightening bolts around a thin steel flange at the mid-body level. A thin silicone rubber gasket provides a light weather seal between the base and cover outer shell sections. Filler $A$ and filler B denote the upper and lower foam inserts, the lower of which is $20 \mathrm{~mm}(0.8 \mathrm{in}$.) thicker than the upper. A $3.2 \mathrm{~mm}$ (0.125 in.) thick cylindrical aluminum inner container assembly holds the RV midsection and assists with load spreading to the flexible foam inserts. The inner container assembly includes a $3.2 \mathrm{~mm}(0.125 \mathrm{in}$.) aluminum bottom plate welded circumferentially to the cylinder, but is open at the top end for insertion of the RV midsection and has open cut-outs or windows for heat dissipation along its mid plane longitudinally. A $19 \mathrm{~mm}(0.75 \mathrm{in}$.) thick plywood load spreader rests between the lower foam insert and the inner container assembly (see Figure $3.2)$.

The $\mathrm{H} 1223 \mathrm{~B}$ is an assembly which includes the RV midsection aft protective cover and fore (nose end) plate (with necessary threaded rings and bolts). The $13 \mathrm{~mm}(0.5 \mathrm{in}$.) 6064-T6 aluminum fore plate is threaded into the nose of the RV midsection acting as a load spreader and a balance. The aft protective cover is $7 \mathrm{~mm}(0.28 \mathrm{in}$.) thick forged $6061-\mathrm{T} 6$ aluminum and threads onto the aft end of the RV midsection protecting critical components, as shown in Figure 3.3 and partially assembled into the container in Figure 3.4.

The H1224A container is actually a modification to the original H1224 container designed for the W62 warhead midsection. Most parts internal to the outer container shell are different, but the only outer container shell difference is the addition of four tie-down loops (just below the original H1224 loops) and $9.5 \times 76 \times 178 \mathrm{~mm}(0.375 \times 3 \times 7$ in.) reinforcements inside the ends and at the bottom of the aluminum forklift channels. For impact testing purposes, therefore, H1224 container outer shells are essentially identical to H1224A outer shells and were used interchangeably in these tests due to limited availability of the newer H1224A outer shells for testing. Most of the test units arrived at Sandia with a number of small dents, which were "hammered out" in order to better replicate the performance of actual WR (war reserve) dent-free units.

The W78 warhead midsection was simulated using a Mk12a Mod6c midsection. The aeroshell/heatshield consists of an approximately $13 \mathrm{~mm}(0.5 \mathrm{in}$.) carbon fiber reinforced phenolic over a thin aluminum substrate. A series of fore and aft weighted plates simulate the mass properties of a W78 physics package, bolted to the aeroshell at points shown in Figure 3.5. 


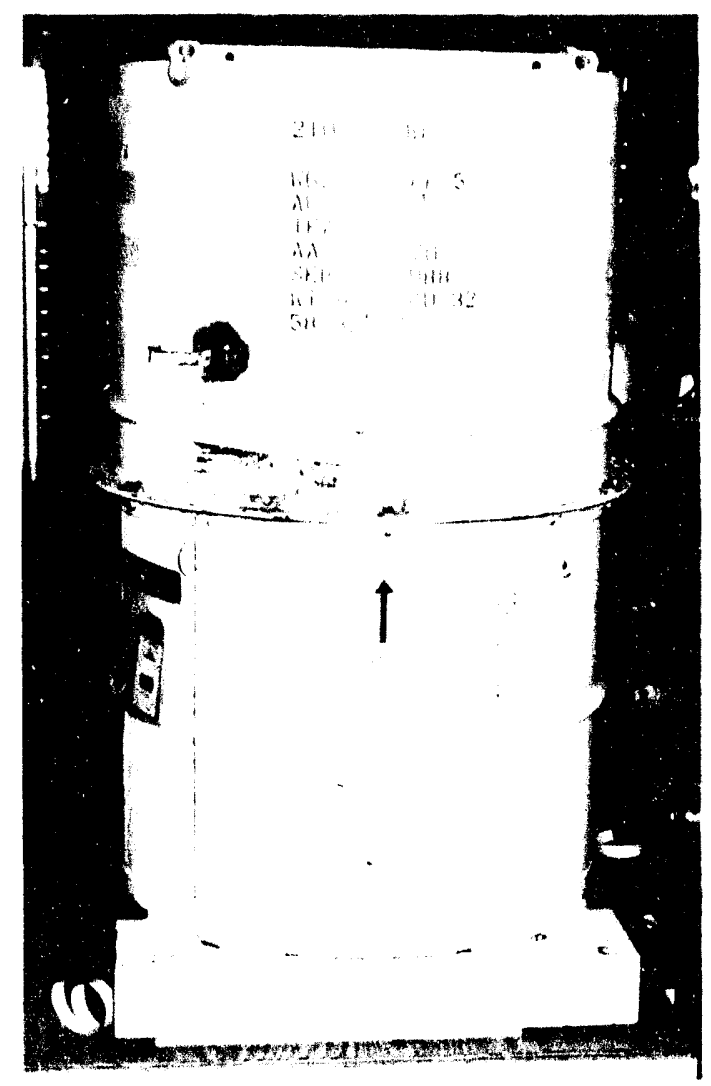

Figure 3.1 H1224/ H1224A container body photograph

Quantification of H1224A deformations resulting from impact tests was performed using detailed pre- and post-test measurements. On the outer container shell, length and diametral measurements were recorded at locations indicated in Figure 3.6, at each $45^{\circ}$ angular increment. Deformations in the internal container assembly were recorded as lengths and diameters at locations indicated in Figure 3.7, at each $60^{\circ}$ angular increment. And finally, deformations of the carbon phenolic aeroshell, fore end plate, and aft cover were recorded as pre- and post-test lengths, outer diameters, and inner diameters as indicated in Figure 3.8, at each $60^{\circ}$ angular increment. 


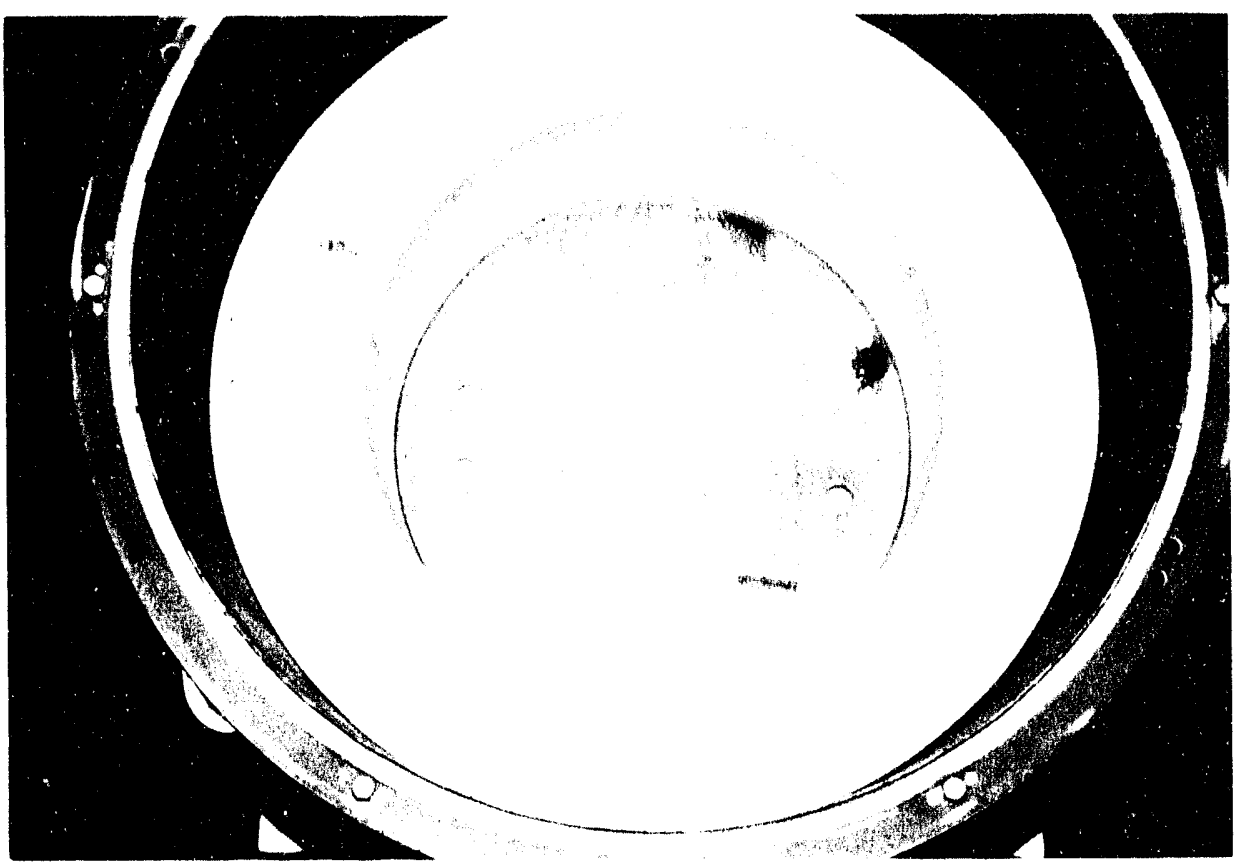

Figure 3.2 H1224A lower flexible foam insert and plywood load spreader

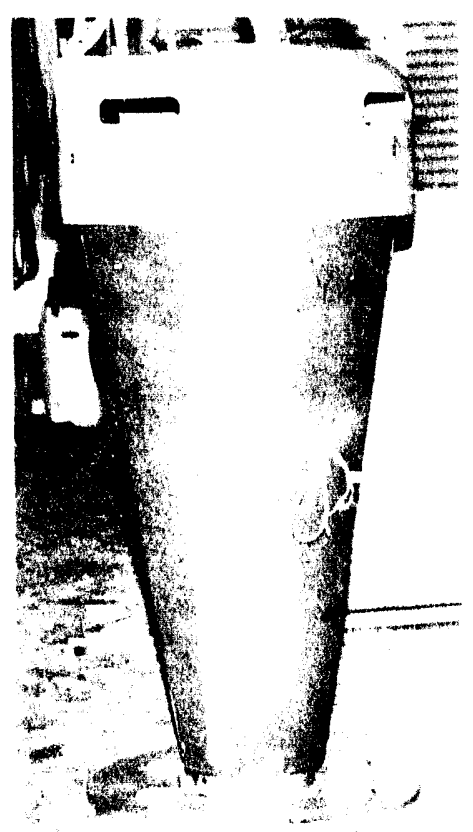

Figure 3.3 RV midsection with threaded fore plate and aft cover 


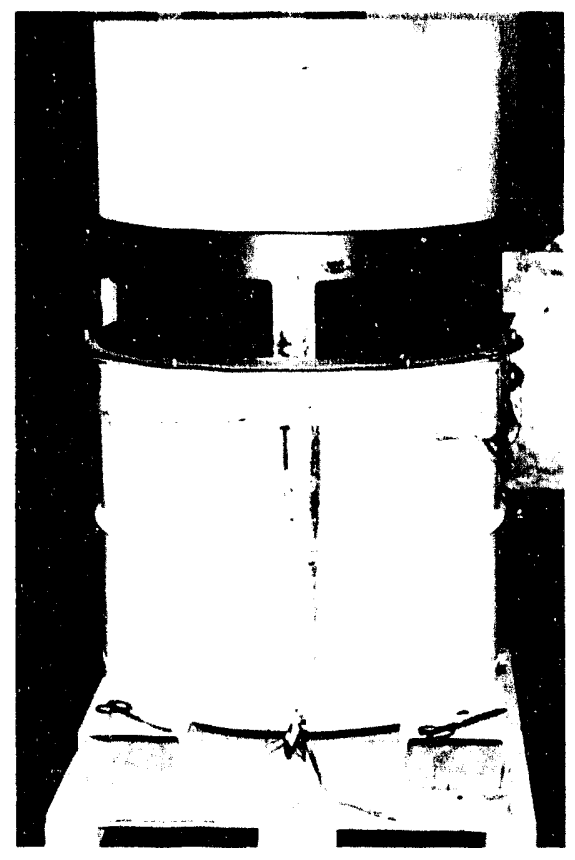

Figure 3.4 RV midsection inside inner container and foam and H1224A outer shell

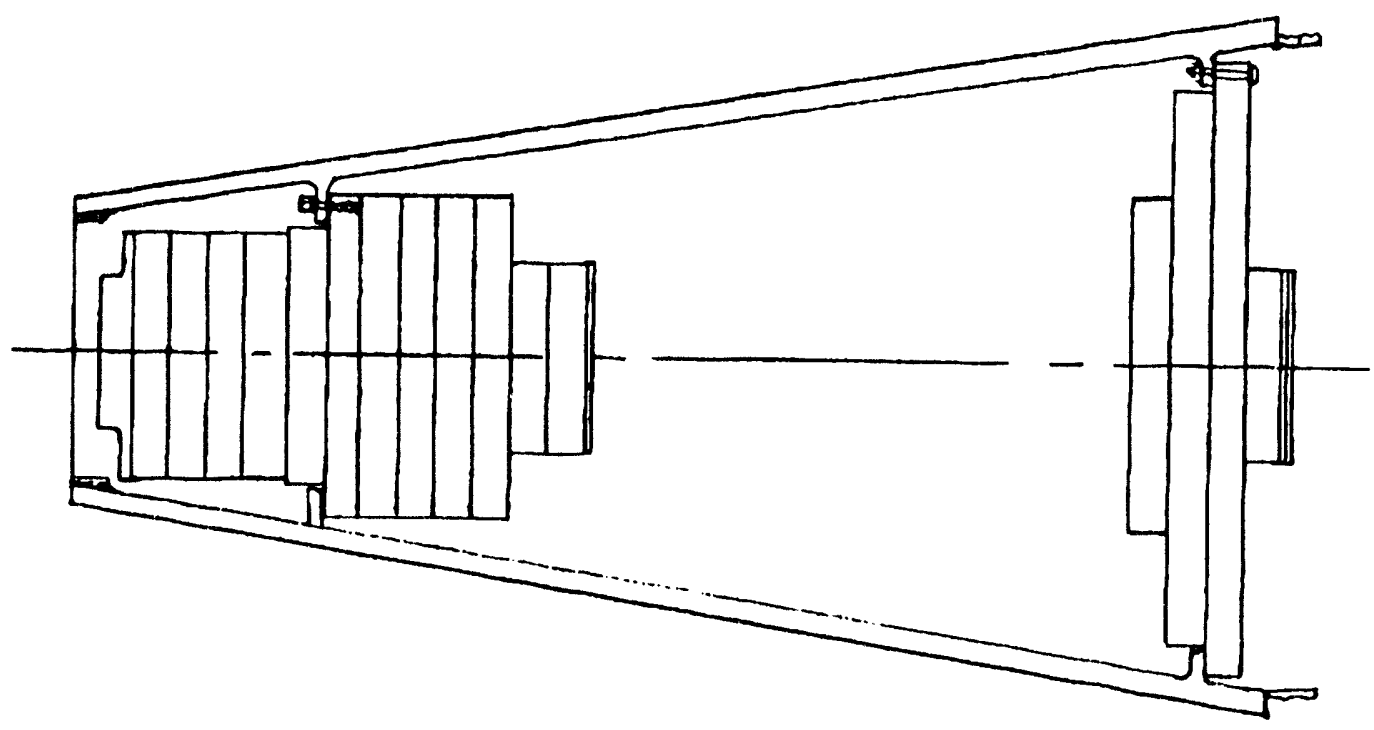

Figure 3.5 Mk12a Mod6c schematic with internal weight plates 


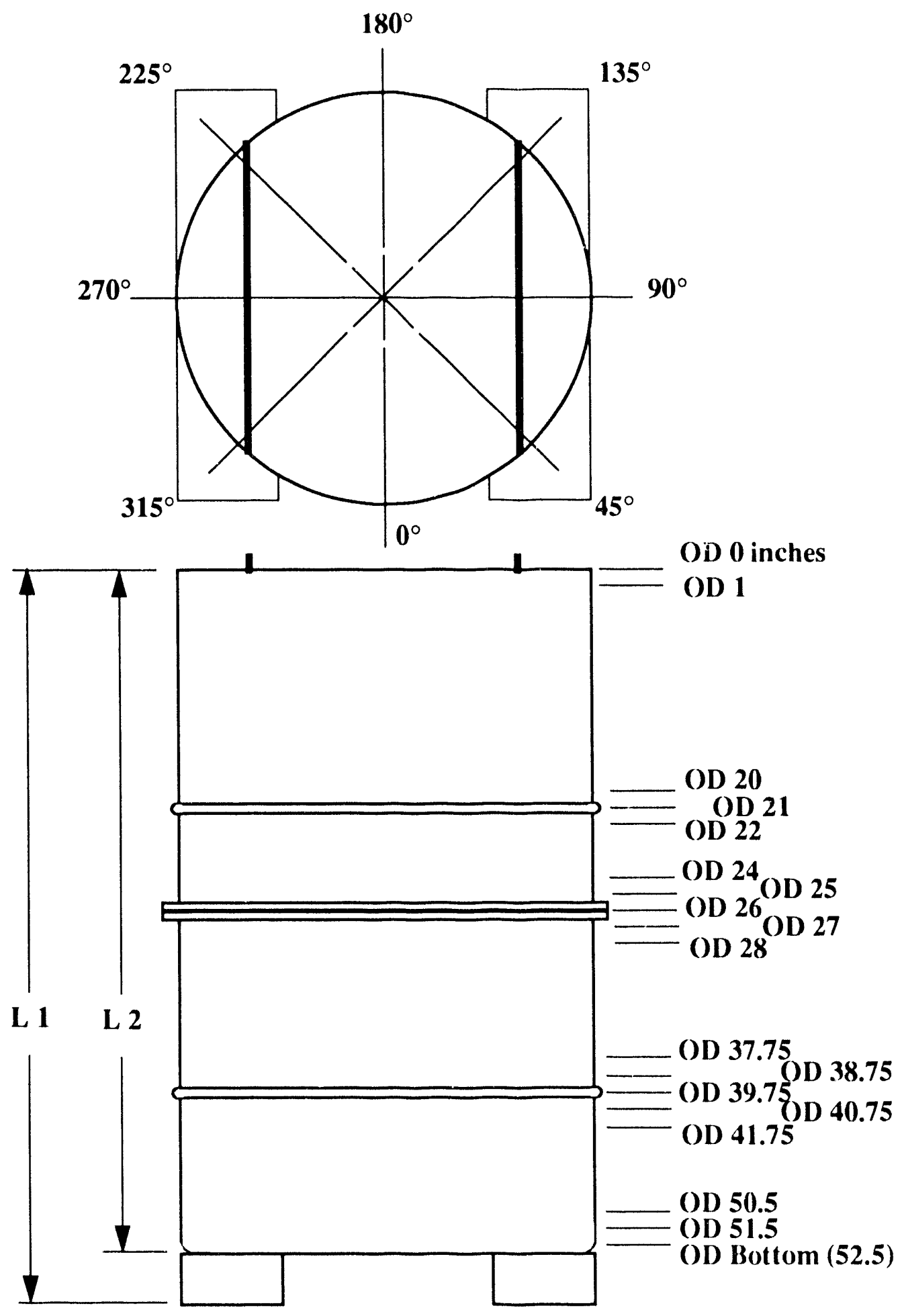

Figure 3.6 H1224A container body measurement locations 

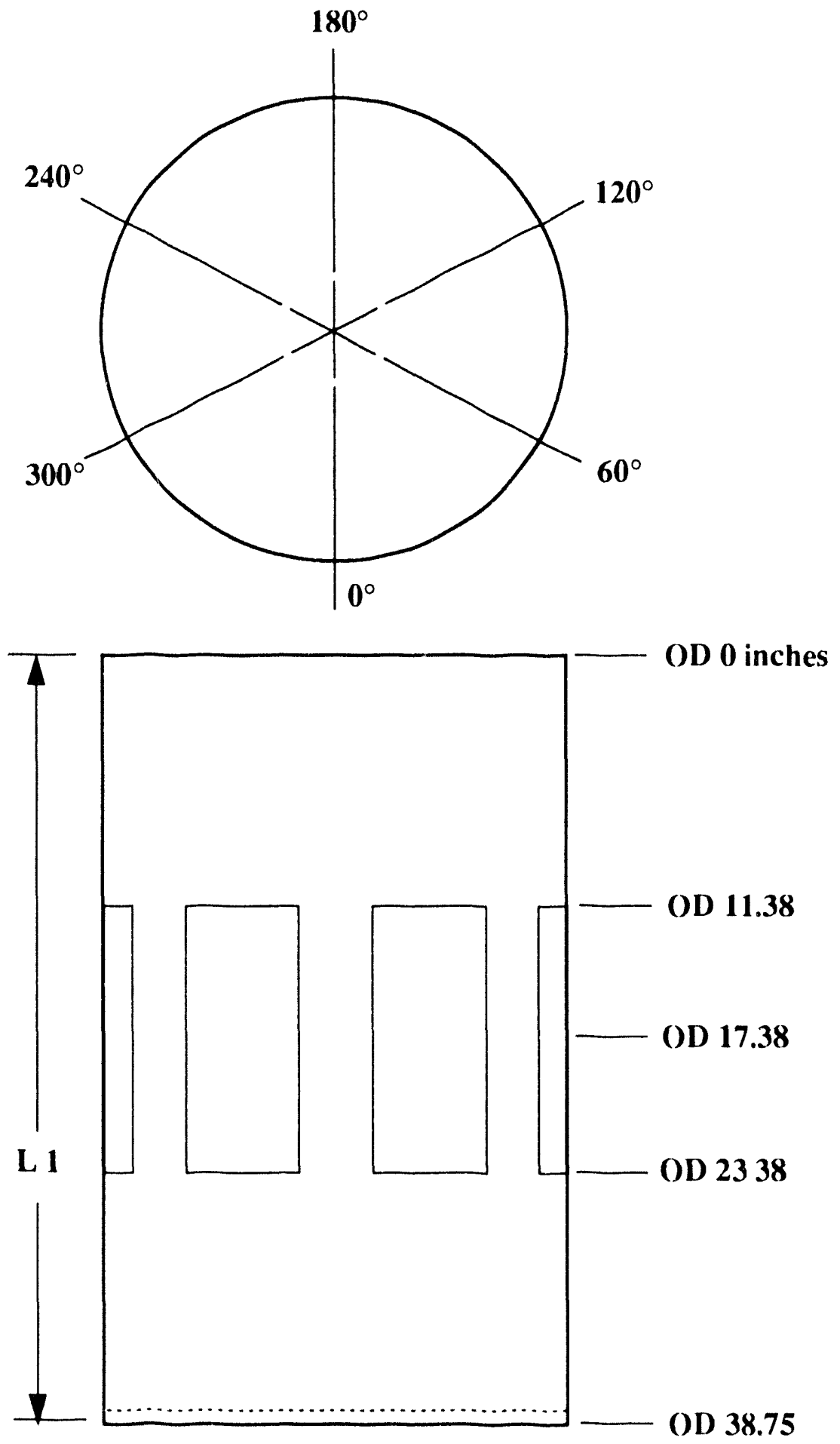

Figure 3.7 H1224A inner container measurement locations 

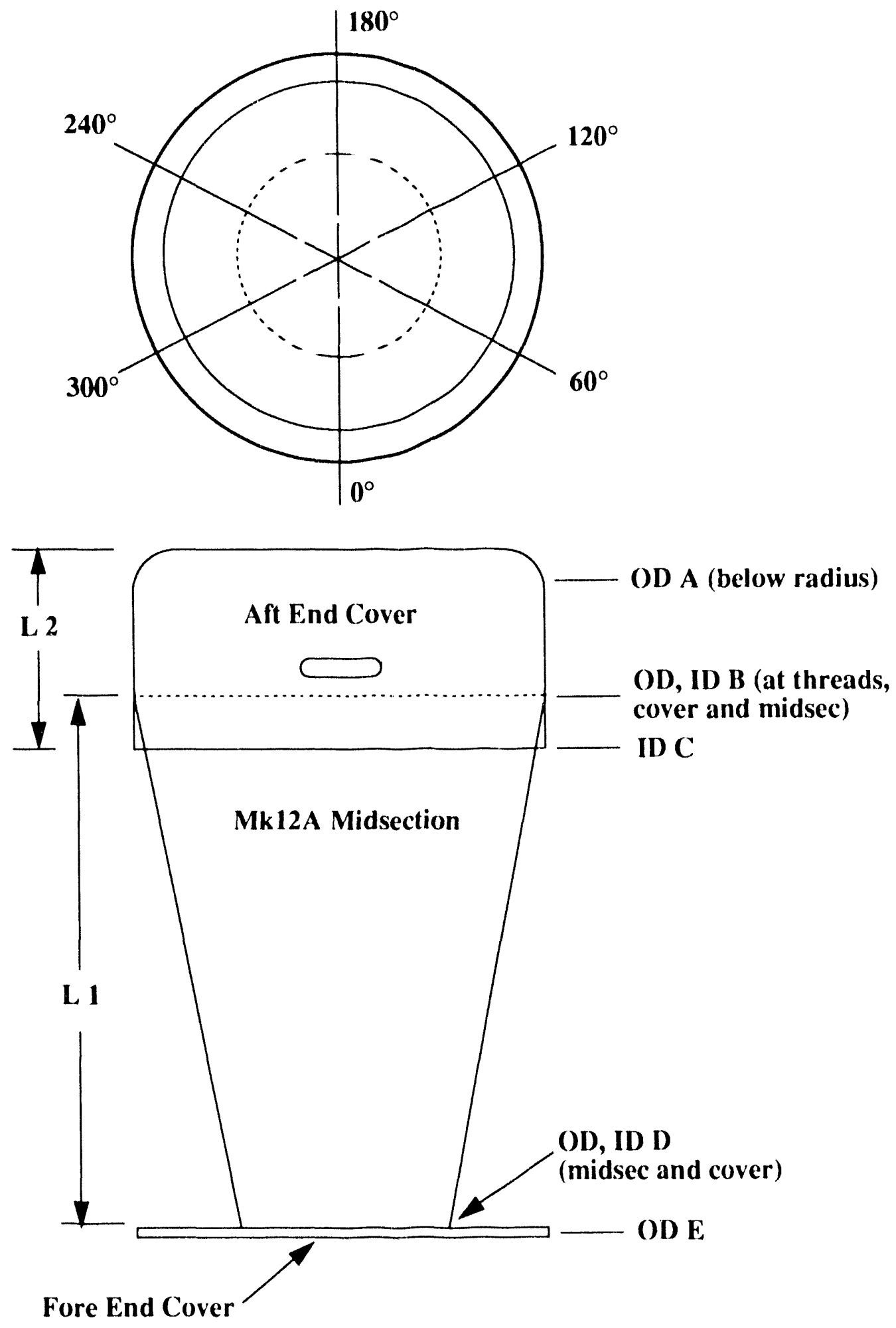

Figure 3.8 Mk12A midsection and fore and aft cover measurement locations 


\section{Instrumentation}

Accelerometers, strain gages, and photometrics were used in each of the four impact tests to provide quantitative experimental data necessary for determining overall structural response of the H1224A shipping/storage container and to validate analytical model predictions.

Accelerometers and strain gages were monitored through instrumentation cables attached to the container. Each impact test was sequenced by a microprocessor providing event signals for the explosive cable cutters, instrumentation, and high-speed photometrics. Instrumentation data acquisition was provided by Sandia's MIDAS system [16,17], a self-contained mobile data collection and processing facility. This data acquisition system included signal conditioners that supplied input voltage, bridge balance, and shunt calibration capabilities. Electrical signals proportional to acceleration and strain at specific locations on the container were amplified, passed through a voltage-controlled oscillator, and recorded digitally through primary and secondary devices. The digital backup (secondary) recorder provided the capability of linearly recording data with amplitudes two-and-a-half times the value of the calibration signal. The secondary data was sampled at a rate of 500,000 samples per second, then transferred to a computer workstation for data analysis and reduction, including filtering, integrating, and displaying in the form of plots. Fast Fourier transforms (FFTs) were performed on each data set to analyze amplitude information in the frequency domain. All raw and reduced data plots are included in the Appendices.

The uncertainty band associated with this accelerometer and strain gage data is approximately 15 percent [18]. The primary contributors to the uncertainty include the accelerometers and strain gages themselves including their attachment method, accuracy of the data acquisition system, and the ability to record and reduce this data.

Strain gage instrumentation was used to quantify dynamic strains at key locations for future validation with analytical model predictions. Eighth-inch 5-percent-strain Micro Measurements CEA-series axial and biaxial constantan gages, compatible with the aluminum H1224A container in terms of thermal expansion, were mounted as per manufacturer's specifications [19] as shown in Figures 4.1 and 4.2 as well as Tables 4.1 and 4.2. After installation, each gage was coated with a thin layer of RTV 3145 for protection. "Dummy" strain gage channels with impedance similar to active channels, were used to characterize background noise and any other potential spurious voltage signals acquired during the impact tests.

Dynamic accelerations throughout the container and RV during impact tests were recorded using Endevco 7270A 2,000-g, 6,000-g, and 20,000-g piezoresistive accelerometers [20]. "Dummy" accelerometers, whose physical appearance and impedance are identical to active units, were used to characterize background noise and any other potential spurious voltage signals acquired during the impact tests. Accelerometers for each test were bolted to the container body screwed to mounting blocks (glued and screwed) at mounting locations shown in Figures 4.3 and 4.4 and in Tables $4.3 \mathrm{a}, 4.3 \mathrm{~b}, 4.4 \mathrm{a}$, and $4.4 \mathrm{~b}$. These miniature units are only $14.2 \mathrm{~mm}(0.56 \mathrm{in}.) \times 7.1 \mathrm{~mm}$ (0.28 in.) $\times 2.8 \mathrm{~mm}(0.11 \mathrm{in}$.) thick, adding virtually zero mass and thus not affecting the dynamic response of the measurement location. High resonant frequencies $(90)$ to $350 \mathrm{kHz}$ ) and zero damp- 
ing also allow the accelerometers to respond accurately to fast rise time, short duration shock motion all the way down to dc or steady state accelerations. The flat amplitude frequency response $( \pm 5 \%$ max) for these accelerometers extends to 10 to $50 \mathrm{kHz}$, depending on the acceleration limit, providing linearity below these limits. Container structural response was separated from the accelerometer response using IIR 6-stage Butterworth (low-pass) filters with cutoff frequencies of 2 $\mathrm{kHz}$ and $250 \mathrm{~Hz}$, bracketing the internationally recommended range to eliminate high-frequency noise [21]. Prior to and after each impact test, each accelerometer was calibrated using drop ball, shaker, and centrifuge methods [22-24] by Sandia's Measurement Standard Department. Post-test calibration ensures that the transducer has not been damaged during testing.

The tests were recorded photometrically by orthogonal high-speed motion-picture cameras, operating at $400 \mathrm{frames} / \mathrm{s}$ and $2000 \mathrm{frames} / \mathrm{s}$ to capture detailed deformation histories. Each camera also recorded a synchronized $1000 \mathrm{~Hz}$ IRIG timing signal to verify velocity measurements. Gridded stadia-board backgrounds aided displacement and velocity determination from the highspeed films.

Photographs showing more detailed mounting locations of strain gages, accelerometers, and terminal strips for the Longitudinal Low Velocity (LLV), Horizontal Low Velocity (HLV), Longitudinal High Velocity (LHV), and Horizontal High Velocity (HHV) impact tests are presented in Figures 4.5 through 4.19. As shown in some of these photographs, strain relief was designed into placement of instrumentation lead wires and cables in order to minimize the chance of overstressing these wires and losing test data. 

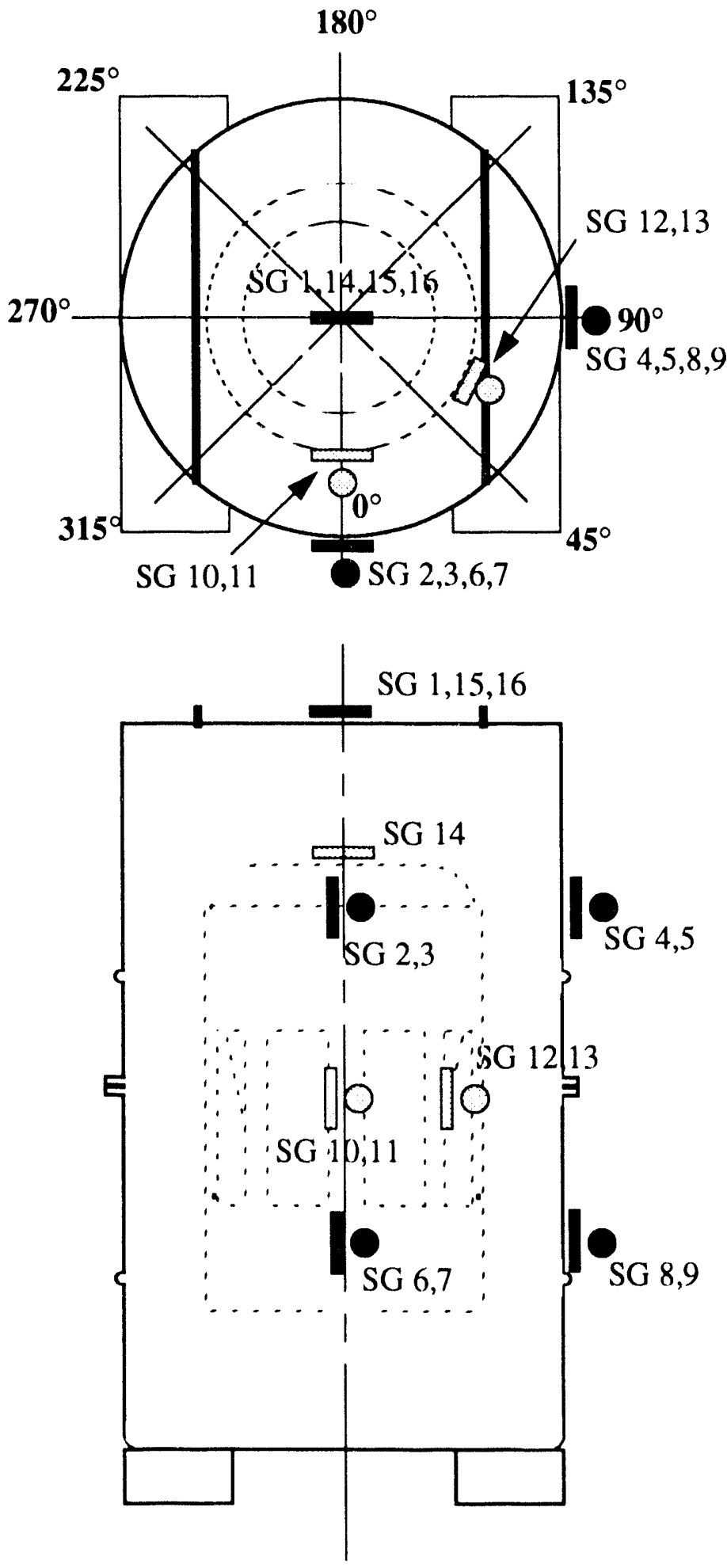

- Axial or Radial Gage

Circumferential Gage

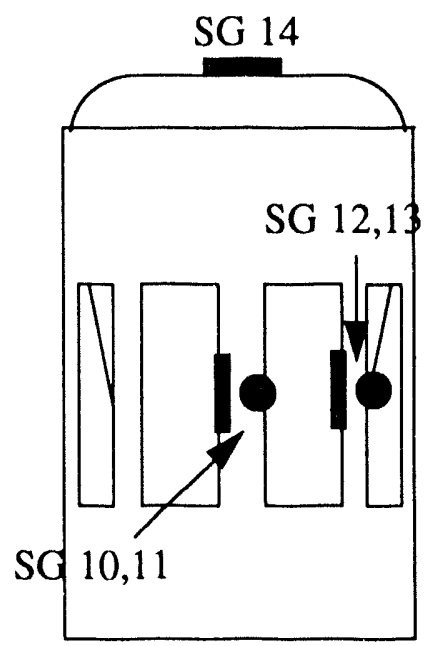

Figure 4.1 Strain Gage Locations for Low and High Velocity Longitudinal Impact Tests 


\section{TABLE 4.1}

LONGITUDINAL IMPACT INSTRUMENTATION REQUIREMENTS - STRAIN GAGES

\begin{tabular}{|c|c|c|c|}
\hline $\begin{array}{l}\text { Strain } \\
\text { Desig, }\end{array}$ & $\begin{array}{c}\text { Type/Catalog } \\
\text { Number }\end{array}$ & Location & Direction \\
\hline SG1 & CEA-13-125UW-350 & Top, Off-Center (3" toward $0^{\circ}$ ) & radial \\
\hline SG2 & СEA-13-125UT-350 & 13" Down, Side, $0^{\circ}$ & axial \\
\hline SG3 & CEA-13-125UT-350 & 13" Down, Side, $0^{\circ}$ & circumferential \\
\hline SG4 & CEA-13-125UT-350 & 13"' Down, Side, $90^{\circ}$ & axial \\
\hline SG5 & CEA-13-125UT-350 & 13" Down, Side, $90^{\circ}$ & circumferential \\
\hline SG6 & CEA-13-125UT-350 & $37^{\prime \prime}$ Down, Side, $0^{\circ}$ & axial \\
\hline SG7 & CEA-13-125UT-350 & $37^{\prime \prime}$ Down, Side, $0^{\circ}$ & circumferential \\
\hline SG8 & CEA-13-125UT-350 & 37" Down, Side, $90^{\circ}$ & axial \\
\hline SG9 & CEA-13-125UT-350 & $37^{\prime \prime}$ Down, Side, $90^{\circ}$ & circumferential \\
\hline SG10 & CEA-13-125UT-350 & 19.38" Down, Inner, $0^{\circ}$ & axial \\
\hline SG11 & CEA-13-125UT-350 & 19.38" Down, Inner, $0^{\circ}$ & circumferential \\
\hline SG12 & CEA-13-125UT-350 & 19.38" Down, Inner, $60^{\circ}$ & axial \\
\hline SG13 & CEA-13-125UT-350 & 19.38" Down, Inner, $60^{\circ}$ & circumferential \\
\hline SG14 & CEA-13-125UW-350 & Top of $1223 B$, Center & radial \\
\hline SG15 & 7270A-R / GW & Top, Center & N/A \\
\hline SG16 & $7270 A-R / R B$ & Top, Center & N/A \\
\hline
\end{tabular}

NOTE:

1. Strain gages 15 and 16 are dummy gages

2. Axial direction refers to along the length of the container axis 


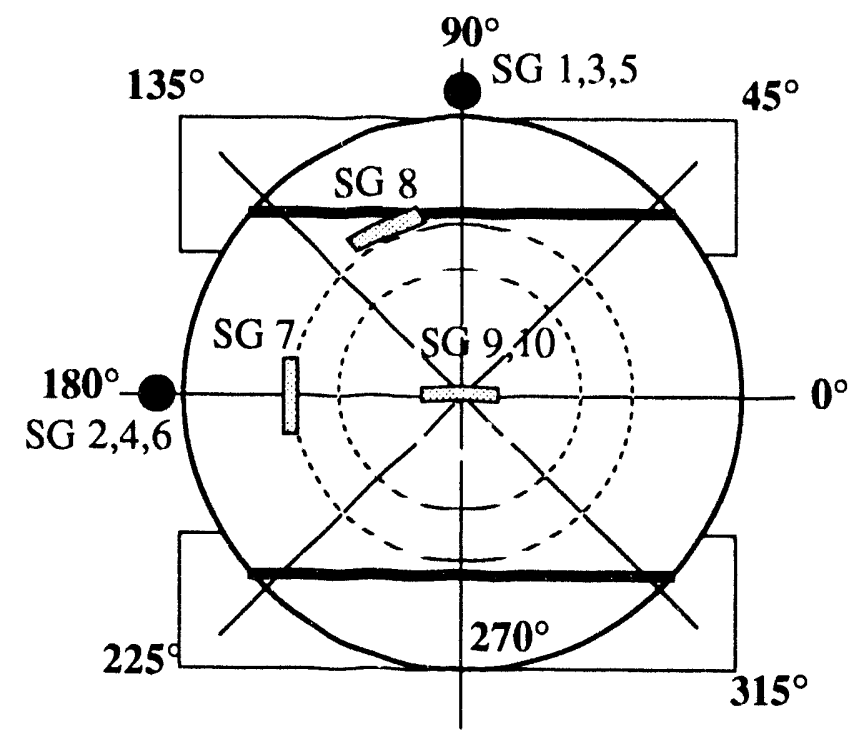

- Circumferential Gage

Axial Gage

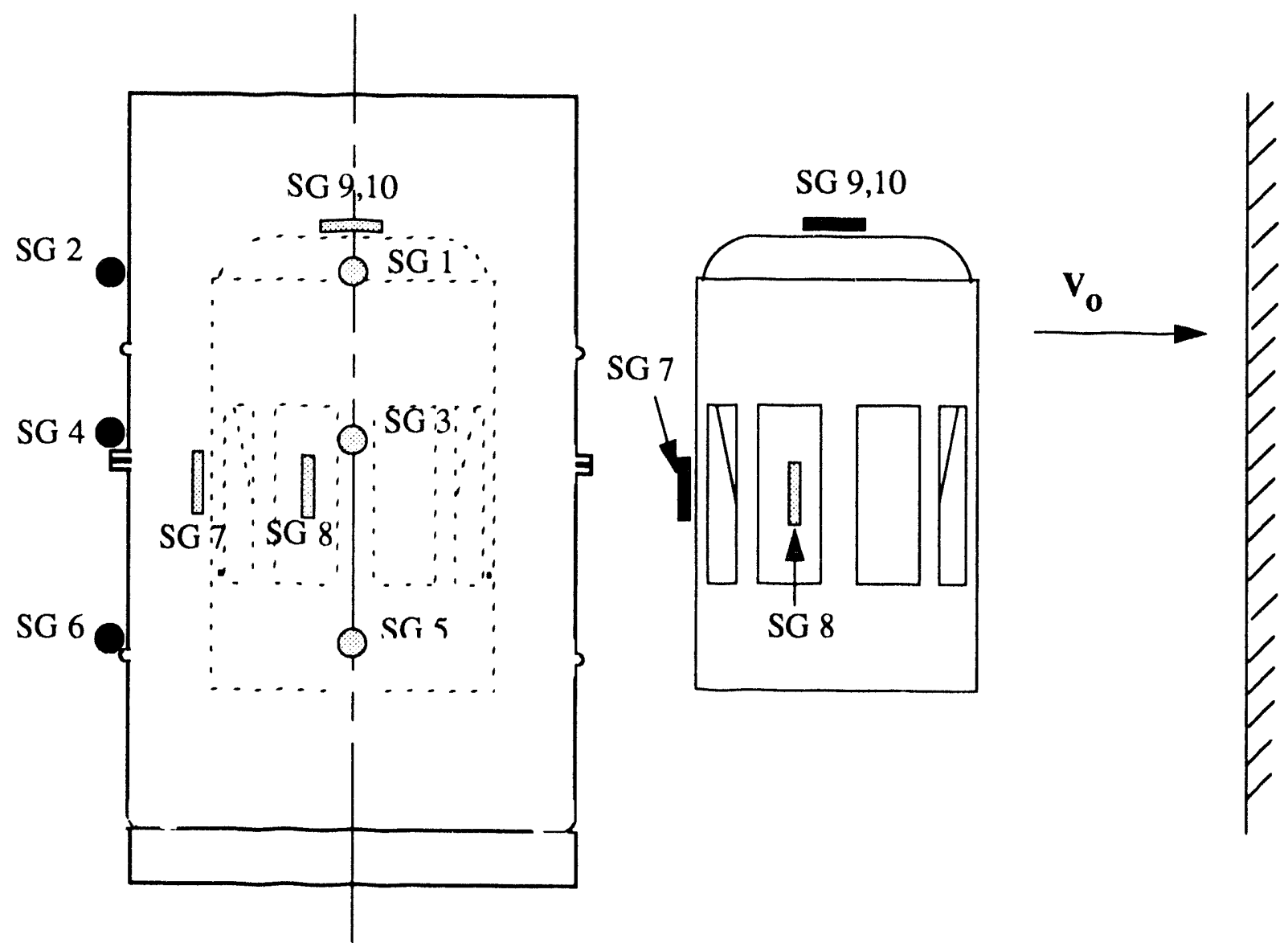

Figure 4.2 Strain Gage Locations for Low and High Velocity Horizontal Impact Tests 
TABLE 4.2

HORIZONTAL IMPACT INSTRUMENTATION REQUIREMENTS - STRAIN GAGES

Strain

Desig.

SG1

SG2

SG3

SG4

SG5

SG6

SG7

SG8

SG9

SG10
Type/Catalog

Number

CEA-13-125UW-350

CEA-13-125UW-350

CEA-13-125UW-350

CEA-13-125UW-350

CEA-13-125UW-350

CEA-13-125UW-350

CEA-13-125UW-350 CEA-13-125UW-350

7270A-R/GW

7270A-R / RB
Location

13" Down, Side, $90^{\circ}$ circumferential

13" Down, Side, $180^{\circ}$ circumferential

22.75" Down, Side, $90^{\circ}$ circumferential

22.75" Down, Side, $180^{\circ}$ circumferential

37" Down, Side, $90^{\circ} \quad$ circumferential

37" Down, Side, $180^{\circ} \quad$ circumferential

NOTE:

1. Strain gages 9 and 10 were dummy gages

2. Axial direction refers to along the length of the container axis 

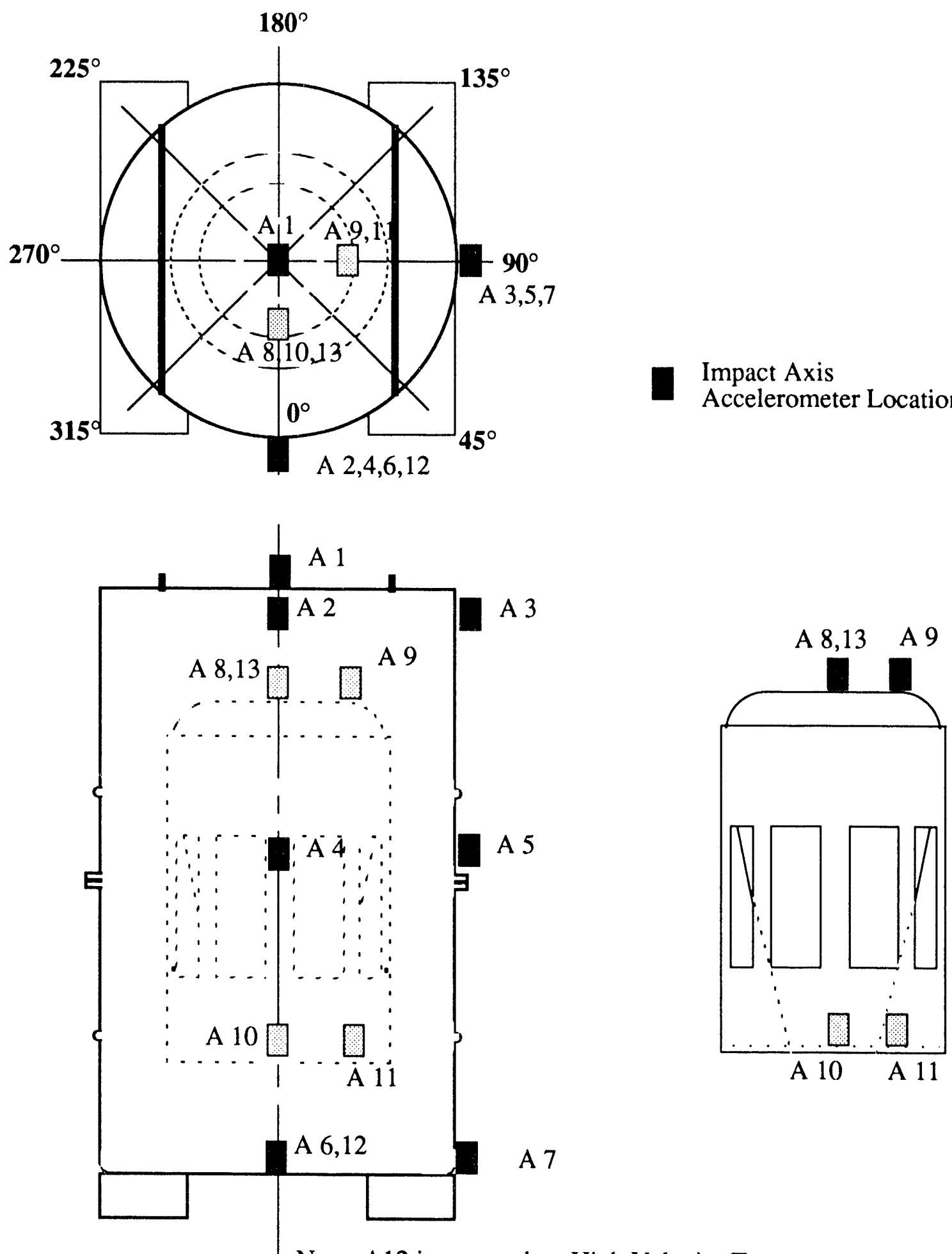

Note: A12 is not used on High Velocity Test

Figure 4.3 Accelerometer Locations for Low and High Velocity Longitudinal Impact Tests 


\section{TABLE 4.3a}

LONGITUDINAL 40 FT/S IMPACT INSTRUMENTATION REQUIREMENTS ACCELEROMETERS

\begin{tabular}{|c|c|c|c|}
\hline $\begin{array}{l}\text { Accel. } \\
\text { Desig. }\end{array}$ & $\begin{array}{c}\text { Type/Catalog } \\
\text { Number }\end{array}$ & Location & Direction \\
\hline A1 & $7270 \mathrm{~A}-2 \mathrm{~K}$ & Top, Center & Impact Axis \\
\hline $\mathrm{A} 2$ & $7270 \mathrm{~A}-2 \mathrm{~K}$ & Top, Side, $0^{\circ}$ & Impact Axis \\
\hline A3 & $7270 \mathrm{~A}-2 \mathrm{~K}$ & Top, Side, $90^{\circ}$ & Impact Axis \\
\hline A4 & $7270 \mathrm{~A}-2 \mathrm{~K}$ & 24.5" Down, Side, $0^{\circ}$ & Impact Axis \\
\hline A5 & $7270 \mathrm{~A}-2 \mathrm{~K}$ & 24.5" Down, Side, $90^{\circ}$ & Impact Axis \\
\hline A6 & $7270 \mathrm{~A}-6 \mathrm{~K}$ & Bottom, Side, $0^{\circ}$ & Impact Axis \\
\hline A7 & $7270 \mathrm{~A}-6 \mathrm{~K}$ & Bottom, Side, $90^{\circ}$ & Impact Axis \\
\hline A8 & $7270 \mathrm{~A}-2 \mathrm{~K}$ & 1223B Top, End, $0^{\circ}$ & Impact Axis \\
\hline A9 & $7270 \mathrm{~A}-2 \mathrm{~K}$ & $122 \vdots \mathrm{B}$ Top, End, $90^{\circ}$ & Impact Axis \\
\hline A 10 & $7270 \mathrm{~A}-2 \mathrm{~K}$ & Fore Mount Plate, 1/2" From Inner Edge, $0^{\circ}$ & Impact Axis \\
\hline A11 & $7270 \mathrm{~A}-2 \mathrm{~K}$ & Fore Mount Plate, $1 / 2^{\prime \prime}$ From Inner Edge, $90^{\circ}$ & Impact Axis \\
\hline A 12 & $7270 \mathrm{~A}-20 \mathrm{~K}$ & Bottom, Side, $0^{\circ}$ & Impact Axis \\
\hline A 13 & $7270 \mathrm{~A}-\mathrm{Z}$ & 1223B Top, End, $0^{\circ}$ & N/A \\
\hline
\end{tabular}

Note:

1. A13 was a dummy accelerometer 


\section{TABLE 4.3b}

LONGITUDINAL 125 FT/S IMPACT INSTRUMENTATION REQUIREMENTS ACCELEROMETERS

$\begin{array}{cccc}\text { Accel. } & \begin{array}{c}\text { Type/Catalog } \\ \text { Number }\end{array} & \text { Location } & \text { Direction } \\ \text { A1 } & \begin{array}{c}\text { Lesig. } \\ 7270 \mathrm{~A}-20 \mathrm{~K}\end{array} & \text { Top, Center } & \text { Impact Axis } \\ \text { A2 } & 7270 \mathrm{~A}-20 \mathrm{~K} & \text { Top, Side, } 0^{\circ} & \text { Impact Axis } \\ \text { A3 } & 7270 \mathrm{~A}-20 \mathrm{~K} & \text { Top, Side, } 90^{\circ} & \text { Impact Axis } \\ \text { A4 } & 7270 \mathrm{~A}-20 \mathrm{~K} & 24.5^{\prime \prime} \text { Down, Side, } 0^{\circ} & \text { Impact Axis } \\ \text { A5 } & 7270 \mathrm{~A}-20 \mathrm{~K} & 24.5^{\prime \prime} \text { Down, Side, } 90^{\circ} & \text { Impact Axis } \\ \text { A6 } & 7270 \mathrm{~A}-20 \mathrm{~K} & \text { Bottom, Side, } 0^{\circ} & \text { Impact Axis } \\ \text { A7 } & 7270 \mathrm{~A}-20 \mathrm{~K} & \text { Bottom, Side, } 90^{\circ} & \text { Impact Axis } \\ \text { A8 } & 7270 \mathrm{~A}-20 \mathrm{~K} & 1223 \mathrm{~B} \text { Top, End, } 0^{\circ} & \text { Impact Axis } \\ \text { A9 } & 7270 \mathrm{~A}-20 \mathrm{~K} & 1223 \mathrm{~B} \text { Top, End, } 90^{\circ} & \text { Impact Axis } \\ \text { A10 } & 7270 \mathrm{~A}-20 \mathrm{~K} & \text { Fore Mount Plate, } 1 / 2^{\prime \prime} \text { From Inner Edge, } 0^{\circ} \text { Impact Axis } \\ \text { A11 } & 7270 \mathrm{~A}-20 \mathrm{~K} & \text { Fore Mount Plate, } 1 / 2^{\prime \prime} \text { From Inner Edge, } 90^{\circ} \text { Impact Axis } \\ \text { A13 } & 7270 \mathrm{~A}-\mathrm{Z} & \text { 1223B Top, End, } 0^{\circ} & \text { N/A }\end{array}$

Note:

1. A13 was a dummy accelerometer 

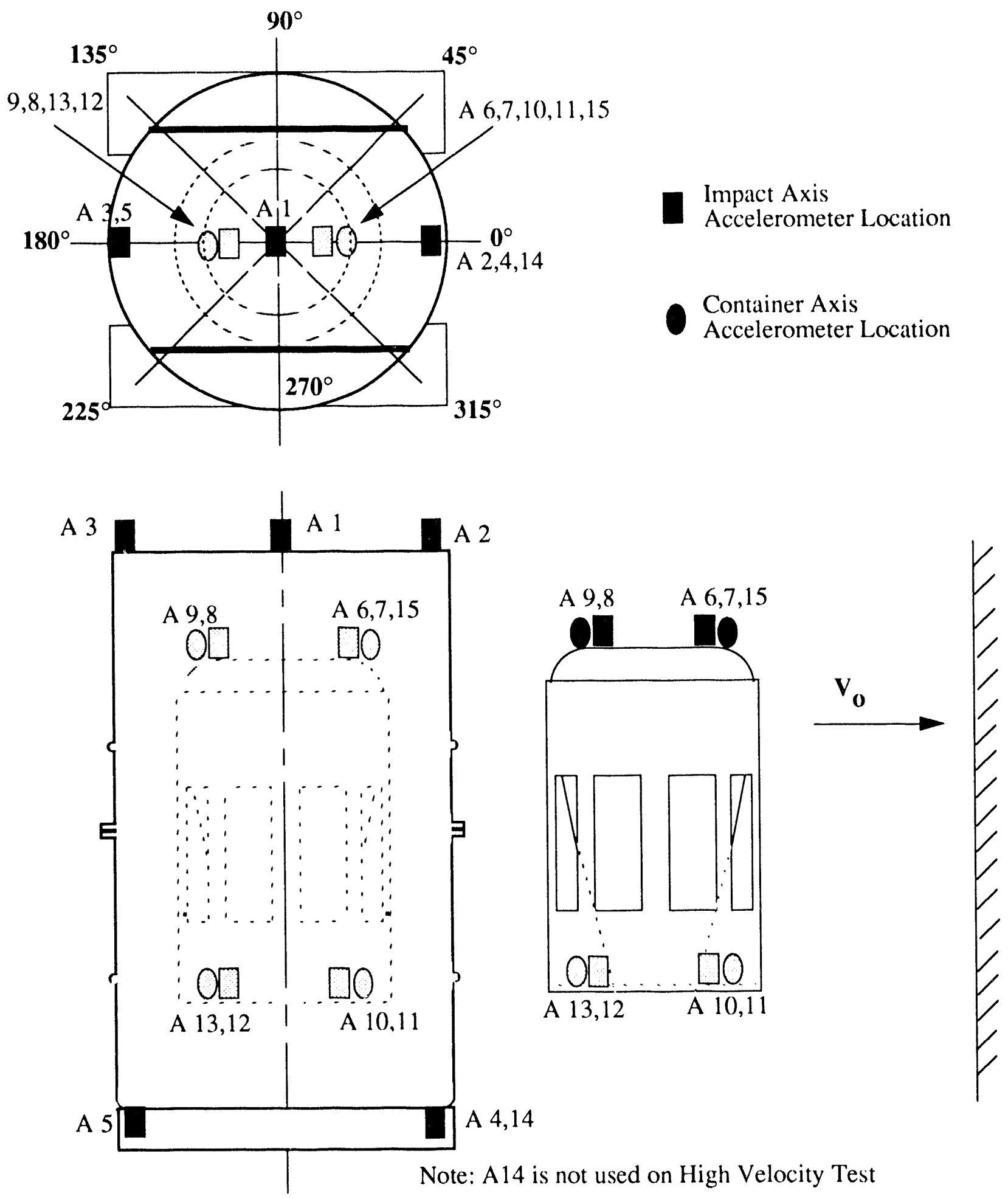

Figure 4.4 Accelerometer Locations for Low and High Velocity Horizontal Impact 'Tests 
TABLE 4.4a

\section{HORIZONTAL 40 FT/S IMPACT INSTRUMENTATION REQUIREMENTS - ACCELEROMETERS}

\begin{tabular}{|c|c|c|c|}
\hline $\begin{array}{l}\text { Accel. } \\
\text { Desig. }\end{array}$ & $\begin{array}{c}\text { Type/Catalog } \\
\text { Number }\end{array}$ & Location & Direction \\
\hline $\mathrm{A} 1$ & $7270 \mathrm{~A}-2 \mathrm{~K}$ & Top, Center & Impact Axis \\
\hline $\mathrm{A} 2$ & $7270 \mathrm{~A}-6 \mathrm{~K}$ & Top, End, $0^{\circ}$ & Impact Axis \\
\hline A3 & $7270 \mathrm{~A}-2 \mathrm{~K}$ & Top, End, $180^{\circ}$ & Impact Axis \\
\hline A4 & $7270 \mathrm{~A}-6 \mathrm{~K}$ & Bottom, End, $0^{\circ}$ & Impact Axis \\
\hline A5 & $7270 \mathrm{~A}-2 \mathrm{~K}$ & Bottom, End, $180^{\circ}$ & Impact Axis \\
\hline A6 & $7270 \mathrm{~A}-2 \mathrm{~K}$ & 1223B Top, End, $0^{\circ}$ & Impact Axis \\
\hline A7 & $7270 \mathrm{~A}-2 \mathrm{~K}$ & 1223B Top, End, $0^{\circ}$ & Container Axis \\
\hline A8 & $7270 \mathrm{~A}-2 \mathrm{~K}$ & 1223B Top, End, $180^{\circ}$ & Impact Axis \\
\hline A9 & $7270 \mathrm{~A}-2 \mathrm{~K}$ & 1223B Top, End, $180^{\circ}$ & Container Axis \\
\hline A 10 & $7270 \mathrm{~A}-2 \mathrm{~K}$ & Fore Mount Plate, 1/2" From Inner Edge, $0^{\circ}$ & Impact Axis \\
\hline A 11 & $7270 \mathrm{~A}-2 \mathrm{~K}$ & Fore Mount Plate, 1/2" From Inner Edge, $0^{\circ}$ & Container Axis \\
\hline A 12 & $7270 \mathrm{~A}-2 \mathrm{~K}$ & Fore Mount Plate, $1 / 2^{\prime \prime}$ From Inner Edge, $180^{\circ}$ & Impact Axis \\
\hline A 13 & $7270 \mathrm{~A}-2 \mathrm{~K}$ & Fore Mount Plate, 1/2" From Inner Edge, $180^{\circ}$ & Container Axis \\
\hline A 14 & $7270 \mathrm{~A}-20 \mathrm{~K}$ & Bottom, End, $0^{\circ}$ & Impact Axis \\
\hline A 15 & $7270 \mathrm{~A}-\mathrm{Z}$ & 1223B Top, End, $180^{\circ}$ & N/A \\
\hline
\end{tabular}

Note:

1. A15 was a dummy accelerometer 
TABLE 4,4b

HORIZONTAL 125 FT/S IMPACT INSTRUMENTATION REQUIREMENTS ACCELEROMETERS

\begin{tabular}{|c|c|c|c|}
\hline $\begin{array}{l}\text { Accel. } \\
\text { Desig. }\end{array}$ & $\begin{array}{c}\text { Type/Catalog } \\
\text { Number }\end{array}$ & Location & Direction \\
\hline $\mathrm{Al}$ & $7270 \mathrm{~A}-20 \mathrm{~K}$ & Top, Center & Impact Axis \\
\hline $\mathrm{A} 2$ & $7270 \mathrm{~A}-20 \mathrm{~K}$ & Top, End, $0^{\circ}$ & Impact Axis \\
\hline A3 & $7270 \mathrm{~A}-20 \mathrm{~K}$ & Top, End, $180^{\circ}$ & Impact Axis \\
\hline A4 & $7270 \mathrm{~A}-20 \mathrm{~K}$ & Bottom, End, $0^{\circ}$ & Impact Axis \\
\hline A5 & $7270 \mathrm{~A}-20 \mathrm{~K}$ & Bottom, End, $180^{\circ}$ & Impact Axis \\
\hline A6 & 727() $\mathrm{A}-2() \mathrm{K}$ & 1223B Top, End, $0^{\circ}$ & Impact Axis \\
\hline A7 & $7270 \mathrm{~A}-20 \mathrm{~K}$ & 1223B Top, End, $0^{\circ}$ & Container Axis \\
\hline A8 & $7270 \mathrm{~A}-20 \mathrm{~K}$ & 1223B Top, End, $180^{\circ}$ & Impact Axis \\
\hline A9 & $7270 \mathrm{~A}-20 \mathrm{~K}$ & 1223B Top, End, $180^{\circ}$ & Container Axis \\
\hline A 10 & $7270 \mathrm{~A}-20 \mathrm{~K}$ & Fore Mount Plate, 1/2" From Inner Edge, $0^{\circ}$ & Impact Axis \\
\hline A 11 & $7270 \mathrm{~A}-20 \mathrm{~K}$ & Fore Mount Plate, 1/2" From Inner Edge, $0^{\circ}$ & Container Axis \\
\hline A 12 & $7270 \mathrm{~A}-20 \mathrm{~K}$ & Fore Mount Plate, 1/2" From Inner Edge, $180^{\circ}$ & Impact Axis \\
\hline A 13 & $7270 \mathrm{~A}-20 \mathrm{~K}$ & Fore Mount Plate, 1/2" From Inner Edge, $180^{\circ}$ & Container Axis \\
\hline A 15 & $7270 \mathrm{~A}-\mathrm{Z}$ & 1223B Top, End, $180^{\circ}$ & N/A \\
\hline
\end{tabular}

Note:

1. A 15 was a dummy accelerometer 


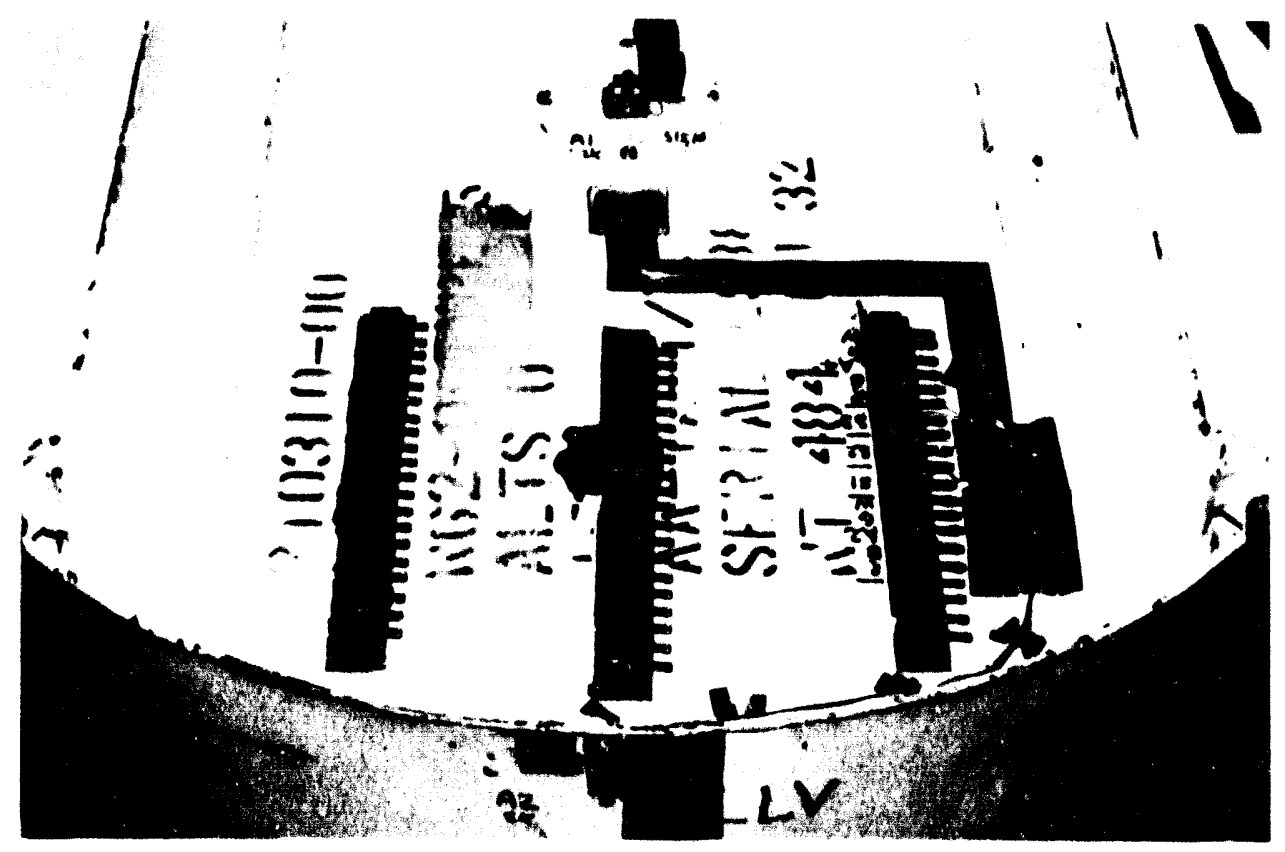

Figure 4.5 LLV mounting locations for A1, A2, S1, S15, S16, and terminal strips

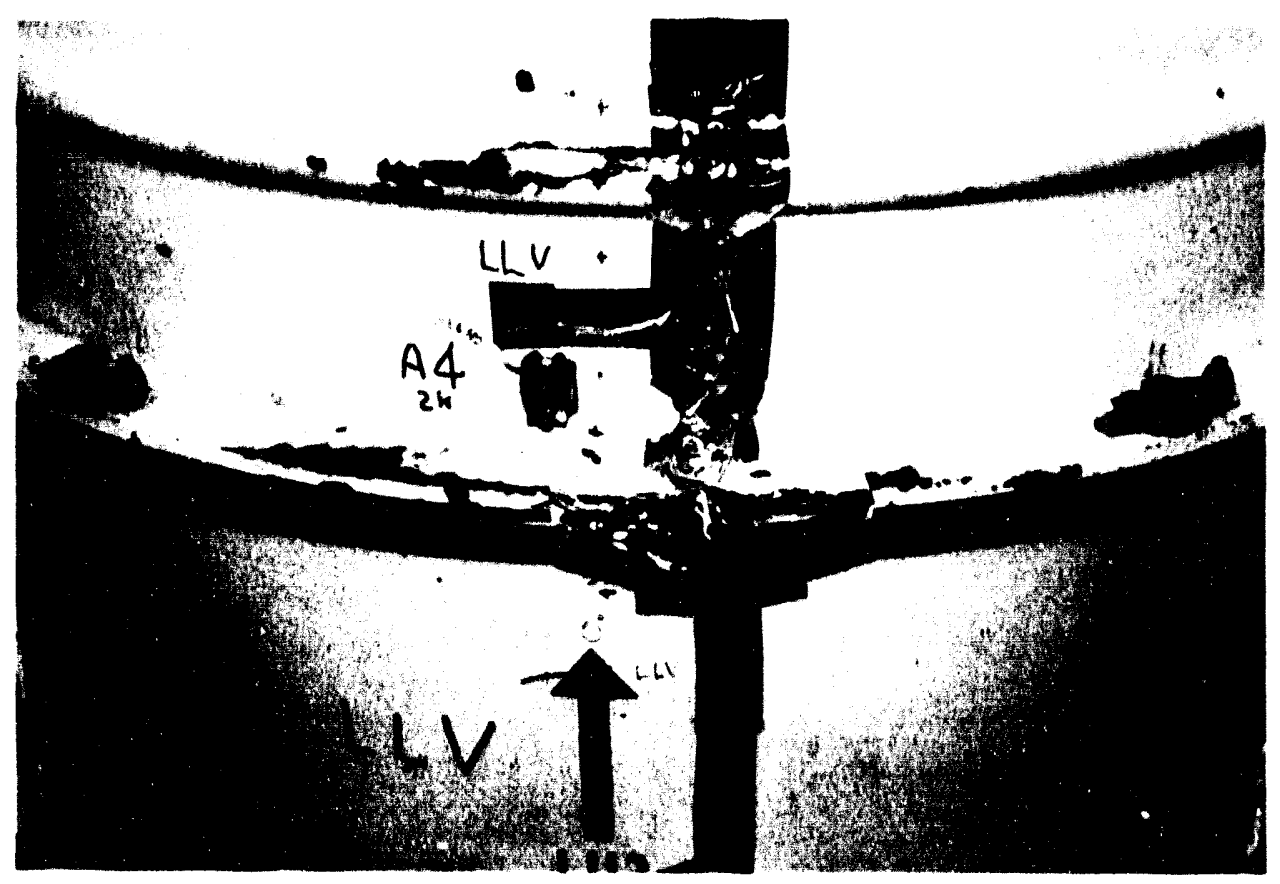

Figure 4.6 LLV mounting location for A4 


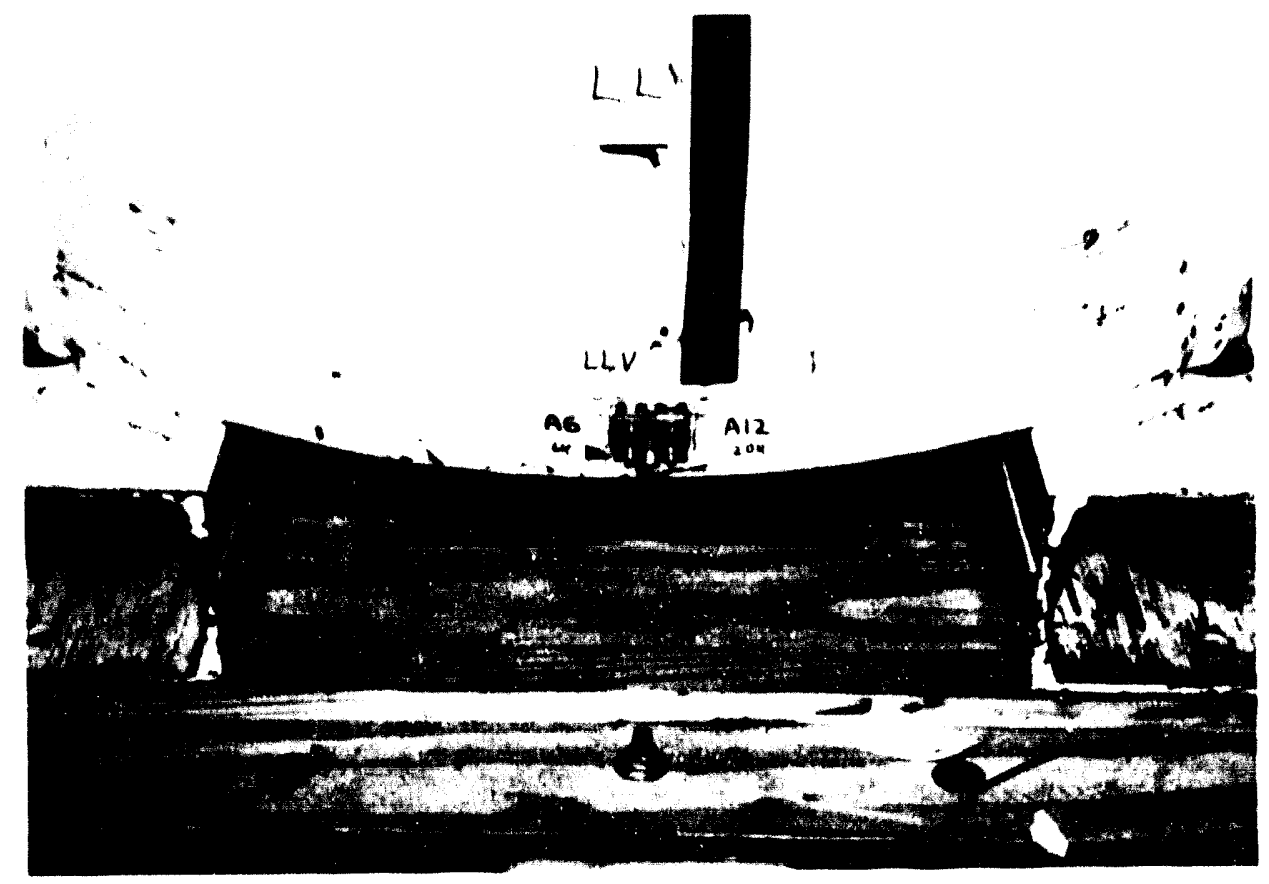

Figure 4.7 LLV mounting location for A6 and A12

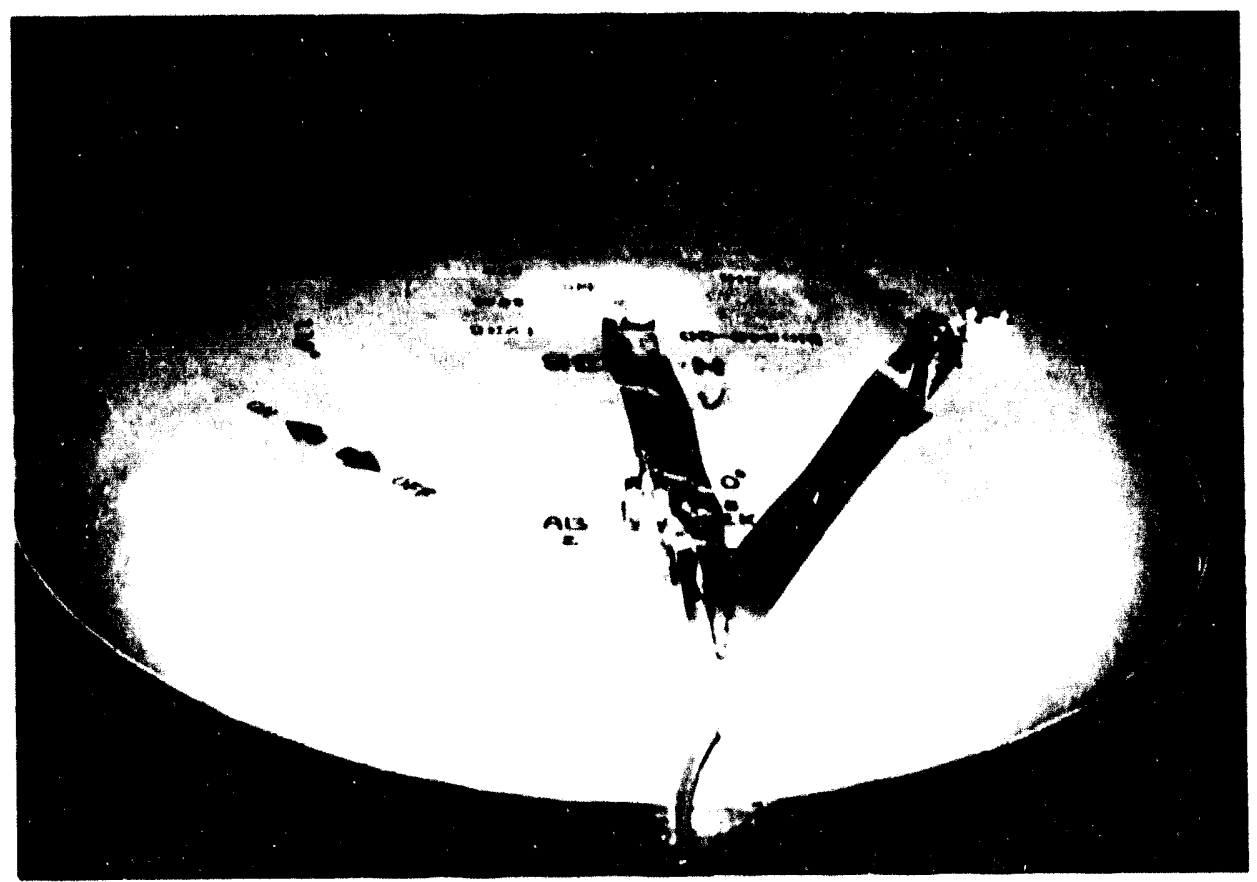

Figure 4.8 LLV mounting locations for A8, A9, A 13, and S14 


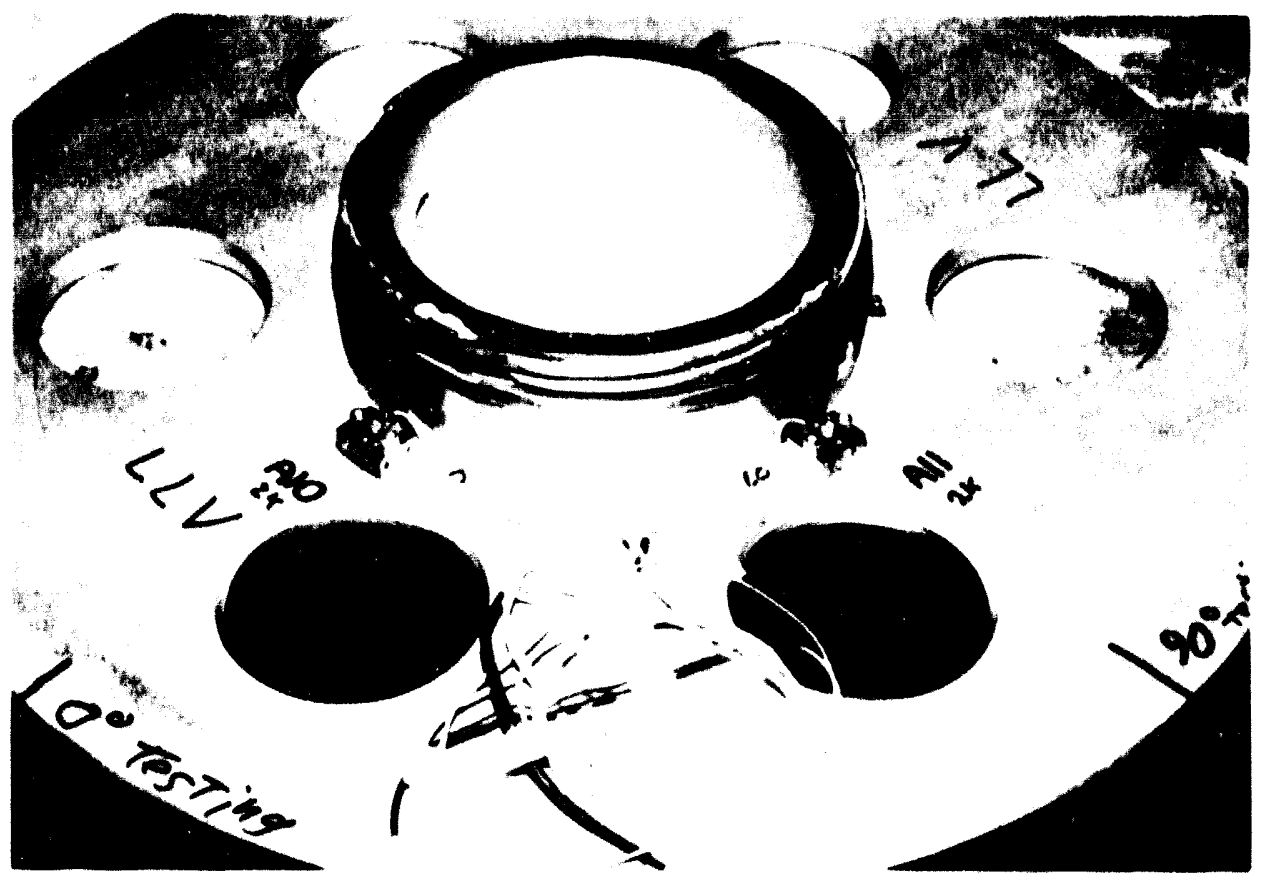

Figure 4.9 LLV mounting locations for A10 and A11

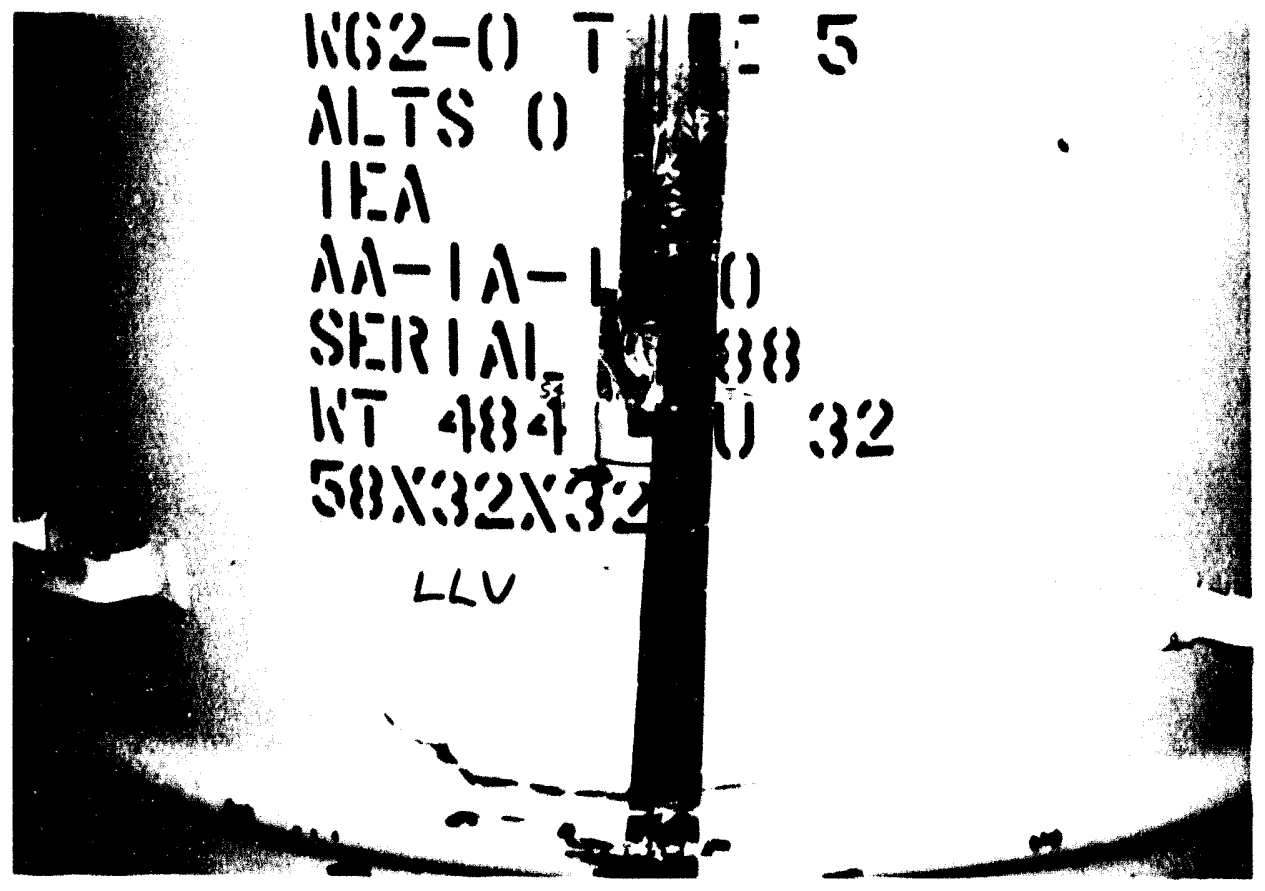

Figure 4.10 LLV mounting location for $\$ 4$ and S5 


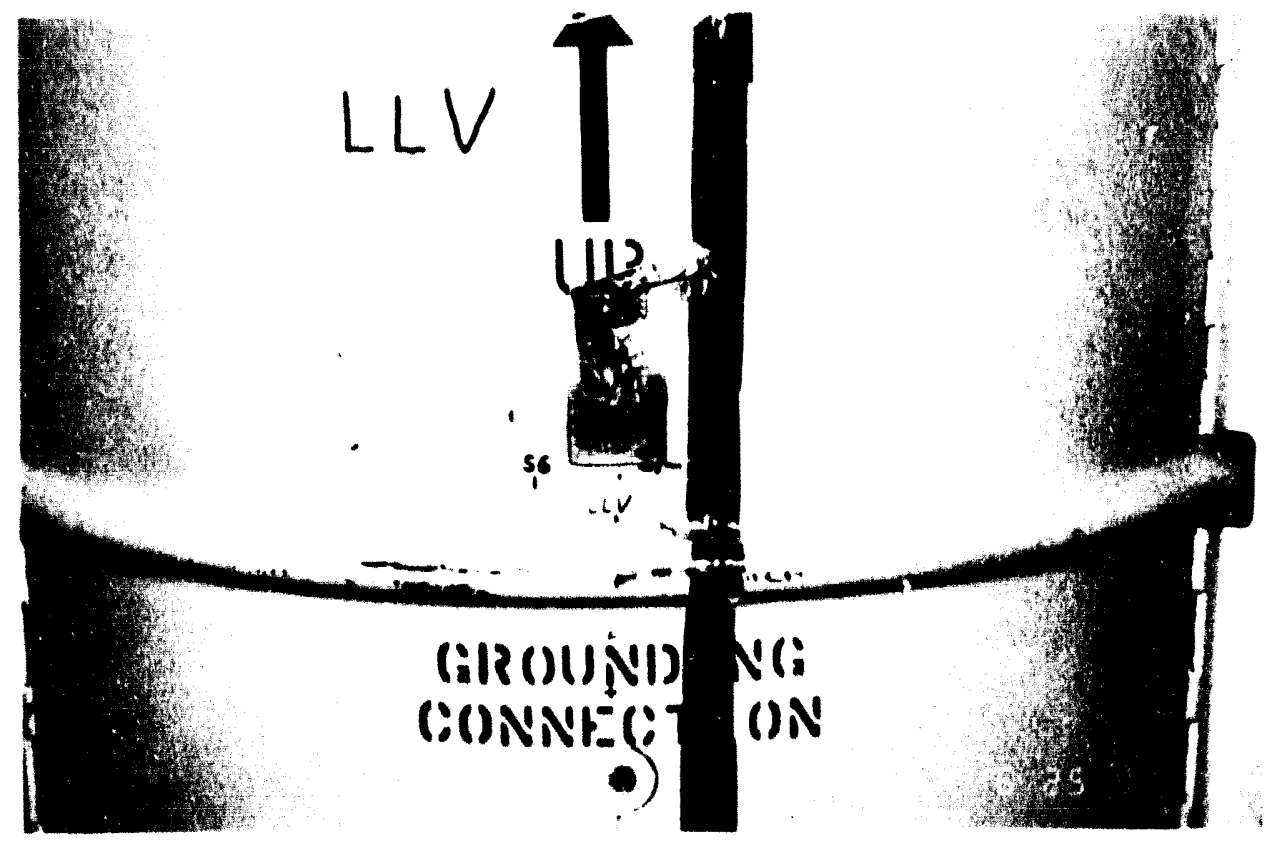

Figure 4.11 LLV mounting location for S6 and S7

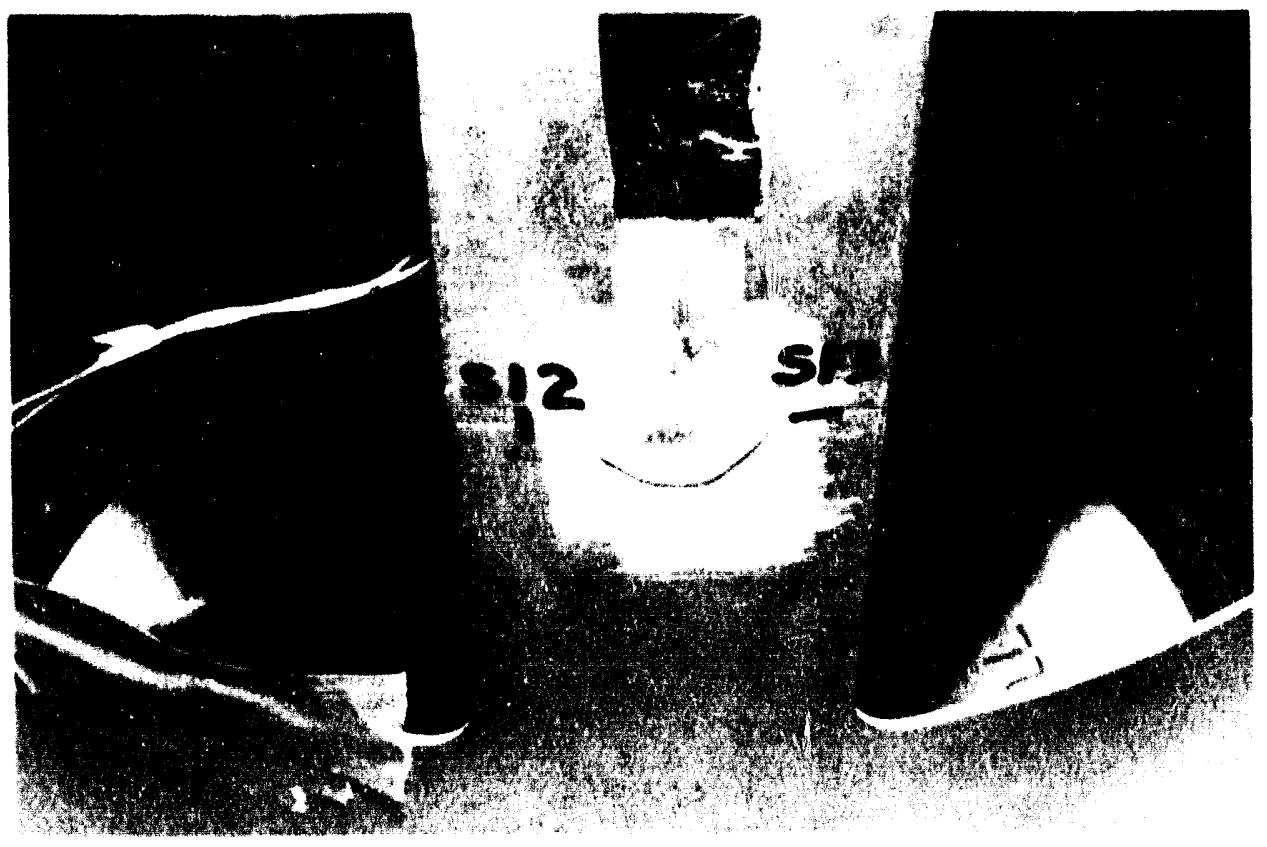

Figure 4.12 LLV mounting location for S12 and S13 


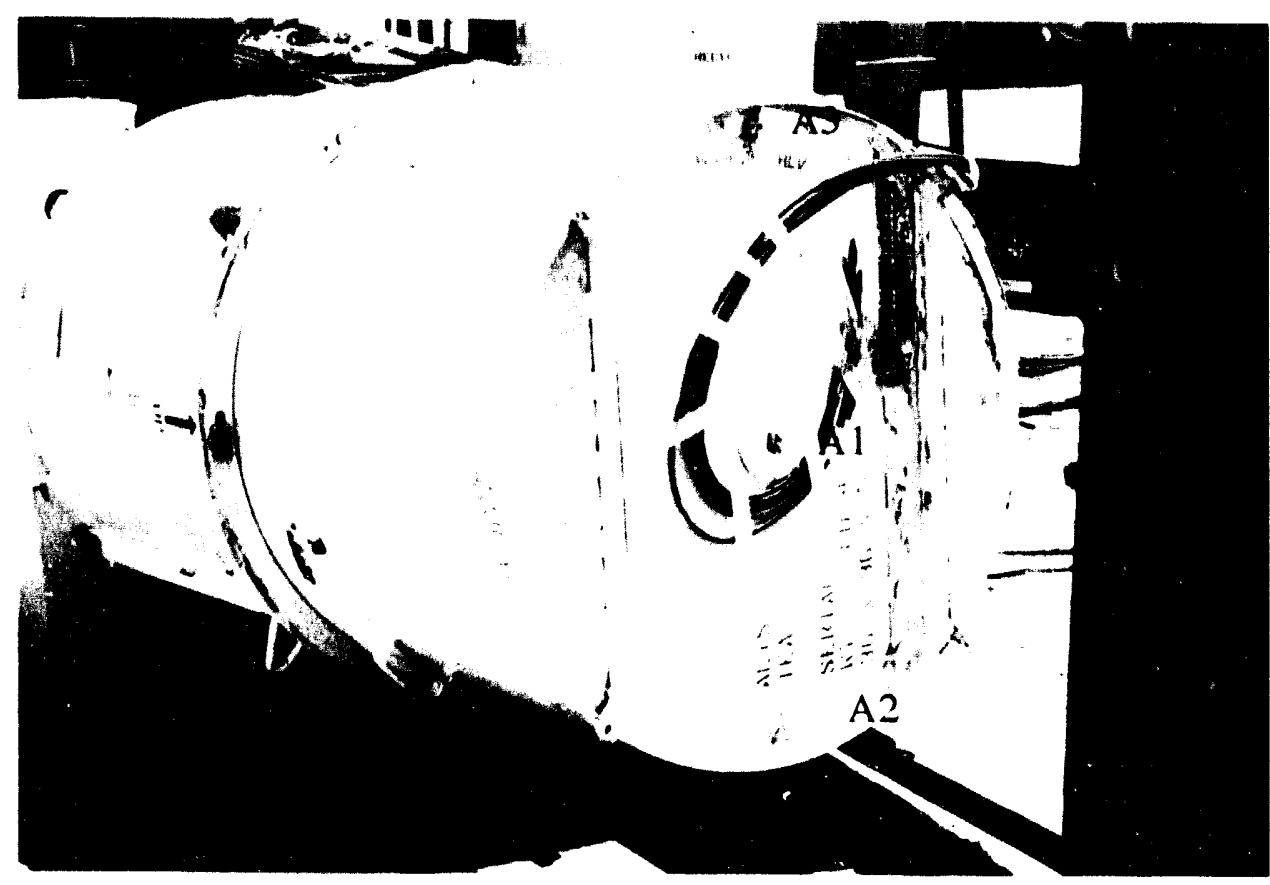

Figure 4.13 HLV mounting locations for A1, A2, $\mathrm{A3}$, and some terminal strips

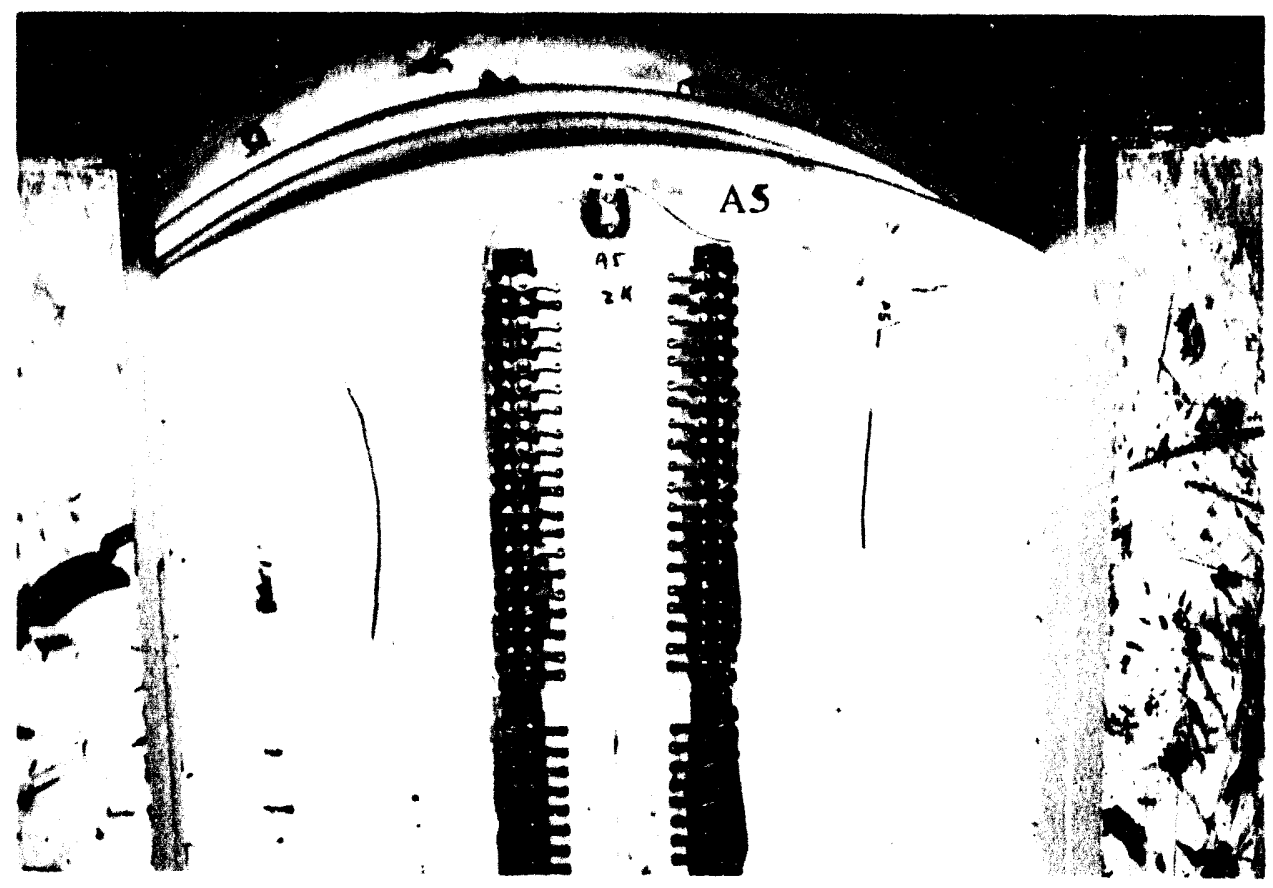

Figure 4.14 HLV mounting location for A5 


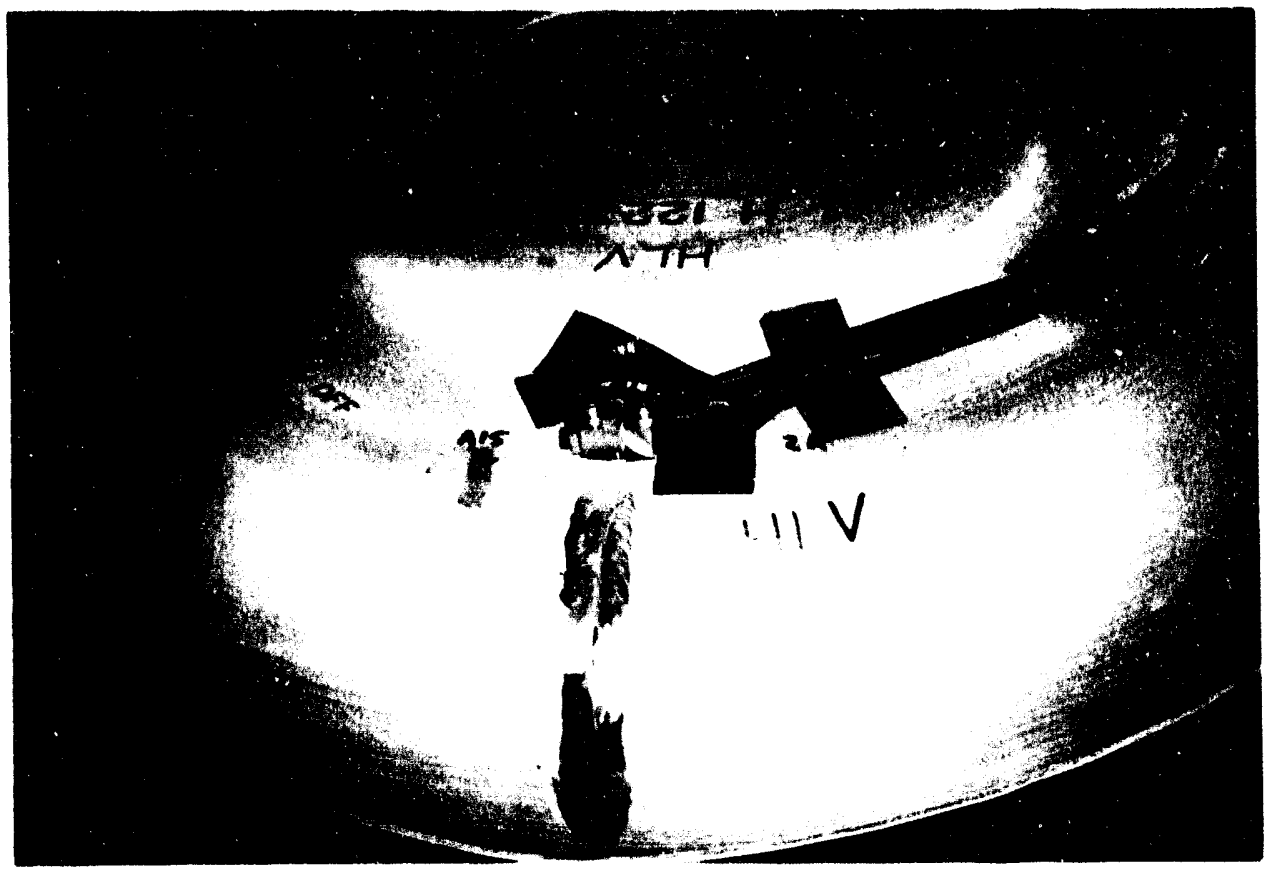

Figure 4.15 HLV mounting location for A6, A7, and A15

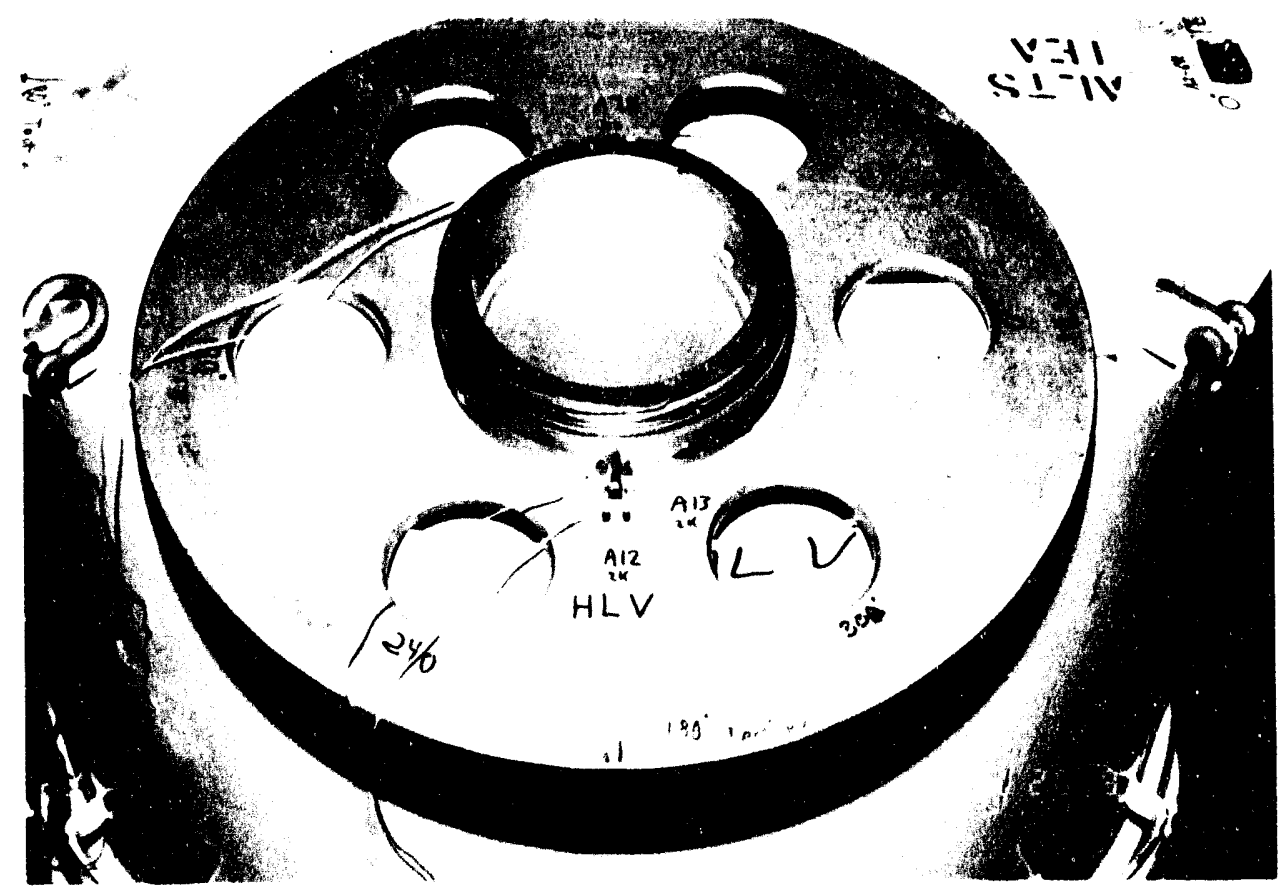

Figure 4.16 HLV mounting location for A12 and A13 


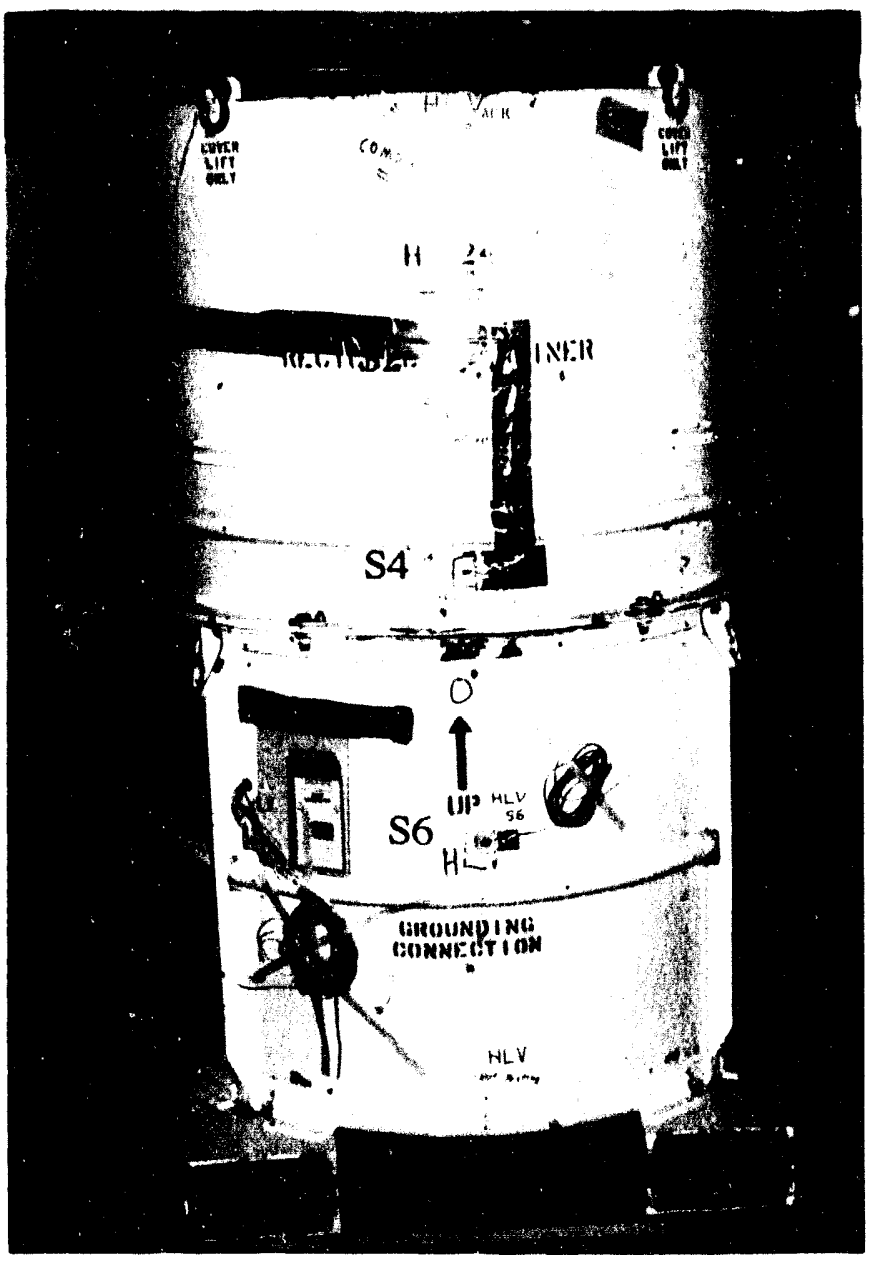

Figure 4.17 HLV mounting locations for S2, S4, and S6 


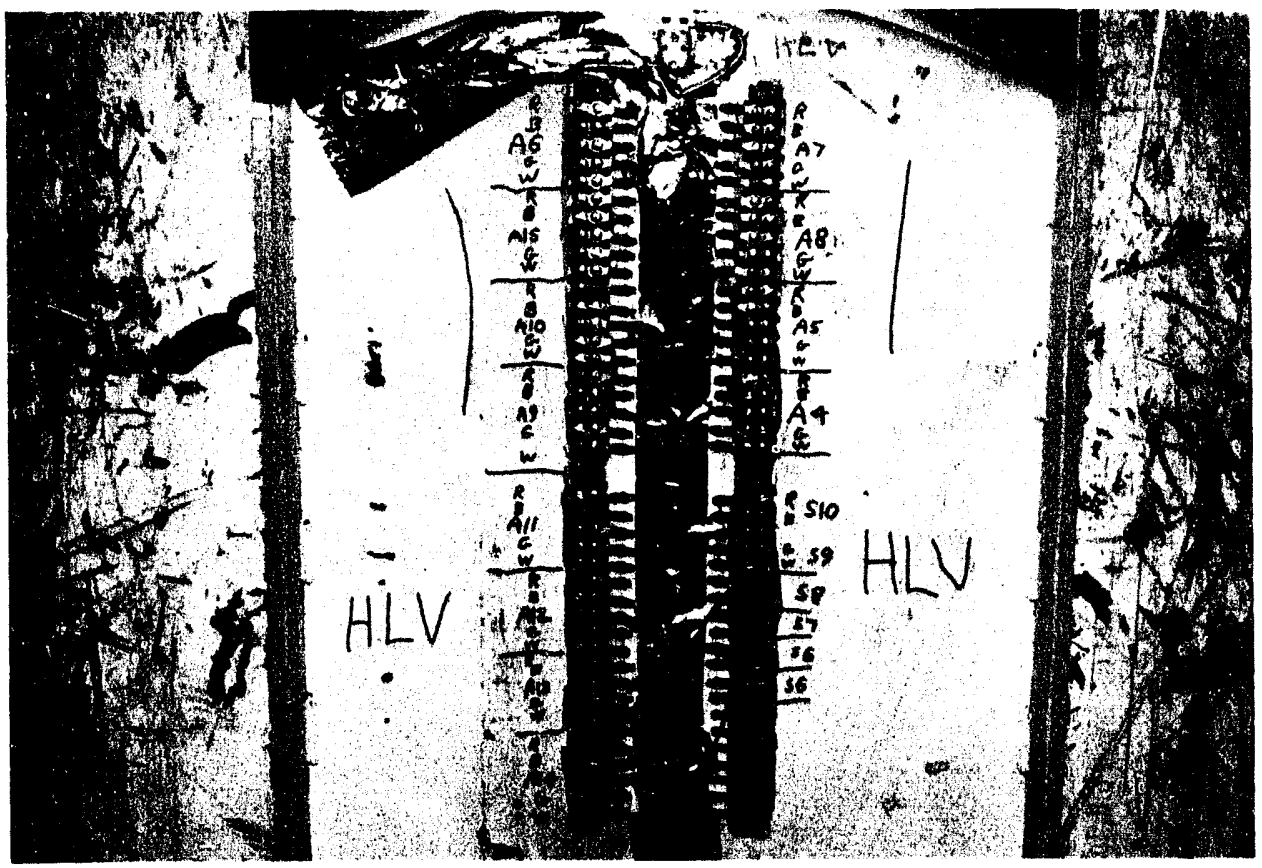

Figure 4.18 HLV mounting location for more terminal strips

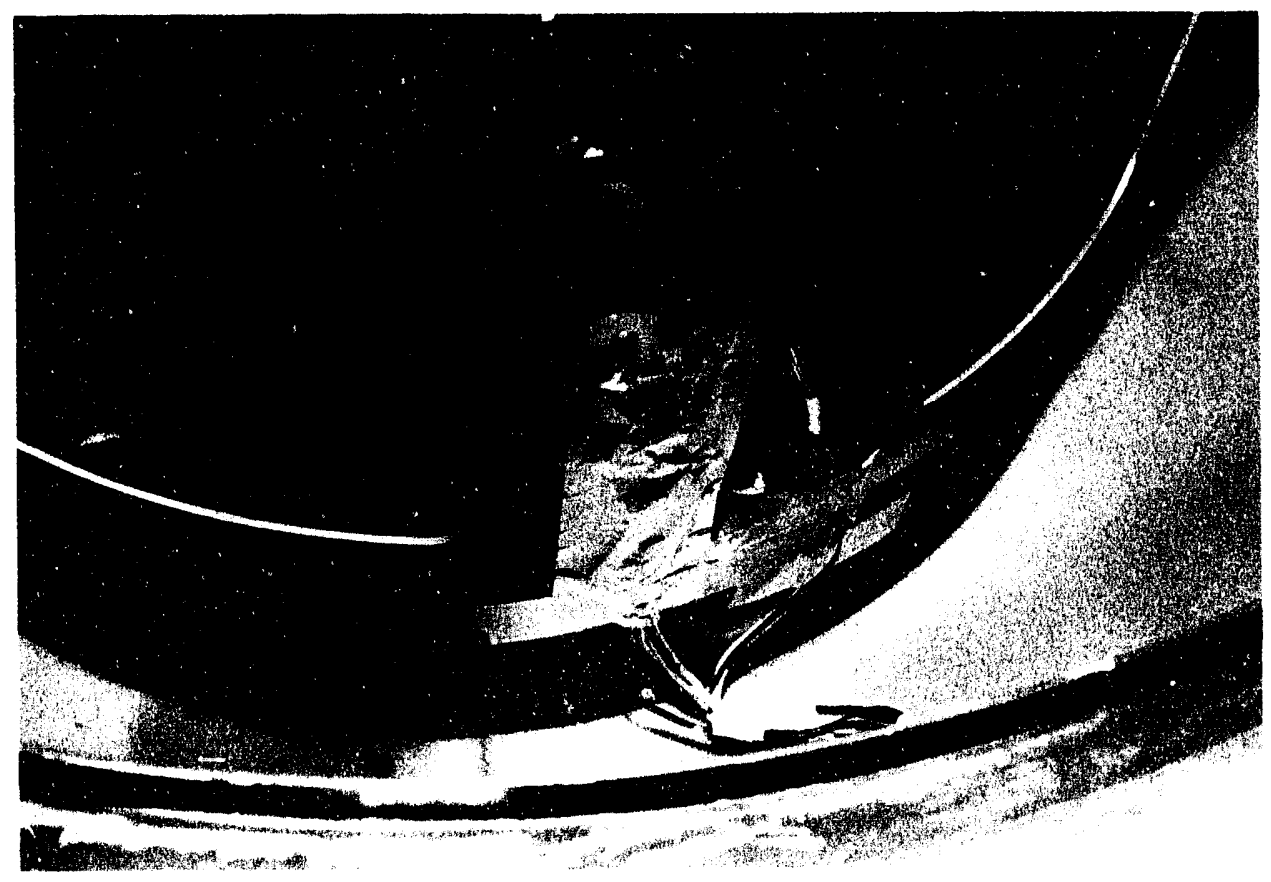

Figure 4.19 HLV mounting location for S7 


\section{Results}

\subsection{Longitudinal Low Velocity}

The longitudinal low-velocity (LLV) impact test was performed on June 29, 1993 at the 185 -

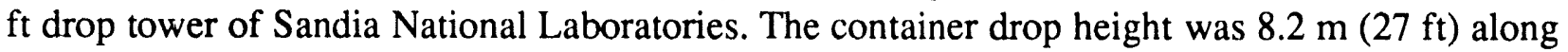
a high-tension cable guided path which controlled impact orientation (see Figure 5.1.1). Analysis of high-speed films yielded an impact velocity of $12.3 \mathrm{~m} / \mathrm{s}(40.5 \mathrm{ft} / \mathrm{s})$ at an impact angle of $1.7^{\circ}$ from perfectly upright. After impact, the test unit rebounded approximately $1.2 \mathrm{~m}(4 \mathrm{ft})$ from the unyielding target, tilting slightly in mid-air causing the unit to fall from the raised target after the second impact.

$\mathrm{H} 1224 \mathrm{~A}$ outer shell deformation resulting from the $12.3 \mathrm{~m} / \mathrm{s}$ longitudinal impact was minimal, as shown in Figure 5.1.2. The lower longitudinal stiffeners buckled slightly at the container's lower circumferential bulge, reducing the container's overall length by up to $31 \mathrm{~mm}(1.22 \mathrm{in}$.) on the side shown in Figure 5.1.2, or $0^{\circ}$ circumferentially (see Appendix E: Inspection Data, Table E 1.1). On the opposite side of the container, slight weld tearing occurred in the joints between the container's bottom pan and its fork lift channels, as shown in Figure 5.1.3.

Inside the container, the upper foam insert glue joint partially separated (see Figure 5.1.4) due to deceleration of its own mass. Weld tearing along the bottom of the inner container (see Figure 5.1.5) occurred where it was unsupported by the fork lift channels. Similar deformation to the RV's threaded fore plate is shown in Figure 5.1.6, where the bending moment was provided by asymmetric loading through the fork lift channels. Bulging of the outer container's bottom pan between the fork lift channels can be seen in Figure 5.1.7. Container deformations for the LLV impact test are quantified in Tables E 1.1, E 1.2, and E 1.3 of Appendix E, from measurement locations specified in Figures 3.6, 3.7, and 3.8.

Accelerations measured (and low-pass filtered to $2 \mathrm{kHz}$ ) at the fore and aft ends of the RV midsection are presented in Figures 5.1.8 and 5.1.9. The accelerometers in each figure were located $90^{\circ}$ apart and show similar acceleration peaks of approximately $600 \mathrm{Gs}$ at the nose or fore end and $250 \mathrm{Gs}$ at the aft end. Since the carbon phenolic aeroshell is not a rigid body, some attenuation of the impact loading occurs through the RV. As identified by the time of peak acceleration and by the time of zero velocity in the integrated acceleration plots of Appendix A, the RV midsection began rebounding approximately 14 to 16 milliseconds after container impact began.

Note that dynamic strain histories, as well as all raw and filtered data, FFTs and integrated accelerations are presented for the LLV impact test in Appendix A. 


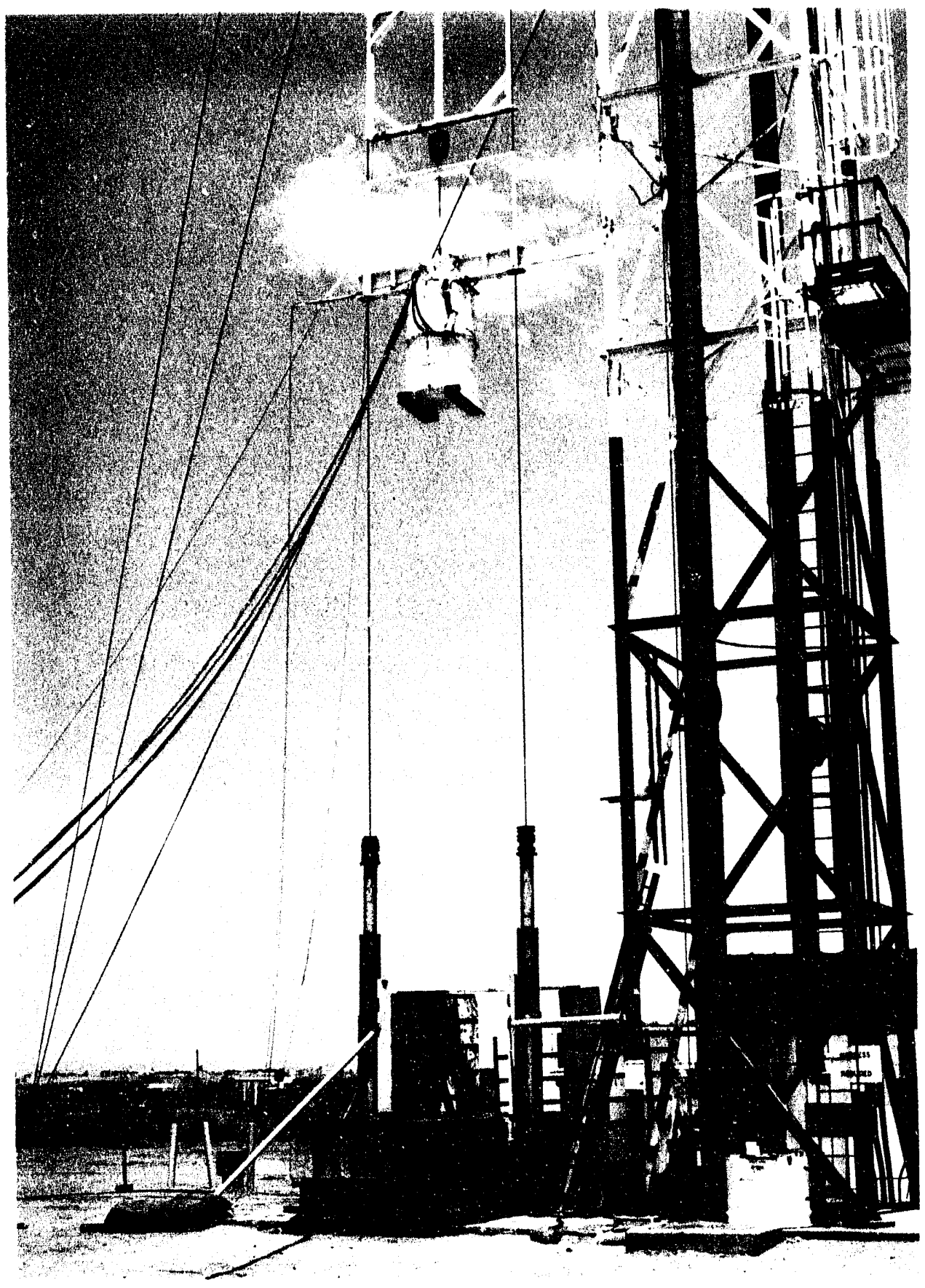

Figure 5.1.1 LLV impact test pre-drop 


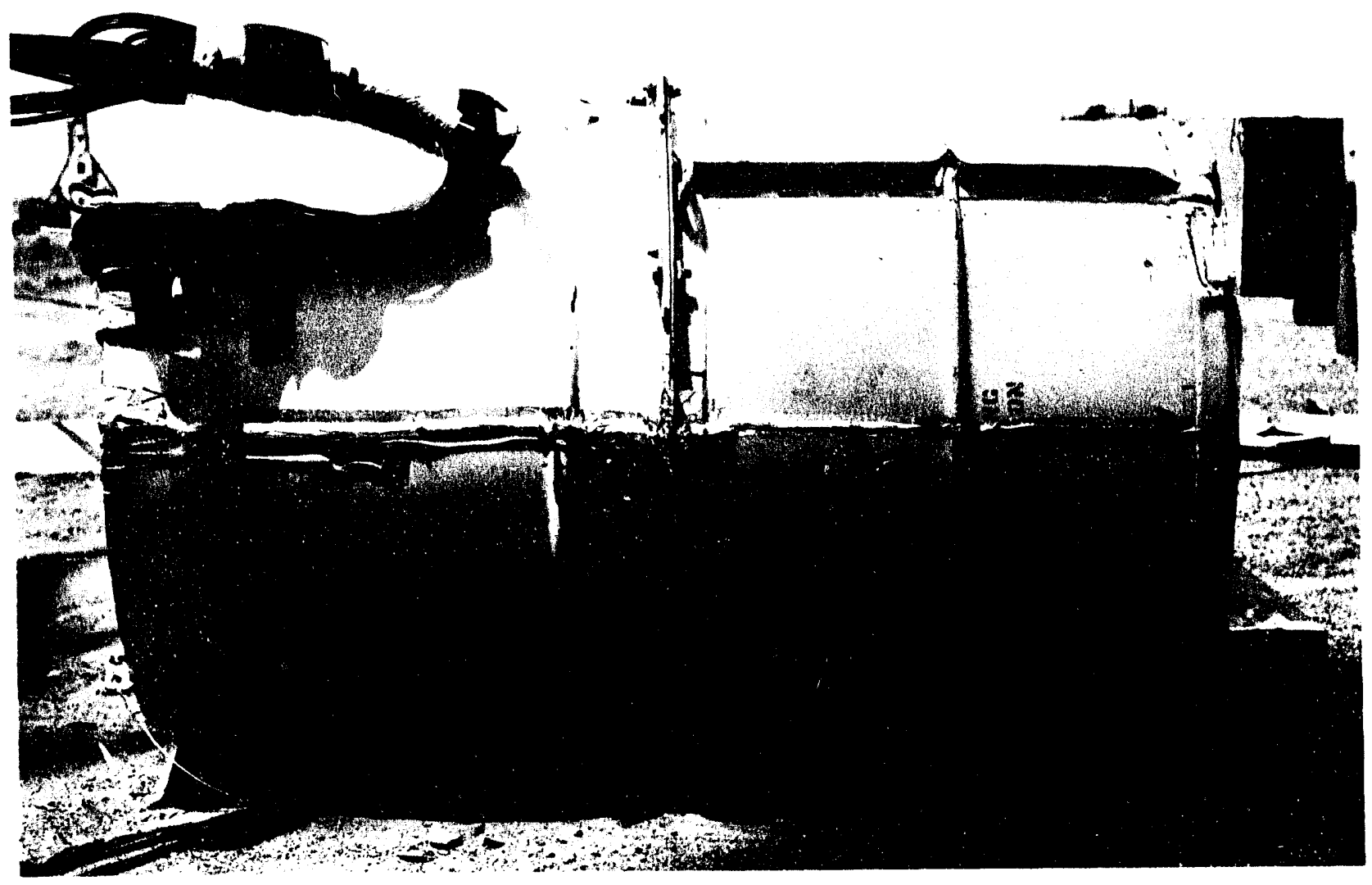

Figure 5.1.2 LLV H1224A post-test deformation 


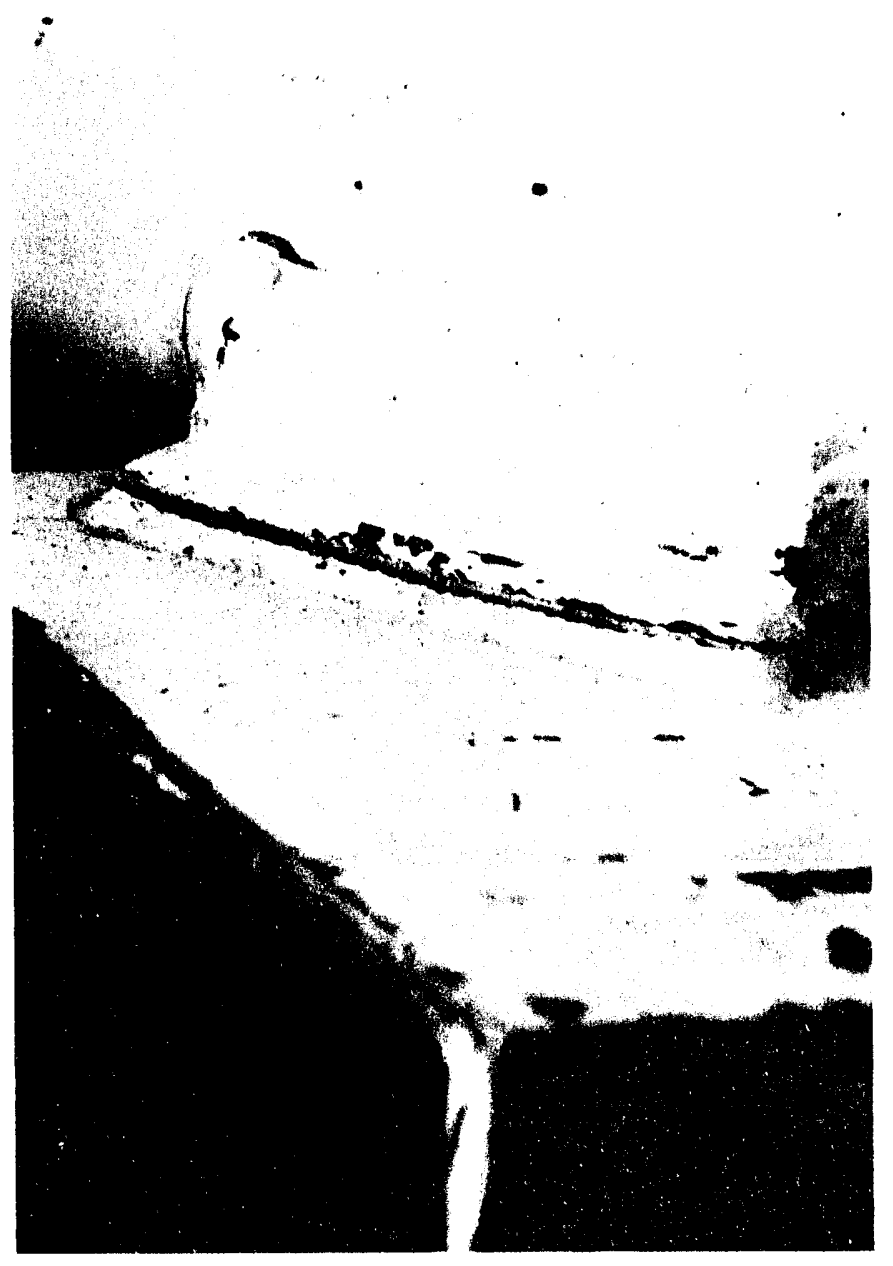

Figure 5.1.3 LLV H1224A weld crack 


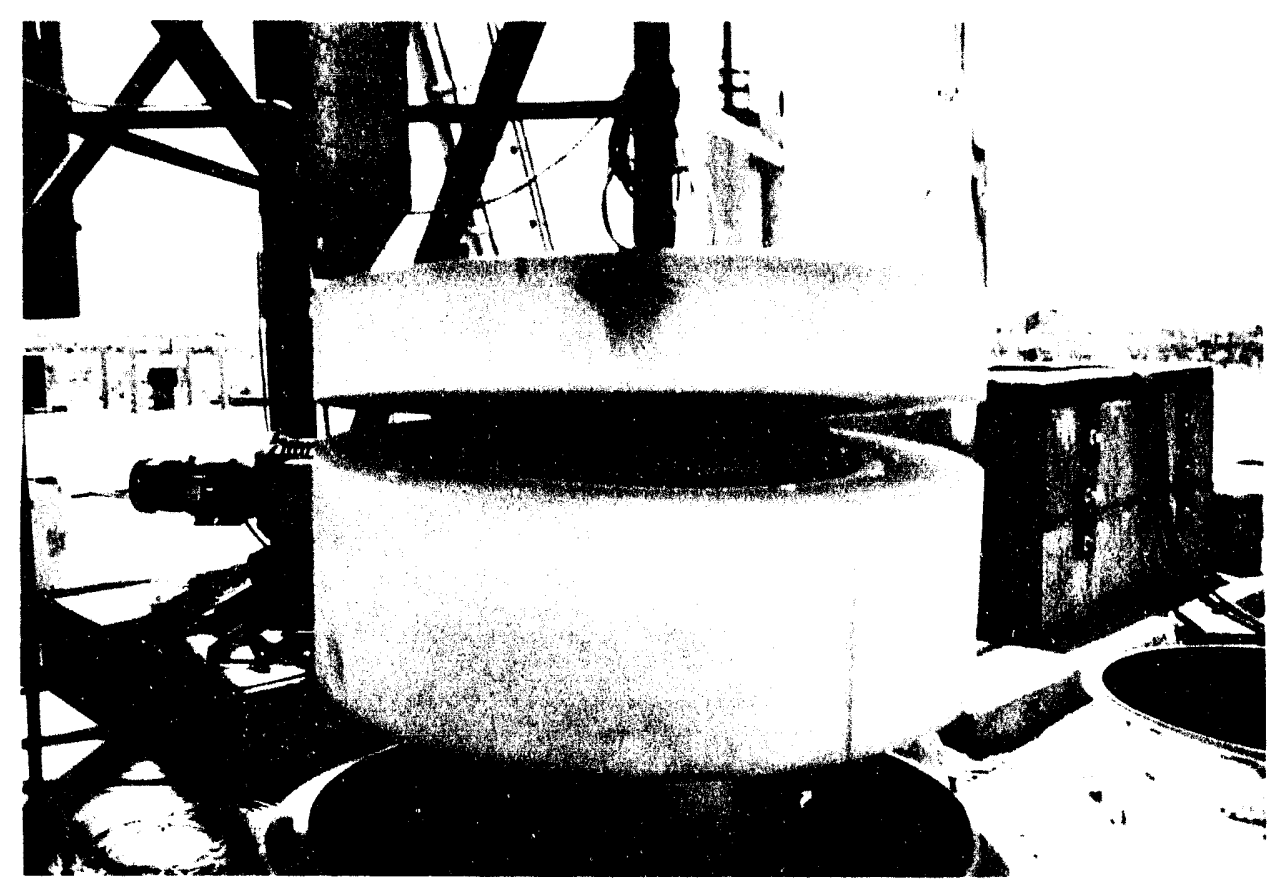

Figure 5.1.4 LLV upper foam insert joint separation

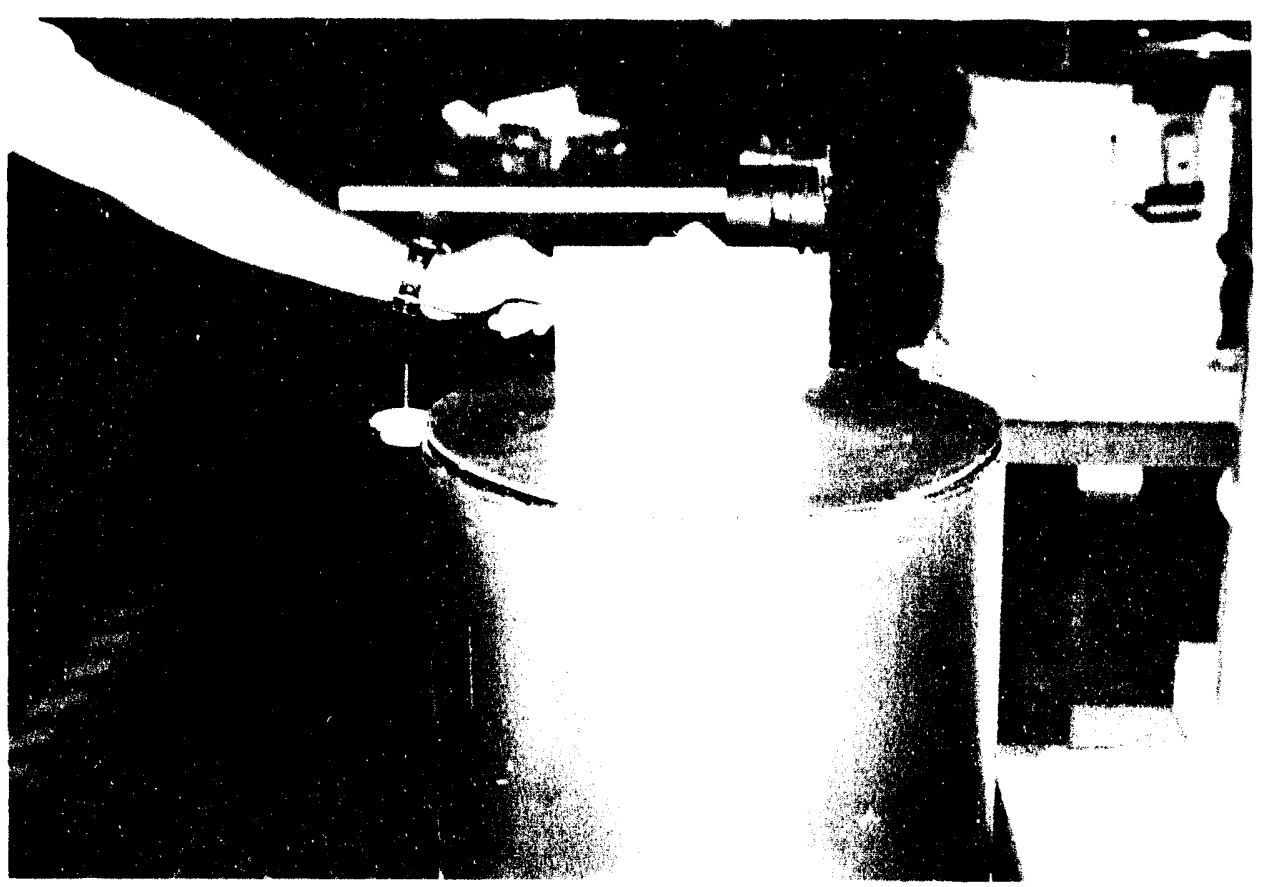

Figure 5.1.5 LLV inner container weld tears 


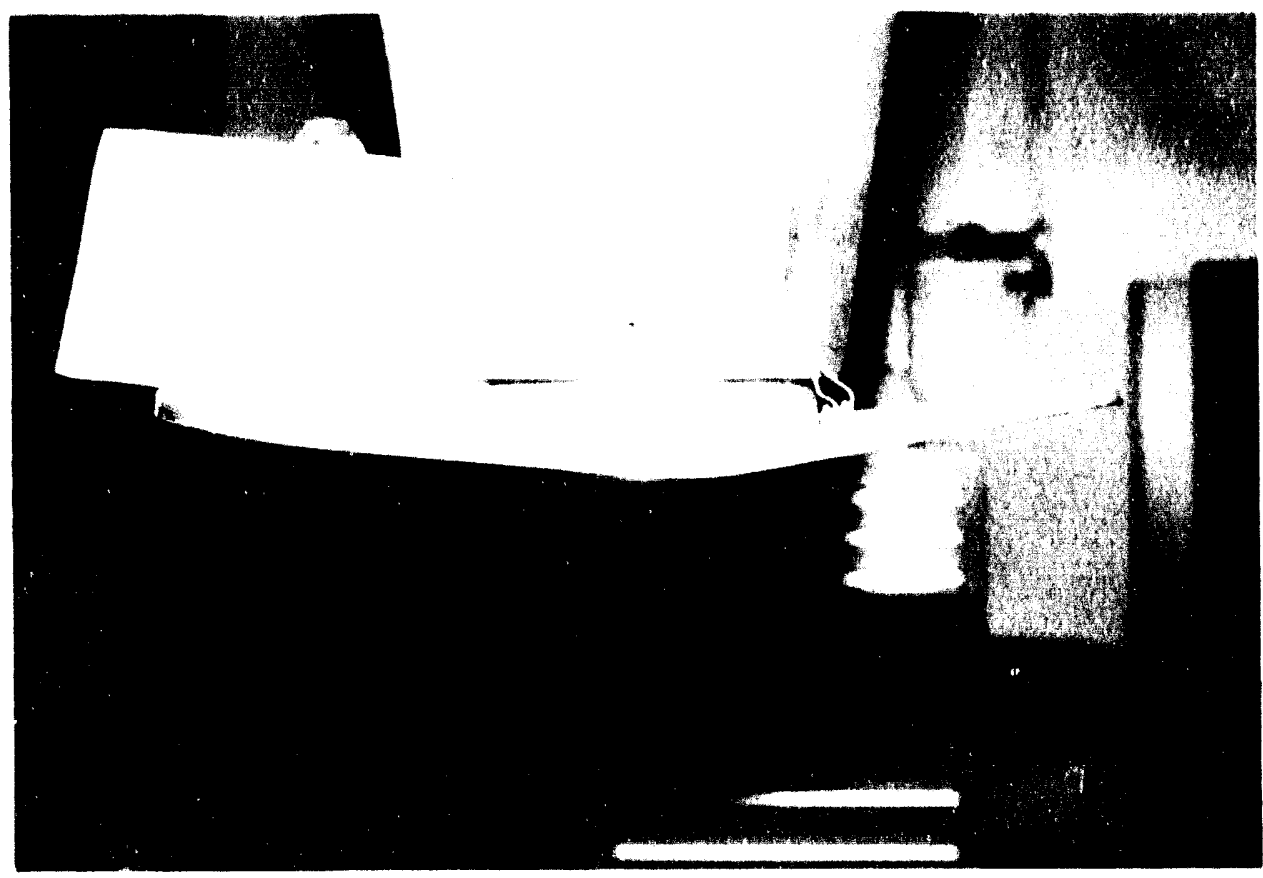

Figure 5.1.6 LLV fore plate bending

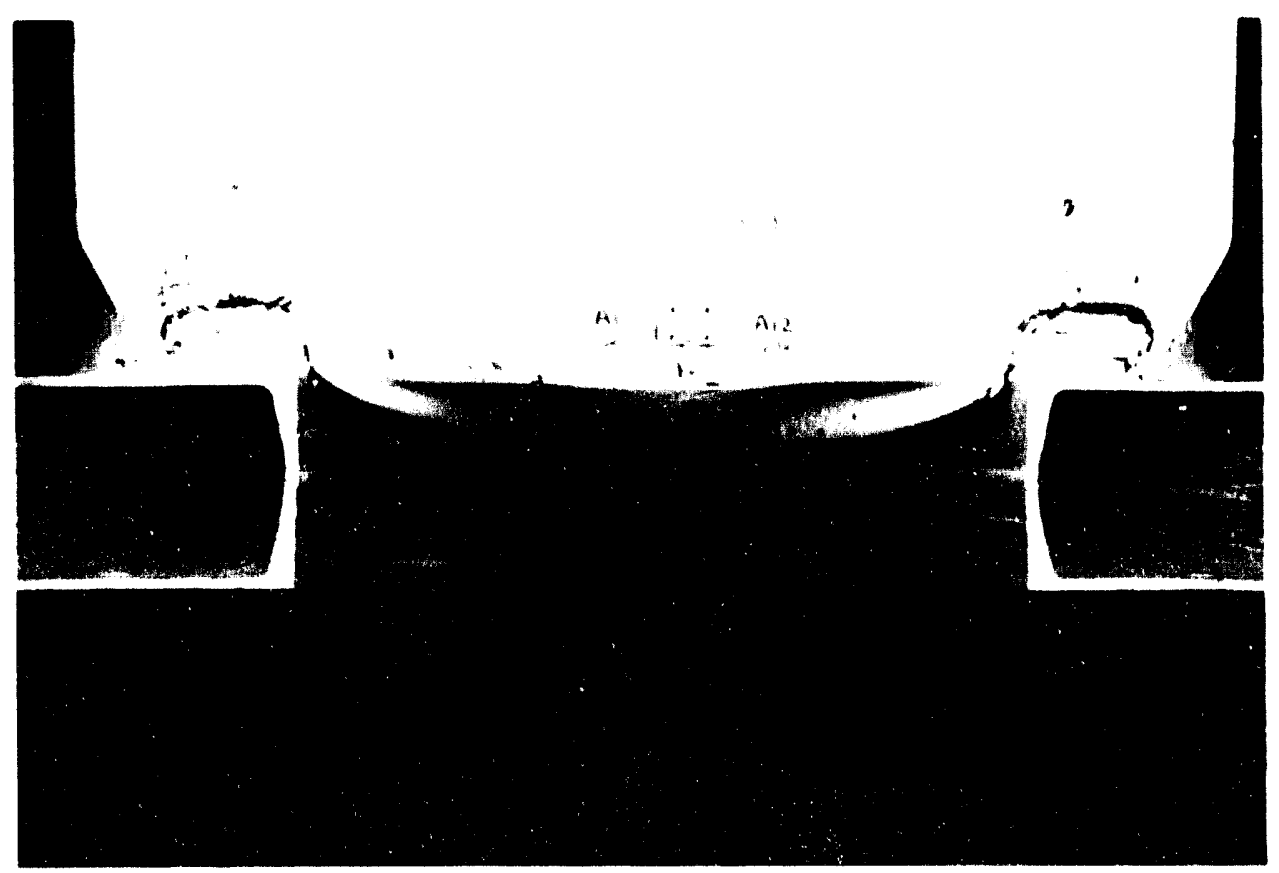

Figure 5.1.7 LLV H1224A bottom pan deformation 


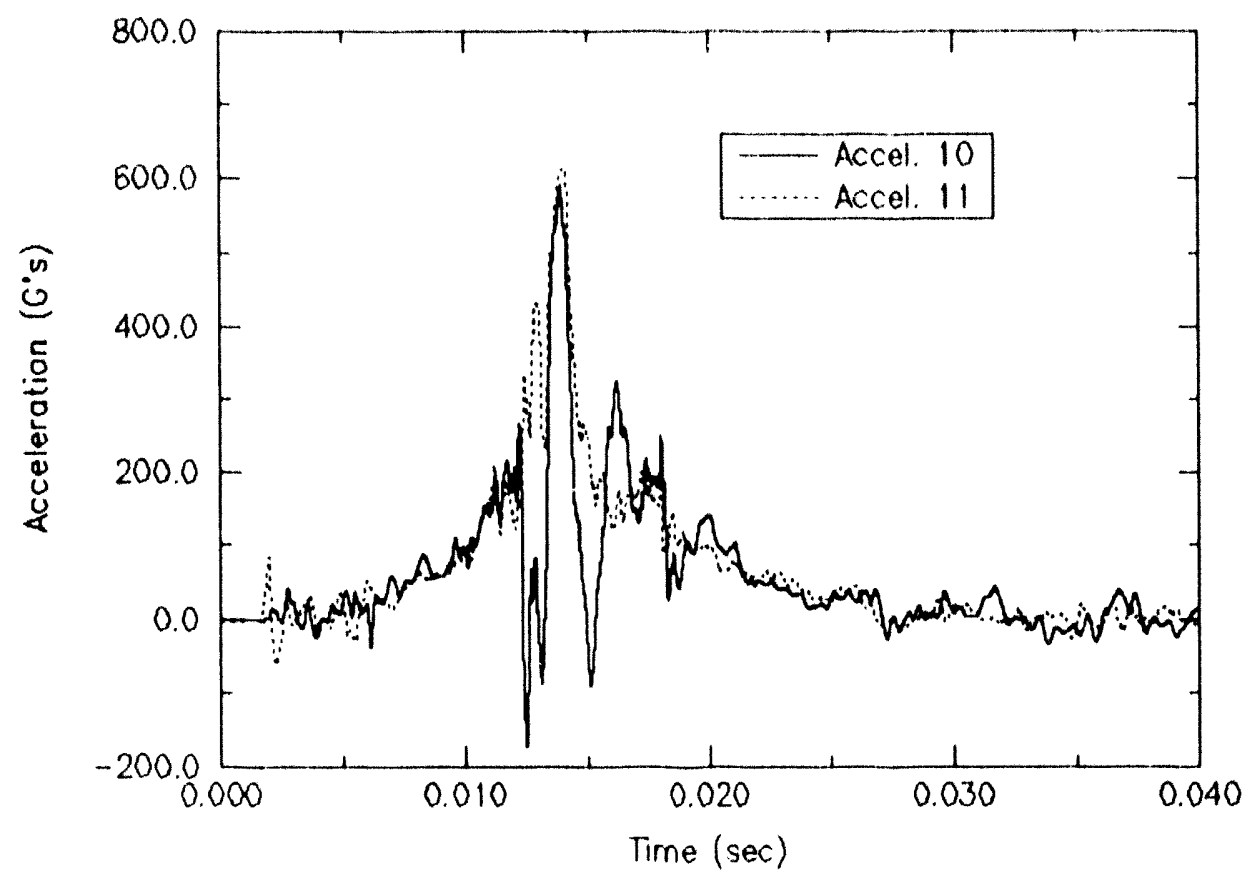

Figure 5.1.8 LLV fore plate (nose end, RV) accelerations (2 kHz filter)

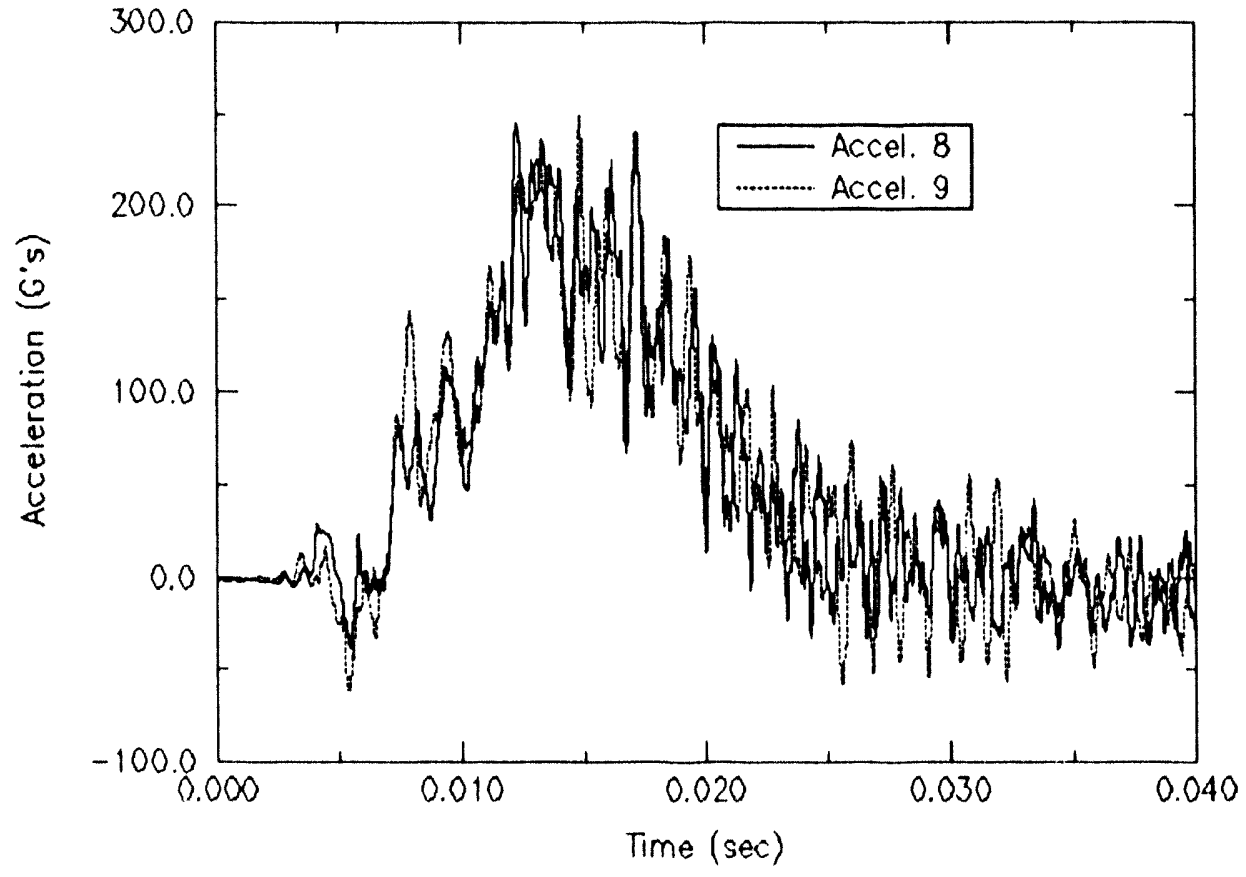

Figure 5.1.9 LLV aft cover (tail end, RV) accelerations ( $2 \mathrm{kHz}$ filter) 


\subsection{Horizontal Low Velocity}

The horizontal low-velocity (HLV) impact test was performed on June 30,1993 at the $185-\mathrm{ft}$ drop tower of Sandia National Laboratories. The container drop height was $7.9 \mathrm{~m}(26 \mathrm{ft})$ along a high-tension cable guided path which controlled impact orientation (see Figure 5.2.1). Analysis of high-speed films yielded an impact velocity of $12.1 \mathrm{~m} / \mathrm{s}(39.8 \mathrm{f} / \mathrm{s})$ at an impact angle of $3.3^{\circ}$ from perfectly horizontal. After impact, the test unit rebounded approximately $1.2 \mathrm{~m}(4 \mathrm{ft})$ from the unyielding target, tilting in mid-air toward the fork lift channel end, and impacting lightly at approximately $30^{\circ}$ to horizontal after rebounding.

H1224A outer shell deformation resulting from the $12.1 \mathrm{~m} / \mathrm{s}$ horizontal impact was greatest at the top end, as shown in Figure 5.2.2. The flexible foam inserts helped force the upper container shell back out to nearly its original diameter at the top end. The diameter at the container's outer shell midsection was reduced by approximately $82 \mathrm{~mm}\left(3.2 \mathrm{in}\right.$.) at $0^{\circ}$ circumferentially (see Appendix E: Inspection Data, Table E 2.1, and Figure 5.2.5). On the opposite end of the container near the fork lift channels, no deformation is visible, as shown in Figure 5.2.3.

Inside the container, the inner container diameter was decreased at its midsection slightly, as shown in Figure 5.2.4, due to contact with the outer shell during impact. The bending moment through the RV midsection due to support only at its ends during the side-on impact caused slight fracture of the carbon phenolic aeroshell at its midpoint and fore end $\left(0^{\circ}\right.$ circumferentially), as shown in Figures 5.2.6a and 5.2.6b. The rapid loading of the RV after the flexible foam "bottomed out" caused bolts on the fore-most fore end weight plate to shear, as shown in Figure 5.2.7. No deformation was visible on the fore plate and aft cover. Container and RV deformations for the HLV impact test are quantified in Tables E 2.1, E 2.2, and E 2.3 of Appendix E, from measurement locations specified in Figures 3.6, 3.7, and 3.8.

Accelerations measured (and low-pass filtered to $2 \mathrm{kHz}$ ) at the aft and fore ends of the RV midsection are presented in Figures 5.2.8 and 5.2.9. The accelerometers in each figure were located $90^{\circ}$ apart and show similar acceler ation peaks of approximately 350 Gs at the aft end and 600 Gs at the nose or fore end. As identified by the time of peak acceleration and by the time of zero velocity in the integrated acceleration plots of Appendix B, the RV midsection aft end began rebounding approximately 15 milliseconds after container impact began and the fore end approximately 19 milliseconds after impact. The time delay between RV aft and fore end rebound is due in part to the slightly off-horizontal container impact.

Dynamic strain histories, as well as all raw and filtered data, FFTs and integrated accelerations are presented for the HLV impact test in Appendix B. 


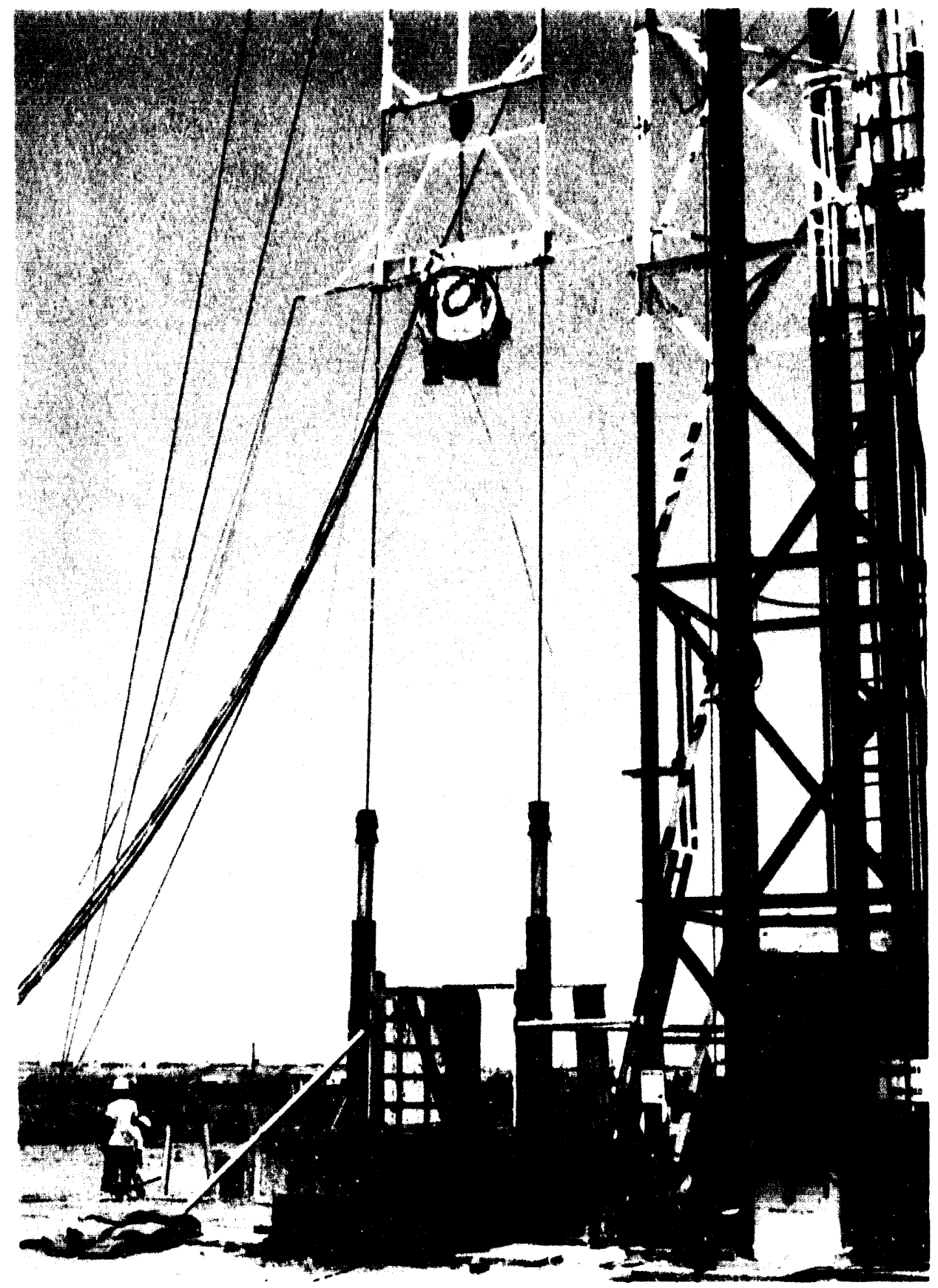

Figure 5.2.1 HLV impact test pre-drop 


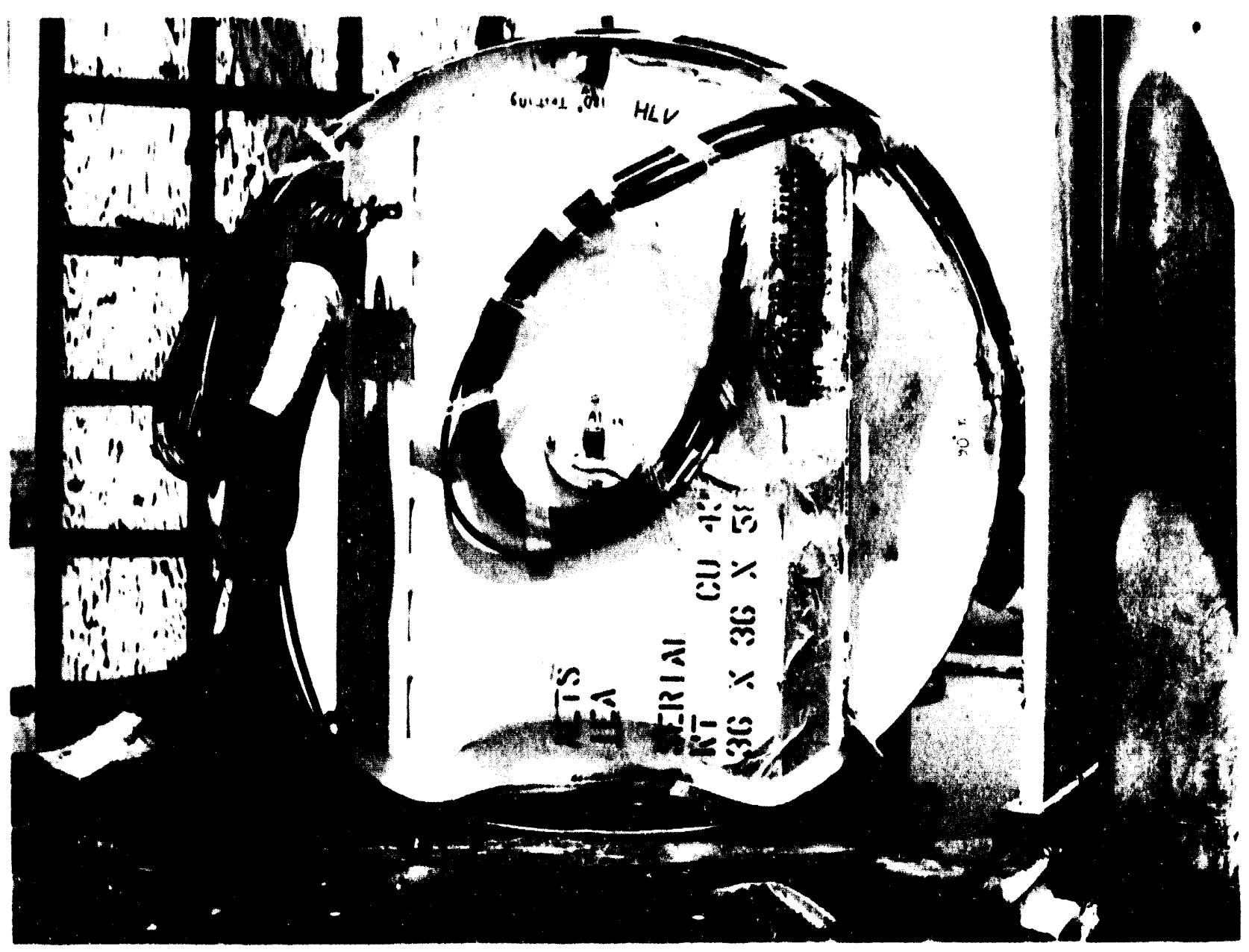

Figure 5.2.2 HLV H1224A top-end post-test deformation 


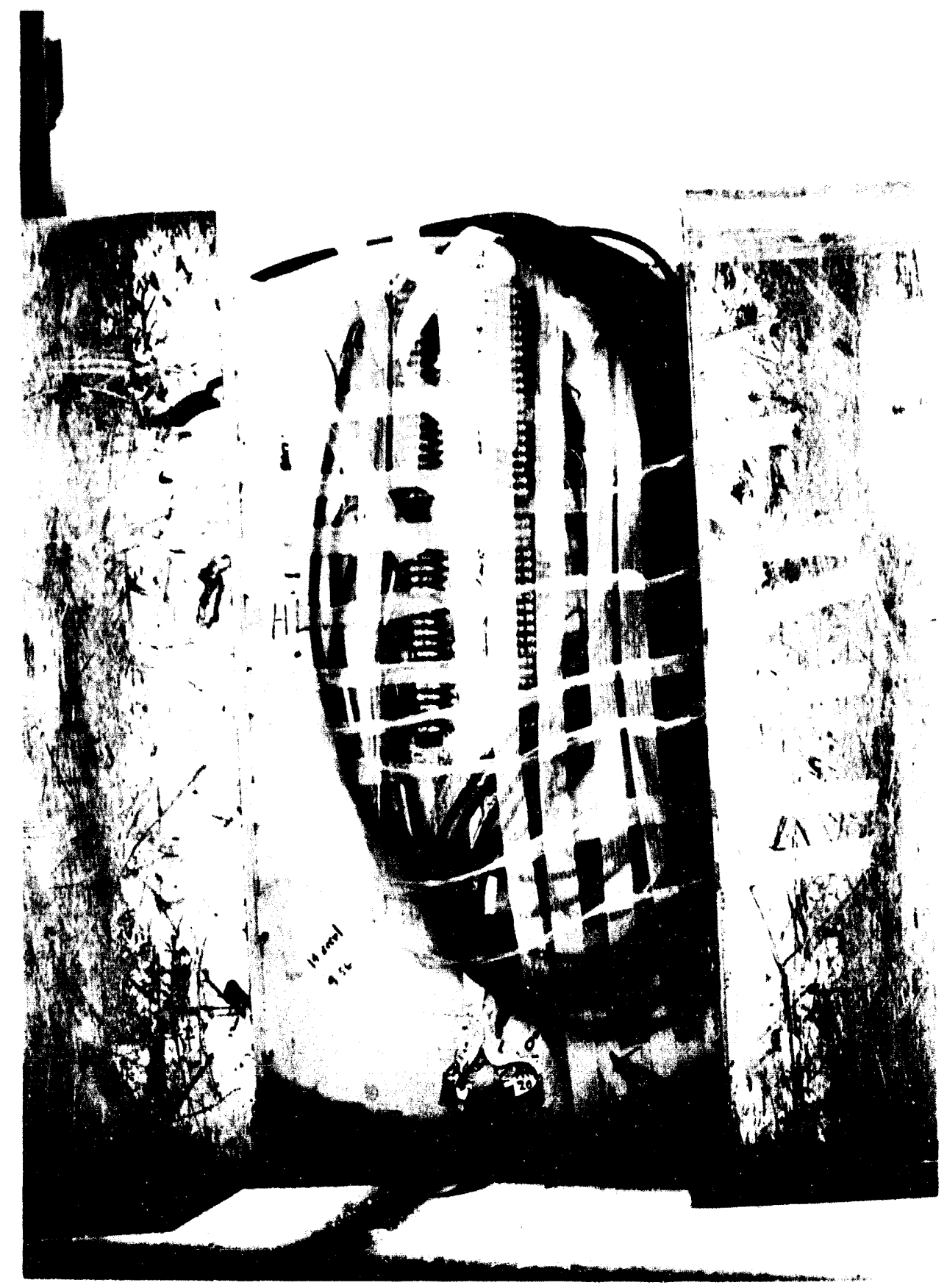

Figure 5.2.3 HLV H1224A bottom-end post-test deformation 


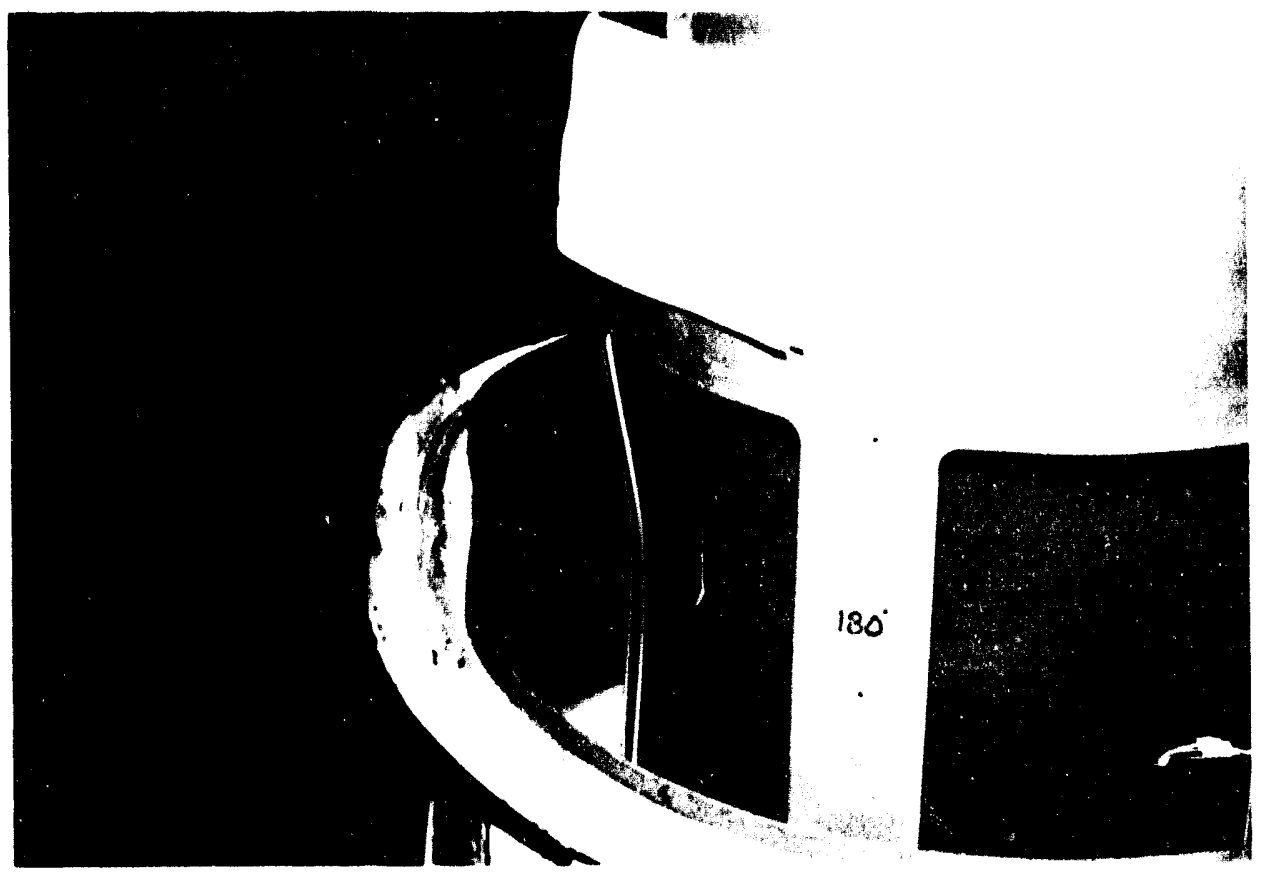

Figure 5.2.4 HLV inner container bending

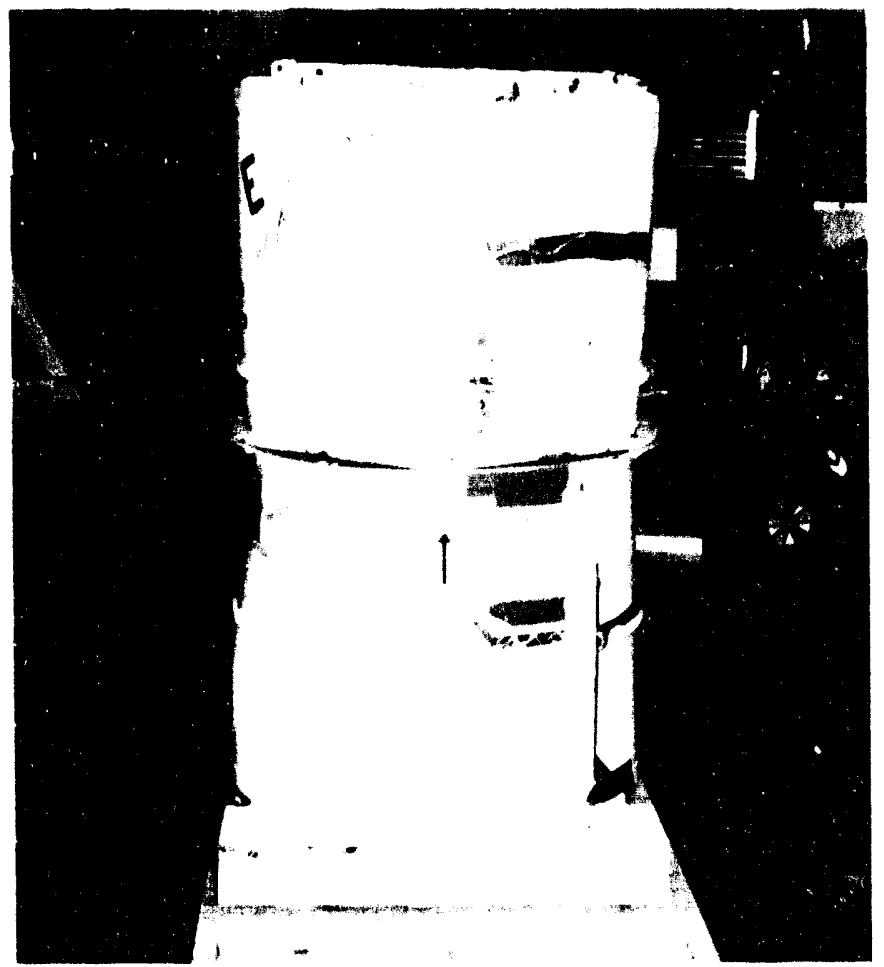

Figure 5.2.5 HLV H1224A outer shell mid-body bending 


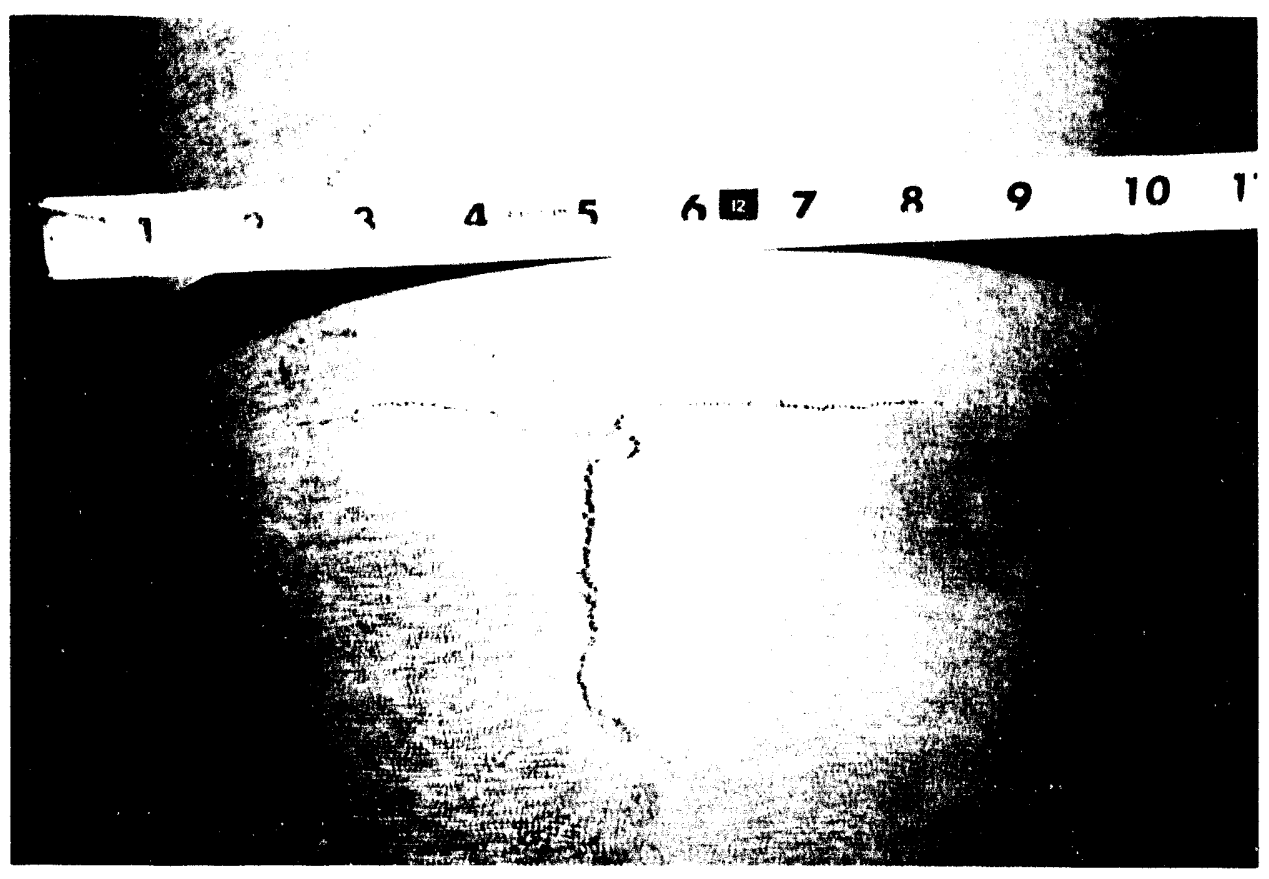

Figure 5.2.6a HLV Mk12a Mod6c cracking

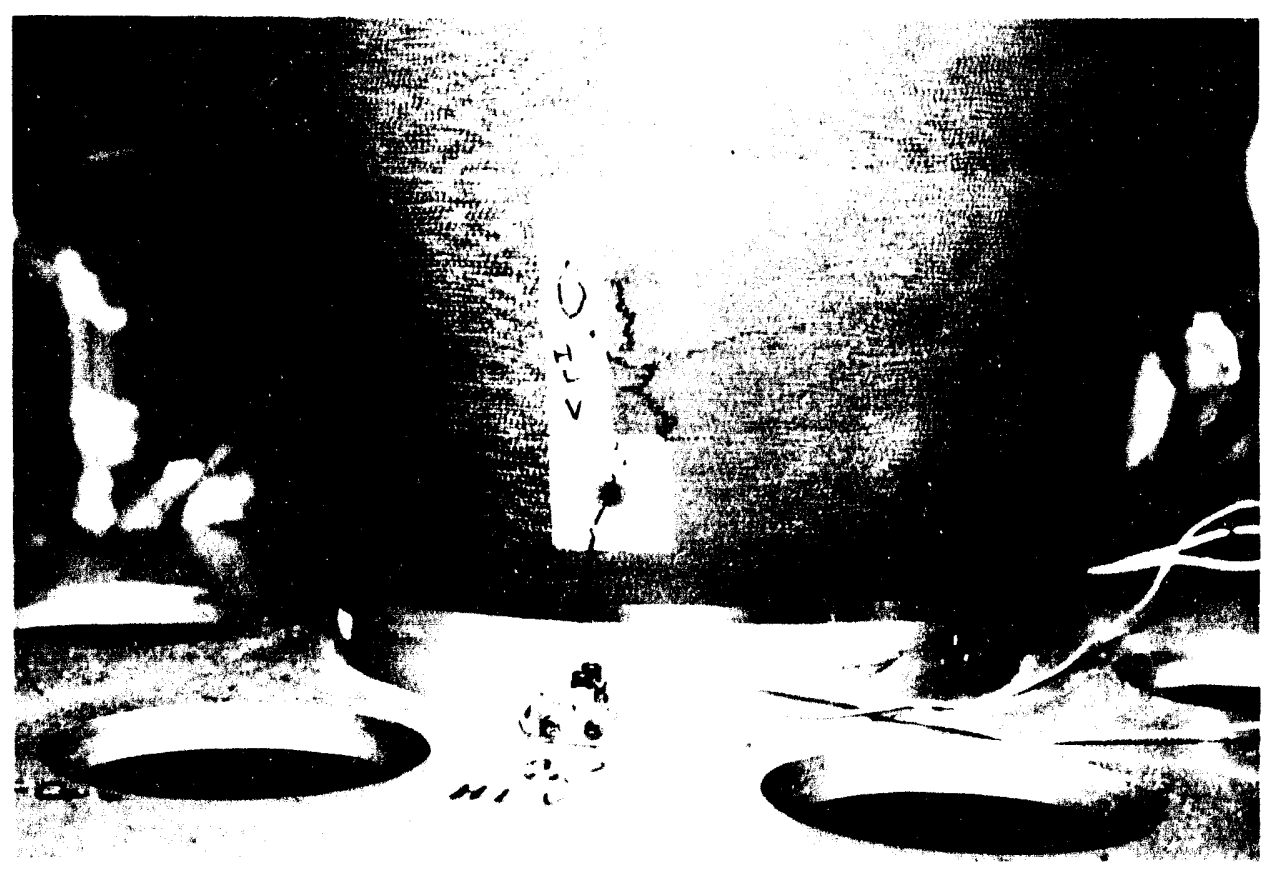

Figure 5.2.6b HLV Mk12a Mod6c cracking 


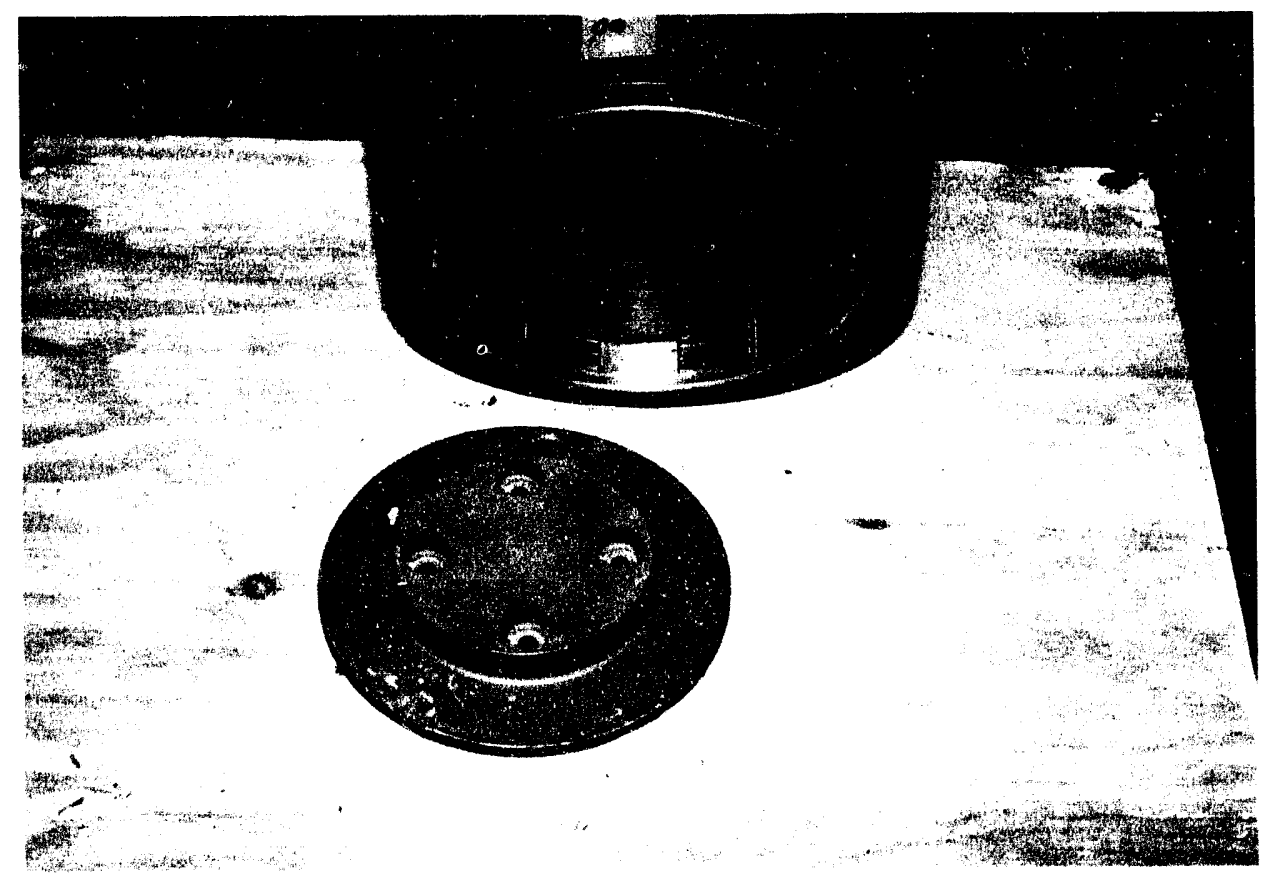

Figure 5.2.7 HLV RV weight plate bolt shearing 


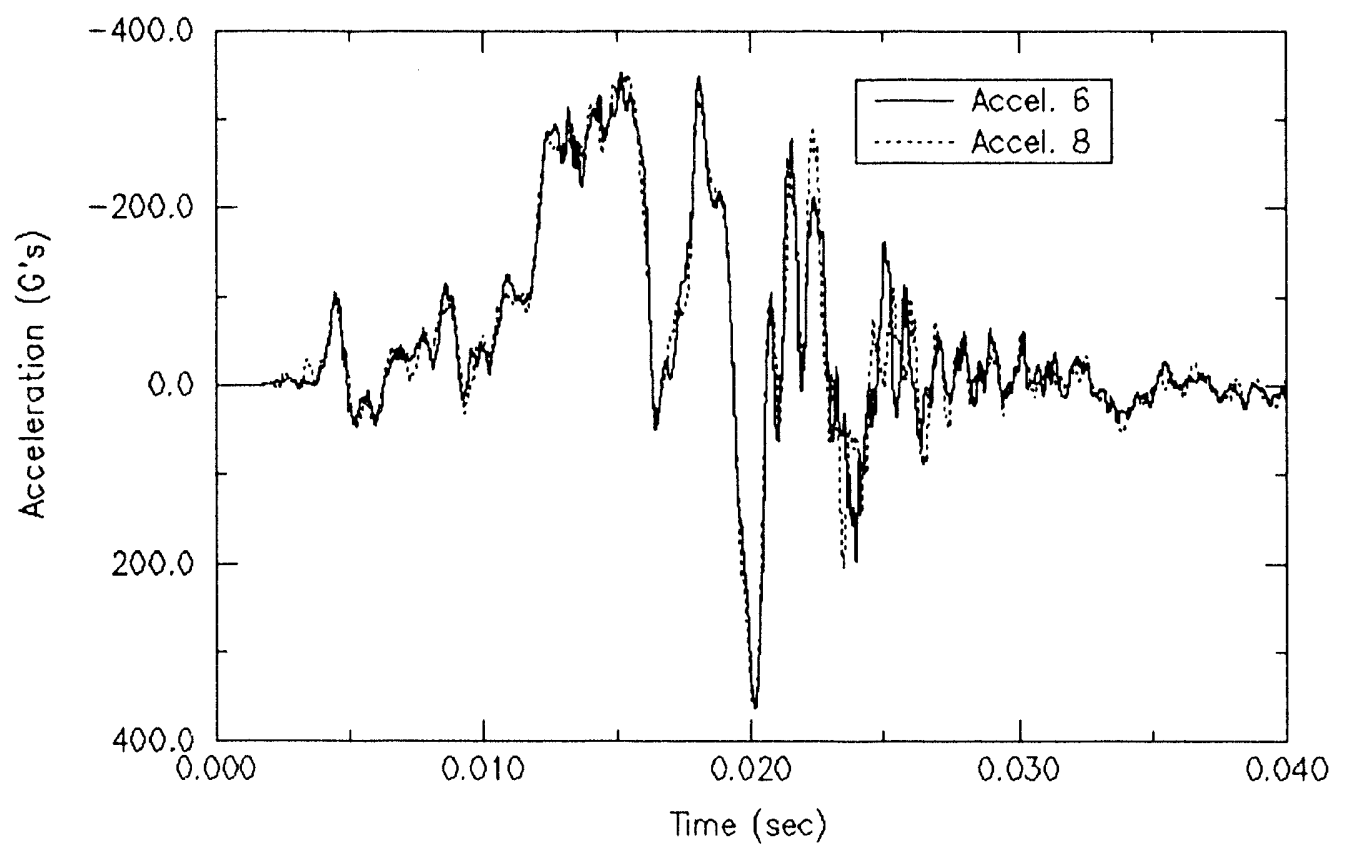

Figure 5.2.8 HLV aft cover (tail end, RV) accelerations ( $2 \mathrm{kHz}$ filter)

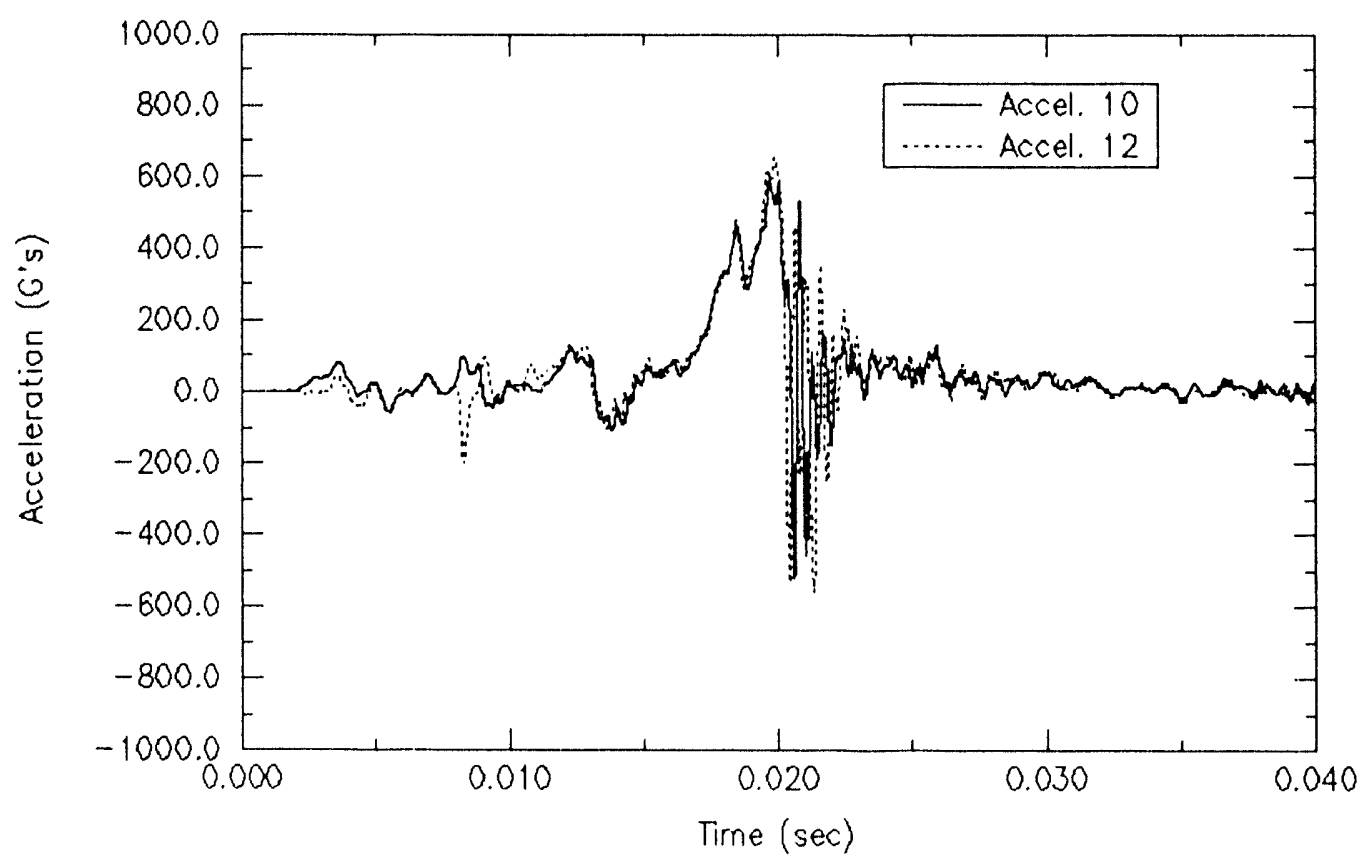

Figure 5.2.9 HLV fore plate (nose end, RV) accelerations ( $2 \mathrm{kHz}$ filter) 


\subsection{Longitudinal High Velocity}

The longitudinal high-velocity (LHV) impact test was performed on August 12, 1993 at the Aerial Cable Facility of Sandia National Laboratories. The container drop height was $86 \mathrm{~m}$ (283 $\mathrm{ft}$ ) along a high-tension cable guided path which controlled impact orientation (see Figure 2.1). The LHV test unit is shown in Figure 5.3.1 before impact. Analysis of high-speed films yielded an impact velocity of $38.0 \mathrm{~m} / \mathrm{s}(124.7 \mathrm{ft} / \mathrm{s})$ at an impact angle of $0.7^{\circ}$ from perfectly upright. After impact, the test unit rebounded about $10 \mathrm{~cm}(4 \mathrm{in}$.) at most from the unyielding target, tilting in mid-air very slightly toward the $0^{\circ}$ circumferential axis.

H1224A outer shell deformation resulting from the $38.0 \mathrm{~m} / \mathrm{s}$ longitudinal impact was greatest at the bottom end and in the fork lift channels, as shown in Figure 5.3.2a, 5.3.2b, and 5.3.2c. Buckling in the container's lower half of the outer shell was not significantly greater than that observed in the LLV impact test, but fork lift channel weld fracture and bending was incomparable. The upper half of the outer container shell suffered no visible deformation but, similar to the LLV impact tests, lower longitudinal stiffeners buckled at the container's lower circumferential bulge combining with fork lift channel deformation to reduce the container's overall length by up to 180 $\mathrm{mm}$ (7.1 in.) at $225^{\circ}$ circumferentially (see Appendix E: Inspection Data, Table E 3.1).

Inside the container, the inner container buckled severely, as shown in Figure 5.3.3, reducing its overall length by up to $170 \mathrm{~mm}(6.8 \mathrm{in}$.). Extreme deformation of the carbon phenolic aeroshell, however, caused the aft cover to end up below the top level of the inner container, as shown in Figure 5.3.4. Both fore and aft RV weight plate groups sheared their mounting flanges and many inter-weight-plate bolts sheared during the severe impact. Weight plate deceleration led to severe fracture in tile RV midsection aeroshell carbon phenolic and aluminum substrate, as shown in Figures 5.3.5 and 5.3.6. Severe bending in the fore plate can also be seen in Figure 5.3.5 and Figure 5.3.8. About 7.5 milliseconds after initial impact, the crushed aeroshell's nose or fore end came into contact with the fore accelerometers and their lead wires, yielding spurious results, as shown in Figures 5.3.7 and 5.3.9. Container and RV deformations for the LHV impact test are quantified in Tables E 3.1, E 3.2, and E 3.3 of Appendix E, from measurement locations specified in Figures 3.6, 3.7, and 3.8.

Accelerations measured (and low-pass filtered to $2 \mathrm{kHz}$ ) at the fore and aft ends of the RV midsection are presented in Figures 5.3.9 and 5.3.10. The accelerometers in each figure were located $90^{\circ}$ apart and show similar acceleration peaks of approximately 10,000$) \mathrm{Gs}$ at the fore end (before the signal became faulty due to aeroshell fracture) and 2,000 Gs at the aft end. As identified by the time of peak acceleration and by the time of zero velocity in the integrated acceleration plots of Appendix C, the RV midsection fore end began rebounding approximately 6.3 milliseconds after container impact began and the aft end approximately 7.5 milliseconds after impact. The time delay between RV fore and aft end peak decelerations is due to energy loss associated with aeroshell fracture.

Dynamic strain histories, as well as all raw and filtered data, FFTs and integrated accelerations are presented for the LHV impact test in Appendix C. 


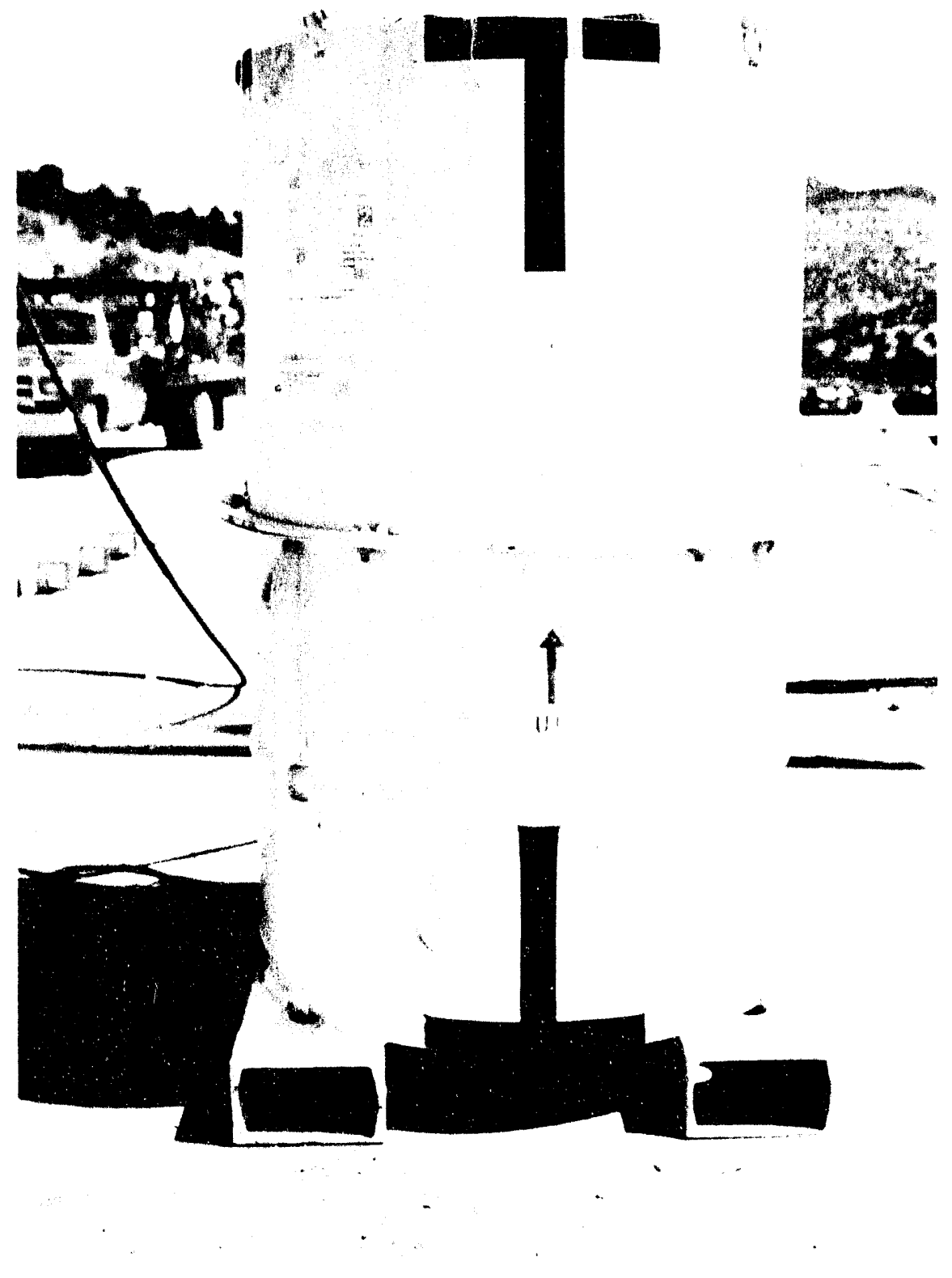

Figure 5.3.1 LHV impact test pre-drop 


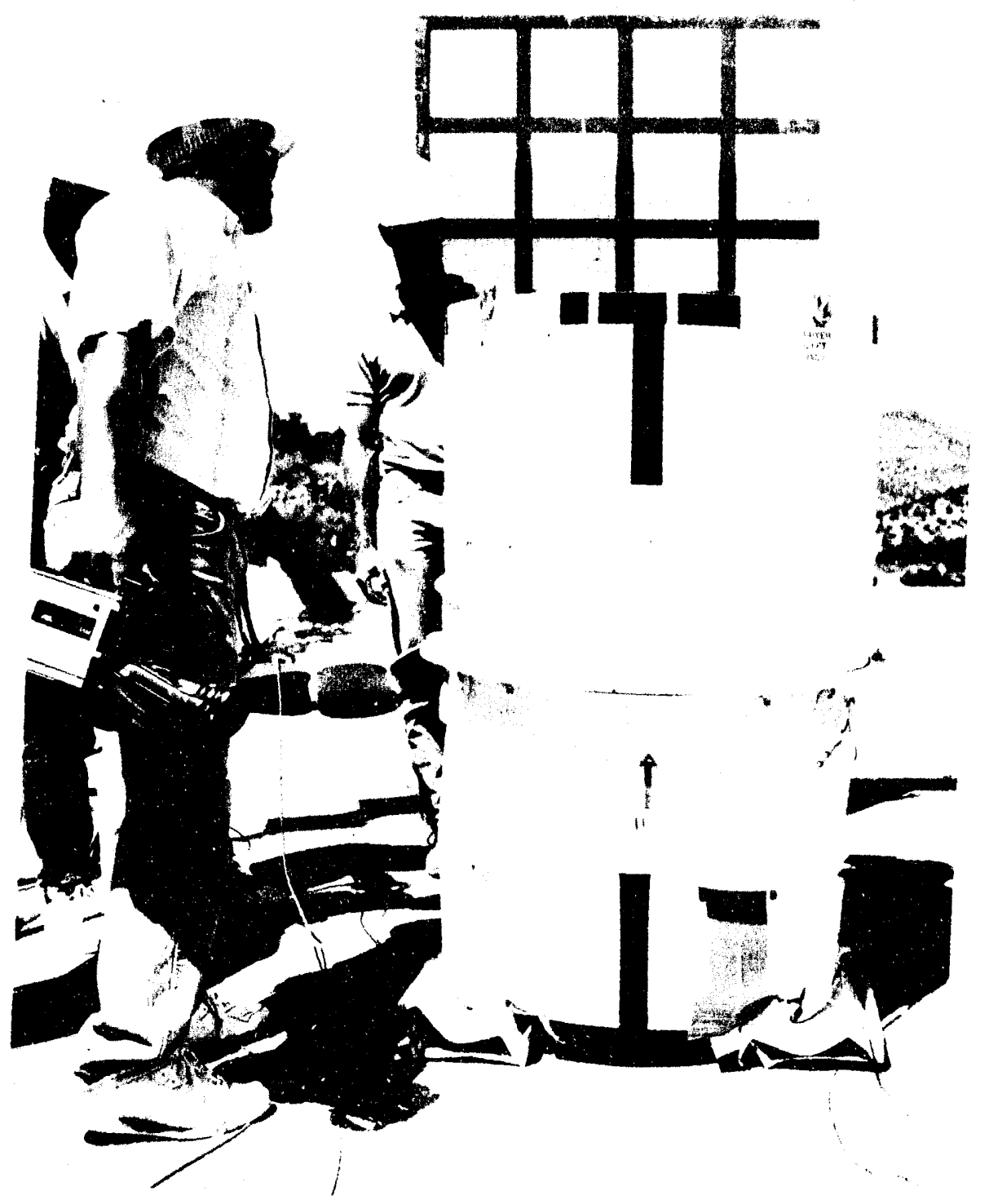

Figure 5.3.2a LHV H1224A post-test deformation 


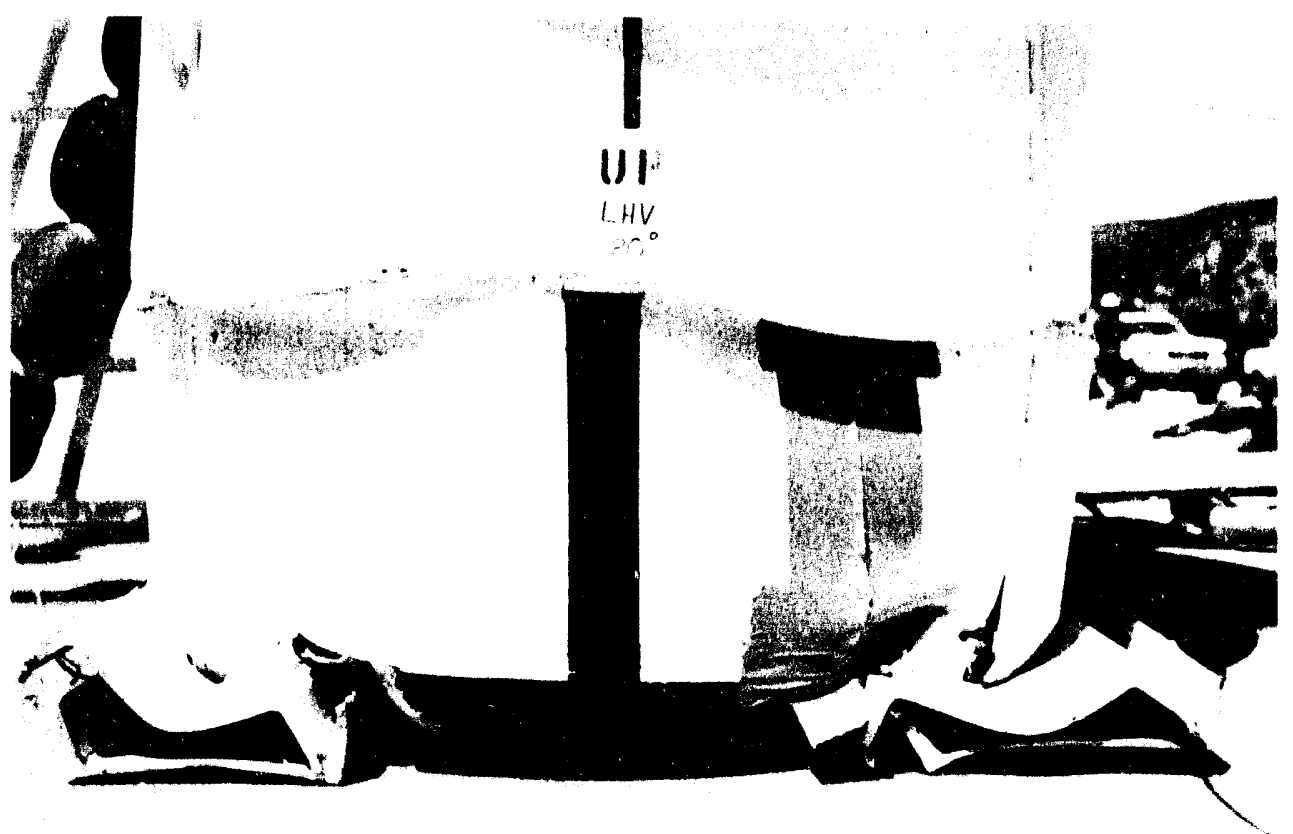

Figure 5.3.2b LHV H1224A post-test deformation

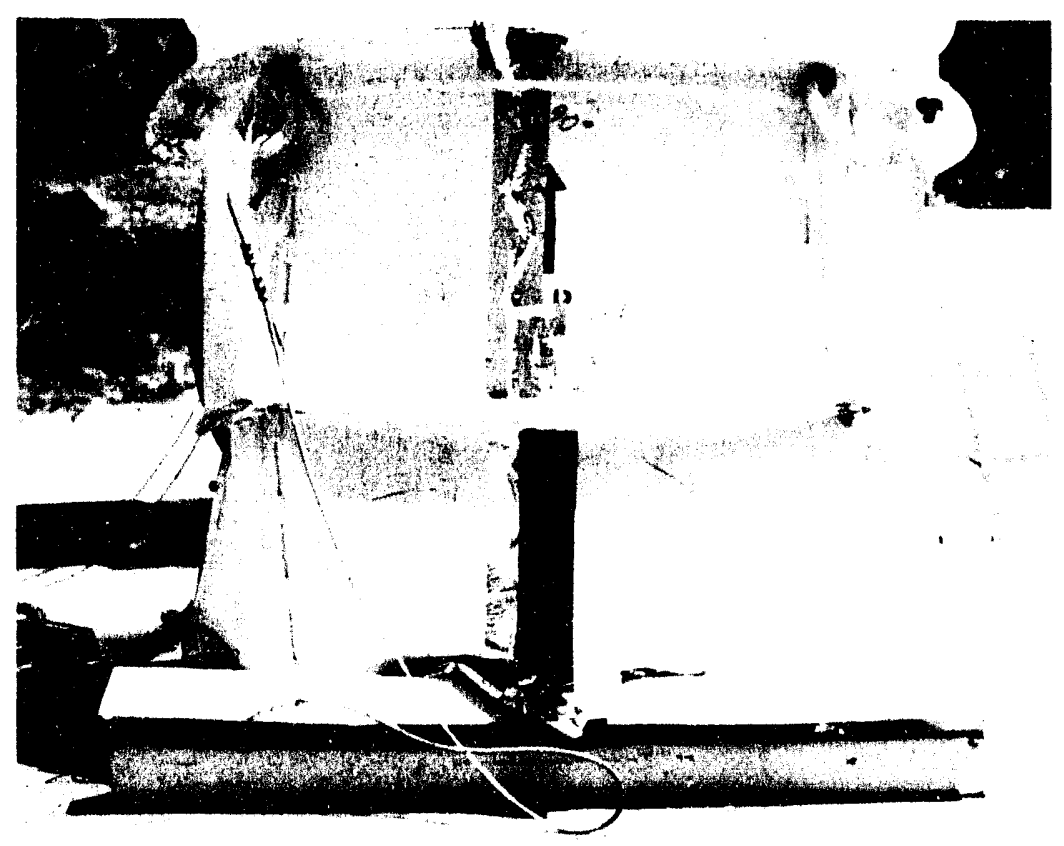

Figure 5.3.2c LHV H1224A post-test deformation 


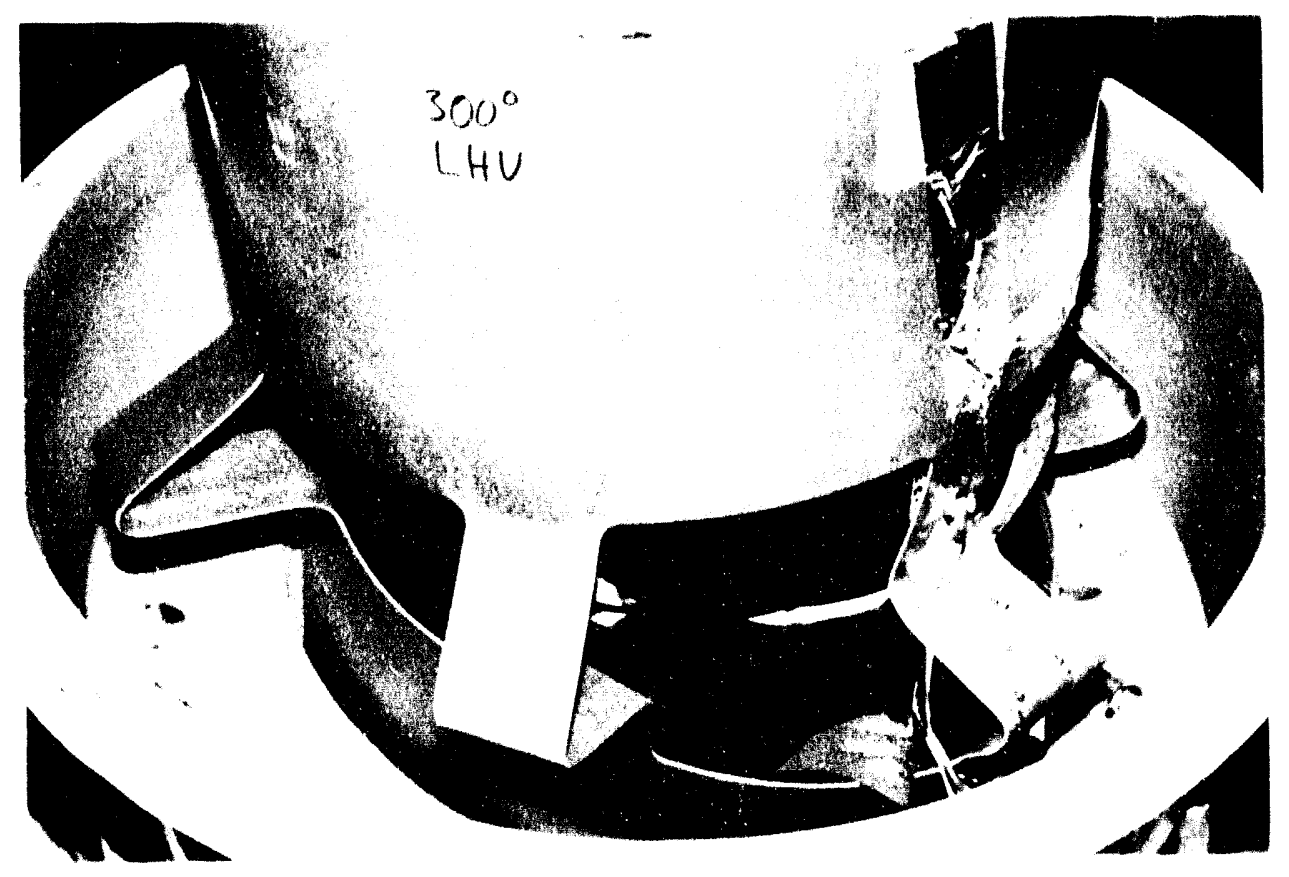

Figure 5.3.3 LHV inner container buckling

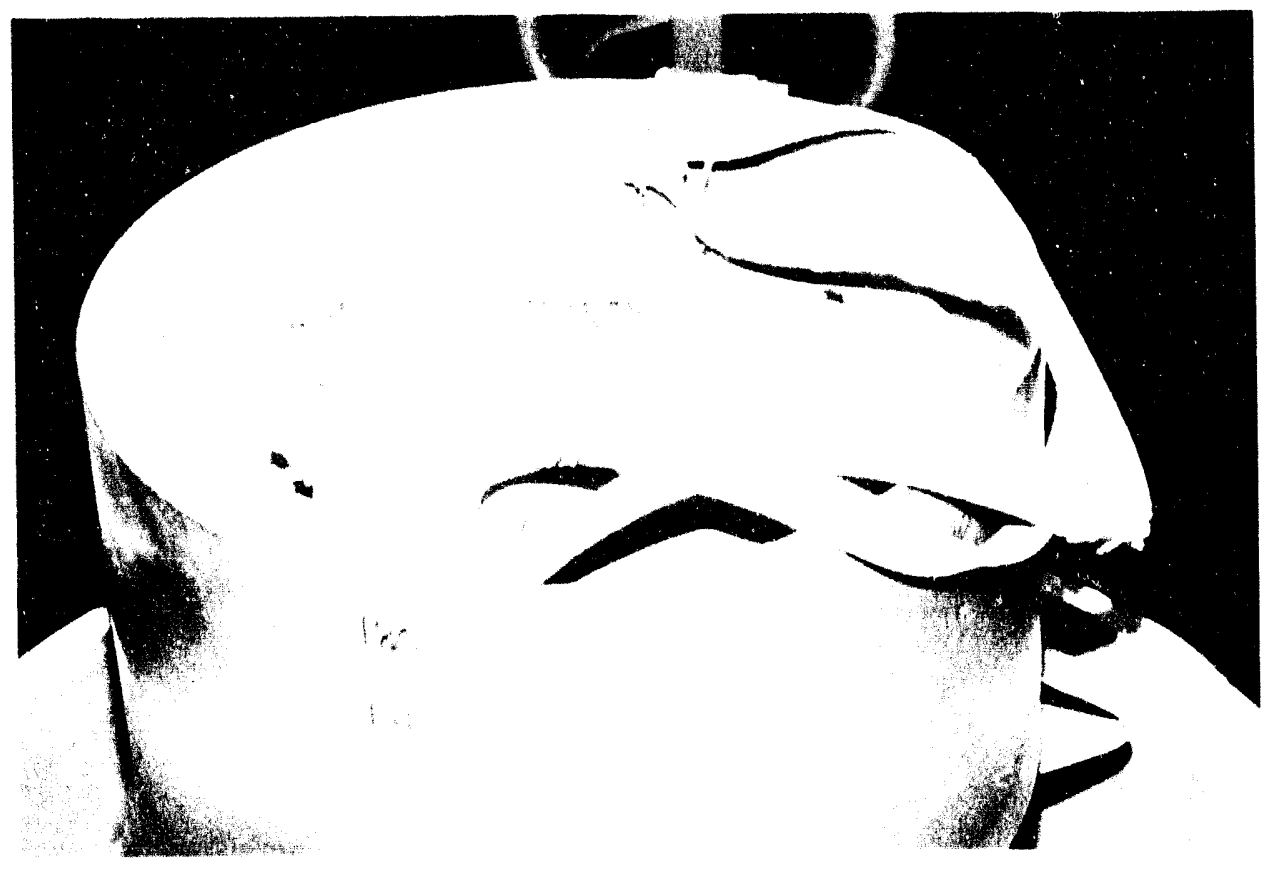

Figure 5.3.4 LHV aft cover below top level of inner container 


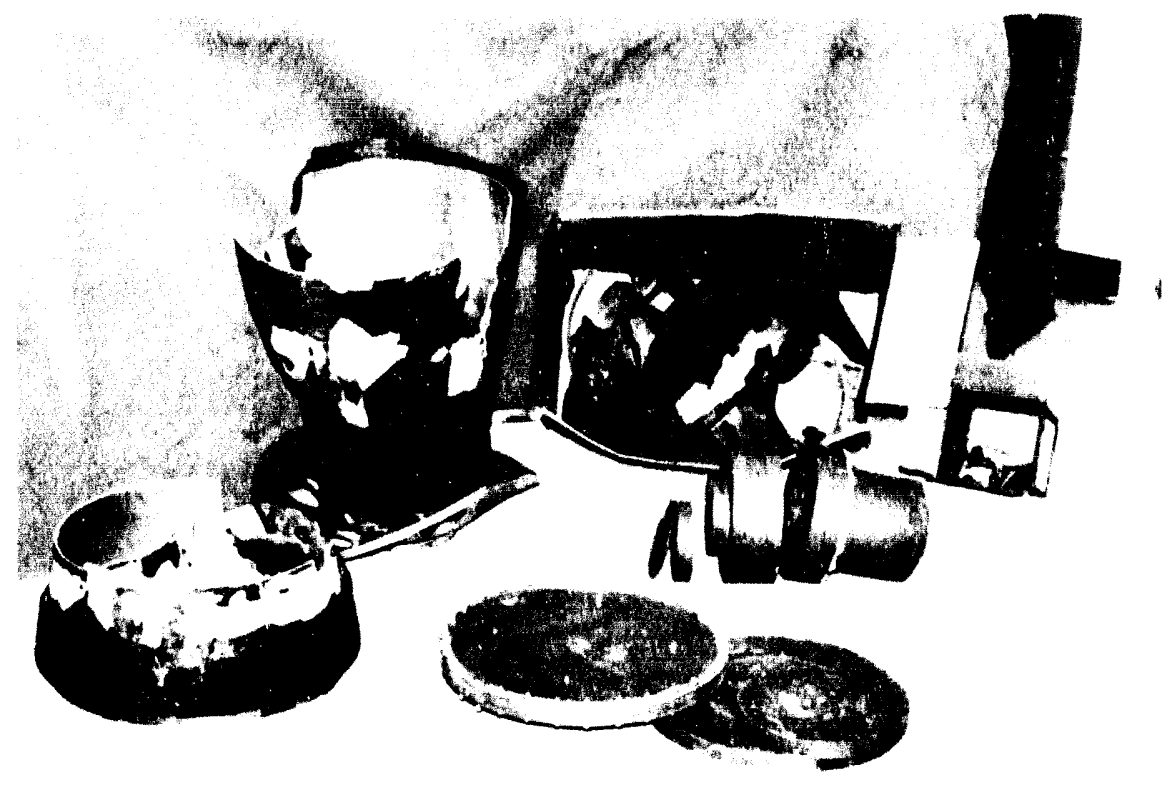

Figure 5.3.5 Mk12a Mod6c aeroshell fracture and weight plate detachment 


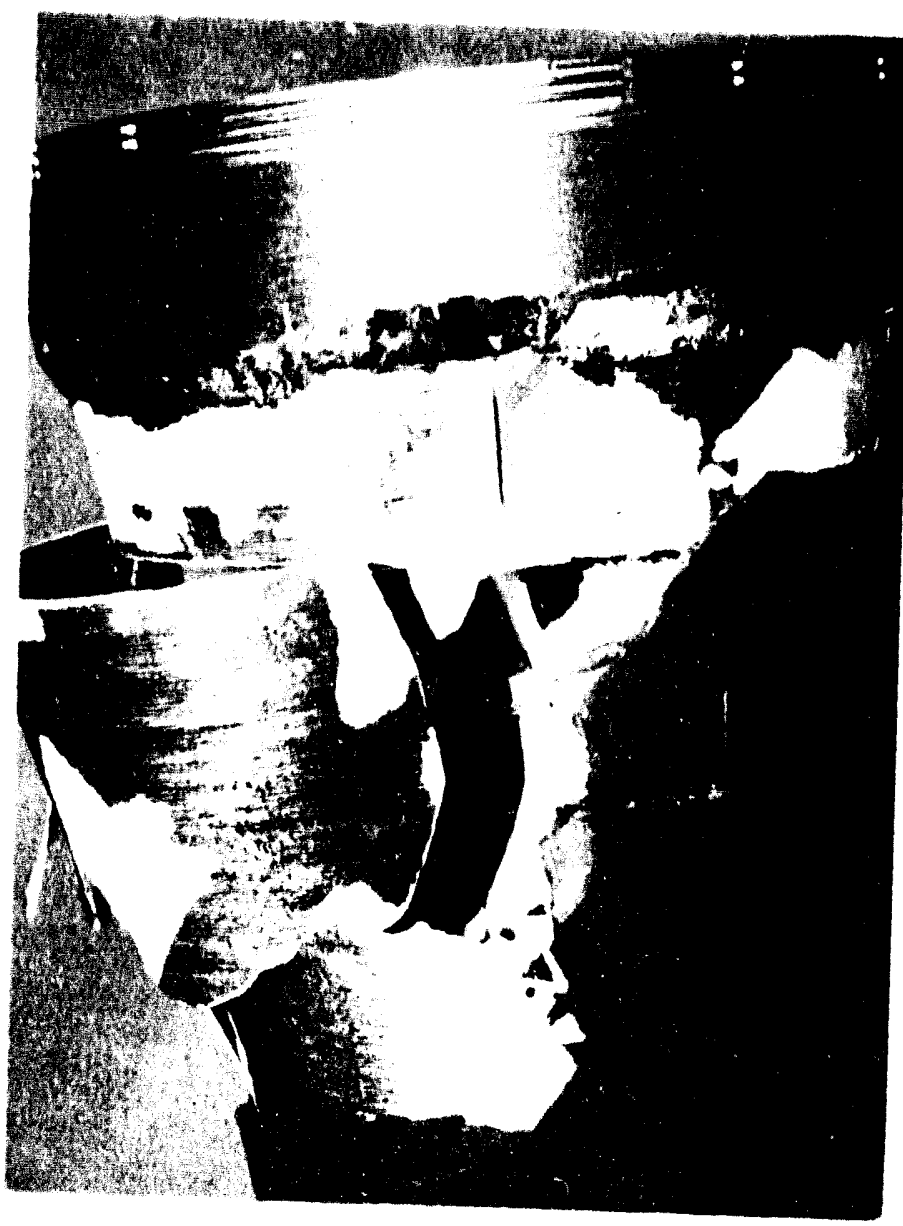

Figure 5.3.6 LHV RV carbon phenolic aeroshell fracture 


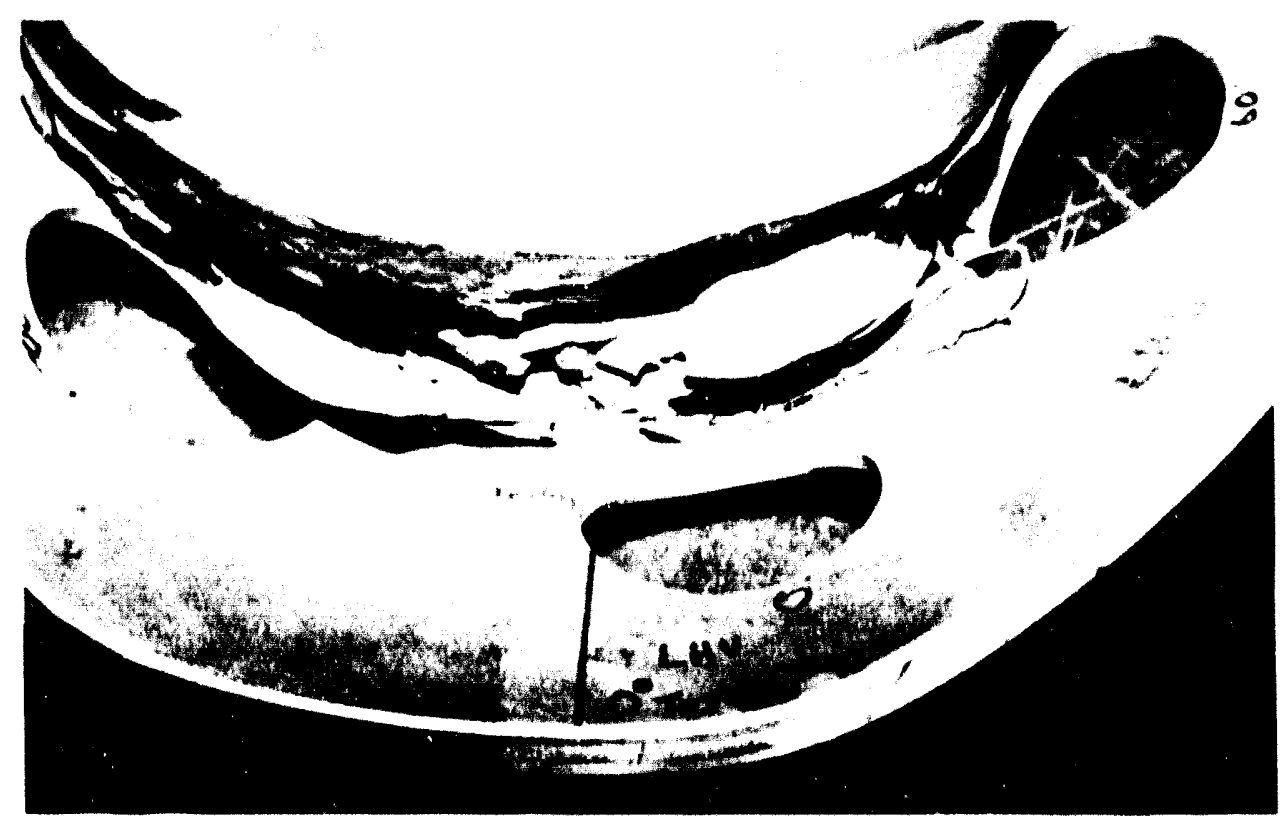

Figure 5.3.7 LHV RV aeroshell nose-end fracture and impact onto accelerometers

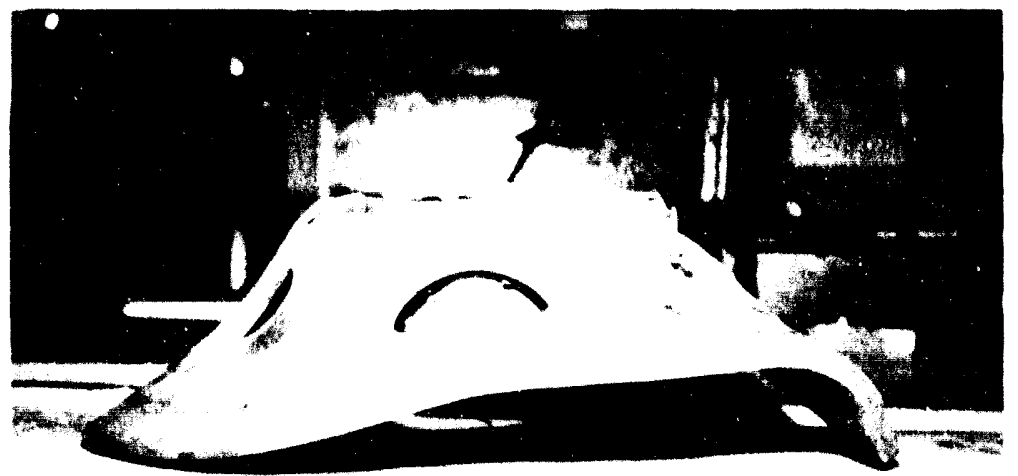

Figure 5.3.8 LHV fore plate deformation 


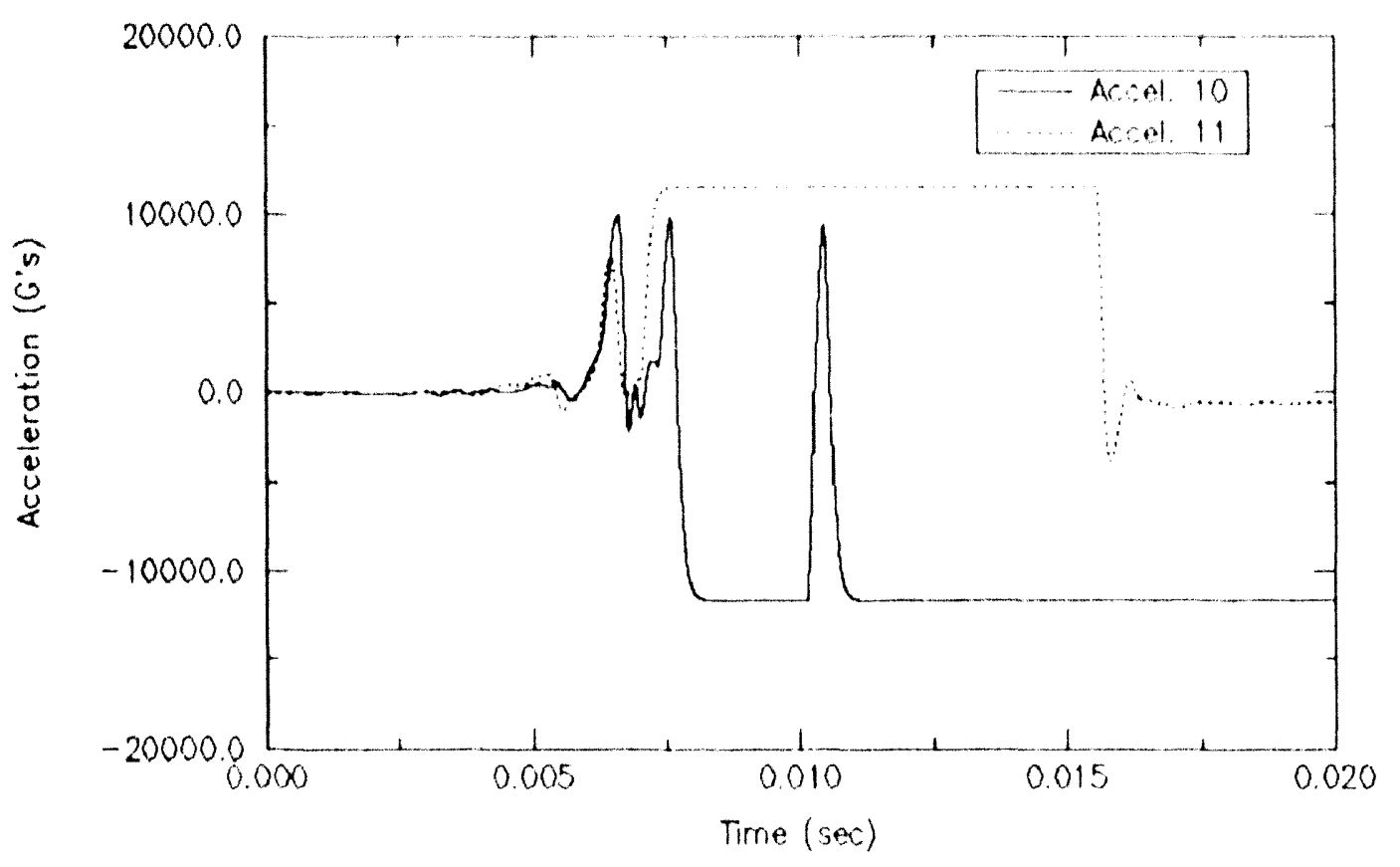

Figure 5.3.9 LHV fore plate (nose end, RV) accelerations (2 kHz filter)

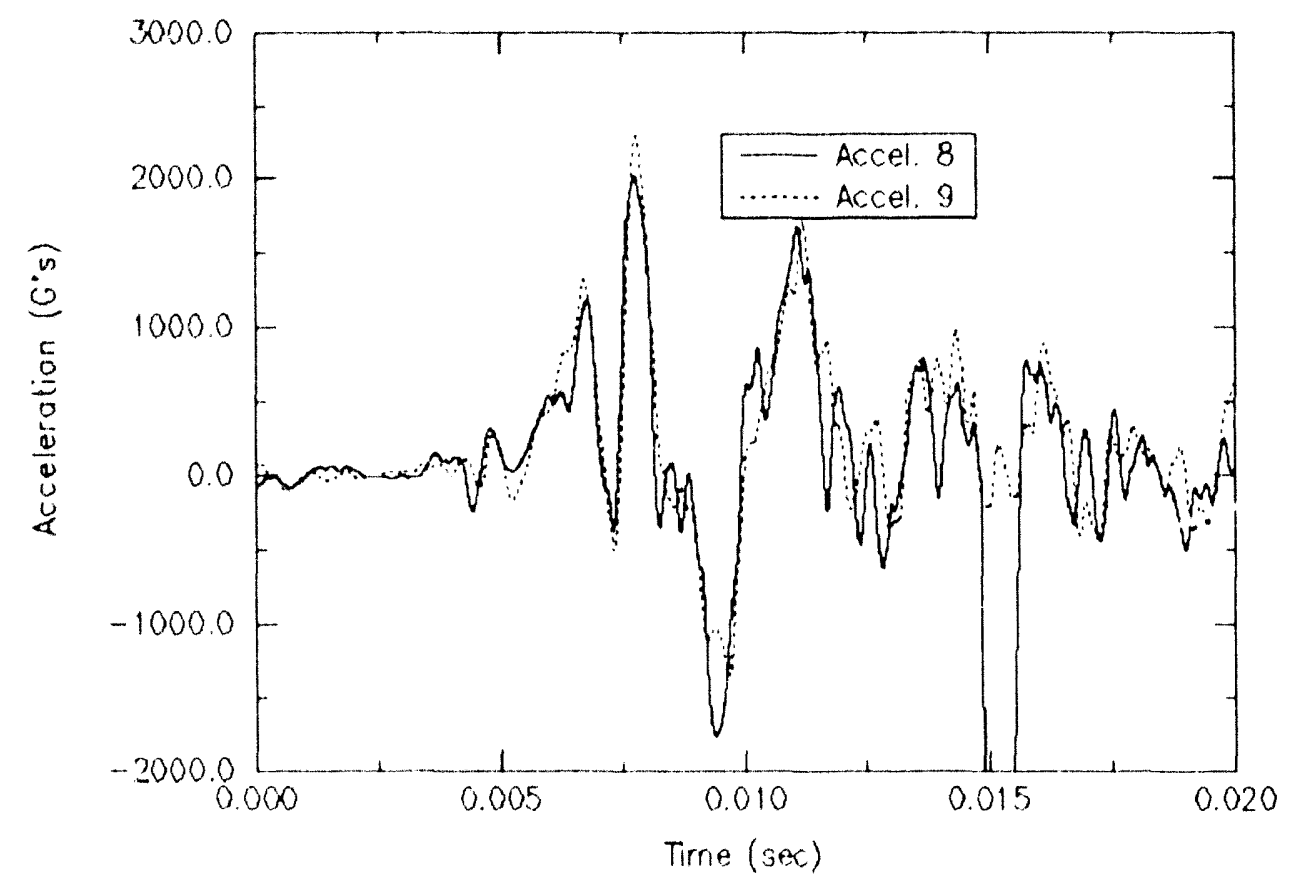

Figure 5.3.10 LHV aft cover (tail end, RV) accelerations ( $2 \mathrm{kHz}$ filter) 


\subsection{Horizontal High Velocity}

The horizontal high-velocity (HHV) impact test was performed on August 13, 1993 at the Aerial Cable Facility of Sandia National Laboratories. The container drop height was $88 \mathrm{~m}$ (288 ft) along a high-tension cable guided path which controlled impact orientation (see Figure 2.2). The HHV test unit is shown in Figure 5.4.1 before impact. Analysis of high-speed films yielded an impact velocity of $38.2 \mathrm{~m} / \mathrm{s}(125.3 \mathrm{ft} / \mathrm{s})$ at an impact angle of $1.1^{\circ}$ from periectly horizontal. After impact, the test unit rebounded about $1.5 \mathrm{~m}(5 \mathrm{ft})$ from the unyielding target, rotating longitudinally about $120^{\circ}$ impacting partially on its bottom (fork lift channel) side after rebound.

H1224A outer shell deformation resulting from the $38.2 \mathrm{~m} / \mathrm{s}$ horizontal impact is shown in Figure 5.4.2a, 5.4.2b, and 5.4.2c. Similar to the HLV impact test results, the top container shell returned nearly to its undeformed diameter at the top surface (Figure 5.4.2b) and remained deformed at its midsection (Figure $5.4 .2 \mathrm{c}$ ) by as much as $2.35 \mathrm{~mm}(9.2 \mathrm{in}$.) (see Appendix E: Inspection Data, Table E 4.1). But the fork lift channel, bottom pan, and inner container lower plate weld joints all sheared and tore, along with the lower foam insert glue joint, exposing the fore plate and RV aeroshell, as shown in Figure 5.4.2a.

Inside the container, the fore plate bolts (attaching it to its threaded ring) sheared upon impact and prevented severe deformation of the fore plate, as shown in Figure 5.4.3. The aft cover deformed severely (reducing its diameter by $49 \mathrm{~mm} \mathrm{|1.9} \mathrm{in.|}$ ), tearing the inner container, as shown in Figure 5.4.4. Ovalization of the outer container shell midsection is shown in Figure 5.4.5. Large bending loads in the RV midsection caused severe fracture in the aeroshell's carbon phenolic outer layer and aluminum substrate, as shown in Figures 5.4.6 and 5.4.7, releasing most of the weight plates and shearing some of the inter-plate bolts. Container and RV deformations for the HHV impact test are quantified in Tables E 4.1, E 4.2, and E 4.3 of Appendix E, from measurement locations specified in Figures 3.6, 3.7, and 3.8.

Accelerations measured (and low-pass filtered to $2 \mathrm{kHz}$ ) at the fore and aft ends of the RV midsection are presented in Figures 5.4.8 and 5.4.9. The accelerometers in each figure were located $90^{\circ}$ apart and show rather dissimilar acceleration histories. Acceleration pulses from accelerometers $6,8,10$, and 12 (fore and aft ends of the mass mock-up midsection, in the impact axis appeared to be much longer in duration than comparable acceleration pulse histories from the high speed end-on impact. Also, integration of these pulses showed that only a much shorter duration pulse was necessary to slow the re-entry vehicle midsection velocity from $125 \mathrm{ft} / \mathrm{s}$ to approximately $-20 \mathrm{ft} / \mathrm{s}$ (negative denoting upward after downward impact).

After reviewing high-speed film views of the impact event, dummy accelerometer output, and the post-test accelerometer calibrations, the cause of the abnormal acceleration histories was determined. During impact, separation of the welded joint between the H1224A lower cylinder and the bottom pan caused stretching of accelerometer and strain gage channel wires. Before the wires completely failed, the stretching caused resistance changes thus inducing spurious accelerations. From high-speed films, stretching appears to begin occurring at about 2.5 to 3 milliseconds into the impact event, thus the acceleration data from these four accelerometers is suspect after 
this point in time. The dummy channel (A15 in Appendix D, full scale output equals (0.05 Volts) indicates that wire stretching may have begun as early as $1.25 \mathrm{~ms}$ into the impact event. This is also approximately the time at which the re-entry vehicle midsection has zero velocity (see integrated velocity histories). Since the instantaneous rebound velocity of the relatively rigid attachment points for the accelerometers is much greater than zero, actual peak acceleration magnitudes should be greater than those shown in the data plots at approximately $3 \mathrm{~ms}$.

It is estimated that valid acceleration data was recorded up through about peaks of approximately $8,000 \mathrm{Gs}$ at the fore end and $10,000 \mathrm{Gs}$ at the aft end. As identified by the time of peak acceleration and by the time of zero velocity in the integrated acceleration plots of Appendix D, the RV midsection began rebounding approximately 3 milliseconds after container impact began. This lesser peak RV deceleration time compared to the LHV test results is justified by the reduced effective container thickness in this impact orientation, since the fork lift channels have no influence.

Dynamic strain histories, as well as all raw and filtered data, FFTs and integrated accelerations are presented for the HHV impact test in Appendix D.

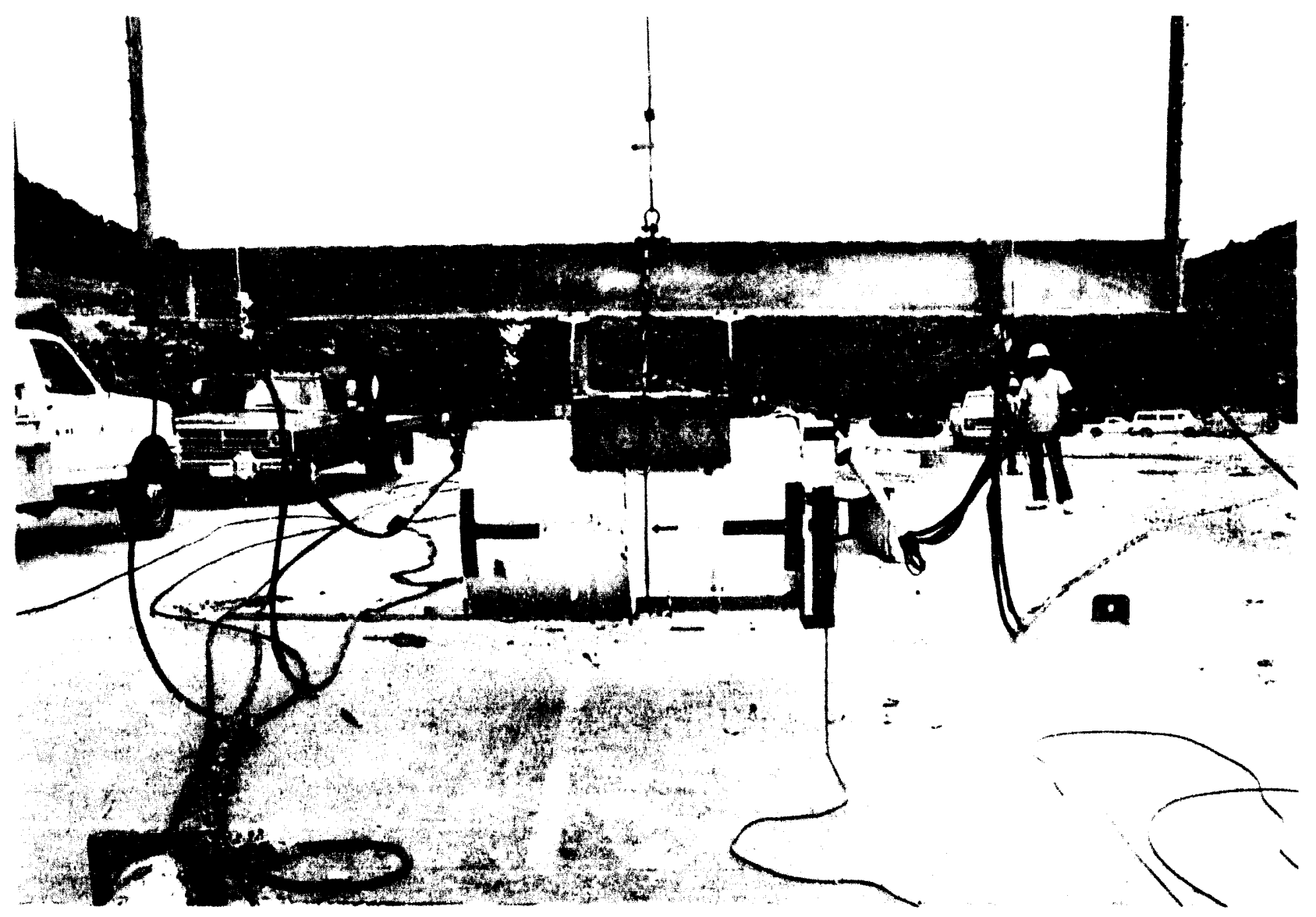

Figure 5.4.1 HHV impact test pre-test 


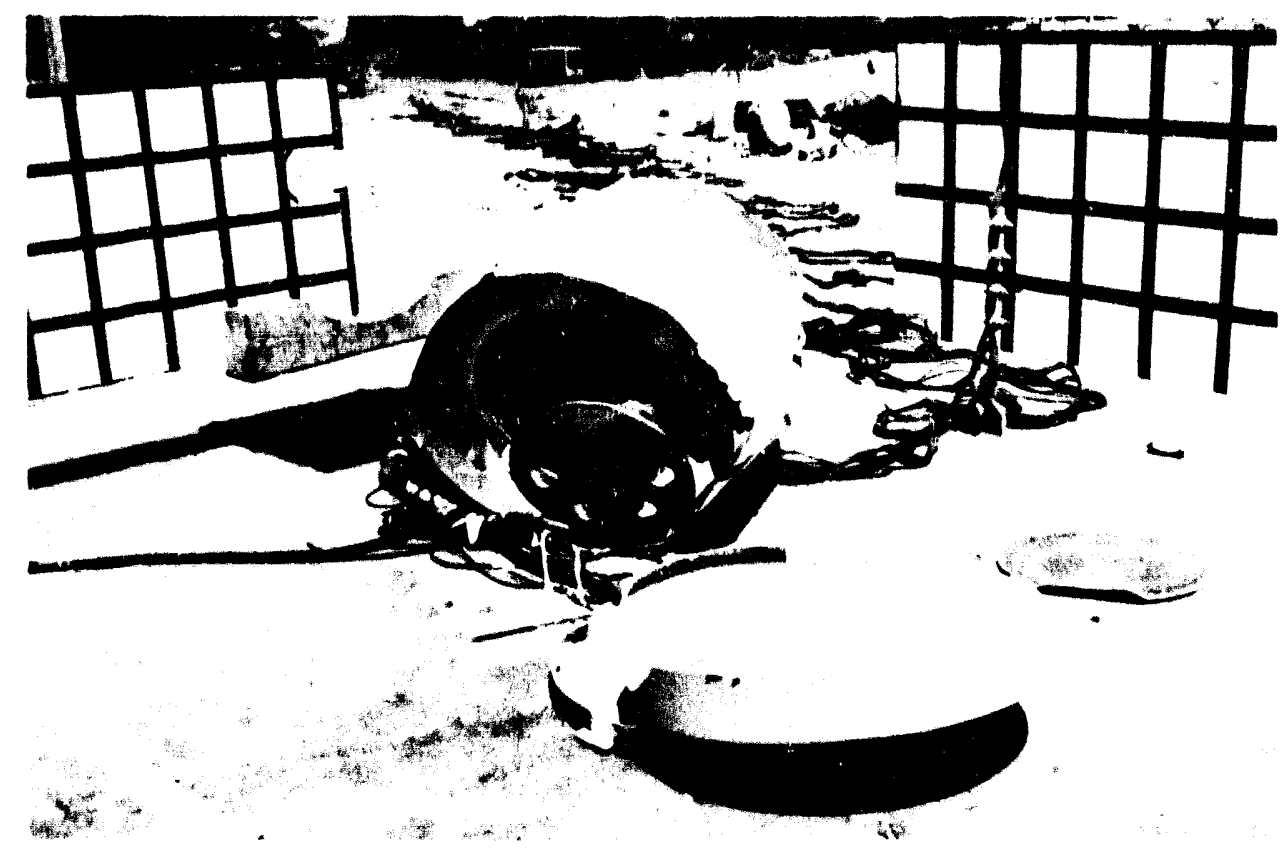

Figure 5.4.2a HHV H1224A post-test deformation

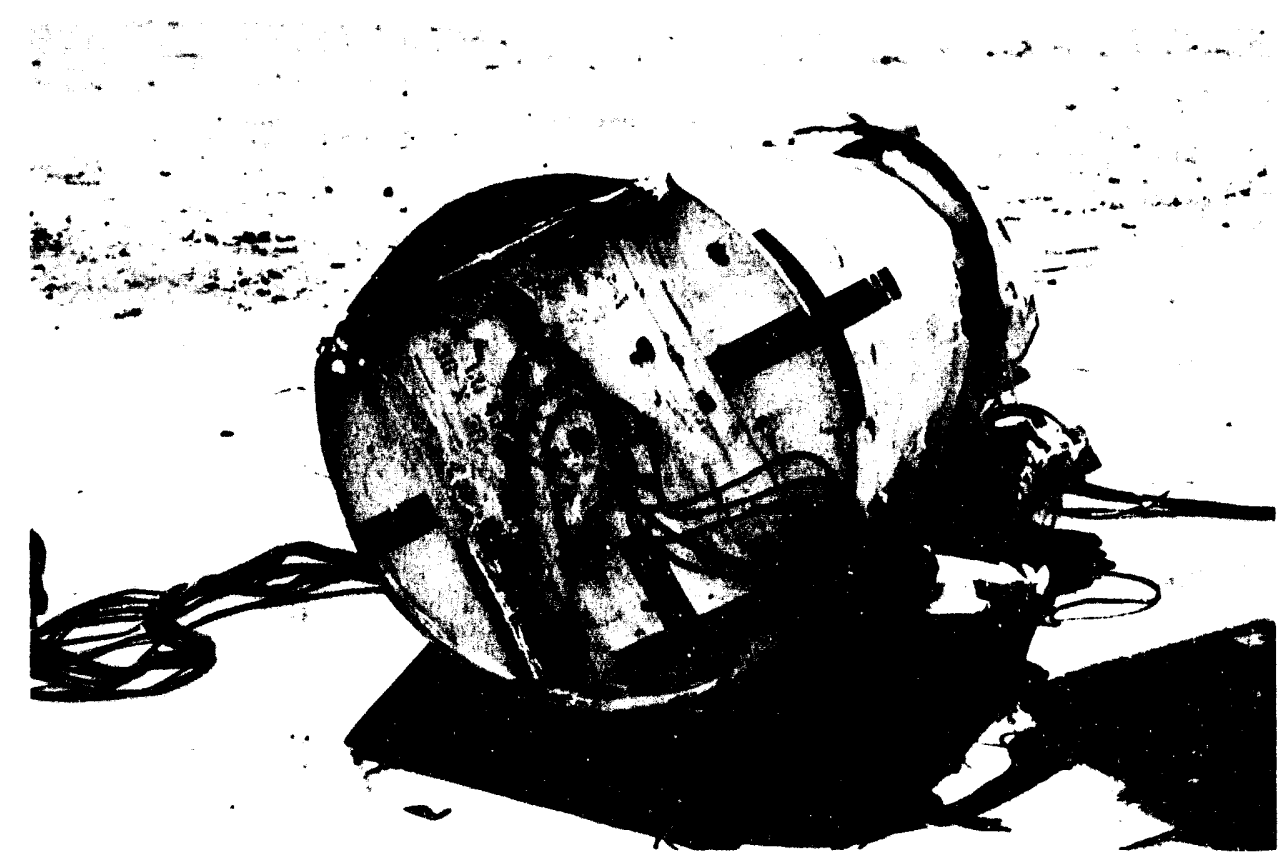

Figure 5.4.2b HHV H1224A post-test deformation 


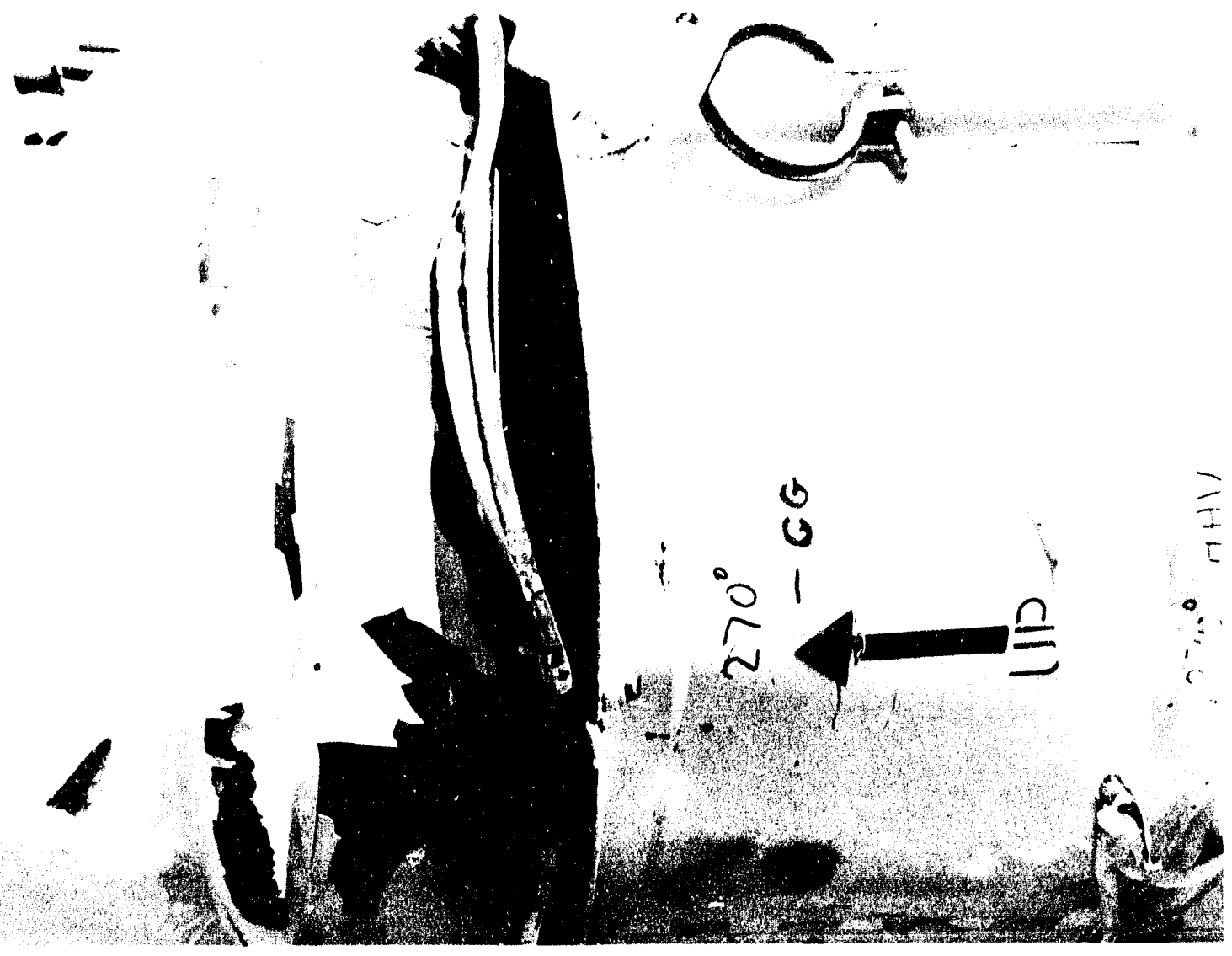

Figure 5.4.2c HHV H1224A post-test deformation 


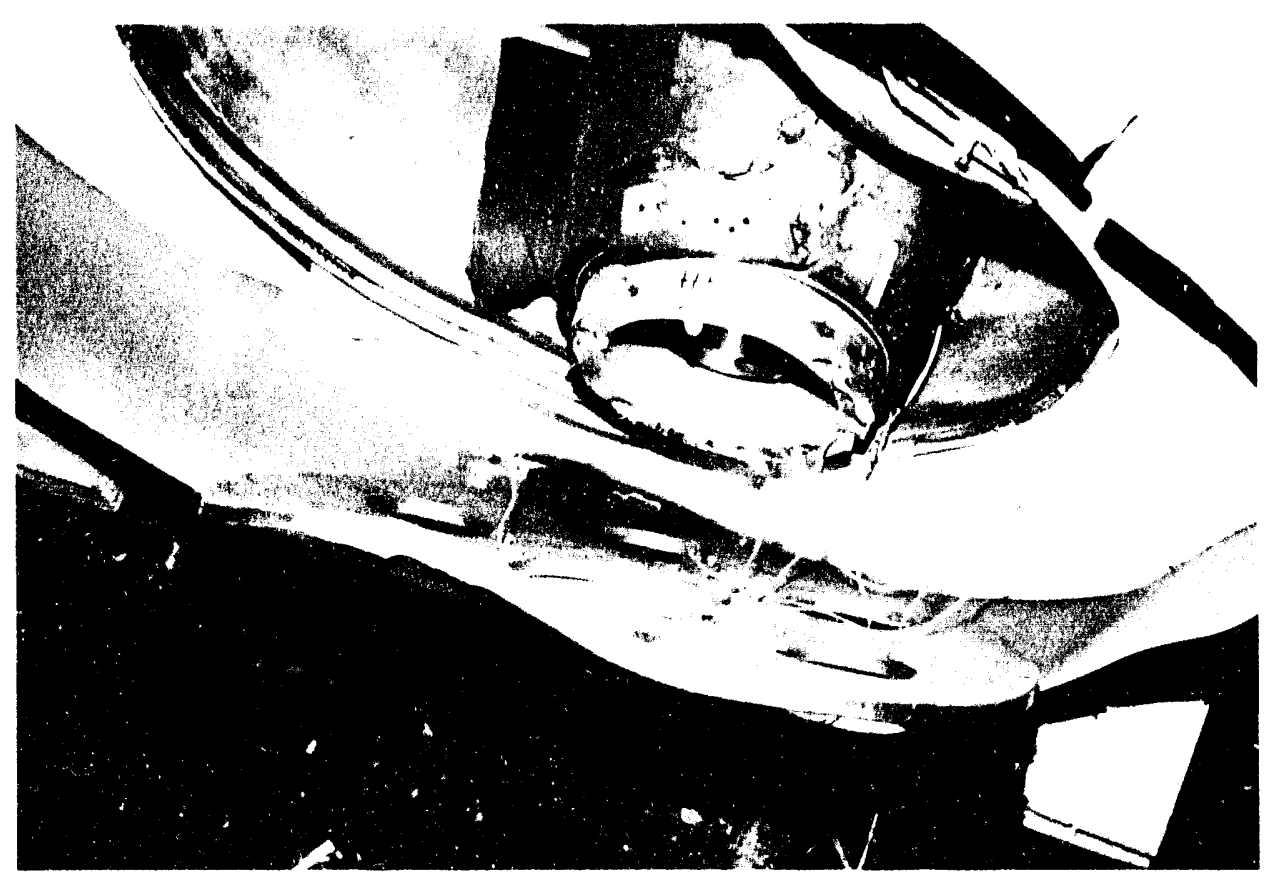

Figure 5.4.3 HHV fore plate deformation and bolt shearing

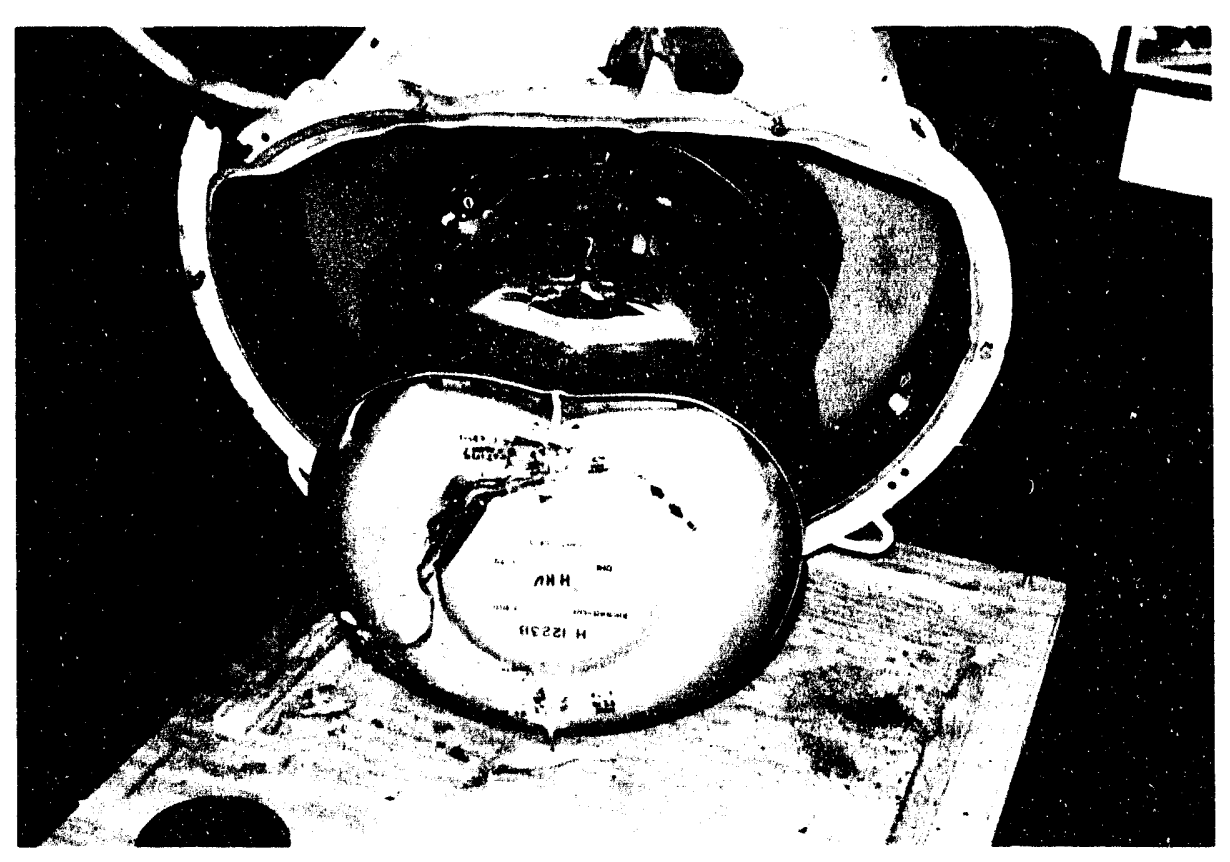

Figure 5.4.4 HHV inner container and aft cover deformation 


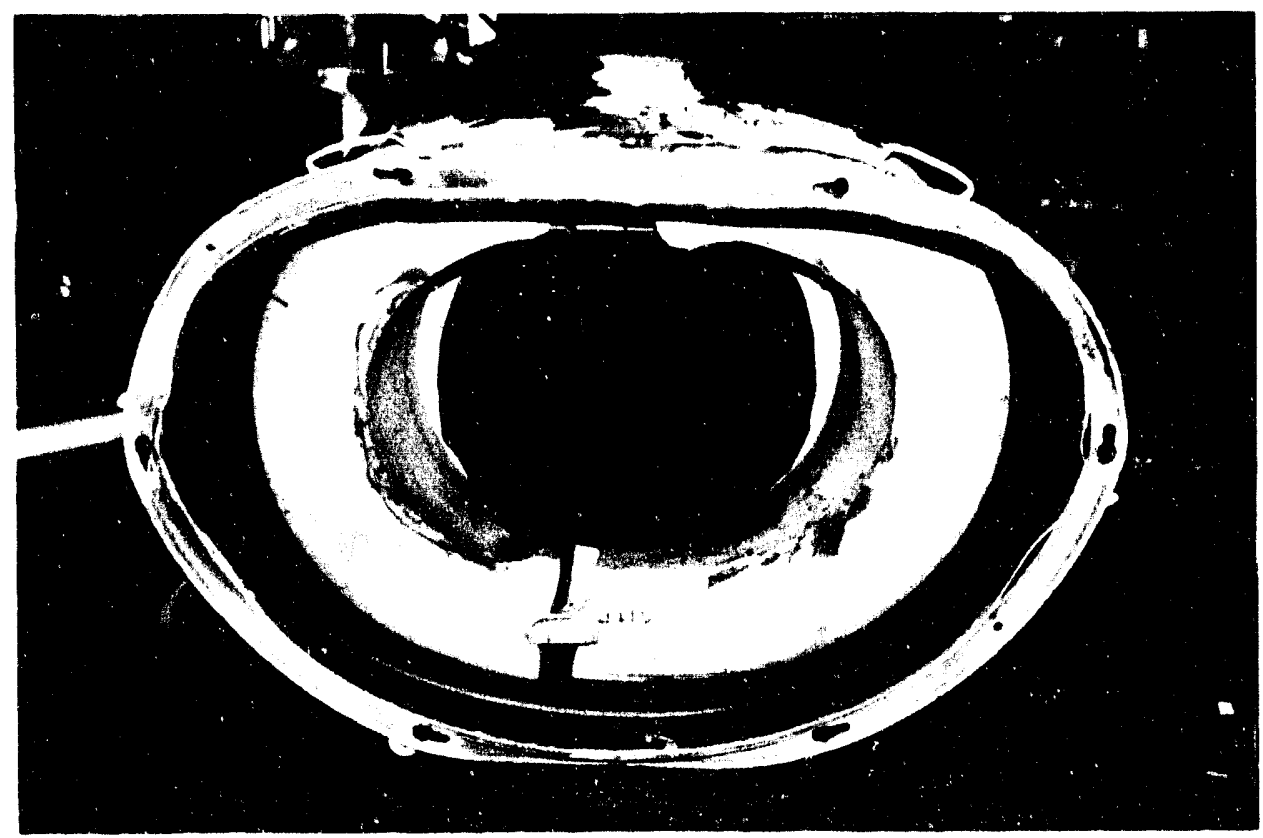

Figure 5.4.5 HHV H1224A outer shell deformation

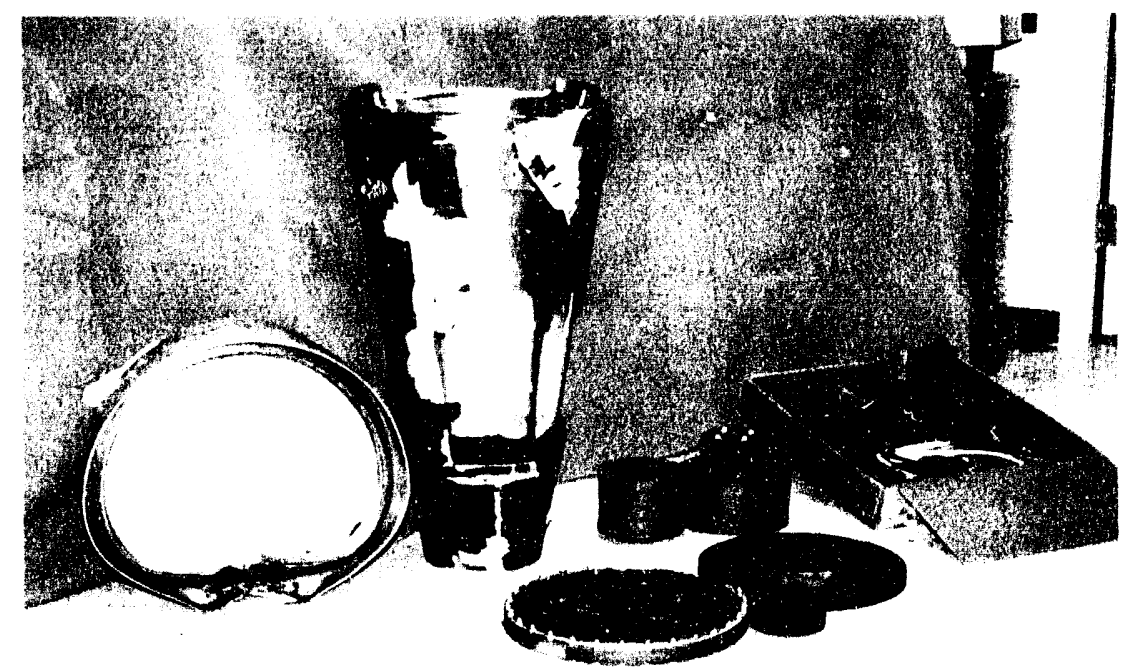

Figure 5.4.6 HHV Mk12a Mod6c aeroshell fracture and detached weight plates 


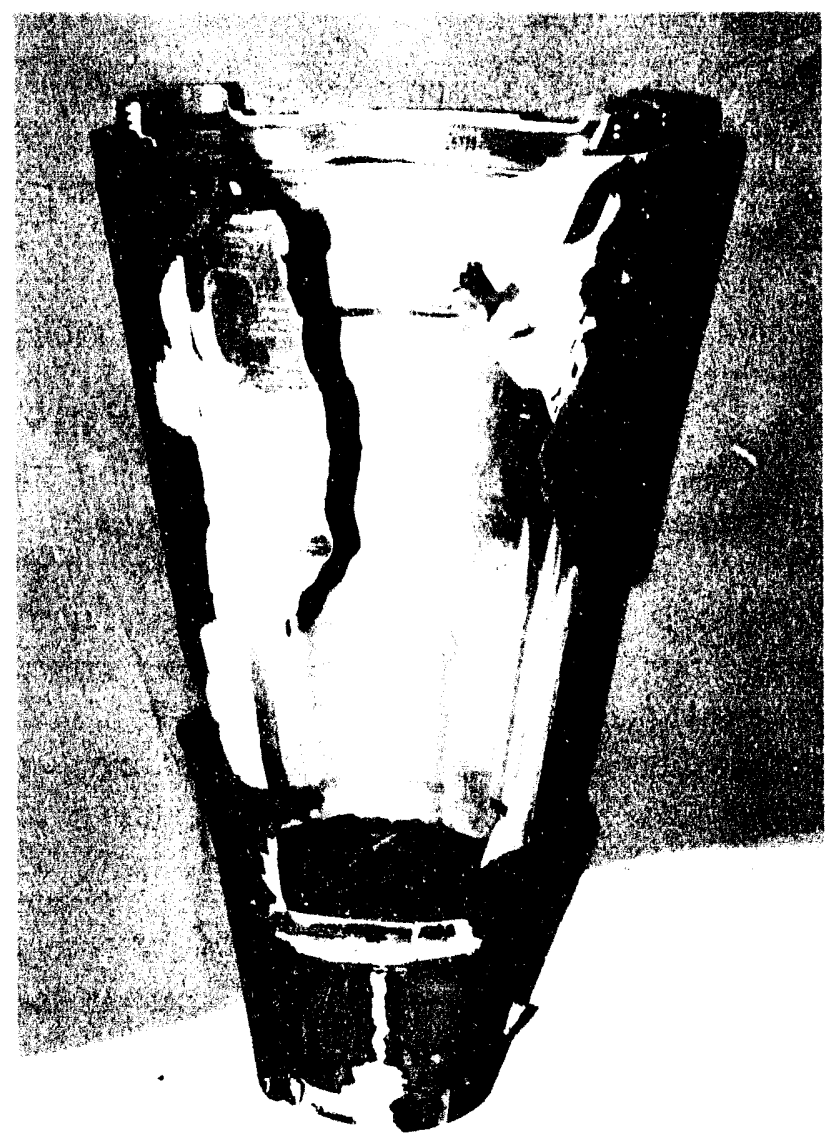

Figure 5.4.7 HHV RV carbon phenolic aeroshell fracture 


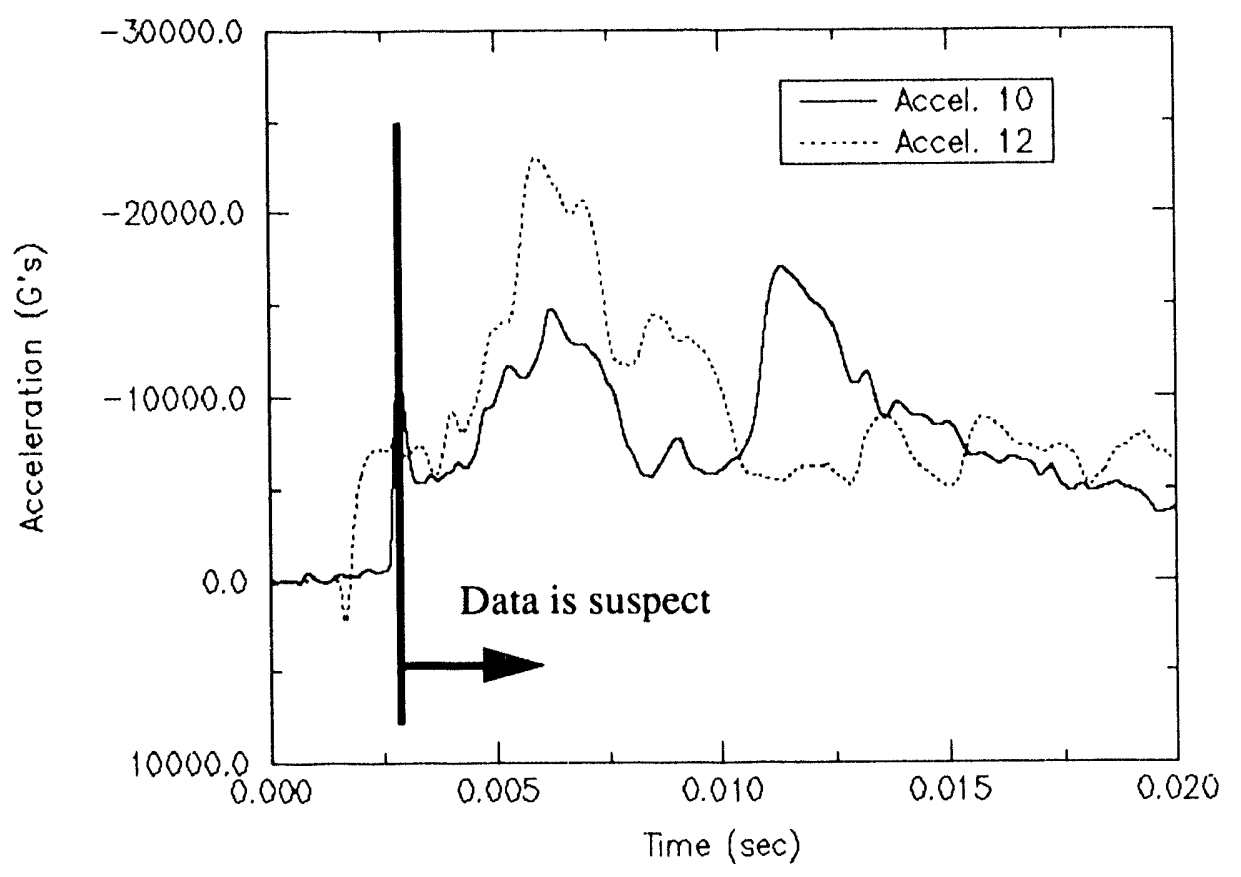

Figure 5.4.8 HHV fore plate (nose end, RV) accelerations

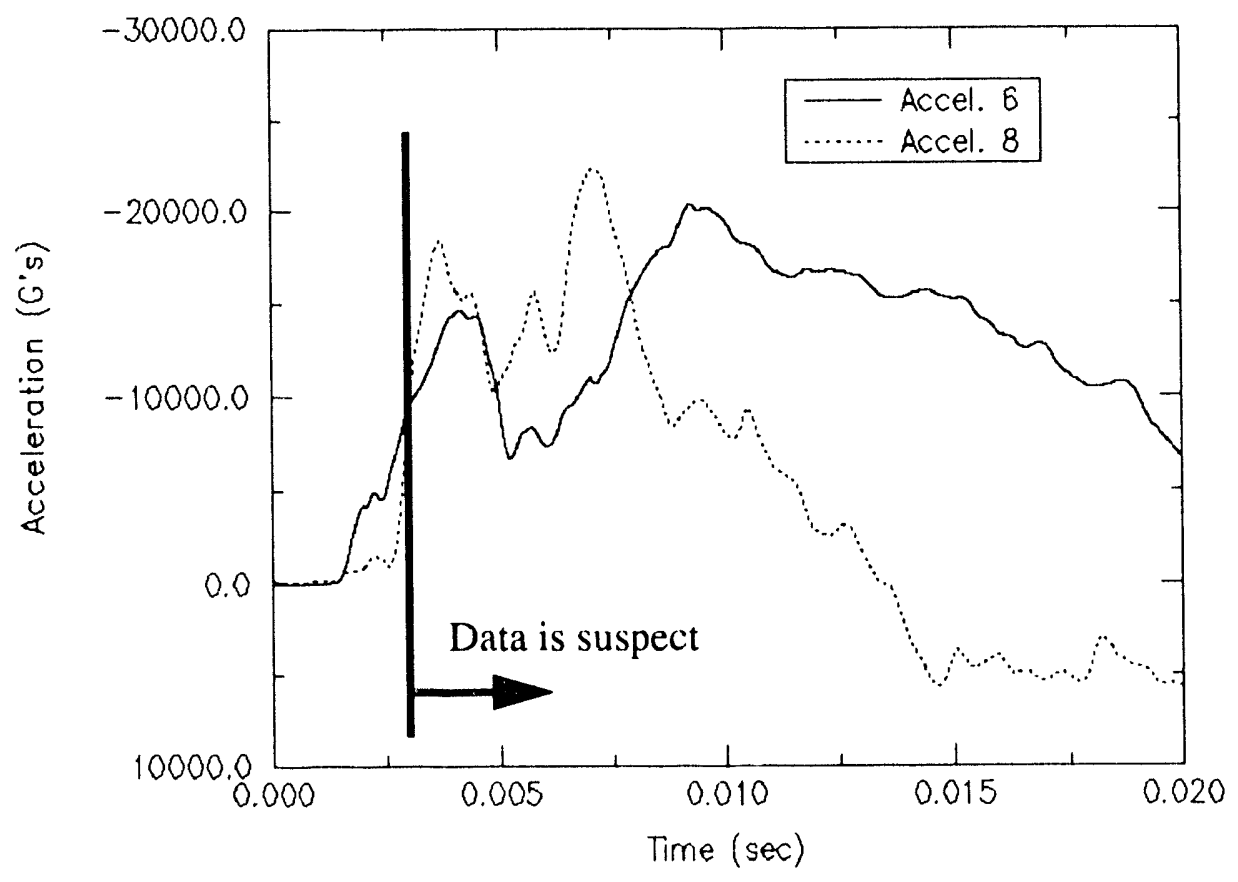

Figure 5.4.9 HHV aft cover (tail end, RV) accelerations 


\section{Conclusions}

Sandia National Laboratories has performed four impact tests of the H1224A shipping/storage container for the Mk12a W78 warhead midsection. The $12.2 \mathrm{~m} / \mathrm{s}(40 \mathrm{ft} / \mathrm{s})$ and $38.1 \mathrm{~m} / \mathrm{s}(125$ $\mathrm{ft} / \mathrm{s}$ ) impact velocities onto unyielding targets encompass a range of potential accident conditions associated with the weapon's STS. Acceleration and deformation results should be useful in validating analytical models, which can be used to predict weapon response throughout the range of accident conditions.

Some acceleration and strain data was lost during the HHV impact test. Post-test review of the test unit, accelerometer and strain gage output histories, dummy channel output histories, and high-speed films indicated that unanticipated container deformations led to stretching and even severing of transducer lead wires. The wire stretching resulted in spurious transducer output histories at approximately 2.5 to 3 millisecunds after initial impact, limiting the usefulness of data after this point. For accelerations on the fore and aft end of the RV, however, most of the downward kinetic energy was absorbed at the time of wire stretching and can be used to partially benchmark analytical predictions.

Accelerations measured at points on the Mk12a Mod6c's fore plate and aft cover during impact tests are point measurements on a test unit, which may differ significantly from accelerat ons experienced by an actual WR Mk12a midsection under identical conditions. Dissimilar acrerations measured at opposite ends of the RV prove the non-rigidness of the body during longitudinal impact tests. Thus, modelling the RV as a rigid body should yield different results than those measured. Similarly, although mass properties are identical for undeformed WR Mk12a and Mk12a Mod6c midsections, mass distributions and interactions with the support structure of the aeroshell during severe impacts are very different. Thus, RV accelerations measured during these impact tests may only approximite those experienced by WR hardware in identical impact conditions.

Deformations in the RV midsection aeroshells during impact tests can be misleading. They are caused not only by interactions with the container and the impact surface, but also interactions with masses inside. The severe fracture patterns of RV aeroshells and aluminum substrates observed in the high-speed impact tests is unique to these test units with extremely dense, steel weight plate mass simulators at each end. The sharp cylindrical edges may aide in the fracture process as compared to an actual physics package which could deform and absorb more of its own kinetic energy upon impact. The distinction between WR and tested RV midsections is important not only for use in proper application of RV loads during accident modelling, but also in assumed levels of aeroshell deformation for containment of potentially hazardous materials.

Acknowledging differences between the tested Mk12a Mod6c midsection and a WR Mk12a, acceleration and strain results obtained during this series of low and high velocity impact tests should prove useful in approximating W78 midsection load levels and validating finite element model results for similar accident conditions. 


\section{References}

[1] Report on the Panel on Nuclear Weapon Safety on the Committee on Armed Forces, House of Representatives, One Hundred First Congress, Second Congressional Session: December 1990. (also known as "Drell Report" of "Report of Drell Panel")

[2] Review of Drell Panel Recommendations for ICBM Systems, TRW Ogden Engineering Operations for the Department of the Air Force, Aug. 9, 1991.

[3] Department of Defense and Department of Energy Study on the Logistic Transportation of Nuclear Weapons, Sept. 1991.

[4] Stockpile to Target Sequence for the Mk12a (W78), Air Force Weapon Laboratory, Sept.27, 1976.

[5] “Mk 12A/JMTP-2D Rail-ATMX Humping Shock Test," Sandia Report \# R705129, April $27,1979$.

[6] "Mk 12A/LTU-3 Simulated ATMX Railroad Humping Shock at High and Low Temperatures," Sandia Report \# R705151, February 22, 1978.

[7] “Mk 12A/LTU-3 Handling and Transportation at High and Low Temperature," Sandia Report \# R705152, March 20, 1978.

[8] "Transportation Vibration Test of the Mk 12A LTU-3," Sandia Report \# R705152-1, March $17,1978$.

[9] “Mk12A-LTU-3A Handling and Transportation Vibration," Sandia Report \# R705207-1, February 18, 1979.

[10] "Mk 12A/JMTP-2D Handling and Transportation Tests," Sandia Report \# R705129, January $17,1979$.

[11] "Final Sandia Laboratories Test Report, Mk 12A/JMTP-7B Handling, Transportation, and Flight Environments," Sandia Report \#s R705211, 212, 213, 214, 216, 217, 218, March 4, 1980.

[12] "Final Sandia Laboratories Test Report, Mk 12A/JMTP-3B, Handling, Transportation, and Flight Environments," Sandia Report \#s R705138, 139, 201, 202, 203, 204, 205, 206, March 4, 1980.

[13] "Final Sandia Laboratories Test Report, Mk 12A/JMTP-2D Handling, Transportation, and Flight Environments," Sandia Report \#s R705121, 122, 123, 124, 125, 126, 128, 129, 130, September 12, 1979.

[14] "Final Test Report, Mk 12A/JMTP-2B Transportation and Handling Tests," Sandia Report 
\#s R705118, 119, July 8, 1978.

[15] SNL drawing \#'s AY316847, AY288436, AY288437, AY327291, AY273717, AY273718, AY273719, 273720, AY316848, AY326801, AY326802, AY326803, AY326805, and AY326806.

[16] "The Mobile Instrumentation Data Acquisition System (MIDAS)," SAND90-2916, 1990.

[17] Uncapher, W. L., Dickinson, J. R., Althaus, B. L., and Holten, J. R., "The Development of a Mobile Instrumentation Data Acquisition System for Use in Cask Testing," Presented at PATRAM '89, September 1989.

[18] Madsen, M. M., Uncapher, W. L., Stenberg, D. R., and Baynes, E. E.,'”Testing the Half-Scale Model of the Defense High Level Waste Transportation Cask," SAND86-1130, TTC-0662, August 1987.

[19] Measurements Group Strain Gage Mounting Specifications Reference Documents B-129, B137-13, and TT-609.

[20] Endevco Corporation, 1992 Dynamic Instrumentation Catalog

[21] International Atomic Energy Agency, Safety Series No. 37 (Advisory Material for the IAEA Regulations for the Safe Transport of Radioactive Material), Paragraph A-601.14, 1990.

[22] F. N. Rebarchik, "Calibration of Accelerometers at the Drop Ball Station," SAND93-1232, August 1993.

[23] F. N. Rebarchik, "Calibration of Accelerometers on the 5,000-G Centrifuge," SAND92--321, May 1992.

[24] F. N. Rebarchik, "Operating Procedures for Calibration of Accelerometers on the UnholtzDickie 100-G Shaker," Sandia Labs Internal Memorandum RS7241/89/00004, March 1989. 


\section{Appendix A. LLV Accelerometer and Strain Gage Data: Raw, Filtered, and Reduced}

The following pages show raw (unfiltered) acceleration and strain gage data for the Longitudinal Low-Velocity (LLV) impact test. Following this raw data are plots of filtered data (using a low-pass Butterworth 6-stage filter) with cutoff frequencies of 250 Hz and 2,000 $\mathrm{Hz}$. Integrated acceleration data, yielding velocity versus time plots, are presented to analyze kinetic energy values during the test. And finally, Fast Fourier Transforms (FFTs) for each raw data channel are included to analyze acceleration and strain amplitudes in the frequency domain. 
Test: LOWGITwing Lou VelocITY H12249 06/29/93 (219) Session: Ton Jul 26 15:15:15 1993 Transtucer: A1 (secondary)

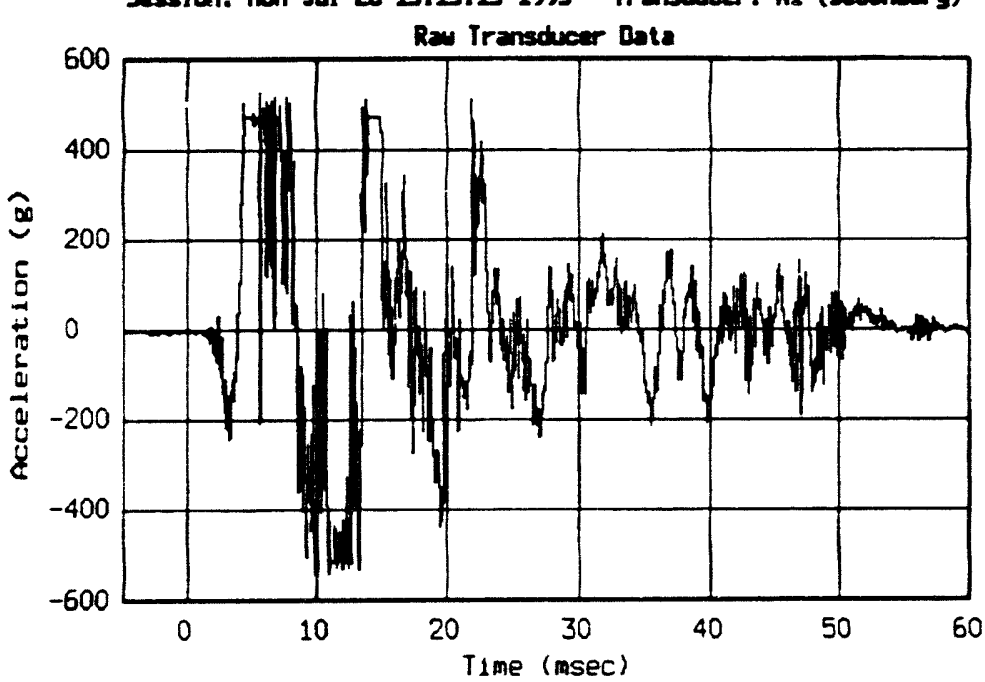

Test: LONGITUDIHA LOU VELOCITY H1224A 06/29/93 (219) Session: Mon Jul 26 15:15:20 1993 Transducer: R2 (secondary)

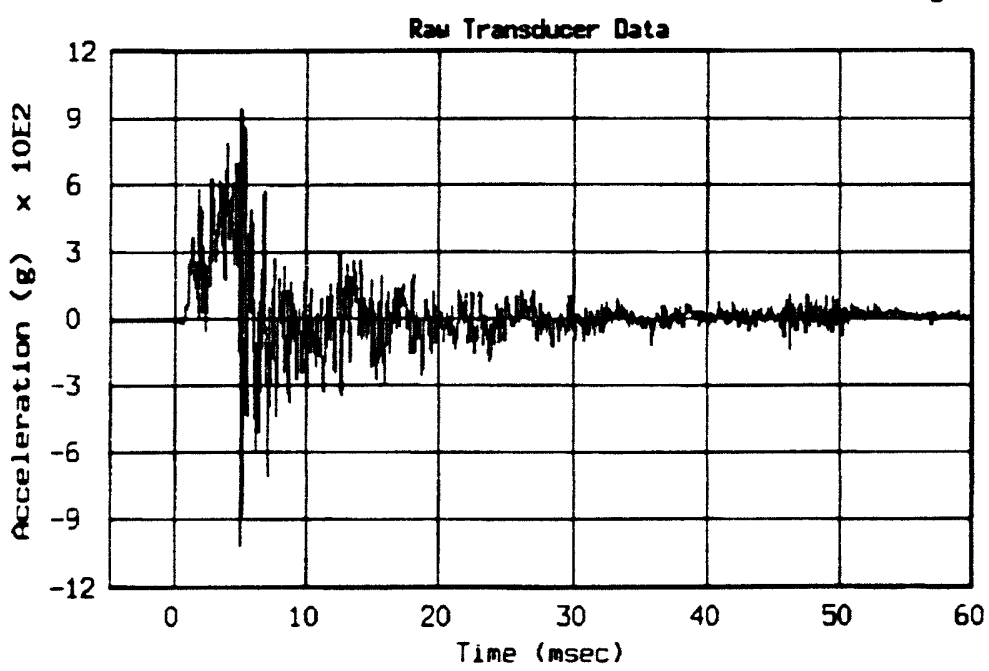

Test: Lowituoinf Lou velocity H1224A 06/29/93 (219) 5ession: Mon Jul Z6 15:15:23 1993 Transctucer: A3 (secondary)

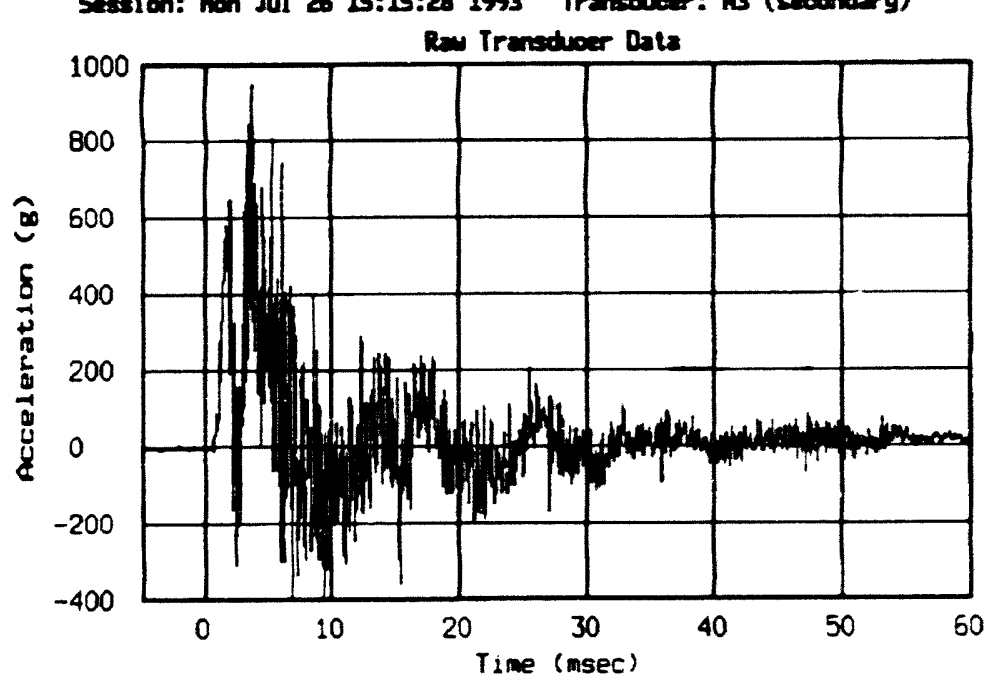

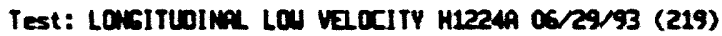
Session: hon Jul 26 15:15:34 1993 Transducer: A4 (secondary)

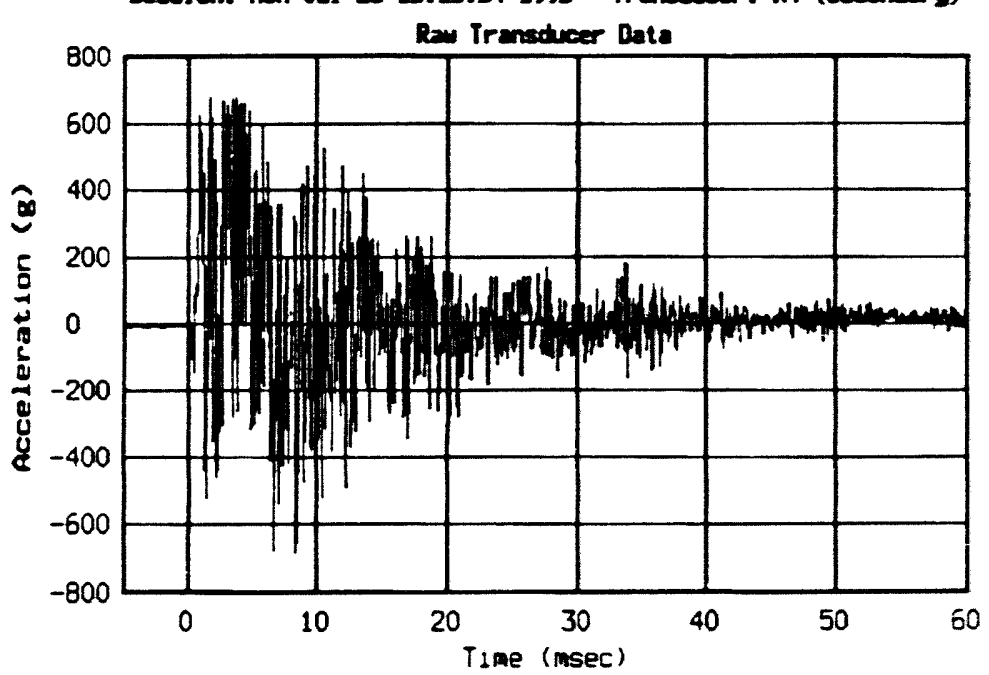




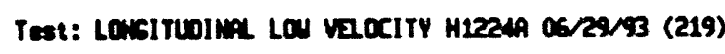
Session: hen Jul 26 15:15:12 1993 Transtucer: PS (secondery)

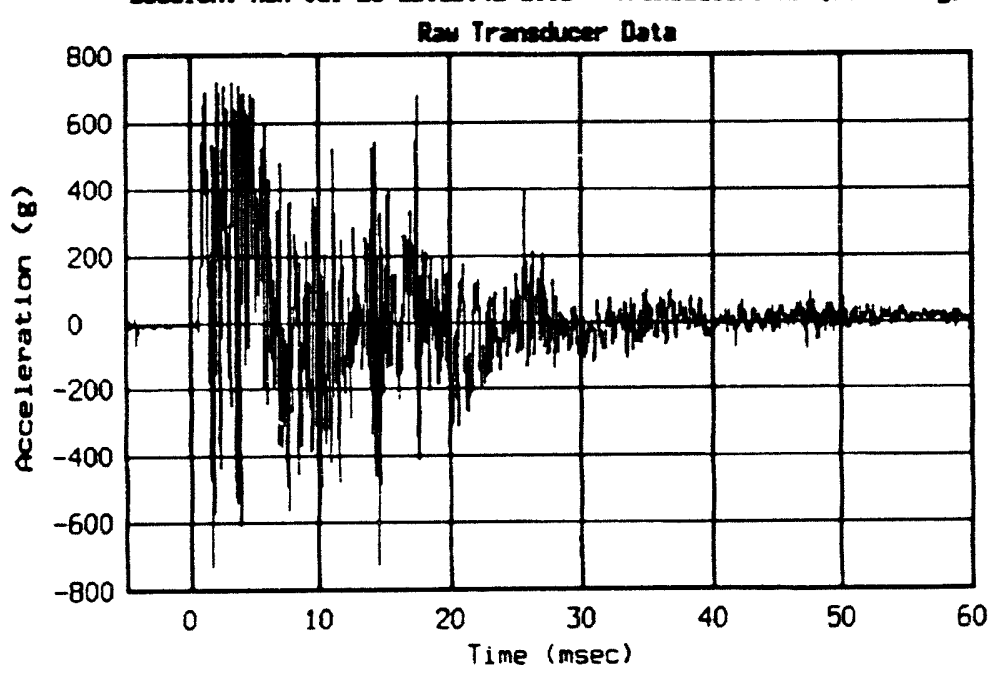

$\vec{\infty}$

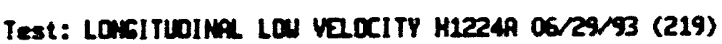
Session: thon Jul 26 15:15:49 1993 Transodveer: A6 (secondary)

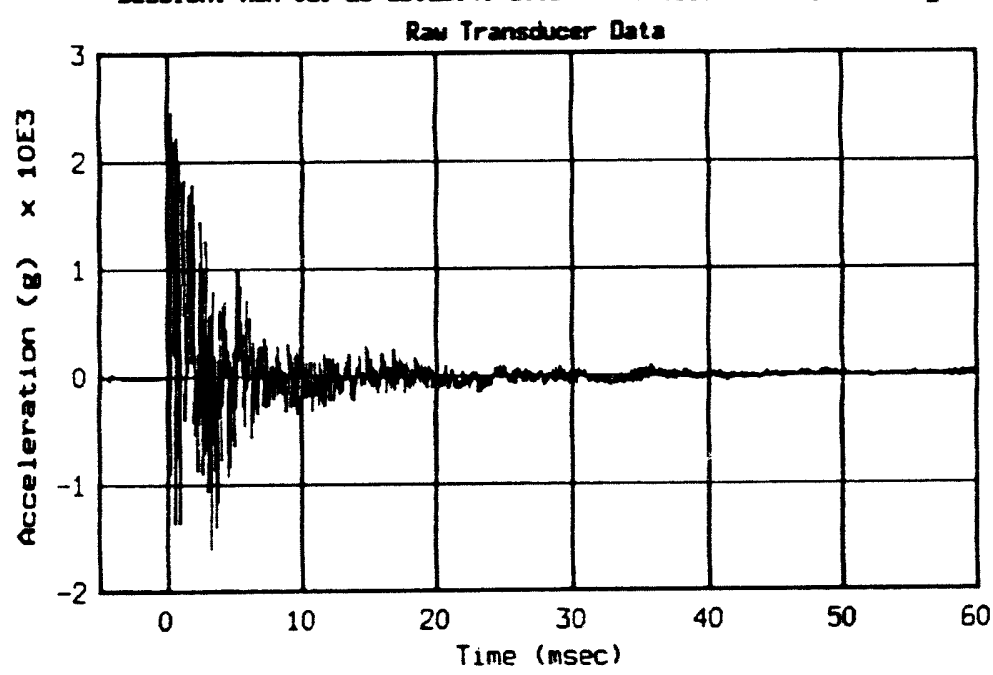

Teat: Locirmini Loy vecily H12249 05/29/93 (219) Sescion: Mon Jul 25 15:15:56 1993 Iranedwer: A7 (scocondery)

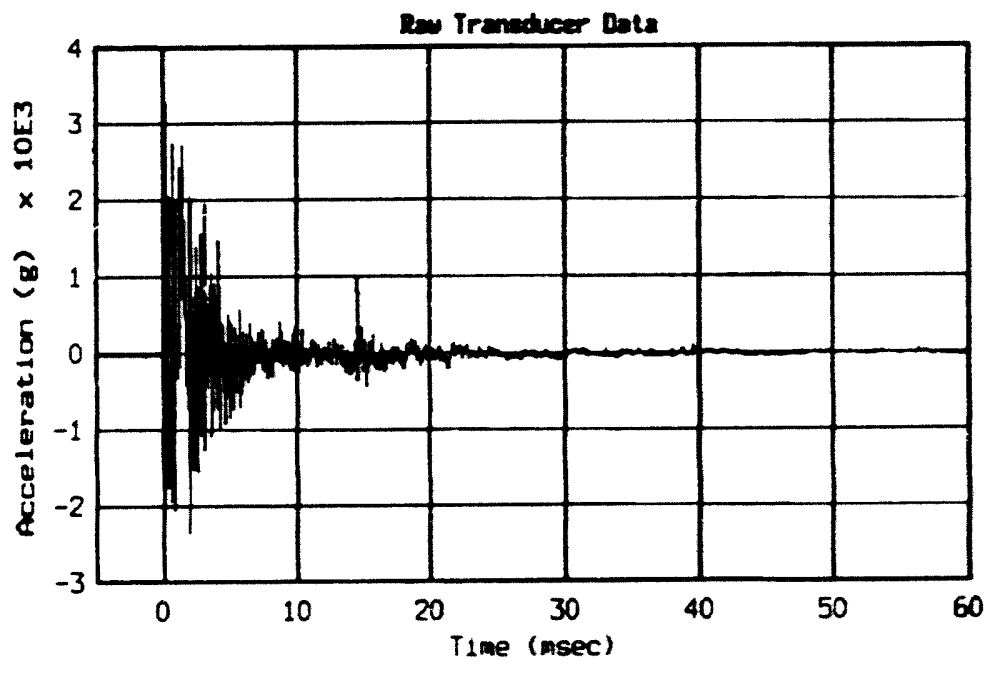

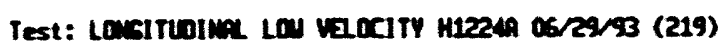
Session: Mon bul X6 15:16:03 1993 Tranedvear: P8 (secondery)

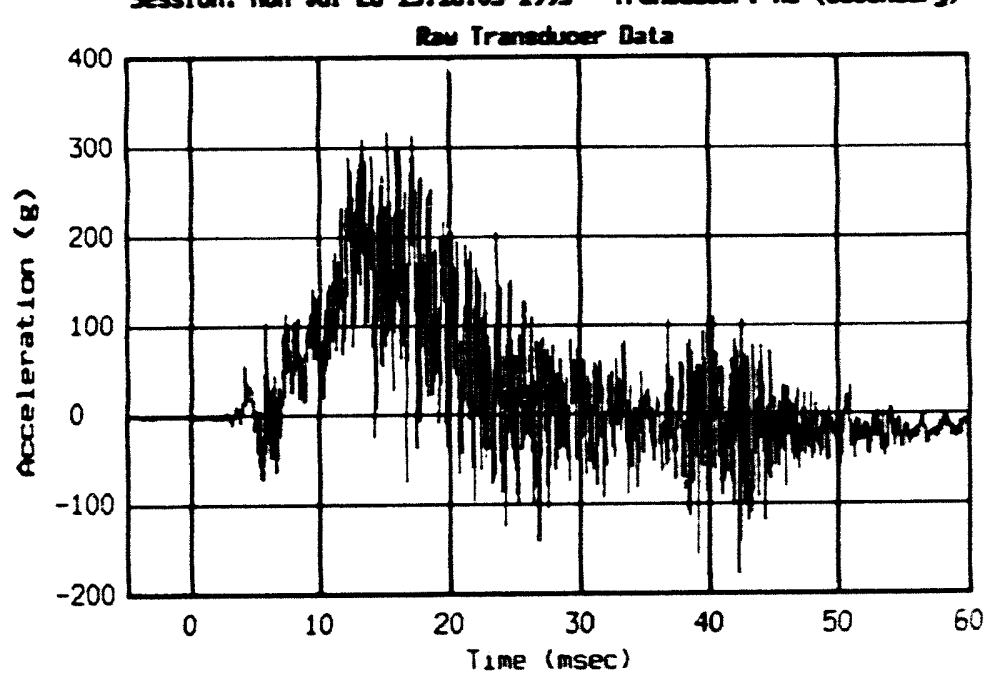




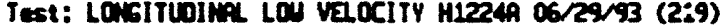
Session: Hon Jul 26 15:16:08 1993 Transtwoer: A9 (secondary)

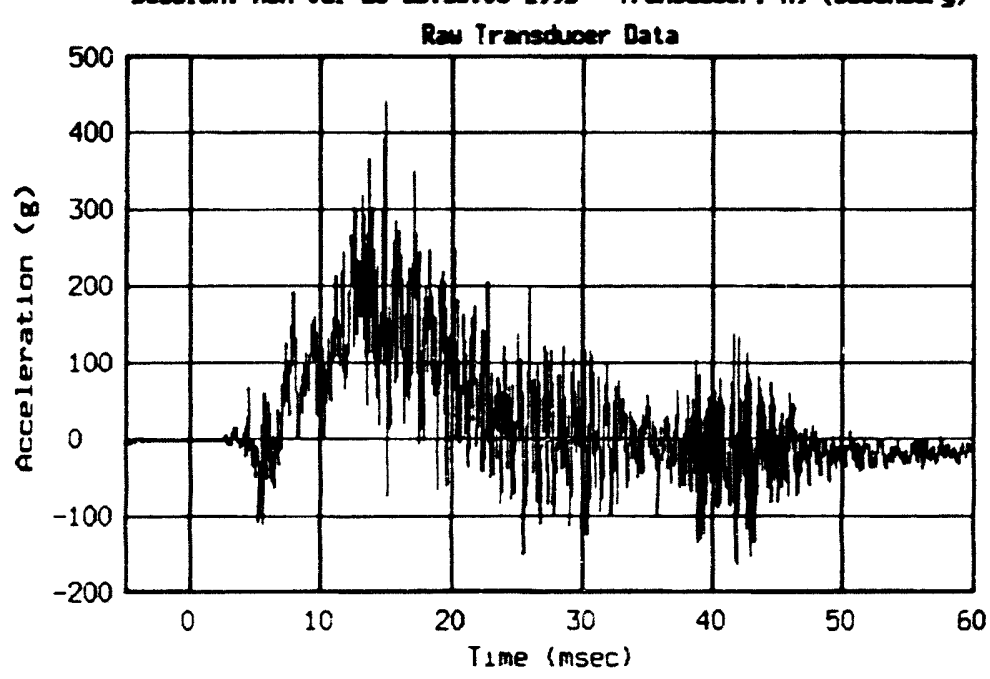

$\vec{c}$

Test: Lonsituoline Lou velocIty H1224A 06/29/93 (219) Session: Mon Jul 26 15:16:17 1993 Transducer: A10 (secondary)

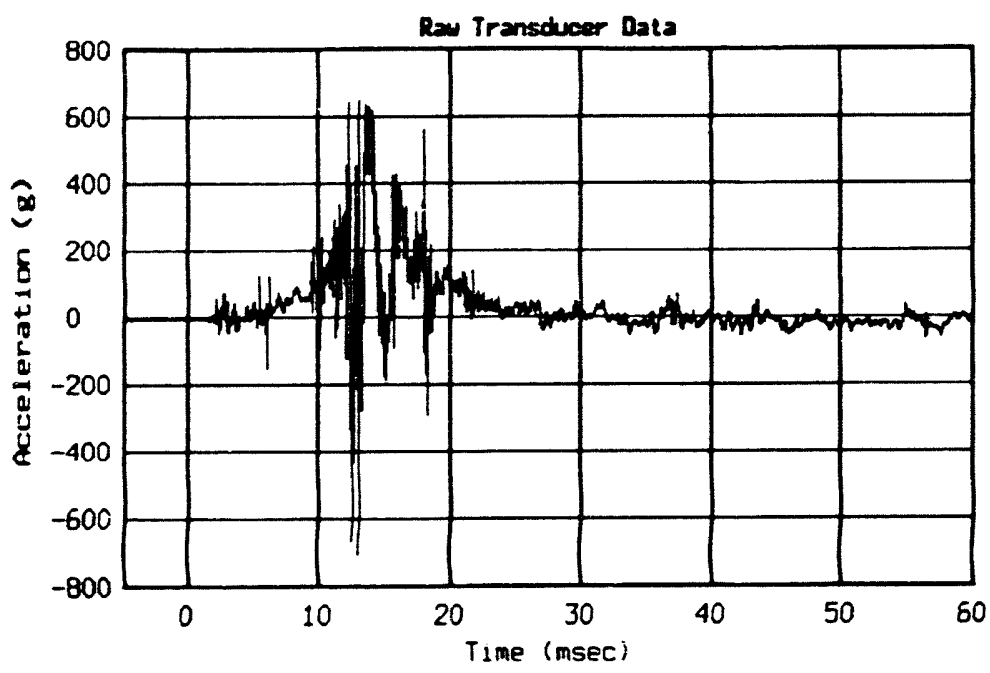

Test: LosituoIm Lo vecity H12249 06/29/93 (219) Session: Mon Jul 26 15:16:23 1993 Transtucar: A11 (secondery)

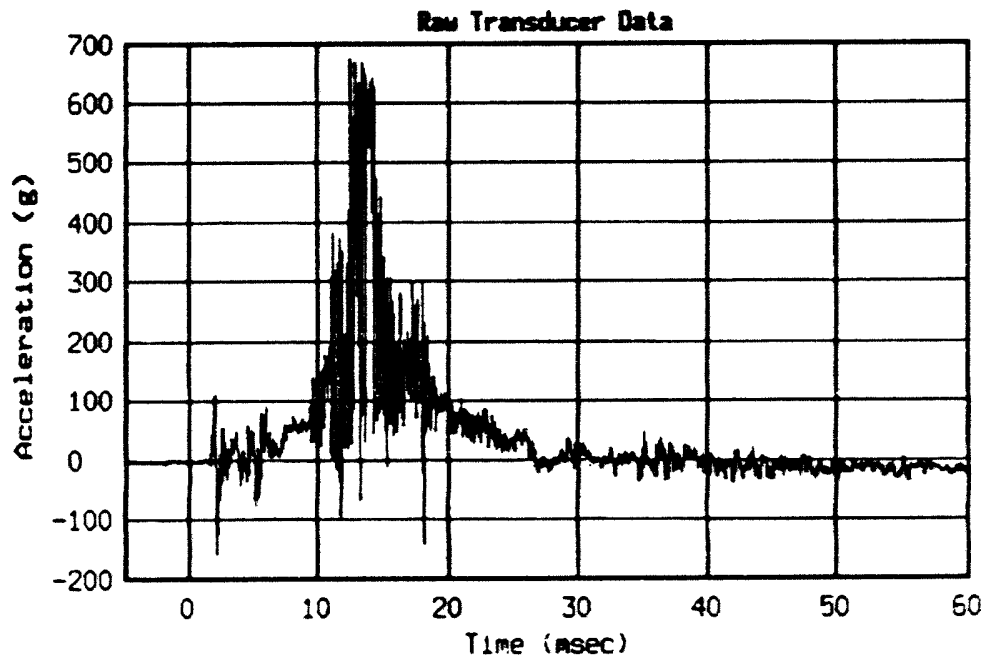

Test: Losituolin LW vacity H12249 06/29/93 (219) Session: Mon Jul 26 15:16:32 1993 irmedveer: 912 (eveondry)

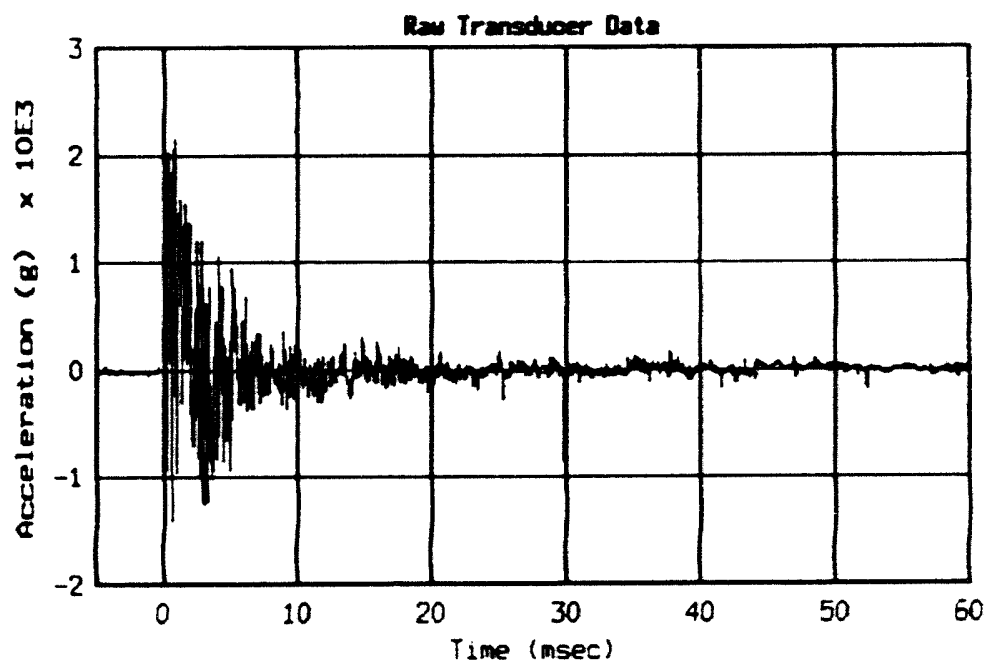


Test: Lowsifuoline Lou valocity H1224A 06/29/93 (219) Session: Mon Jul 26 15:16:37 1993 Transducer: A13 (secondary)

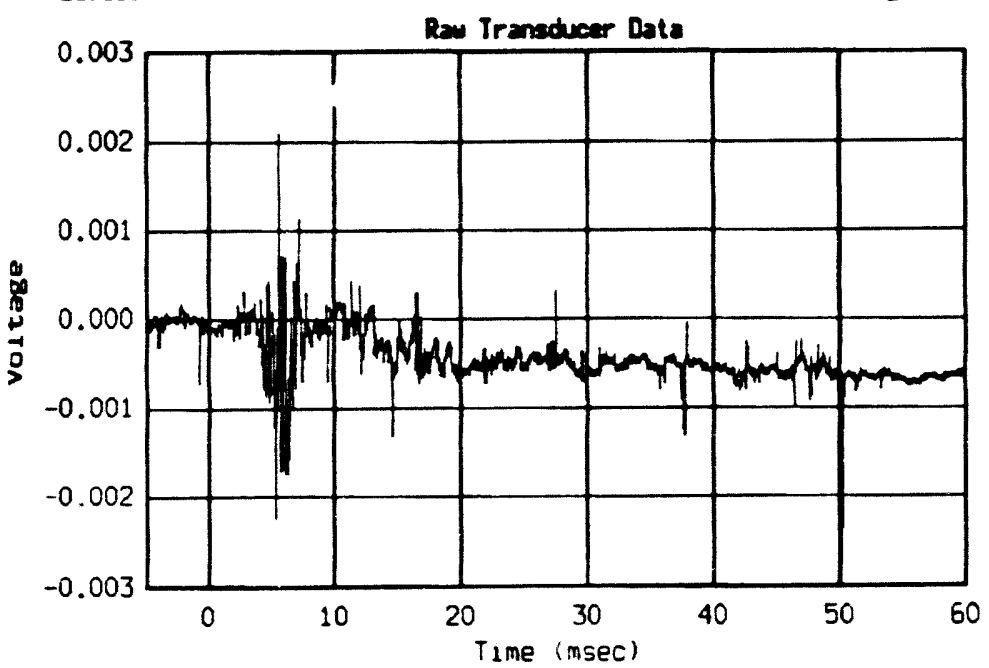

Test: LOWGITUoIfi LOU Velocity H12249 06/29/93 (219) Session: Mon dul 26 15:16:41 1993 Transduoer: 561 (secondary)

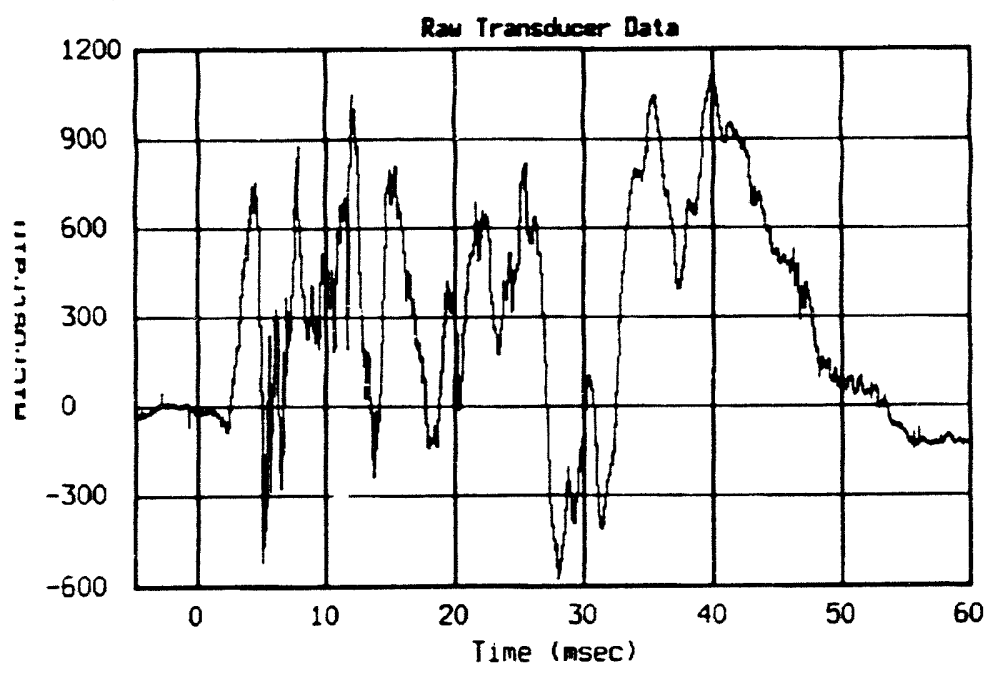

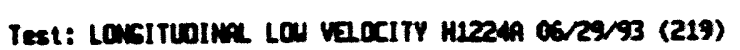
Seavion: Von Jul 26 15:16:49 1993 Transedwoer: 502 (secondary)

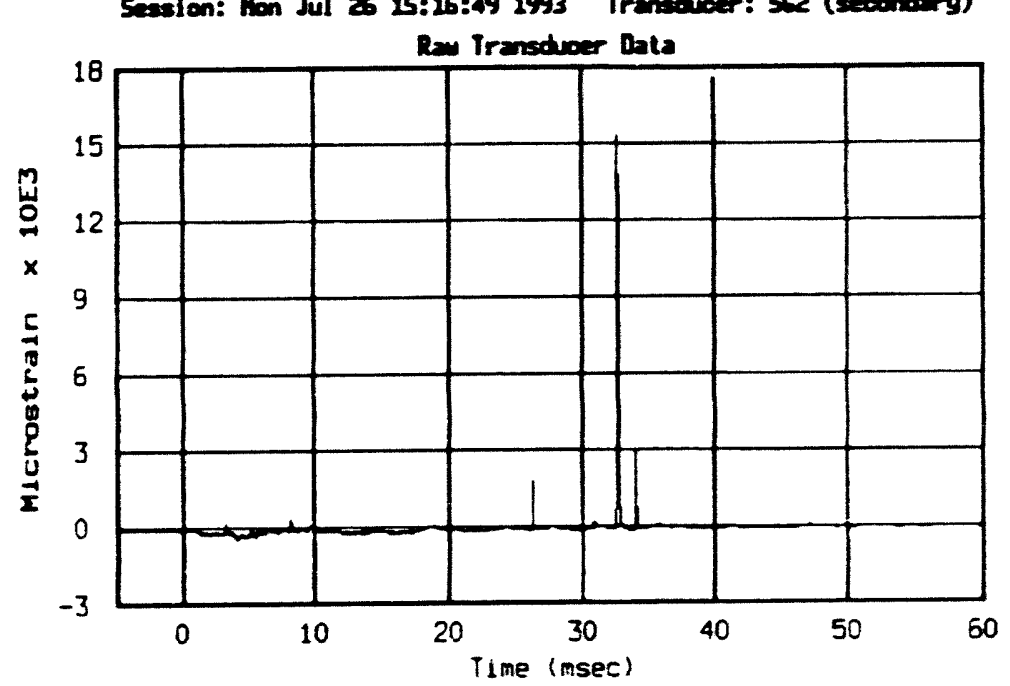

Test: Lonsituoine LoW vaccity H12249 06/29/93 (219) Session: hen Jul 26 15:16:59 1993 Transidver: 503 (secondary)

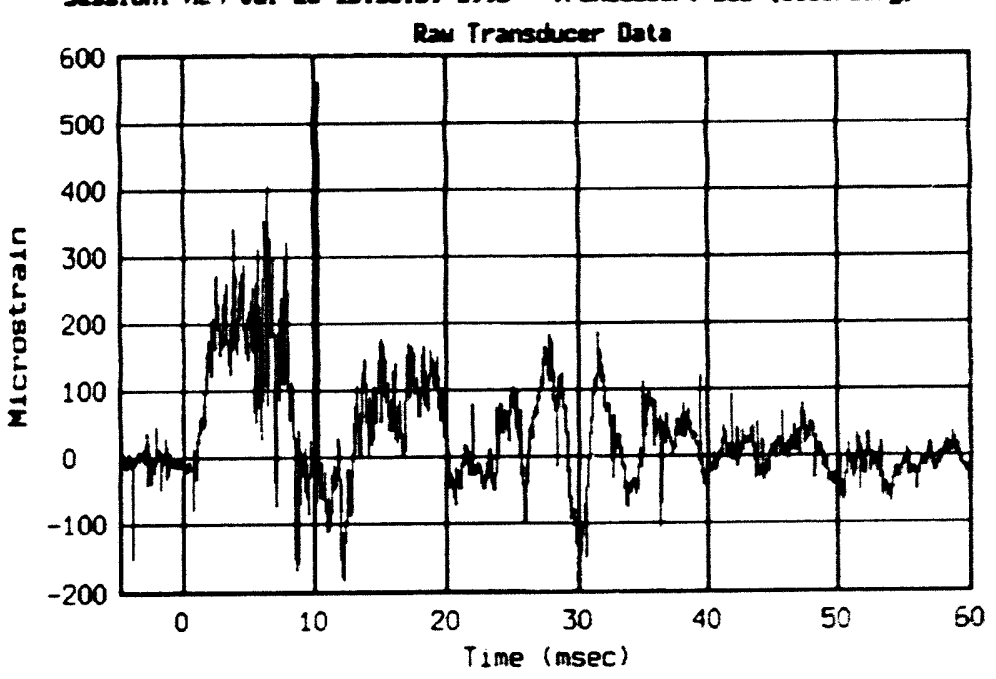




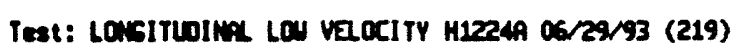
Session: Hon Jul 26 15:17:07 1993 Transchoer: SCA (secondary)

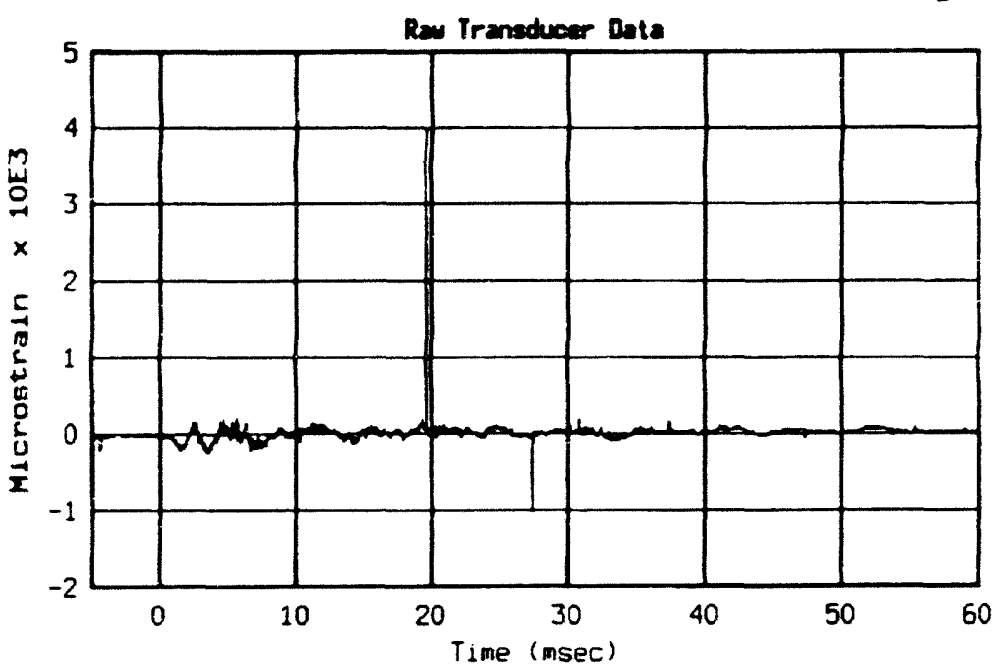

Test: LONGITUDIna LOU yelOCITY H1224A 06/29/93 (219) Session: Mon Jul 26 15:17:16 1993 Transctucer: 565 (secondary)

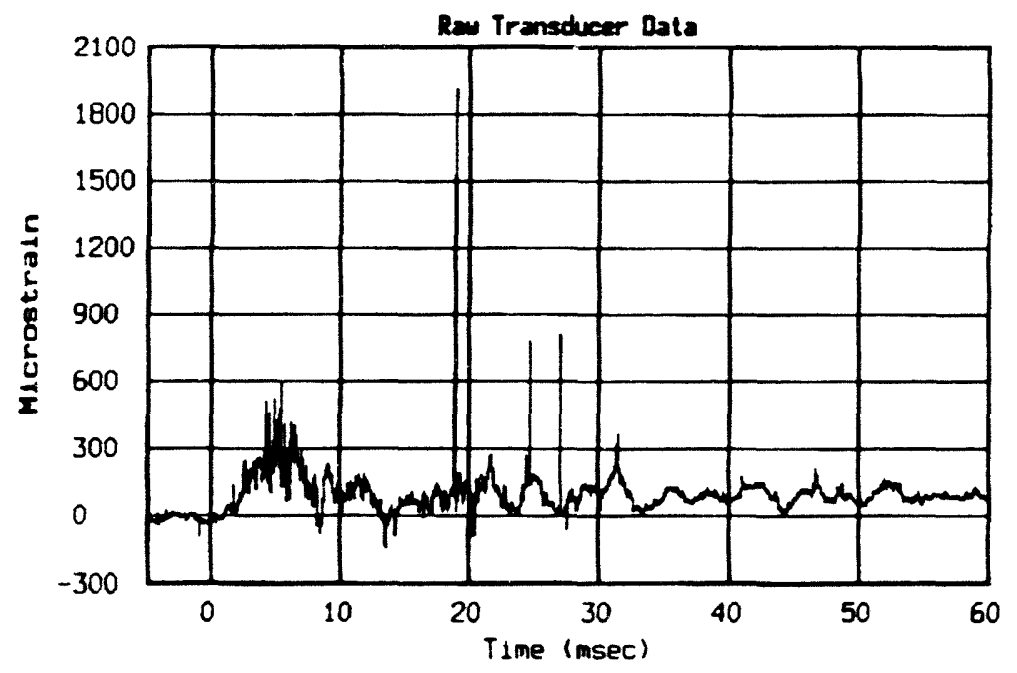

Test: Lowsituinf Low velocITy H1224A $06 / 29 / 93$ (219) Session: Mon Jul 26 15:17:20 1993 Transotveer: 596 (secondary)

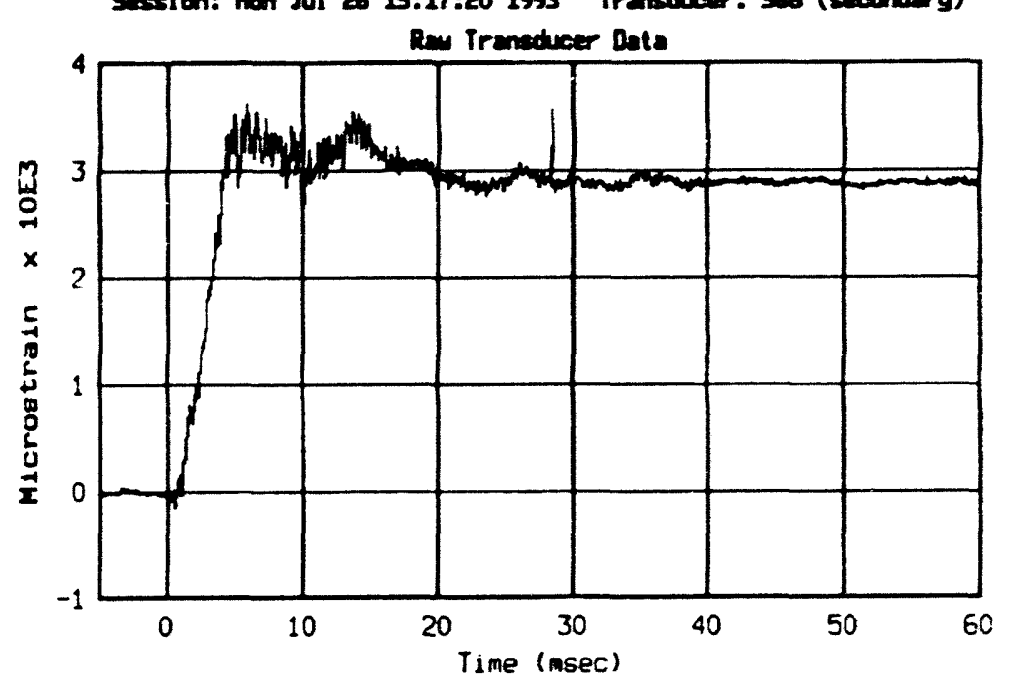

Test: LONGITLIMA Lou veccITY H12249 06/29/93 (219) Session: Mon Jul 26 15:17:27 1993 Transtucer: 567 (secondary)

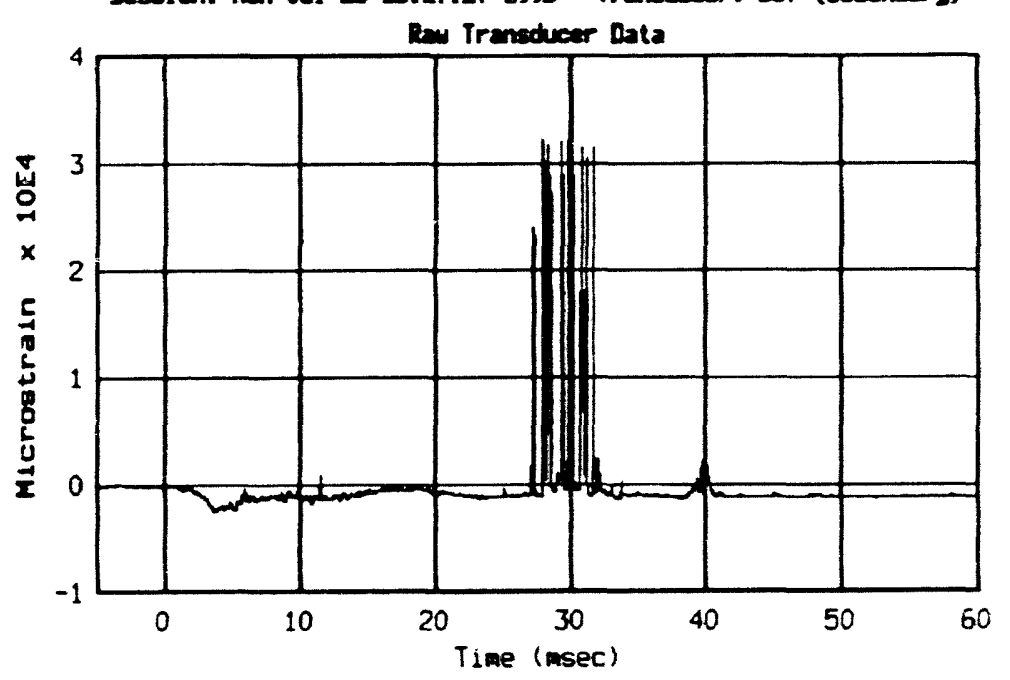



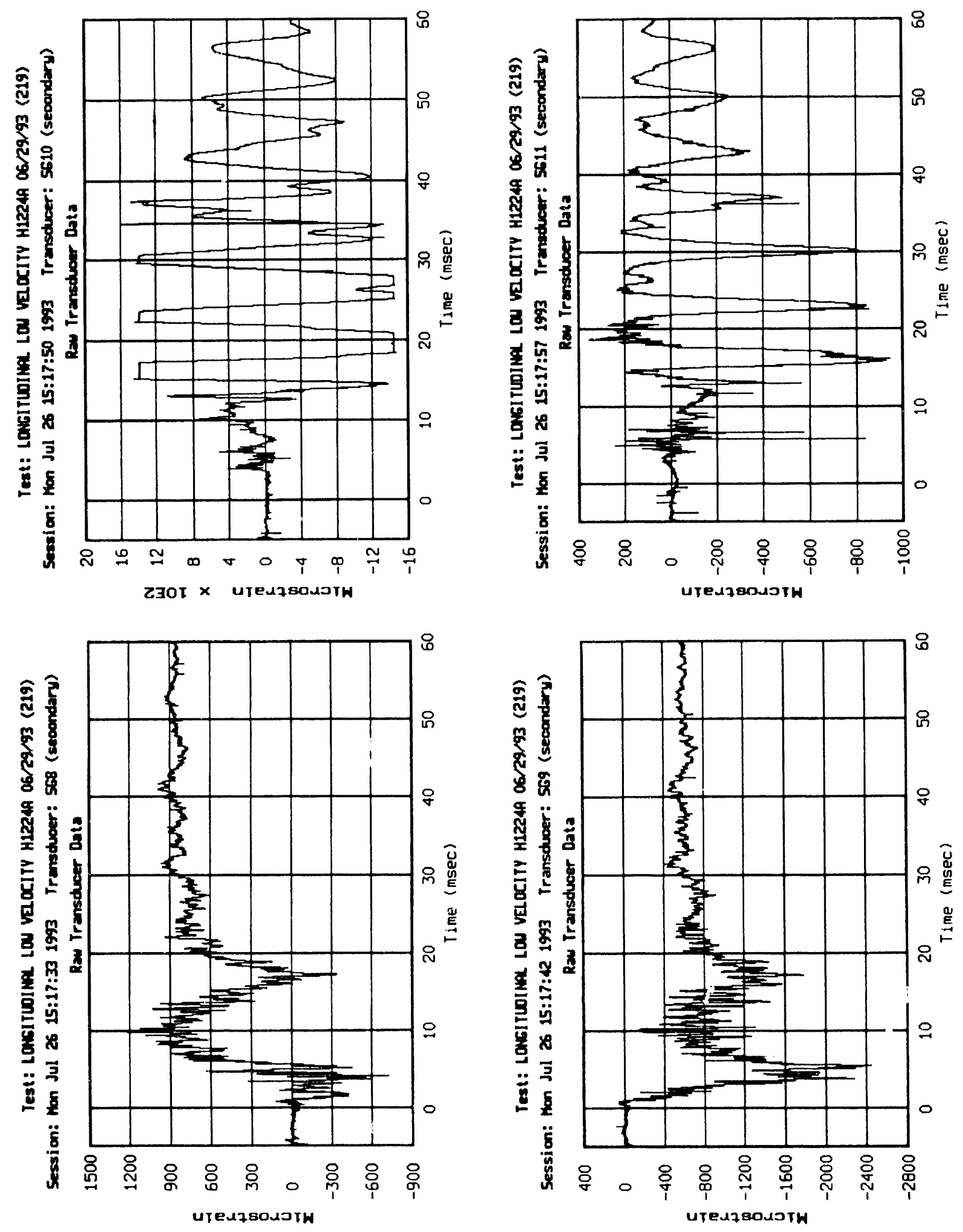
Test: LONGITUDINA Lou velocitY H12244 06/29/93 (219) Sesselon: Mon Jul 26 15:18:13 1993 Transduoer: 5612 (secondary)

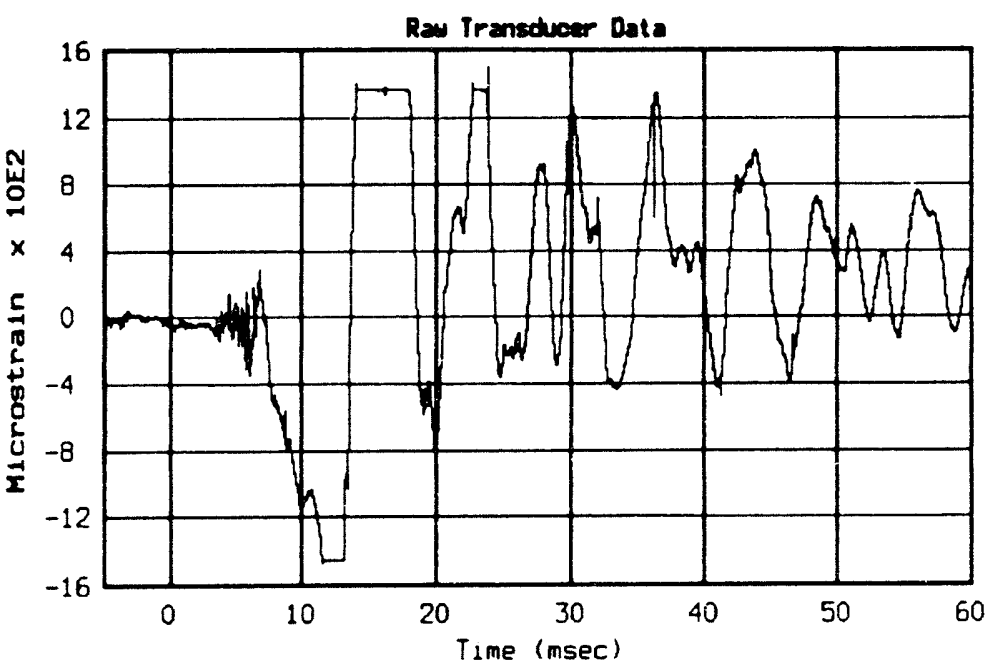

Test: LOWGITLOIMPL LOW VELOCITY H12249 06/29/93 (219) Session: Mon Jul 26 15:18:20 1993 Transtucer: 5613 (secondary)

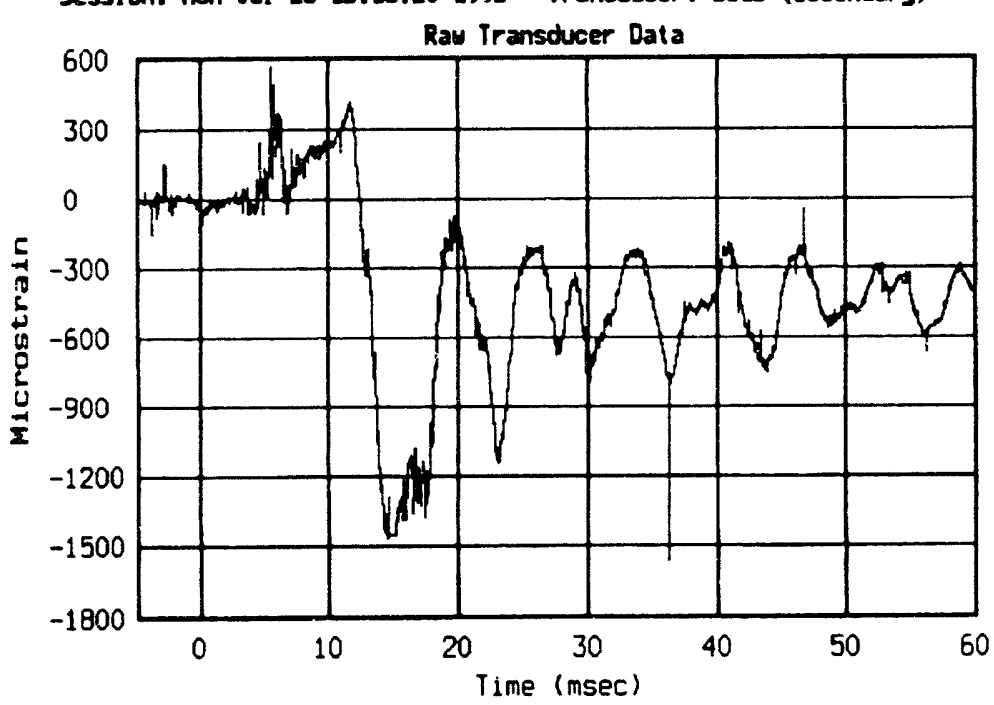

Test: LONGITUOINA LOW VelocITY H12249 06/29/93 (219) Seasion: Mon Jul 26 15:18:03 1993 Transtuoer: 5614 (secondary)

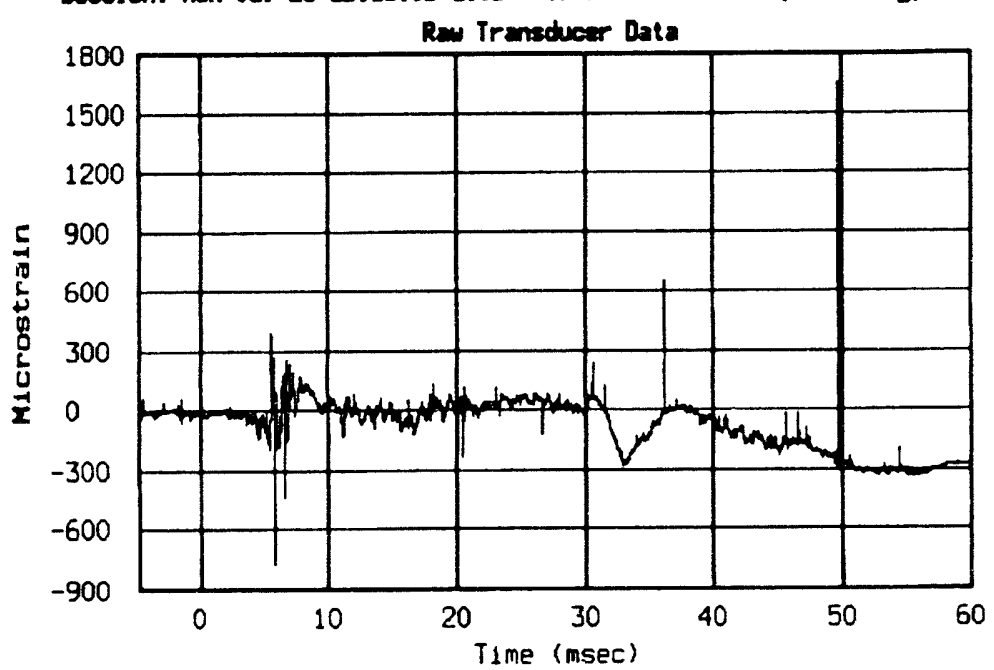

Test: LONGITUDIma LaU VבOCITY H1224A 06/29/93 (219) Session: Mon Jul 26 15:18:31 1993 Transucucer: 515 (secondary)

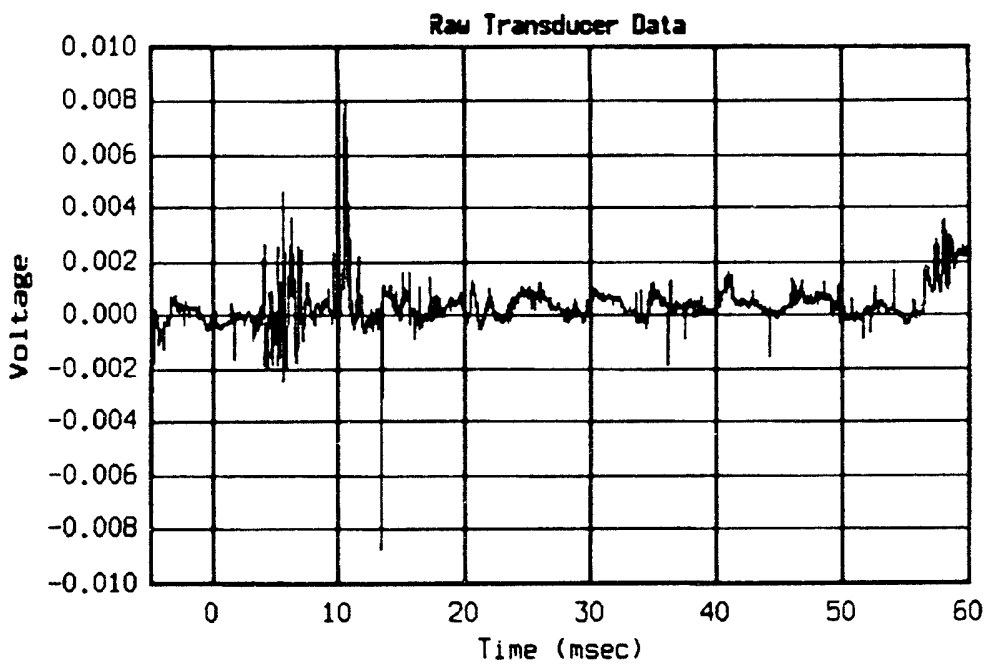


Test: LOHGITLoIn LOU VEcCITY H1224A 06/29/93 (219) Session: Mon Jul 26 15:18:36 1993 Transducer: 516 (seoondary)

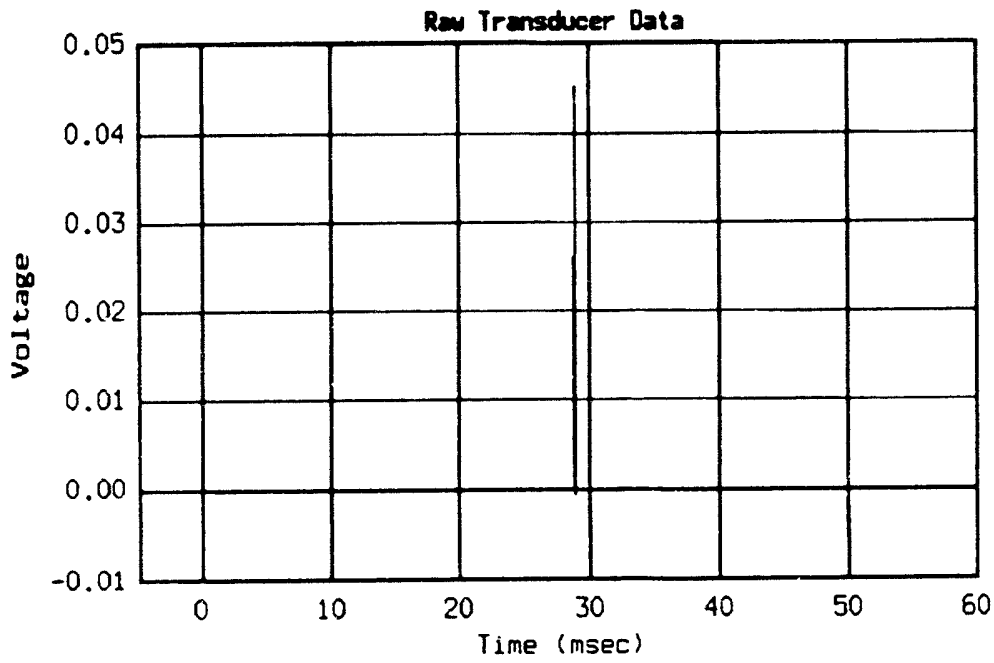

Test: LONGITUDINAL LOU VELOCITY H1224h 06/29/93 (219) Session: Tue Jul 27 10:38:57 1993 Transducer: A1 (secondary) IIR 6-5TAGE BUTTERUORTH FILTER (LONPA5S) $250 \mathrm{~Hz}$

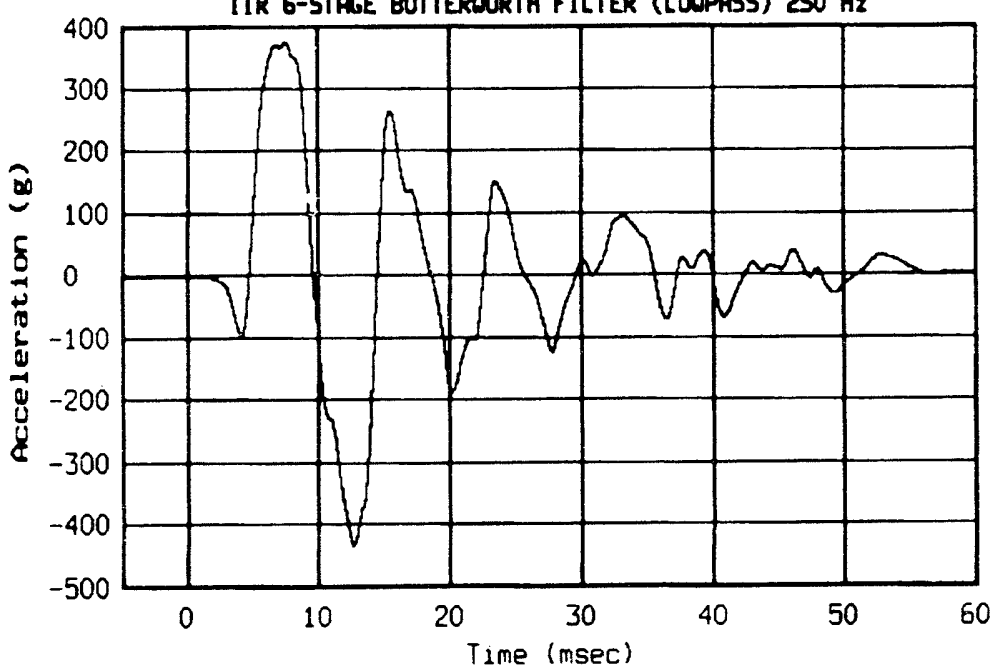

Test: LONGITLINAL LOW VelocITY H12249 06/29/93 (219) Session: Tue Jul 27 10:38:59 1993 Trmaducer: R2 (secondary) IIR 6-STACE BUTTERIORTH FILTER (LOAPAS5) $250 \mathrm{~Hz}$

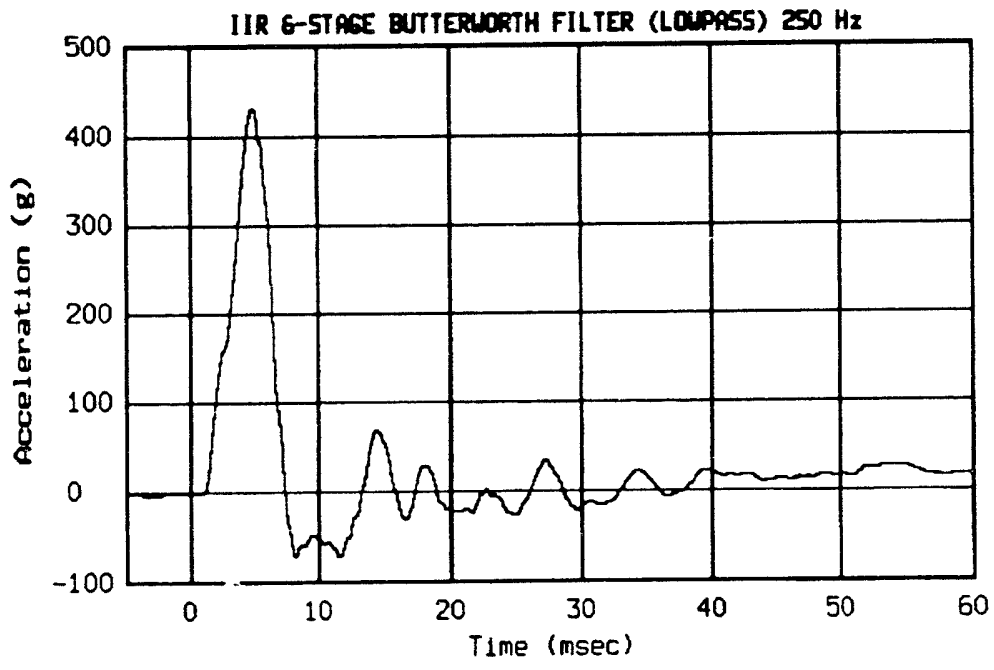

Test: LONGITLOINL LOW VEOCITY H12249 06/29/93 (219) Session: Tue Jul 27 10:39:15 1993 Transducer: $A 3$ (secondary) IIR 6-STAGE BUTTERLORTH FILTER (LOUPASS) $250 \mathrm{~Hz}$

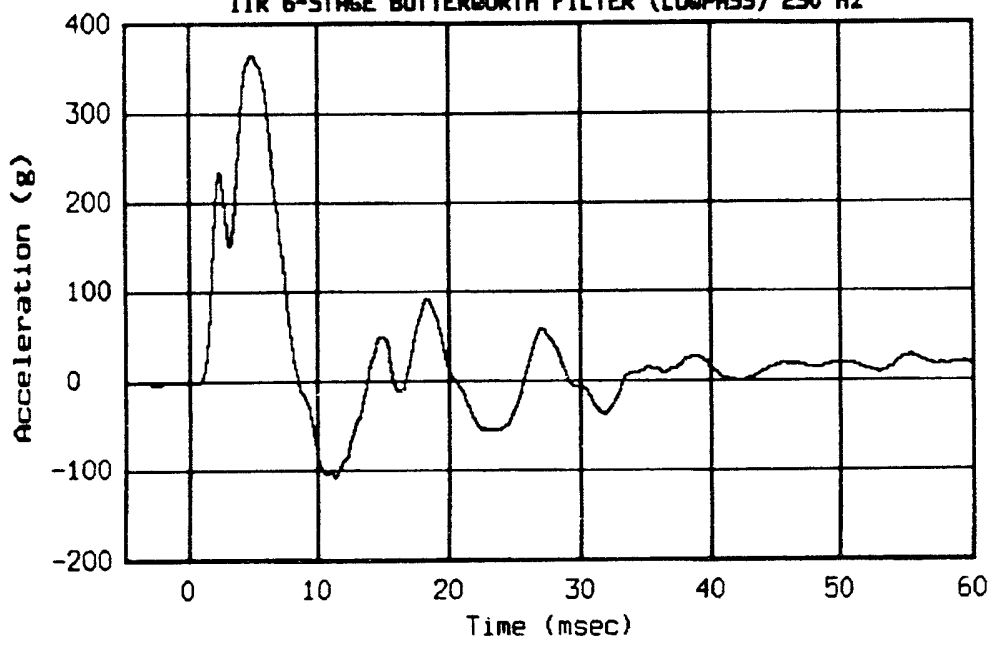


Test: Lancitudina Low Velocity H1224h 06/29/93 (219) Session: Tue Jul 27 10:39:18 1993 Transdwoer: AA (secondery) IIR G-STAGE EUTTERUCRTH FILTER (LOUPA5S) $250 \mathrm{~Hz}$

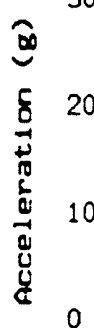

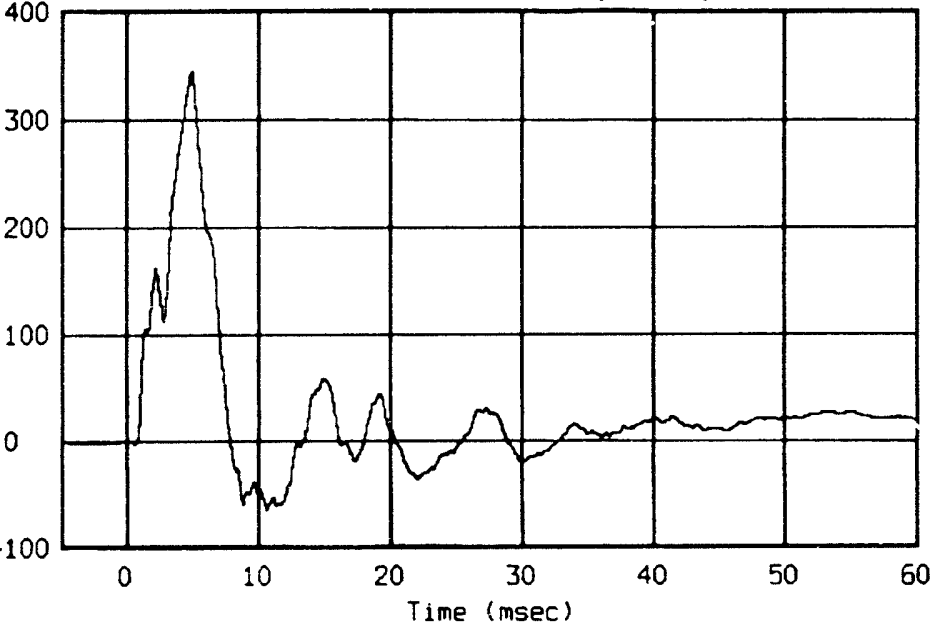

$\stackrel{\infty}{\leftrightarrow}$

Test: LONGITUDI LOU VElocITY H12249 06/29/93 (219)

Session: Tue Jul 27 10:39:42 1993 Transducer: AS (secondary)

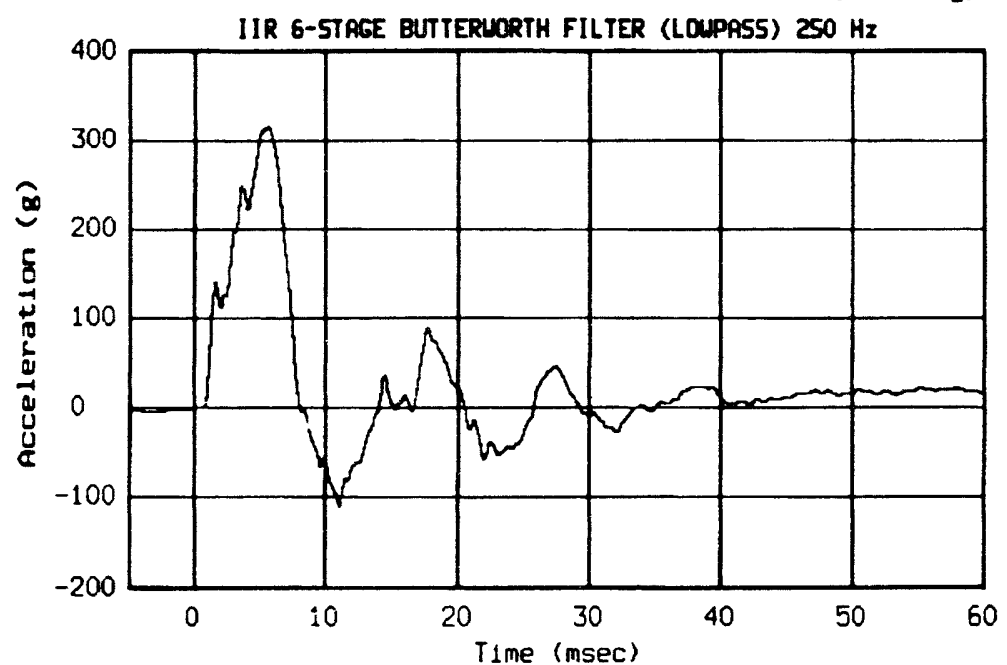

Test: LOHGITWOINL LOW VELOCITY H1224A 06/29/93 (219) Session: Tue Jul 27 10:39:43 1993 Transducer: A6 (secondary) IIR G-STAGE BUTTERLORTH FILTER (LOLPASS) $250 \mathrm{~Hz}$

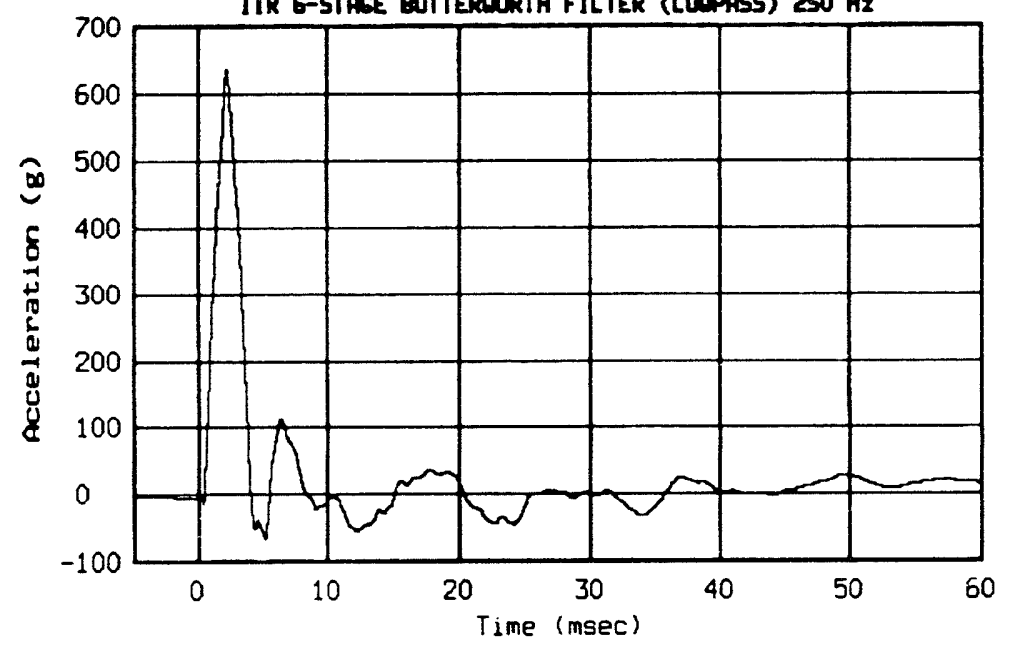

Tes: LONGITLOINA LOU VelocITY H1224A 06/29/93 (219) Session: Tue Jul 27 10:40:11 1993 Transducer: A7 (secondary) IIR 6-STAGE EUTTERLORTH FILTER (LOPASS) $250 \mathrm{~Hz}$

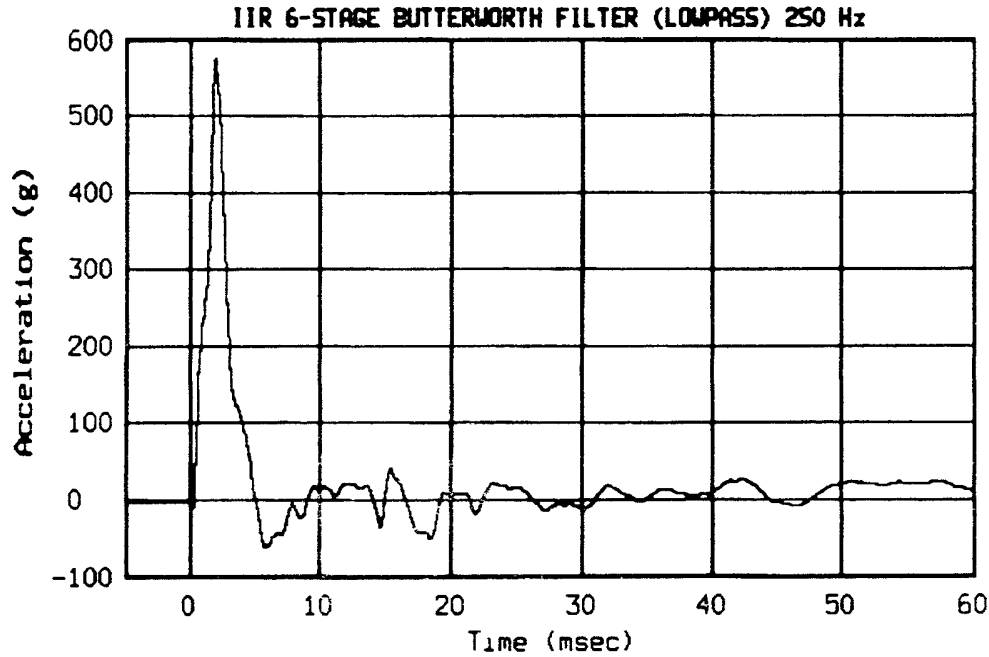


Iest: LOWSITUINAL LOW VELOCITY H1224A 06/29/93 (219) Session: Tue Jul 27 10:40:09 1993 Transducer: $B 8$ (secondary) IIR 6-STAGE EUTTERUORTH FILTER (LOUPASS) $250 \mathrm{~Hz}$

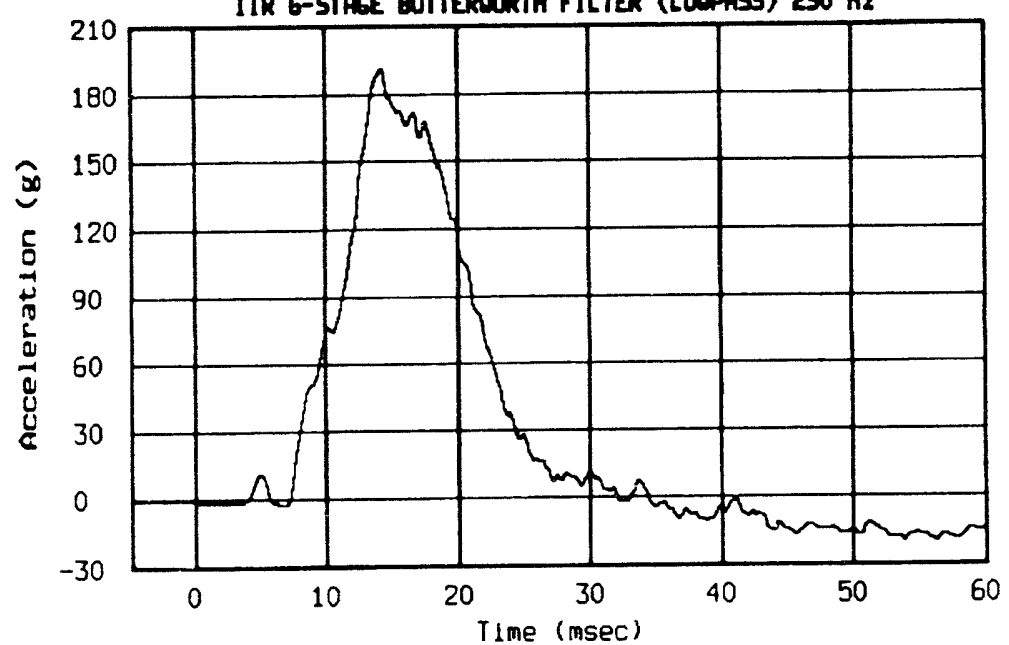

$\stackrel{\infty}{\infty}$

Test: LONGITUDINA LOW VELOCITY H1224A 06/29/93 (219) Session: Tue Jul 27 10:40:37 1993 Transducer: A9 (secondary) IIR G-STREE BUTTERUORTH FILTER (LOUPRSS) $250 \mathrm{~Hz}$

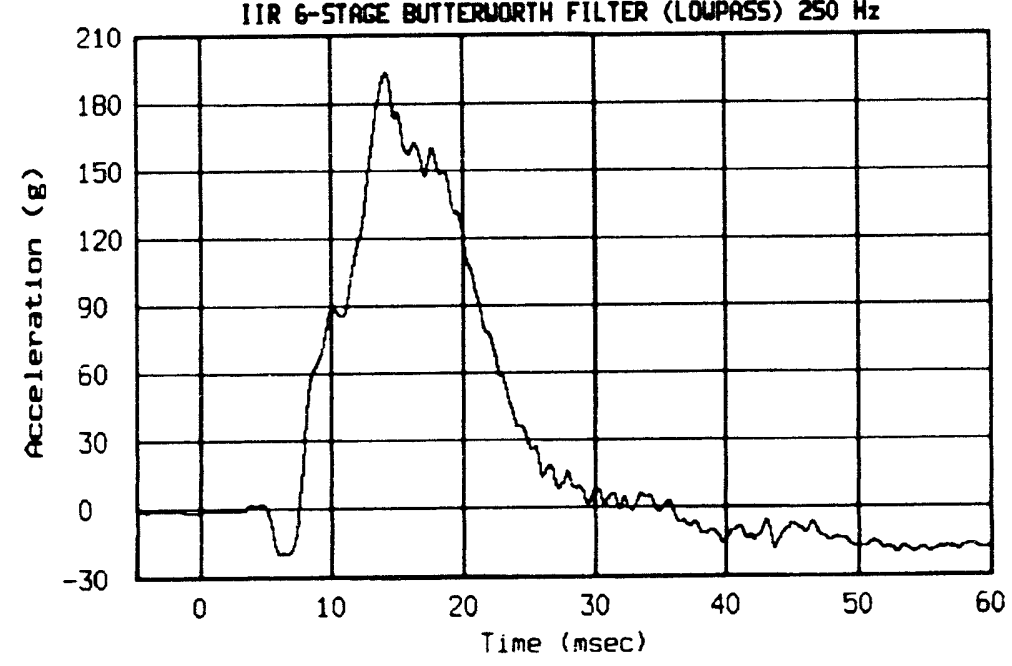

Test: LONGITUDINA LOU ValOCITY H1224A O6/29/93 (219) Session: Tue Jul 27 10:40:38 1993 Transdwoer: A10 (secondary)

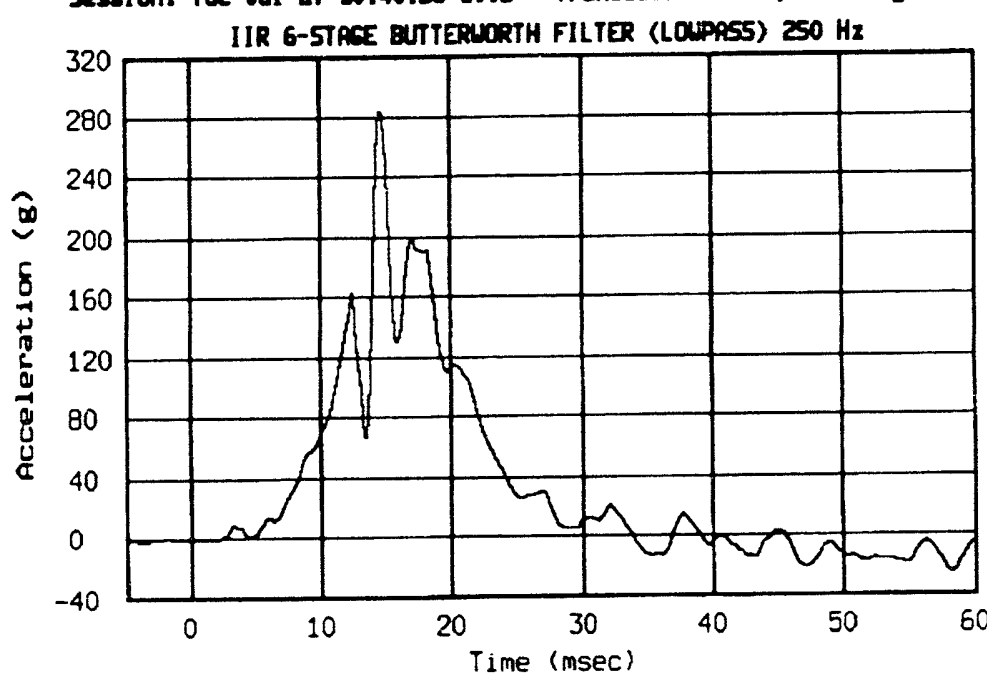

Test: LONGITUDIHA LOW VEOCITY H1224A 06/29/93 (219) Session: Tue Jul 27 10:40:57 1993 Transoducer: A11 (secondary)

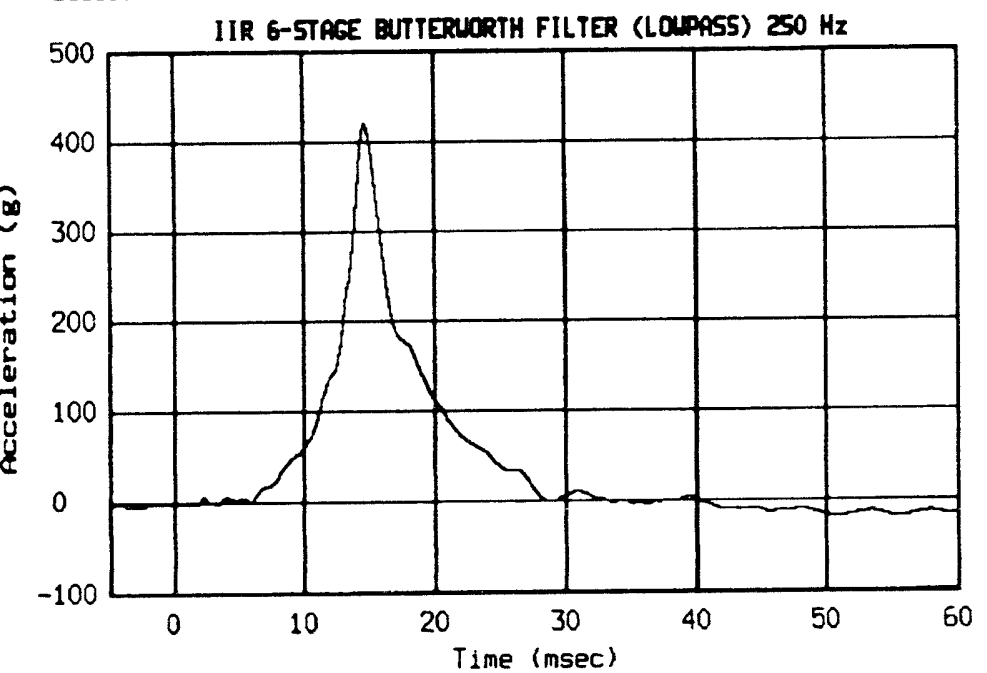


Teat: LOKSITLOIKAL LOU VenOCITY H12249 06/29/93 (219) Session: Tue Jul 27 10:40:58 1993 Transchoer: A12 (secondary)

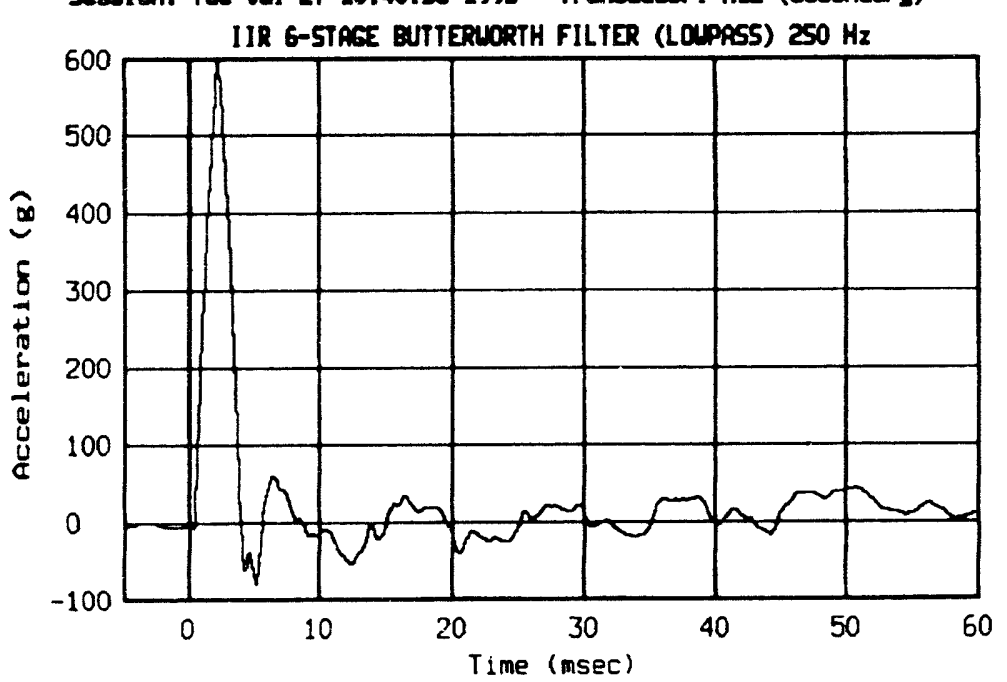

Test: LONGITUDInA LOW VelocITY H1224A 06/29/93 (219) Session: Tue Jul 27 10:41:11 1993 Transducer: A13 (secondary)

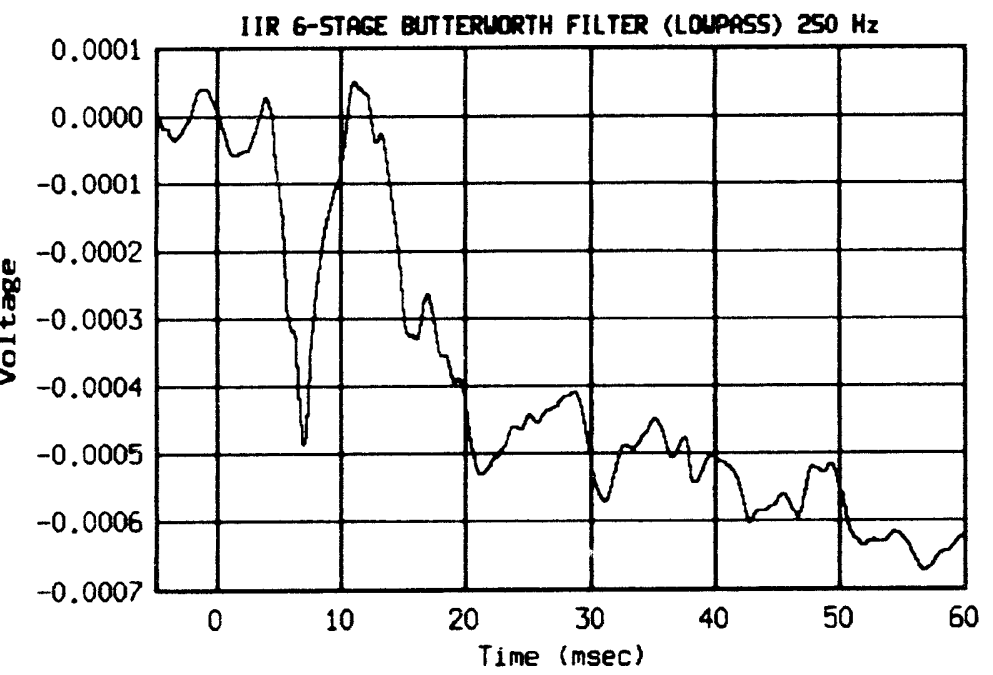

Test: LONGITUDIAL LOU VelocITY H1224A 06/29/93 (219) Session: Tue Jul 27 10:41:10 1993 Trmeducer: S61 (secondery)

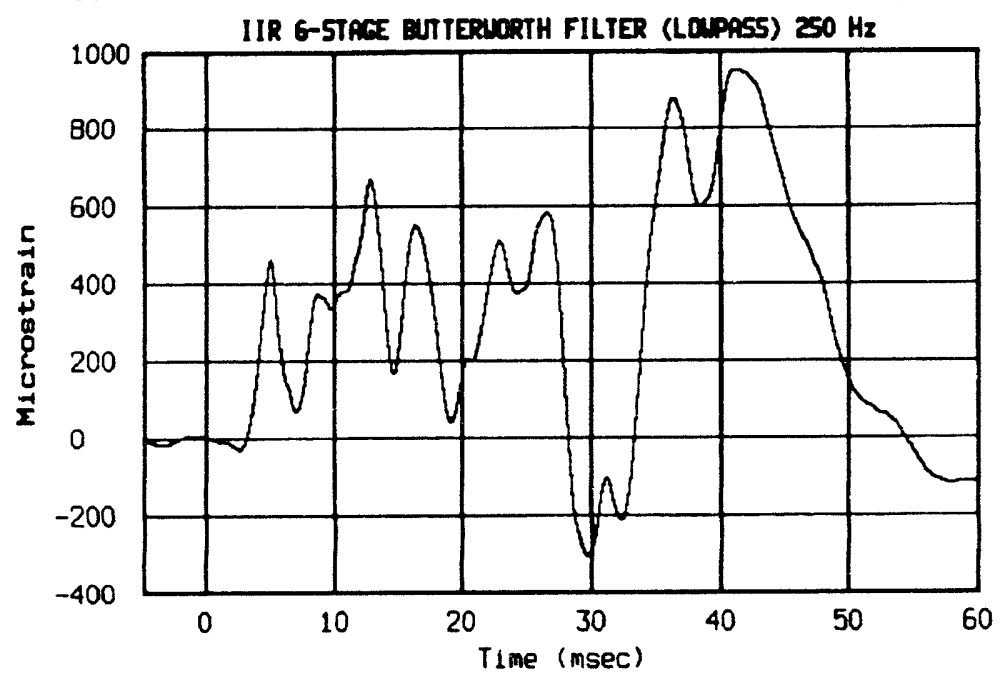

Test: LOASITUINAL LOU VEDOCITY H1224月 06/2\%/93 (219) Session: Tue Jul 27 10:41:25 1993 Transducer: SE2 (secondary)

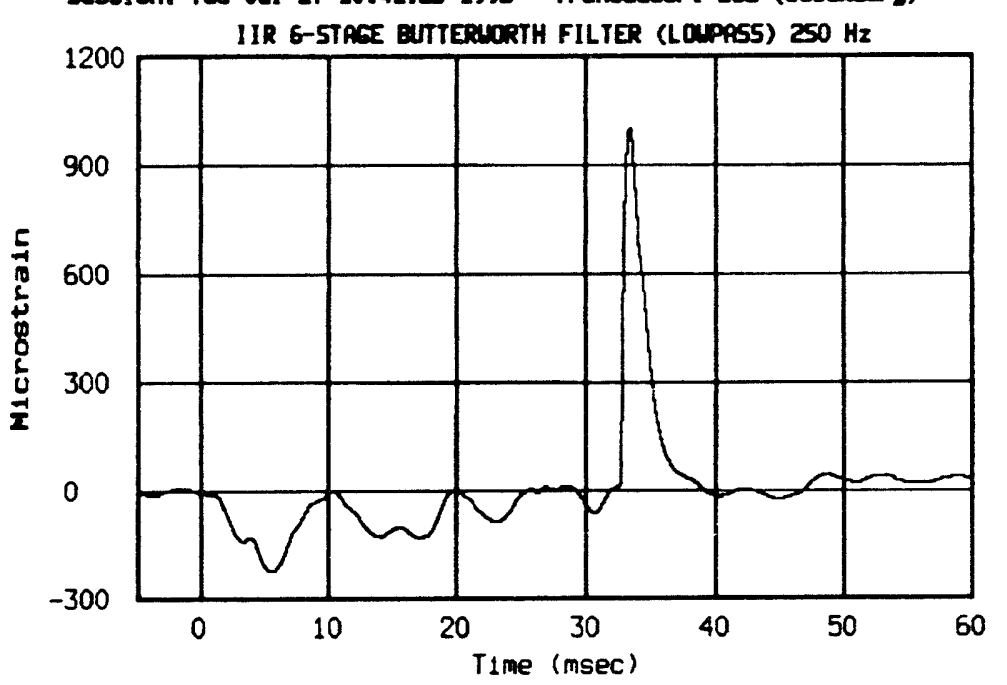


Test: LOWGITUDINAL LOW VE1OCITY H1224A 06/29/93 (219) Session: Tue Jul 27 10:41:24 1993 Trunstuoer: 563 (secondary)

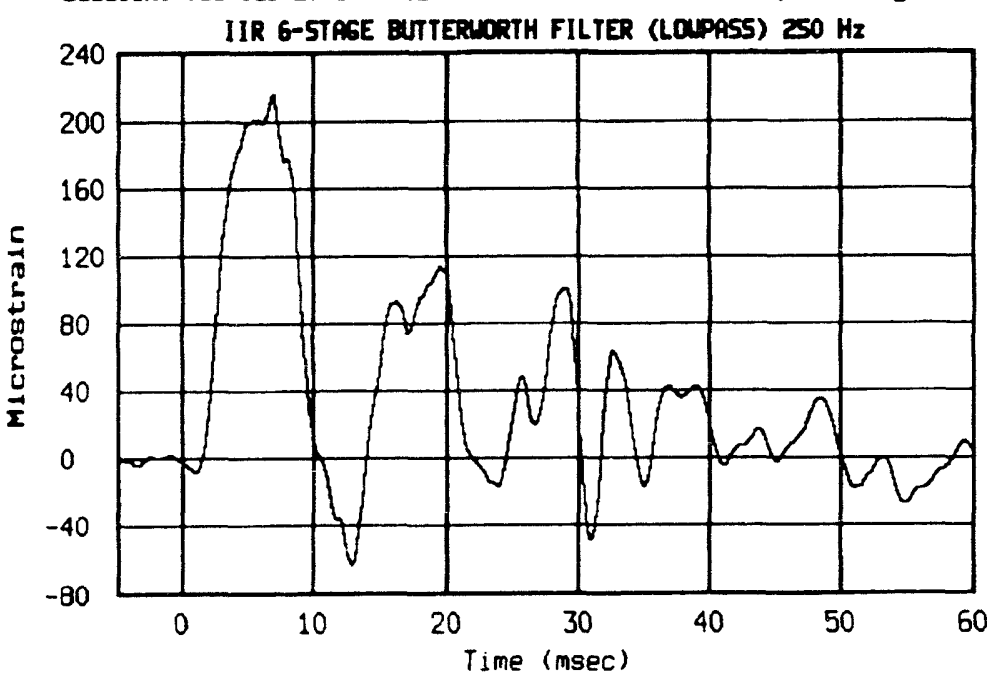

Test: LoigItuoing LoW VelocITY H1224A 06/29/93 (219) Session: Tue Jul 27 10:41:41 1993 Transdwoer: 564 (secondary)

IIR G-STAGE BUTTERIORTH FILTER (LOUPASS) $250 \mathrm{~Hz}$

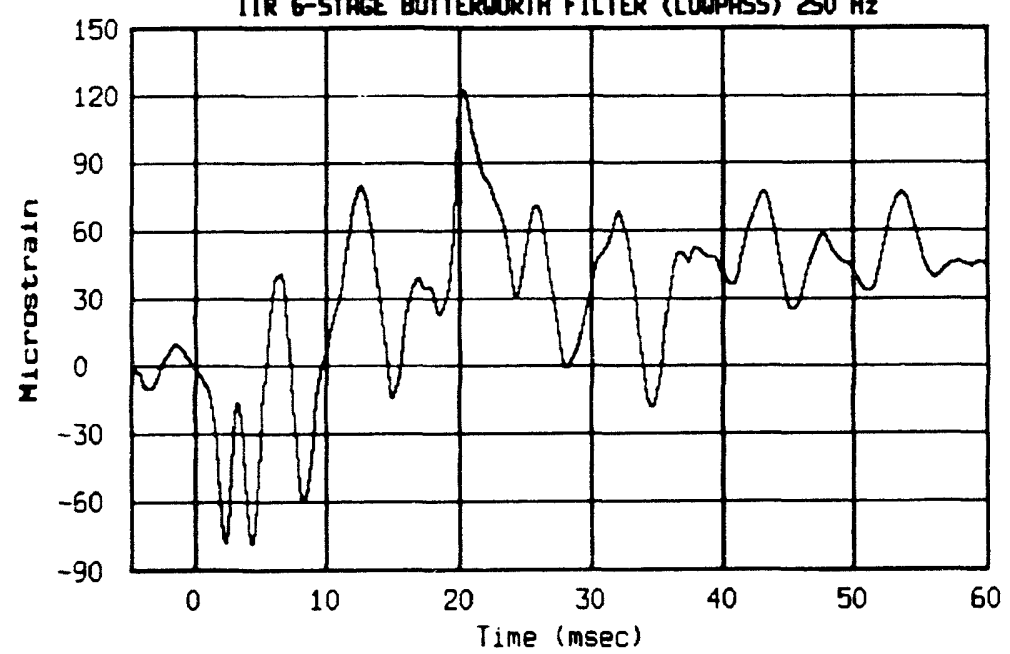

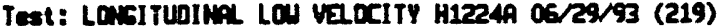
Session: Tue Jul 27 10:41:40 1993 Transducer: 565 (secondary) IIR G-STRGE EUTTERIORTH FILTER (LOAPASS) $250 \mathrm{~Hz}$

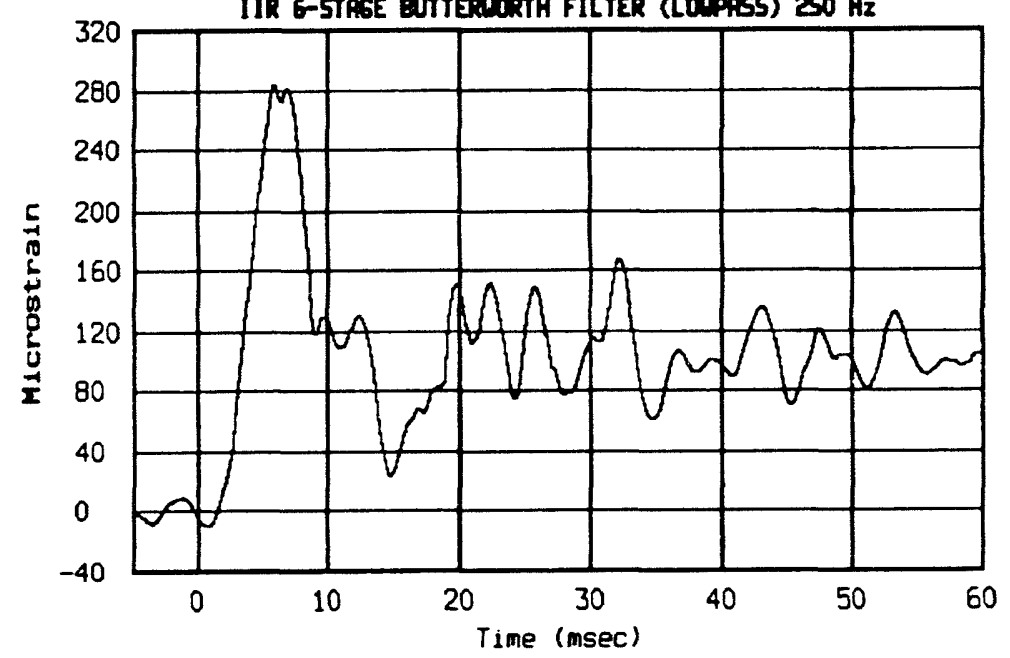

Test: LONSITLOINA Loy VELCCITY H12249 06/29/93 (219) Session: Tue Jul 27 10:41:51 1993 Transdwoer: 586 (secondary) IIR G-STAGE BUTTERUORTH FILTER (LOAPASS) $250 \mathrm{~Hz}$

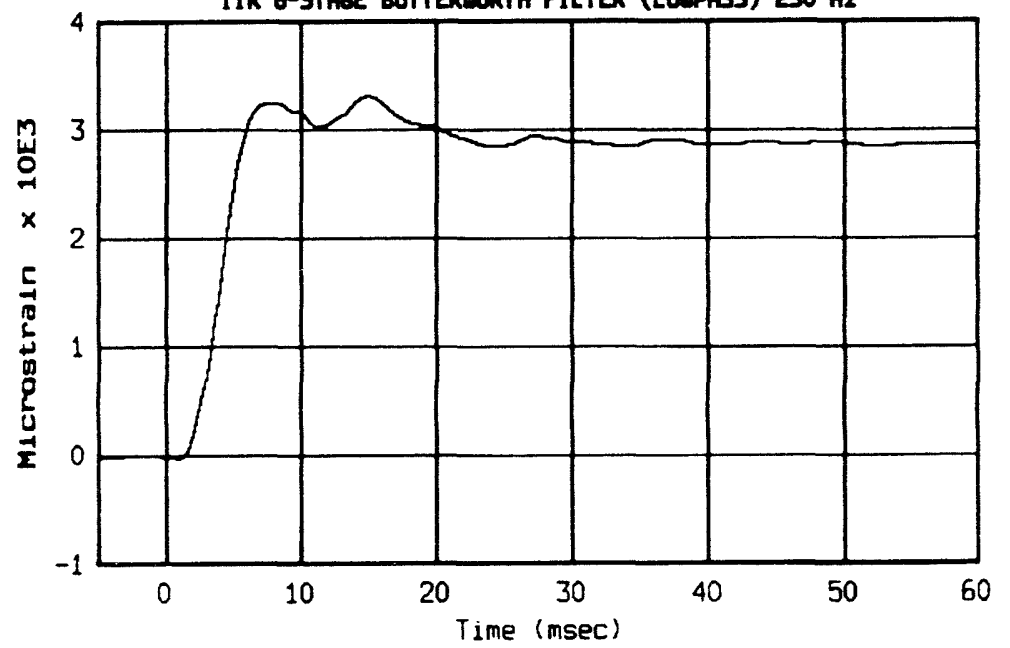


Test: LONGITUDINA LOW ValocITY H1224A 06/29/93 (219) Session: Tue Jul 27 10:41:51 1993 Transiducer: 567 (secondary) IIR 6-STAGE QUTTERUORTH FILTER (LOLPA55) $250 \mathrm{~Hz}$

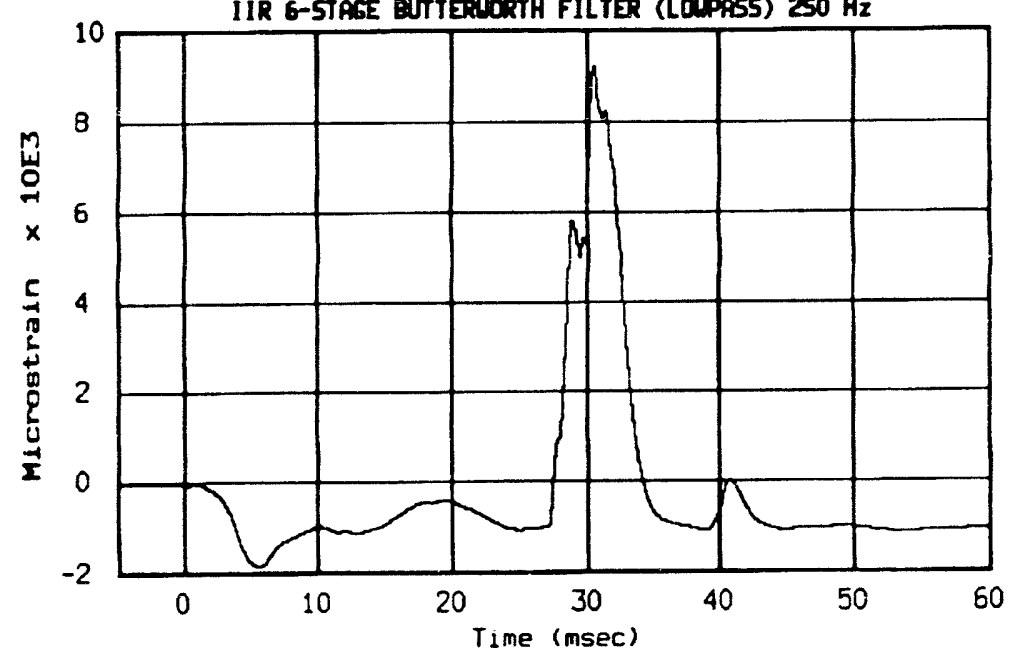

Test: LONGITUDIMP LOW VELOCITY H1224A 06/29/93 (219) Session: Tue Jul 27 10:42:06 1993 Transducer: 568 (secondary)

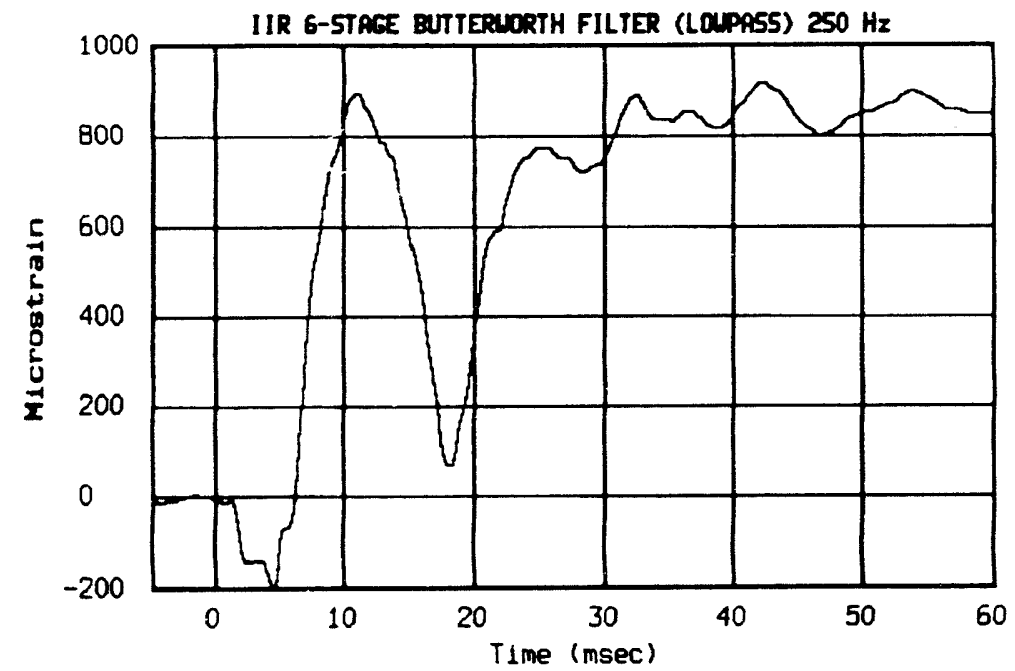

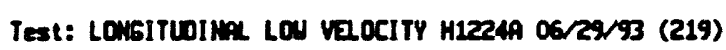
Session: Tue Jul 27 10:42:05 1993 Transedvoer: 569 (secondury)

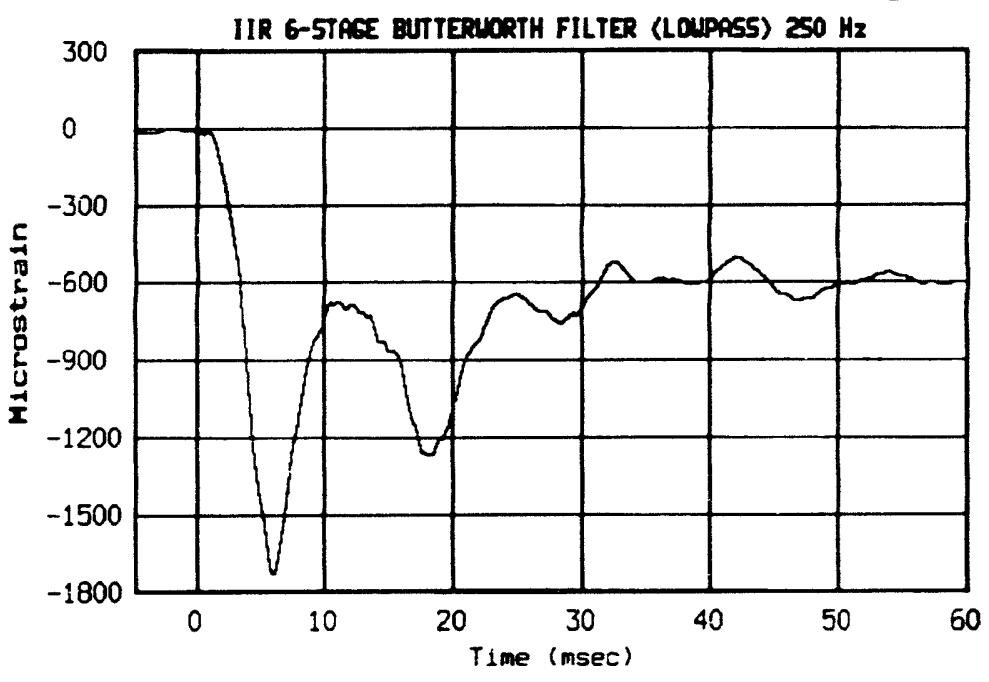

Test: LONGITUOINA LOW VeOCITY H12249 06/29/93 (219) Session: Tue Jul 27 10:42:22 1993 Transoducer: 5610 (secondiry)

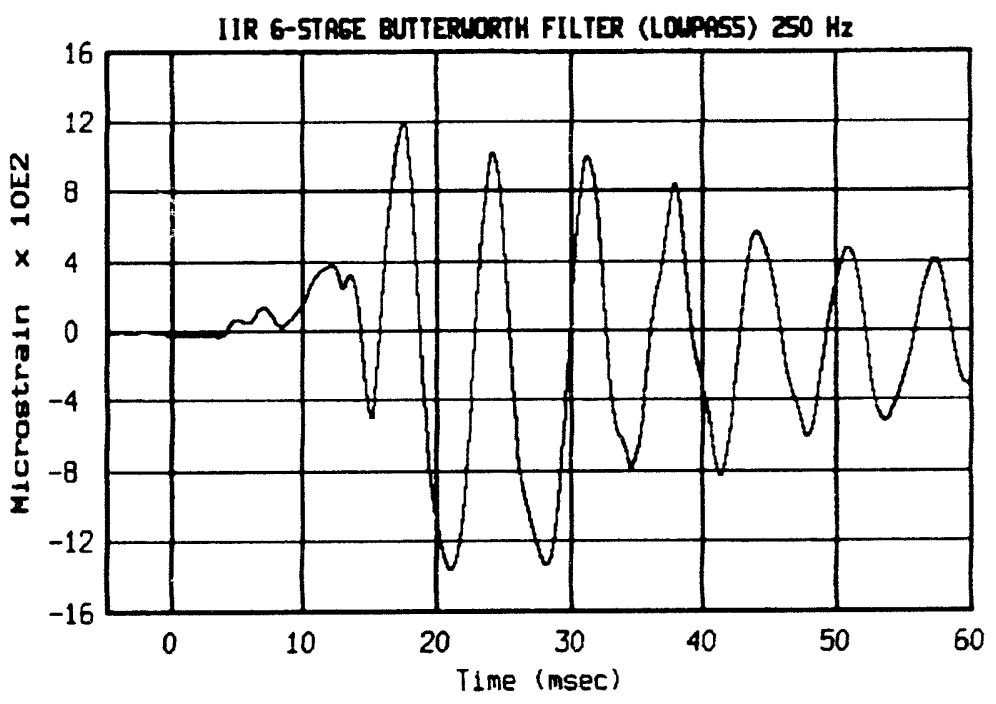


Int: Lovituming Lou ve ority H13049 05/29/93 (219) Session: Tue Jul 27 10:42:22 1993 Transducer: 5611 (secondary)

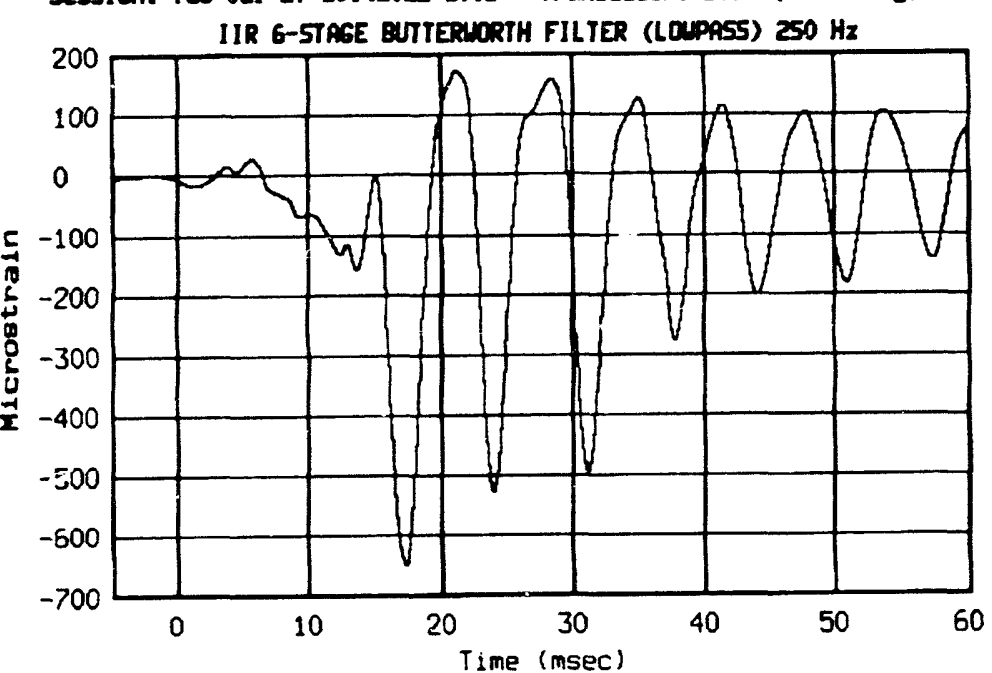

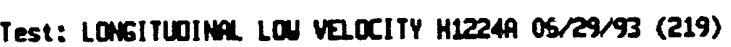
Session: Tue Jul 27 10:42:33 1993 Trmsducer: 5612 (secondary)

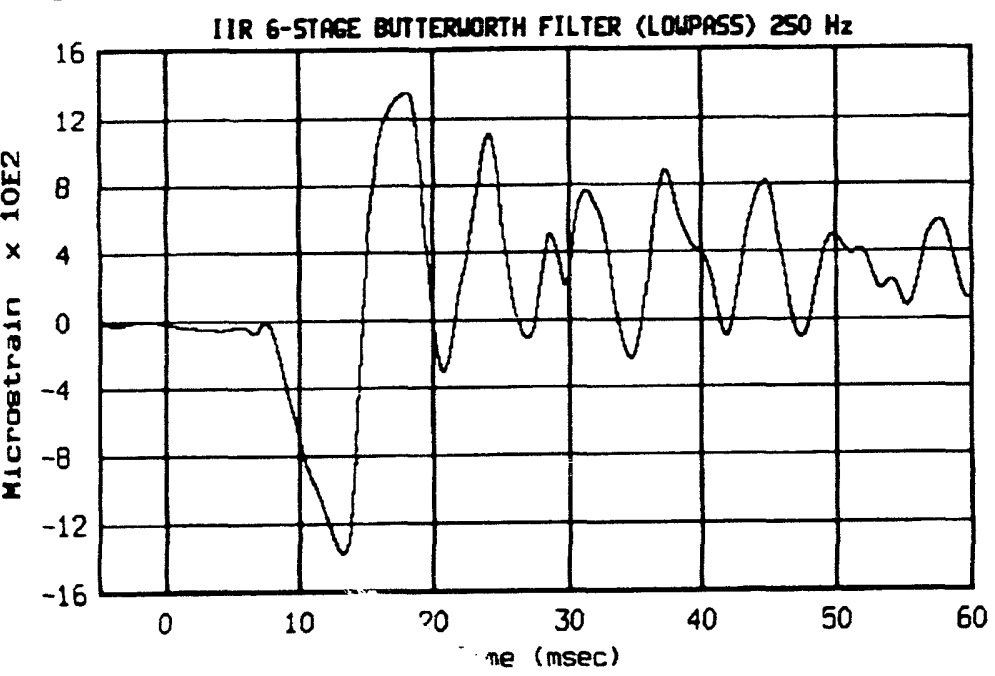

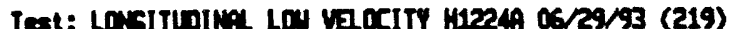
Session: Tue Jul 27 10:42:46 1993 Transiduer: 5513 (secondary)

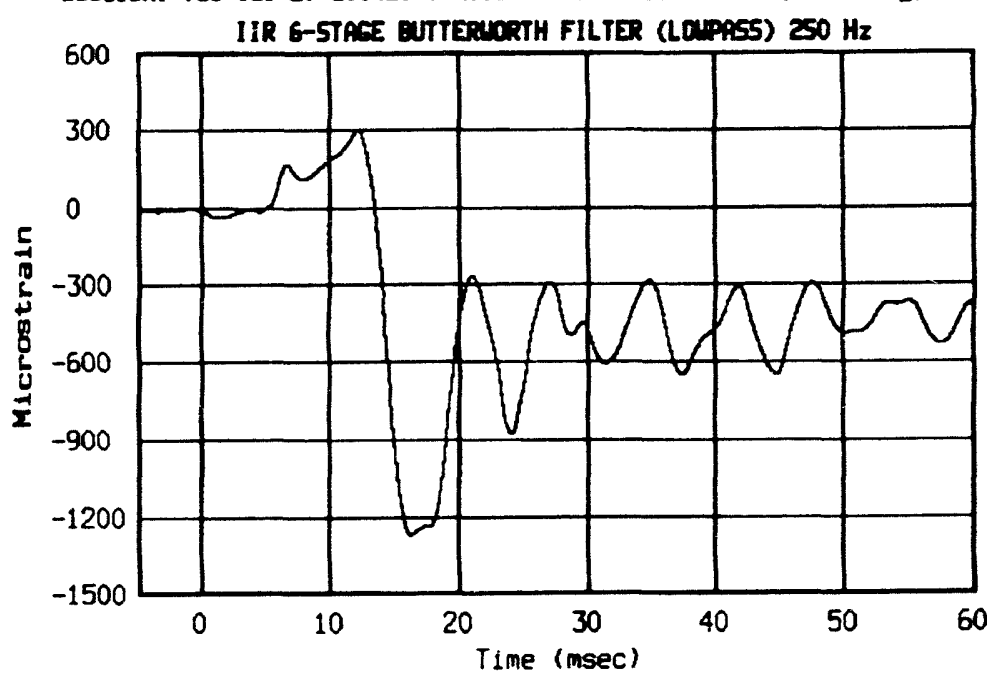

Test: Lovituoline Lou veccity H12249 05/29893 (219) Session: Tue Jul 27 10:42:32 1993 Transucer: 5514 (secondary)

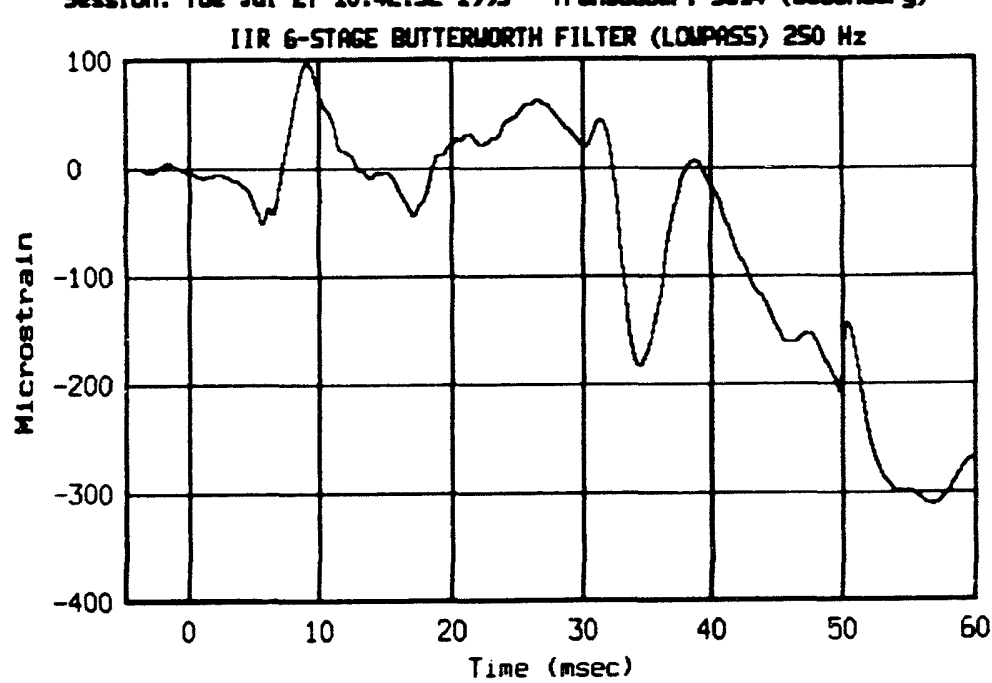


Test: LowsITHIML LOW VEOCITY H1224A 06/29/93 (219) Session: Tue Jul 27 10:42:47 1993 Transducer: 515 (secondary)

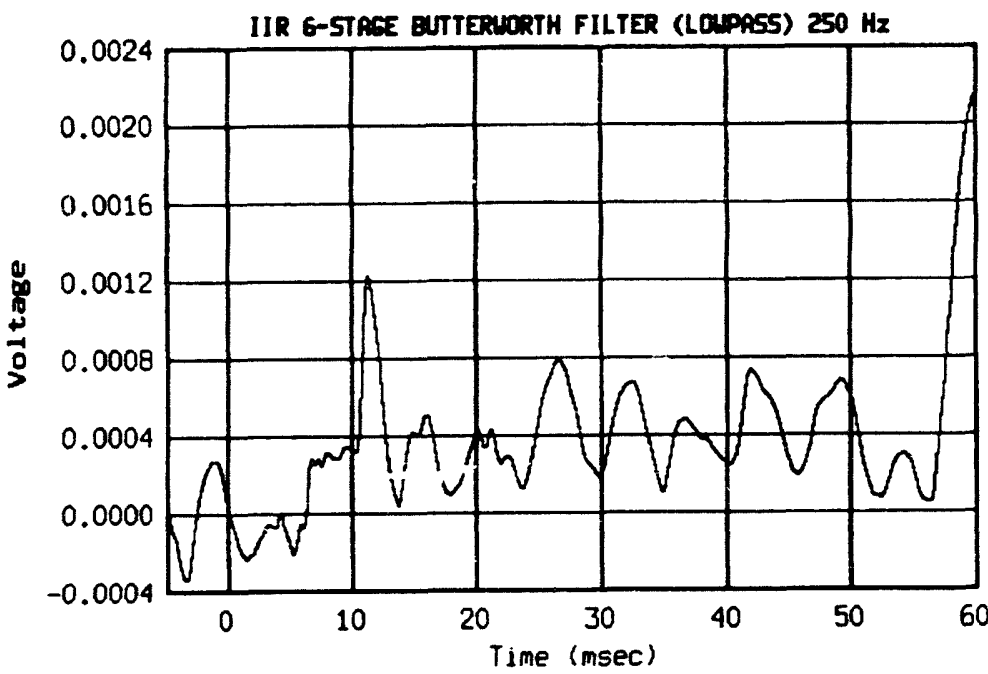

Test: LOASITUOINAL LON VelocITY H1224A 06/29/93 (219) Sessien: Tue Jul 27 10:43:02 1993 Trunsducer: 516 (secondary)

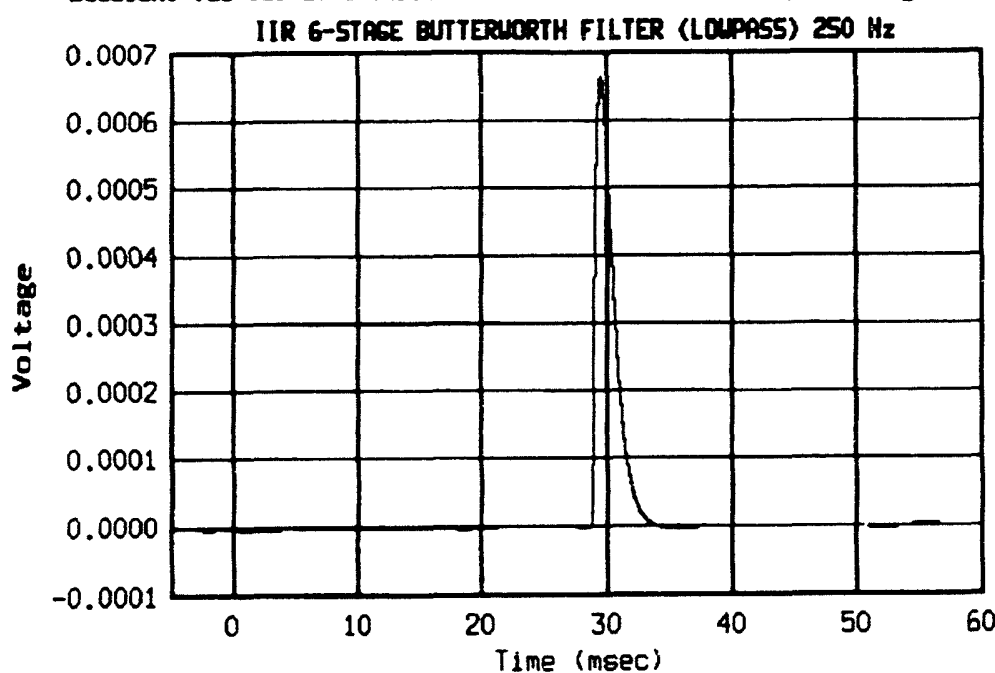

Test: LOWITUDInil Low VEOCITY H12249 06/29/93 (219) Session: Tue Jul 27 11:22:45 1993 Trmaducer: A1 (secondary) IIR 6-STREE EUTTEUUORTH FILTER (LOPPASS) $2000 \mathrm{~Hz}$

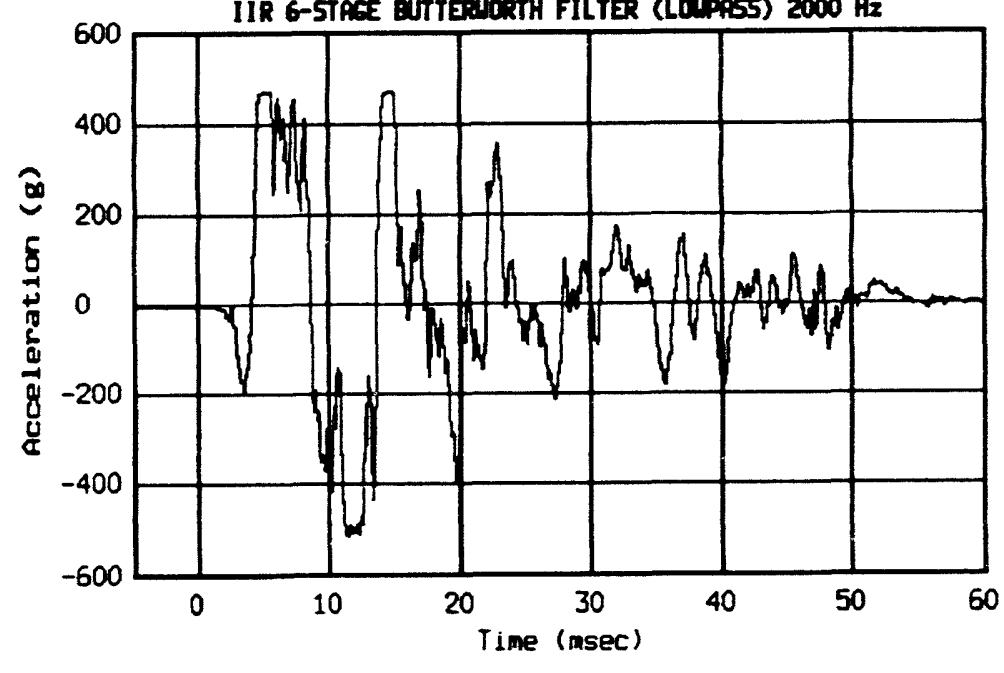

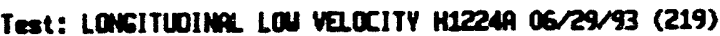
Session: Tue Jul 27 11:22:48 1993 Transducer: R2 (excondary) IIR G-STPEE BTTERIORTH FILTER (LOPASS) $2000 \mathrm{~Hz}$

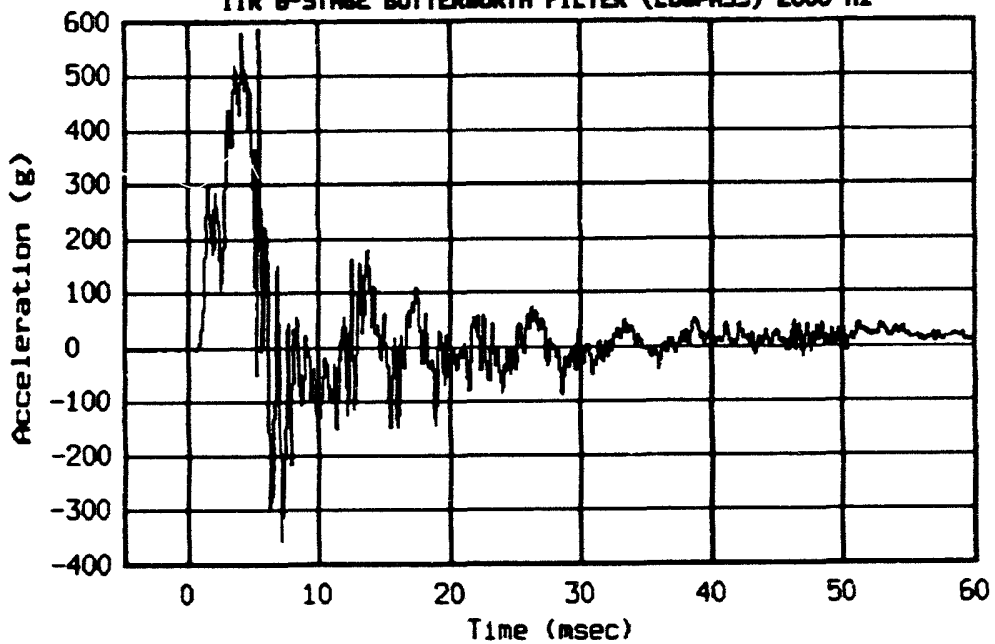



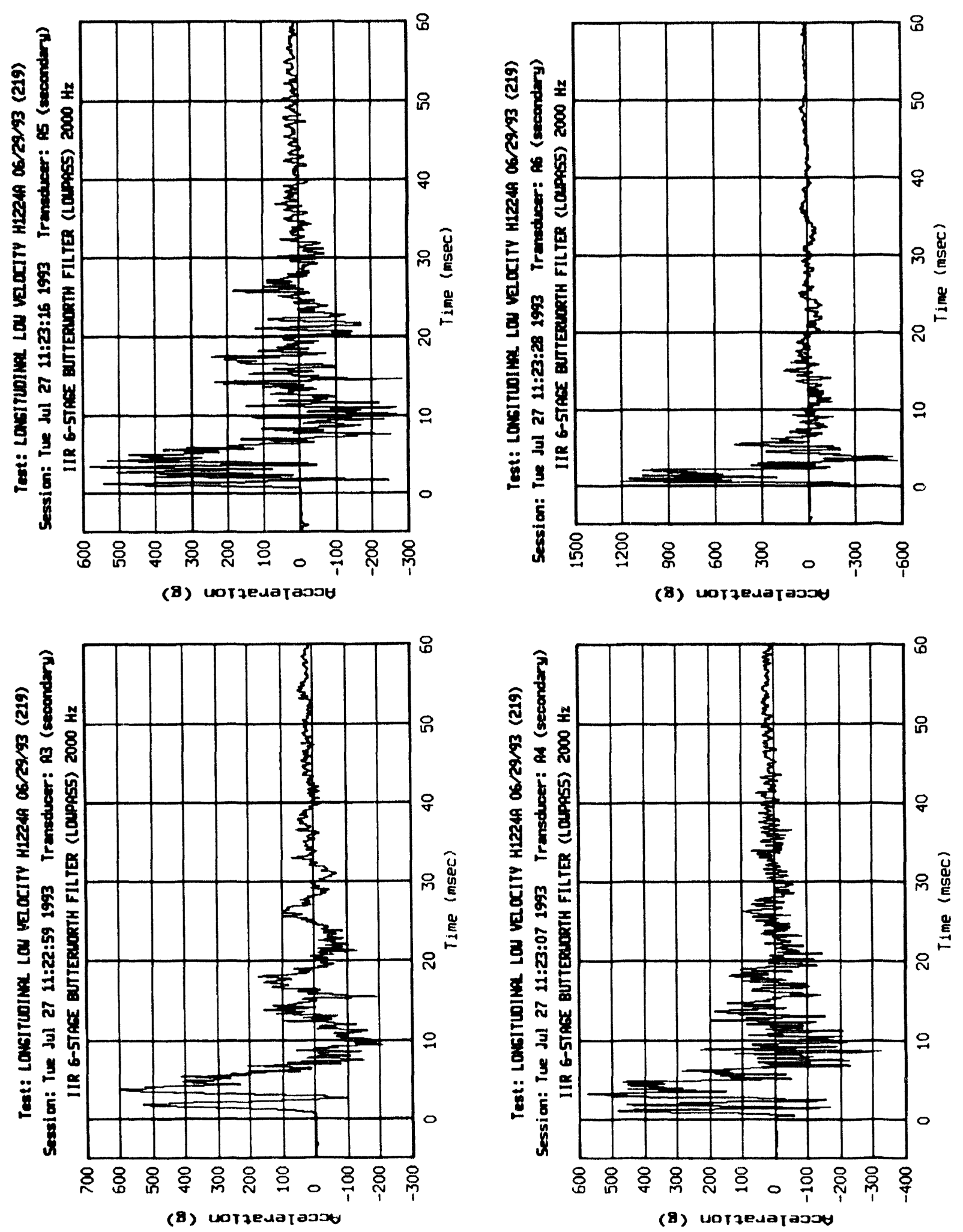
Test: LOWGITUDINL LOU VELOCITY H1224A 06/29/93 (219) Session: Tue Jul 27 11:23:37 1993 Trunsducer: A7 (secondary)

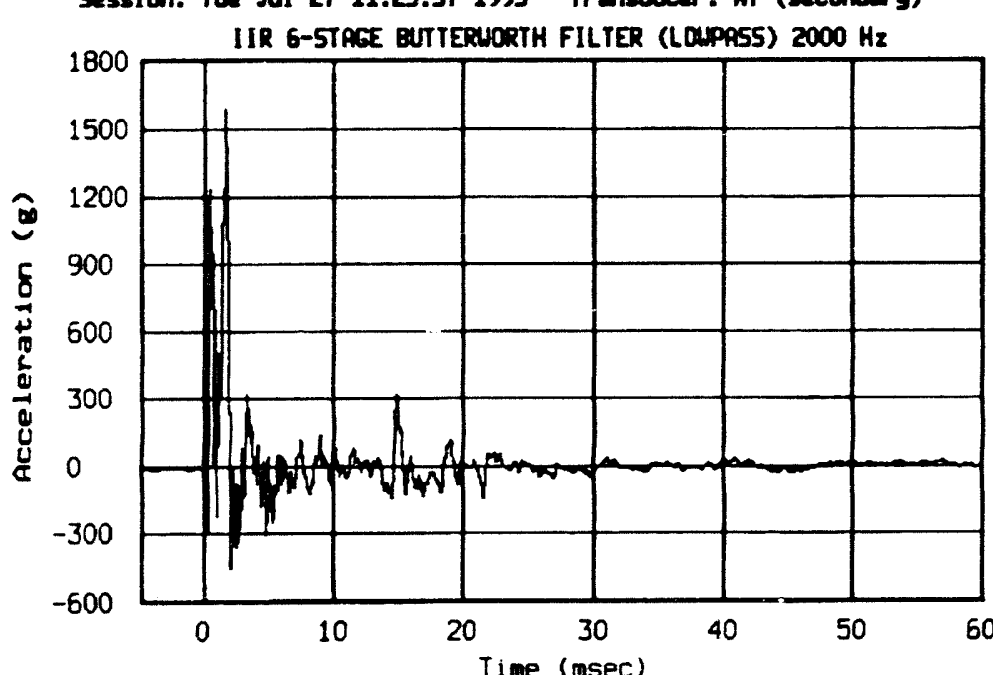

w

Test: LONGITUINA LOU VELOCITY H1224A 06/29/93 (219) Session: Tue Jul 27 11:23:53 1993 Transdwcer: PB (secondary) IIR G-STAGE BUTERUORTH FILTER (LOAPASS) $2000 \mathrm{~Hz}$

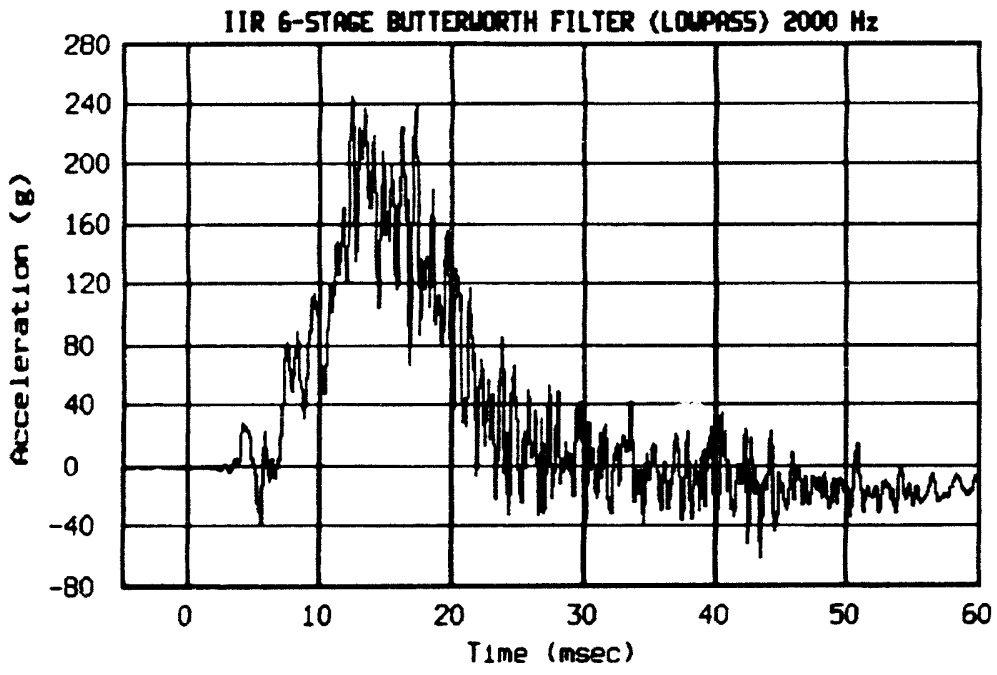

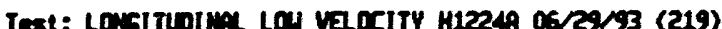
Session: Tue bul 27 11:24:06 1993 Transducer: A9 (secondary) IIR 6-5TPCE BITEEUNRTH FILTER (LOPPSS) $2000 \mathrm{~Hz}$

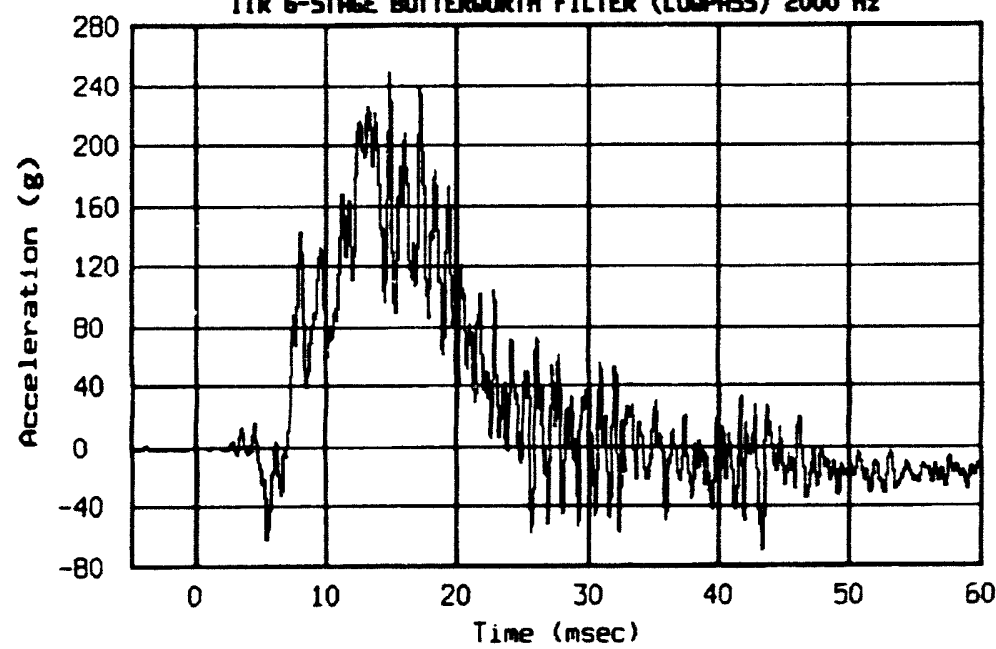

Test: LorsITUDInf Lod veccity H1224A 05/29/93 (219) Session: Tue Jul 27 11:24:20 1993 Transtwoer: A10 (eccondary)

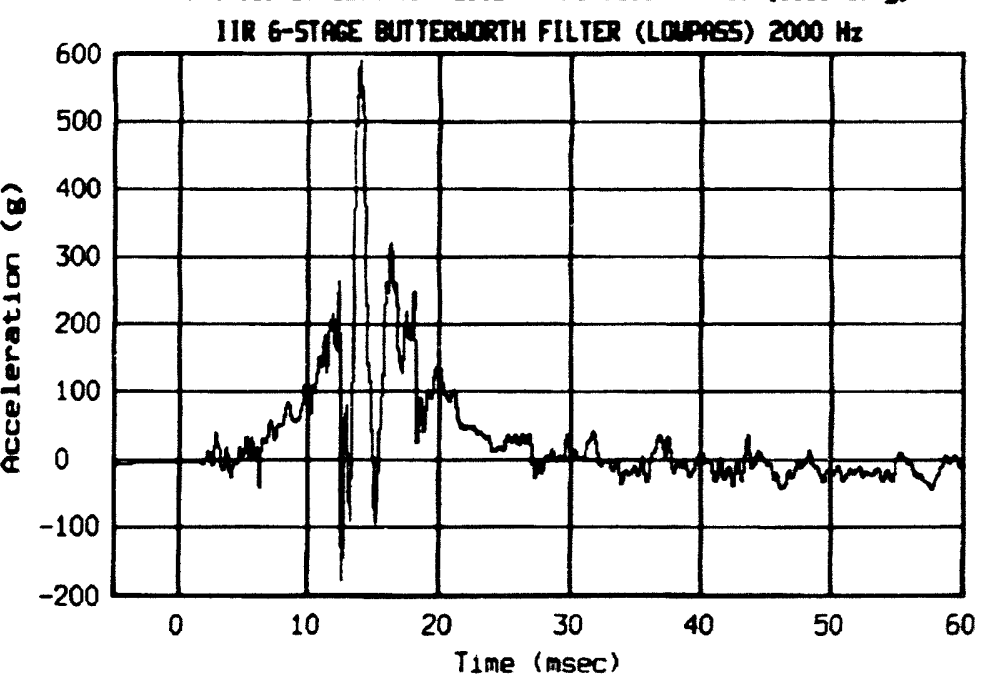




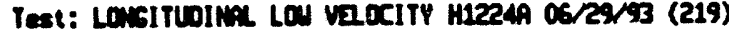
5ession: Tue Jul 27 11:24:32 1993 Tramotucer: A11 (secondary)

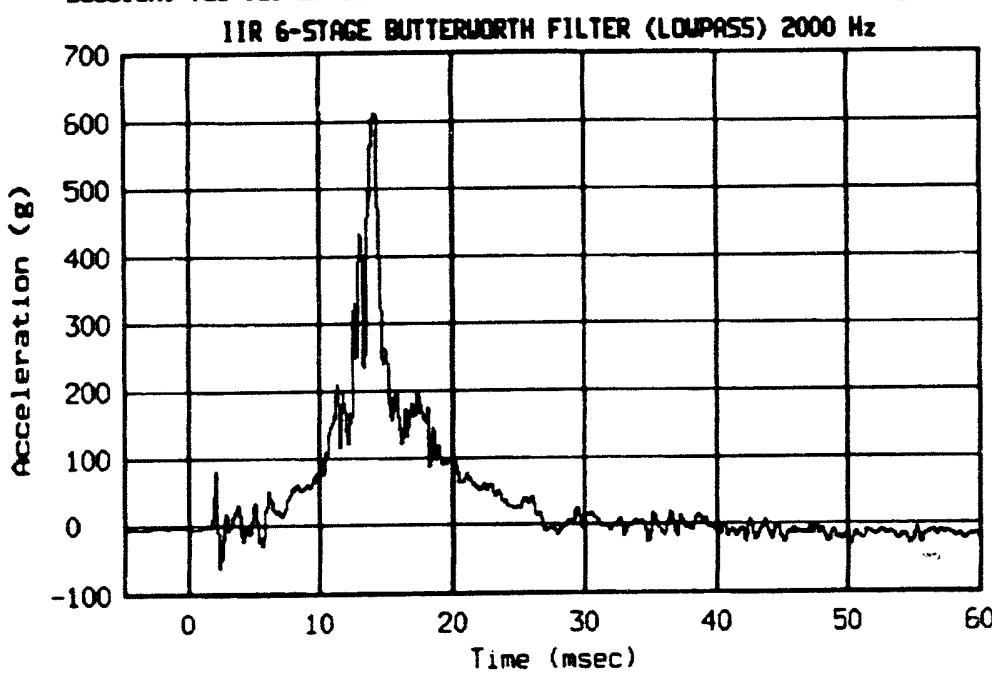

Test: LangIruoline Low velocITY H1224A 06/29/93 (219) Sescion: Tue Jul 27 11:24:50 1993 Transedvear: R12 (secondary)

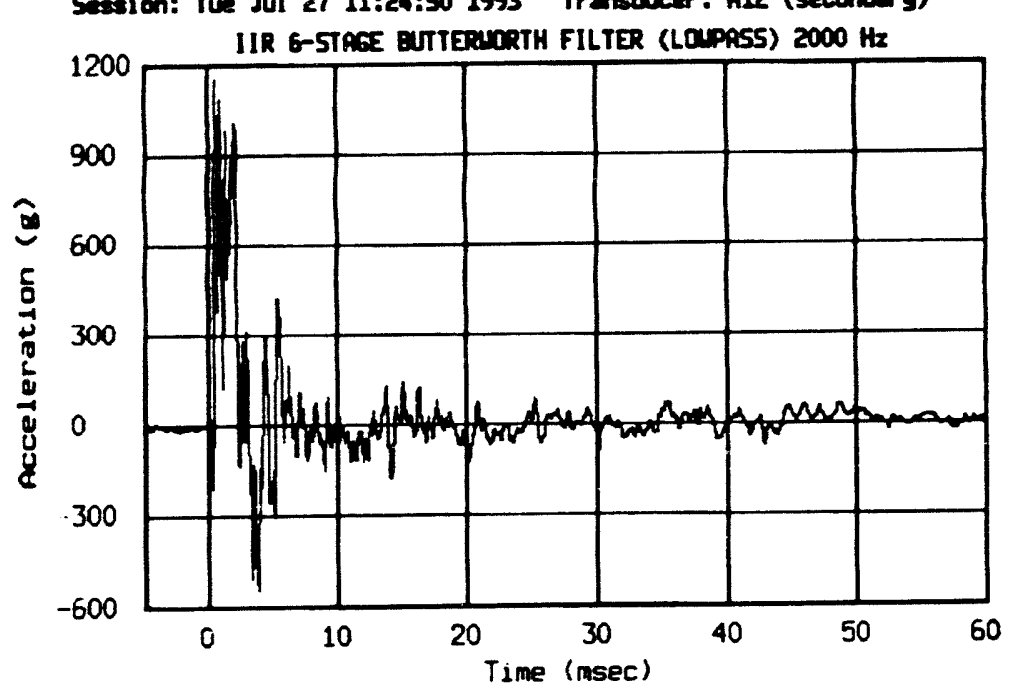

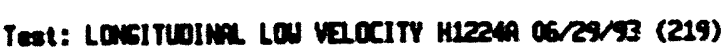
Sexsion: Tue Jul 27 11:24:55 1993 Transotuoer: A13 (secondery)

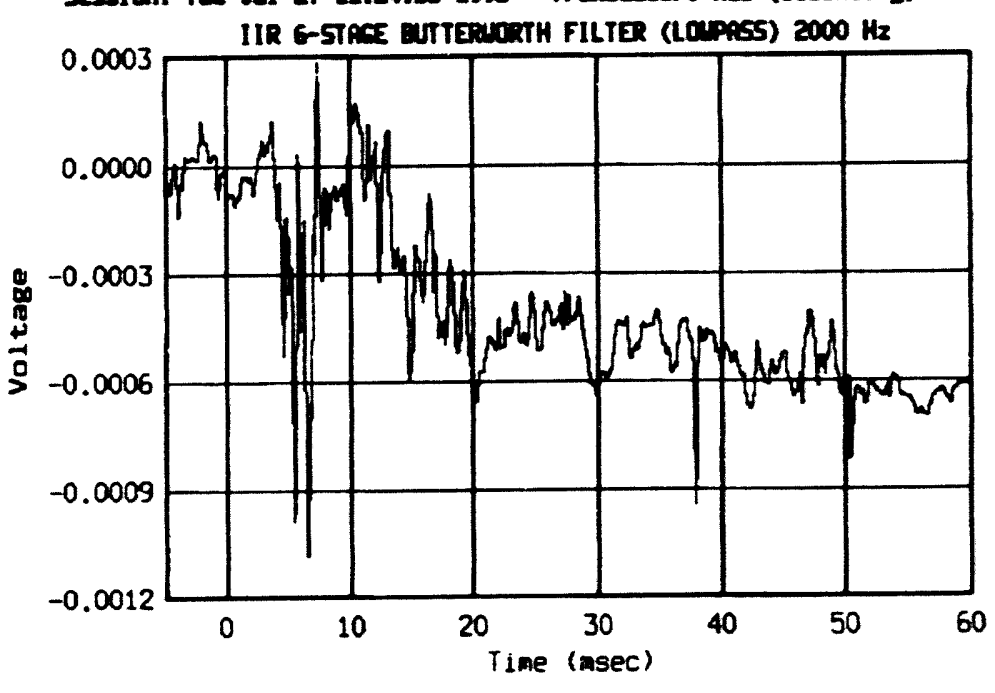

Test: Lowitolime La vecity Mize4A 06/29/93 (219) Seasion: Twe lul 27 11:25:04 1993 Transwoer: 551 (secondwry)

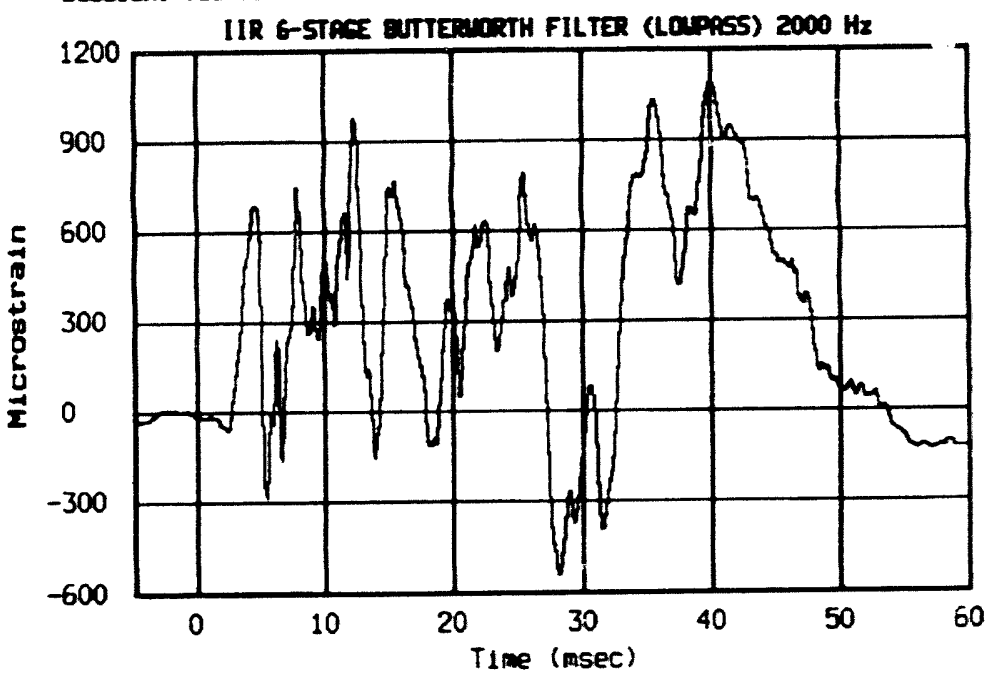




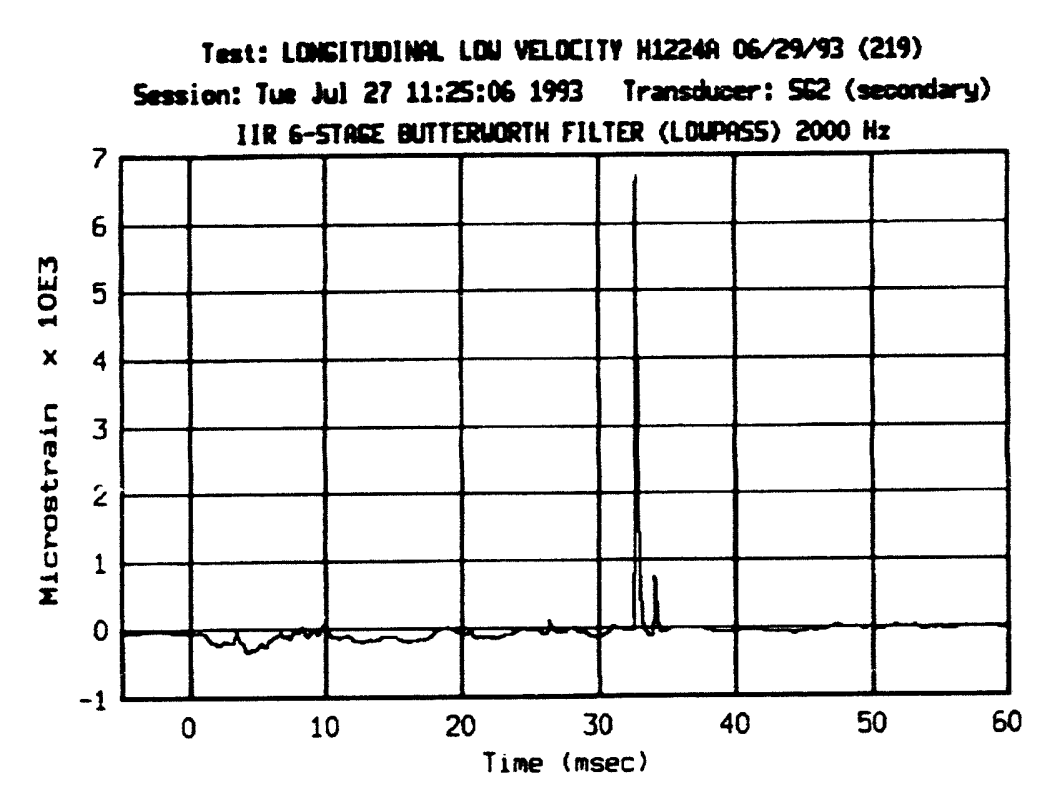

i

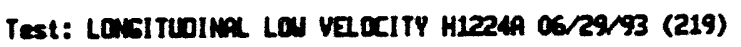
Session: Tue Jul 27 11:25:23 1993 Transducer: 563 (secondary)

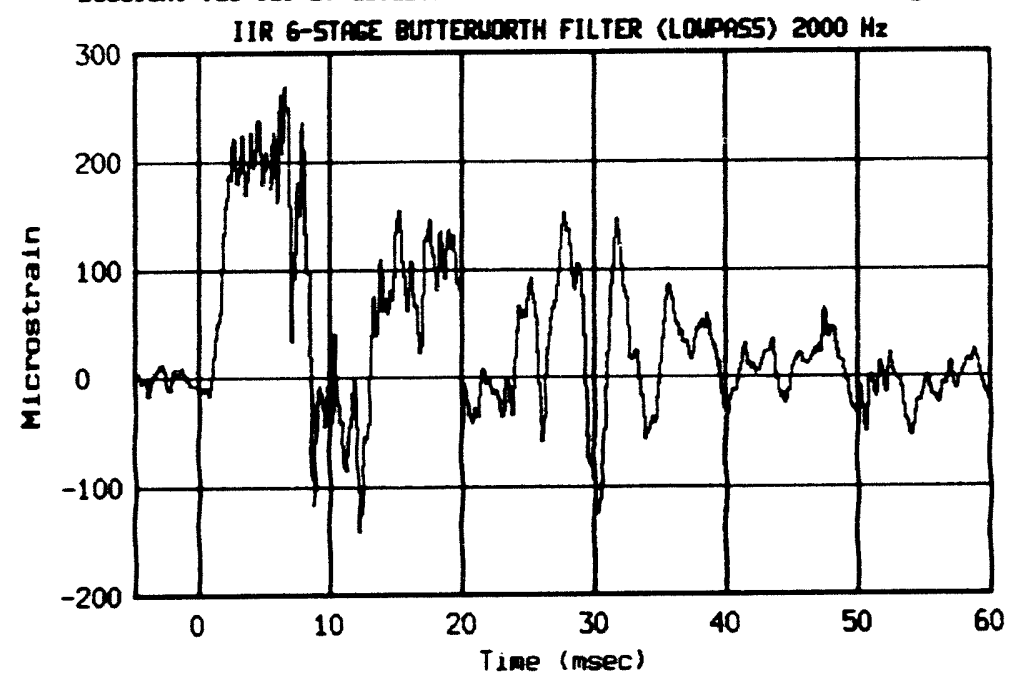

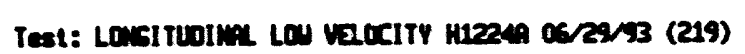
Sescion: Tue dul 27 11:25:23 1993 Transtwoer: SCA (seocondery)

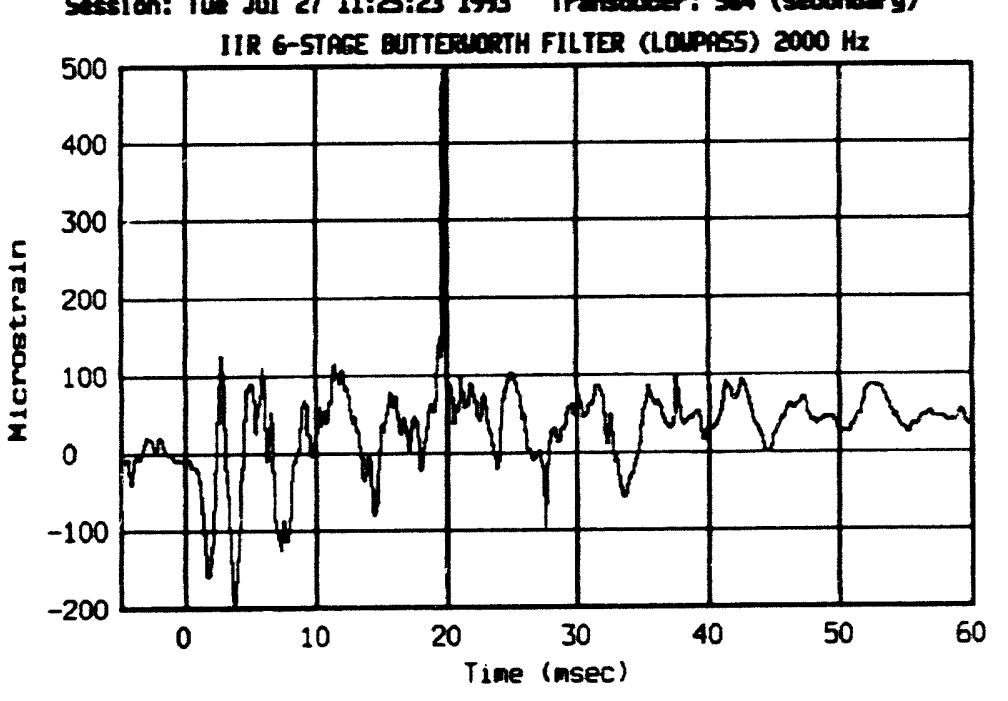

Test: Lowitoolm Lo veccity h1224 06/29/3 (219) Session: Tue Jul 27 11:25:38 1993 Transdveer: 595 (secondary)

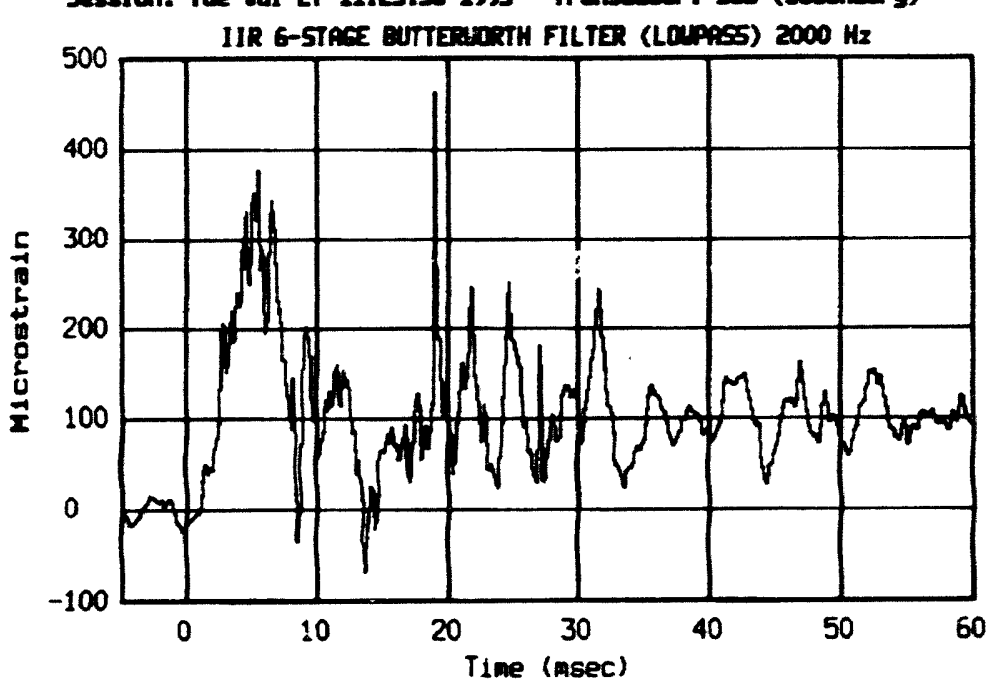



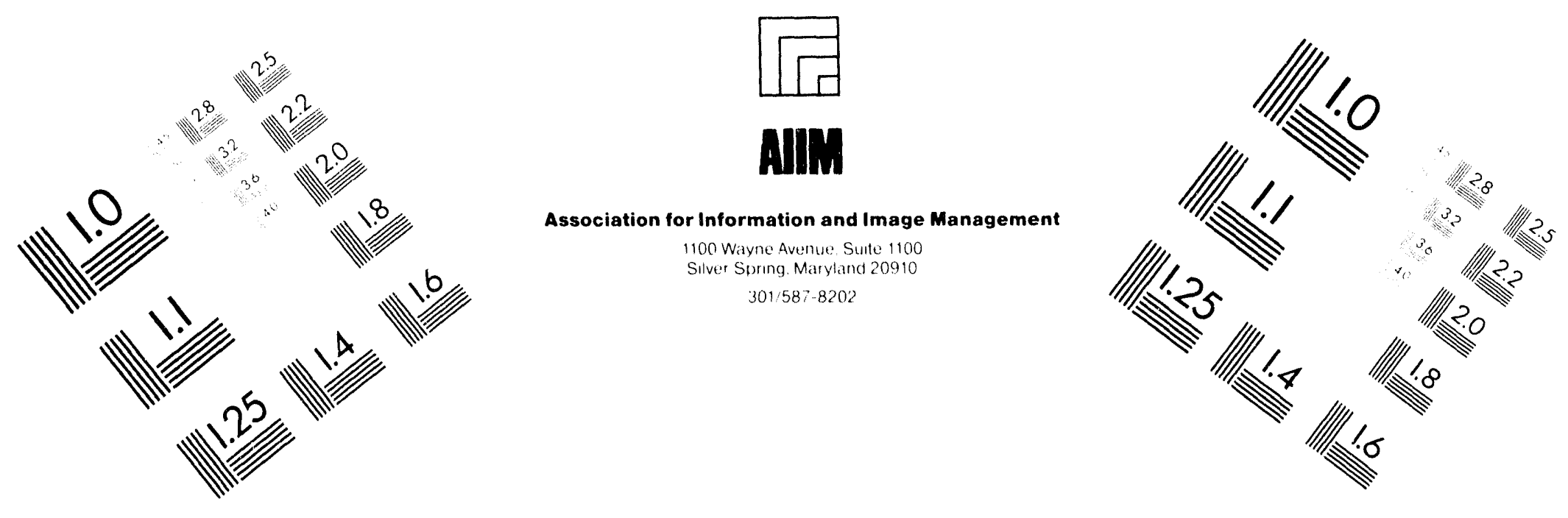

Centimeter

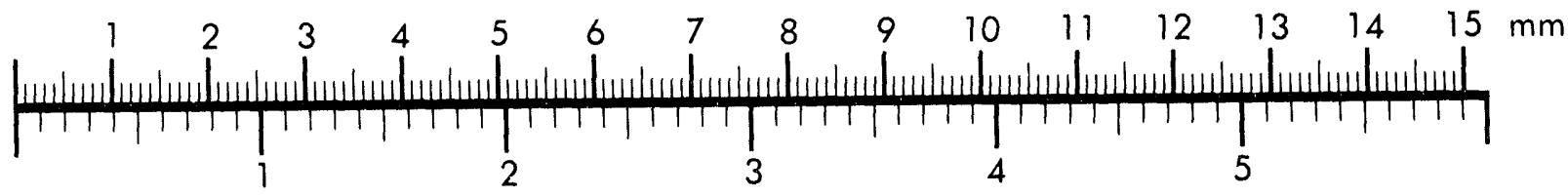
Inches
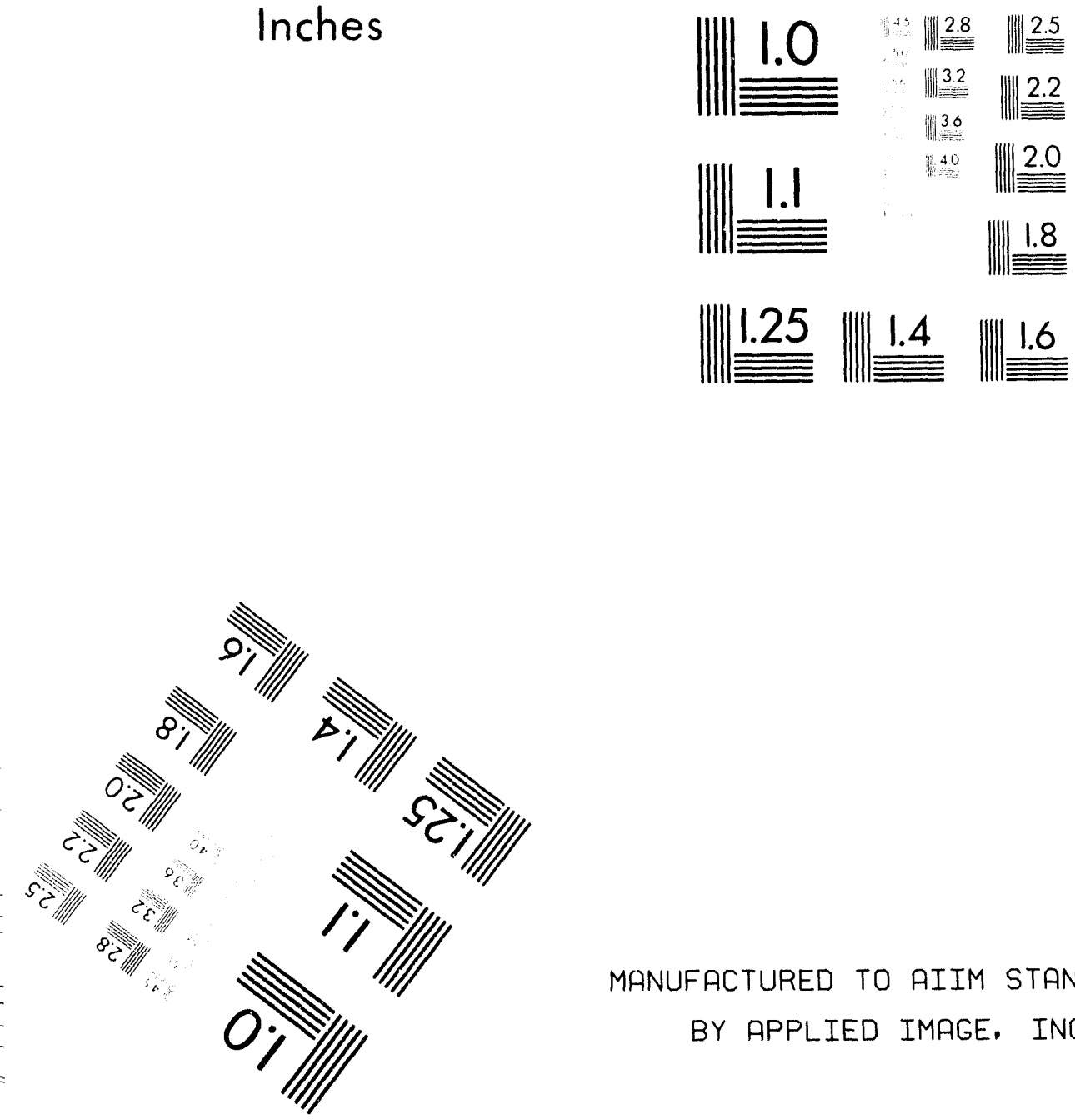

MANUFACTURED TO AIIM STANDARDS BY APPLIED IMAGE, INC.

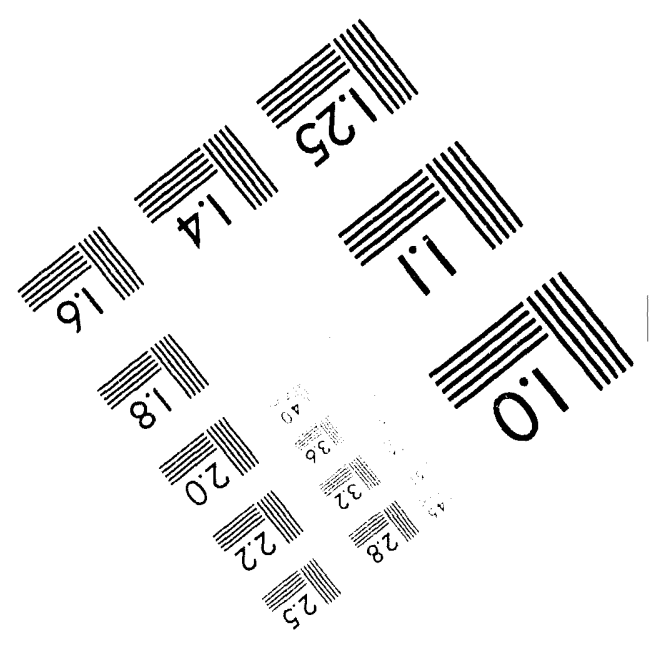



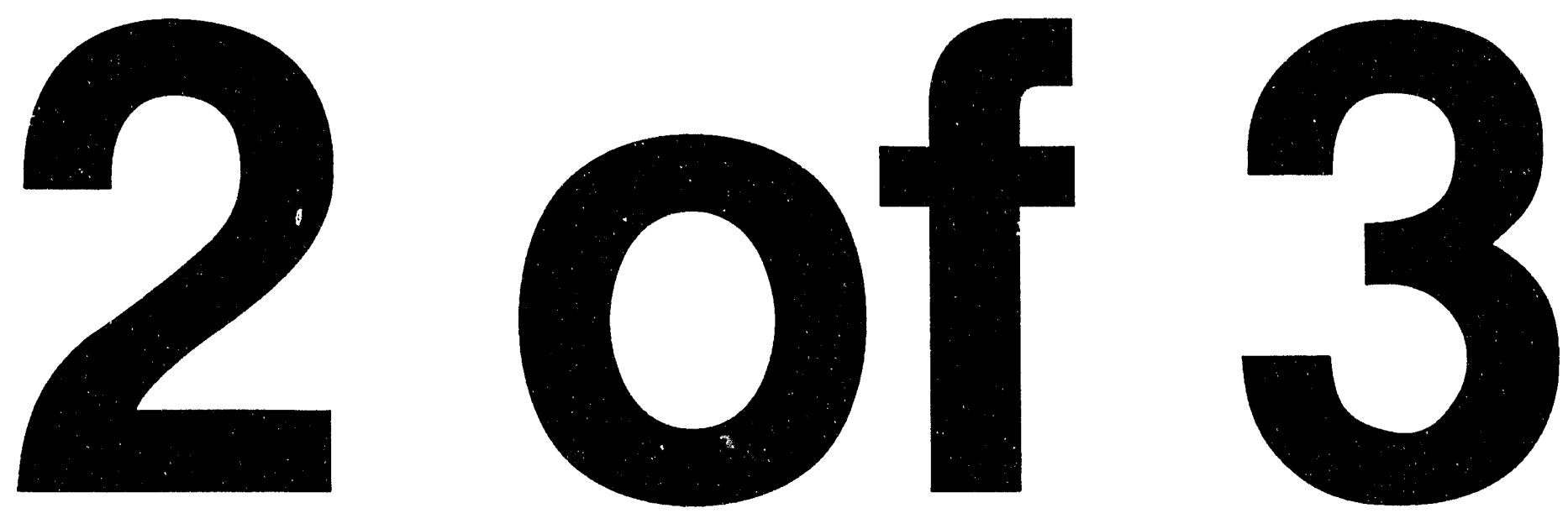

m 
Test: LowsITUIm LOW VelocITY H1224A 06/29/93 (219) Session: Tue Jul 27 11:25:38 1993 Transducer: 566 (secondary) IIR G-STAGE BUTIERLORTH FILTER (LOUPASS) $2000 \mathrm{~Hz}$

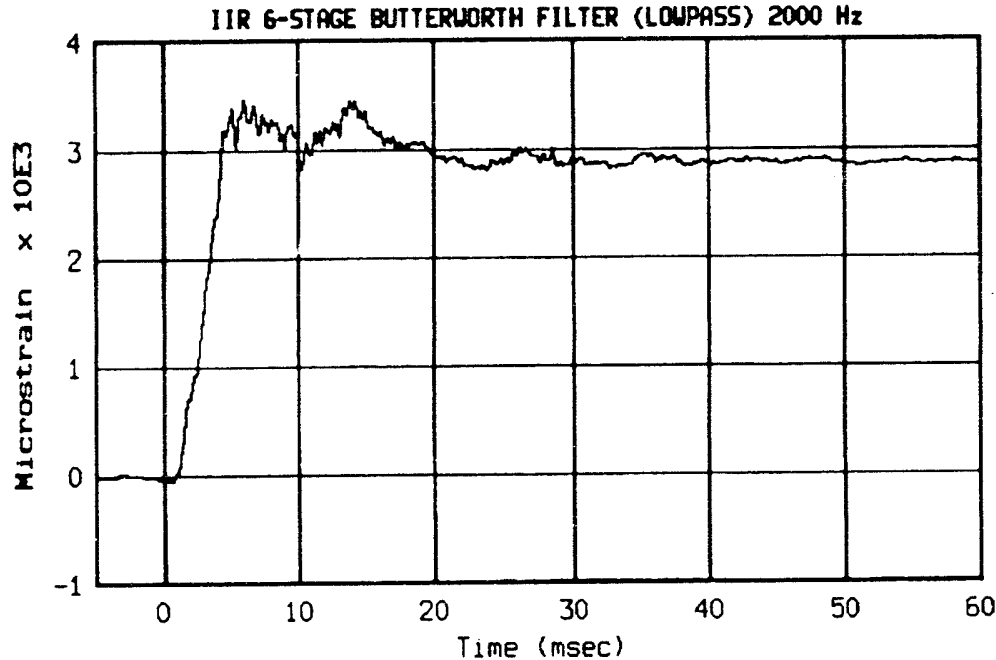

๙

Test: LONGITUDINAL LOW VEOCITY H1224A 06/29/93 (219) 5ession: Tue Jul 27 11:25:55 1993 Transducer: 567 (secondary) IIR 6-5TRGE BUTTERLORTH FILTER (LOUPRSS) $2000 \mathrm{~Hz}$

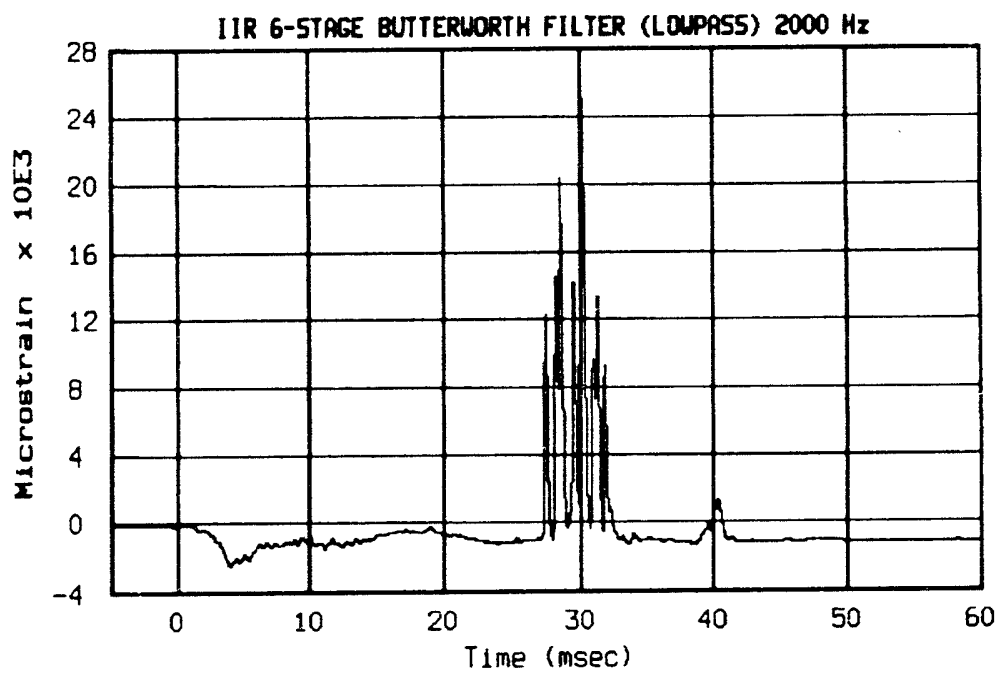

Test: LOWITUOIN LOU VEOCITY H12249 06/29/93 (219) Session: Tue Jul 27 11:25:55 1993 Transclucer: 508 (secondary)

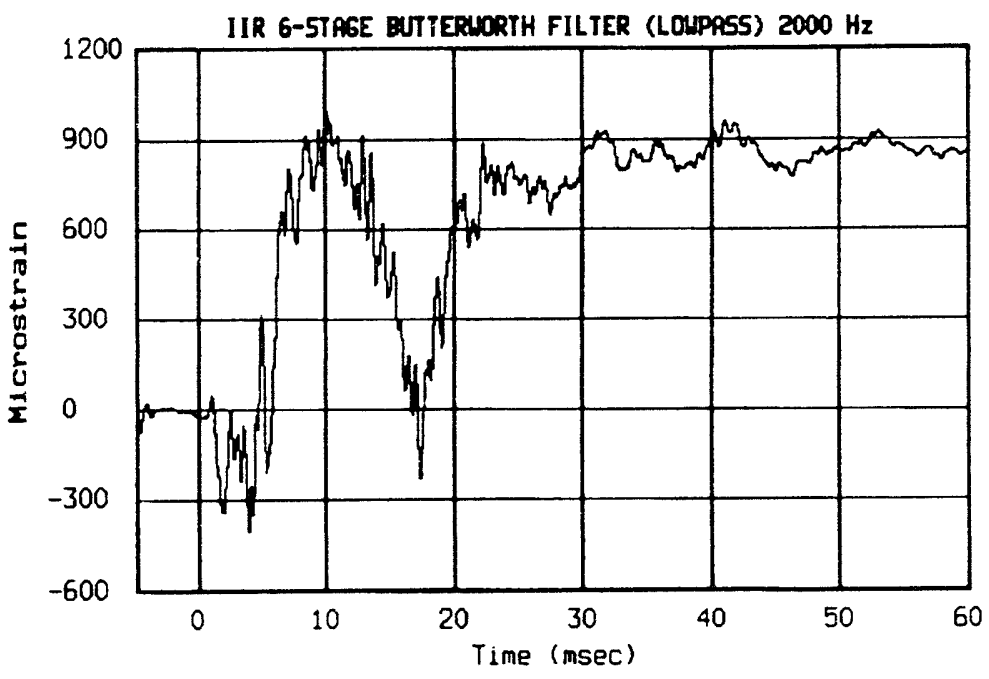

Test: LONGITLOIMAL LOU VELOCITY H1224A 06/29/93 (219) Session: Tue Jul 27 11:26:08 1993 Transducer: 569 (secondary)

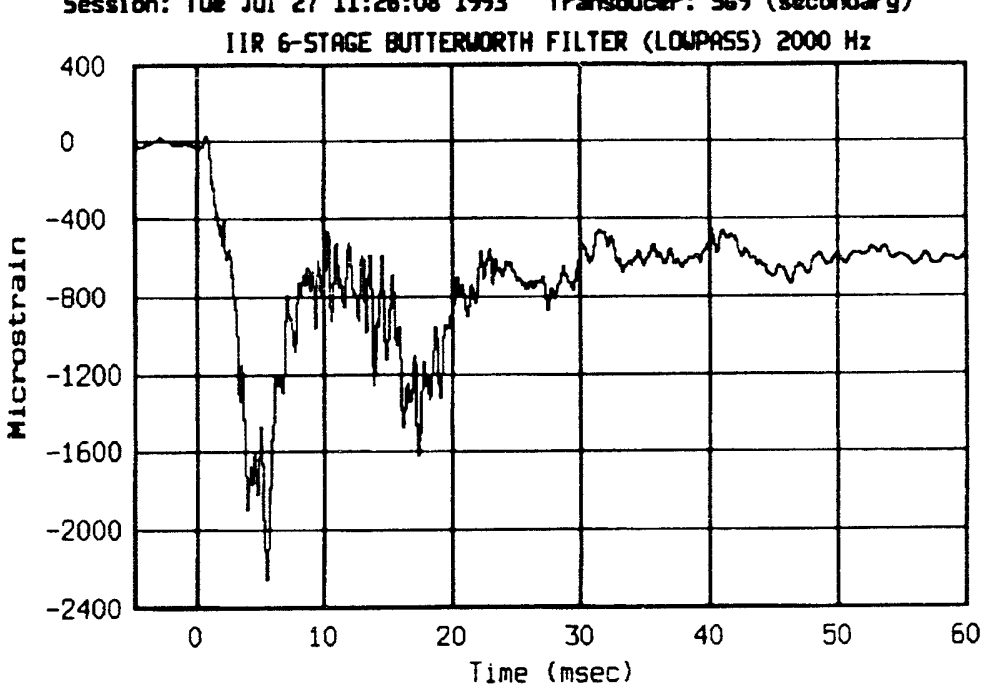



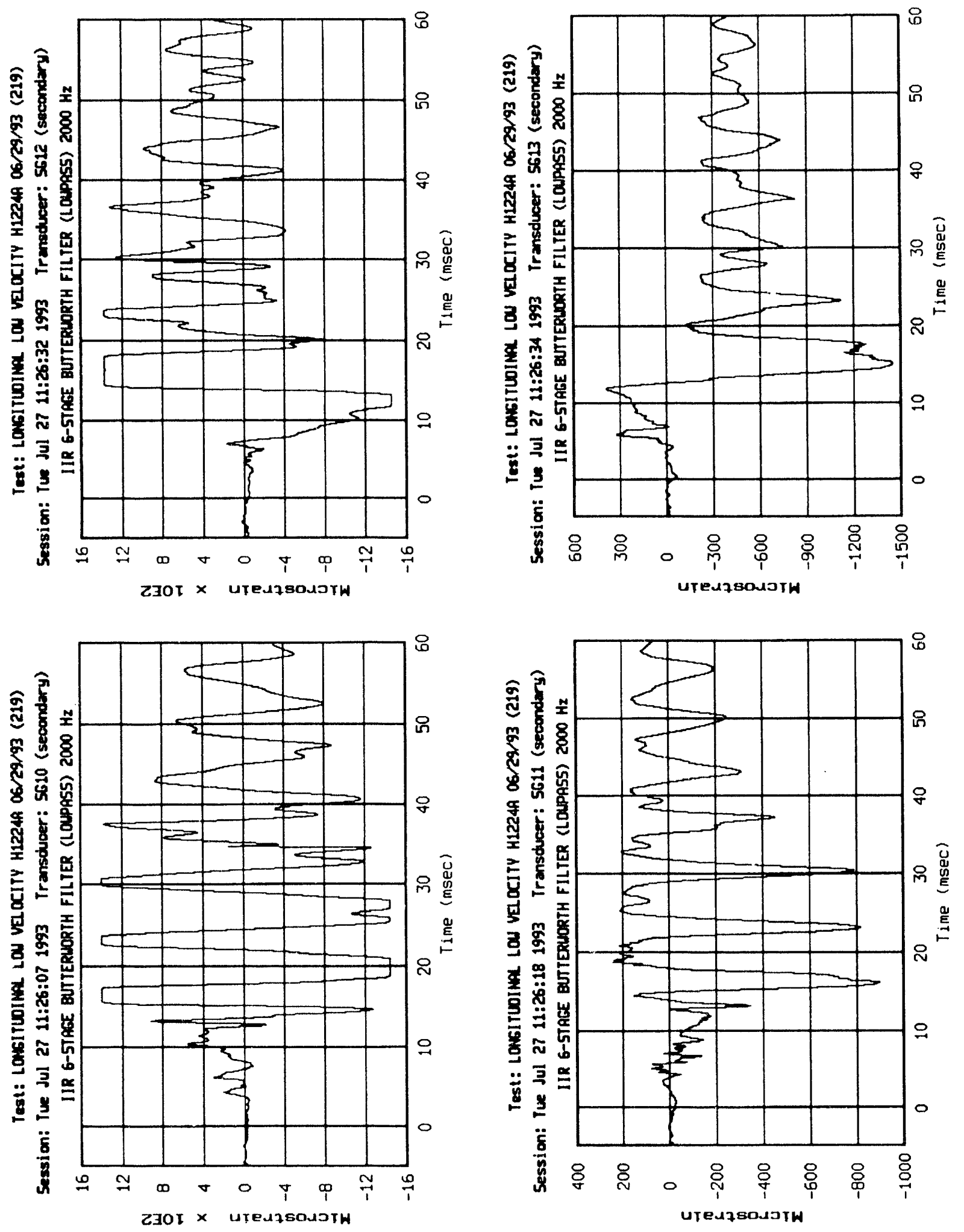
Test: LOASITUDINAL LOW VeLCCITY H1224A 06/29/93 (219) Session: Tue Jul 27 11:26:20 1993 Transtucer: 5614 (secondary)

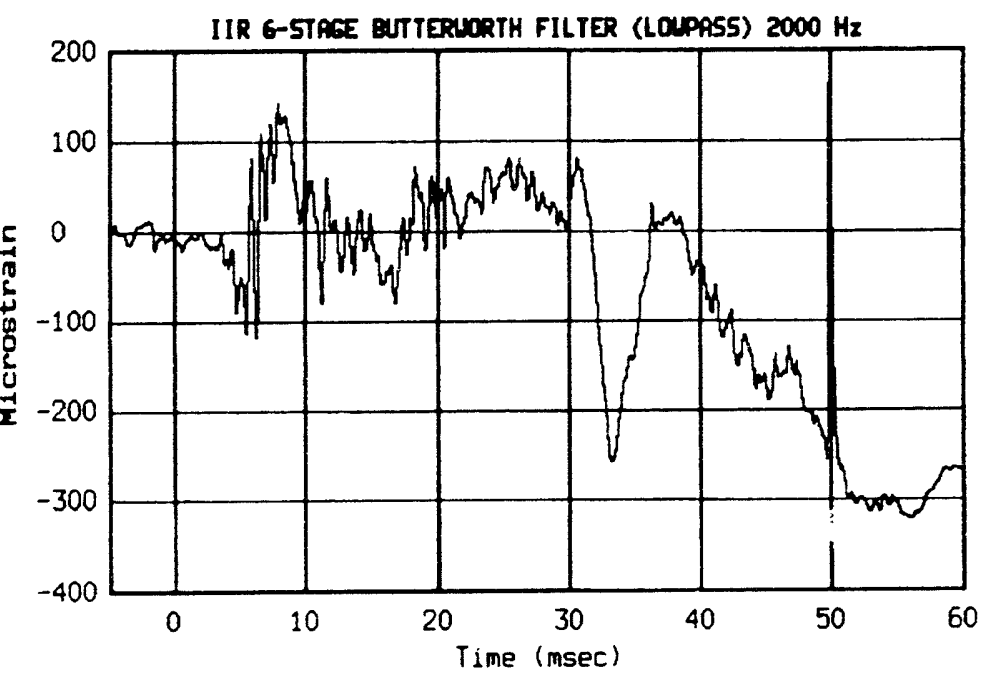

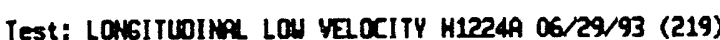
Session: Tue Jul 27 11:26:46 1993 Transducer: 515 (secondary)

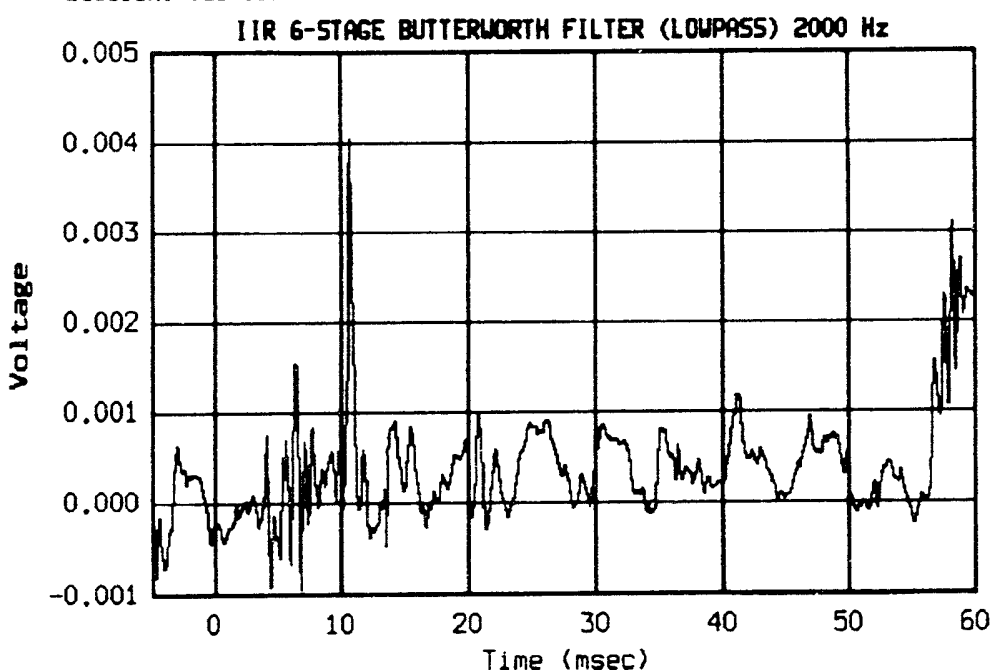

Test: LONGITUDINL LOU VZlocITY H1224A 06/29/93 (219) Session: Tue Jul 27 11:26:47 1993 Transducer: 516 (secondary)

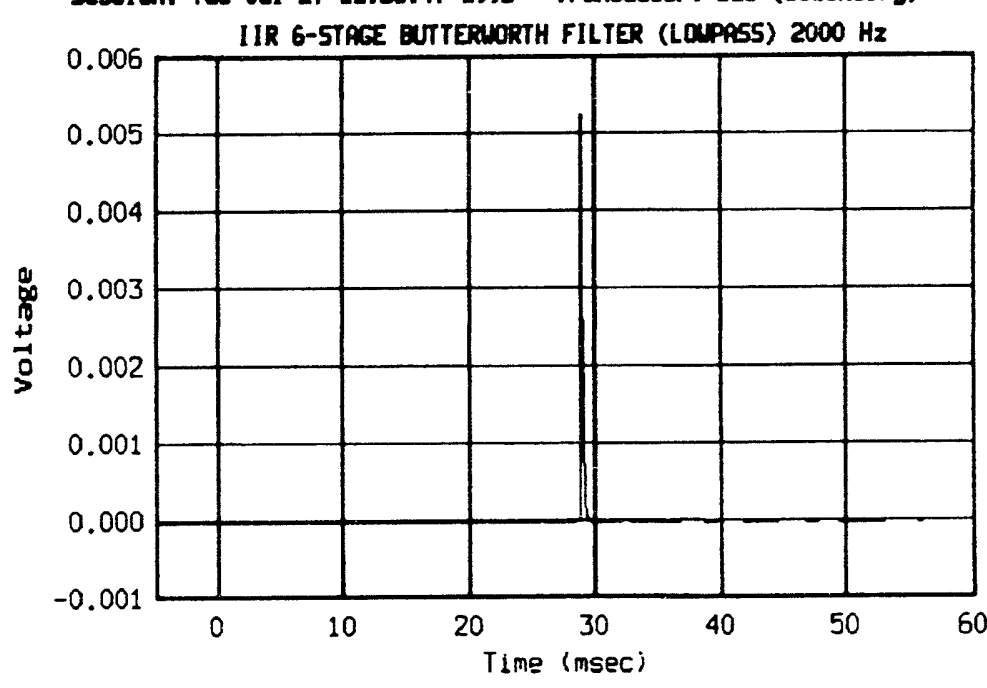

Test: LONGITWInf Lod VelocITY H1224A 06/29/93 (219) Session: Tue Jul 27 13:25:00 1993 Transtucer: A1 (secondary)

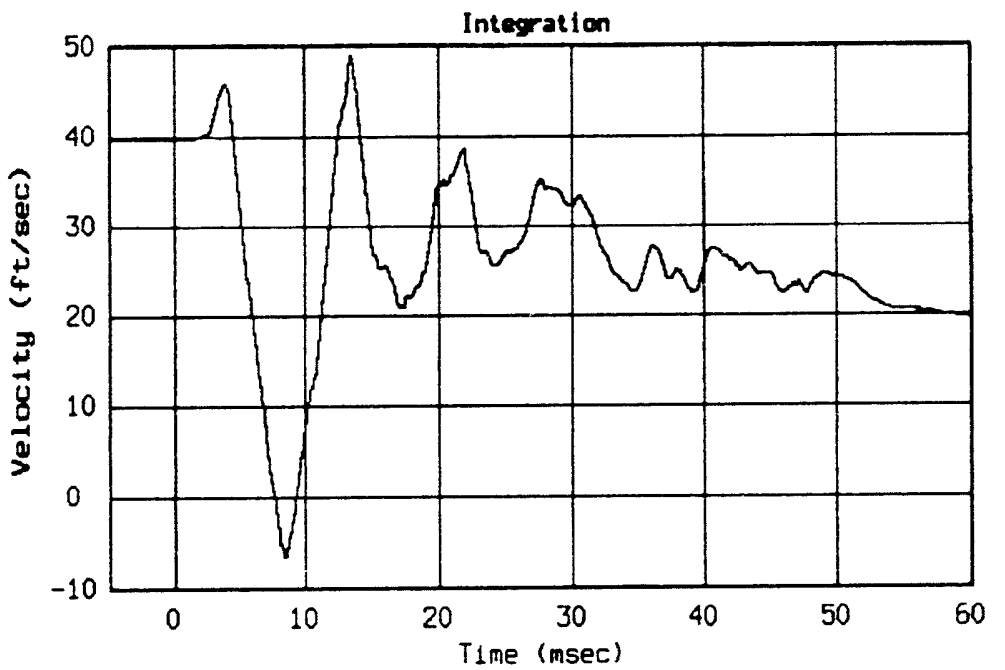


Test: LonsItUoInAL LOU VelocITY H1224A 06/29/93 (219)

5ession: Tue Jul 27 13:25:03 1993 Ir mesducer: PR (secondary)

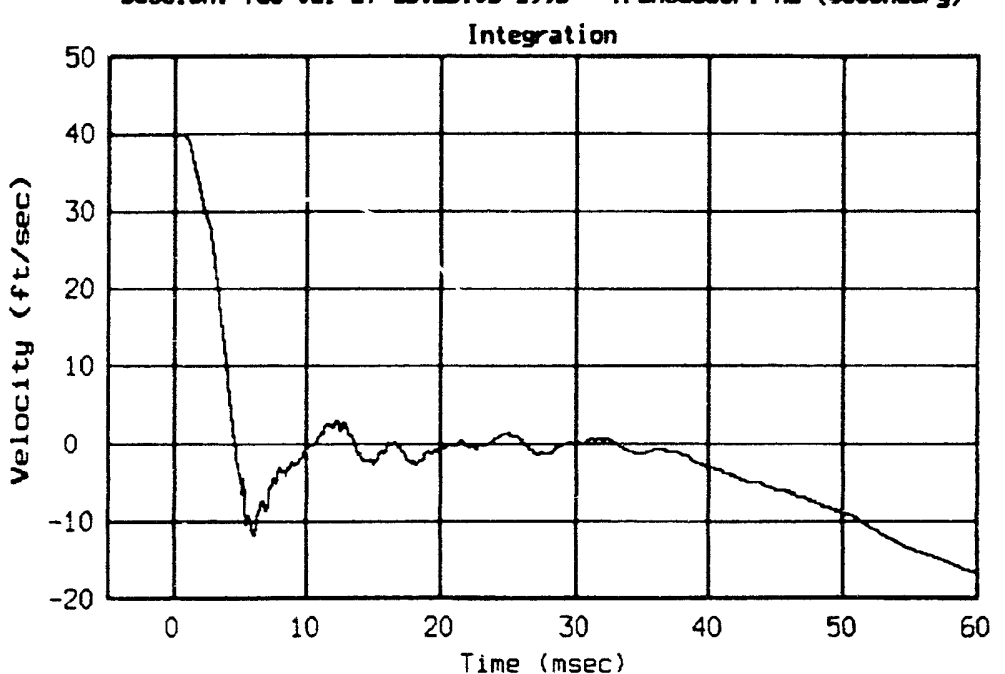

Test: LONGITUDIKPL LOU VELOCITY H1224A 06/29/93 (219) Session: Tue Jul 27 13:25:06 1993 Transducer: A3 (secondary)

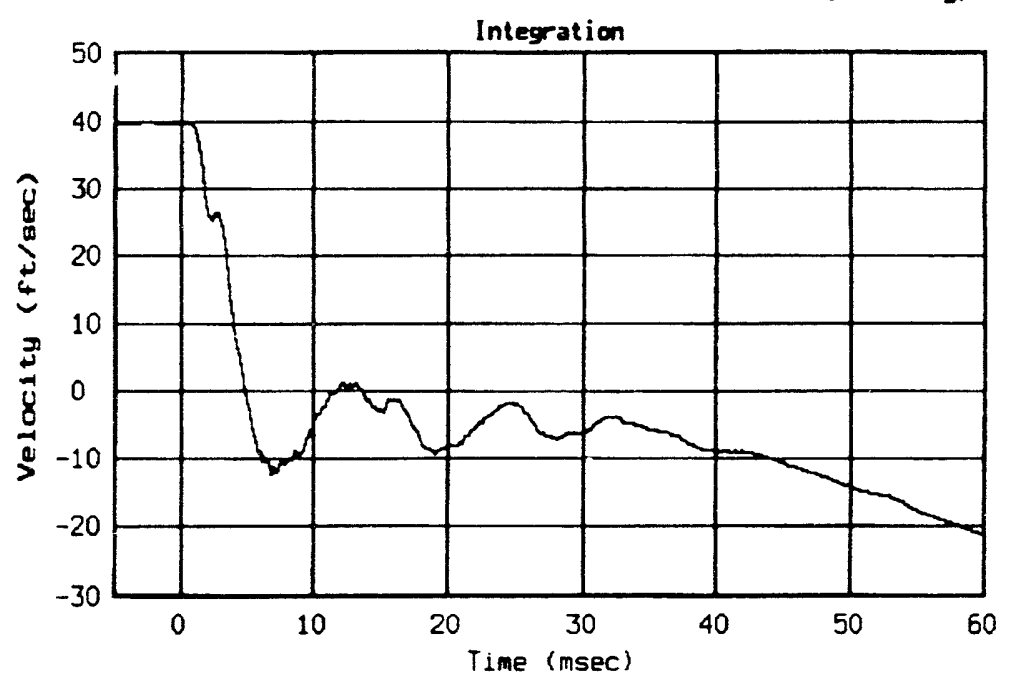

Test: LOHEITUDINAL LOU VELCCITY HI224A 06/29/93 (219) Session: Tue Jul 27 13:25:10 1993 Transeducer: A4 (secondary)

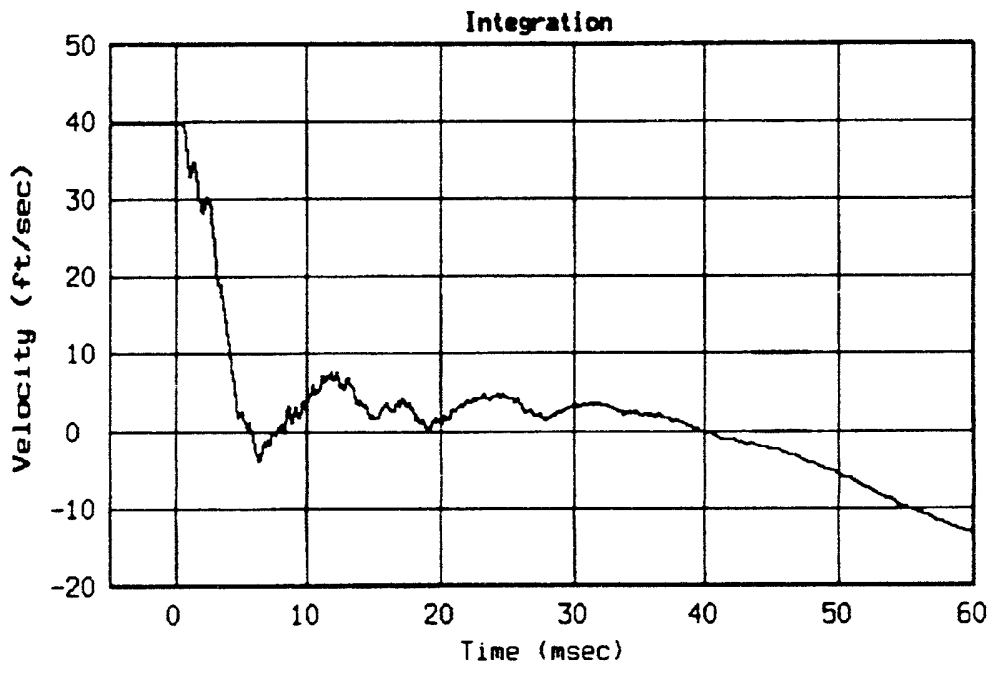

Test: LONGITUDINAL LOU VelOCITY H1224A 06/29/93 (219) Session: Tue Jul 27 13:25:18 1993 Transidwer: A5 (secondary)

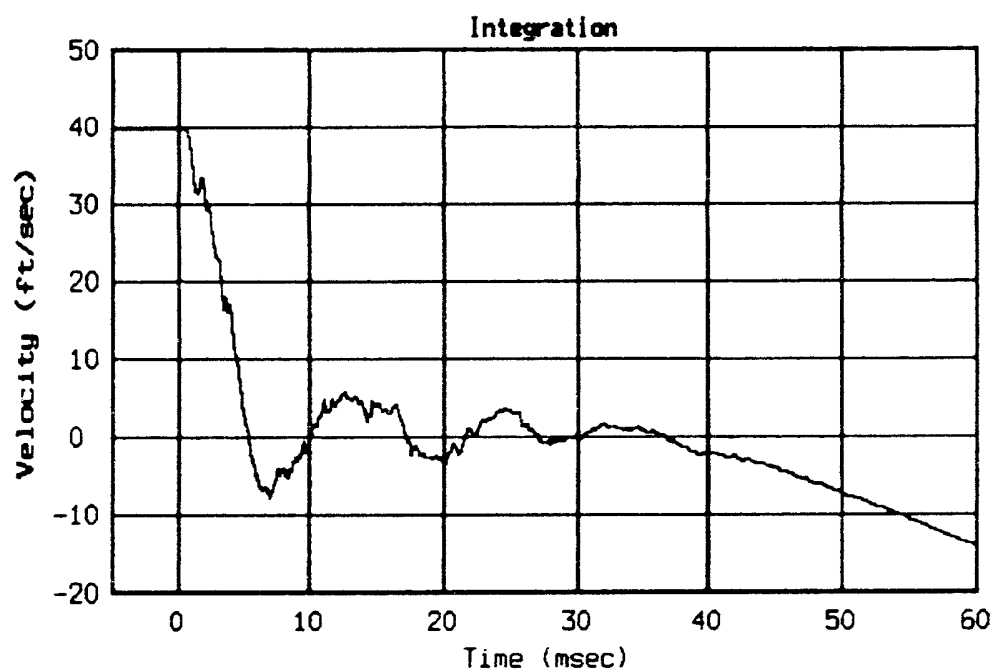


Test: LarituoINAL LOU VEOCITY H12249 06/29/93 (219) Session: Tue Jul 27 13:25:26 1993 Transducer: A6 (secondiry)

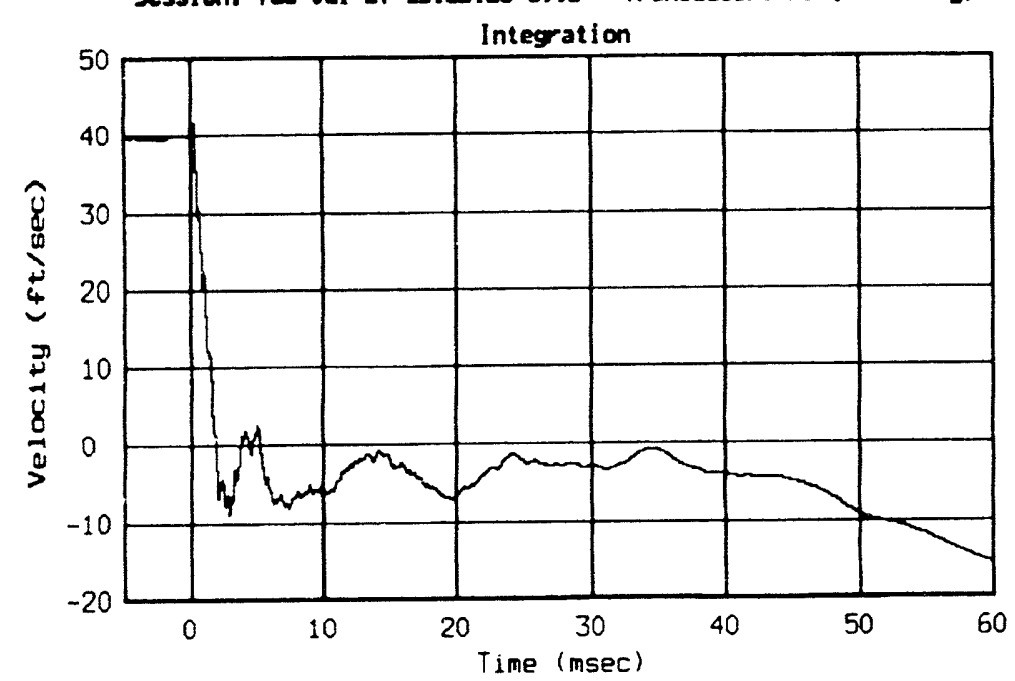

$\Xi$

Test: LONGITUOINAL LON VElOCITY H1224A 06/29/93 (219) Session: Tue Jul 27 13:25:36 1993 Transducer: A7 (secondary)

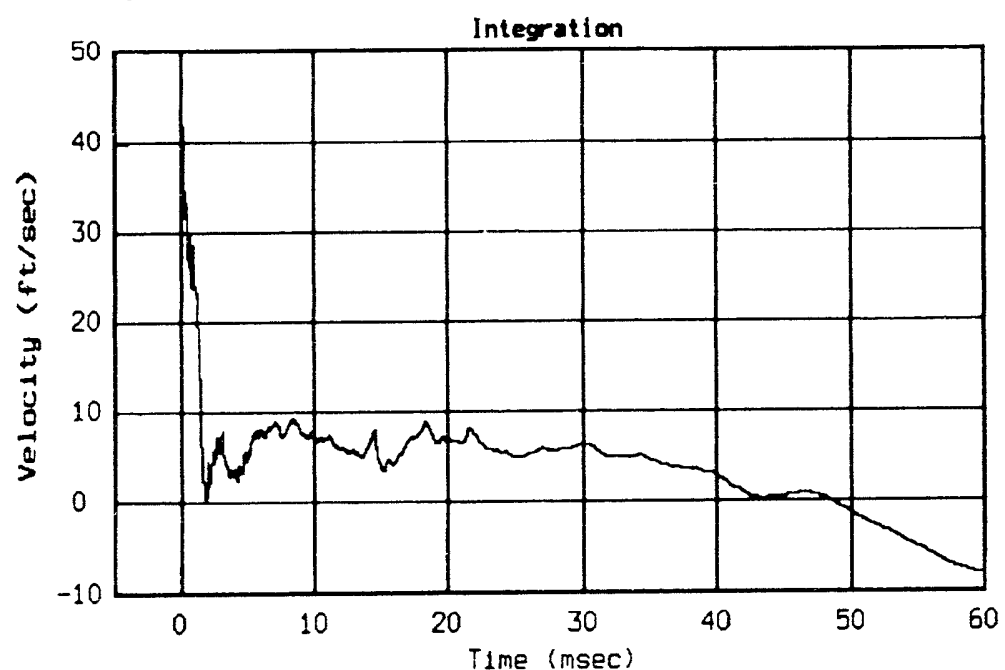

Test: LONGITUDINAL LOU VEDCITY H12249 06/29/93 (219) Session: Tue Jul 27 13:25:44 1993 Transducer: R8 (secondary)

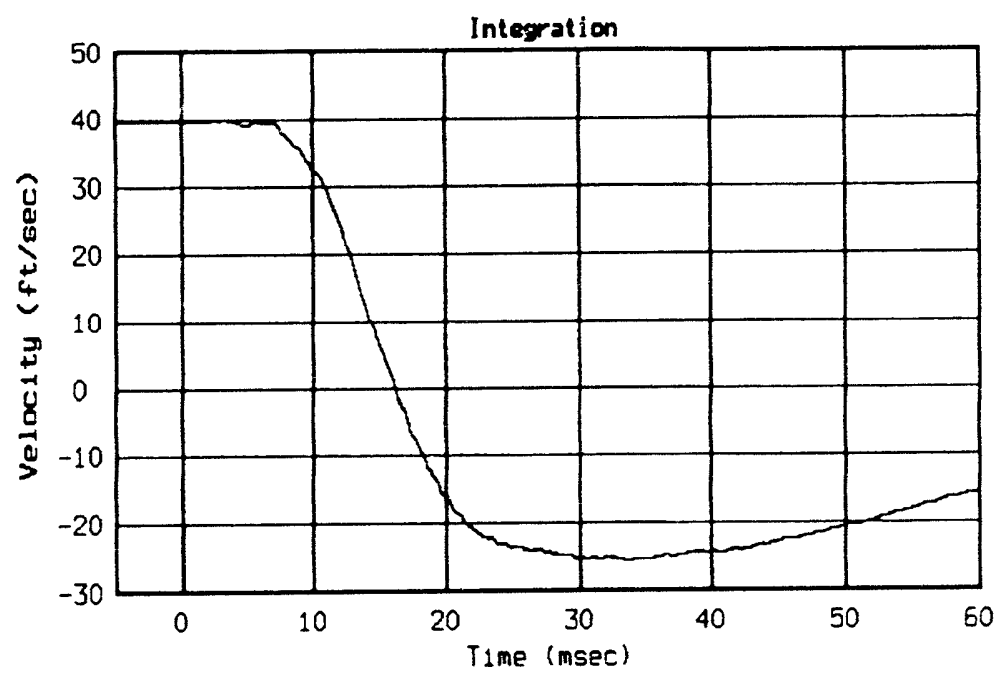

Test: LOAGITUDINAL LOW VELCCITY H1224A 06/29/93 (219) Session: Tue Jul 27 13:25:48 1993 Transclucer: A9 (secondary)

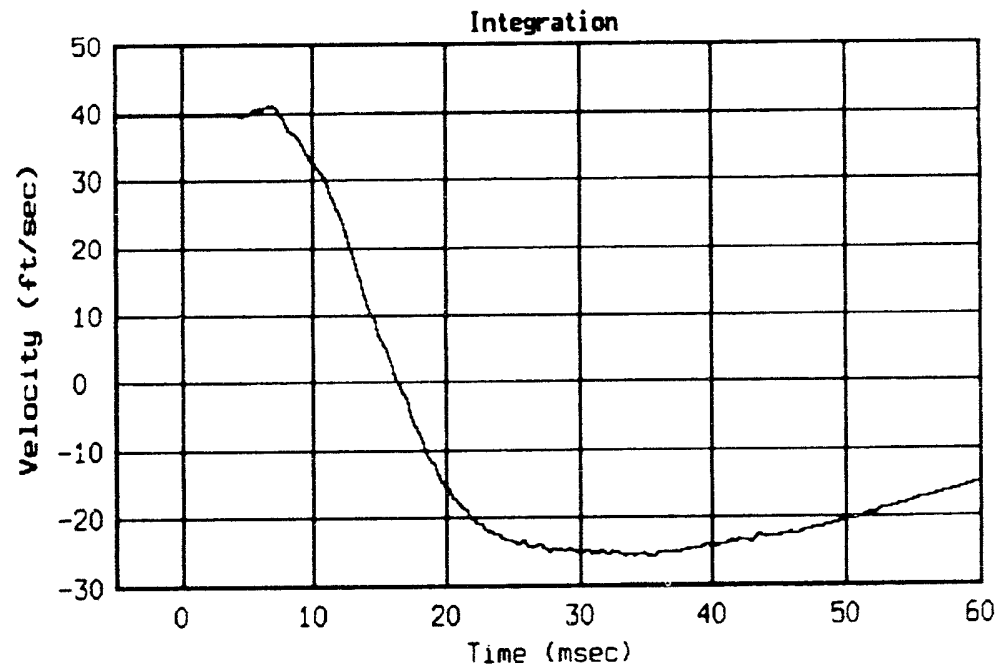


Test: LONGITLOINAL LOW VelocITY H1224A 06/29/93 (219) Session: Tue Jul 27 13:25:55 1993 Transeducer: A10 (secondary)

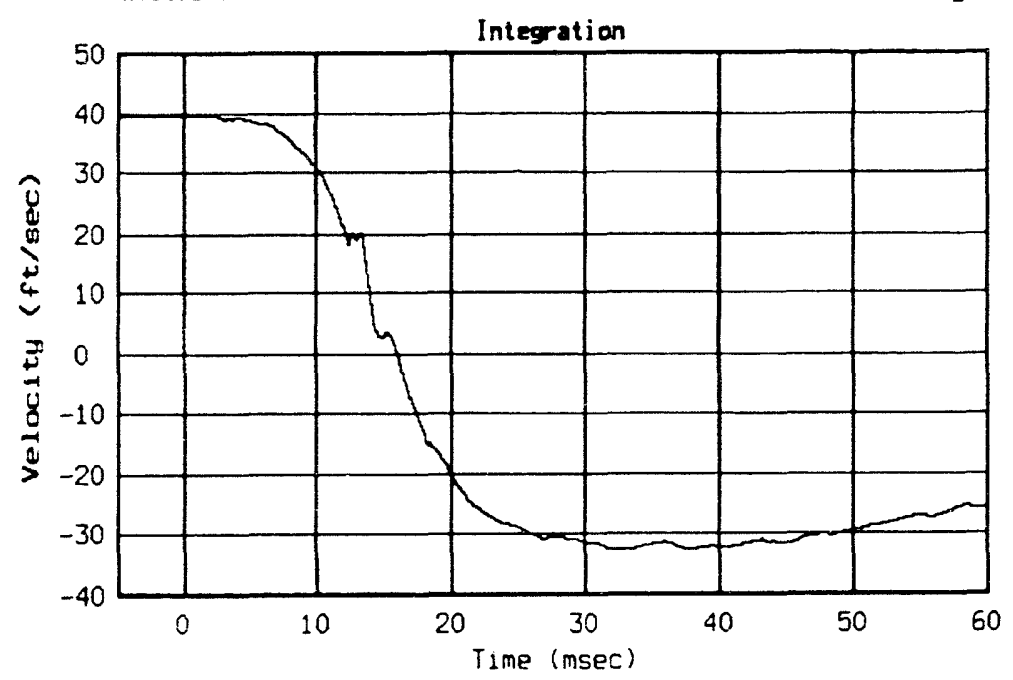

$\bar{\Xi}$

Test: LONGITLOINRL LOU VELCITY H1224A 06/29/93 (219) Session: Tue Jul 27 13:26:05 1993 Transolucer: A11 (secondary)

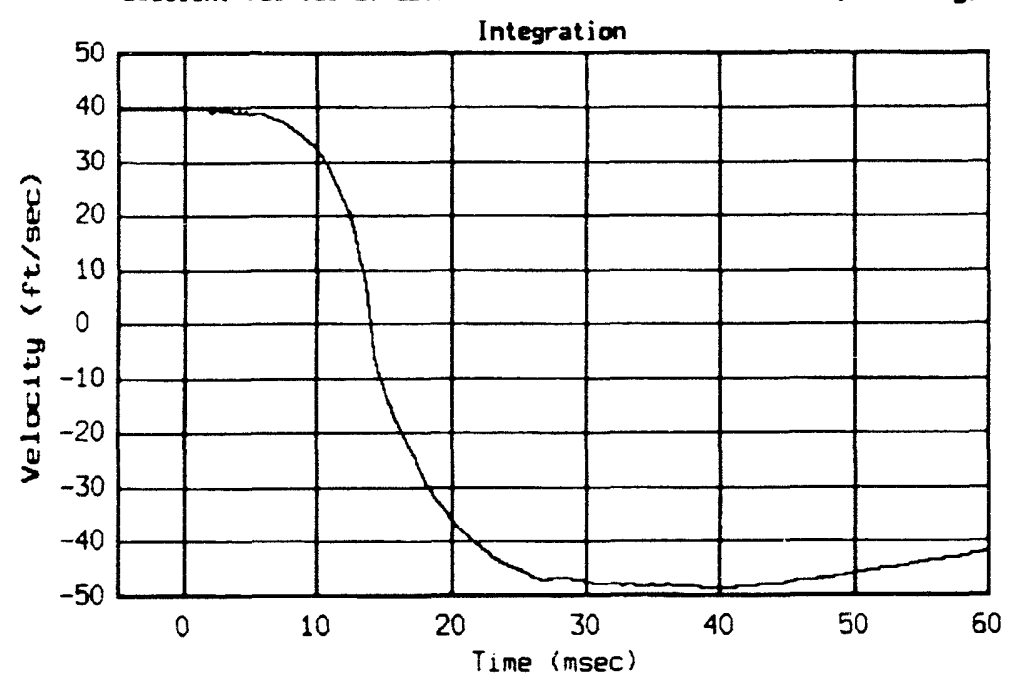

Test: LOWSITUINAL LOW VELOCITY H1224A 06/29/93 (219) Session: Tue Jul 27 13:26:12 1993 Transducer: A12 (secondary)

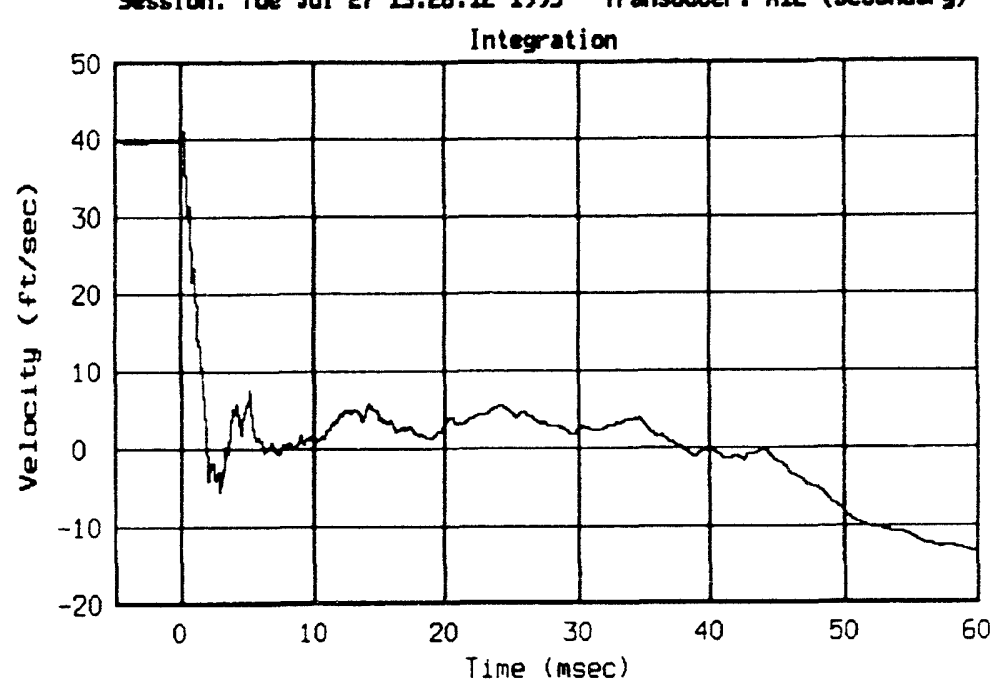

Test: LONGITLINAL LON VelocItY H1224A 06/29/93 (219) Session: Tue Jul 27 13:53:06 1993 Transducer: A1 (secondary) FAST FOURIER TRPASFORY to $20000.0 \mathrm{~Hz}$

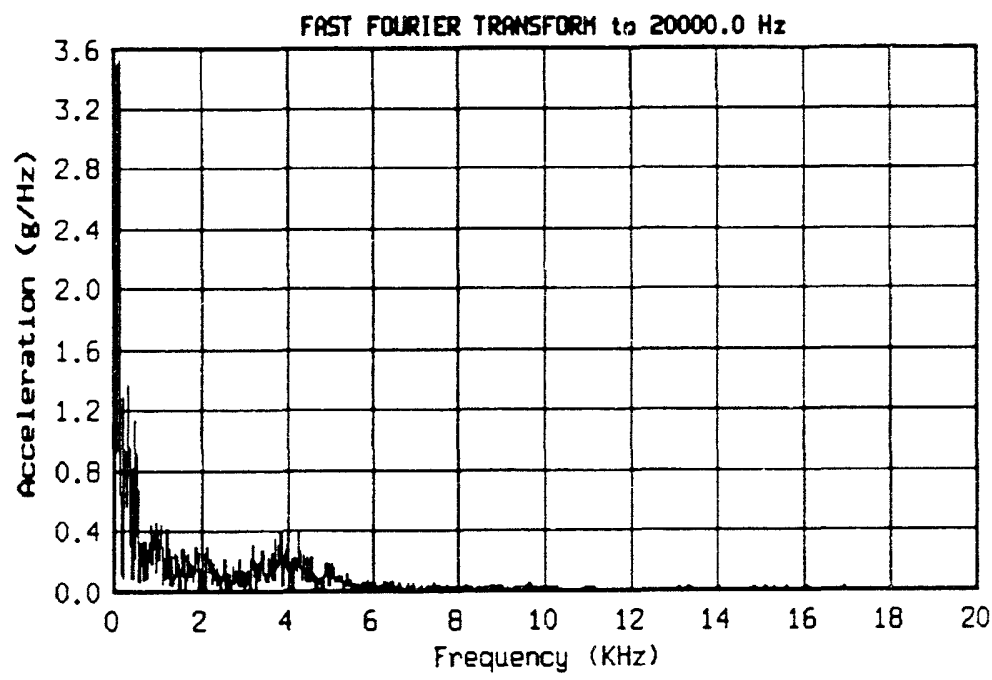


Test: LONGITLINAL LOU VaOCITY H1224A 06/29/93 (219) Session: Tue Jul 27 13:53:24 1993 Trensiducer: R2 (secondary) FRST FORIER TRANSFORM to $20000.0 \mathrm{~Hz}$

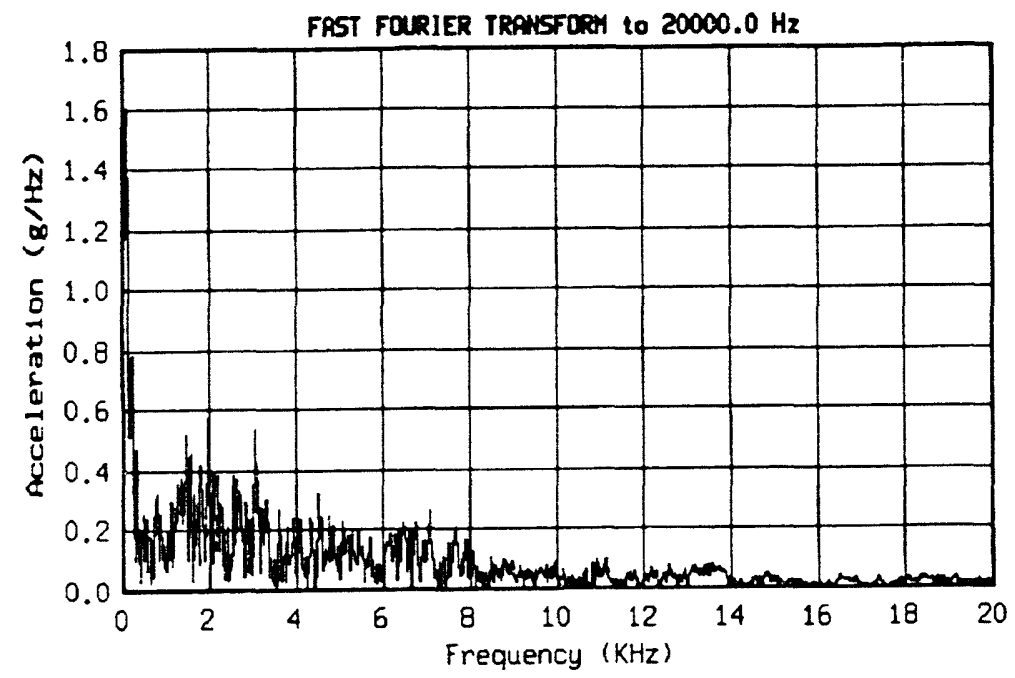

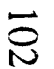

Test: LONGITUDINA LOW VELOCITY H1224h 06/29/93 (219) Session: Tue Jul 27 13:53:41 1993 Transducer: A3 (secondary) FAST FOURIER IRANSFORM to $20000.0 \mathrm{~Hz}$

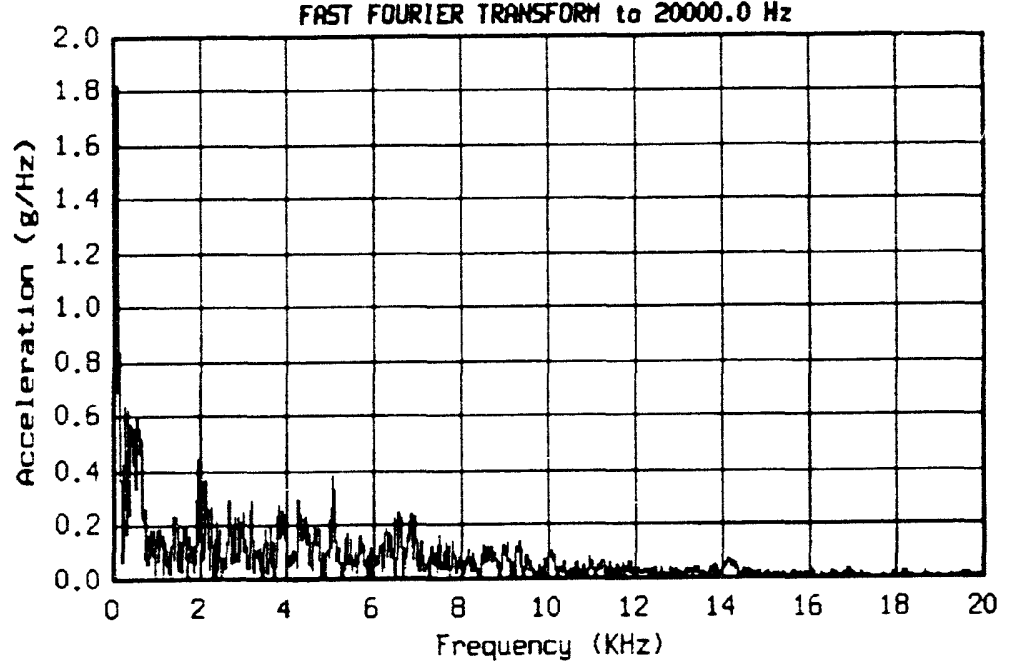

Test: Loxitubina Lo vaceITY H1224A 06/29/93 (219) Session: Tue Jul 27 13:54:03 1993 Transodveer: A4 (secondary) FRST FOURIER TRANSFORH to $20000.0 \mathrm{~Hz}$

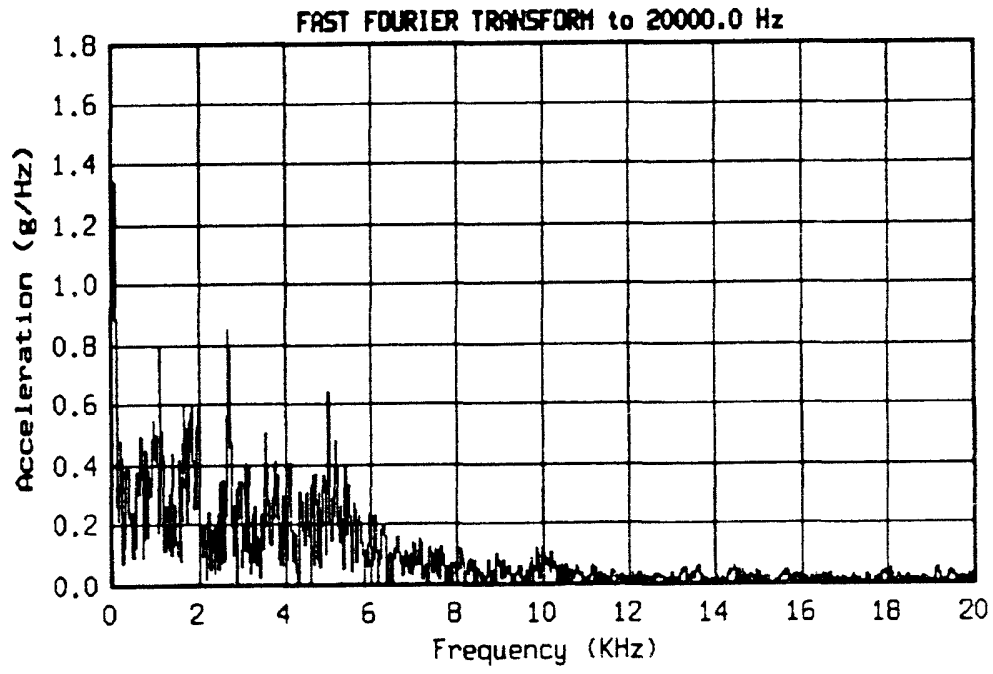

Test: LONGITUDINA LOU VeOCITY H1224A 06/29/93 (219) Session: Tue Jul 27 13:54:26 1993 Trunducer: PS (seoondary) FAST FOURIER TRANSFORY to $20000.0 \mathrm{~Hz}$

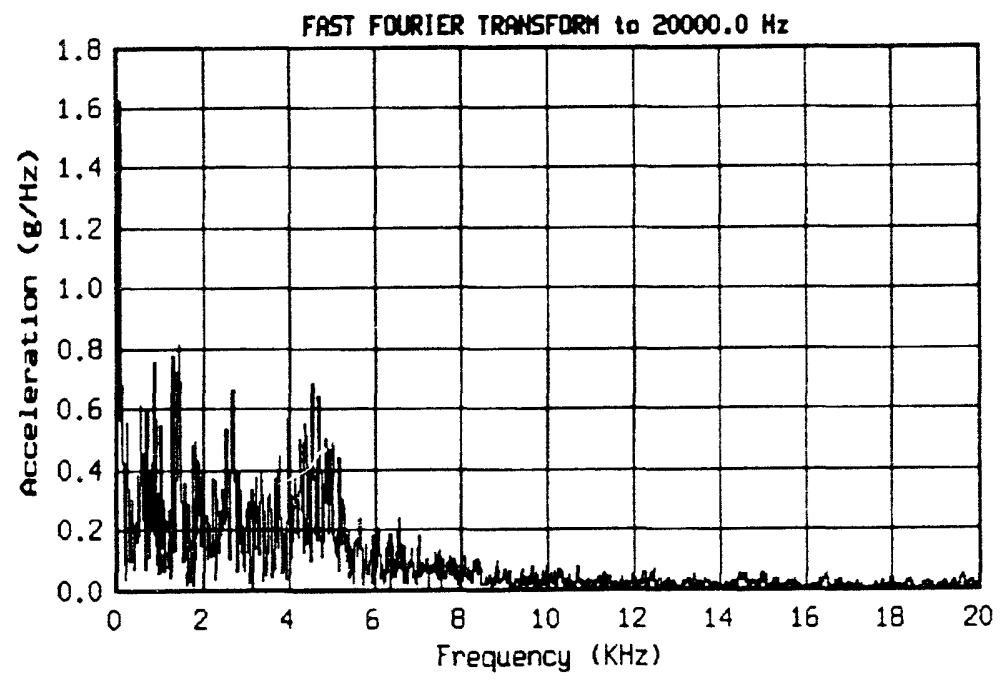



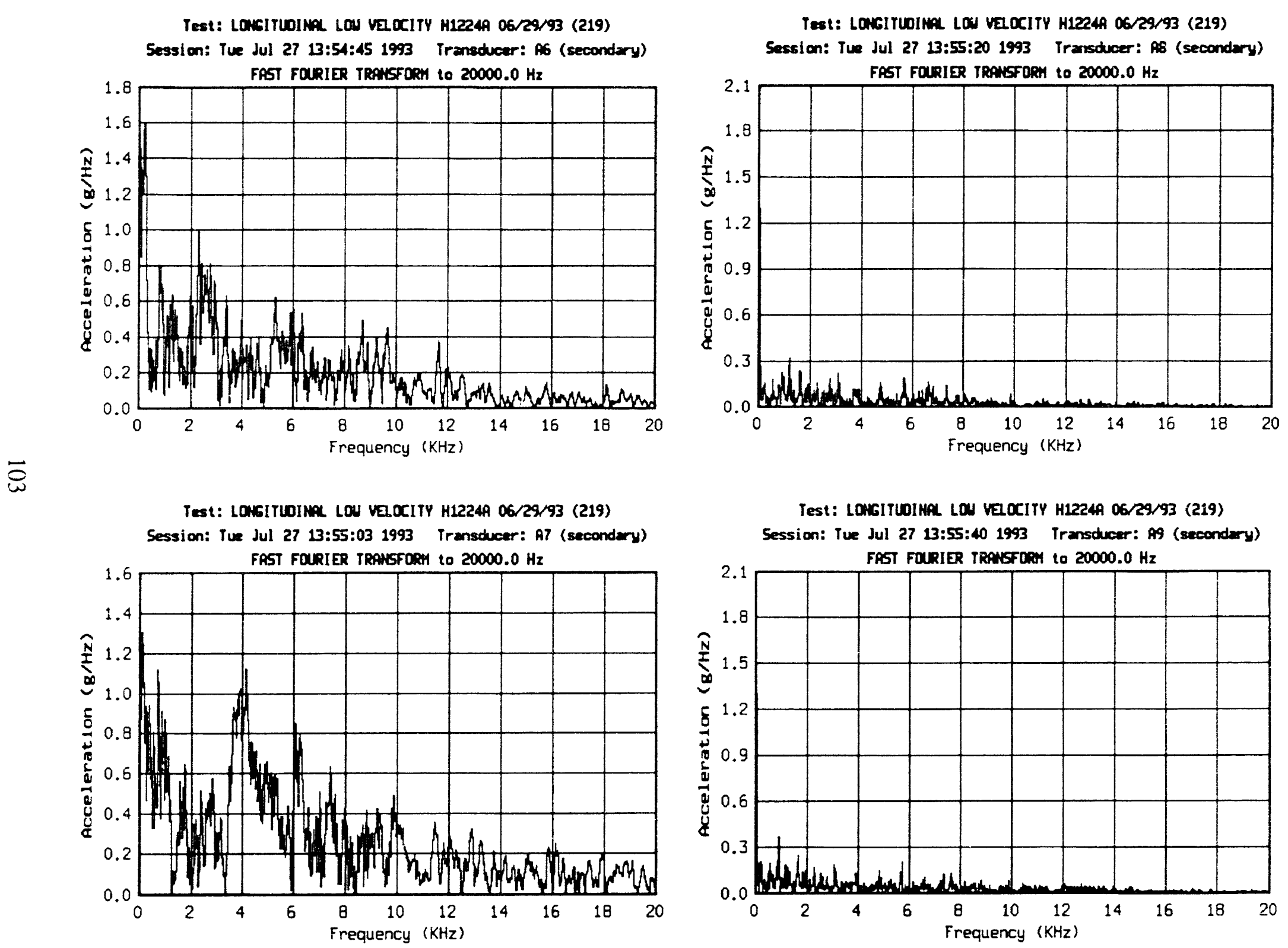
Teat: LONGITWINA LOU VECCITY H12249 O6/29/93 (219) Session: Tue Jul 27 13:55:58 1993 Transducer: A10 (secondary) FAST FOURIER TRAHSFORH to $20000.0 \mathrm{Kz}$

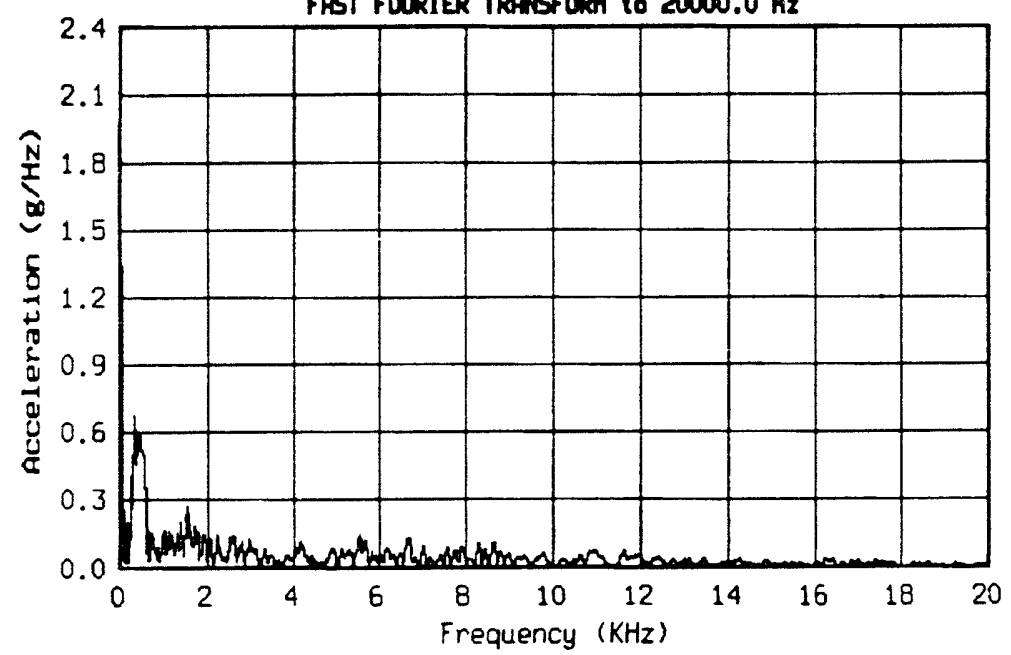

$\ddot{D}$

Test: LONGITUDINAL LOU VELOCITY H1224A 06/29/93 (219) Session: Tue Jul 27 13:56:13 1993 Transiducer: A11 (secondary) FAST FOURIER TRANSFORY to $20000.0 \mathrm{~Hz}$

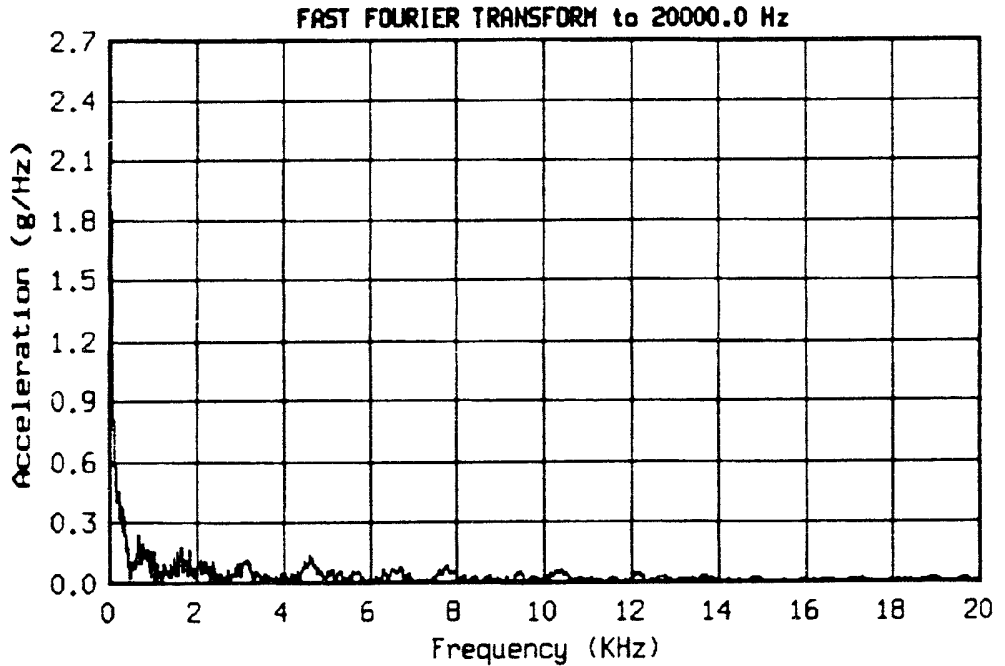

Test: LONGITLINFL LOW VeOCITY H1224A 06/29/93 (219) Session: Tue Jul 27 13:56:31 1993 Transducer: A12 (secondary) FAST FOURIER TRAWSFDQAY to $20000.0 \mathrm{~Hz}$

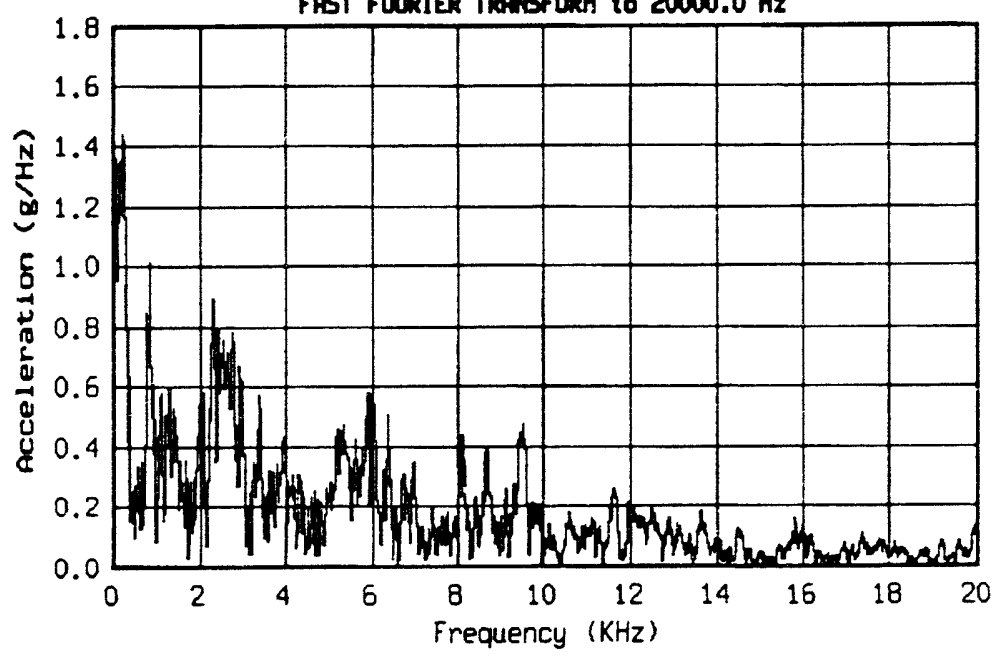

LON6ITUOINA LOU VEOCITY H1224A 06/29/93 (219) Session: Led Dec 8 07:42:20 1993 Iransducer: 561 (secondary) FAST FOURIER TRAMSFORH to $20000.0 \mathrm{~Hz}$

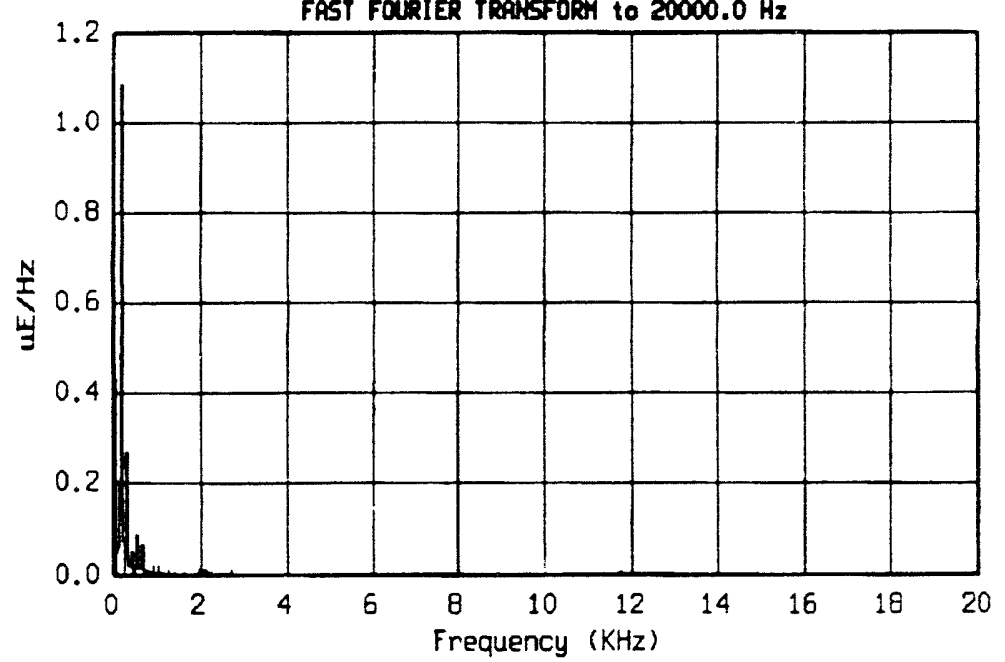



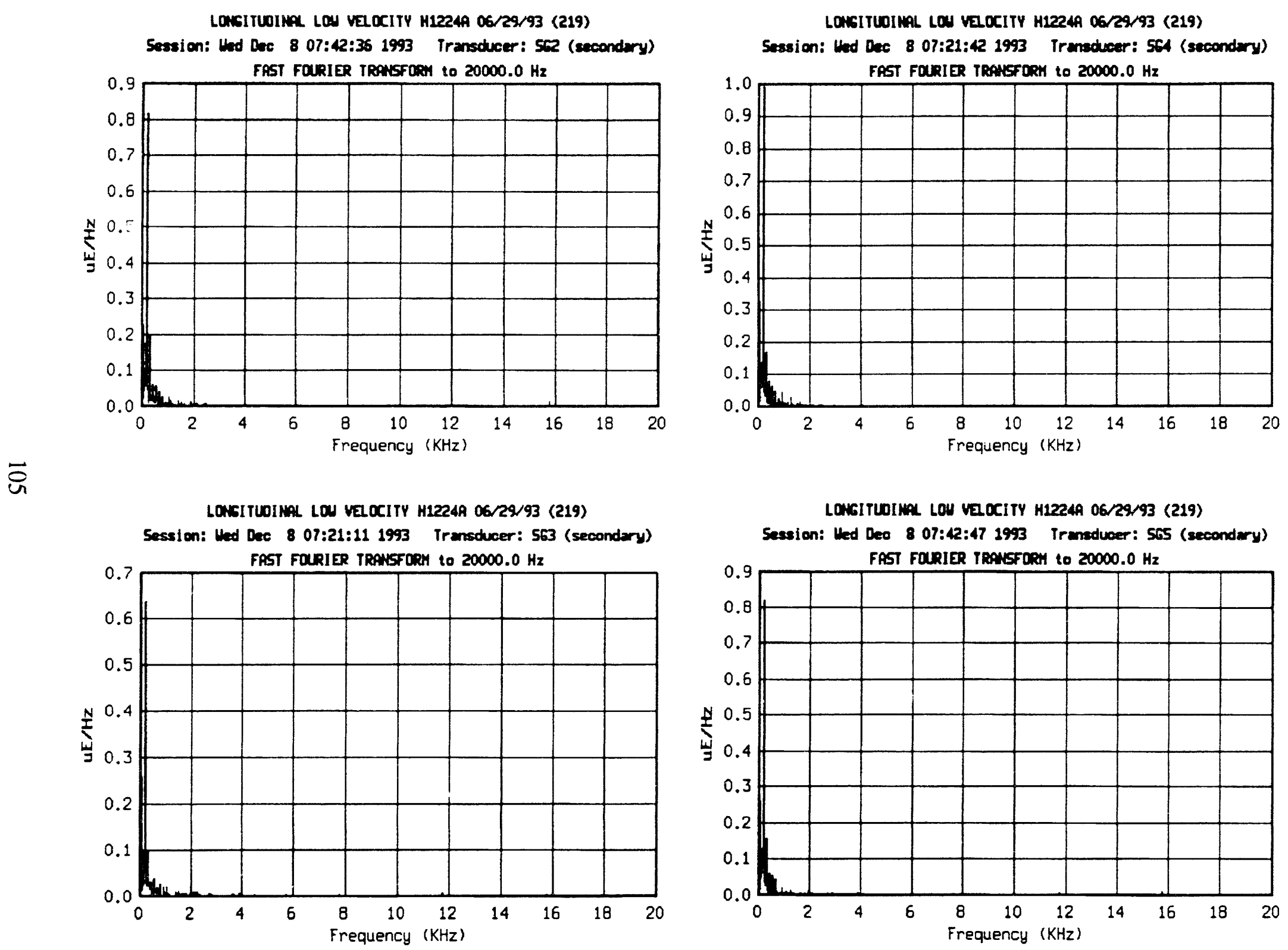

LOHGITUDINAL LOU velocitY H1224A 06/29/93 (219) Session: thed Deo 8 07:42:47 1993 Transducer: S65 (secondary)

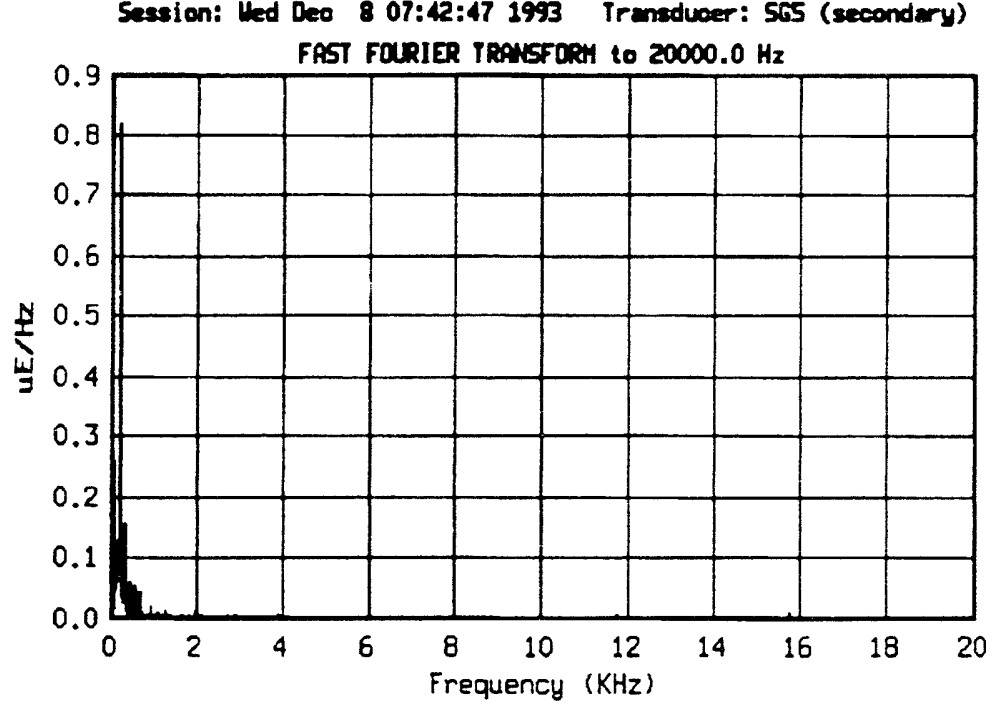



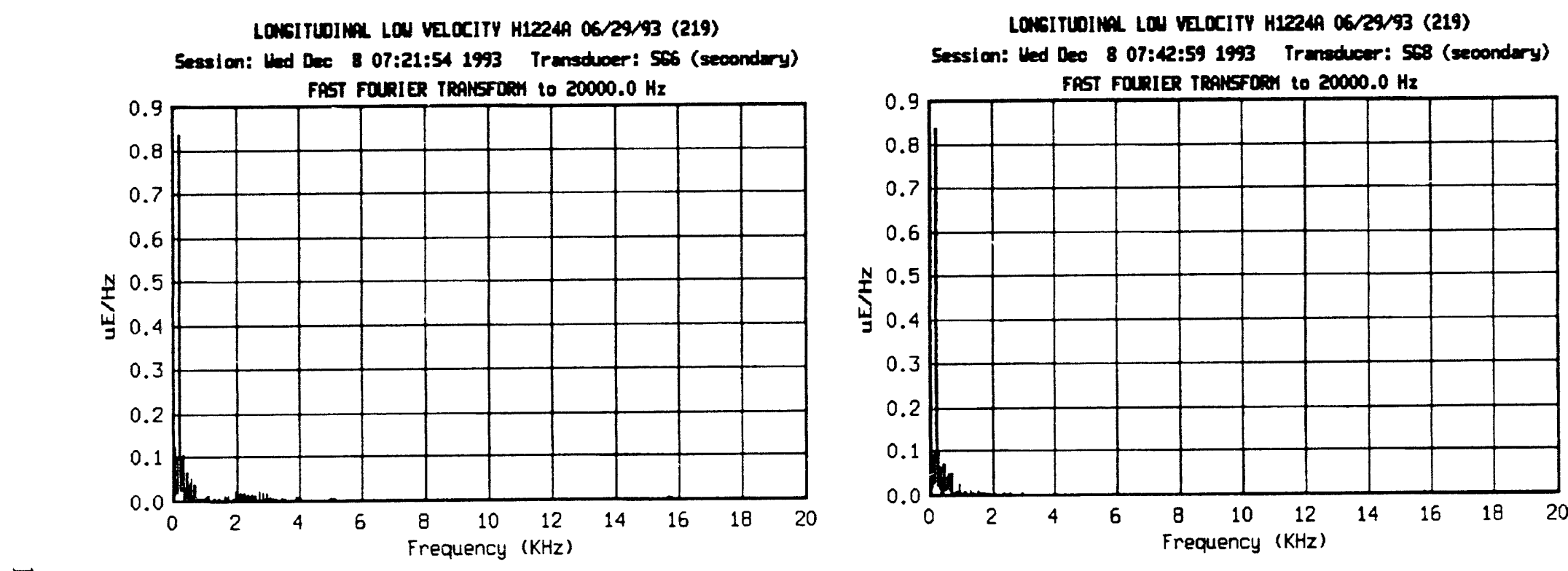

$\overline{\check{~}}$

LOSGITUIMA LOU VELCITY H12249 06/29/93 (219) Session: thed Dee 8 07:42:53 1993 Trensducer: 567 (secondary) FAST FOURIER TRANSFORM to $20000.0 \mathrm{~Hz}$
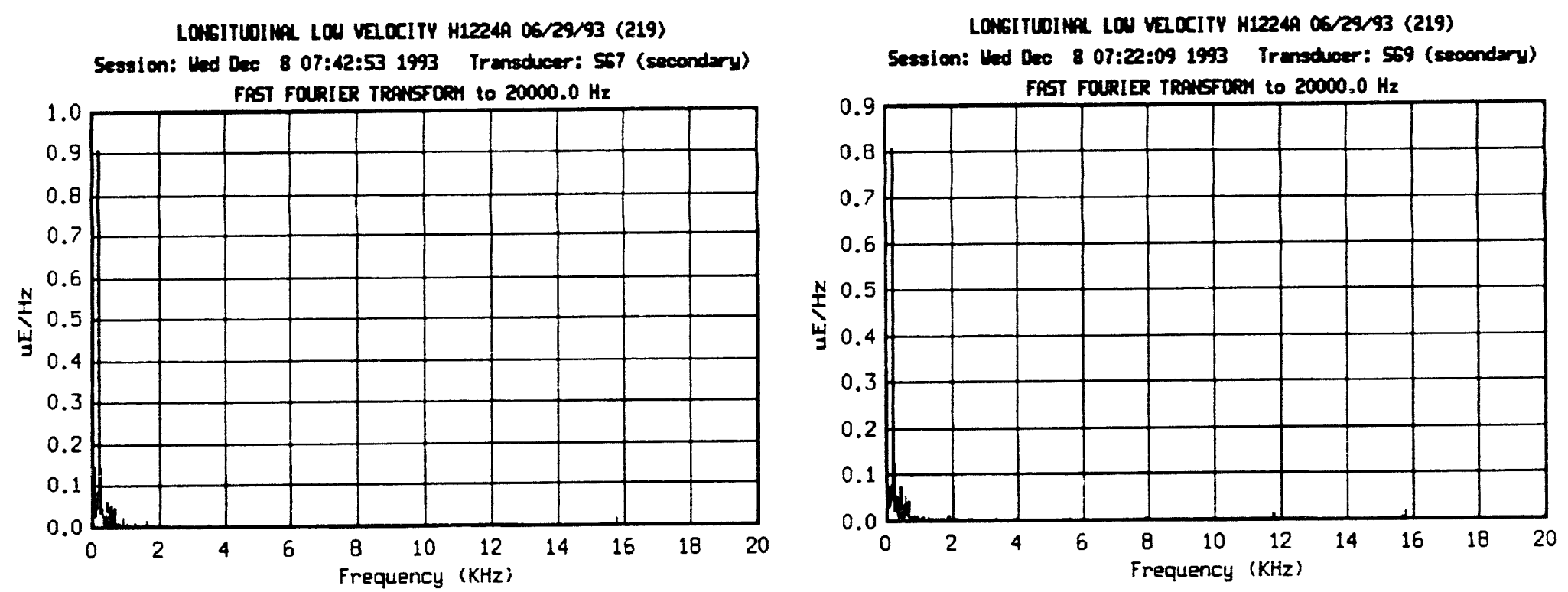
LOXSITUIMA LOW VelocITY H1224A 06/29/93 (219)

Session: thed Dee 8 07:22:20 1993 Trunsduoer: 5610 (secondary)

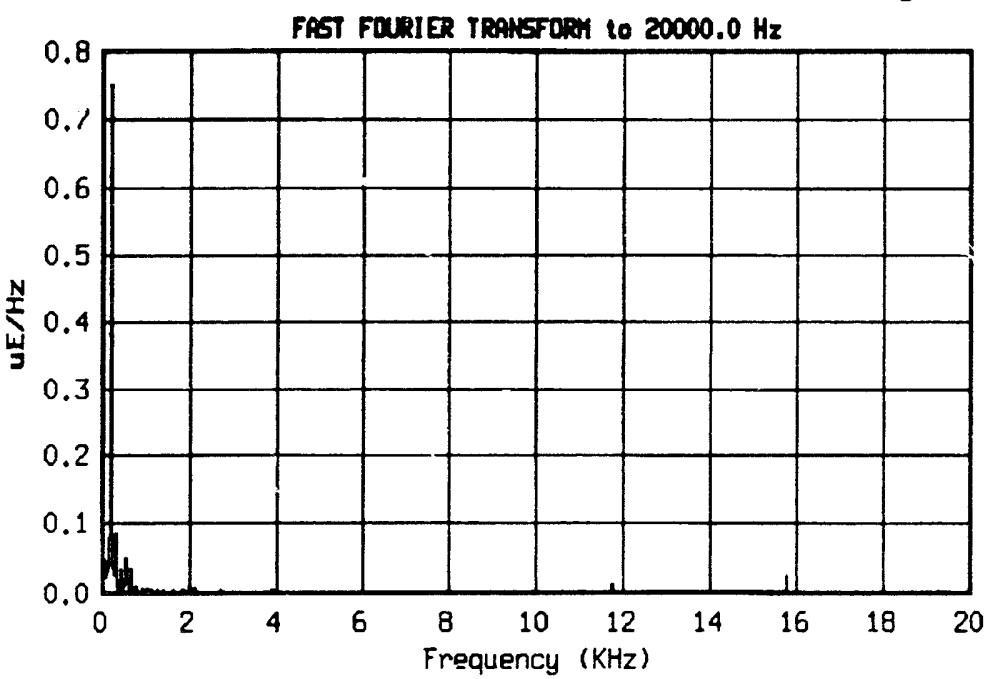

$\vec{s}$

LOWGITUOINA LOU VEDCITY H12249 06/29/93 (219)

Session: thed Dec 8 07:43.06 1993 Transchucer: 5611 (secondary)

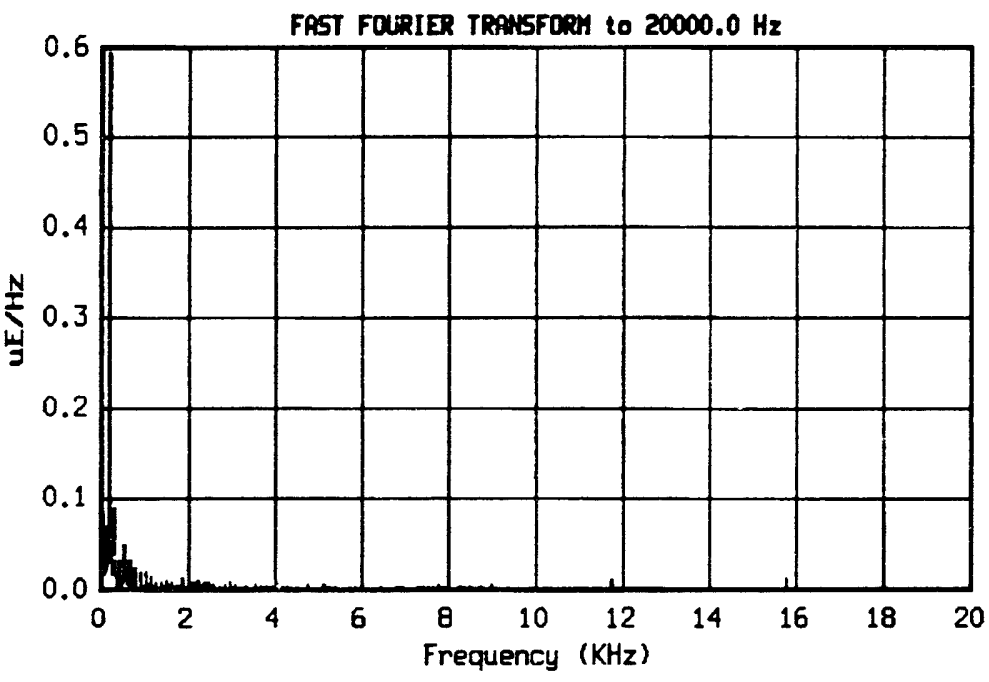

LONSITUINA LOW VelOCITY H1224A 06/29/93 (219)

Sessilon: thed Dec 8 07:47:58 1993 Transducer: S512 (secondary)

FAST FOURIER TROASTOOM to $20000.0 \mathrm{~Hz}$

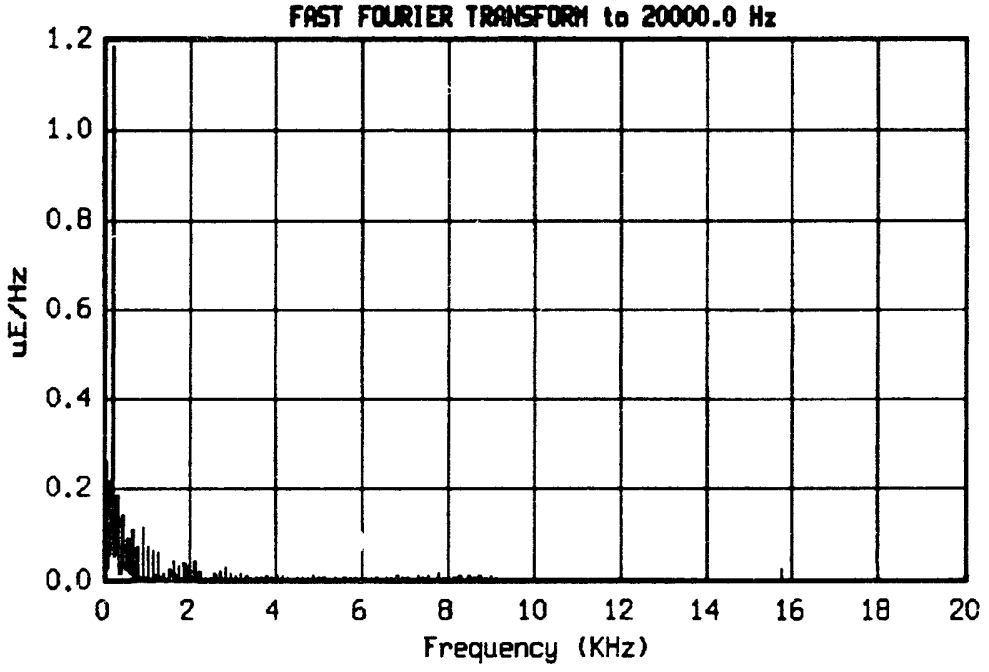

LONGITUIKAL LOU VEOCITY H12249 06/22/93 (219)

Session: thed Dec 8 07:22:45 1993 Transducer: S513 (secondary)

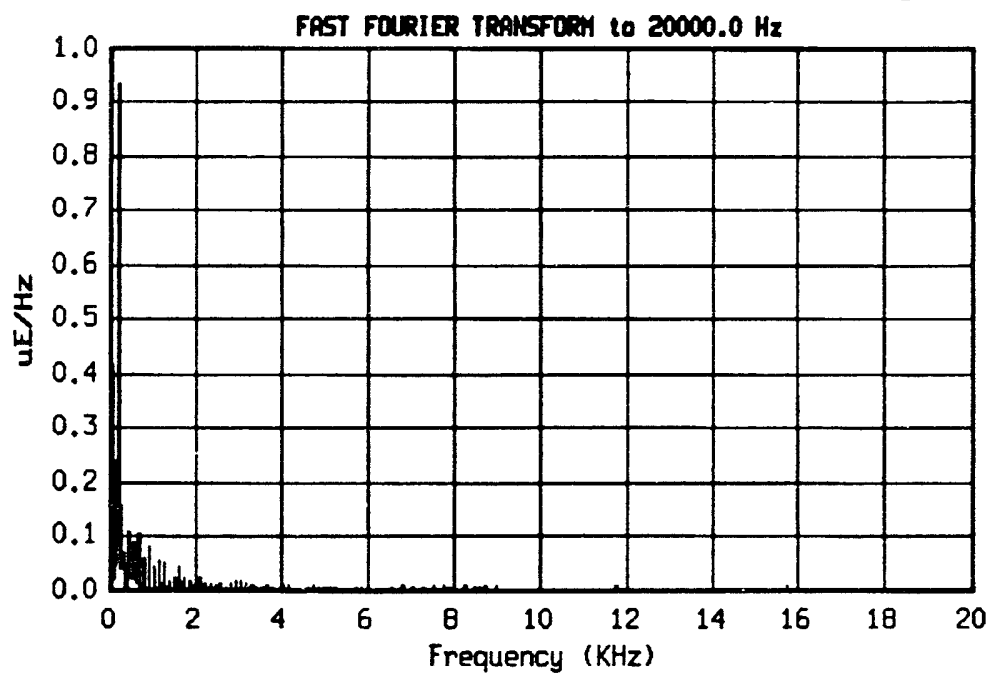


LONGITWINAL LOU Velocity H1224A 06/29/93 (219)

Session: lied Dec 8 07:22:34 1993 Transducer: 5614 (secondary)

FIST FOARIER TRAUSFOAN to $20000.0 \mathrm{~Hz}$

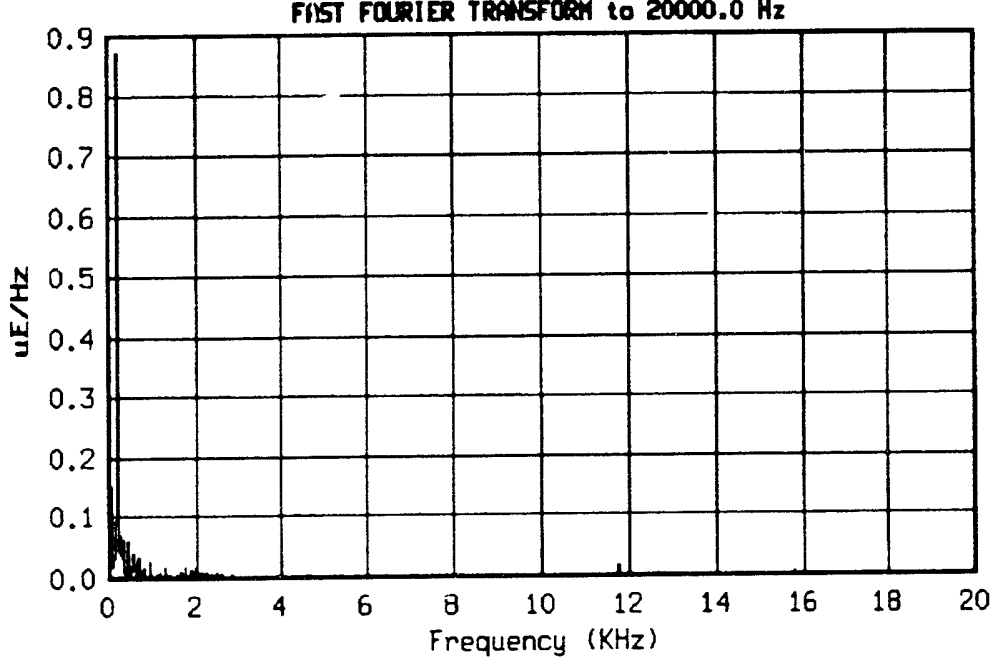

$\bar{\infty}$ 


\section{Appendix B. HLV Accelerometer and Strain Gage Data: Raw, Filtered, and Reduced}

The following pages show raw (unfiltered) acceleration and strain gage data for the Horizontal Low-Velocity (HLV) impact test. Following this raw data are plots of filtered data (using a low-pass Butterworth 6-stage filter) with cutoff frequencies of $250 \mathrm{~Hz}$ and $2,000 \mathrm{~Hz}$. Integrated acceleration data, yielding velocity versus time plots, are presented to analyze kinetic energy values during the test. And finally, Fast Fourier Transforms (FFTs) for each raw data channel are included to analyze acceleration and strain amplitudes in the frequency domain. 
TEst: MORIZONTR. LOU VELOCITY HI224A 06/30/93 (220) Session: Mon Jul 26 15:13:56 1993 Transducer: A1 (secondary)

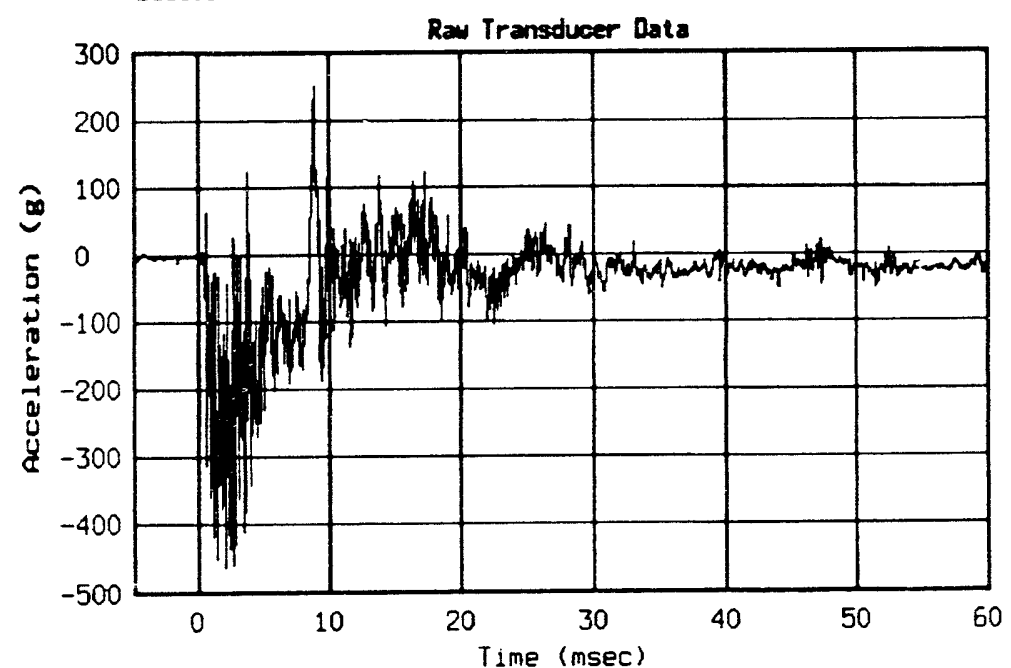

$\Xi$

Test: HORI2ONTAL LOH VELOCITY H1224月 06/30/93 (220) Session: Mon Jul 26 15:44:02 1993 Transiducer: R2 (secondary)

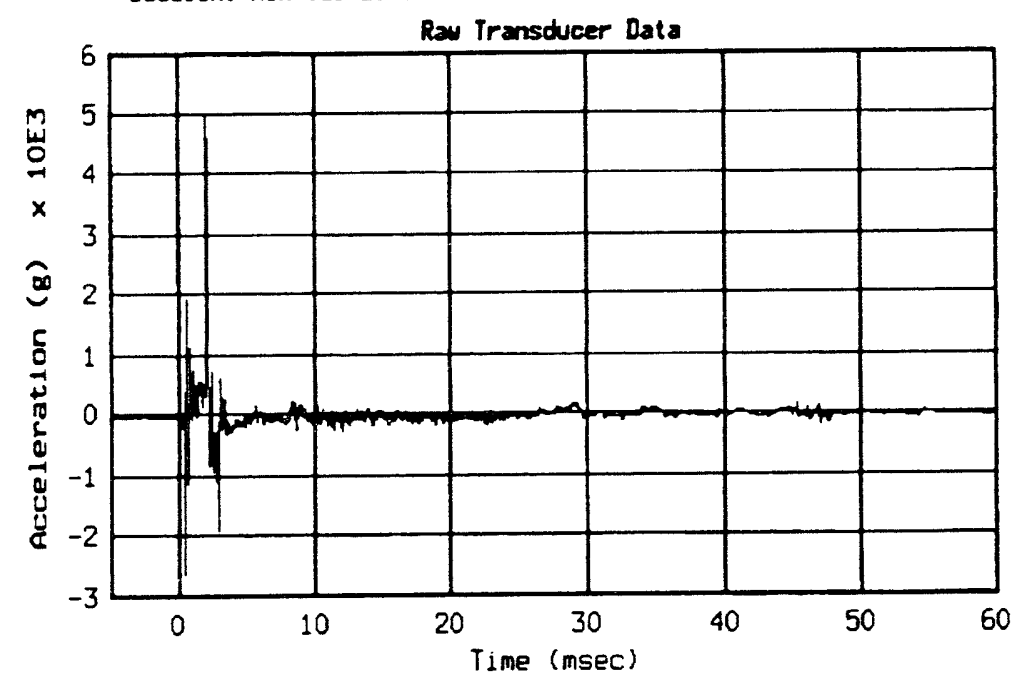

Test: HORIzONTAL LOU VEDCITY HL224A 06/30/93 (220) Session: Mon Jul 26 15:44:09 1993 Transducer: A3 (secondary)

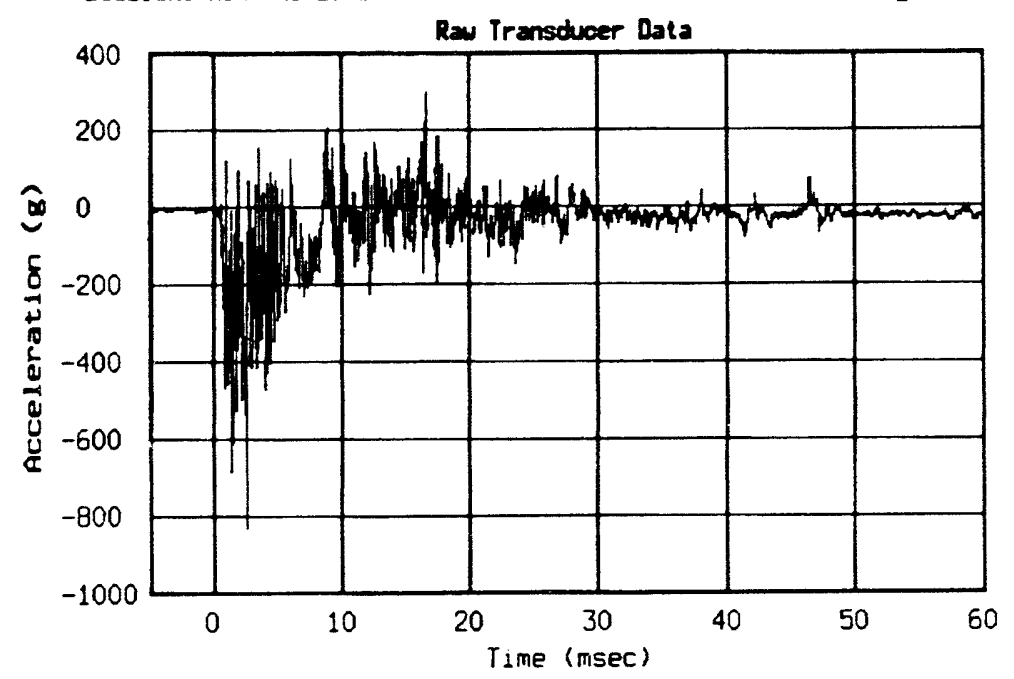

Test: HORIZONTAL LOU VELOCITY H1224A 06/30/93 (220) Session: Mon Jul 26 15:42:34 1993 Transducer: 94 (secondary)

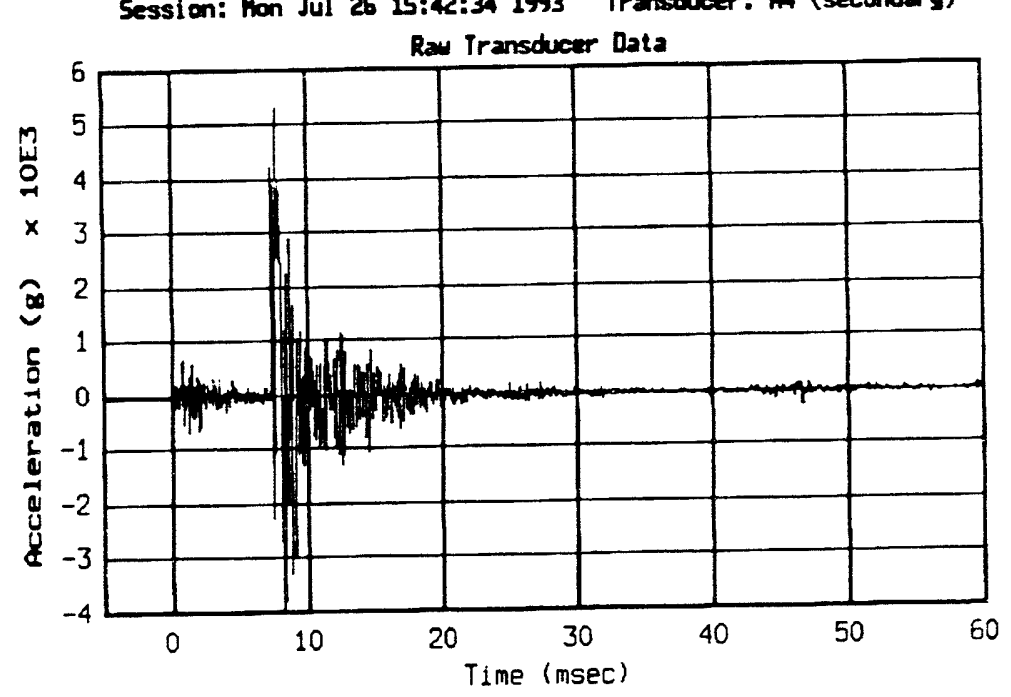



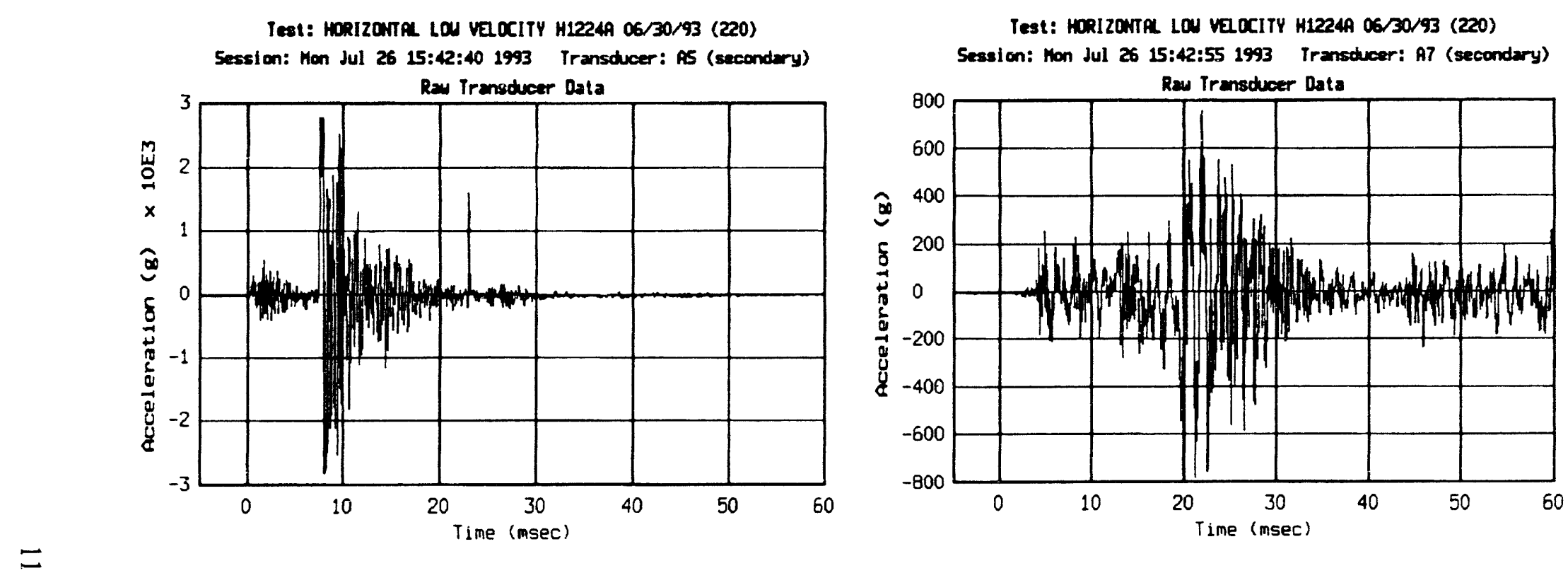

Test: HORIZONTAL LOW VEXCITY H1224A 06/30/93 (220) Session: Mon Jul 26 15:42:46 1993 Transducer: A6 (secondary)
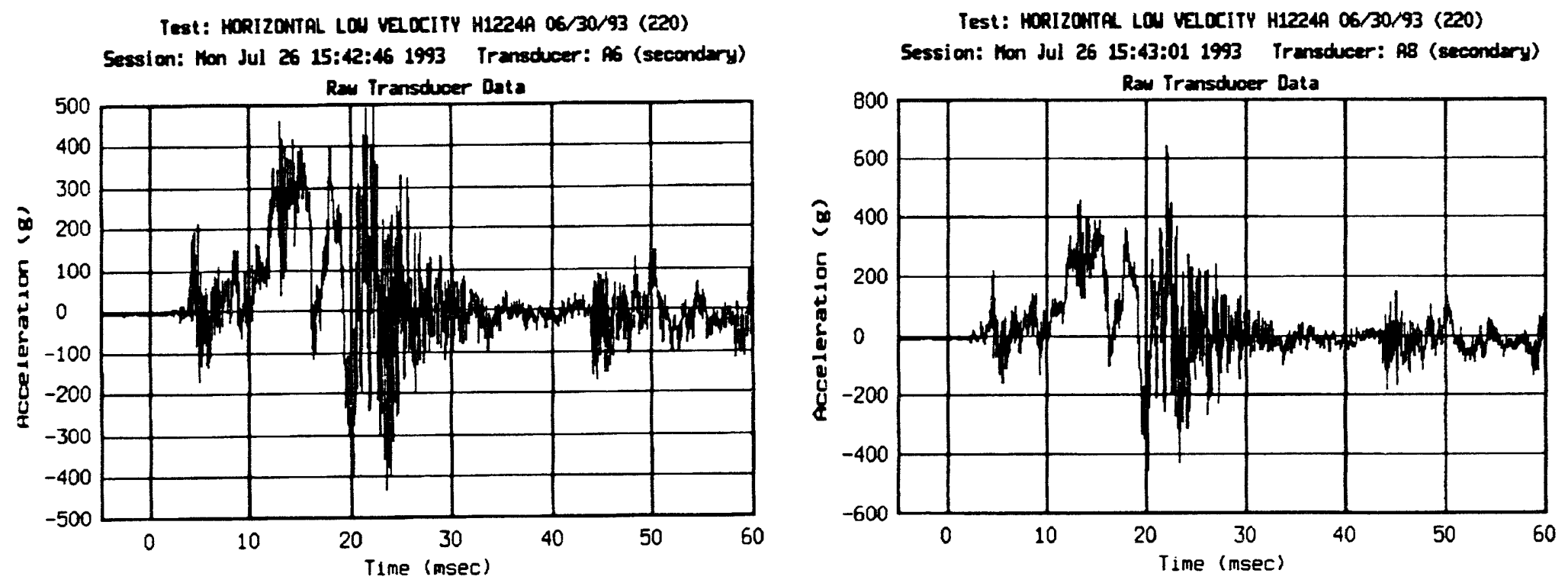
Iest: HORIZONTAL LOW VELOCITY H1224A 06/30/93 (220) Session: Mon Jul 26 15:43:09 1993 Transtucer: A9 (secondary)

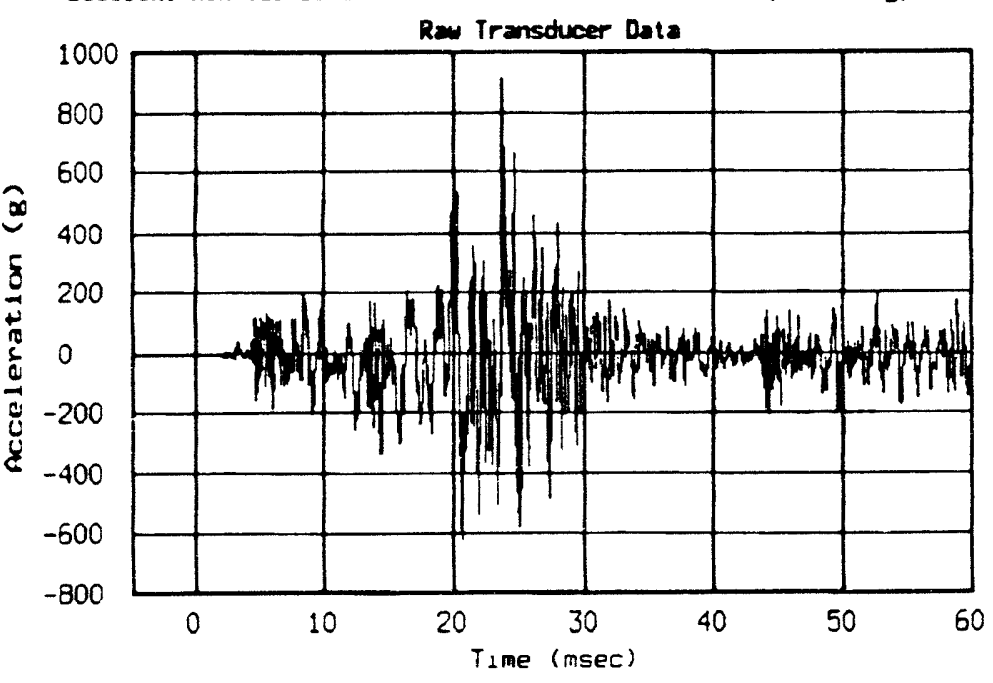

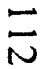

Test: HORIZONTA LOW VEOCITY H1224h 06/30/93 (220) Session: ton Jul Z6 15:43:16 1993 Transducer: A10 (secondary)

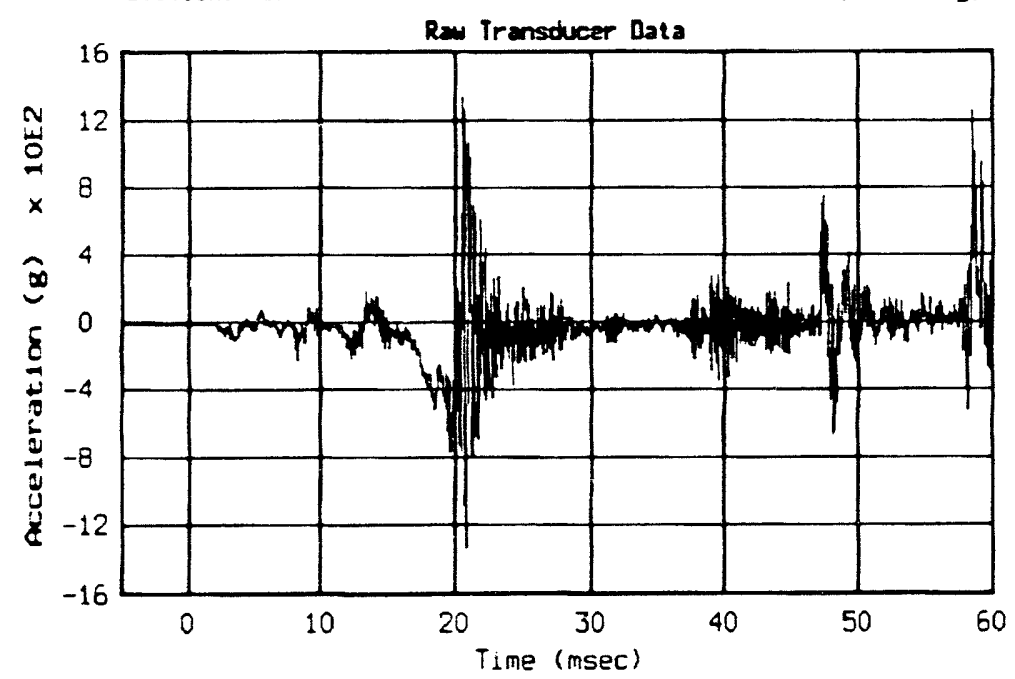

Test: HORIZONTLL LOW VELCITY H1224A 06/30/93 (220) Session: Hon Jul 26 15:43:24 1993 Transducer: A11 (secondary)

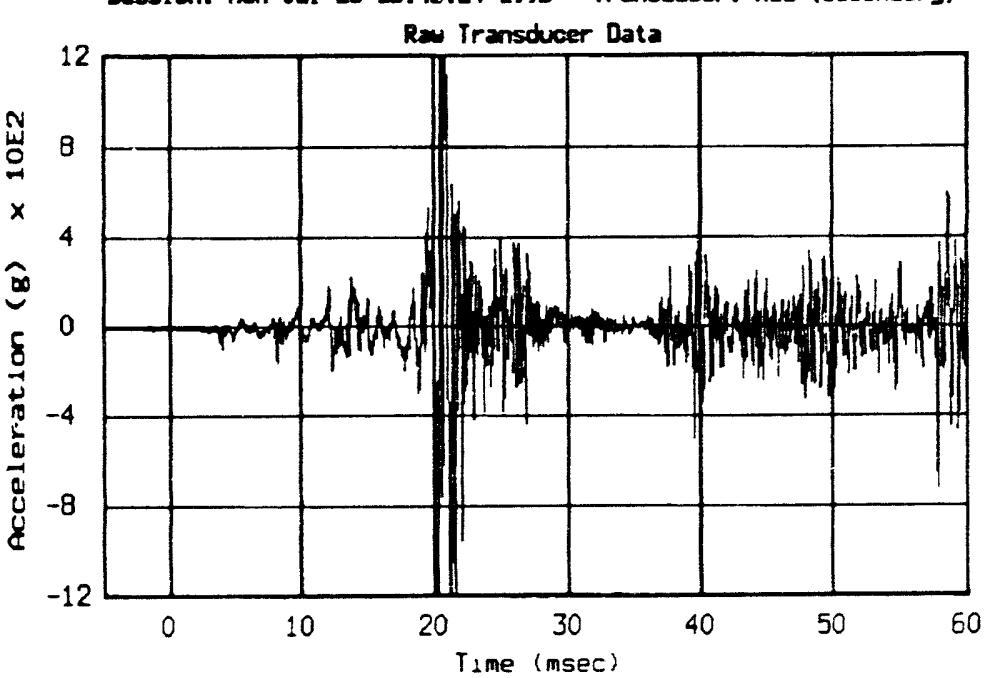

Test: HORIZONTAL LOW VeloCITY H1224A 06/30/93 (220) Session: Mon Jul 26 15:43:30 1993 Transducer: A12 (secondary)

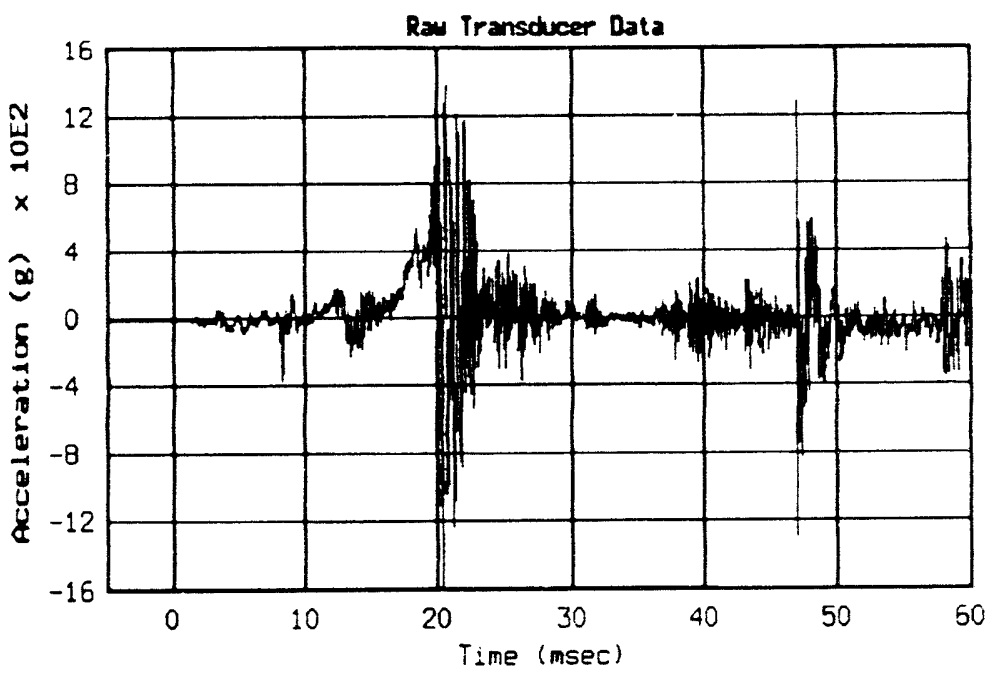


Test: HORIZONTR LOW VELOCITY HL224A 06/30/93 (220) Session: Mon Jul Z6 15:43:38 1993 Transducer: A13 (secondary)

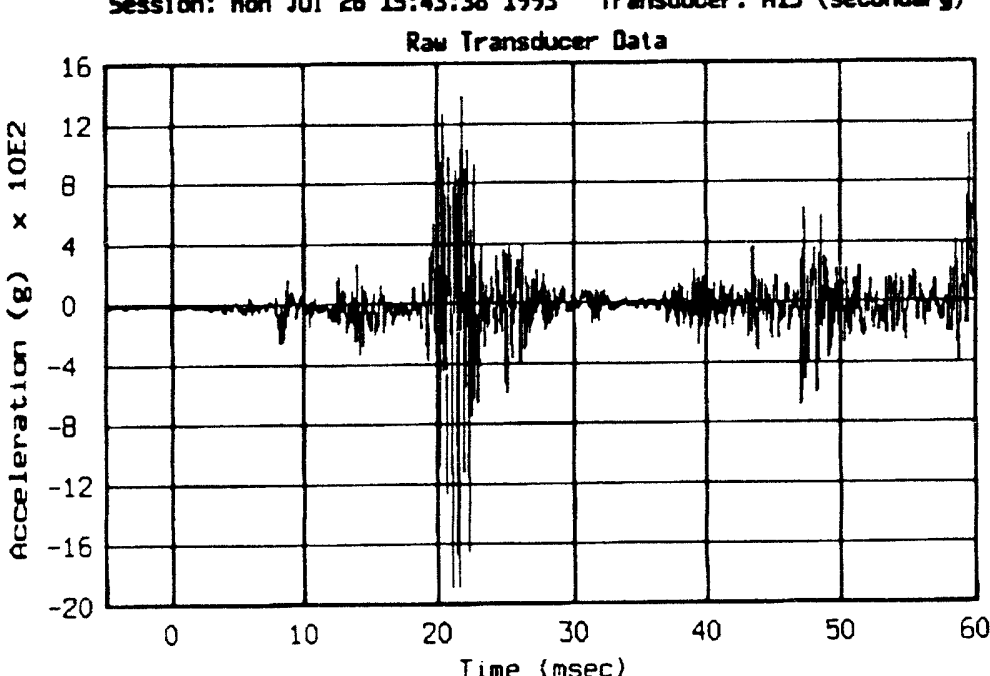

$\bar{\omega}$

Test: HORIZONTA LOW ValOCITY H1224A 06/30/93 (220) Session: Mon Jul Z6 15:43:43 1993 Transducer: A14 (secondary)

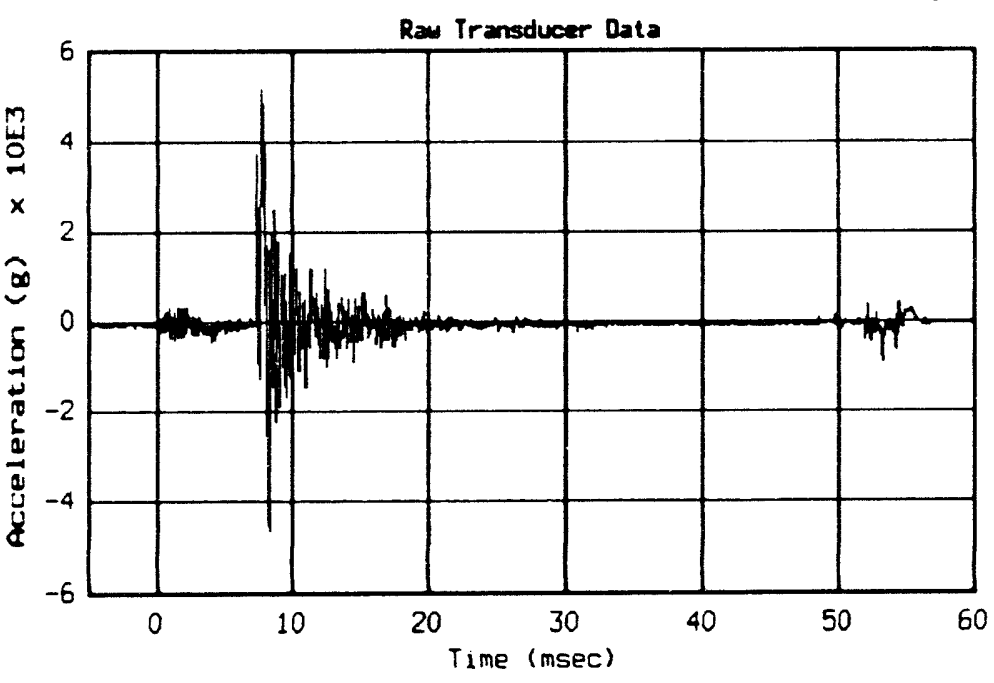

TESL: HORIZONTAL LOW VELOCITY H1224A 06/30/93 (220) Session: Mon Jul 26 15:43:51 1993 Transducer: A15 (secondary)

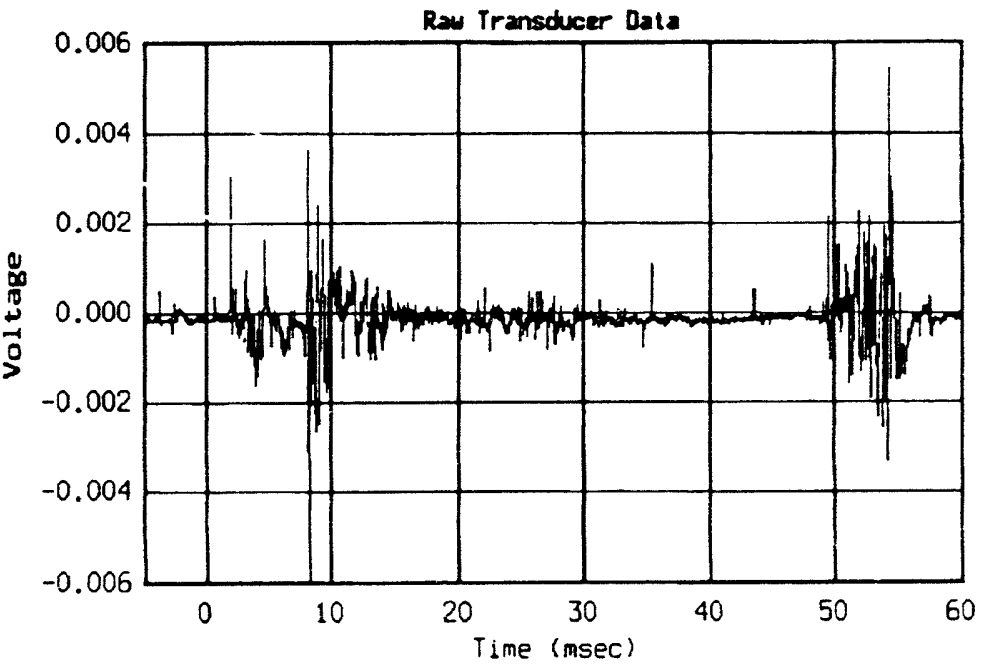

Test: HORIZONTA LOW VelocITY H1224A 06/30/93 (220) Session: Mon Jul 26 15:44:14 1993 Transiducer: S61 (secondary)

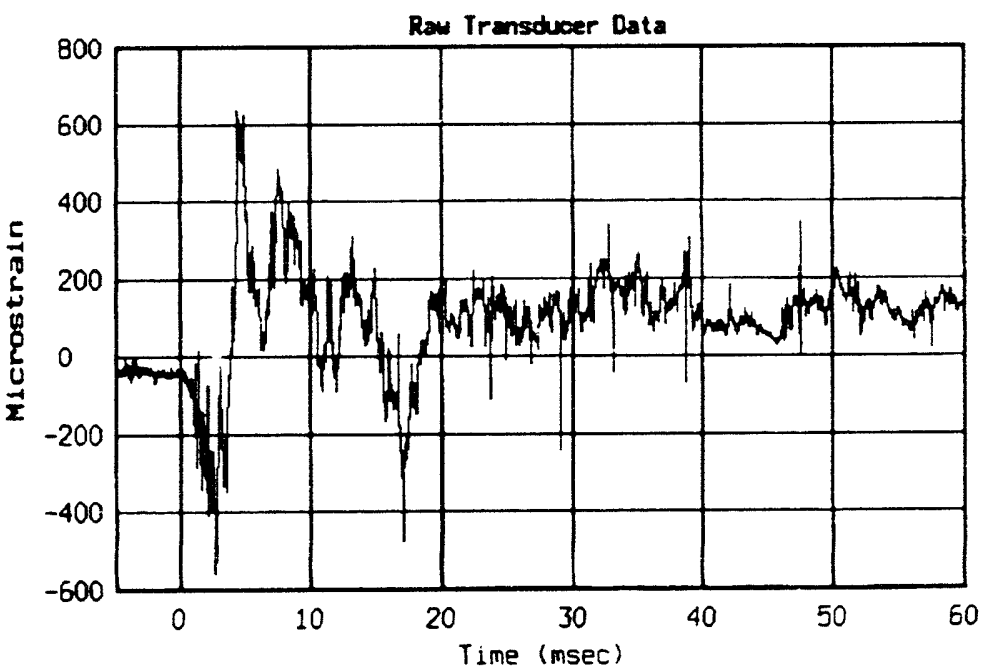


Test: HoRIZONA LON VELOCITY HLZ24A 06/30/93 (220) Session: Mon Jul 26 15:44:21 1993 Transducer: 502 (secondary)

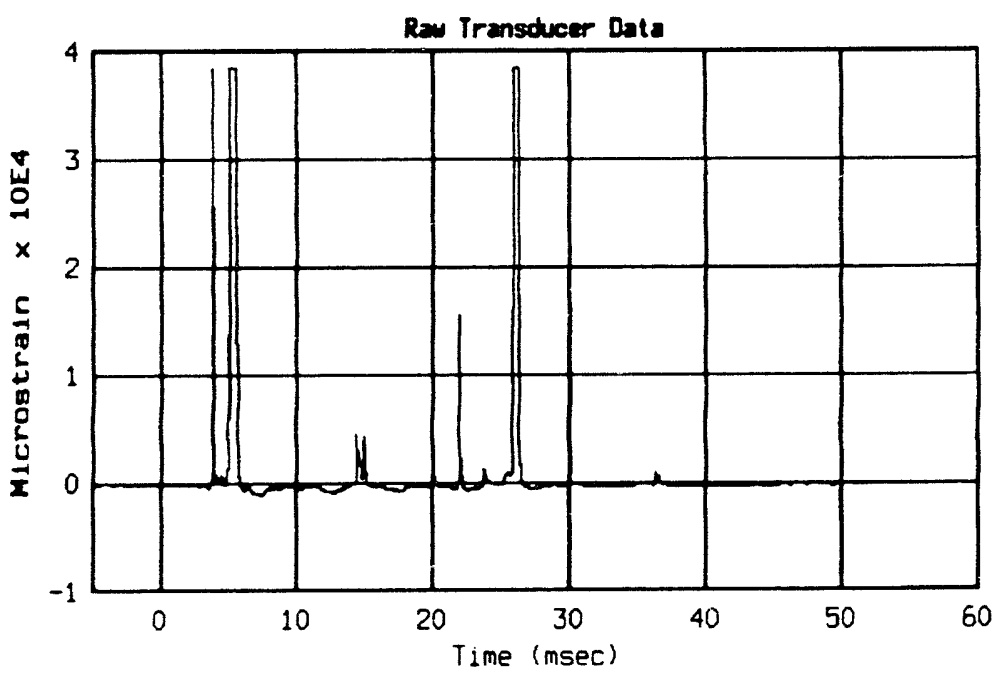

戸

Test: HORIZONTA LOU VECCITY H1224A 06/30/93 (220) Session: Hon Jul Z6 15:44:28 1993 Transducer: 563 (secondary)

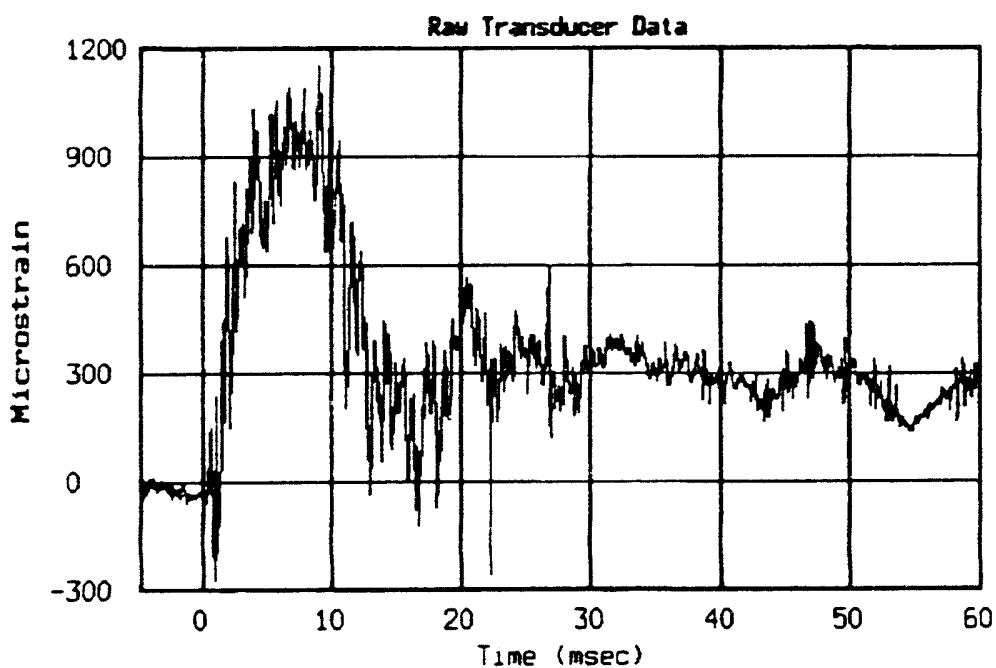

Test: HORIZONTR LOW VelocITY H12244 $06 / 30 / 93$ (220) Session: Mon Jul 26 15:44:35 1993 Iransducer: 564 (secondary)

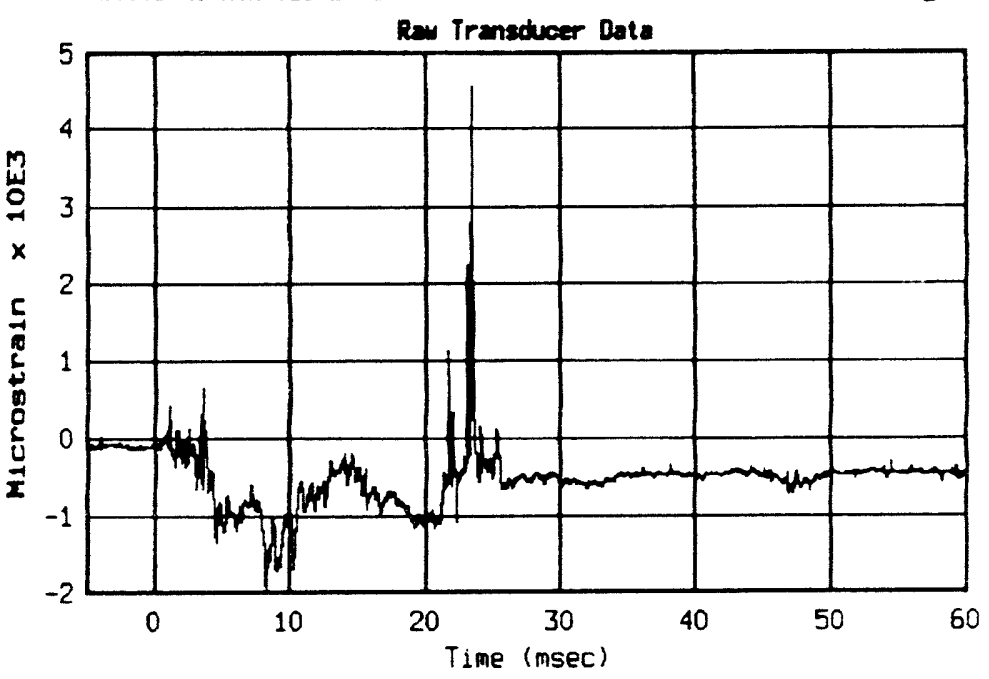

Test: HORIZONTR LOU VEDOCITY H1224A 06/30/93 (220) Session: Hon Jul 26 15:44:40 1993 Transducer: 565 (secondary)

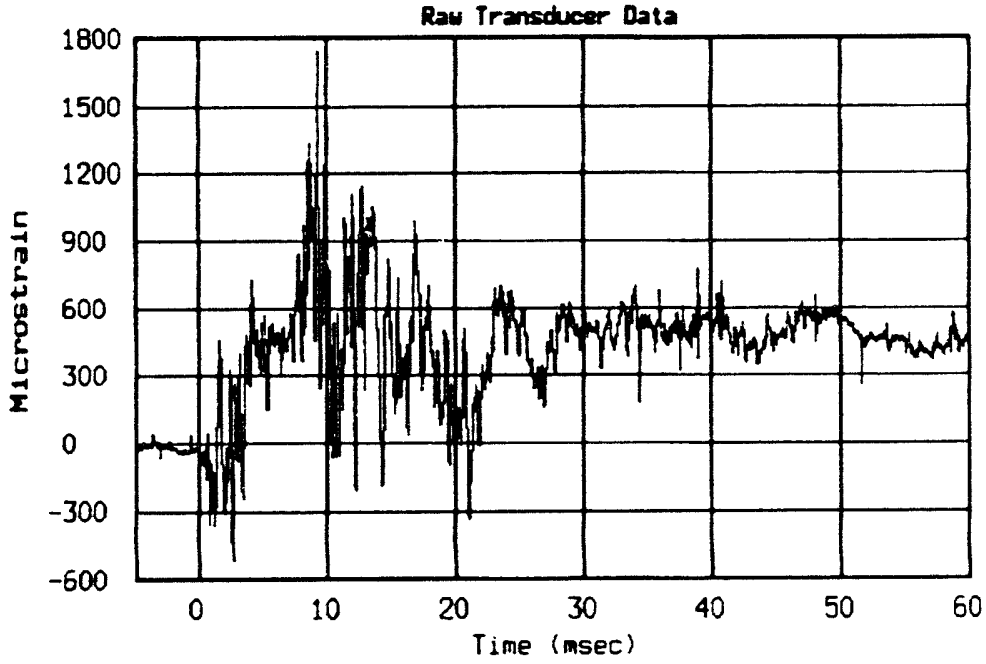



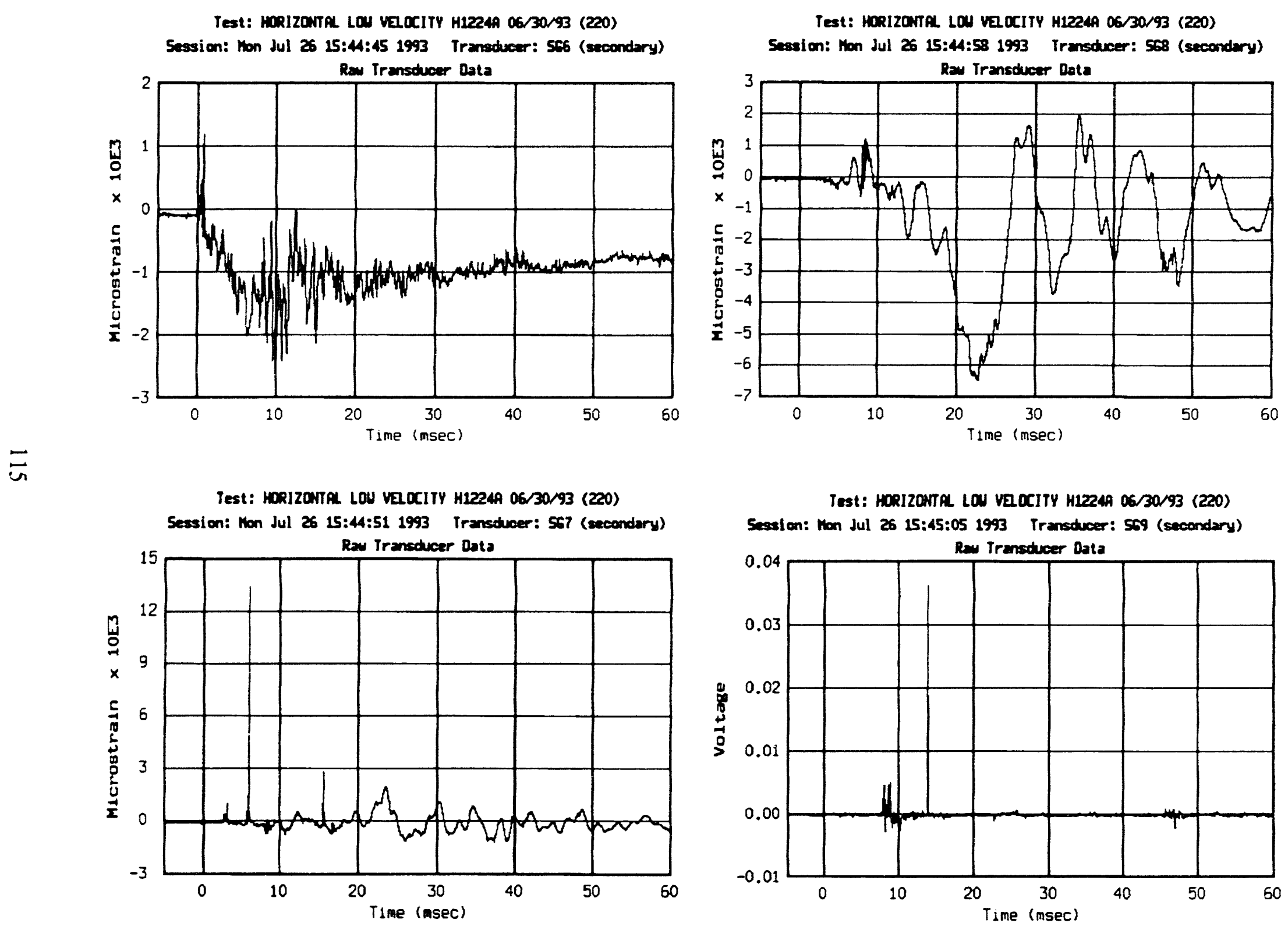

Test: HORIZONTRL LOW VEOCITY H1224A 06/30/93 (220)

Session: ton Jul 26 15:44:45 1993 Transducer: 566 (secondary)

Test: HORIzONTA LOW VeOCITY H12249 06/30/93 (220) Session: Mon Jul 26 15:45:05 1993 Transtucer: 569 (secondary)

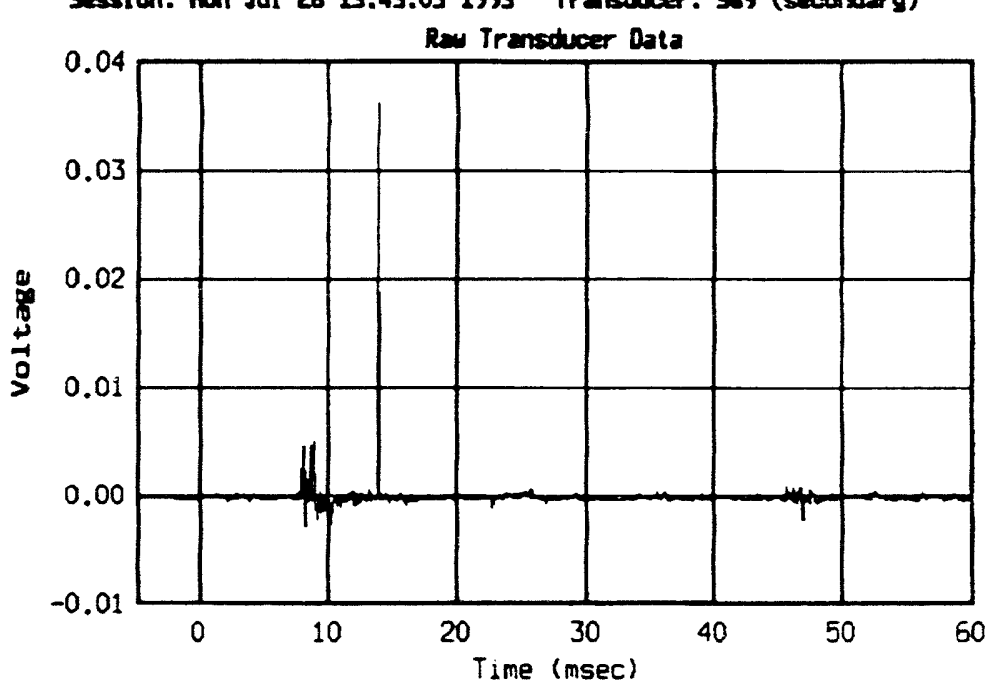



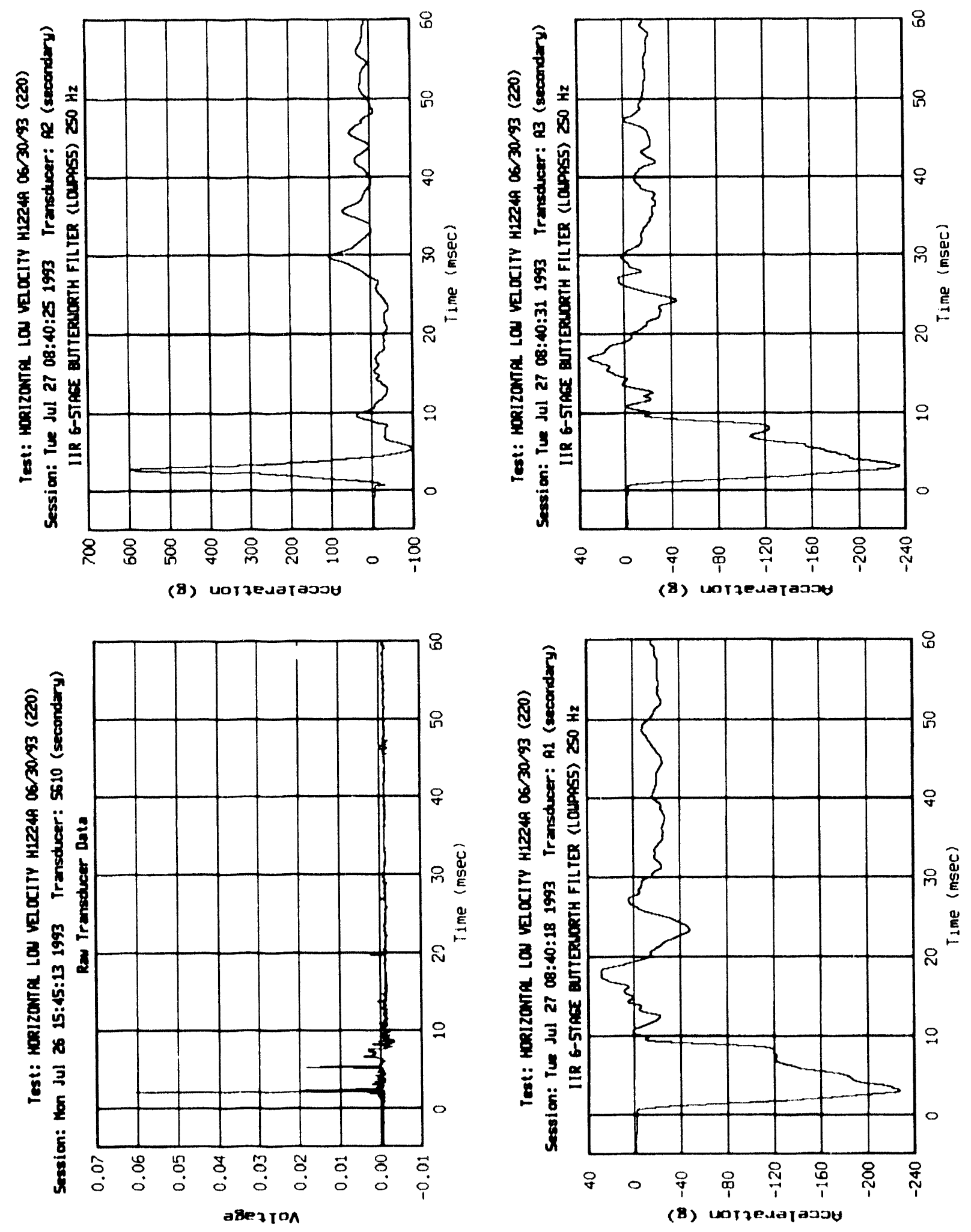

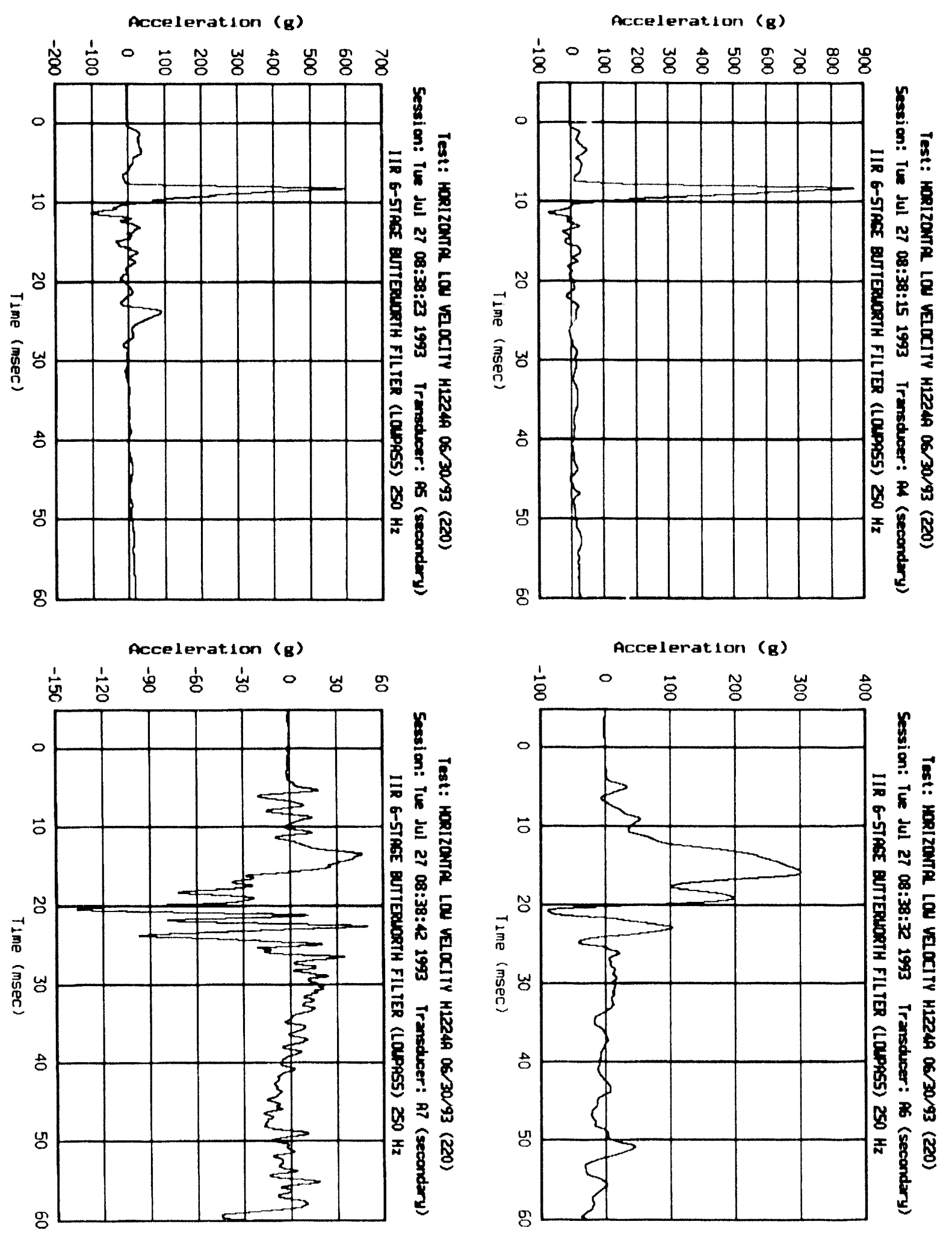
Test: NoRIzONA LOW velocitY H1224A 06/30/93 (220) Session: Tue Jul 27 08:38:56 1993 Transduoer: PB (secondary) IIR 6-STACE BUTERUORTH FILTER (LOAPRSS) $250 \mathrm{~Hz}$

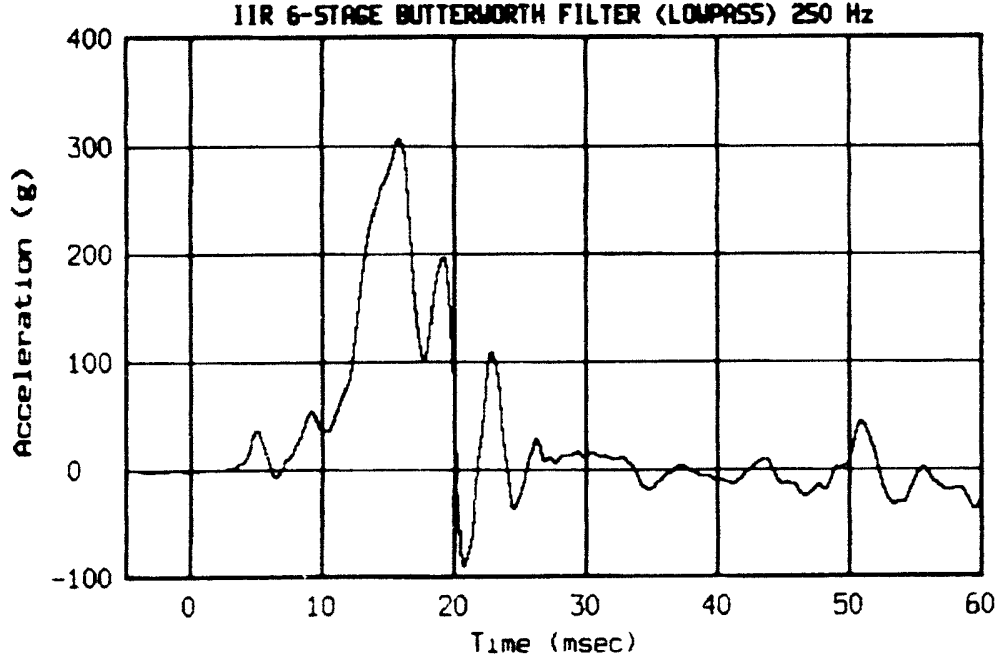

$\bar{x}$

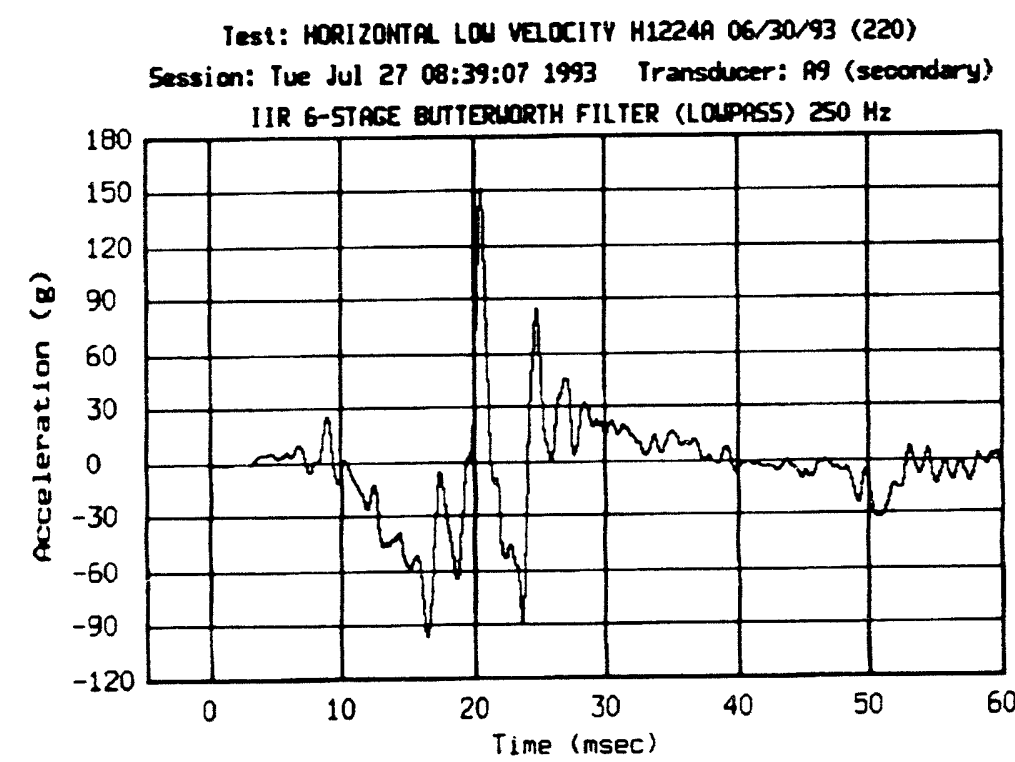

Test: MRIZONTA LOU VEOCITY H1224A 05/30/93 (220) Session: TLe Jul 27 08:39:19 1993 Transducer: A10 (secondery)

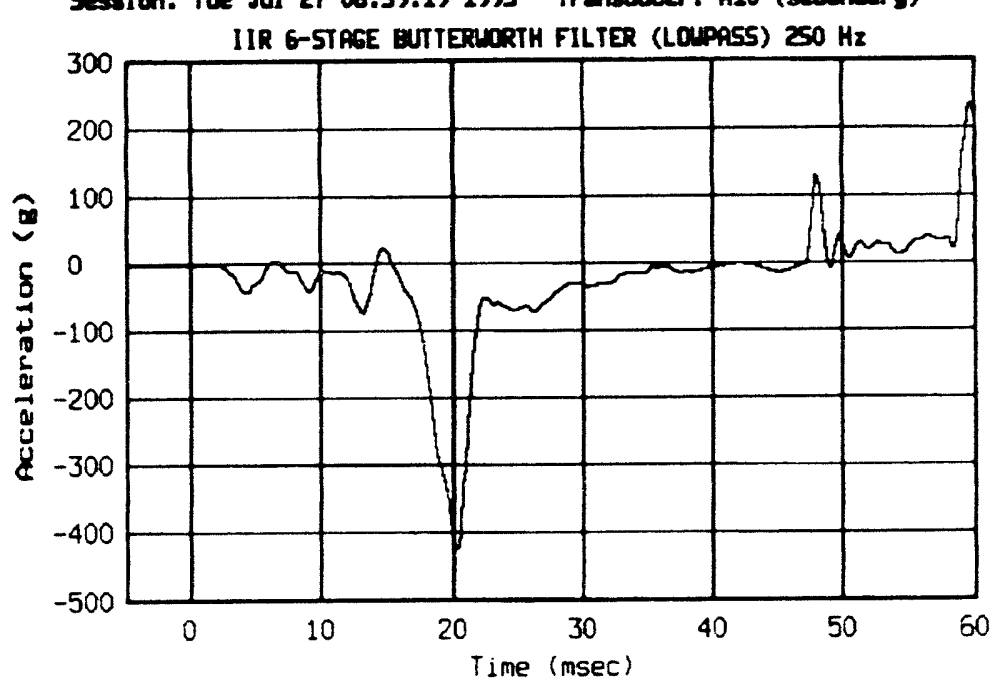

Test: HORIZONTA LOW VEOCITY H1224A 06/30/93 (220) Session: Tue Jul 27 08:39:33 1993 Transiducer: A11 (secondary) IIR 6-5TAGE BUTIERUDRTH FILTER (LOPPSSS) $250 \mathrm{~Hz}$

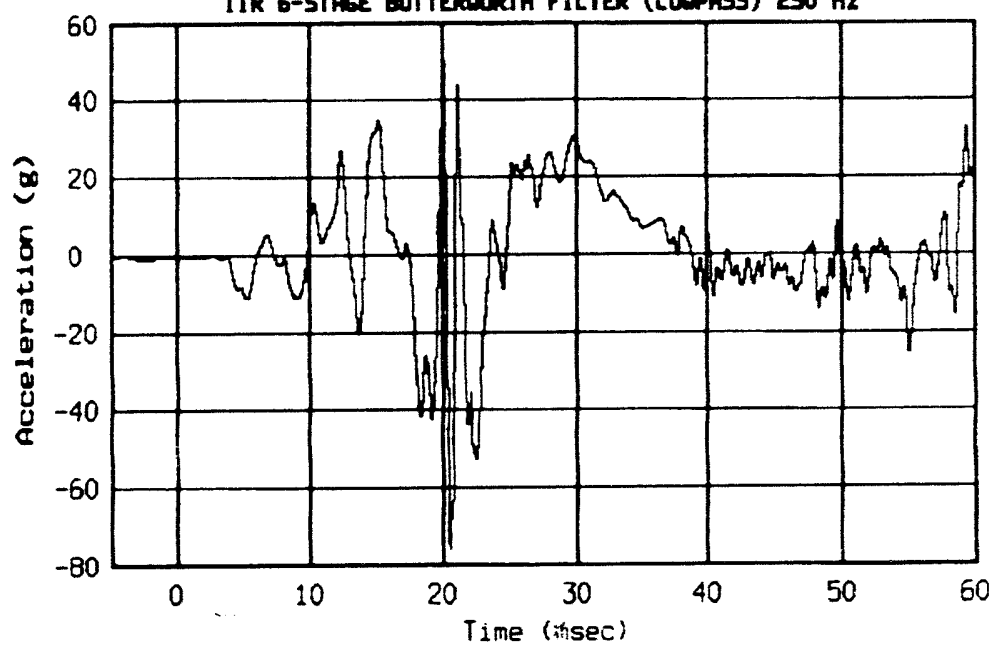


Test: HORIZONTPL LOW VELCLITY H1224A 06/30/93 (220) Session: Tue Jul 27 08:39:47 1993 Transcuceer: A12 (secondary)

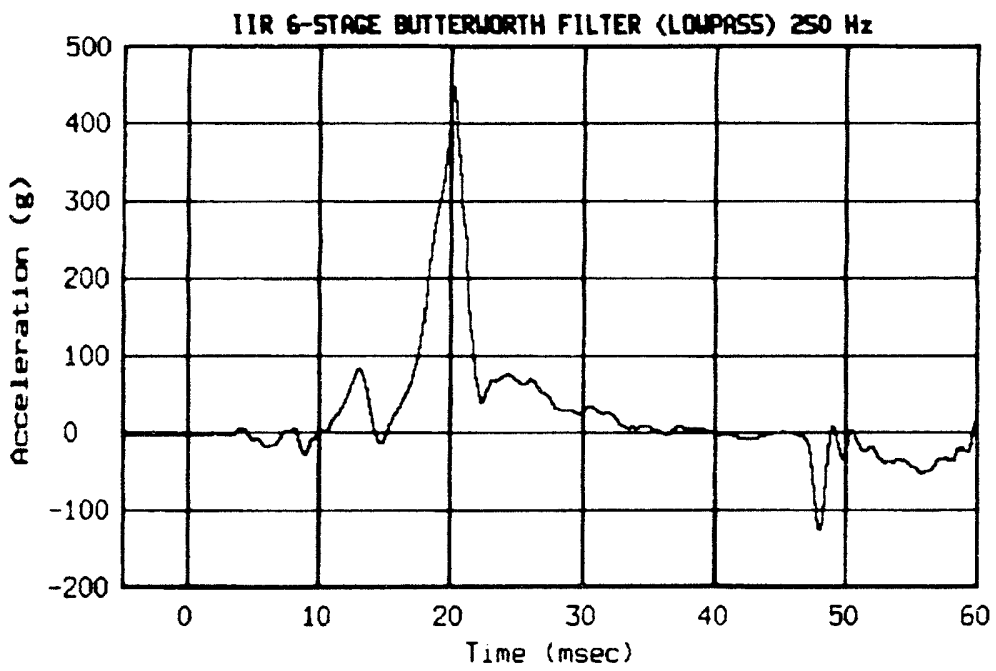

Test: hORIZONTPL LOU VELOCITY H1224A 06/30/93 (220) Session: Tue Jul 27 08:39:58 1993 Transducer: R13 (secondary)

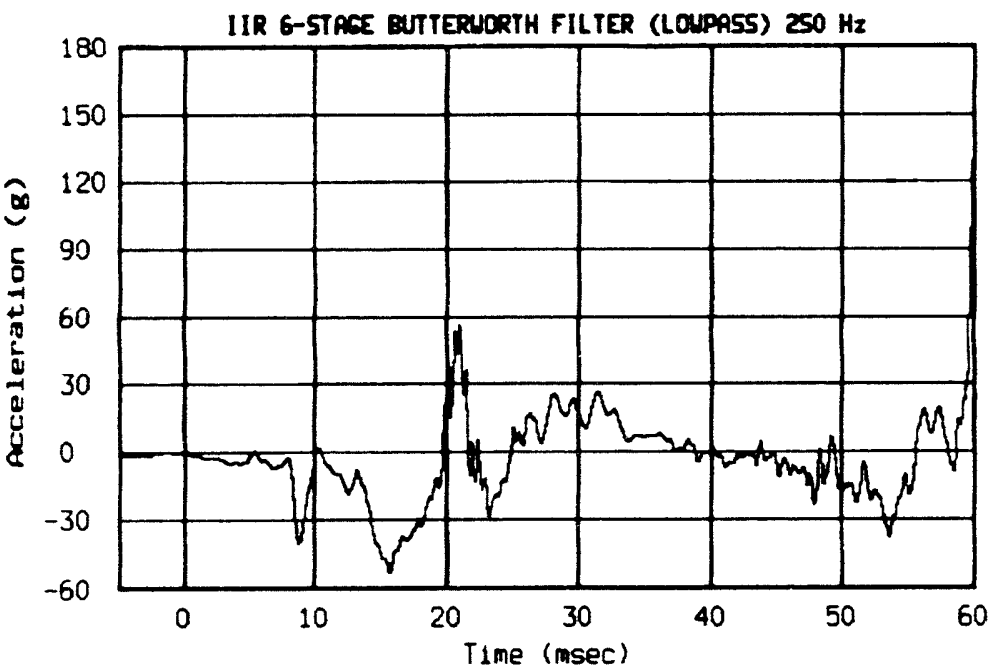

Test: hoRIZONTRL LOU VeloclTY H1224A 06/30/93 (220) Session: Tue Jul 27 08:40:04 1993 Transcucer: A14 (secondary)

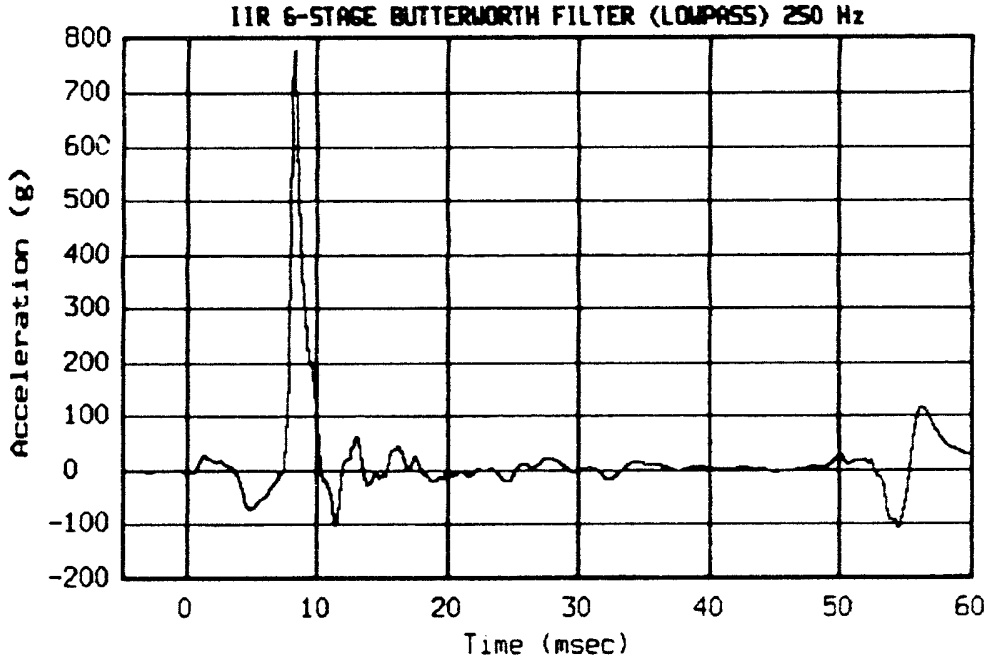

Test: HDRIZONTA LOU VELOCITY H12249 06/30/93 (220) Sescion: Tue Jul 27 08:40:11 1993 Transducer: A15 (secondary)

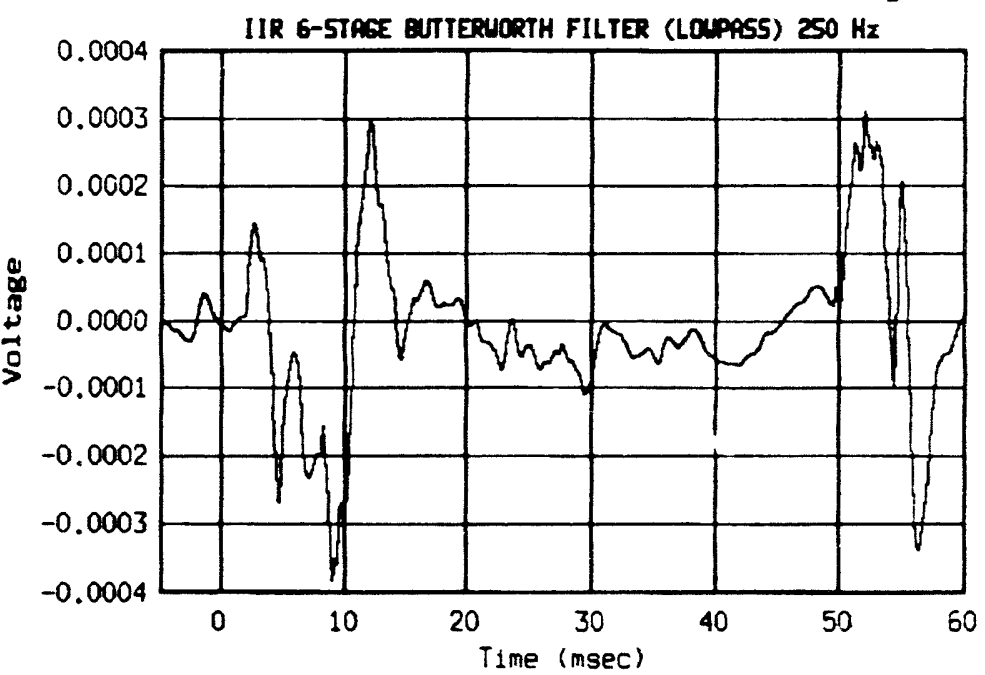


Test: HORIZONTR LOW VELOCITY H1224A 06/30/93 (220) Session: Tue Jul 27 08:40:38 1993 Trensotucer: 561 (sedondary)

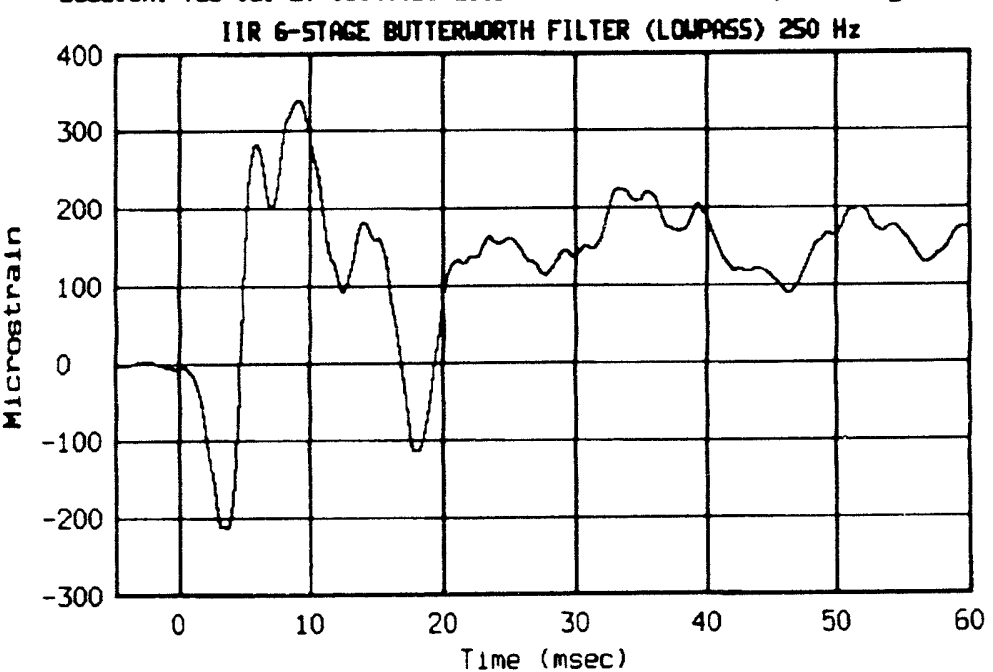

$\bar{\Xi}$

Test: HORIZONTR LOW VELCCITY H1234A 06/30/93 (220) Session: iue Jul 27 08:40:42 1993 Trensducer: 562 (secondary)

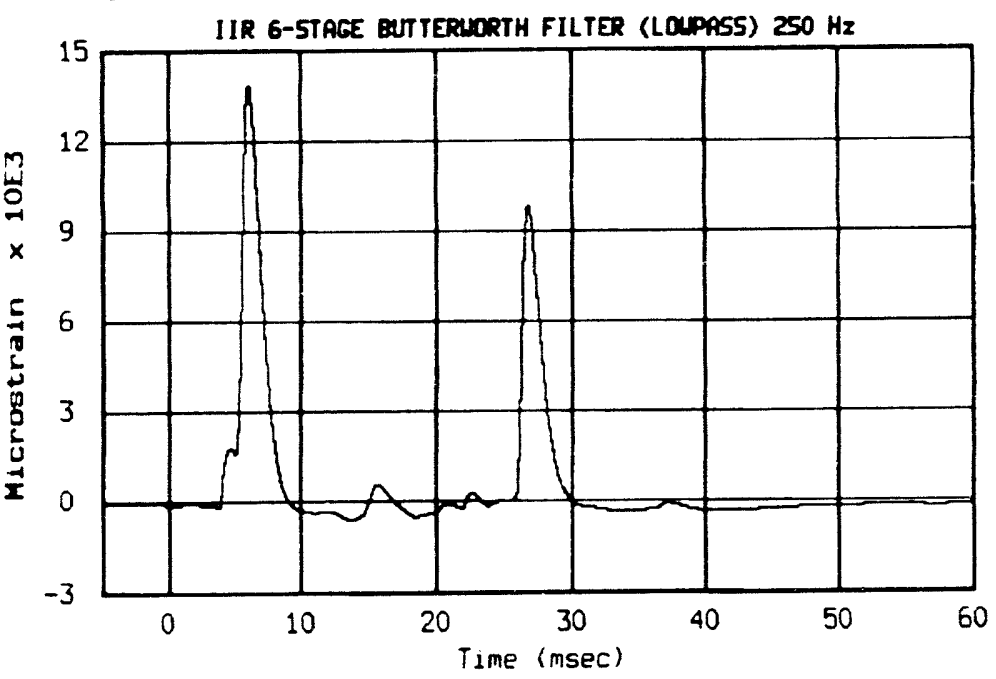

Iest: MORIZOMTR LOU VEOCITY H1224A 06/30/93 (220) Session: Tue Jul 27 08:40:51 1993 Transducer: S63 (secondary)

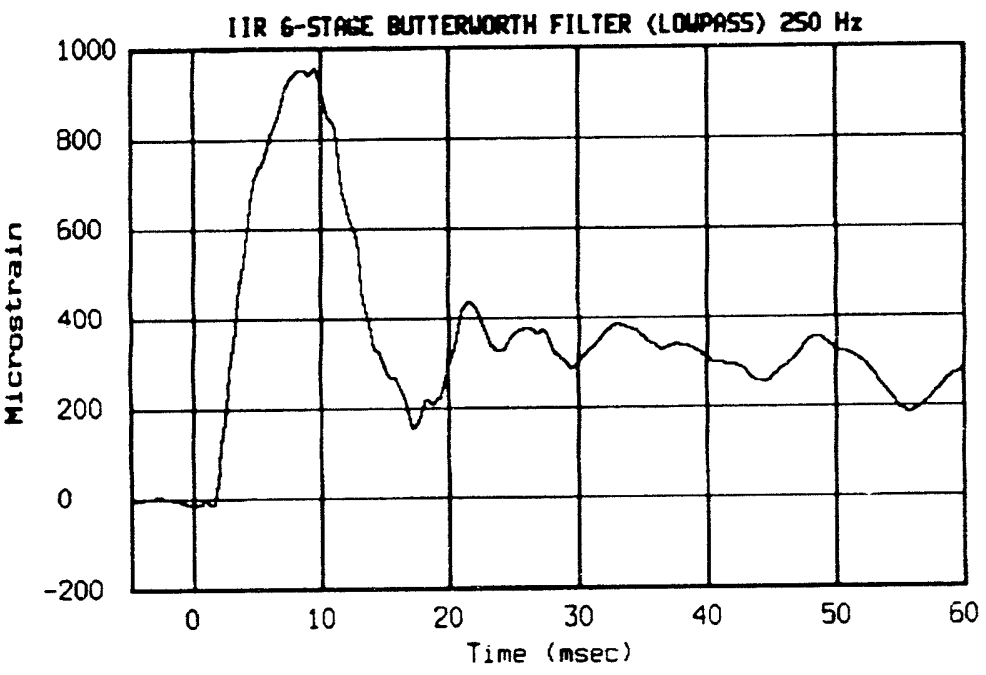

Test: hoRIzONTR. LOU VelocITY H12244 06/30/93 (220) Session: Tue Jul 27 08:41:00 1993 Transducer: S64 (secondary)

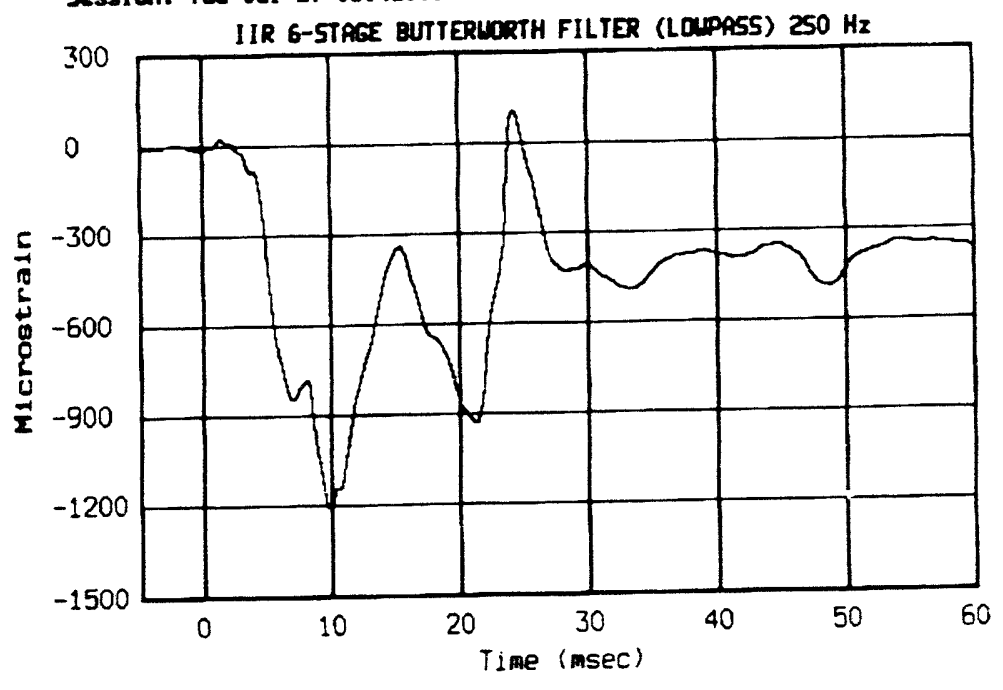



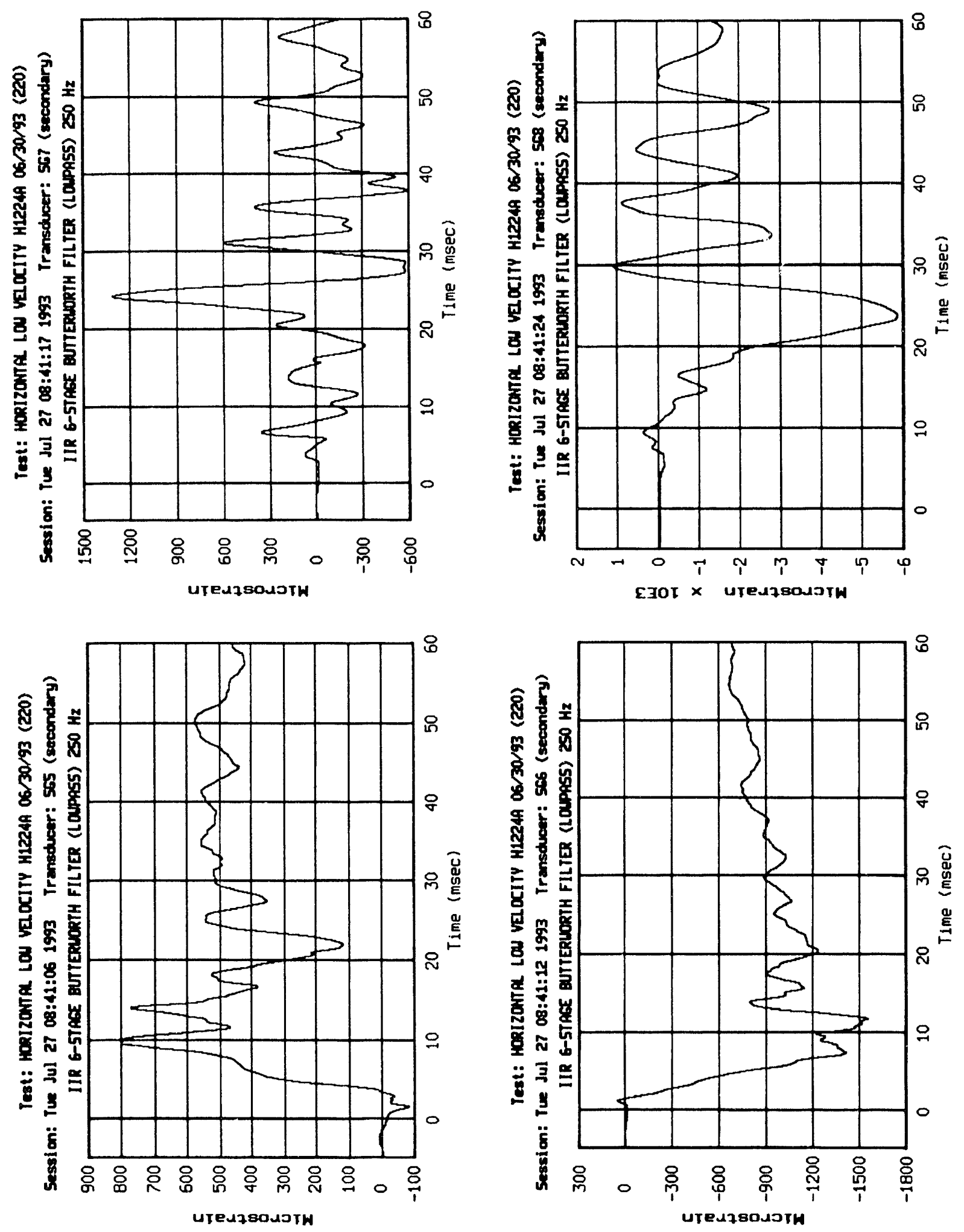
Test: HORIZONTAL LOU VELOCITY H1224A $06 / 30 / 93$ (220) Session: Tue Jul 27 08:41:33 1993 Trunscucer: 569 (secondury)

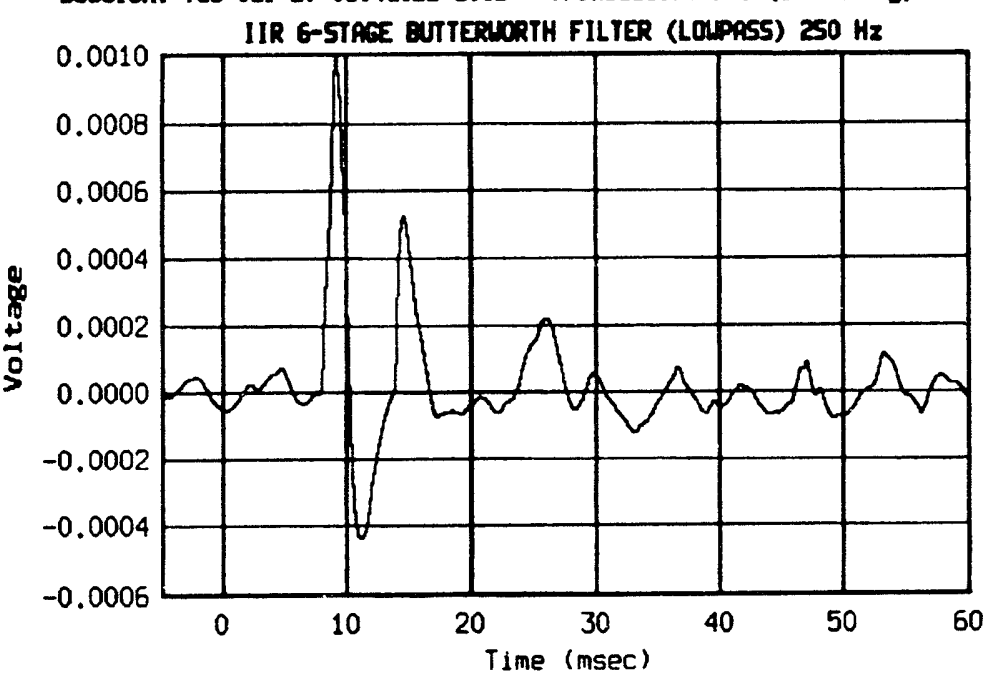

Test: HORIZONTR LOU VeZOCITY H1224A 06/30/93 (220) Session: Tue Jul 27 08:41:42 1993 Transucer: 5610 (secondary)

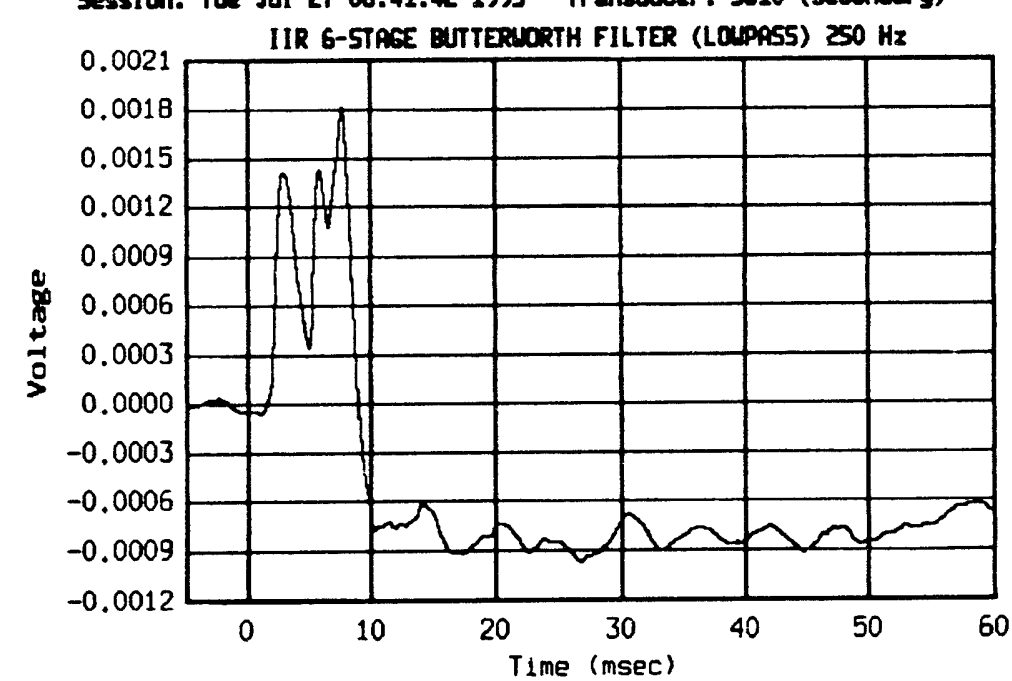

Test: MORIzONAL LOU VZ10CITY H1224A 06/30/93 (220) Session: Mon Jul zs 16:21:22 1993 Trmeducer: A1 (seoondary) IIR 6-STAEE BUTTERUORTH FILTER (LOLPSS) 2000 Hz

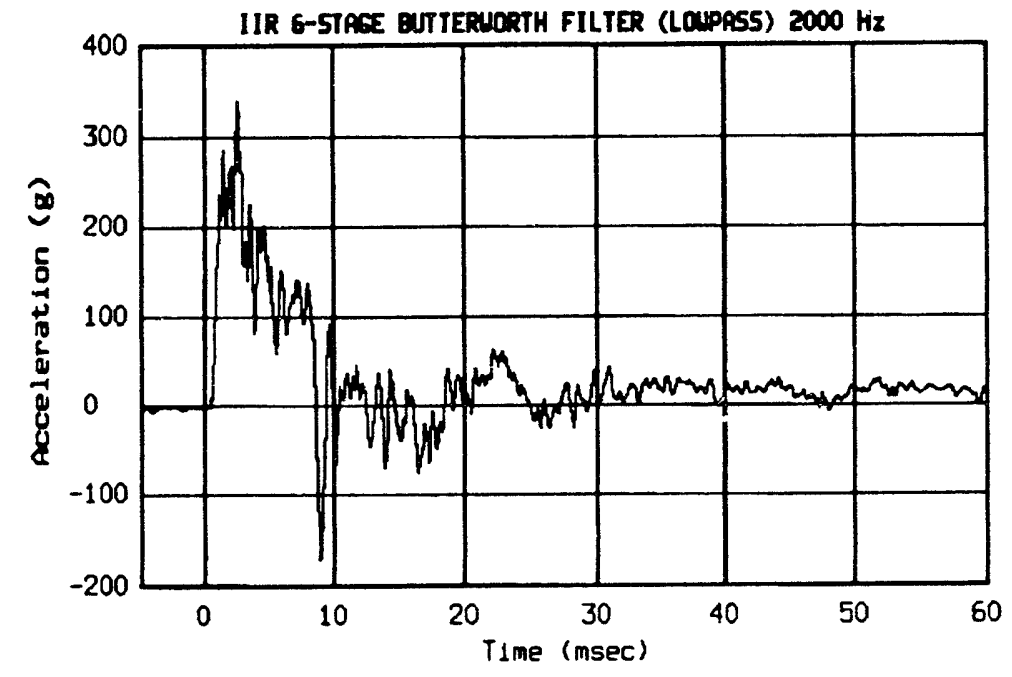

Test: HORIzONTR LON VEOCITY H1224月 06/30/93 (220) Session: Mon dul 26 16:21:02 1993 Trmsducer: PR (secondary) IIR 6-5TREE DUTTERLORTH FILTER (LOPPASS) $2000 \mathrm{~Hz}$

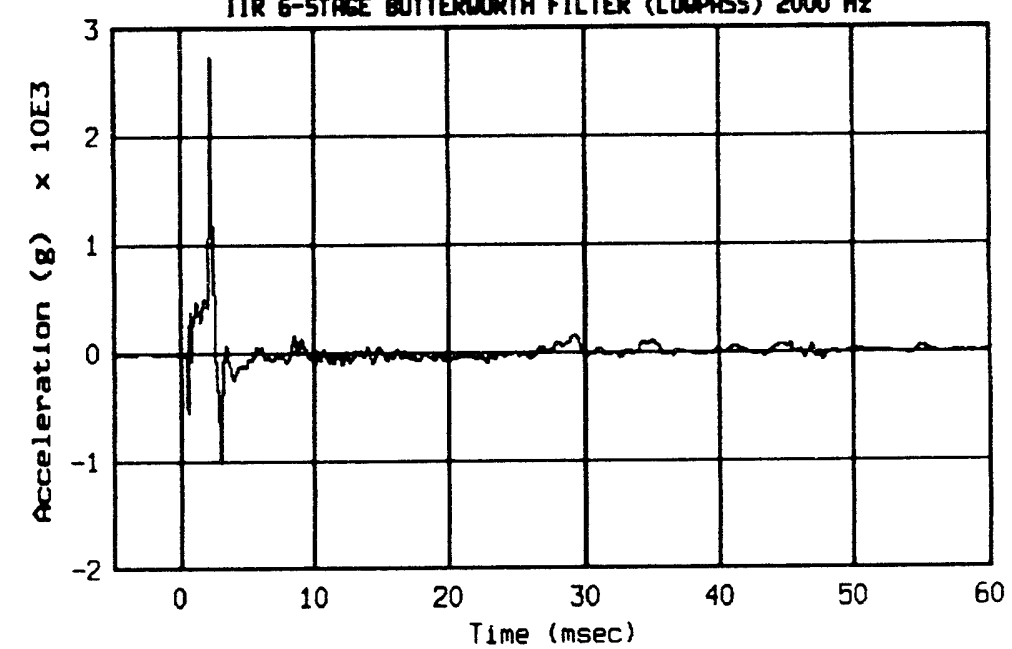


Test: HoRIzOMTA LOU velocitY H1224A 06/30/93 (220)

Session: Mon Jul 26 16:21:28 1993 Transducer: $R 3$ (secondary) IIR 6-5TAOE EUTTERUORTH FILTER (LOPPASS) $2000 \mathrm{~Hz}$

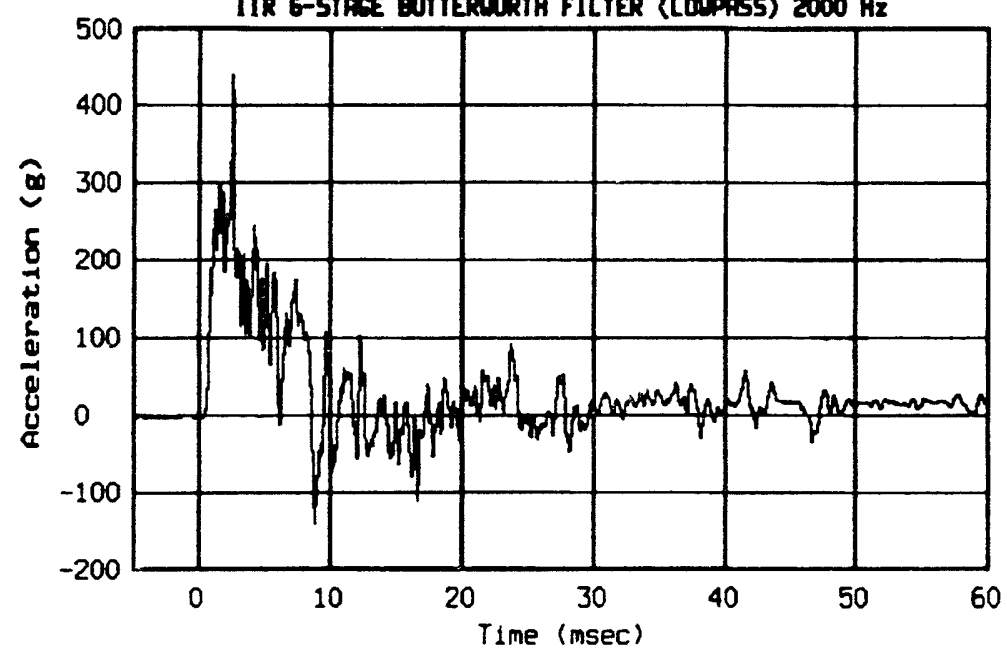

$\widetilde{\omega}$

Test: HORIZONTA LOW VAOCITY H1224A 06/30/93 (220) Session: Mon Jul 26 16:19:50 1993 Transducer: A4 (secondary) IIR 6-5TAGE BUTTERLORTH FILTER (LOUPASS) $2000 \mathrm{~Hz}$

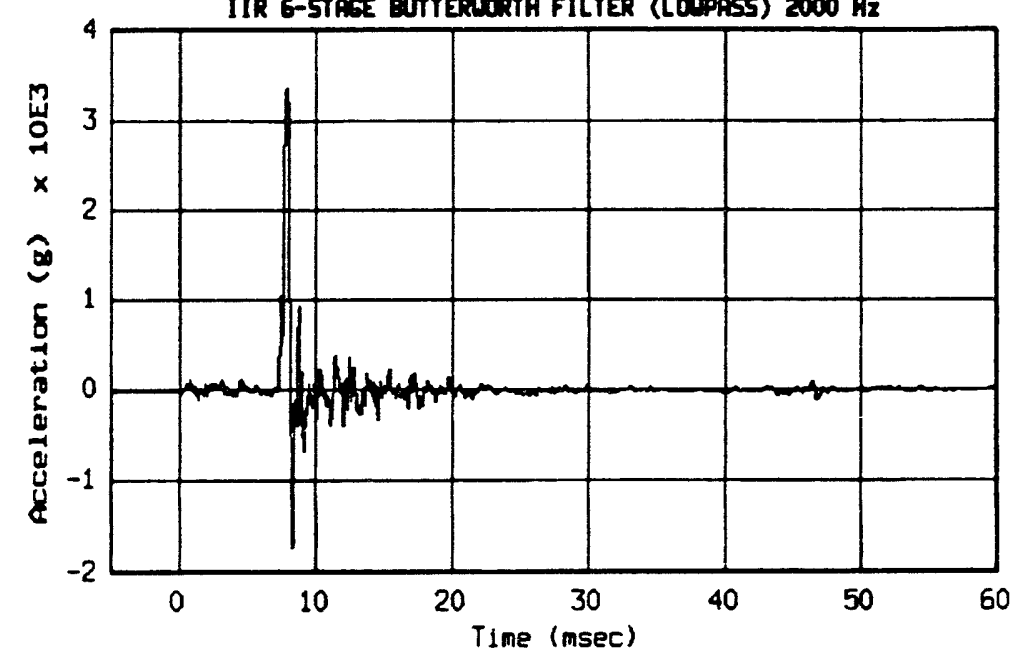

Test: HORIZONRL LOW VELOCITY H12349 $06 / 30 / 93$ (220) Session: Mon Jul 26 16:19:56 1993 Transducer: A5 (secondary) IIR 6-TTPEE EUTTERLDRTH FILTER (LOPASS) $2000 \mathrm{~Hz}$

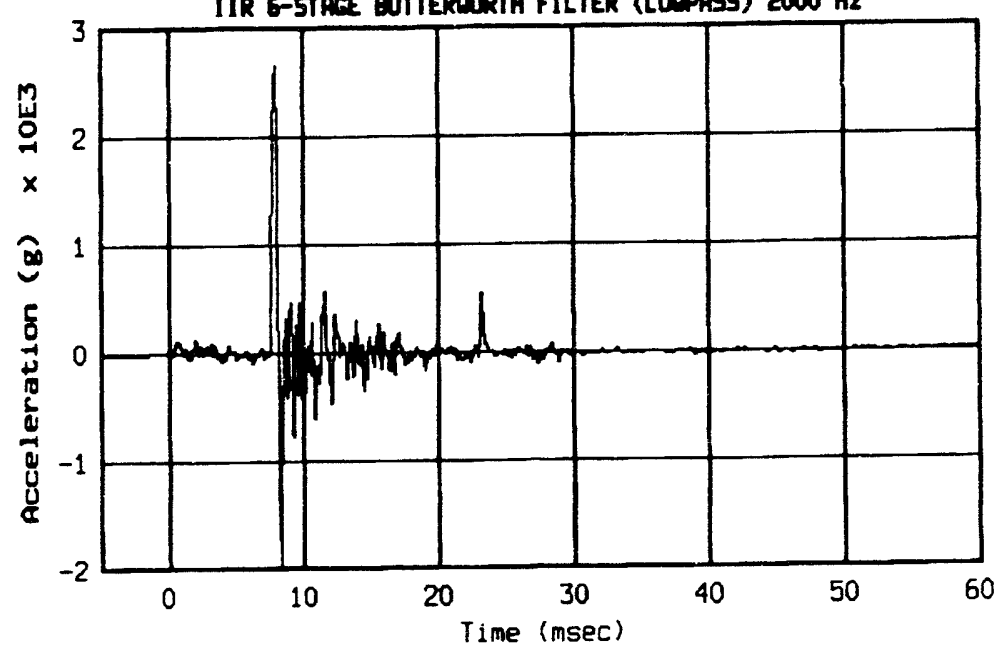

Test: hoRIZOMA LOU VelOCITY H1224A 06/30/93 (220) Session: Hon Jul 26 16:19:53 1993 Traneducer: A6 (secondary) IIR 6-STACE EUTTERUORTH FILTER (LOPASS) $2000 \mathrm{~Hz}$

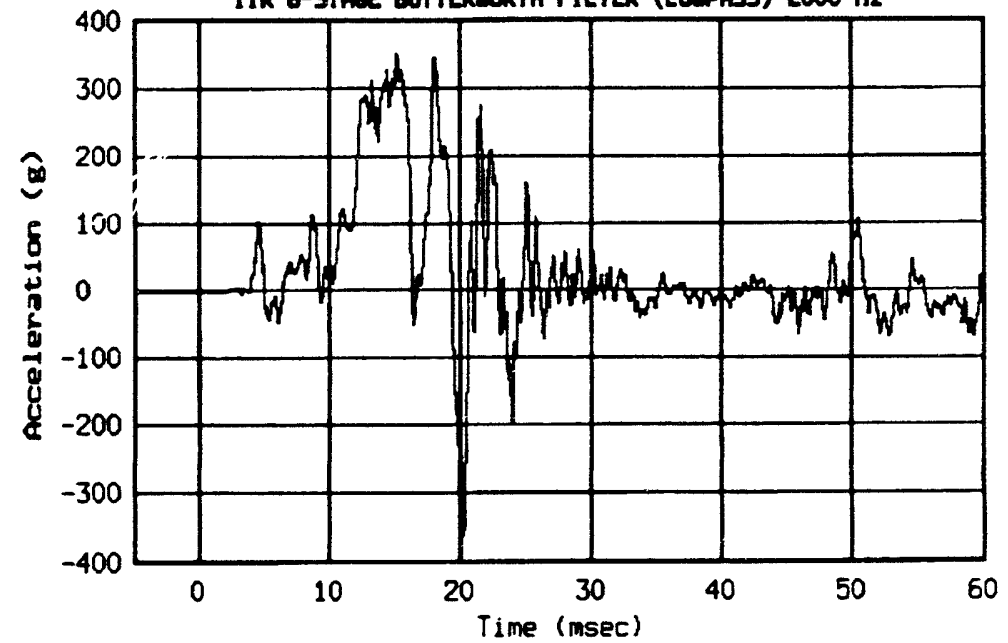




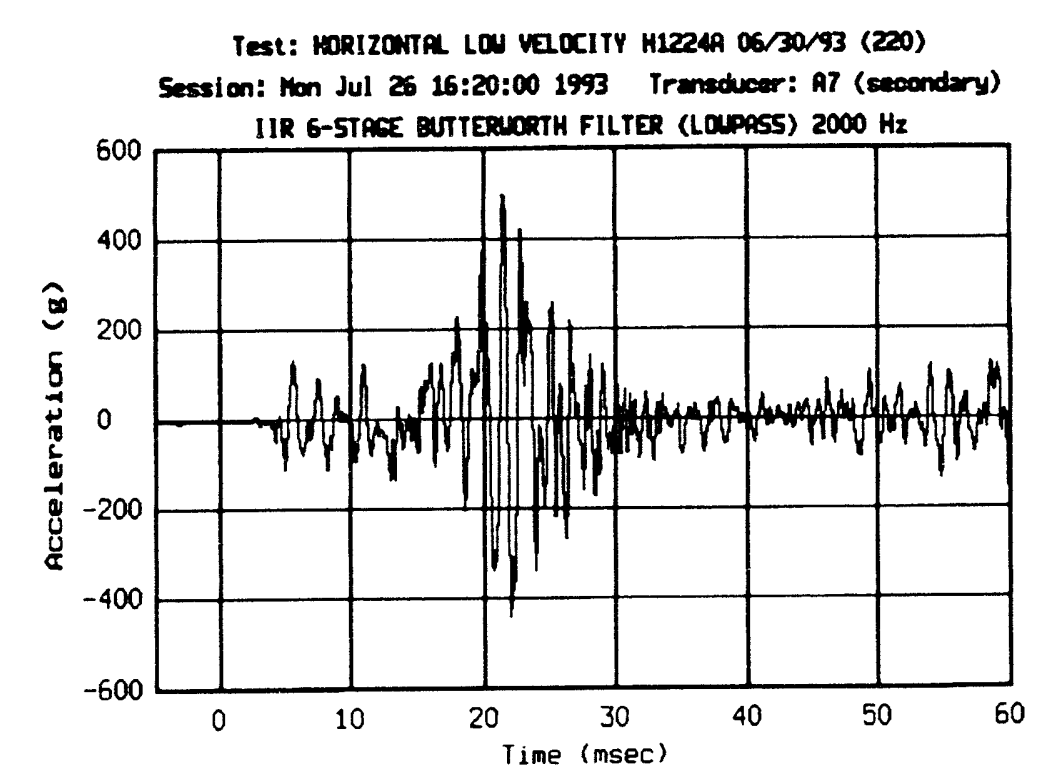

$\bar{n}$

Teat: HORIZONTPL LOW VELOCITY H12224A O6/30/93 (220) Session: Mon Jul Z6 16:20:11 1993 Transiducer: R8 (secondary)

IIR 6-STAGE BUTIERAORTH FILTER (LOAPASS) $2000 \mathrm{~Hz}$

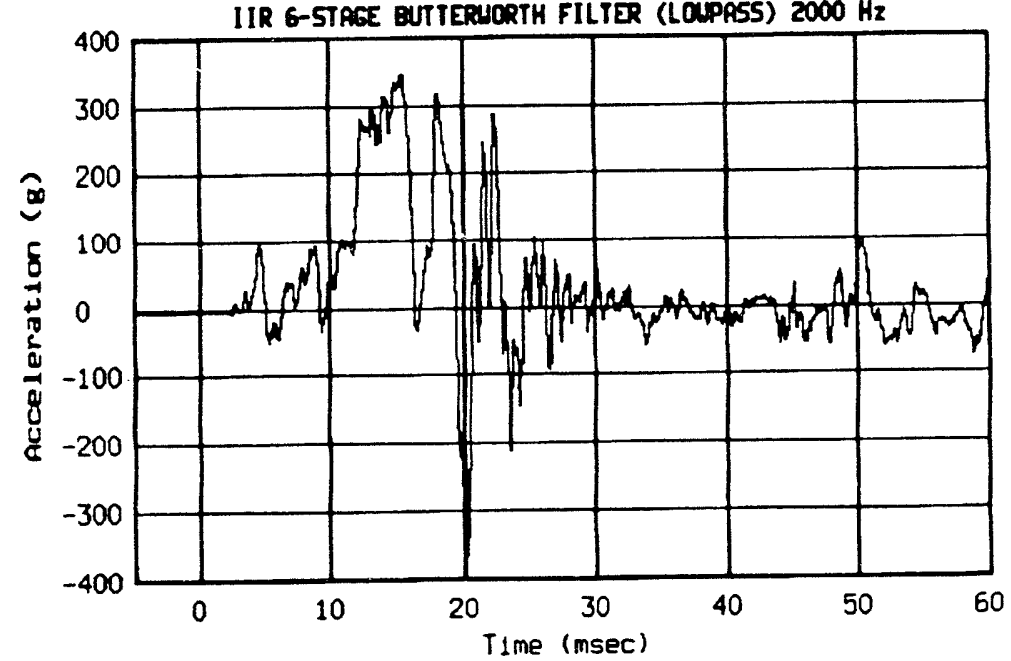

Test: HORIZONAL LOU VEOCITY H1224A 06/30/93 (220)

Session: Mon Jul 26 16:20:06 1993 Trmsducer: A9 (secondary) IIR 6-5TACE BUTERIORTH FILTER (LOAPASS) $2000 \mathrm{~Hz}$

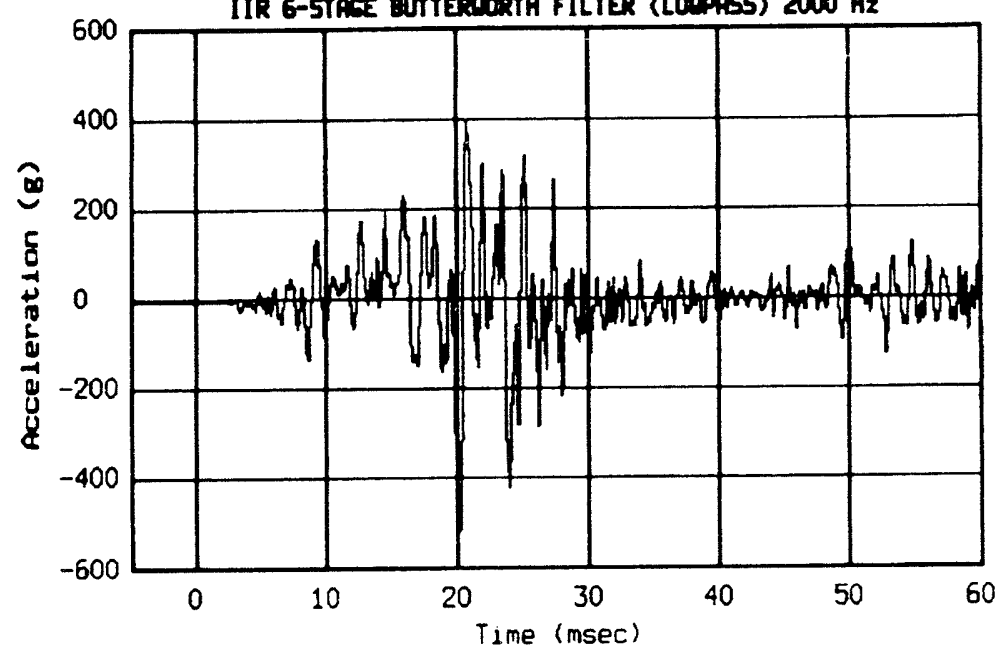

Test: HORIZONTA LOU VEOCITY H1224A O6/30/93 (220) Session: Hon Jul 26 16:20:18 1993 Transoduder: A10 (secondary) IIR 6-STAGE QUTTERLORTH FILTER (LOPAS5) $2000 \mathrm{~Hz}$

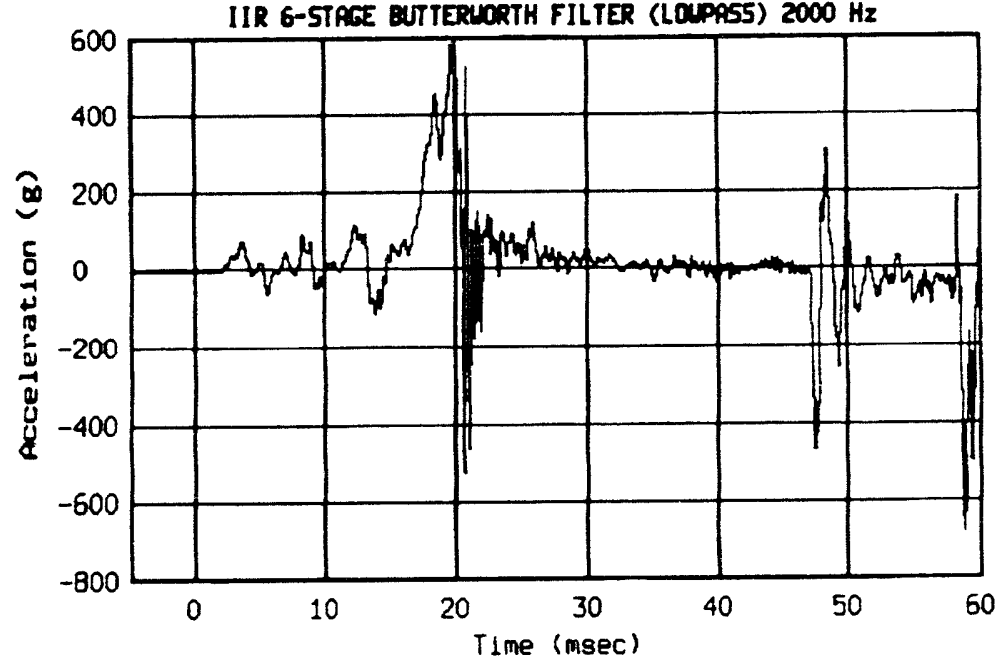


Test: HORIZONTAL LOU VIXCITY H1224A 06/30/93 (220) Session: Mon Jul 26 16:20:25 1993 Transctwoer: A11 (secondary)

IIR 6-5TREE BUTIERIORTH FILTER (LOUPASS) $2000 \mathrm{~Hz}$

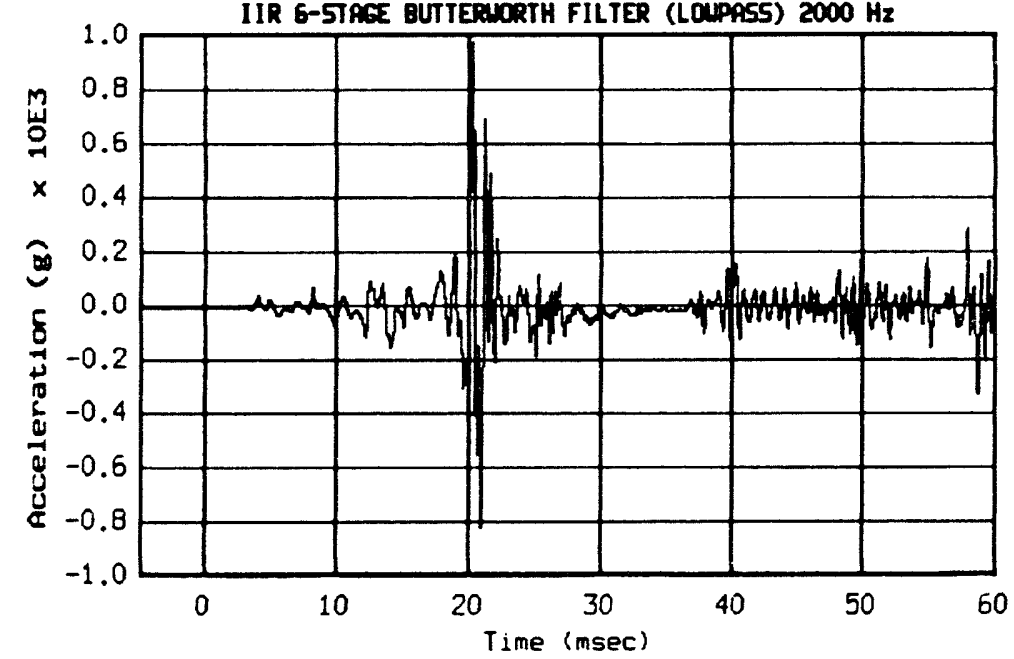

$\bar{\sim}$

Test: HORIZONTR Lou Valocity H1224A 06/30/93 (220) Session: Mon Jul 26 16:20:46 1993 Transtucer: A12 (secondury)

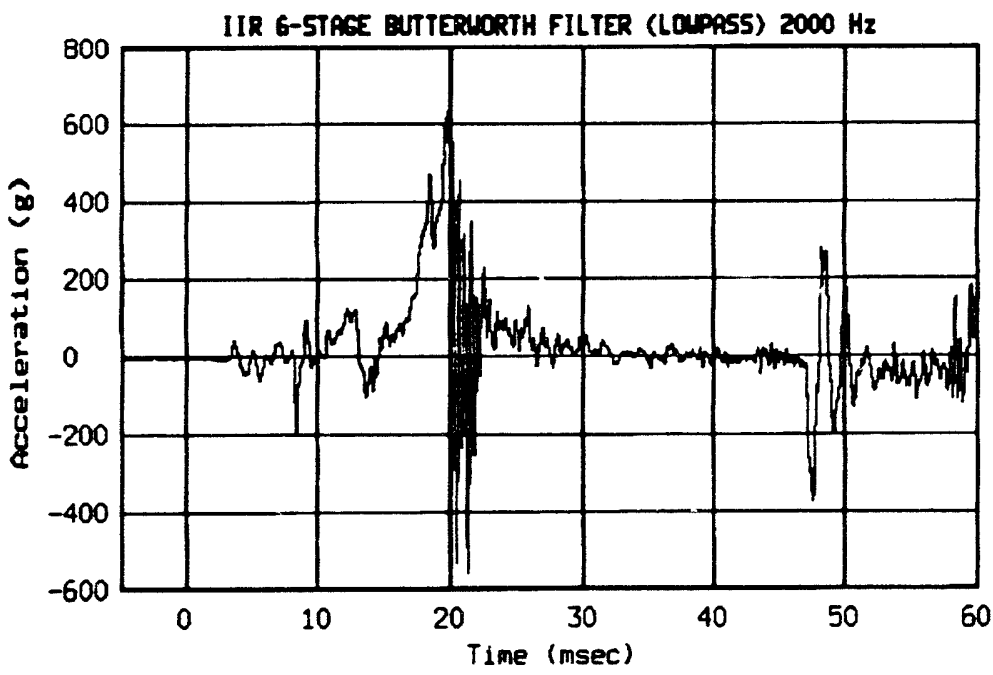

Test: HORIZONAL LOW ValocITY H12249 06/30/93 (220) Session: Mon Jul 26 16:20:34 1993 Trmestucer: A13 (secondary) IIR 6-STREE BUTERUDRTH FILTER (LOUPASS) $2000 \mathrm{~Hz}$

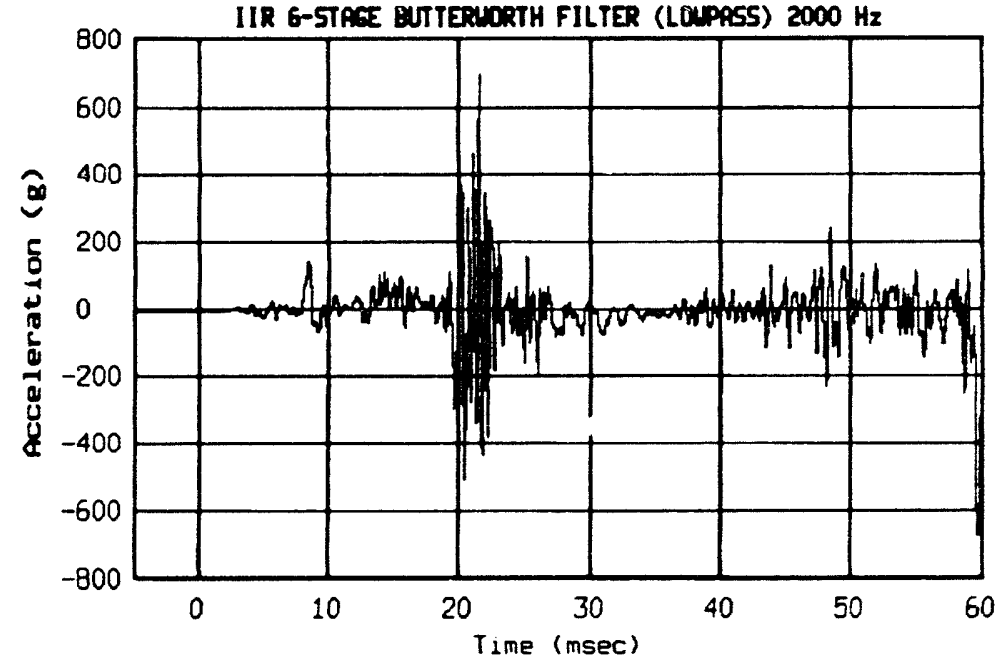

Test: HoRIzONTR LW VEOCITY H1224A 06/30/93 (220) Session: Mon Jul Z6 16:20:51 1993 Transoducer: A14 (secondary)

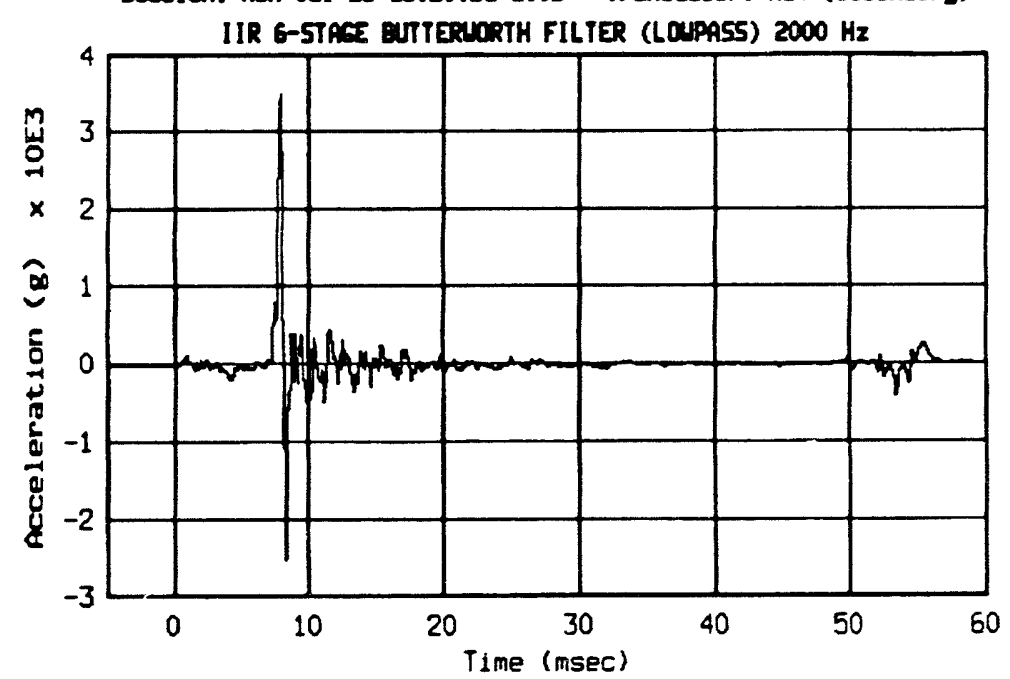



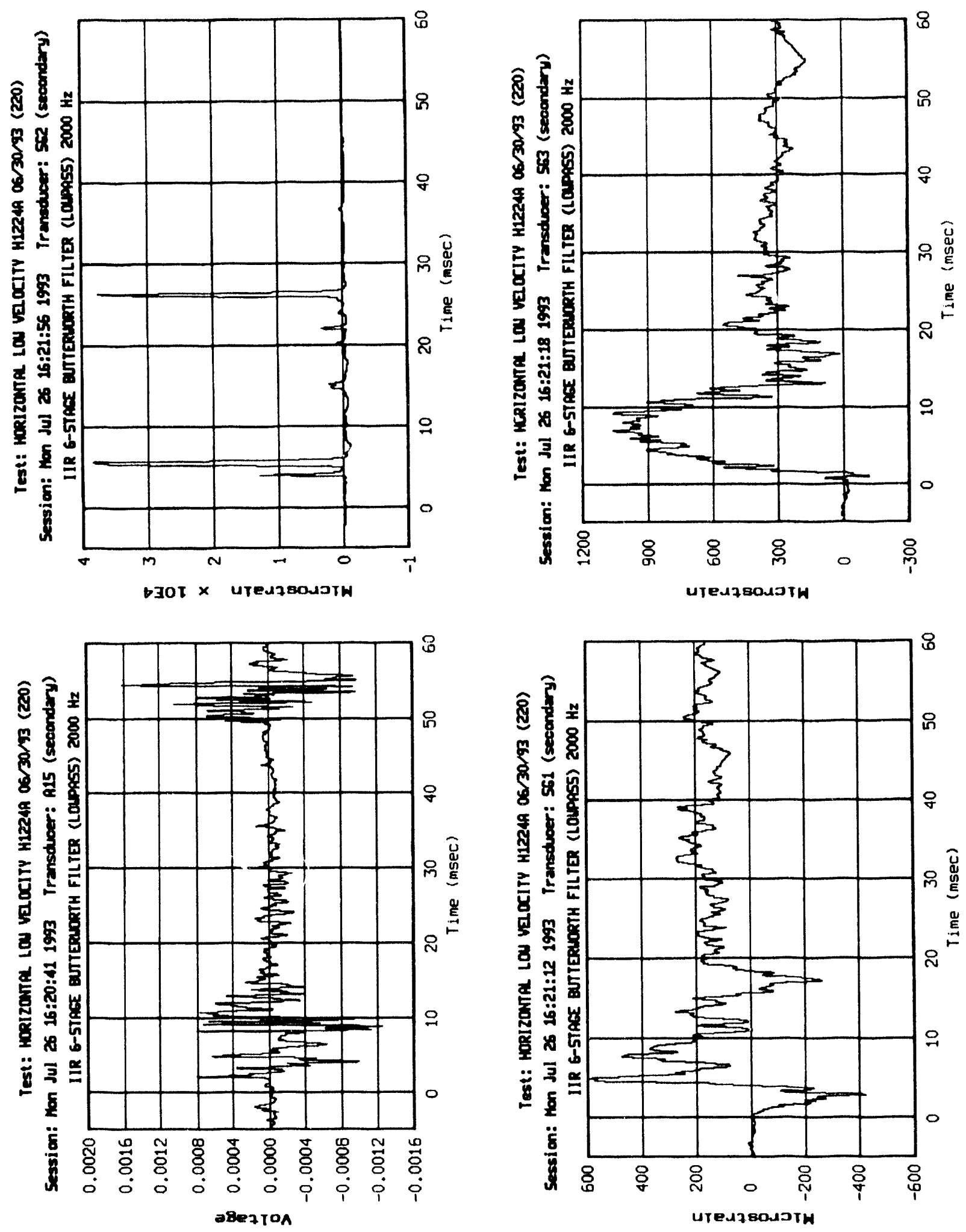

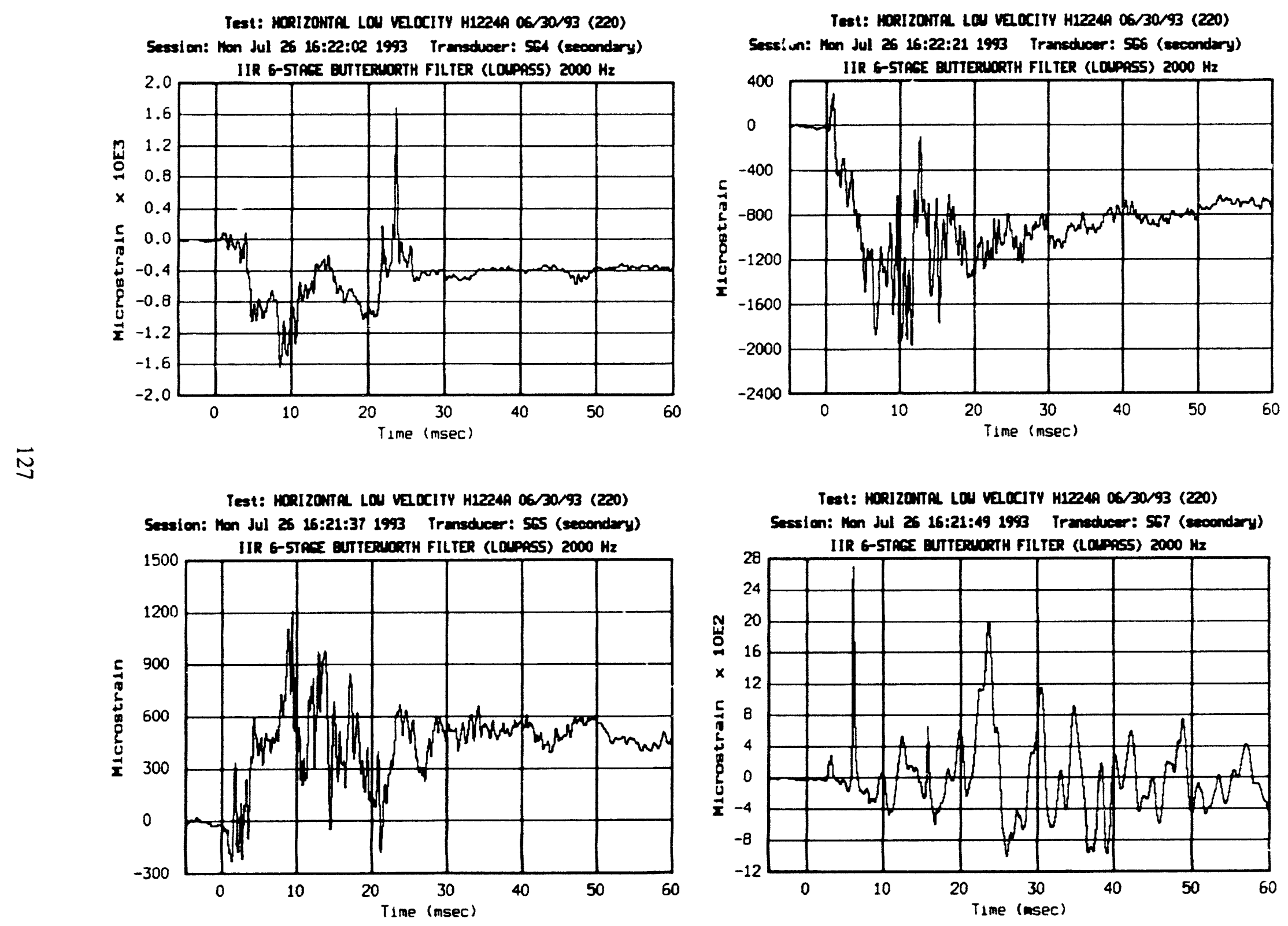

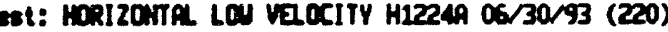

Teat: MRRIZONTAL LOW VEOCITY H1234A 06/30/93 (220) Session: Mon Jul 26 16:21:49 1993 Traneducer: 567 (ecoondary)

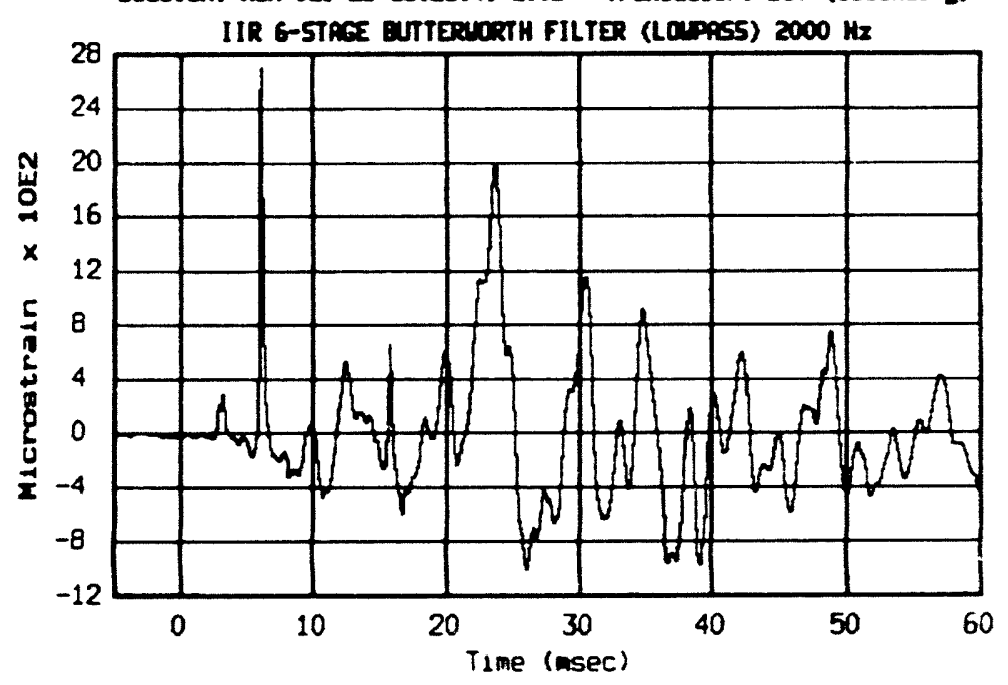


Test: horizonth LOU velocity H1224A 06/30/93 (220) Session: Mon Jul 26 16:22:28 1993 Transducer: SA8 (secondary) IIR 6-STREE EUTTERUORTH FILTER (LOPPSS) $2000 \mathrm{~Hz}$

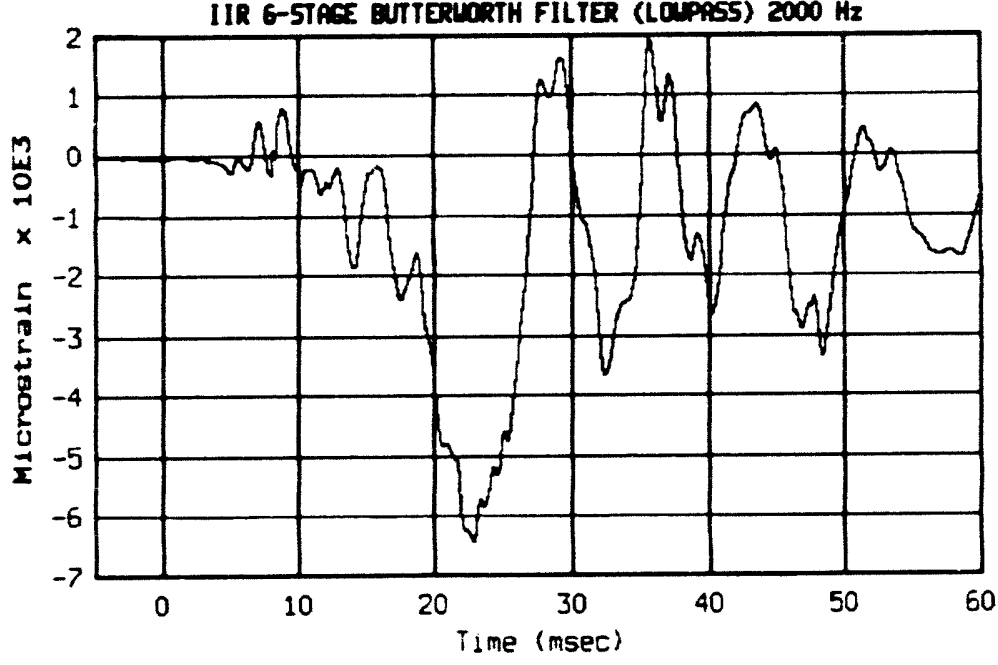

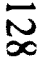

Test: Morizonth LW vecity H12249 06/30/93 (220) Session: Mon bul 26 16:21:54 1993 Irunstwoer: 569 (secendary)

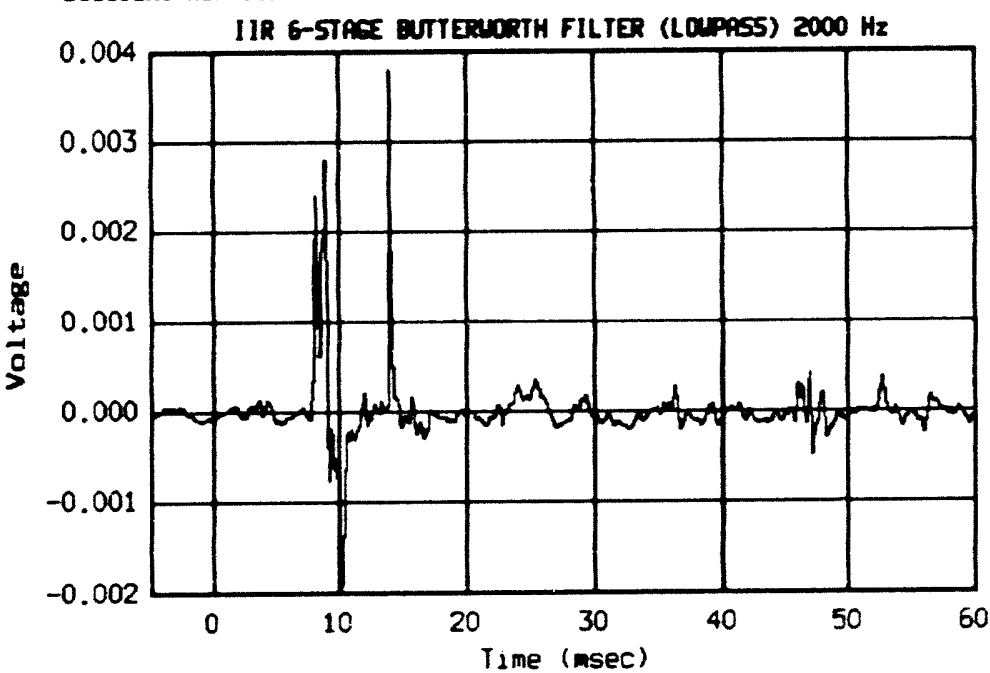

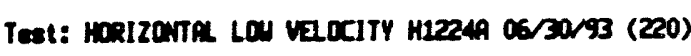
Sescion: Mon Jul 26 16:22:37 1993 Trensucer: 5610 (secondery)

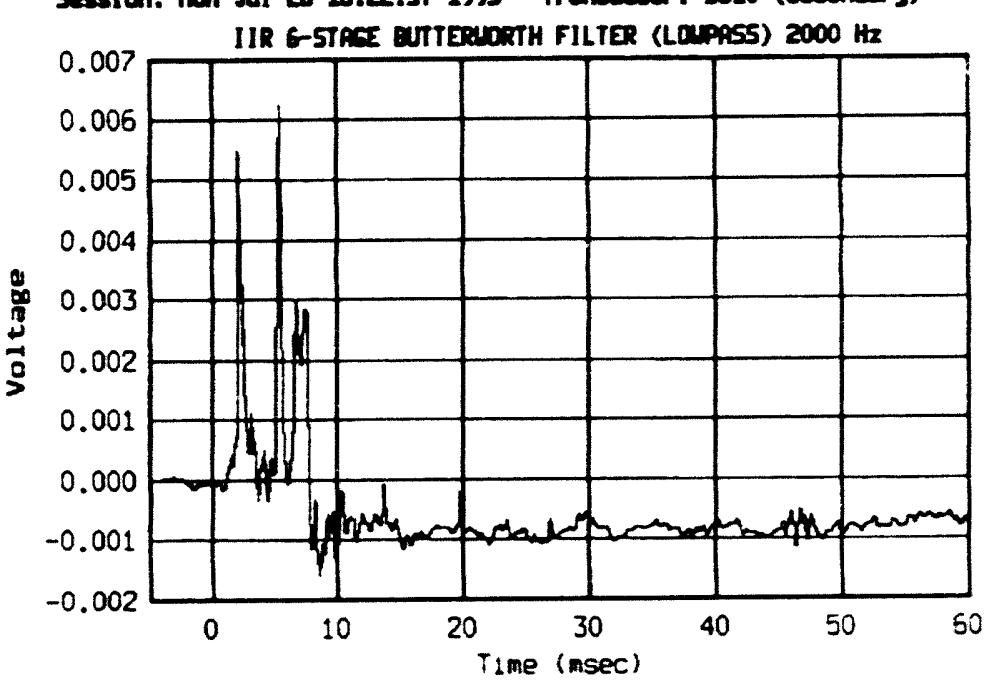

Test: hoRizONAL LOU VaOCITY H12249 06/30/93 (220) Session: Thu Aug 12 10:46:22 1993 Trunstucer: A1 (secondary)

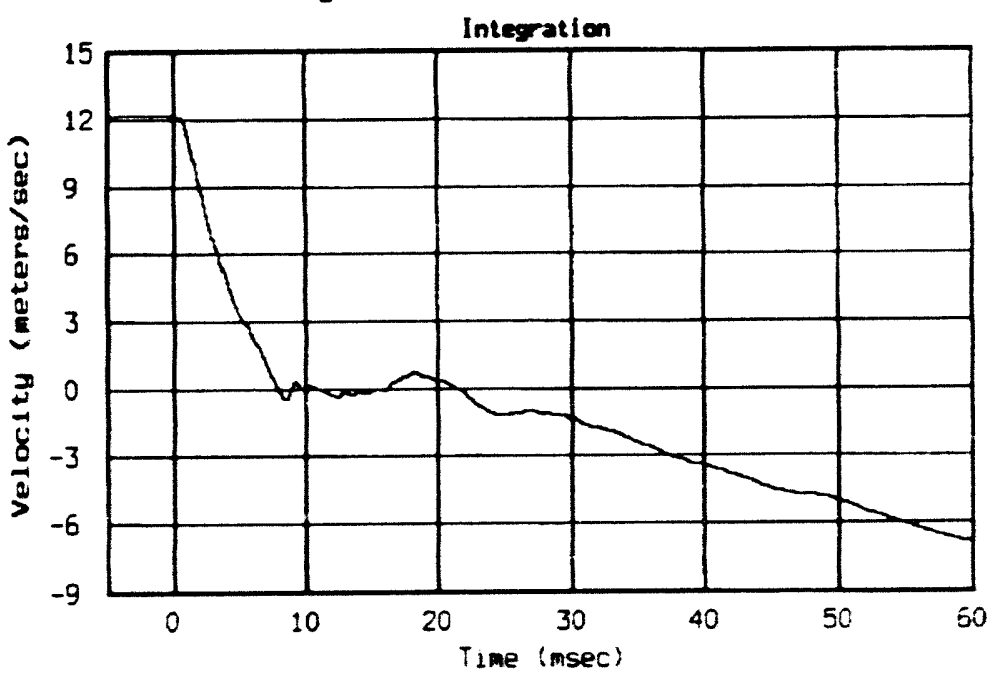


Test: KORIZOMA LOW Velocity H1224A 05/30/93 (220) Session: Thu Aug 12 10:46:35 1993 Transtuoer: R2 (secondry)

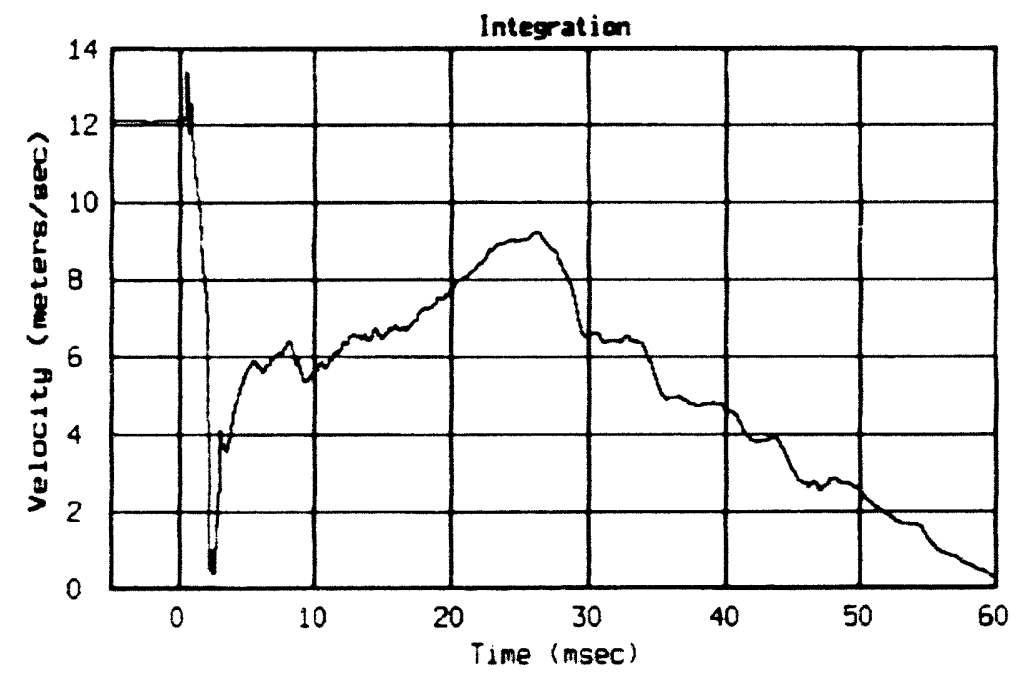

$\bar{N}$

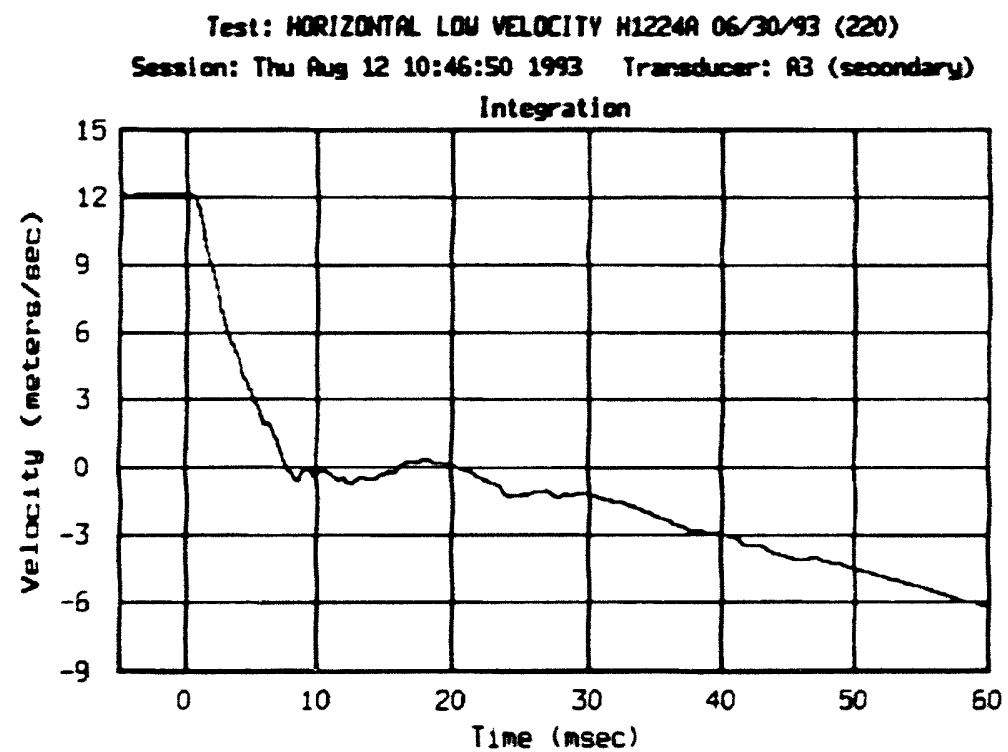

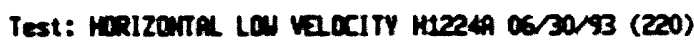
Session: Thu han 12 10:41:33 1993 Transedveer: AN (secondery)

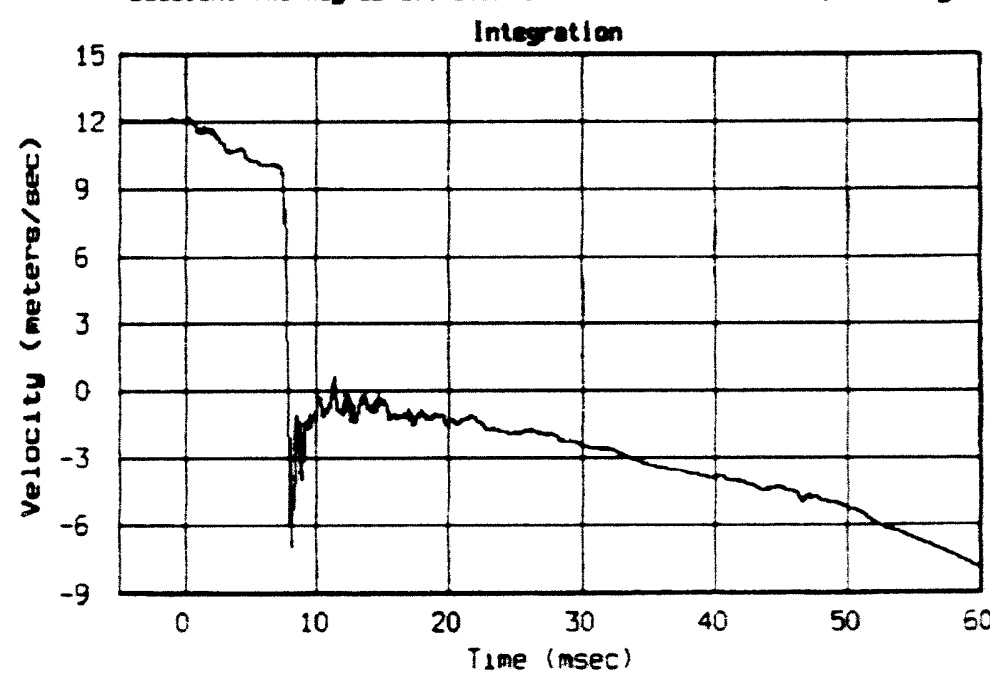

Test: morizonn LW velocity HI224A 06/30/93 (220) Session: Thu Pug 12 10:43:48 1993 Tranedveer: $A 6$ (secondary) Integration

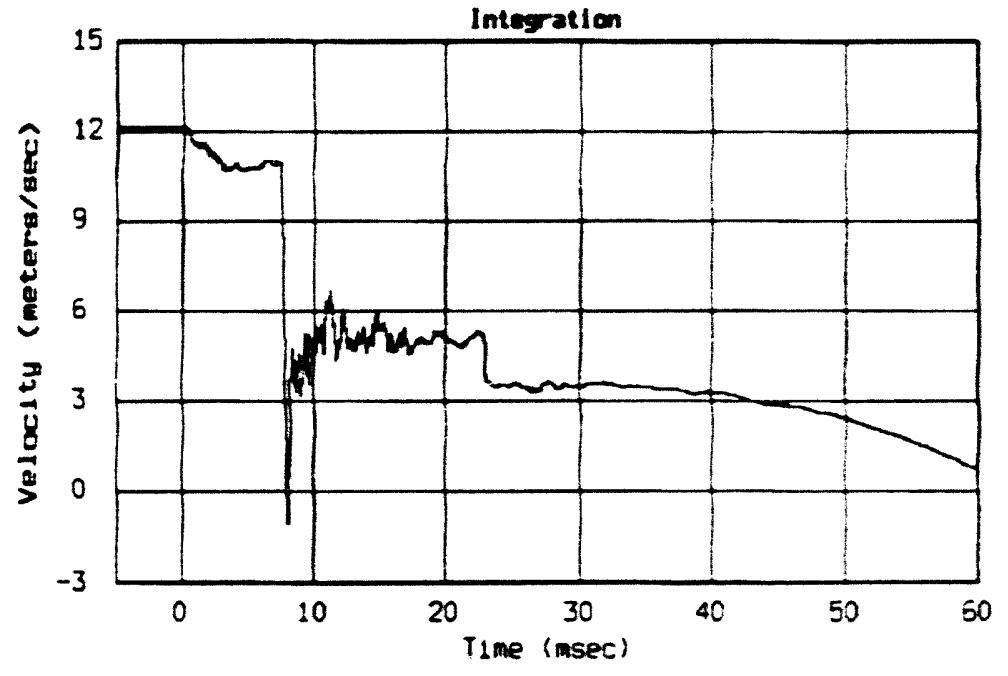



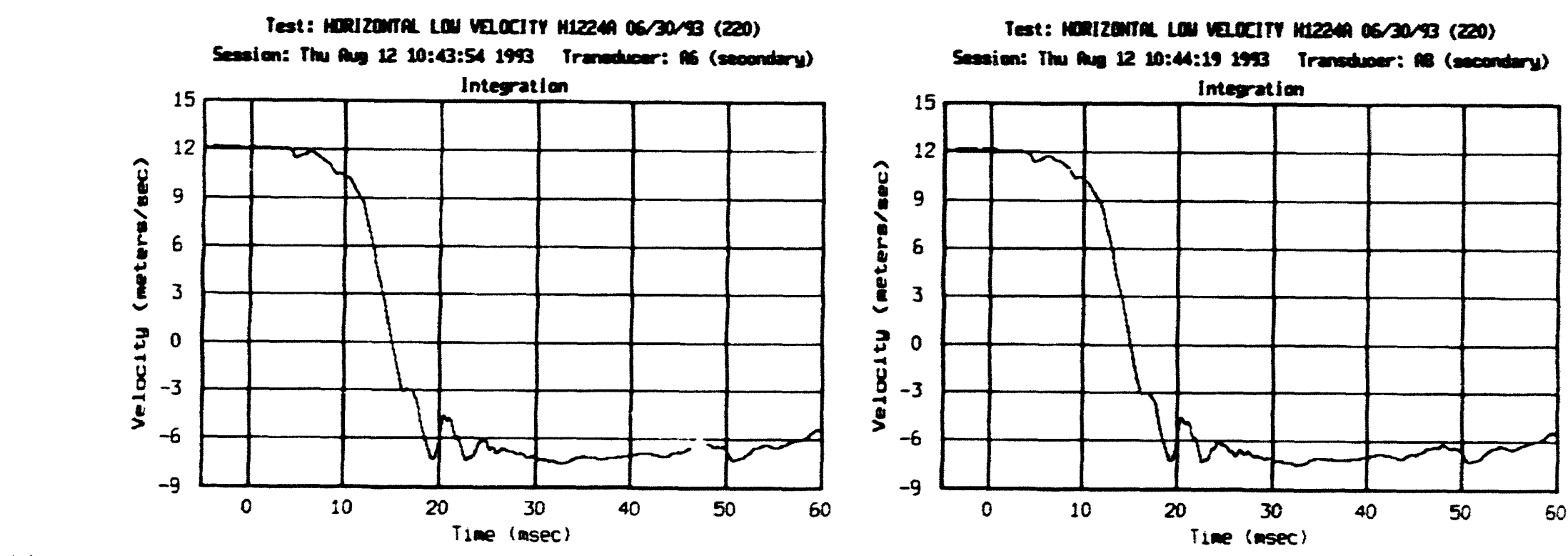

$\breve{\varpi}$

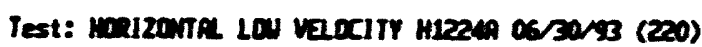

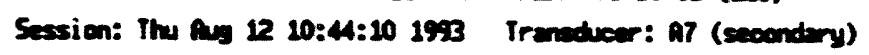

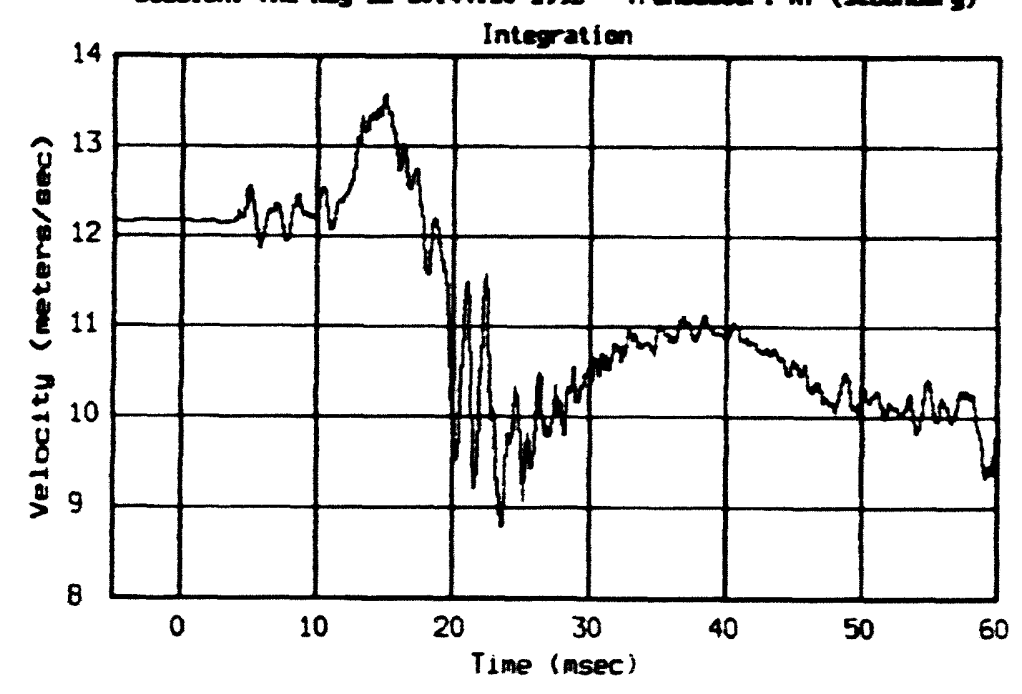

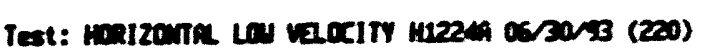

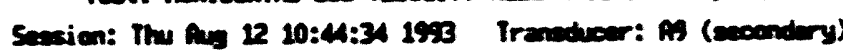

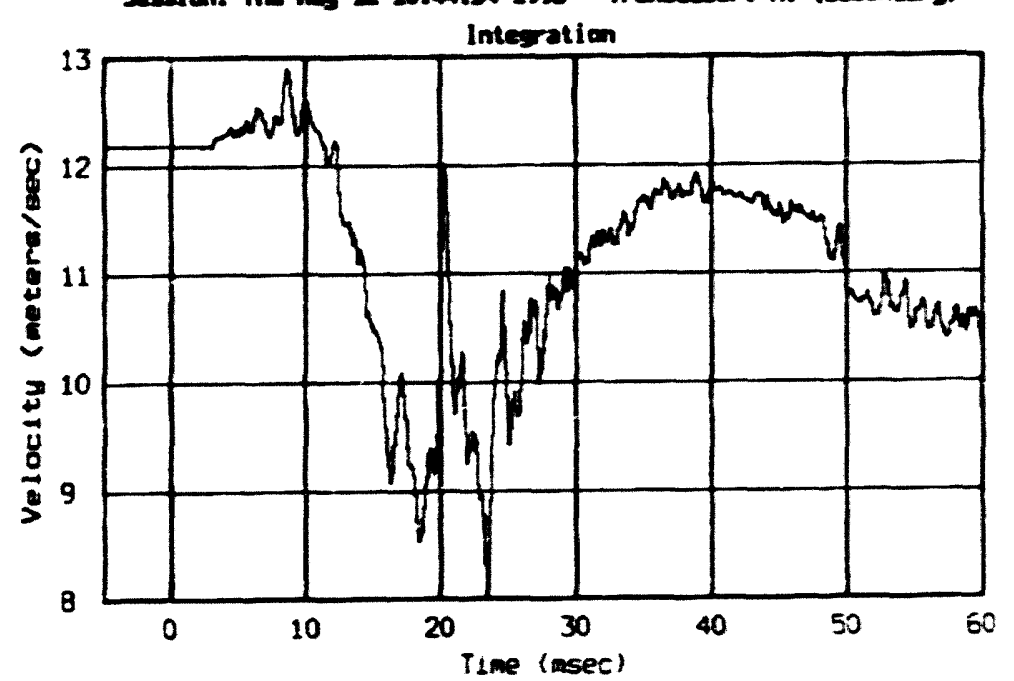



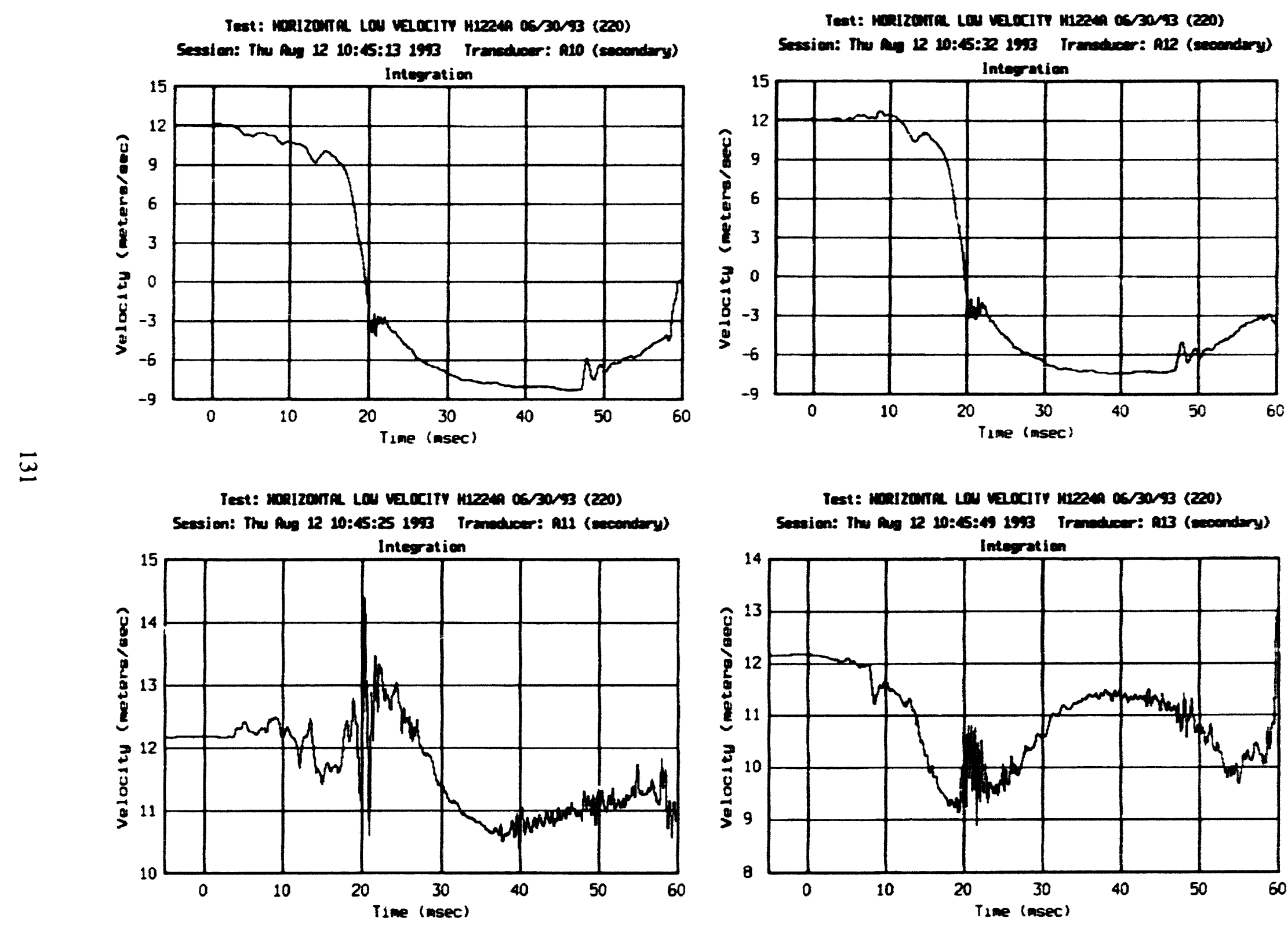

Test: Mazona Lw vacity mezan 06/30/33 (220)

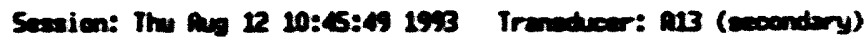

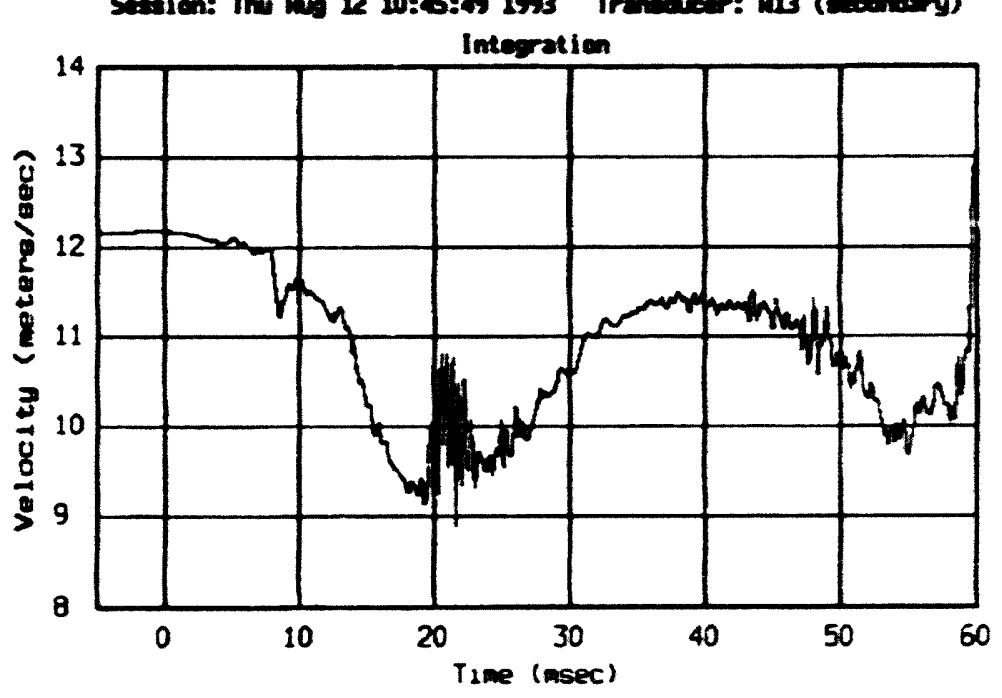




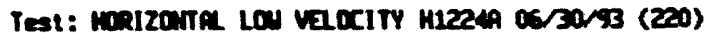
Sescion: Thu his 12 10:46:03 1993 Transwoer: A14 (excondry)

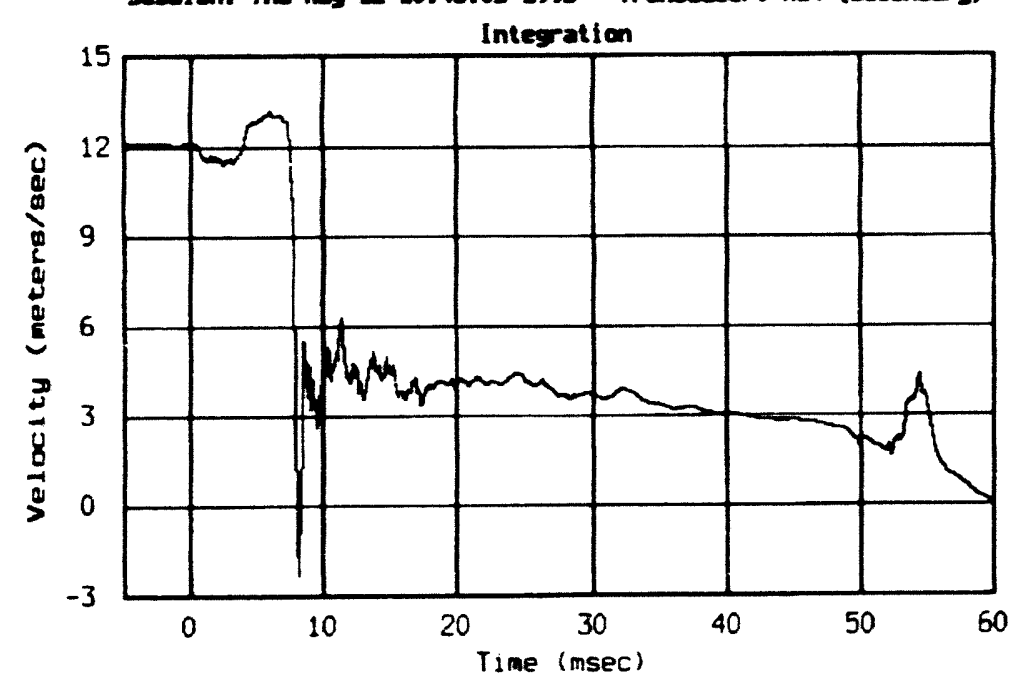

$\ddot{\omega}$ 5easion: Tue Jul 27 08:33:10 1993 Iranstwoer: A1 (secondary)

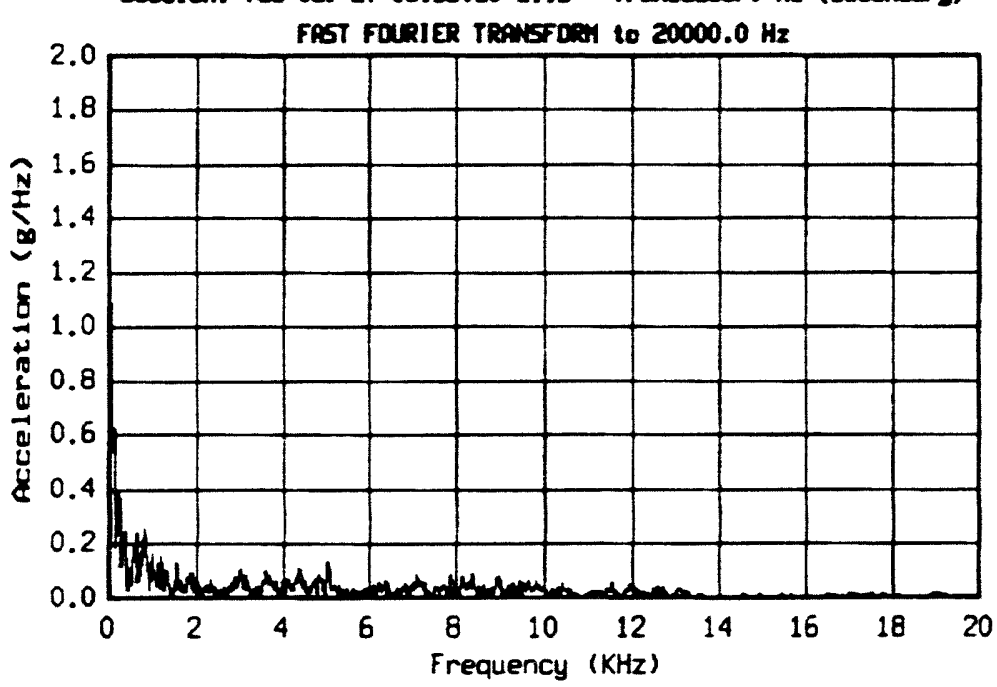

Teat: mazonf Lo vacity mz249 05/30/3 (230)

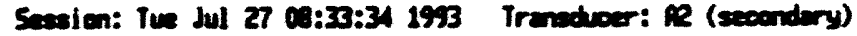

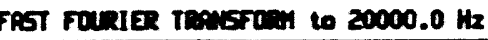

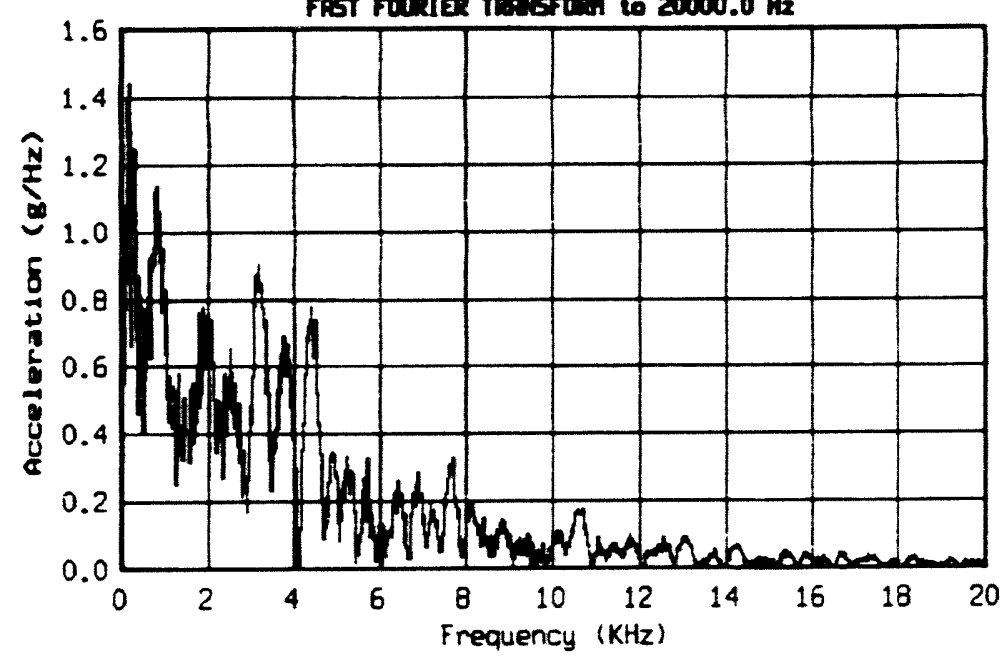

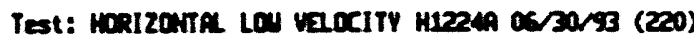
Session: Tue Jul 27 08:33:58 1993 Transducer: RB (secondary) FAST FOURIER TEOUSTOOH to $20000.0 \mathrm{~Hz}$

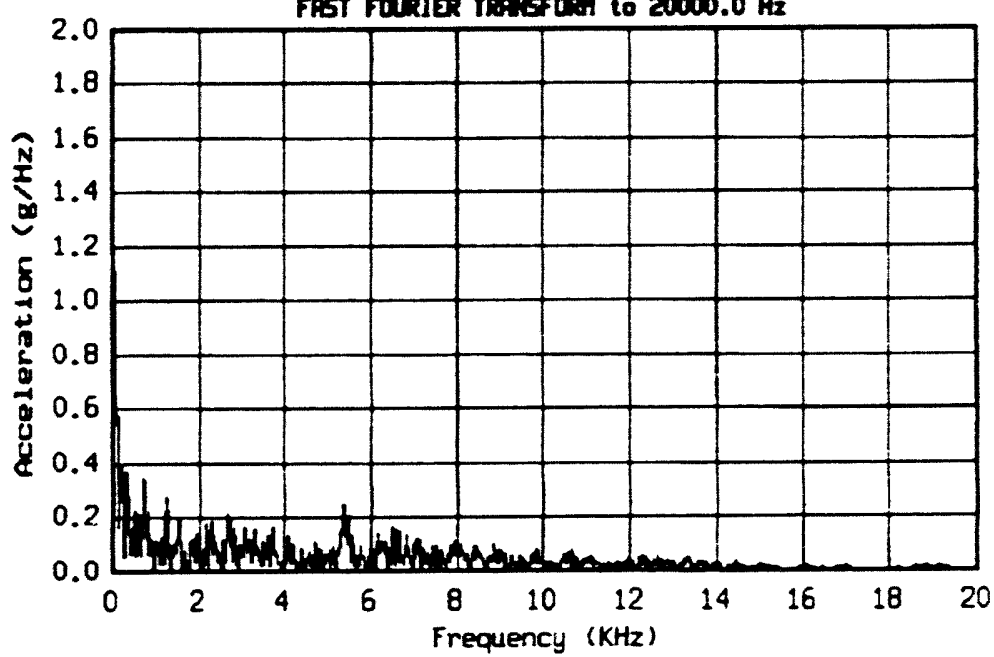



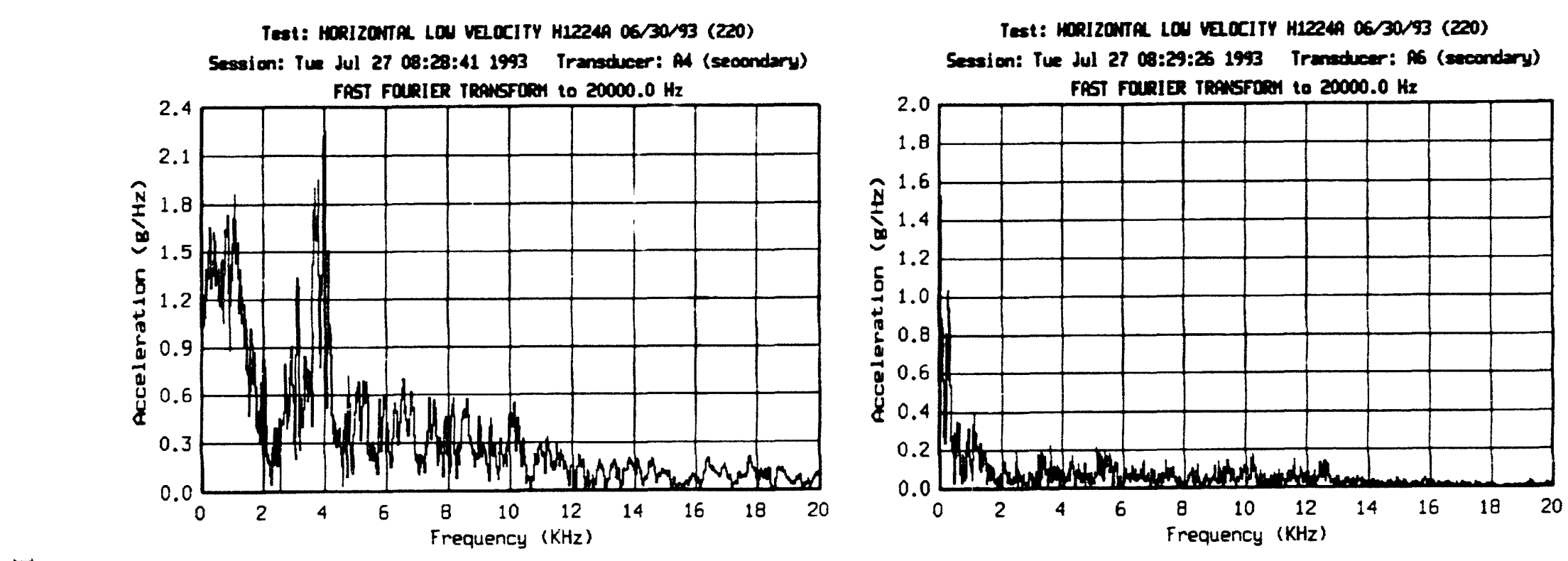

$\bar{w}$

Test: HORILONTA LOU VELOCITY H1224A 06/30/93 (220) Session: Tue Jul 27 08:29:01 1993 Transsucer: AS (secondery) FAST FOURIER TRAHSFORM to $20000.0 \mathrm{~Hz}$

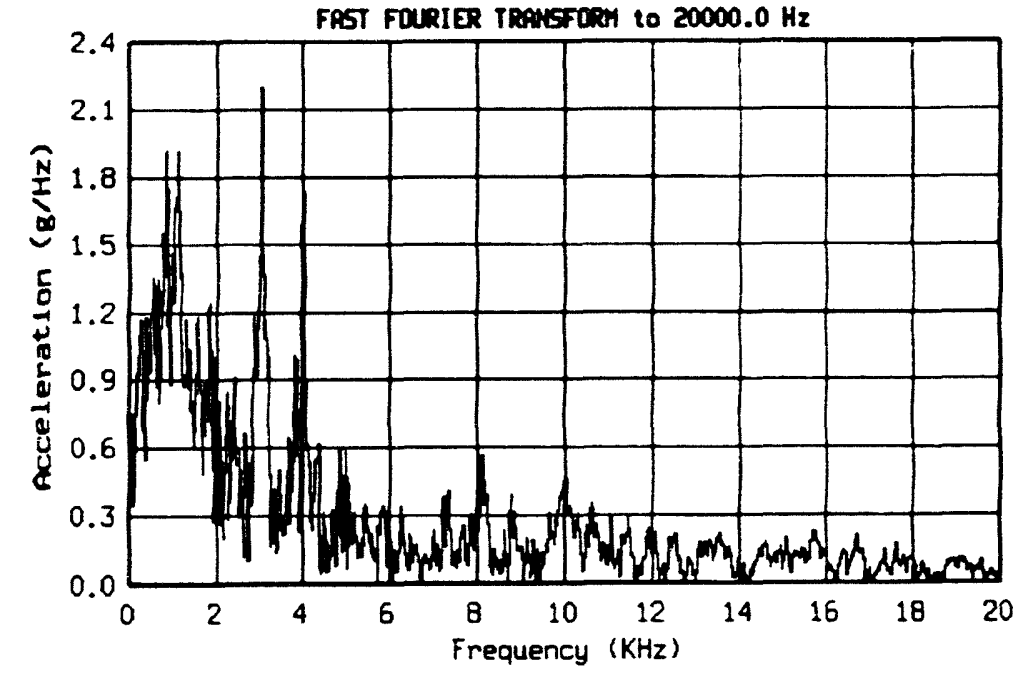

Test: MORIZONTR LOW VEIOCITY H1224A O6/30/93 (220) Session: Twe Jul 27 08:29:47 1993 Transdwoer: A7 (secondery)

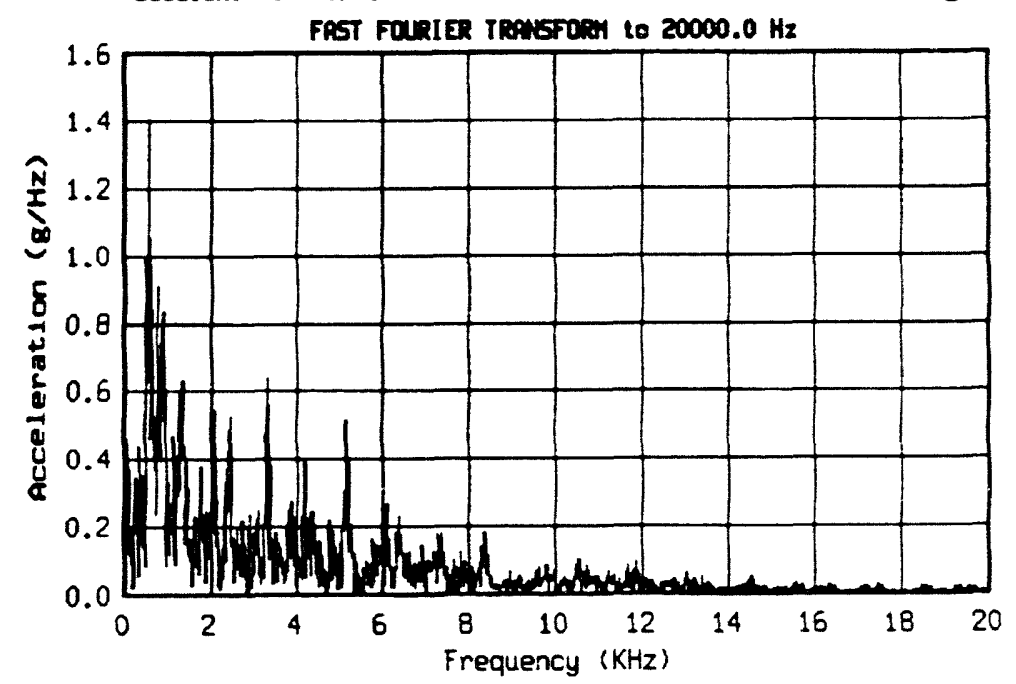



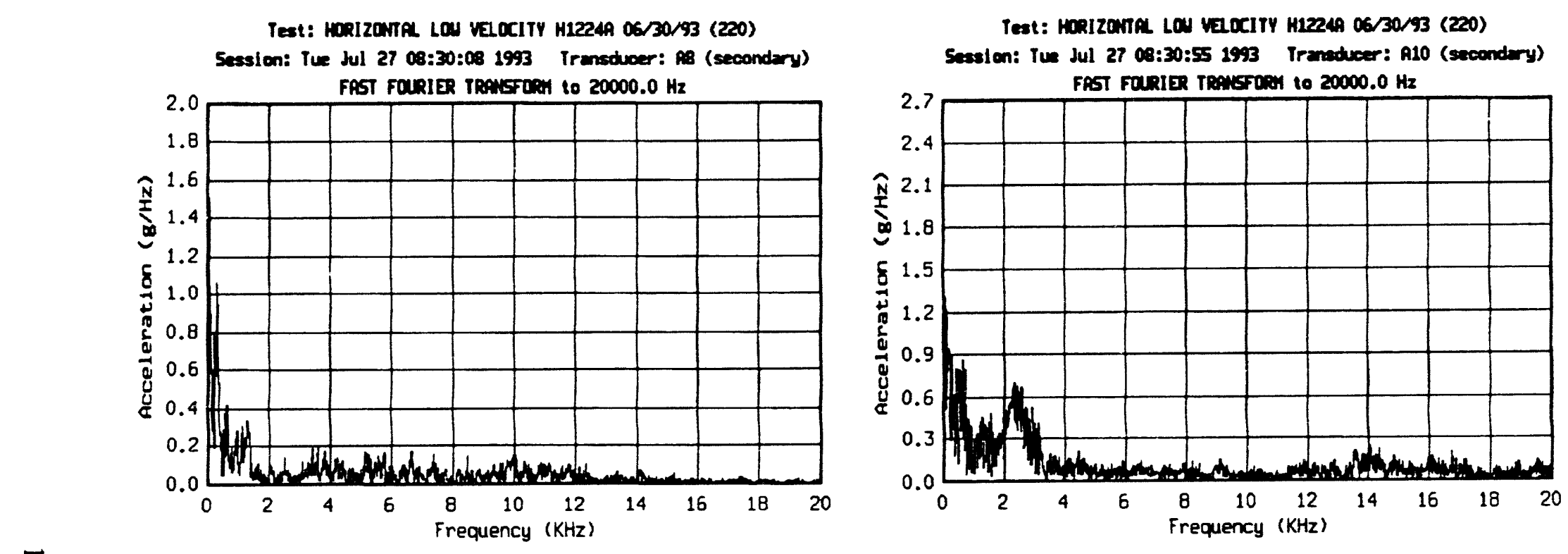

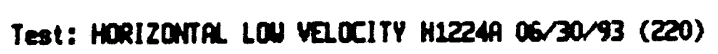
Session: Tue Jul 27 08:30:29 1993 Trenschear: A9 (secondery)
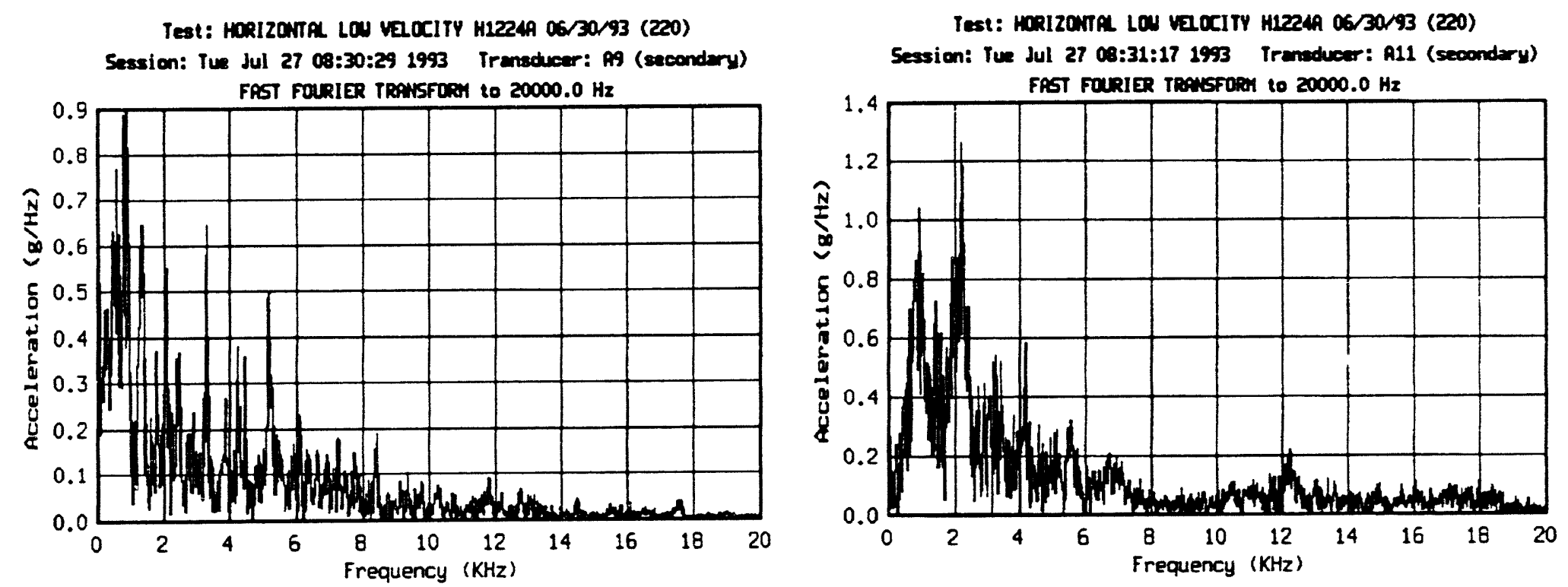

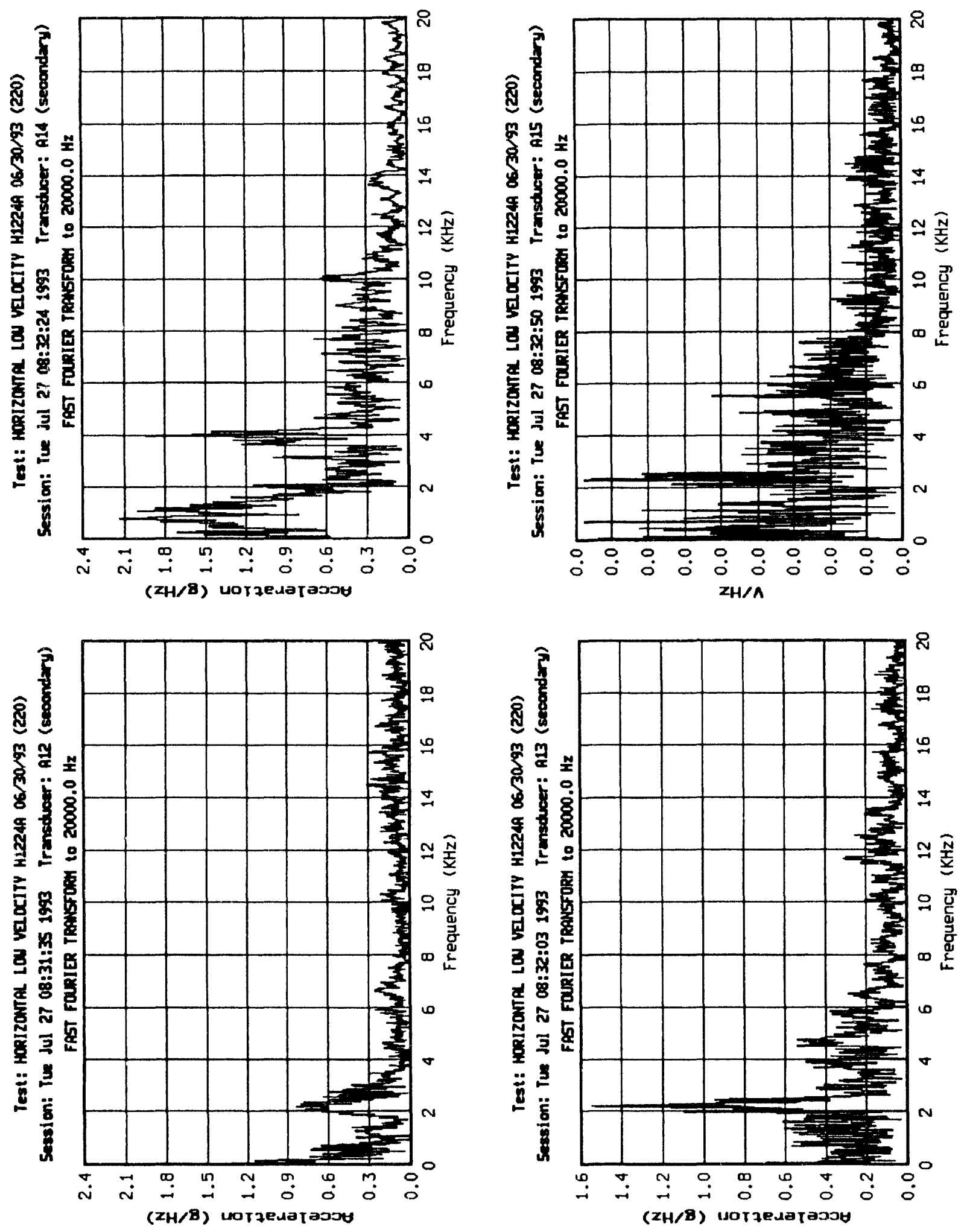
Test: HORIZONTR LOU VELOCITY H1224A 06/30/93 (220) Session: Tue Jul 27 08:31:22 1993 Transctuoer: S61 (secondary) FAST FOURIER TRANSFORH to $20000.0 \mathrm{~Hz}$

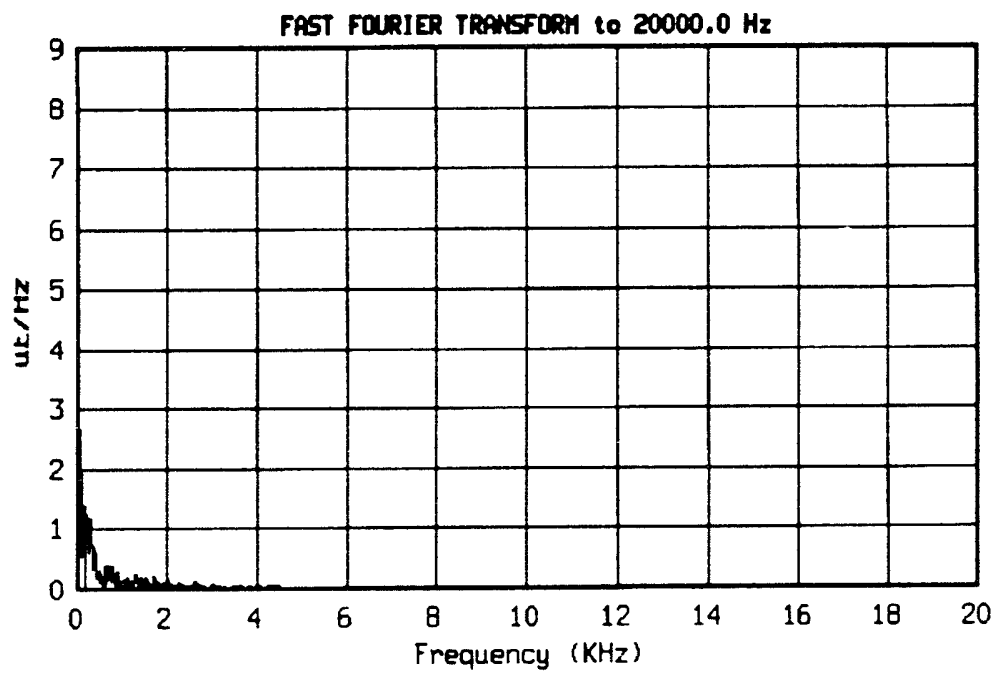

$\bar{w}$

Test: MoRIZOMTR LOW VZlOCITY H1224A 06/30/93 (220) Session: Tue Jul 27 08:34:41 1993 Transcheer: 562 (secondary) FAST FOURIER TRANSFORH to $20000.0 \mathrm{~Hz}$

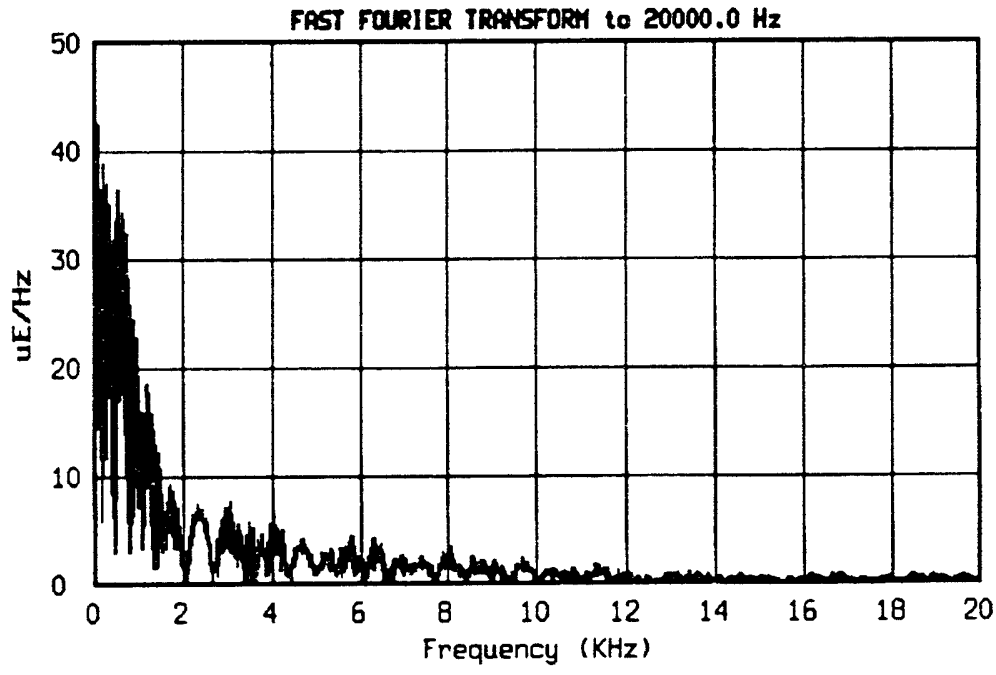

Test: HORIzONTR LOU ValcITY HI224A 06/30/93 (220) Session: Tue Jul 27 08:35:06 1993 Transducer: 563 (secondary) FAGT FOURIER TROAGSTOMH to $20000.0 \mathrm{~Hz}$

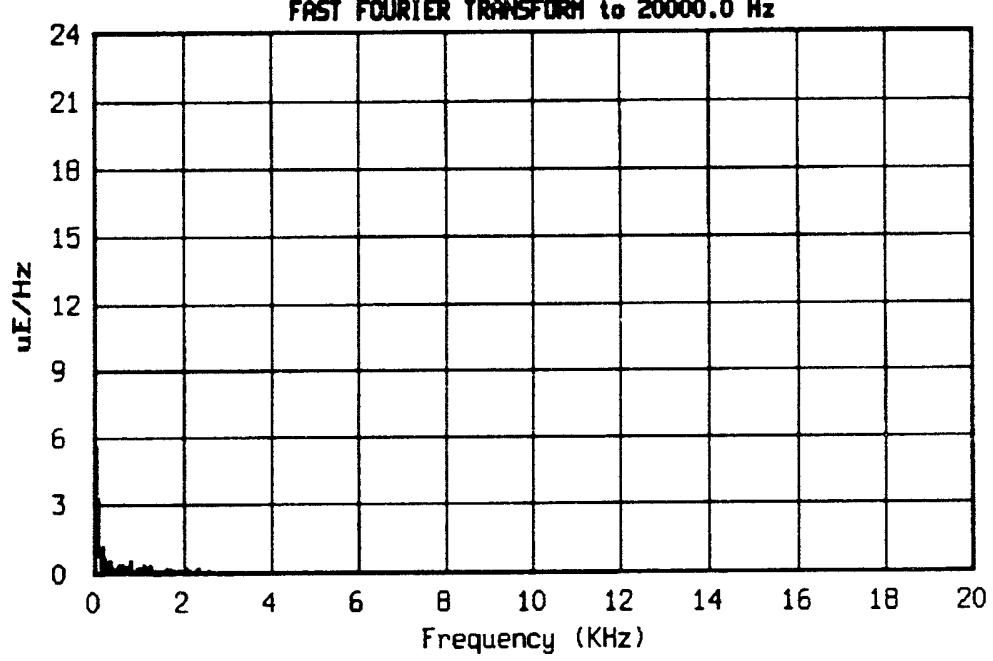

Test: HORIZONTR LOW VELCITY H1224A 06/30/93 (220) 5ession: Tue Jul 27 08:35:23 1993 Transolvoer: 564 (secondary) FAGT FOURIER TROASFORH to $20000.0 \mathrm{~Hz}$

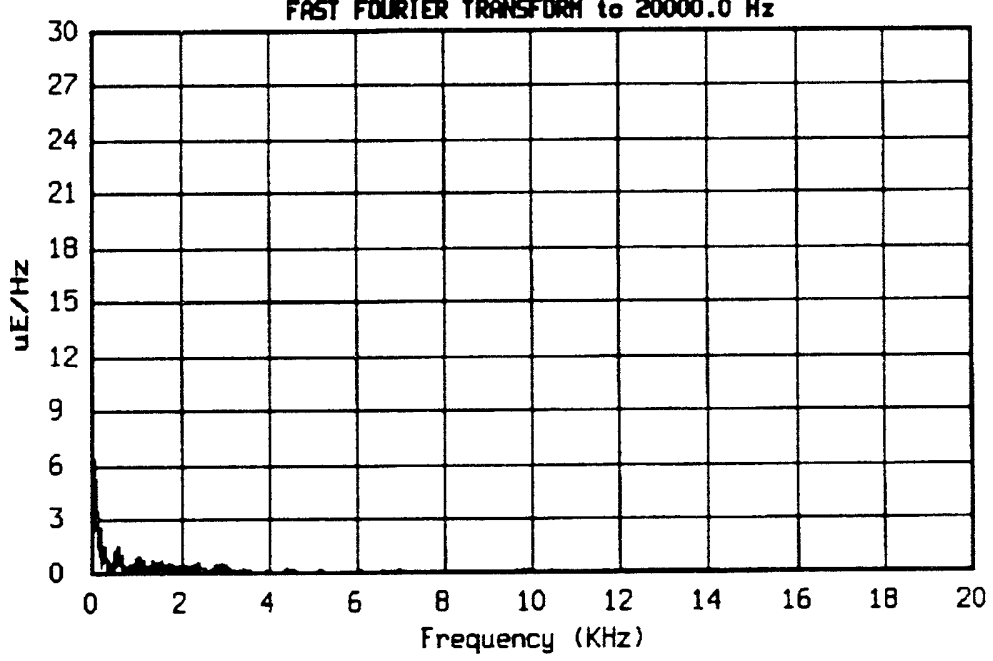



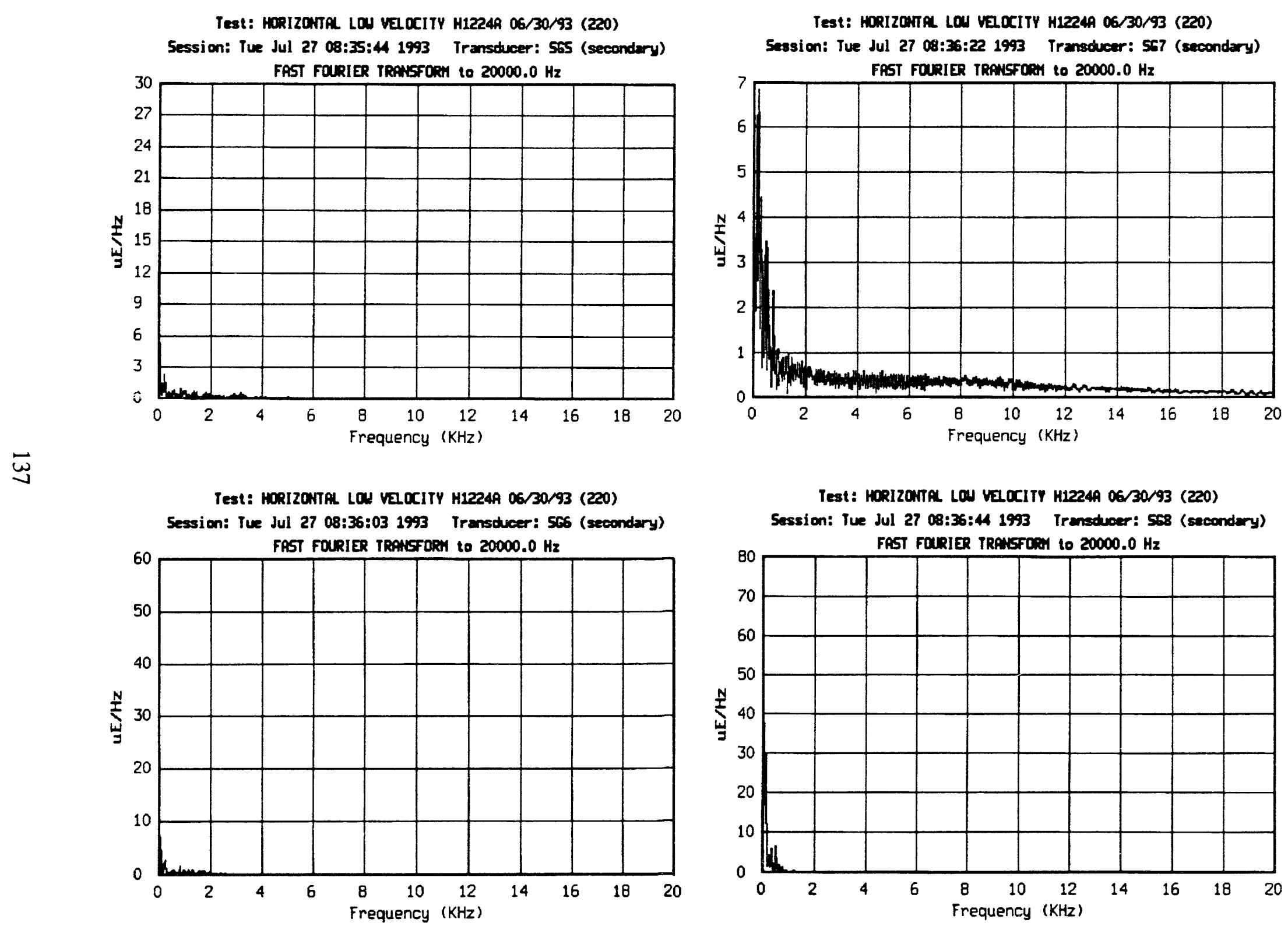

Test: HORIZOMTL LOU VEOCITY H1224A 06/30/93 (220)

The Jul 27 08:36:22 1993 Transducer: 567 (secondary)

FAST FOURIER TRONSF00\% to $20000.0 \mathrm{~Hz}$

Session: Tue Jul 27 08:36:44 1993 Trensetweer: 568 (secondary)

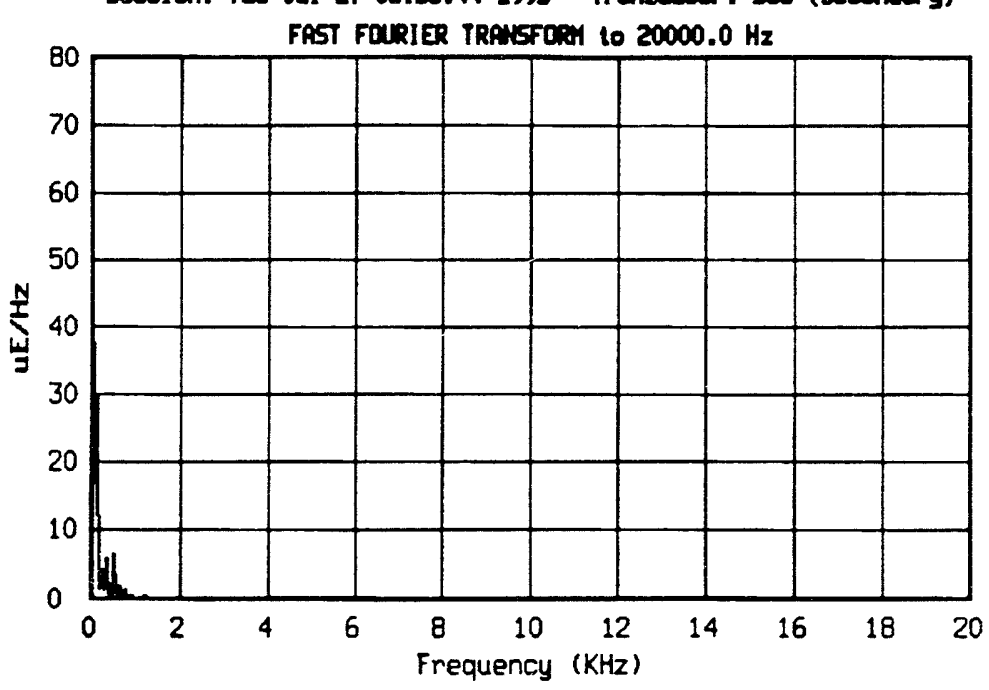


Test: HORIZONTA LOU VEOCITY H12249 06/30/93 (220)

Session: Tue Jul 27 08:37:02 1993 Transiducer: 569 (secondrry)

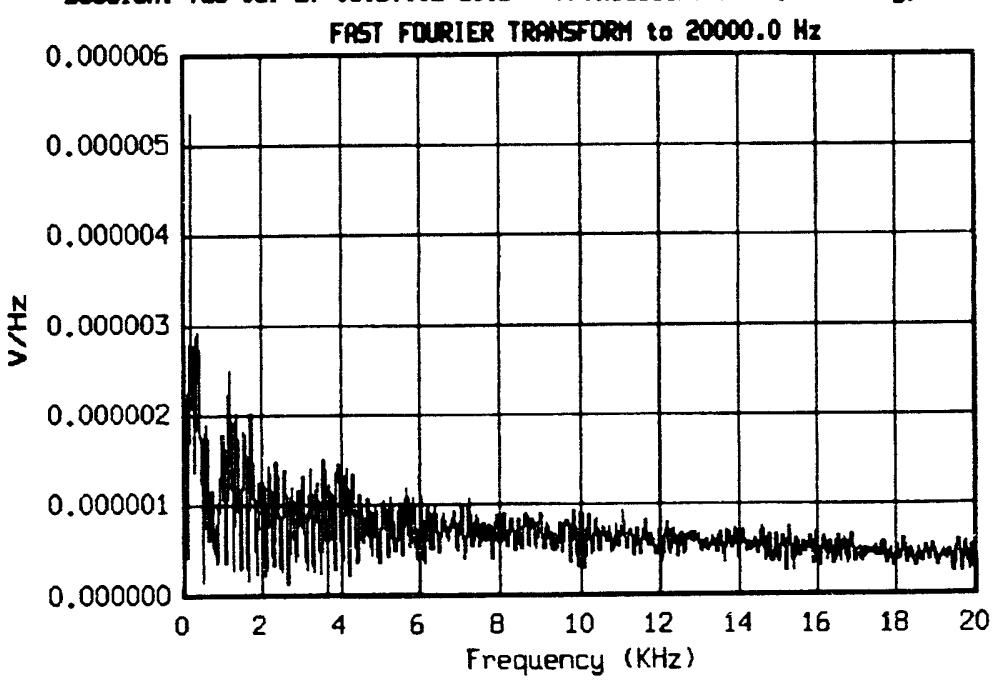

$\underset{\infty}{\omega}$

Test: HORIZONTAL LOW VEOCITY H1224A 06/30/93 (220)

Session: Tue Jul 27 08:37:17 1993 Transducer: 5610 (secondary)

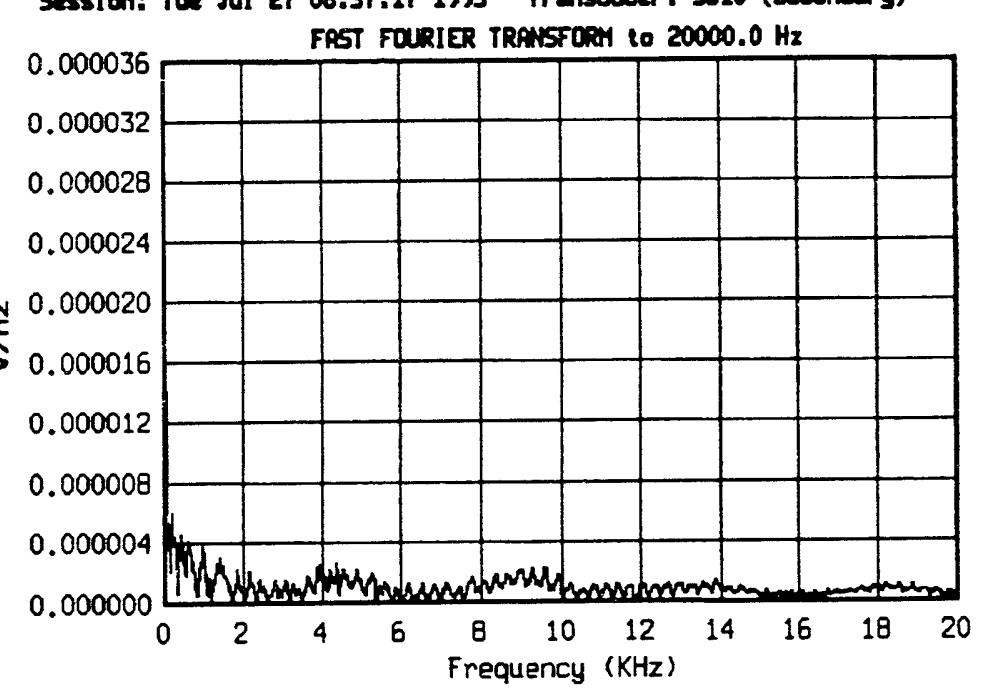




\section{Appendix C. LHV Accelerometer and Strain Gage Data: Raw, Filtered, and Reduced}

The following pages show raw (unfiltered) acceleration and strain gage data for the Longitudinal High-Velocity (LHV) impact test. Following this raw data are plots of filtered data (using a low-pass Butterworth 6-stage filter) with cutoff frequencies of $250 \mathrm{~Hz}$ and 2,000 Hz. Integrated acceleration data, yielding velocity versus time plots, are presented to analyze kinetic energy values during the test. And finally, Fast Fourier Transforms (FFTs) for each raw data channel are included to analyze acceleration and strain amplitudes in the frequency domain. 
Test: LoncITUOINA HIGH VelOCITY H1224A 08/11/93 (223) Session: Led Aug 11 16:14:20 1993 Transducer: A1 (secondary) Raw Transtucer Data

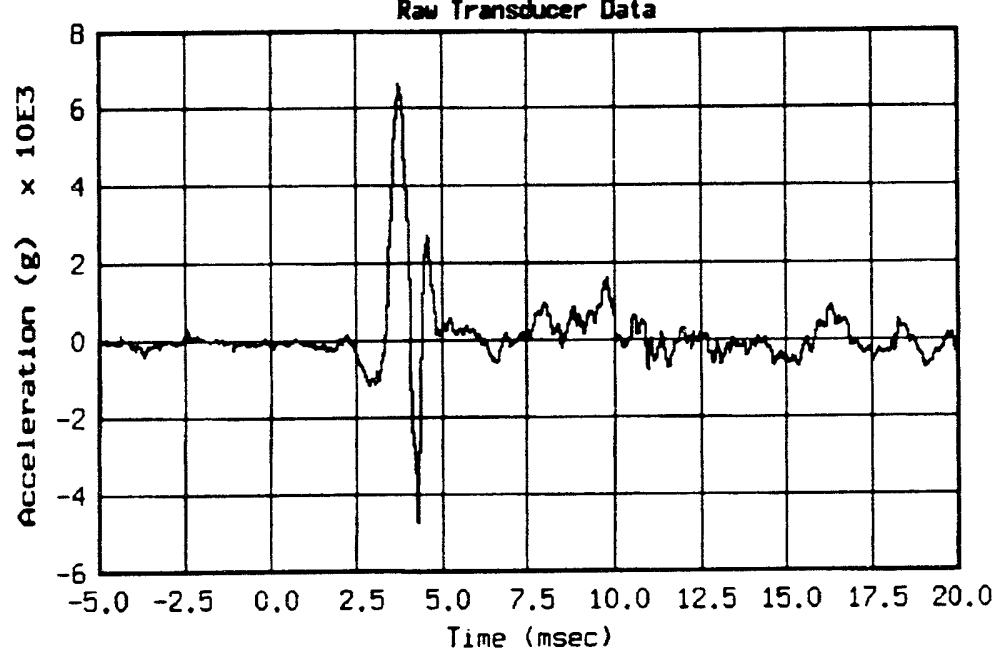

Test: LONGITUDINA HICH VelOCITY H1224A 08/11/93 (223) Session: Led Aug 11 16:14:22 1993 Transducer: A2 (secondary)

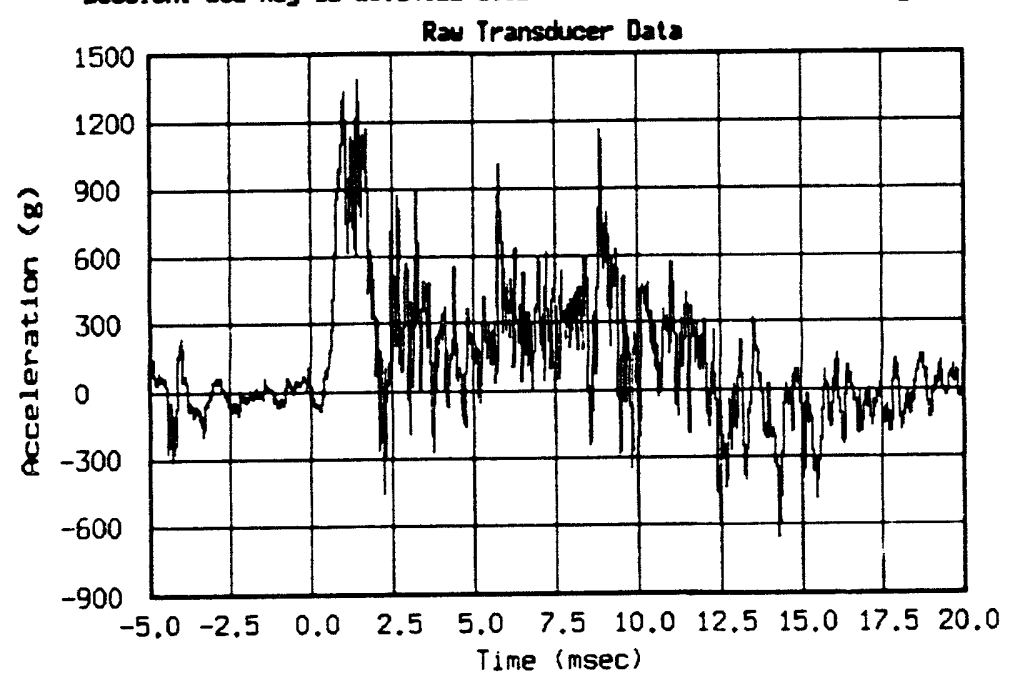

Test: LONGITUIMAL HIGH VEOCITY H12249 08/11/93 (223) Session: thed Aug 11 16:14:35 1993 Transtucer: A3 (secondary)

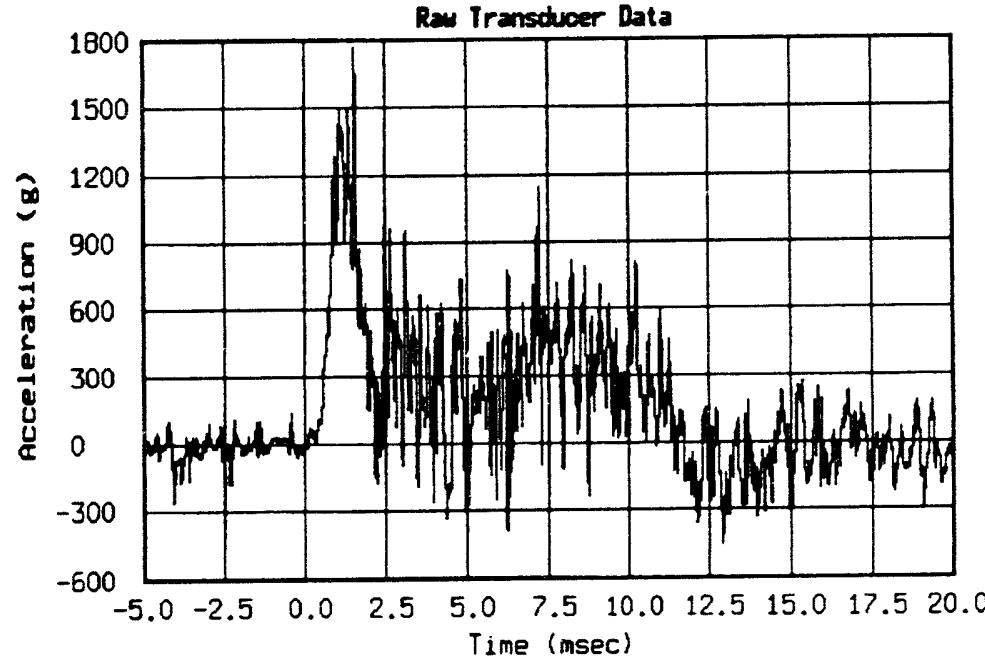

Test: LONGITUOINA HIGH VEOCITY H12249 08/11/93 (223) Session: Lled Aug 11 16:14:11 1993 Transdveer: A4 (secondary)

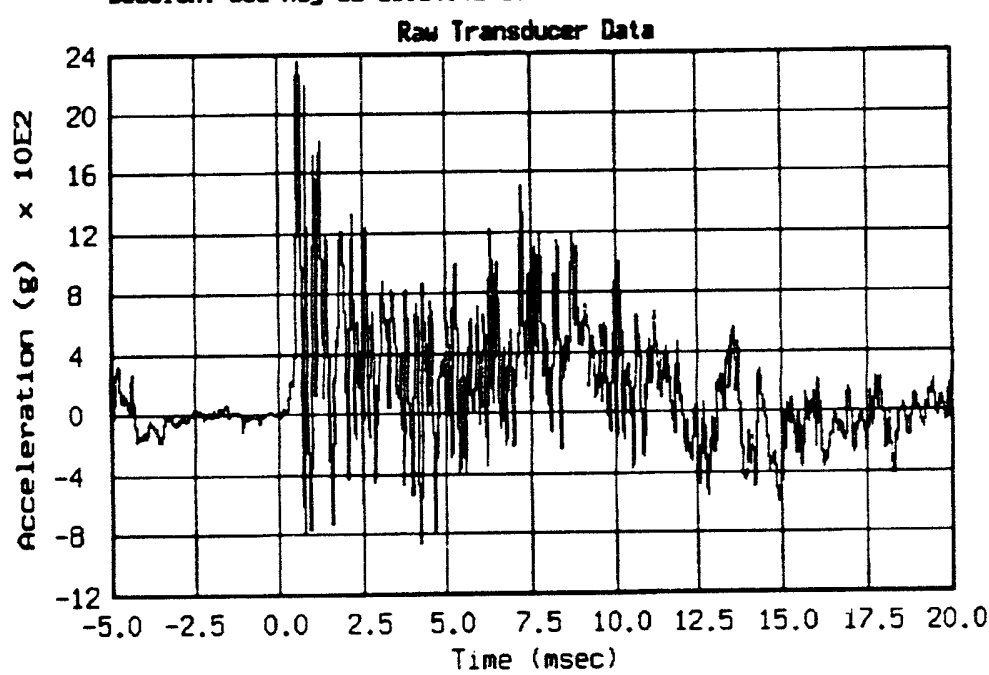



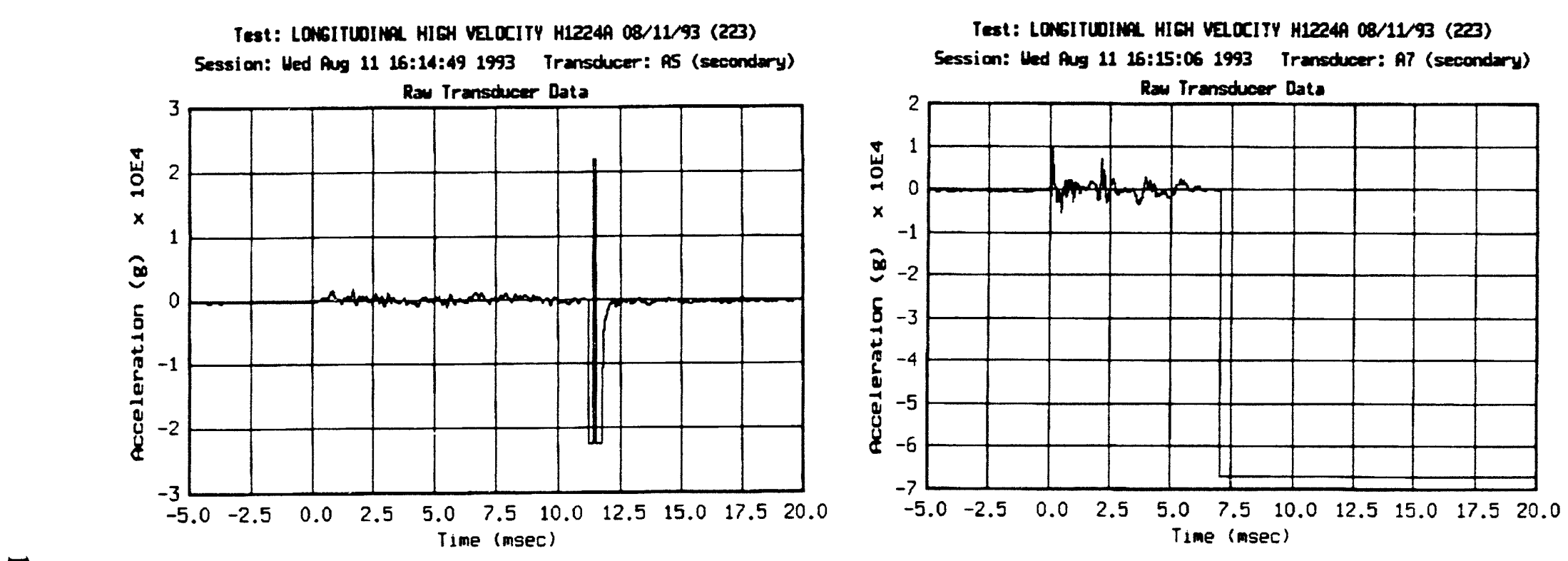

Test: LONGITUOINA HIGH VELOCITY HI224A 08/11/93 (223) Session: hed fug 11 16:14:57 1993 Iransducer: A6 (secondery)

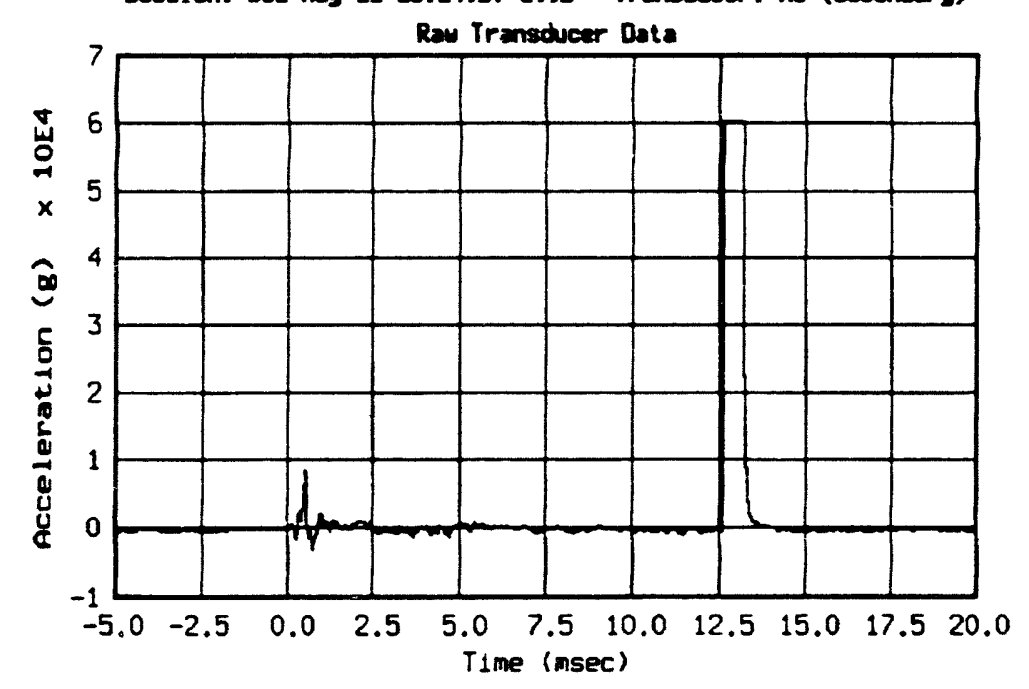

Test: LaxsITUOIM HICH VelOCITY H12249 08/11/93 (223) Session: hed Aug 11 16:15:13 1993 Trmoducer: AB (secondery)

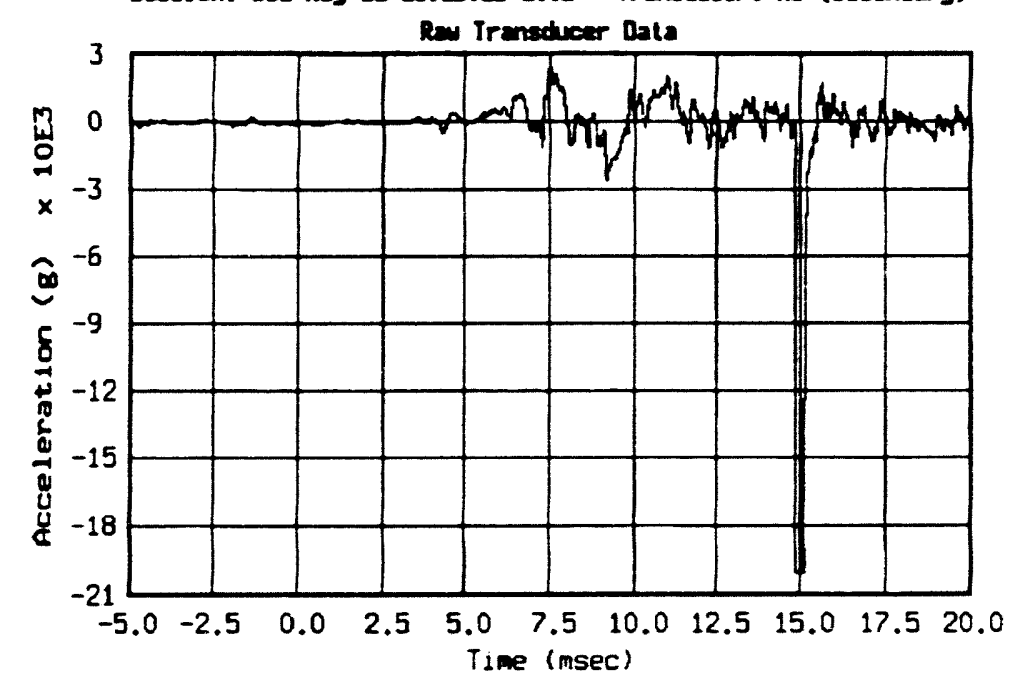


Iest: LOSITLIMA HICH VeOCITY H1224A 08/12/93 (223) Session: Led Aug 11 16:15:28 1993 Trametwoer: 9 (secondary)

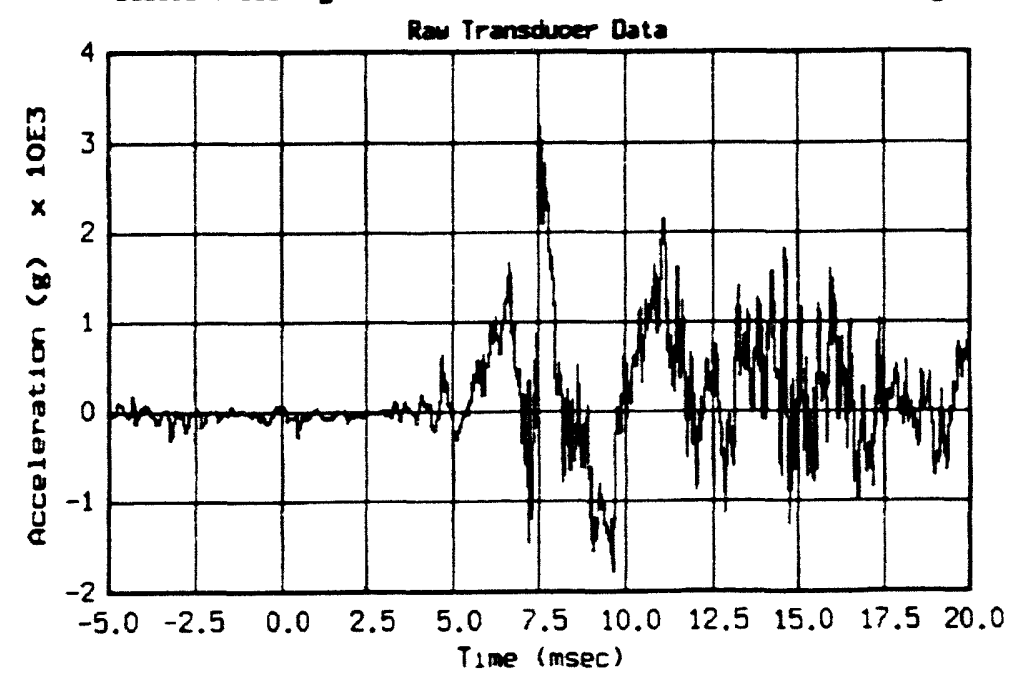

竝

Test: LorsITUIHA HIEH VELOCITY HI2249 08/11/93 (223) Session: Ited an 11 16:15:21 1993 Ir msedveer: A10 (secondary)

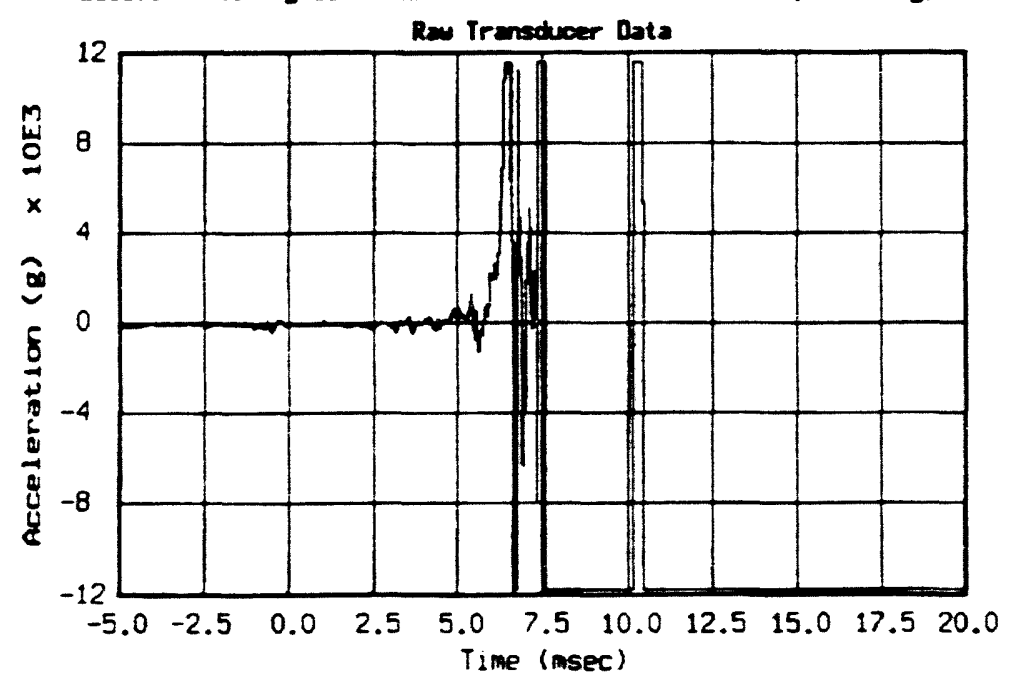

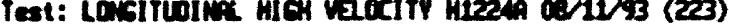
Sexsion: thed an 11 16:15:45 1993 Transtucer: A11 (secondary)

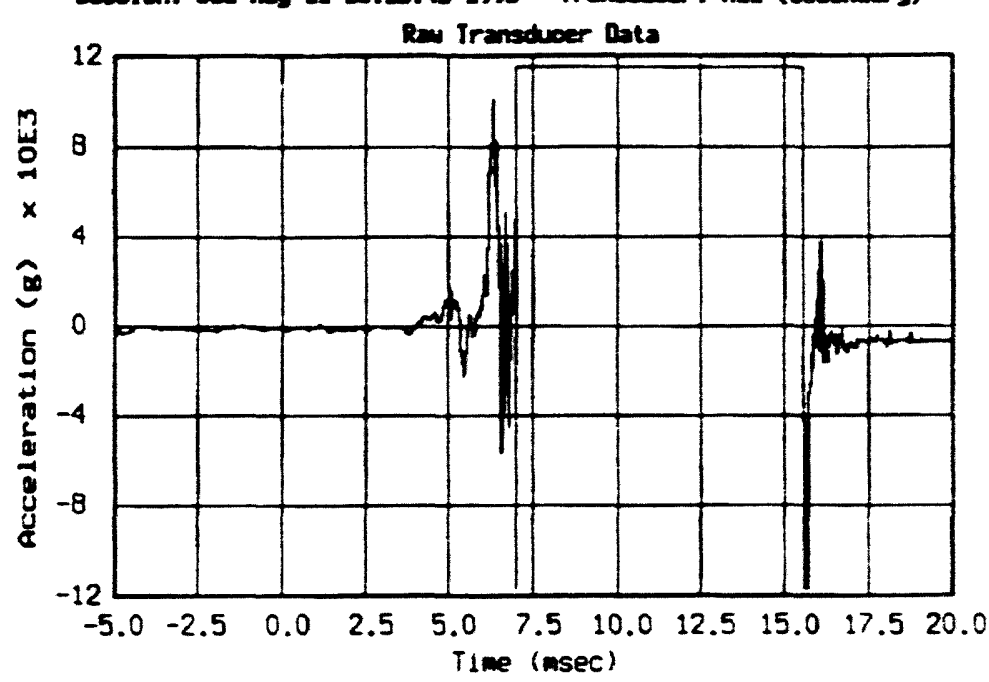

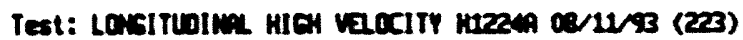
Sescien: thad aug 11 16:15:37 1993 Tremedwer: A13 (secondary)

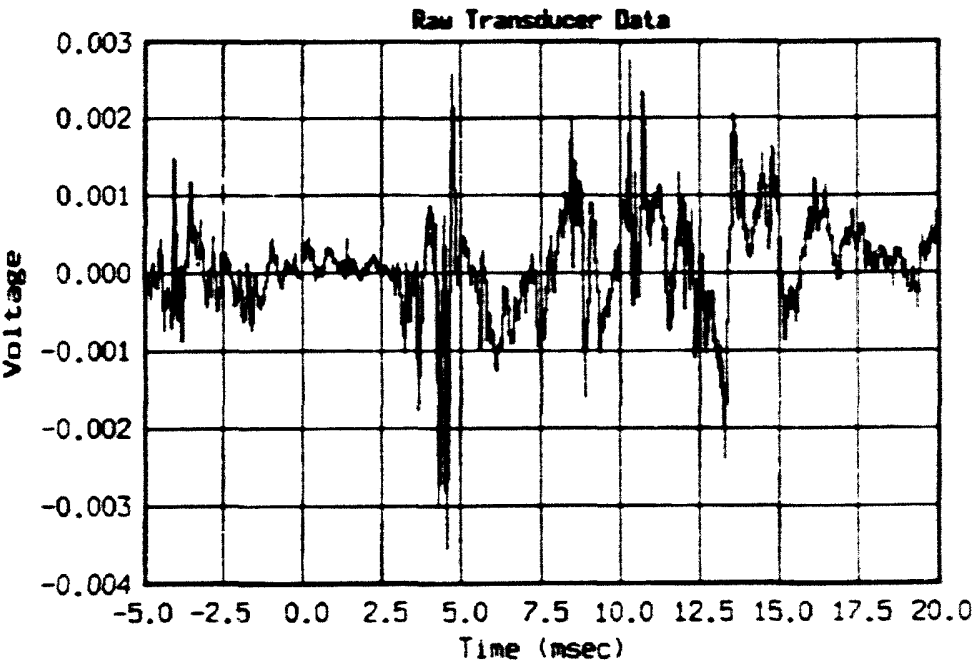



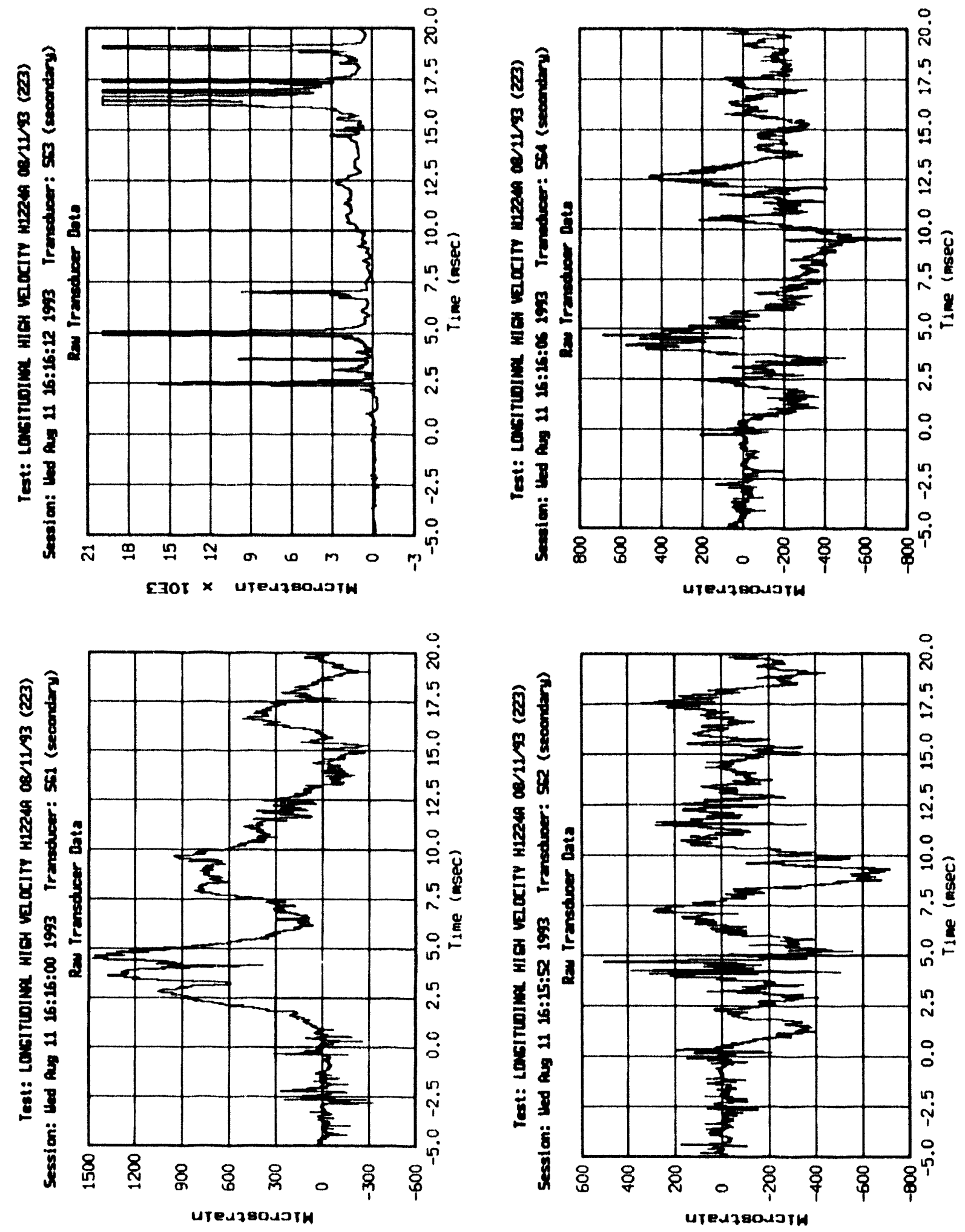


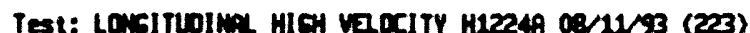
Session: led an 11 16:16:26 1993 Transducar: 505 (secondary)

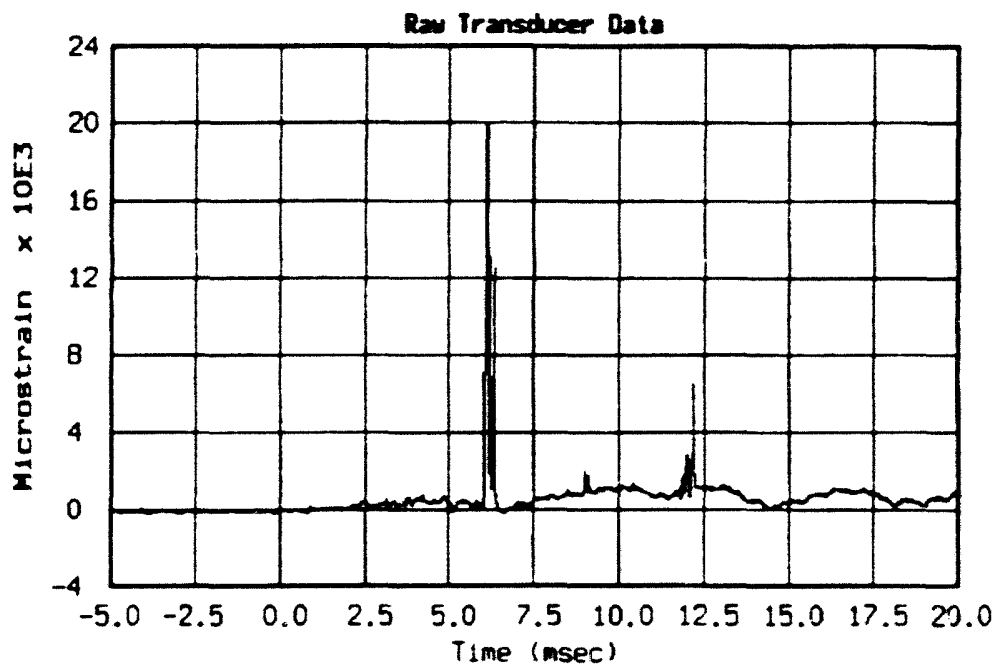

$\bar{E}$

Test: Loxitwink HICH velocity HI2249 08/11/93 (223)

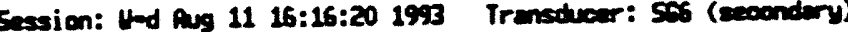

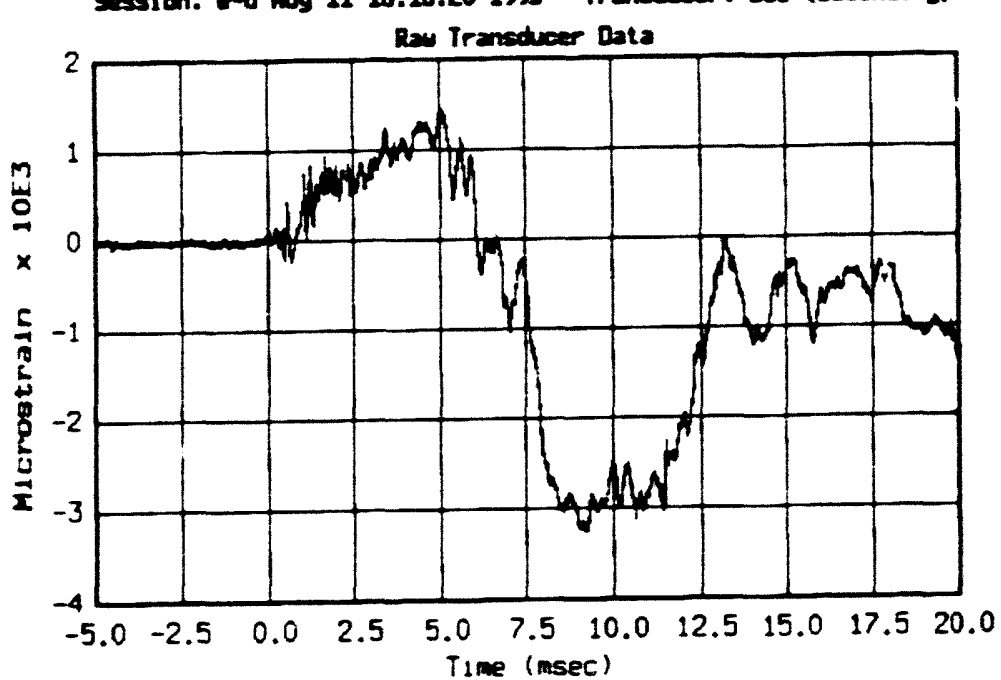

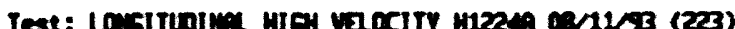

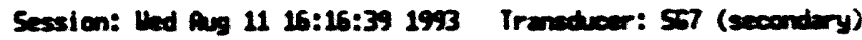
Ban Treswetucer Date

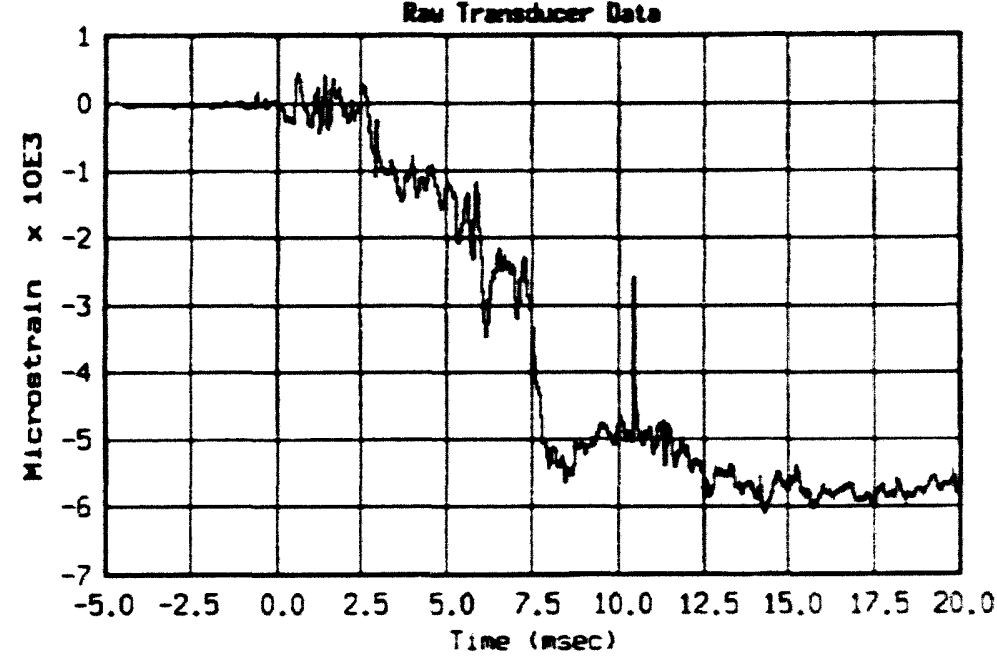

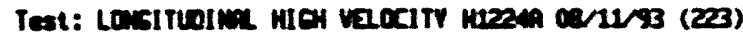

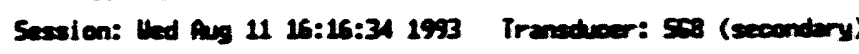

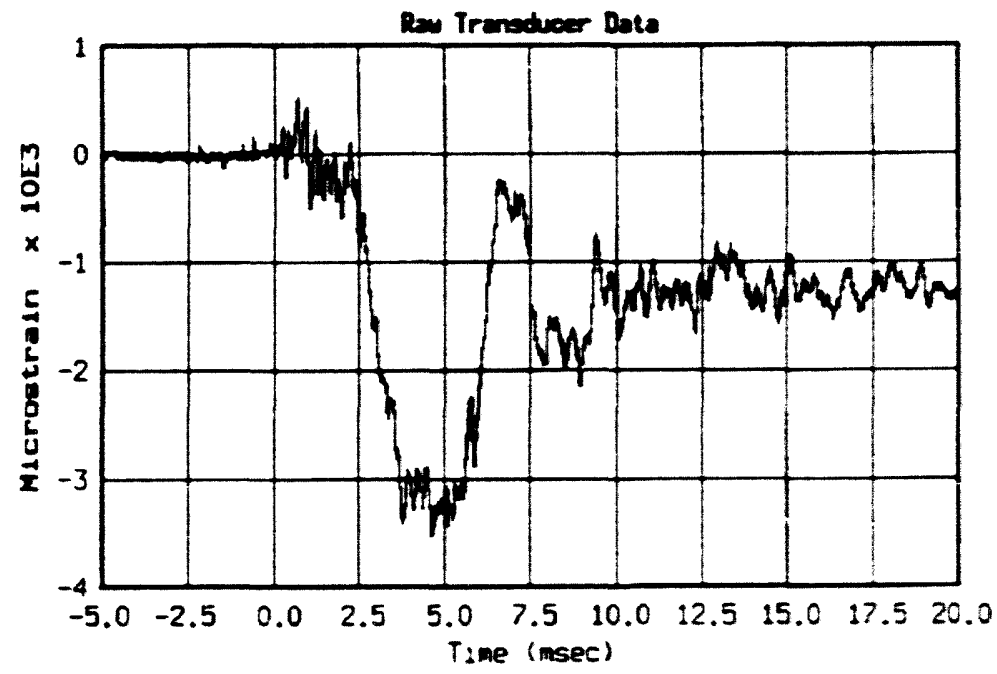




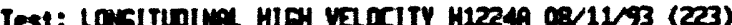
Session: thed Aug 11 15:16:22 1993 Transducer: 559 (secondary)

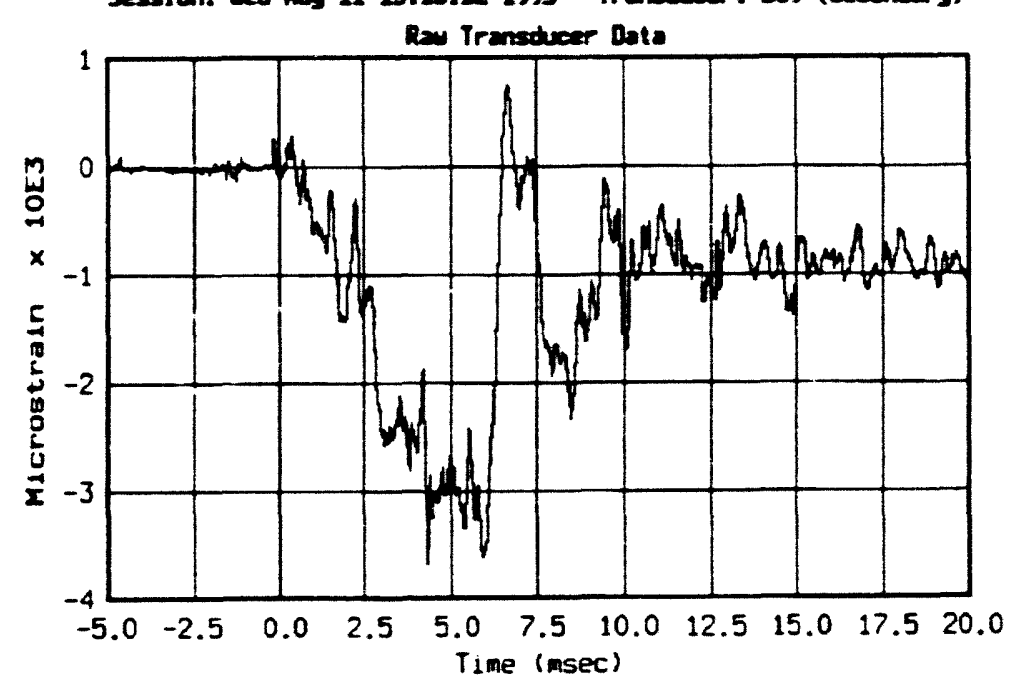

in

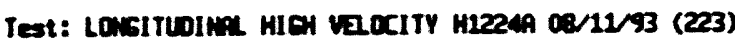
Session: lied Aug 11 16:16:45 1993 Tranadwer: 5610 (secondary)

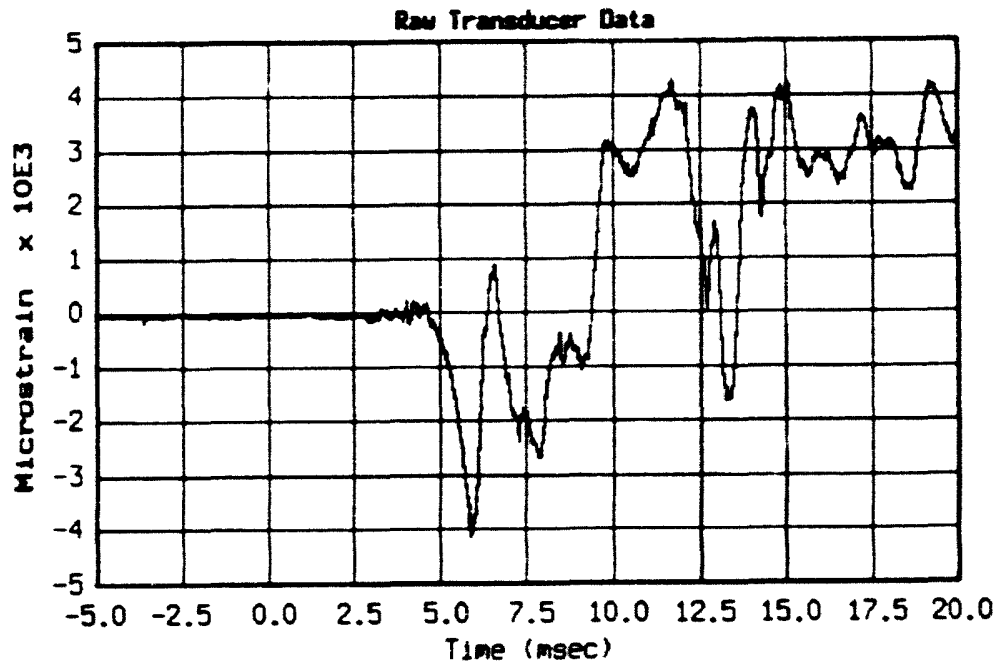

Test: Lowituolin mey veccity M1224

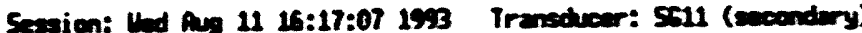

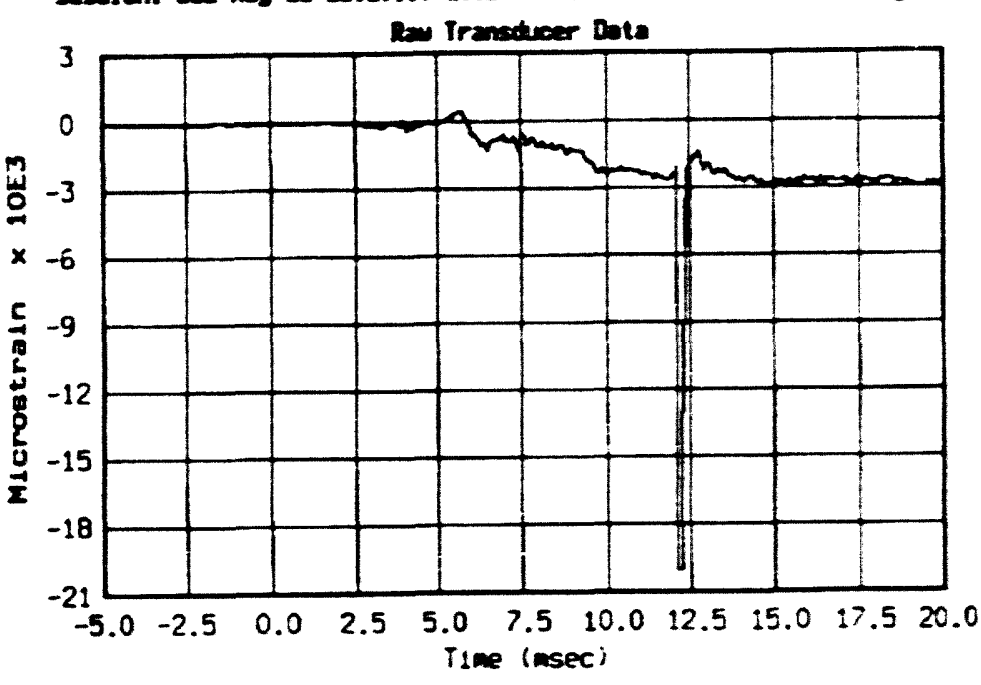

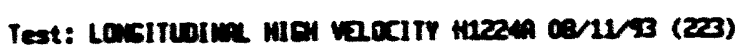

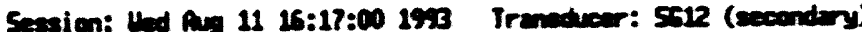

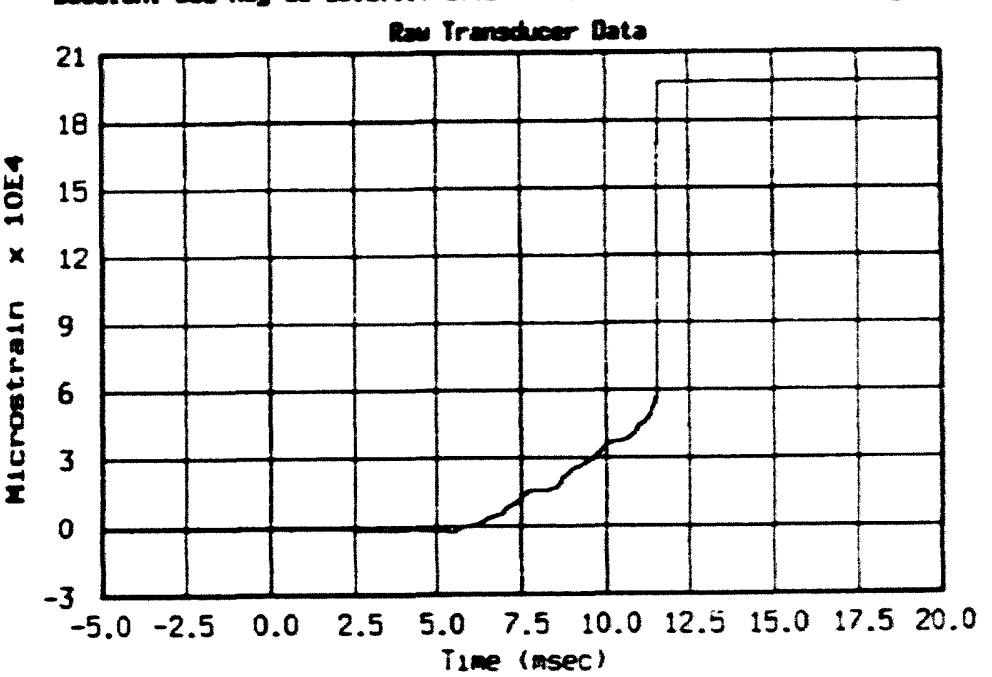


Test: Loxituinil MIGH veccity H1224A 0811/93 (223) Sexsion: thed Aug 11 16:17:19 1993 Transducer: 5613 (secondary)

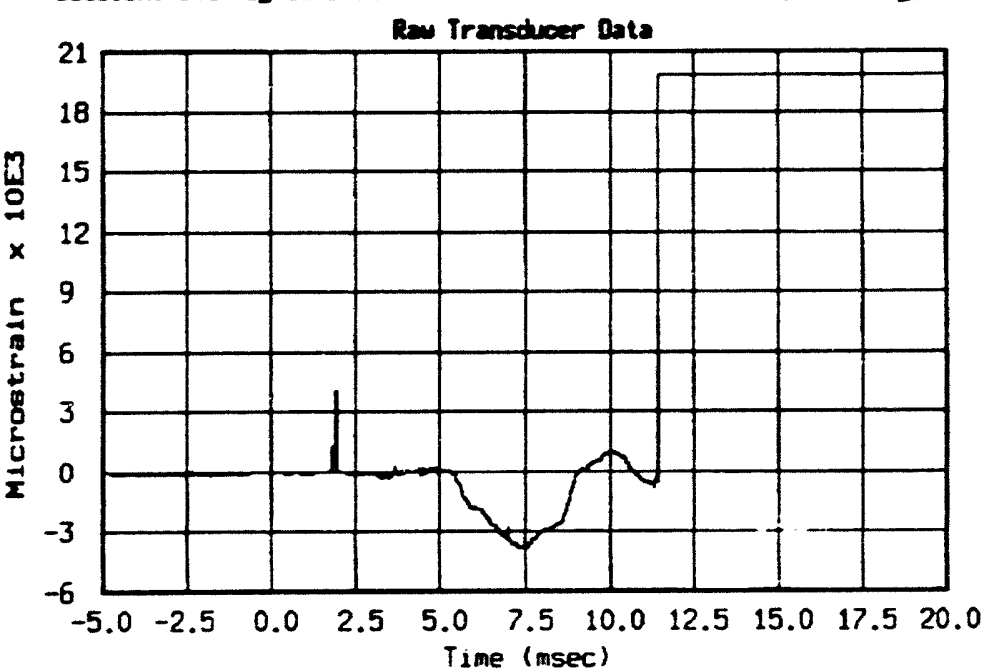

咅

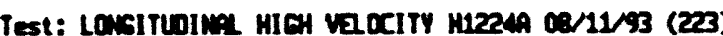
Session: bed aug 11 16:17:13 1993 Transobcer: 5514 (necondery)

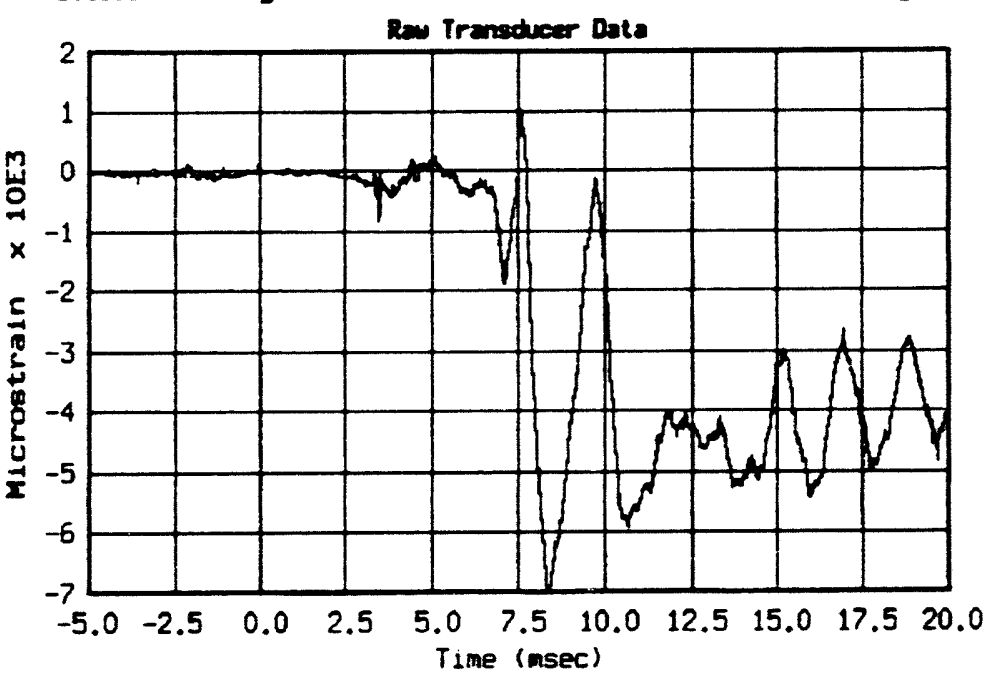

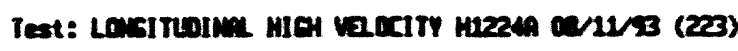

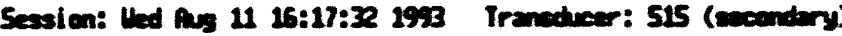

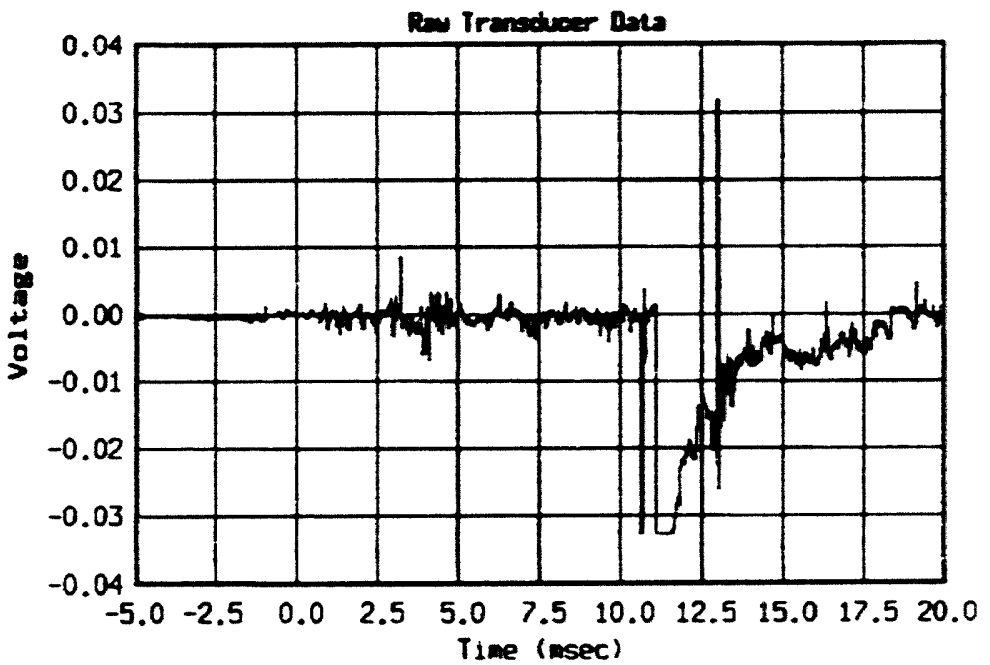

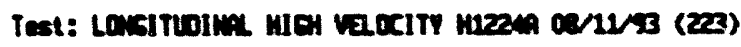
Sextion: Und An 11 15:17:25 1993 Trandwow: 516 (secondary)

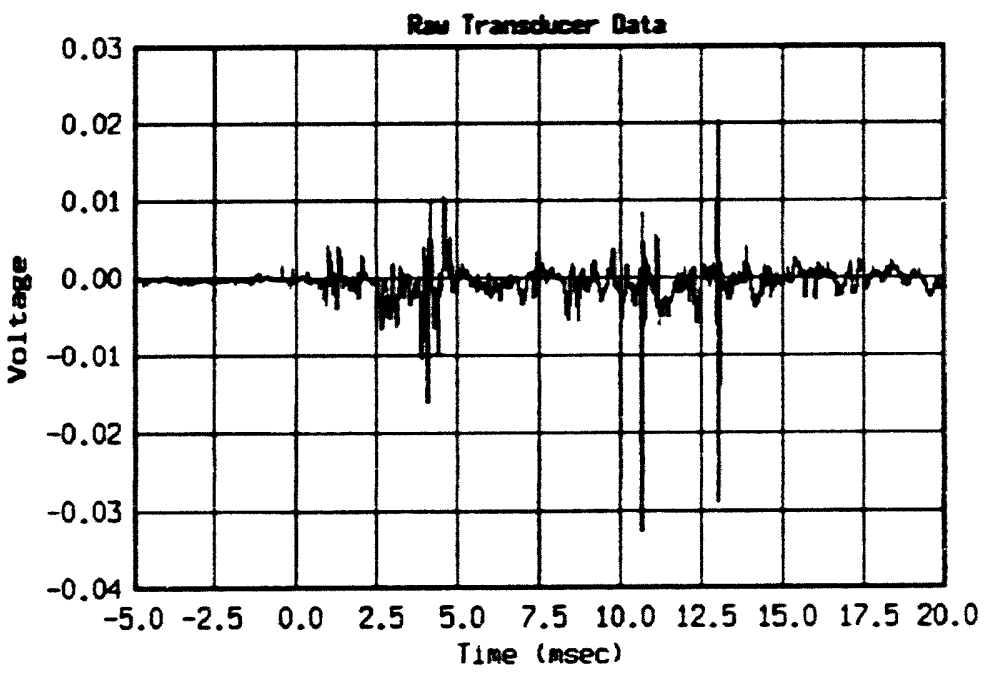




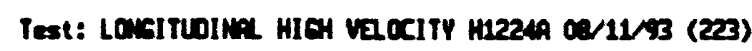
Sexslon: thed Aug 25 14:09:36 1993 Transducer: A1 (secondary)

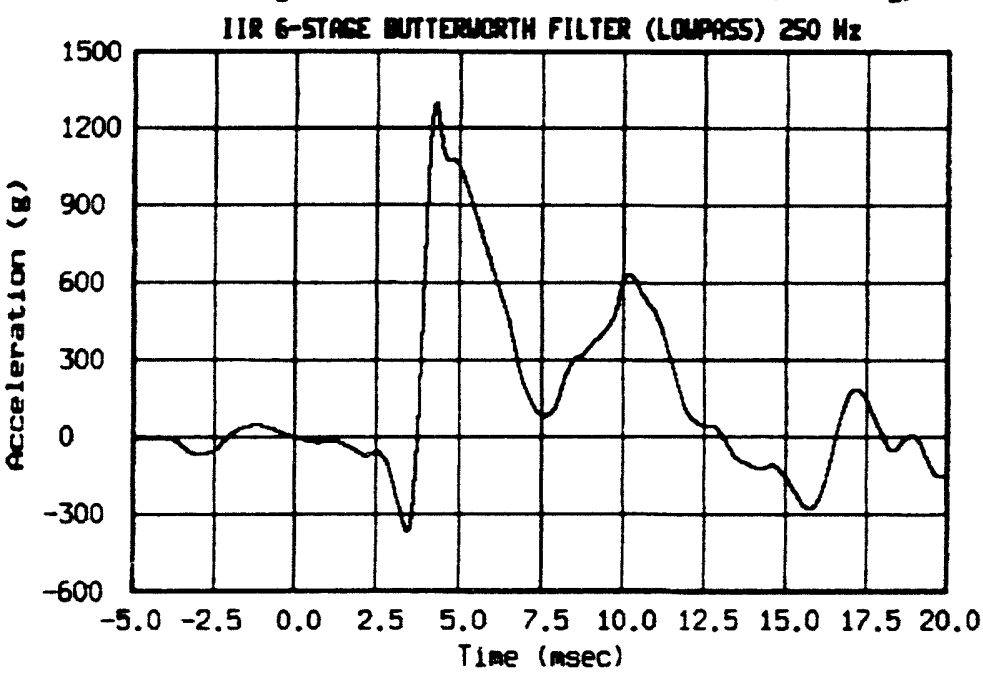

$\bar{E}$

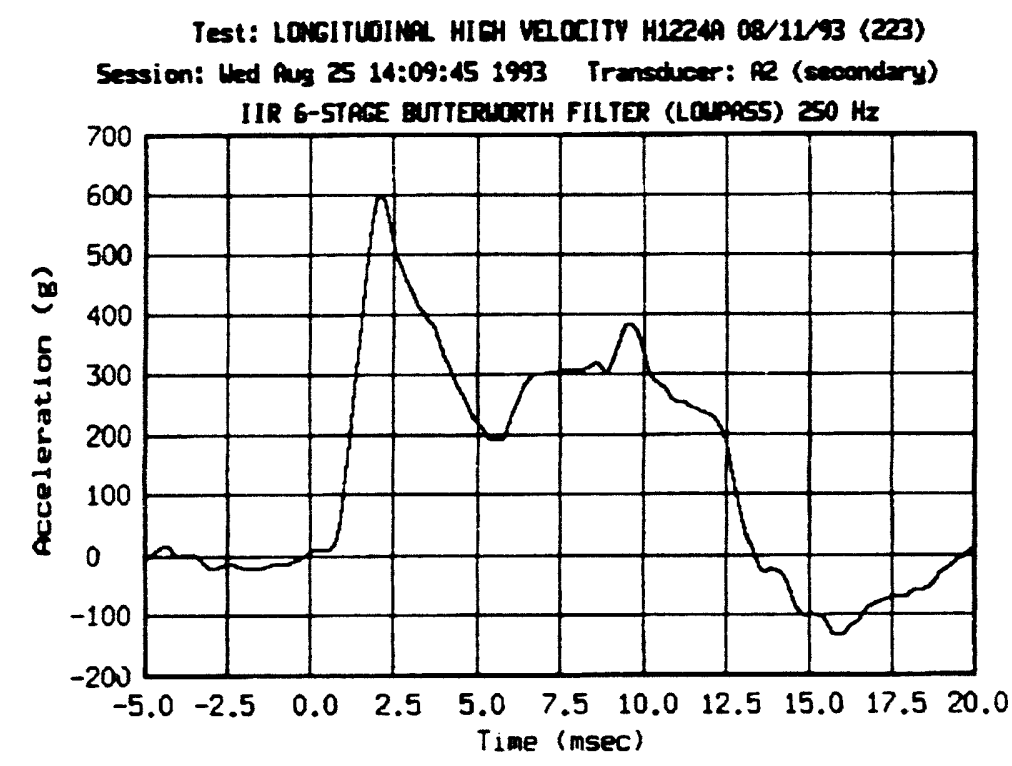

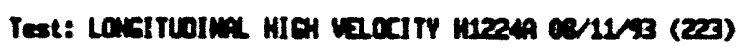
Seavien: led an 25 14:10:00 1993 Tranedwoer: 13 (secendary)

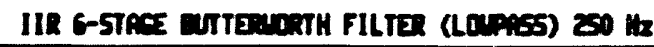

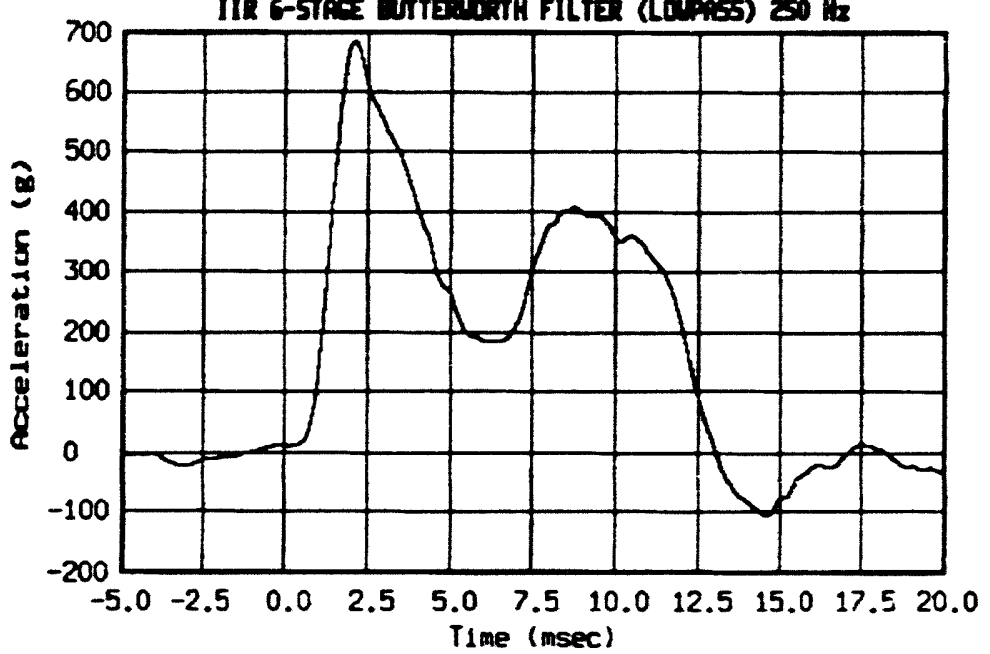

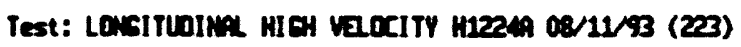
Session: Ued Aug 25 11:10:03 1993 Tranadveer: A4 (secondary) IIR 6-STAEE DUTTERORTH FILTER (LOPASS) $250 \mathrm{~Hz}$

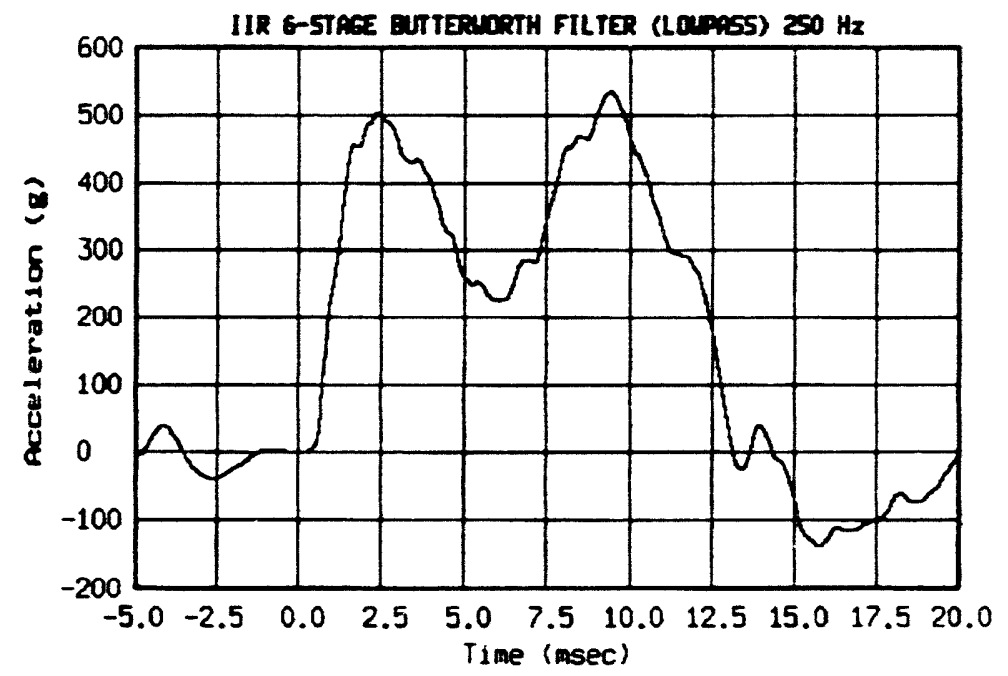



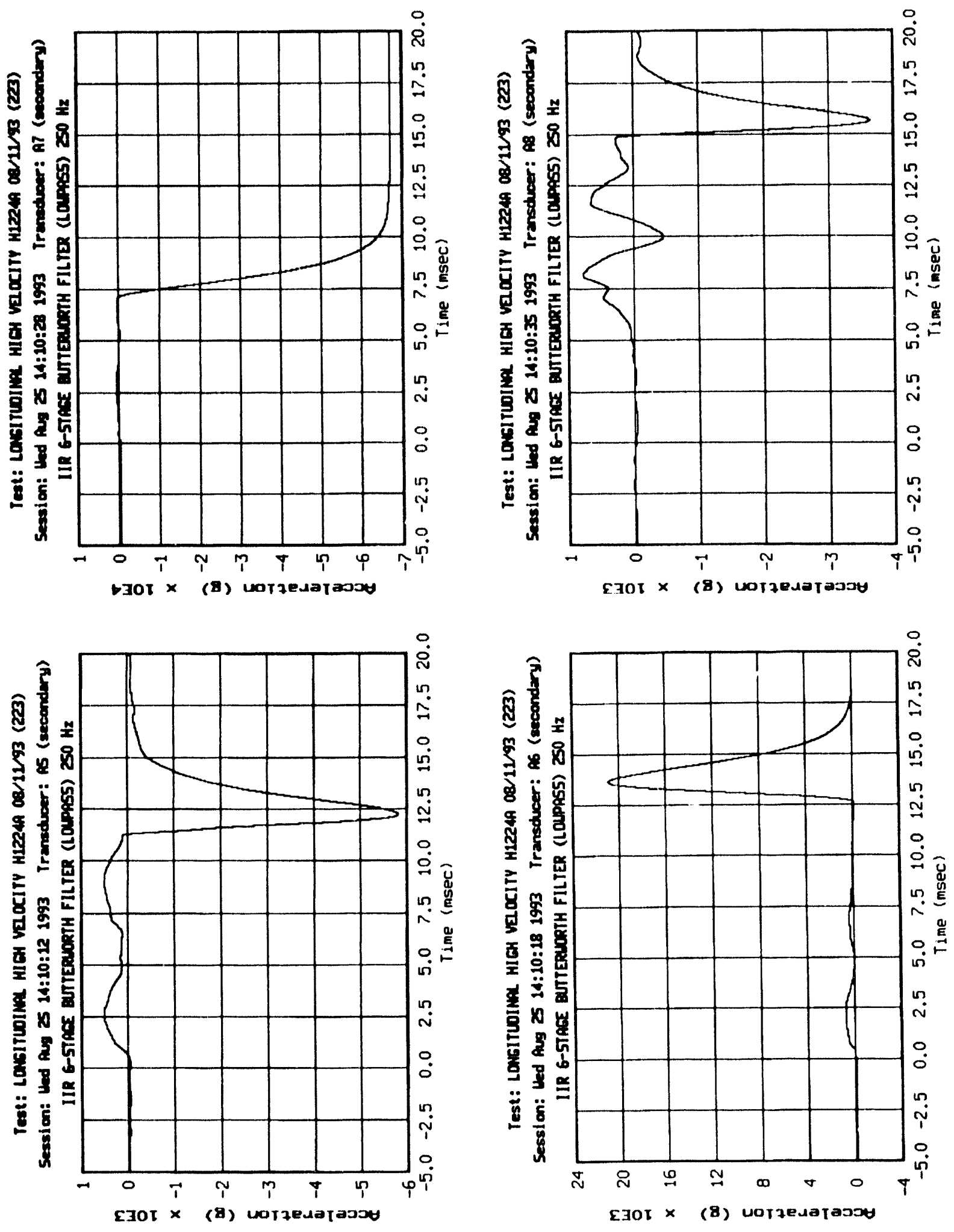
Test: LONGITLOIM HIEH VEOCITY H1224A 08/11/93 (223) Session: Led Aug 25 14:10:43 1993 Trandweer: A9 (secondary) IIR G-STRGE BUTTERIORTH FILTER (LOPASS) $250 \mathrm{~Hz}$

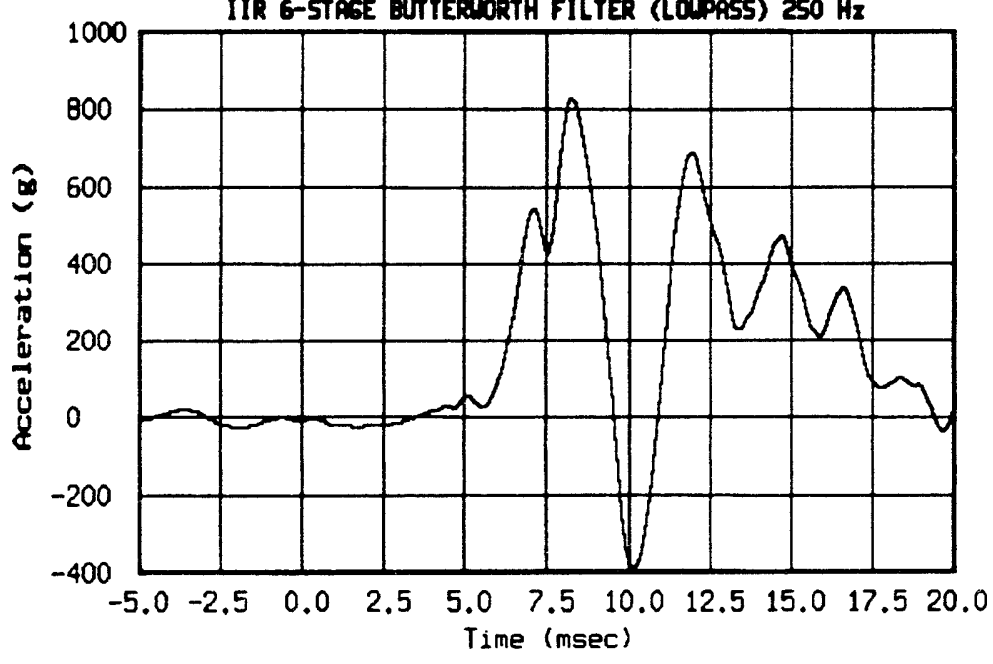

Test: LONGITLDIML HIGH VEOCITY H1224A 08/11/93 (223) Session: thed fug 25 14:10:49 1993 Transducer: A10 (secondary) IIR G-STAGE BUTTERLORTH FILTER (LOLPASS) $250 \mathrm{~Hz}$

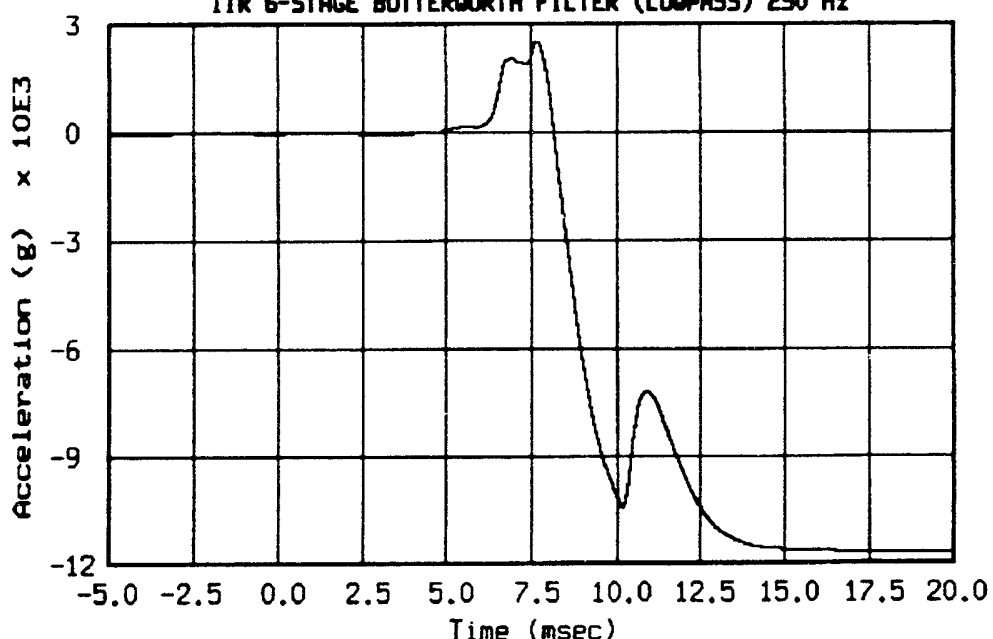

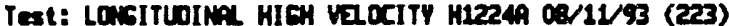
Session: Ued Aug 25 14:10:57 1993 Transtwour: A11 (secondary) IIR G-STAEE BUTERLORTH FILTER (LOAPAS5) $250 \mathrm{~Hz}$

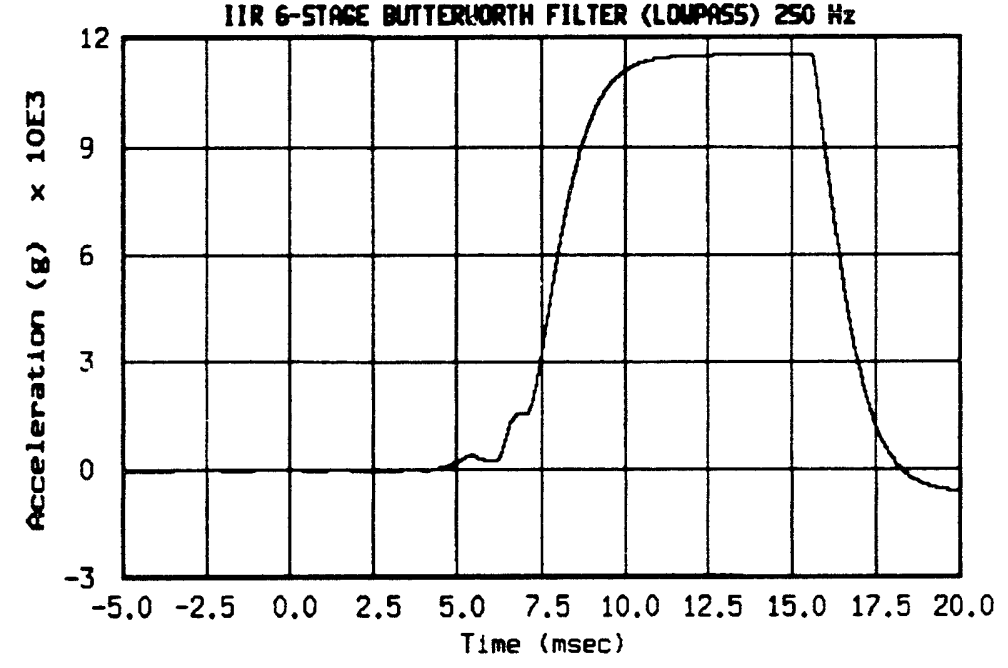

Test: LONGITUDIMAL HIGH VelocITY H1224A 08/11/93 (223) Session: Led Aug ZS 14:11:05 1993 Trunsodveer: A13 (secondary)

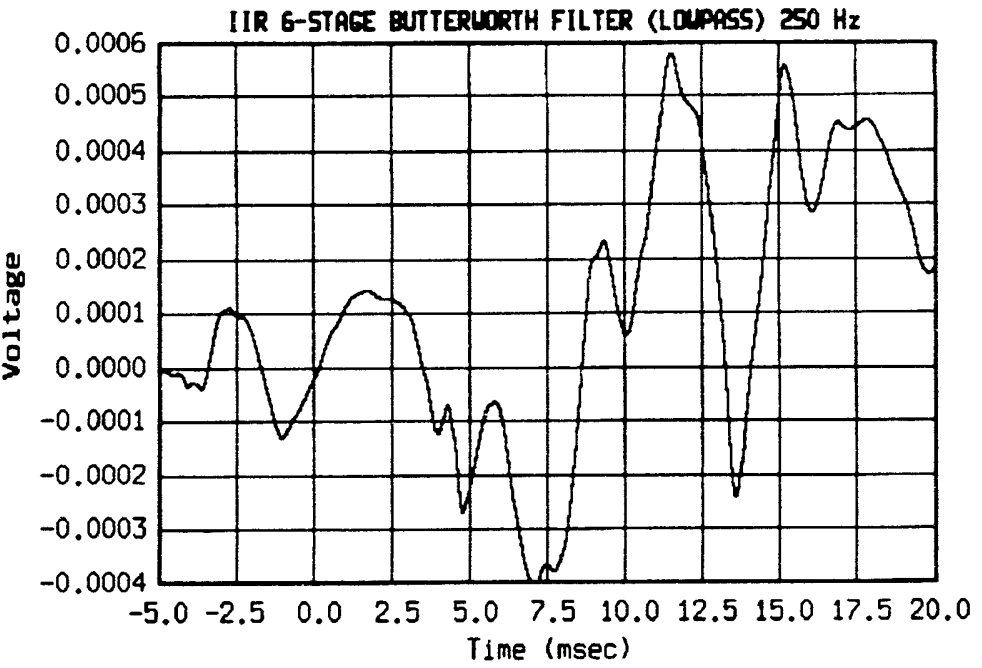


Test: LONGITLDIMA HICH VIOCITY H1224A 08/12/93 (223) Session: lad Aug 25 14:11:14 1993 Transdues: 561 (seoondary)

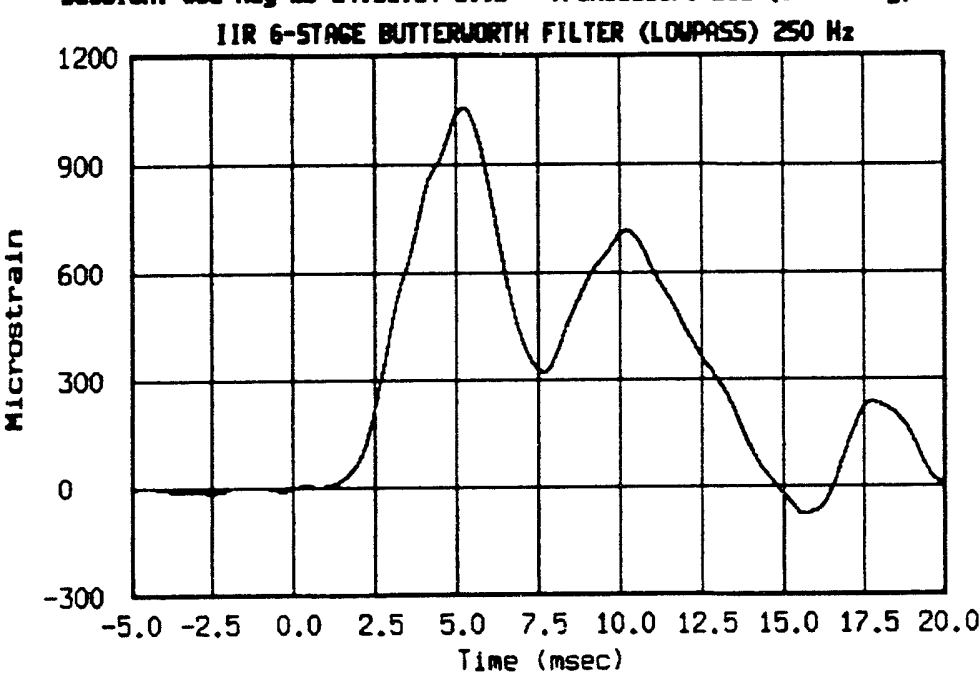

$\overrightarrow{\check{\sigma}}$

Test: LONGITUINA HIGH VEDOCITY H1224A 08/11/93 (223) Session: Led Rug 25 14:11:21 1993 Transducer: 562 (secondary)

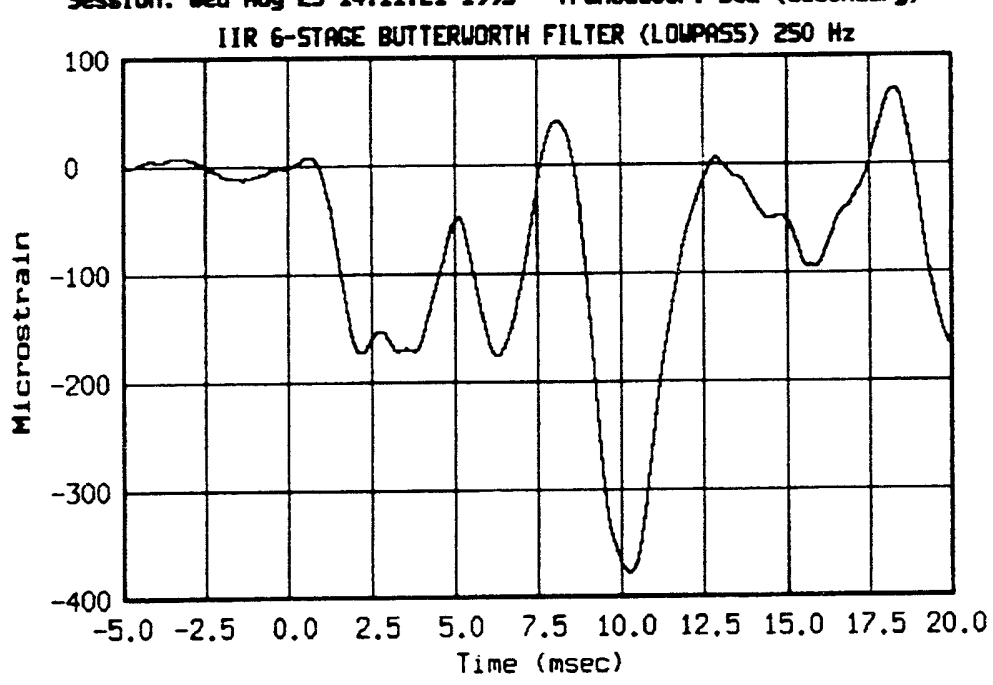

Test: LOXSITLIIML HIEH VELCCITY H12249 08/11/93 (223) Session: led fug 25 14:11:27 1993 Trenedveer: 593 (secondary) IIR G-STAEE GTTERLORTH FILTER (LOAPASS) $250 \mathrm{~Hz}$

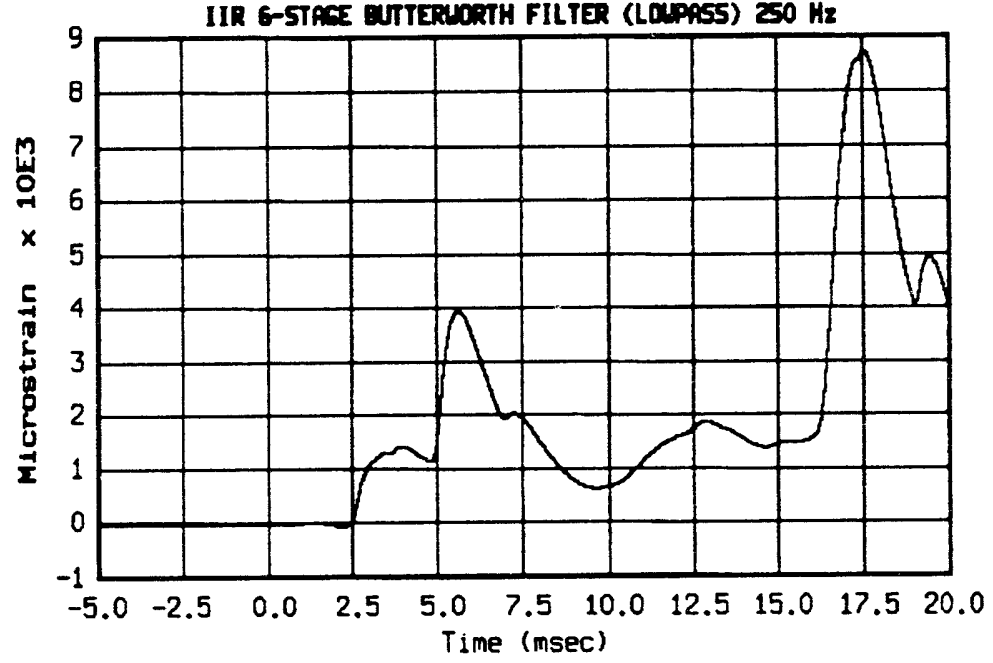

Test: LONGITUOIML HIGH VEDCITY H1224A 08/11/93 (223) Session: leed Aug 25 14:11:32 1993 Transitucer: SS4 (sucondary)

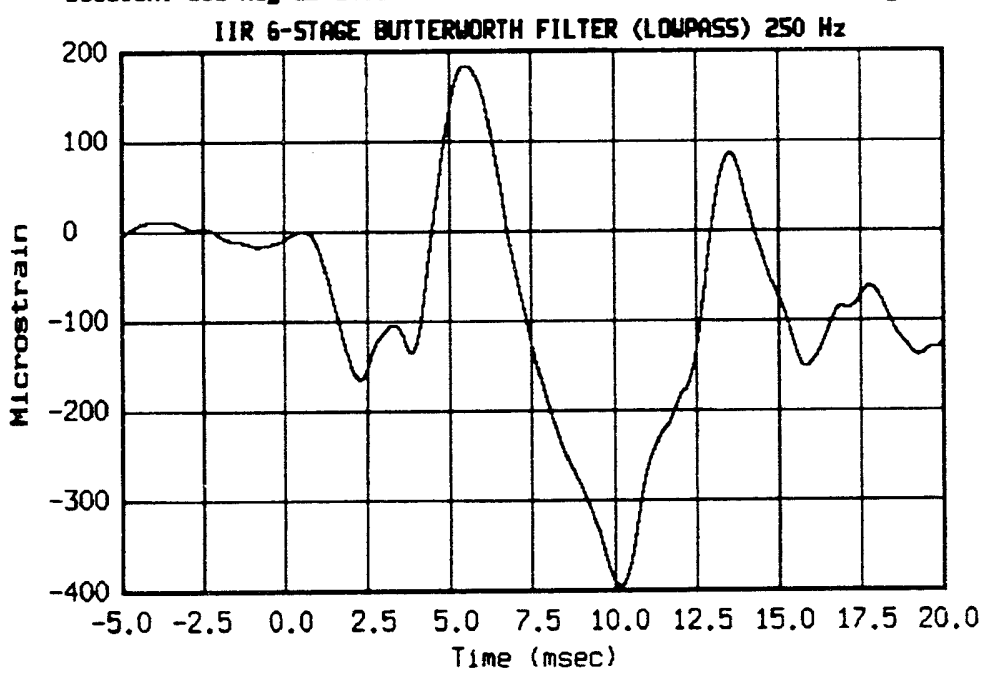




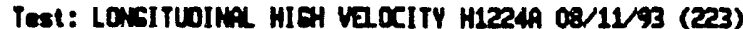
Session: lind Aug 25 14:11:39 1993 Transedveer: S65 (seoondary) IIR G-5TREE OUTHERORTH FILTER (LOPPSS) $250 \mathrm{~Hz}$

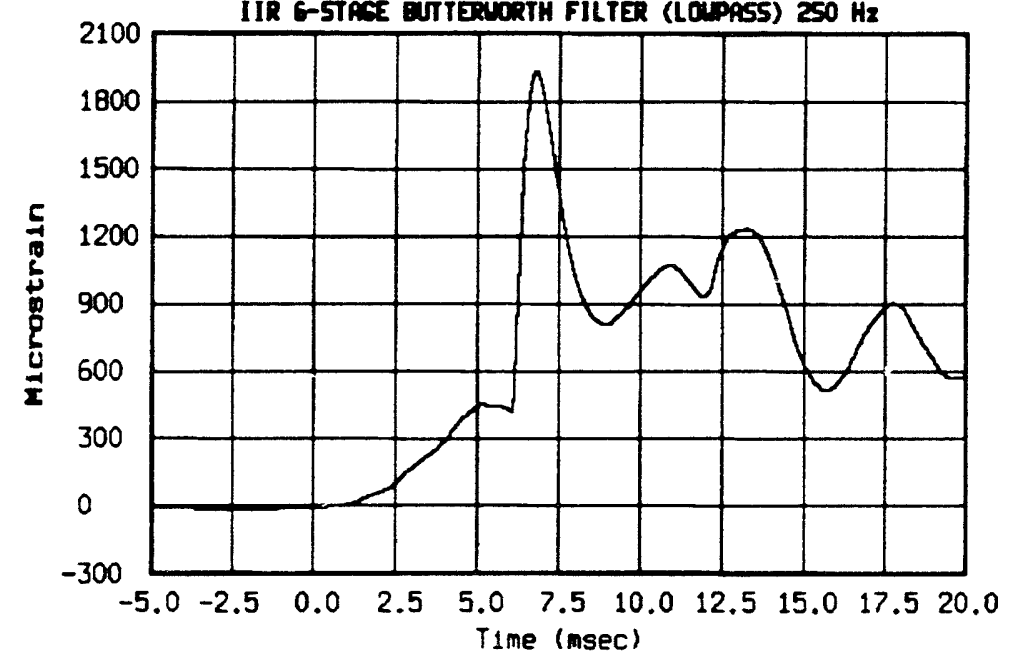

Test: LONGITUDINA HIGH VEOCITY H1224A 08/11/93 (223) 5ession: Led Aug 25 14:11:46 1993 Transodweer: 566 (secondary) IIR G-STREE BUTTERUORTH FILTER (LOLPR55) $250 \mathrm{~Hz}$

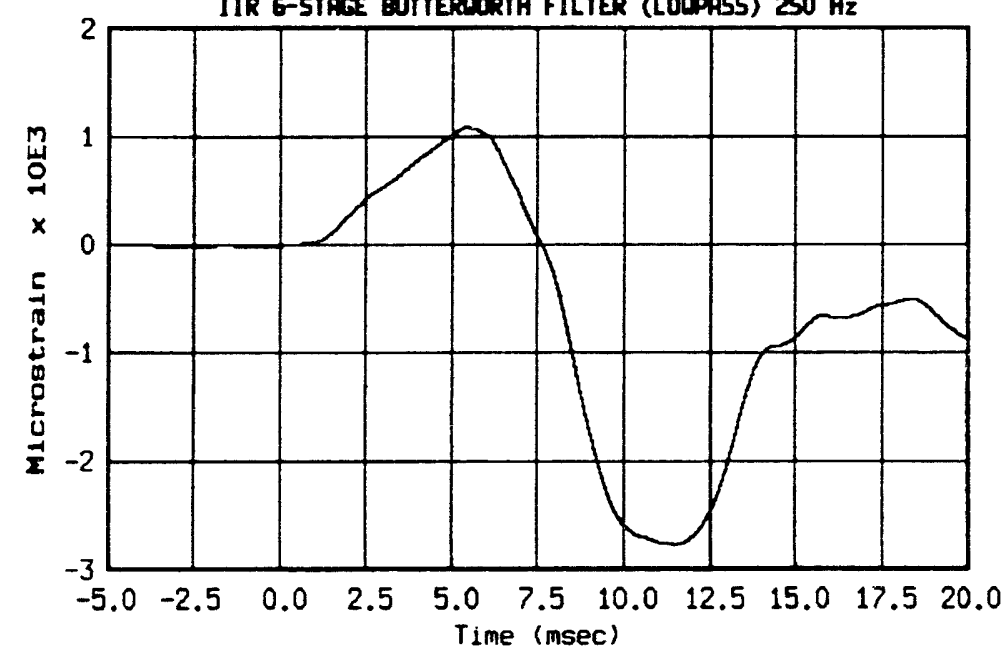

Test: LOWSITOIM HICH VבCCITY H12249 08/11/93 (223) Session: led Aug 25 14:11:54 1993 Trenschoer: 507 (secondary) IIR 6-STREE EUTTEAORTH FILTER (LOPPS5) $250 \mathrm{~Hz}$

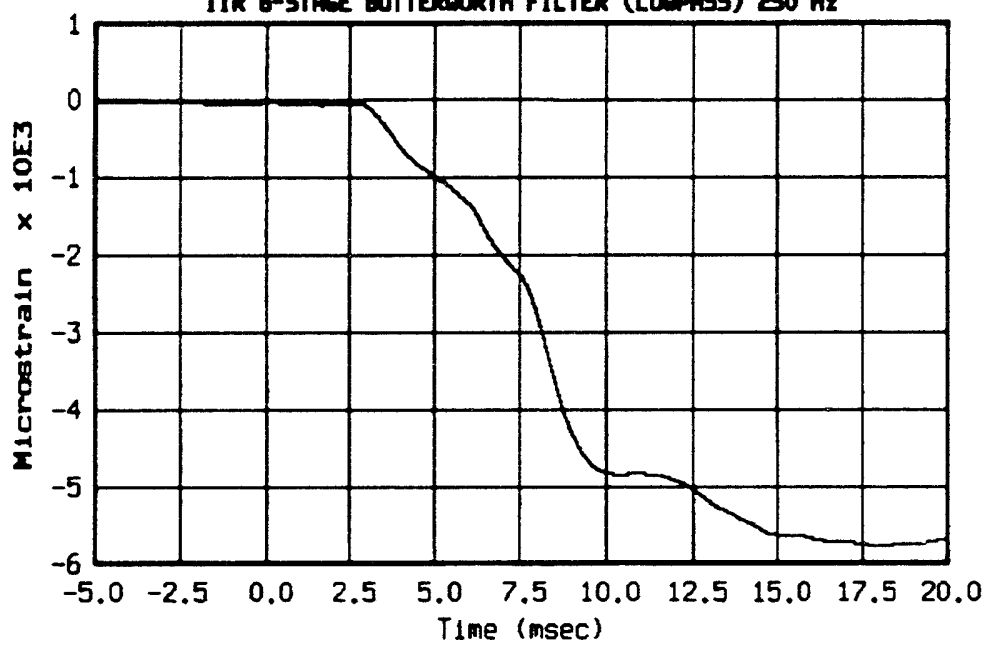

Test: LONGITUDIRL HIEH VELCITY H1224A 08/11/93 (223) Session: Led fus 25 14:12:00 1993 Transotuder: 508 (secondary)

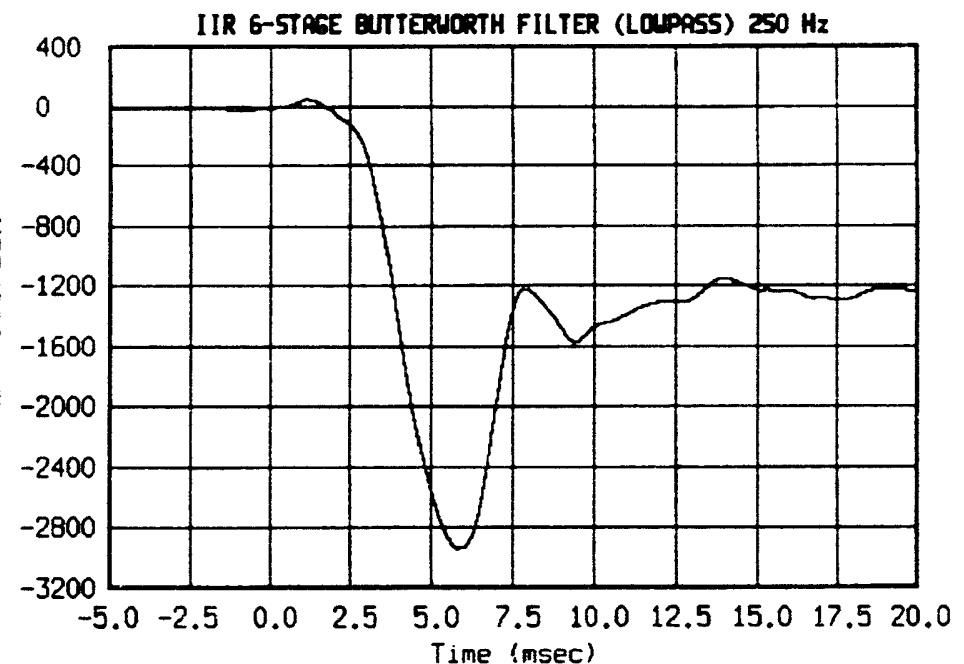




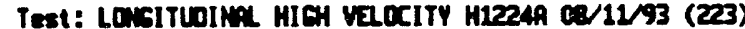
Session: Led Aug 25 14:12:06 1993 Transducer: 599 (secondery) IIR G-STREE EUTTERUORTH FILTER (LOAPRSS) $250 \mathrm{~Hz}$

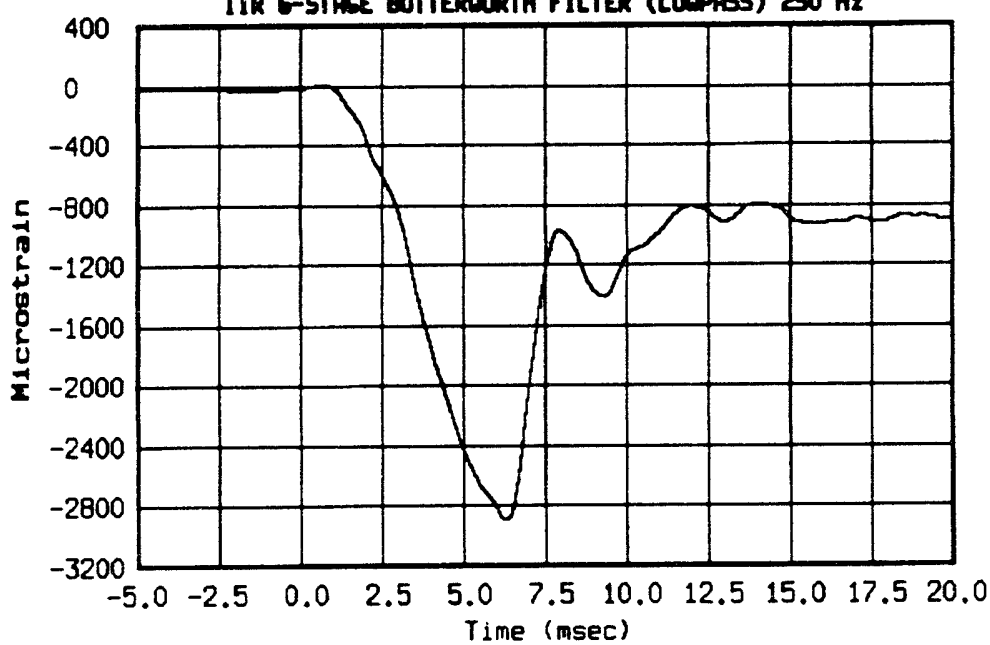

$\bar{N}$ Session: thed fug 25 14:12:12 1993 iransducer: 5610 (secondery)

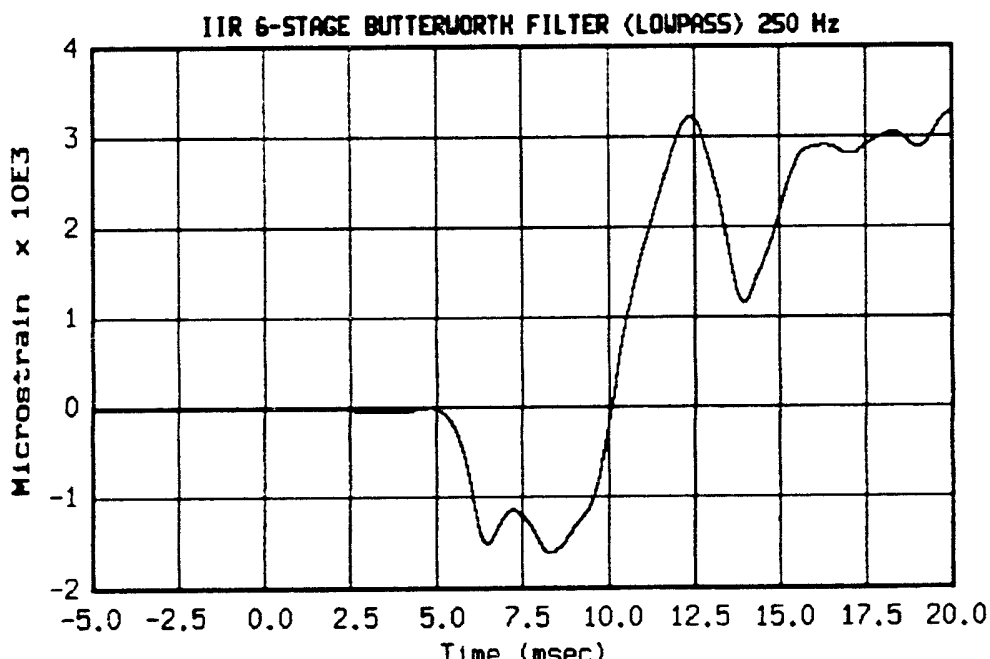

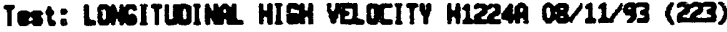
Session: Led Aus 25 14:12:17 1993 Transedver: 5611 (ecoondary)

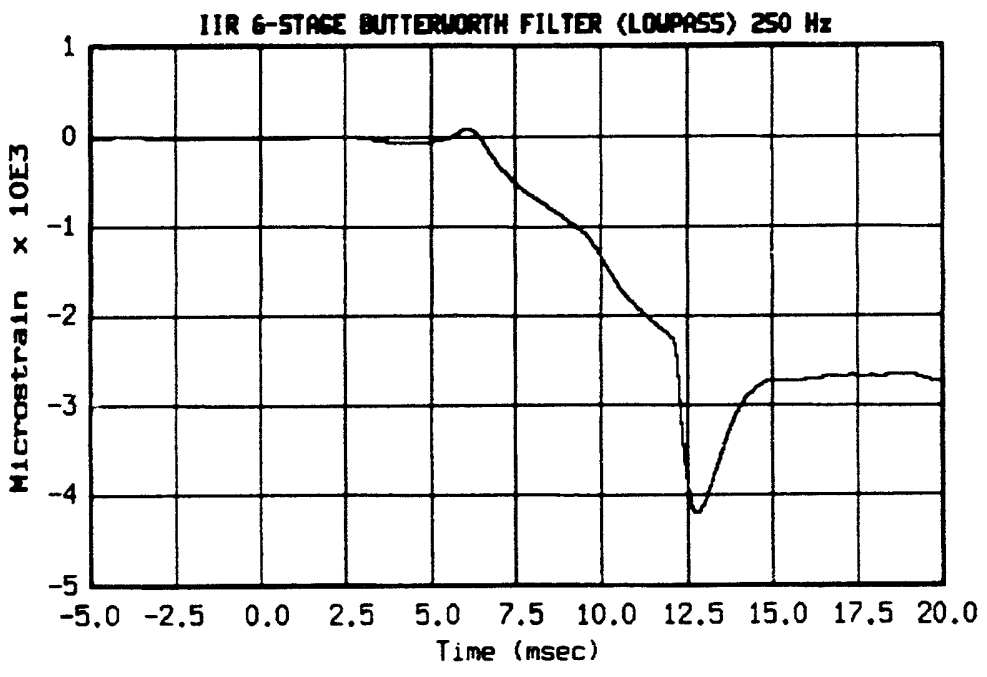

Test: LONGITUDINL HIGH VElOCITY H12249 08/11/93 (223) Session: Hed Aug 25 14:12:25 1993 Transducer: 5612 (secondary)

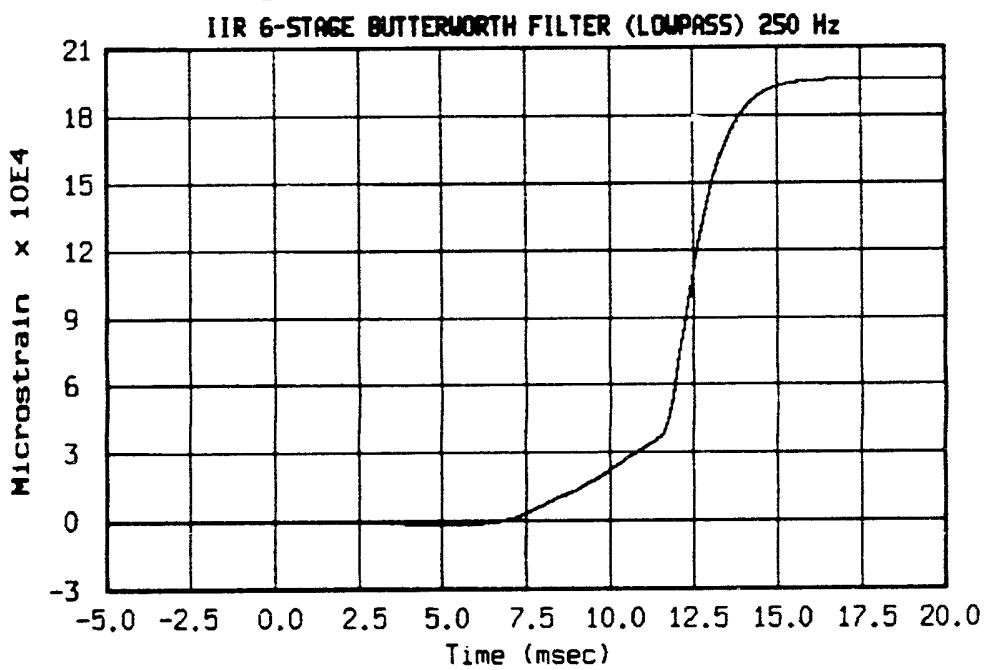


Test: LOKSITUDIMA HIOH VelOCITY H1224A 08/11/93 (223) Session: led fug 25 14:12:31 1993 Trunsducer: 5613 (secondary) IIR G-STAGE BUTERAORTH FILTER (LOAPASS) $250 \mathrm{~Hz}$

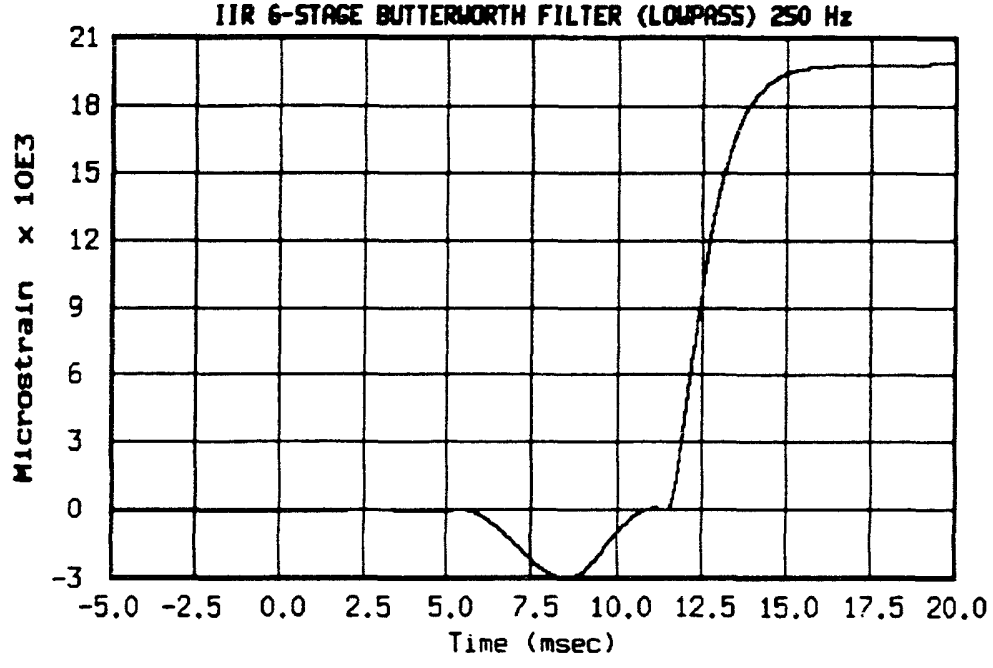

Test: LOWGITLOINAL HIGH VEOCITY H1224A 08/11/93 (223) Session: Ved Aug 25 14:12:39 1993 Transducar: 5614 (secondary) IIR G-STAGE BUTTERLORTH FILTER (LOUPASS) $250 \mathrm{~Hz}$

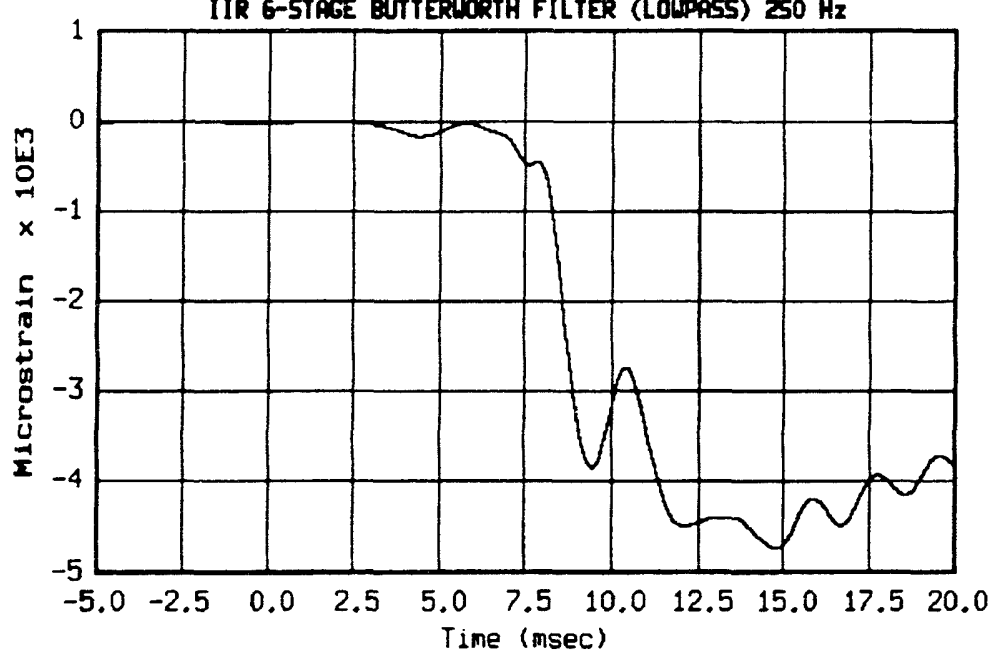

Test: LOWSITLOINL HIEH VElOCITY H12249 08/12/93 (223) Session: thed hug 25 14:12:44 1993 iransdwoer: 515 (secondary)

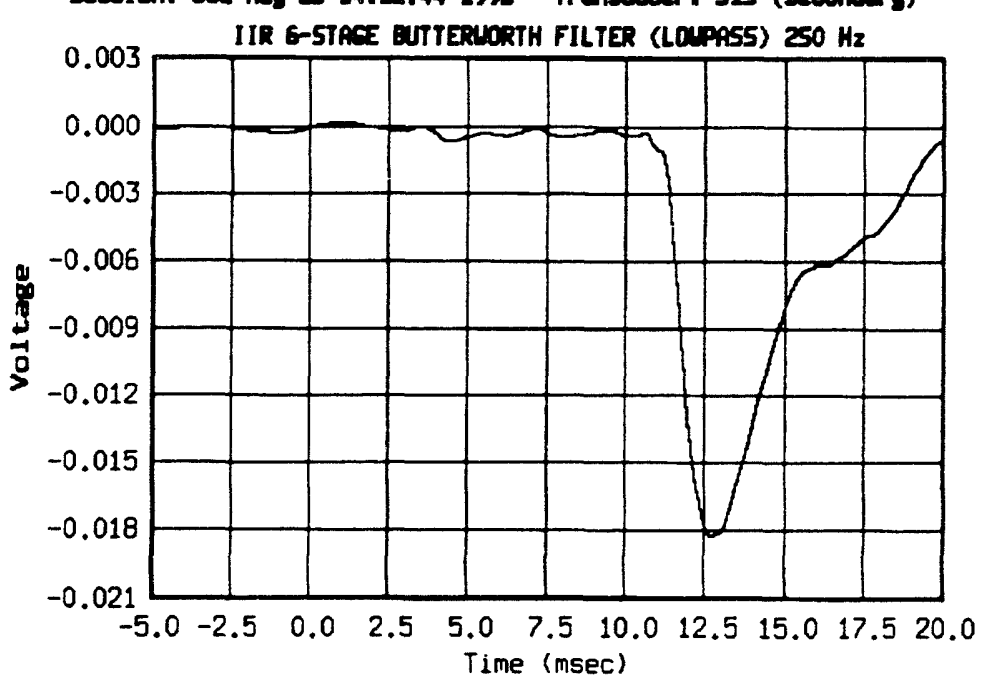

Test: LOAGITUOIMP HIGH VEOCITY H1224A O8/11/93 (223) Session: thed Rug 25 14:12:51 1993 Trunsducer: 516 (secondary)

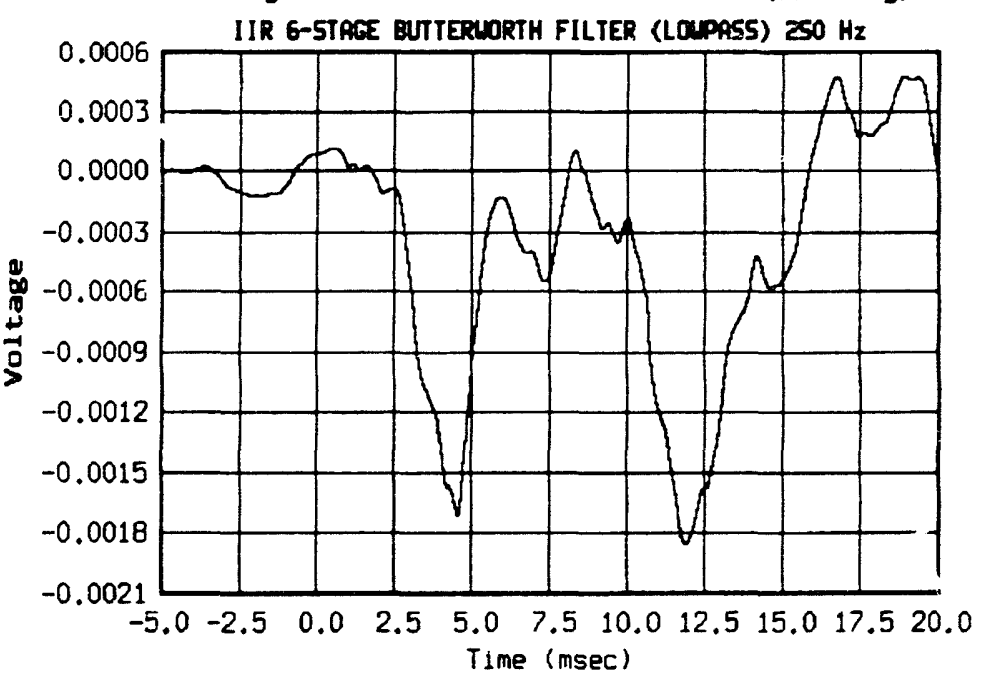


Test: LONGITLIMA HICH VEOCITY HI224A 08/11/93 (223) 5ession: Thu Aug 12 11:07:29 1993 Transducer: A1 (secondary) IIR 6-STAEE QUTTERLORTH FILTER (LOUPASS) $2000 \mathrm{~Hz}$

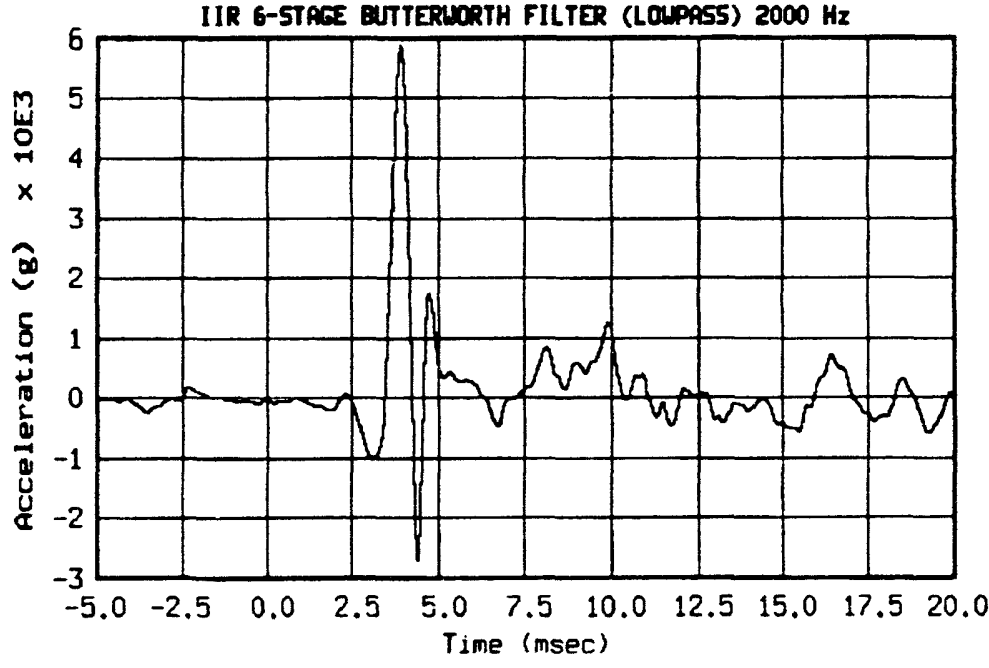

TEst: LONGITWIML HIOH VEOCITY H12249 08/11/93 (223) Session: Thu Rug 12 11:07:26 1993 Transducer: R2 (secondary)

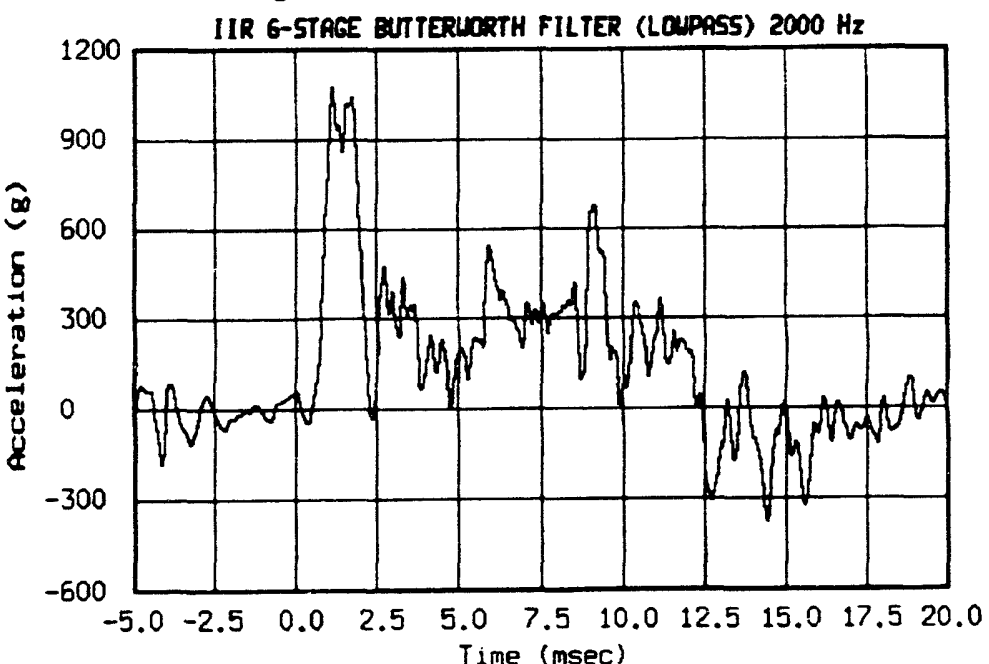

Test: LONSITUINL HICH VEOCITY H1224月 08/12/93 (223) Seseion: Thu Pug 12 11:07:44 1993 Transducer: A3 (secondary)

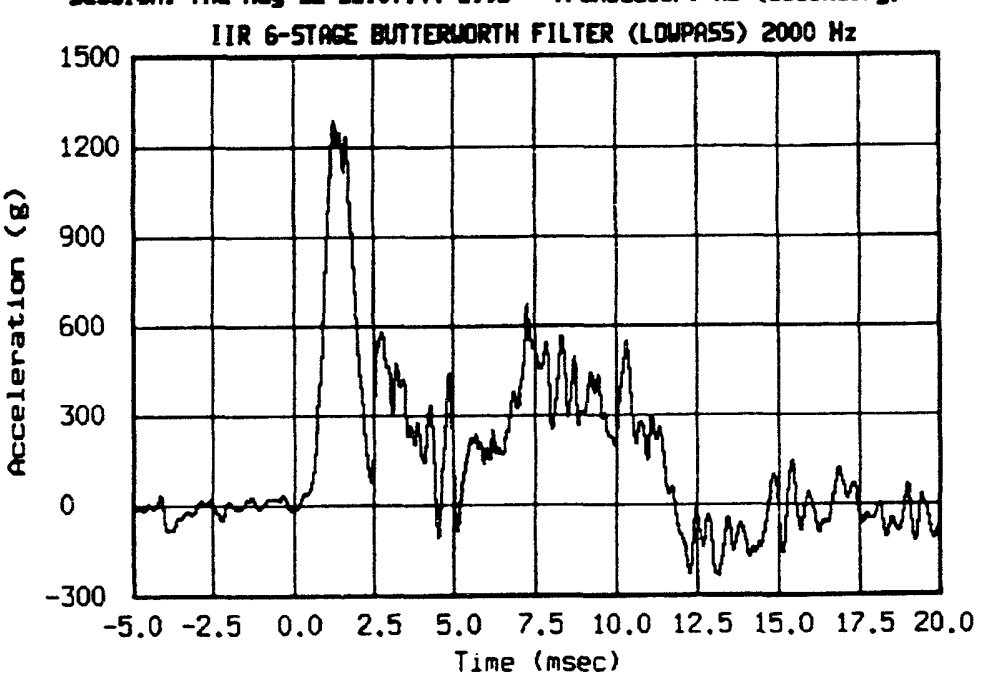

Test: LOGGITUIMLL HIEH VeOCITY H1224A 08/12/93 (223) Session: Thu Aug 12 11:07:40 1993 Transducer: A4 (secondary)

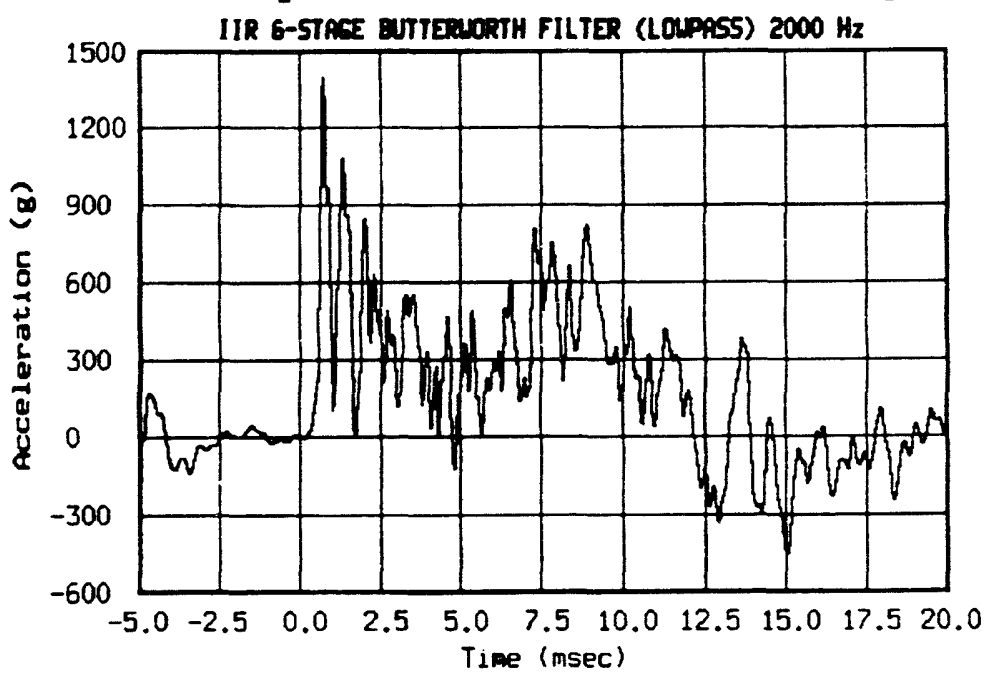


Tes: LONGITUINAL HIGH VeבCITY H1224A 08/11/93 (223)

Session: Thu Aug 12 11:07:58 1993 Transctucer: A5 (secondary) IIR 6-5TAEE BUTTERUORTH FILTER (LOAPASS) $2000 \mathrm{~Hz}$

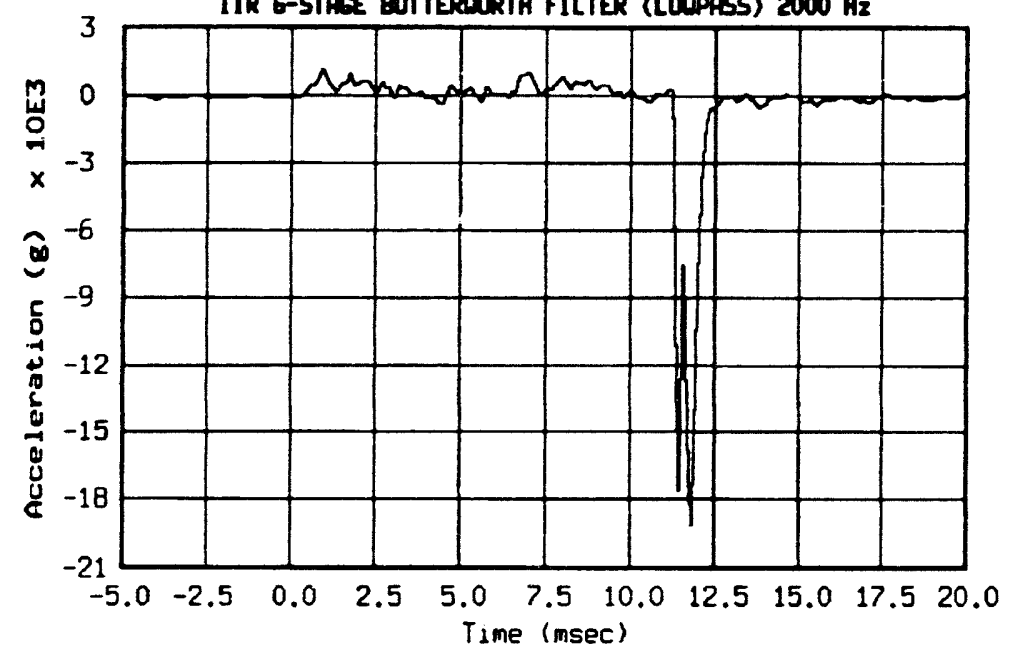

Test: LONGITLINAL HIGH VEDCITY H12249 08/12/93 (223) Session: Thu Aug 12 11:07:54 1993 Transducer: A6 (secondary) IIR G-STAGE BUTTERUORTH FILTER (LOPPASS) $2000 \mathrm{~Hz}$

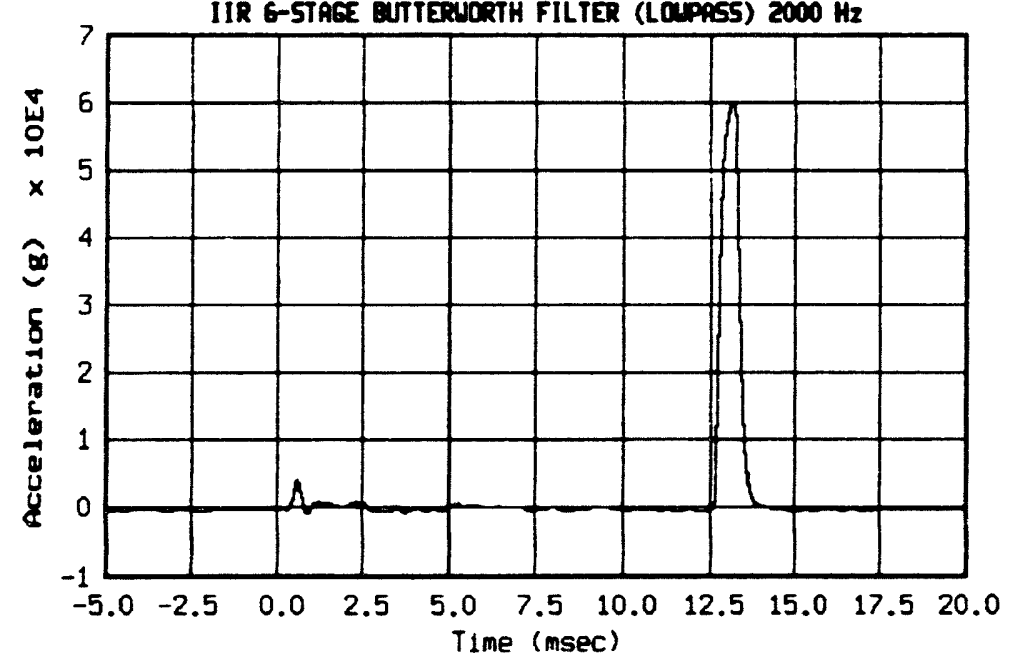

Test: LOWSITUDIn HIG VElOCITY H1224h 08/11/93 (223) Sexsion: The Aur 12 11:08:15 1993 Transducer: A7 (secondary) IIR 6-5TREE UITERUDRTH FILTER (LOUPA5S) $2000 \mathrm{~Hz}$

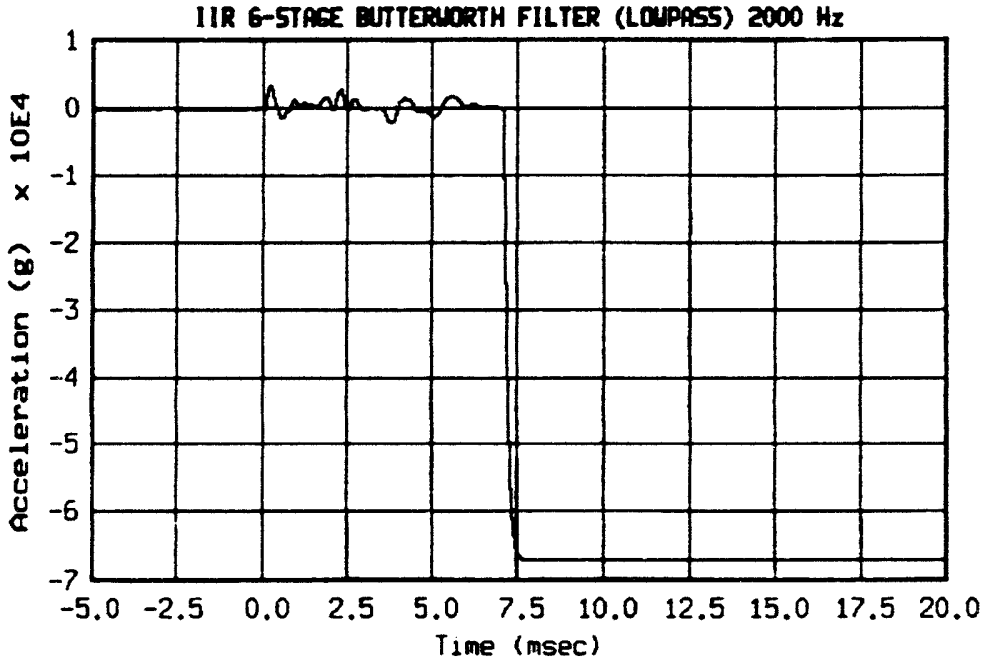

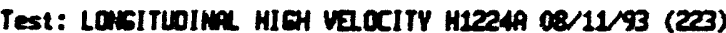
Session: Thu Aug 12 11:08:11 1993 Transducer: 18 (seoondary)

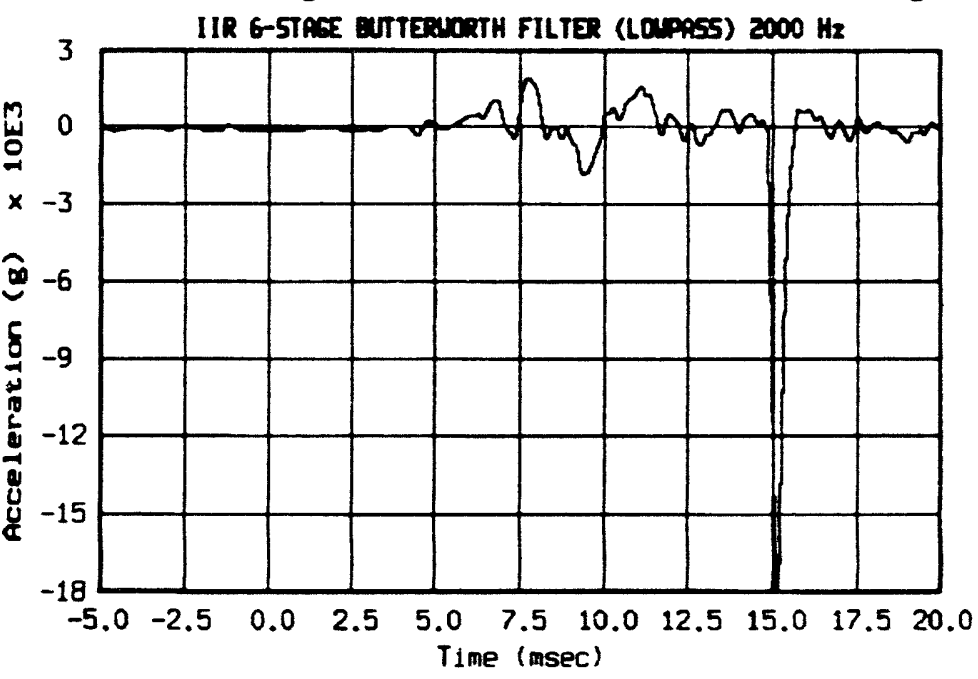


Test: LONGITUDIML HIGH VeocITY H12249 08/11/93 (223)

Session: Thu Aug 12 11:08:25 1993 Transtucer: 99 (secondary) IIR 6-STACE BUTTERAORTH FILTER (LOLPASS) $2000 \mathrm{~Hz}$

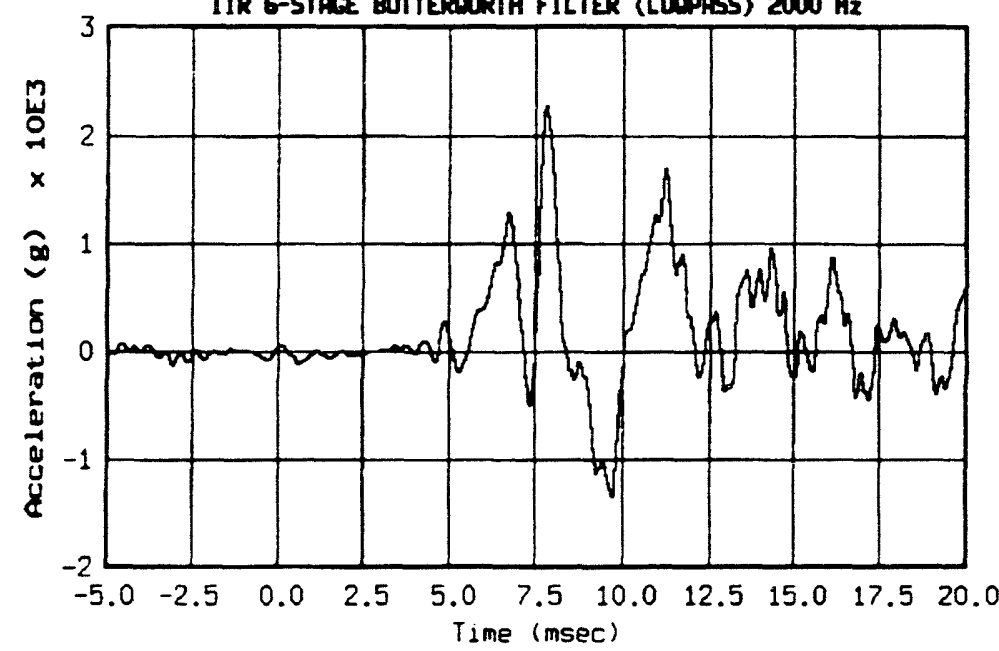

Test: LOWSITUIM HIGH VEOCITY H1224A 08/11/93 (223) Session: Thu Aug 12 11:08:30 1993 Transducer: A10 (secondary)

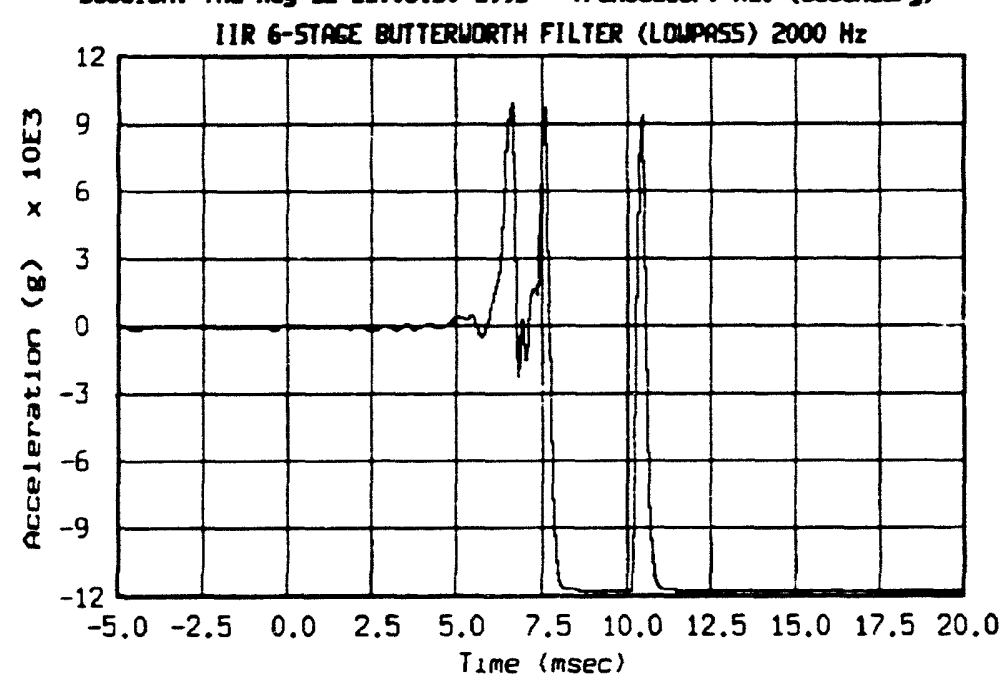

Test: LasITLIMP HIGH VacciTy M12249 08/12/93 (223) Session: Thu 12 11:08:39 1993 Transtucer: A11 (secondary) IIR G-STAGE EITTEUUORTH FILTER (LOAPA5S) $2000 \mathrm{~Hz}$

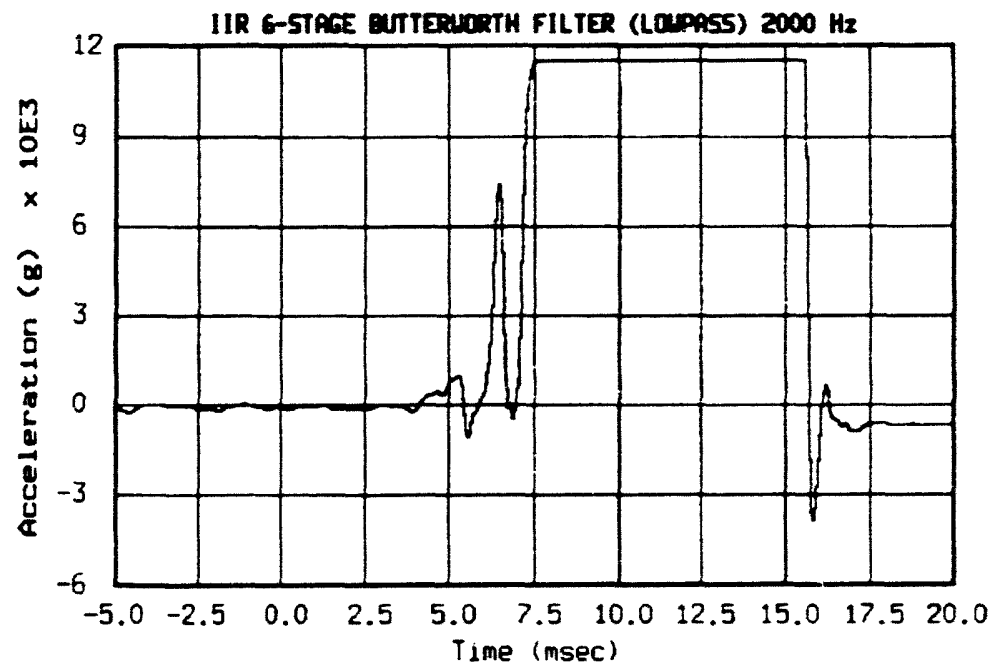

Test: LO5ITLIMP HIGH VaOCITY H12244 08/21/93 (223) Session: Thu fur 12 11:08:45 1993 Transucer: $A 13$ (secondary)

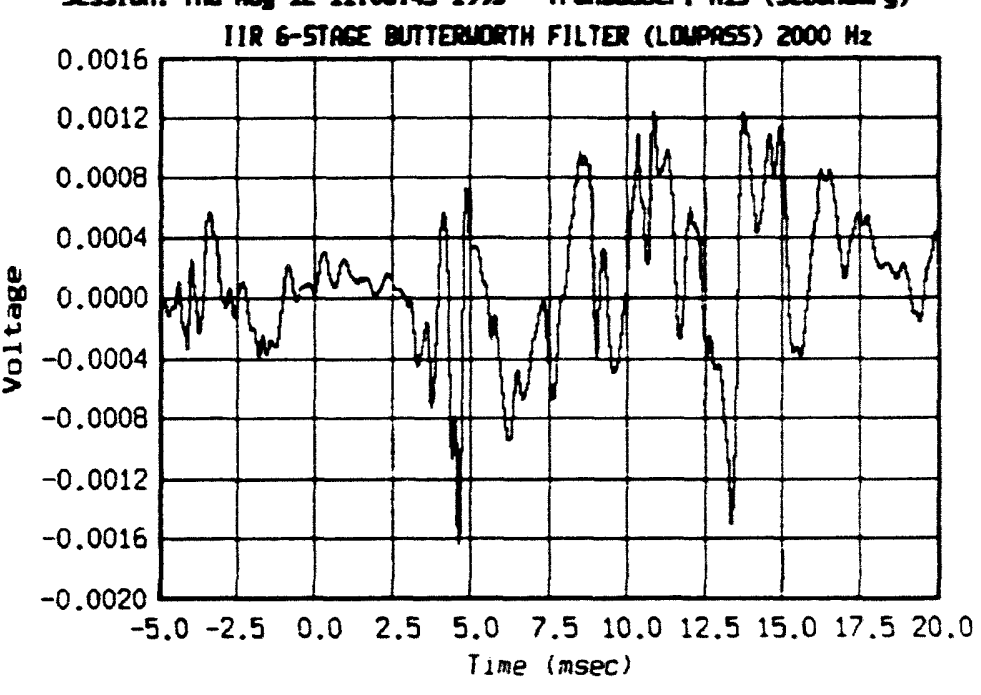


Test: LOSITLDIM HIGH VEOCITY H1224A 08/11/93 (223) Session: Thu Aug 12 11:08:55 1993 Transotucer: 561 (secondary)

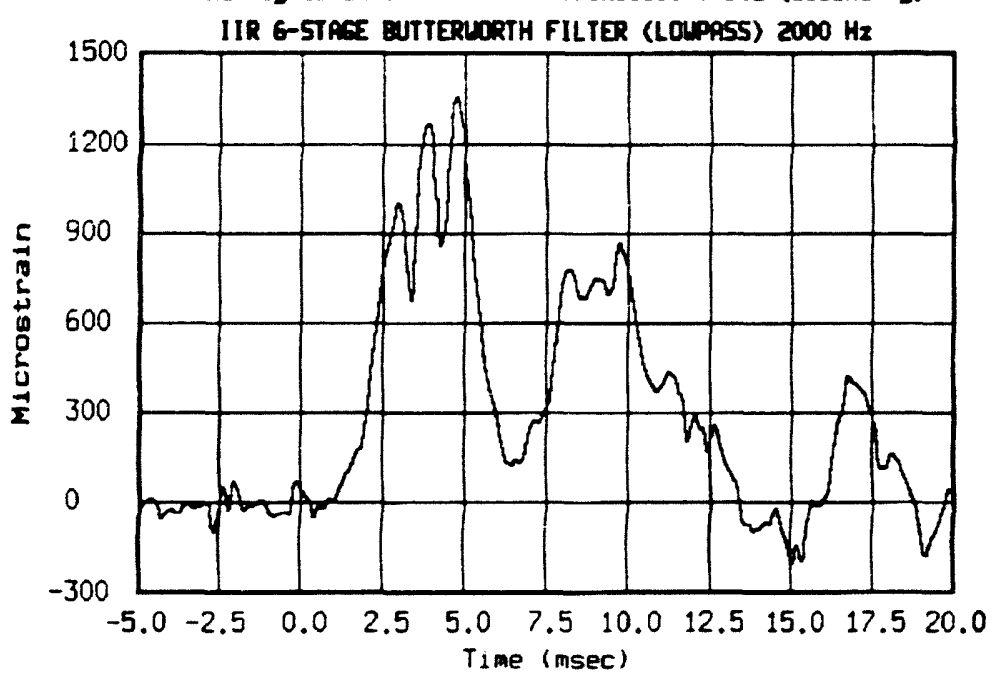
Session: Thu fug 12 11:09:01 1993 Transducer: 502 (secondary)

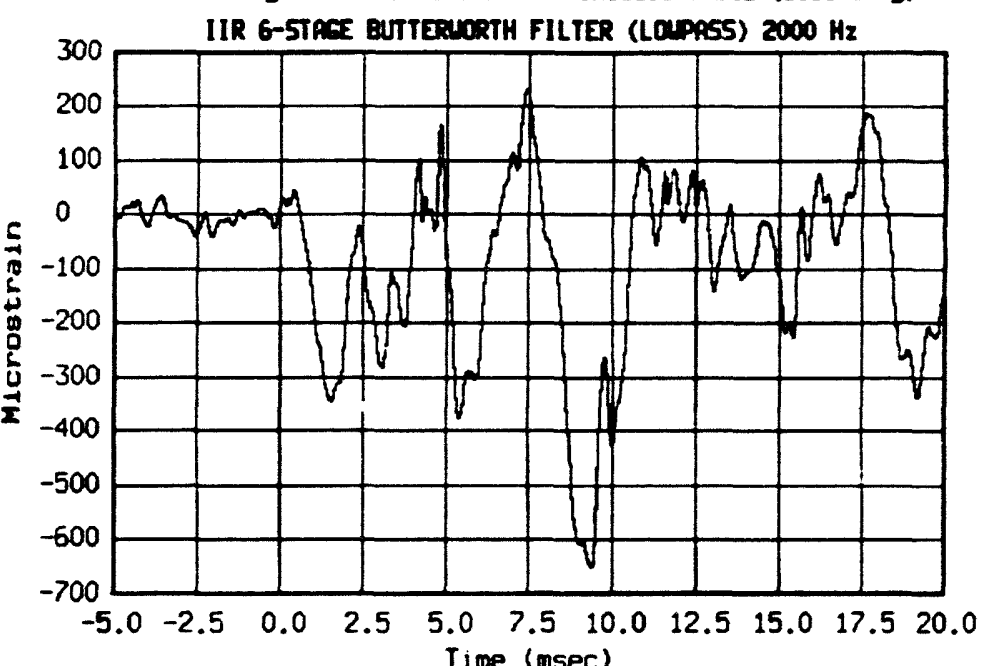

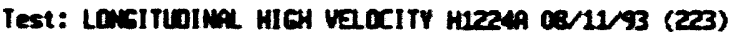
Session: Thu Pug 12 11:09:08 1993 Transtucer: 563 (secondery)

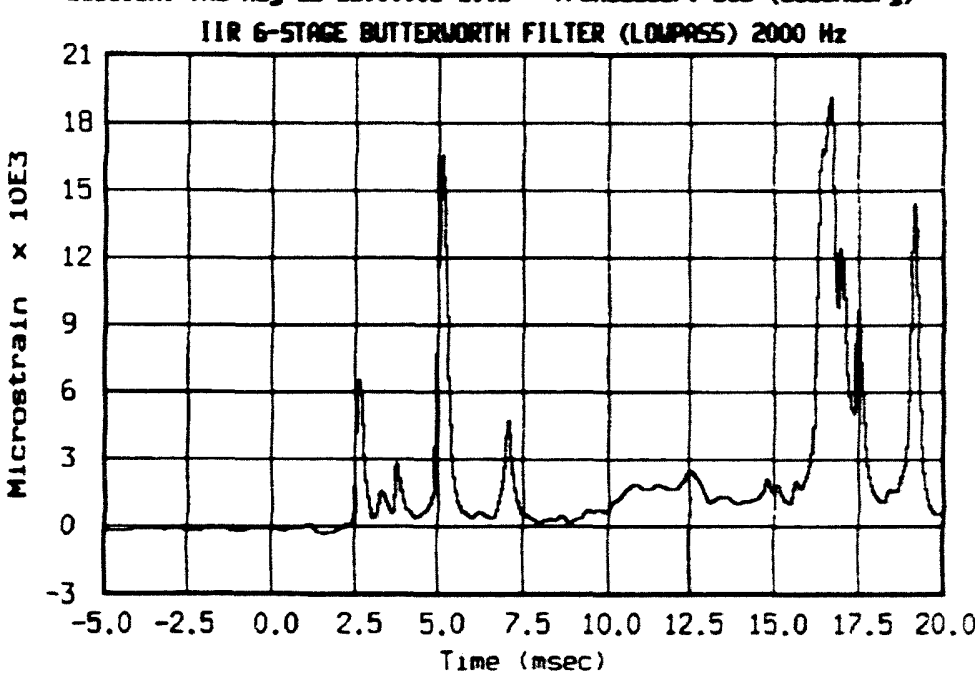

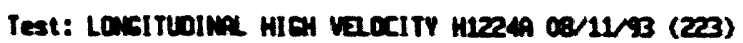
Session: The fug 12 11:09:14 1993 Tranedveer: SAt (secondary) IIR 6-5TREE BUTTERUORTH FILTER (LOUPPSS) $2000 \mathrm{~Hz}$

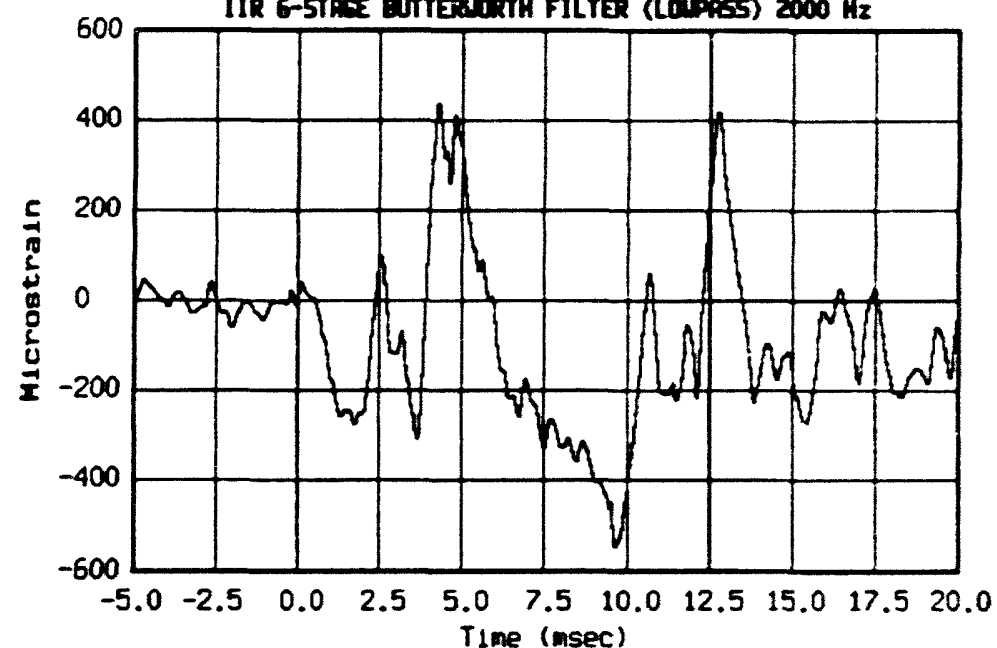




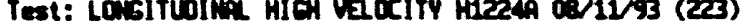
Session: Thu Aug 12 11:09:21 1993 Transoducer: S65 (secondary)

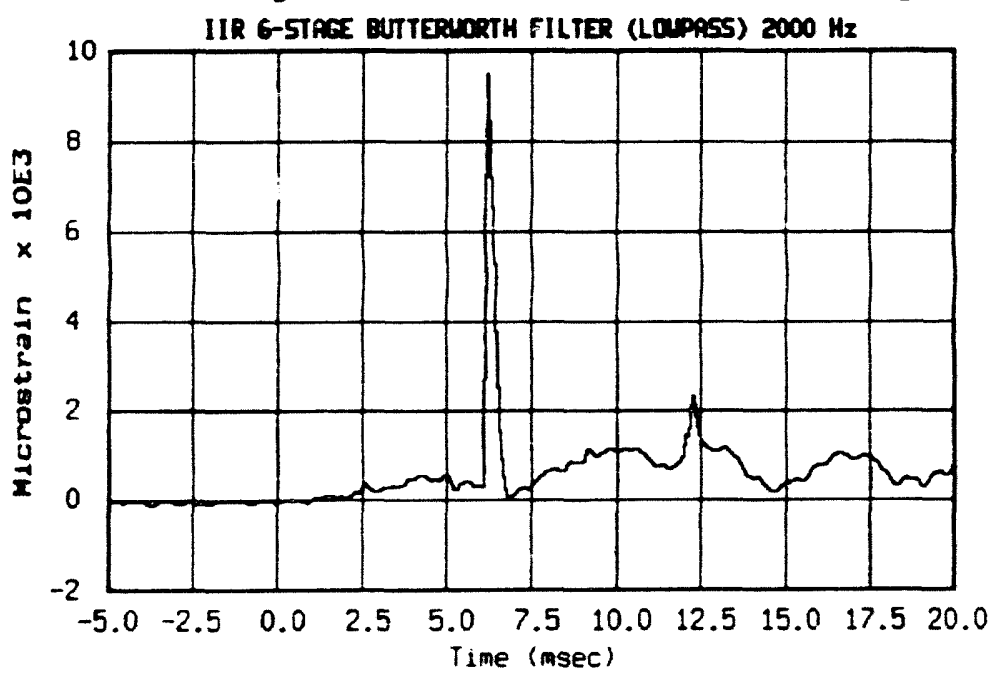

$\bar{x}$

Test: LOKCITLDIM HICH VeOCITY H1224h 08/12/93 (223) Session: Thu Aug 12 11:09:27 1993 Transdvoer: 506 (secondary) IIR 6-STAEE BUTTEXUCRTH FILTER (LOUPASS) $2000 \mathrm{~Hz}$

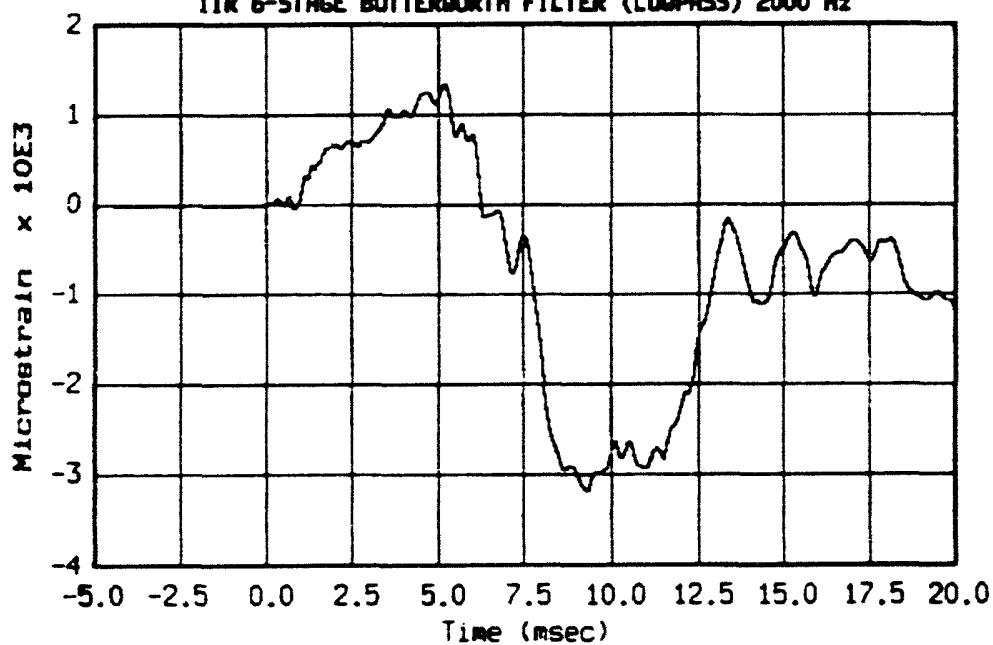

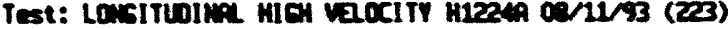
Session: Thu aus 12 11:09:35 1993 Iranoducer: 567 (secondary) IIR 6-STRE EUTTEUNRTH FILTER (LOAPRSS) $2000 \mathrm{~Hz}$

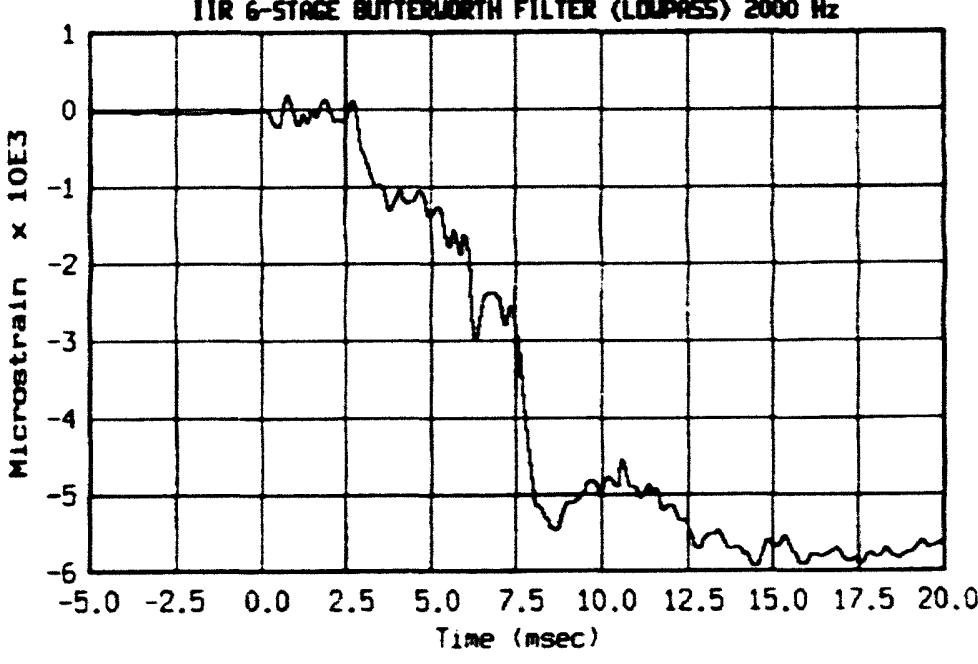

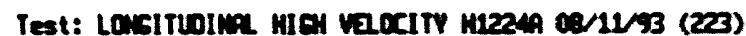

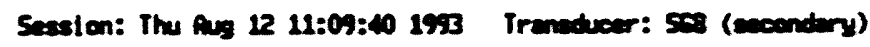
IIR 6-STPCE AITTEUMRTH FILTER (LOAPSS) $2000 \mathrm{~Hz}$

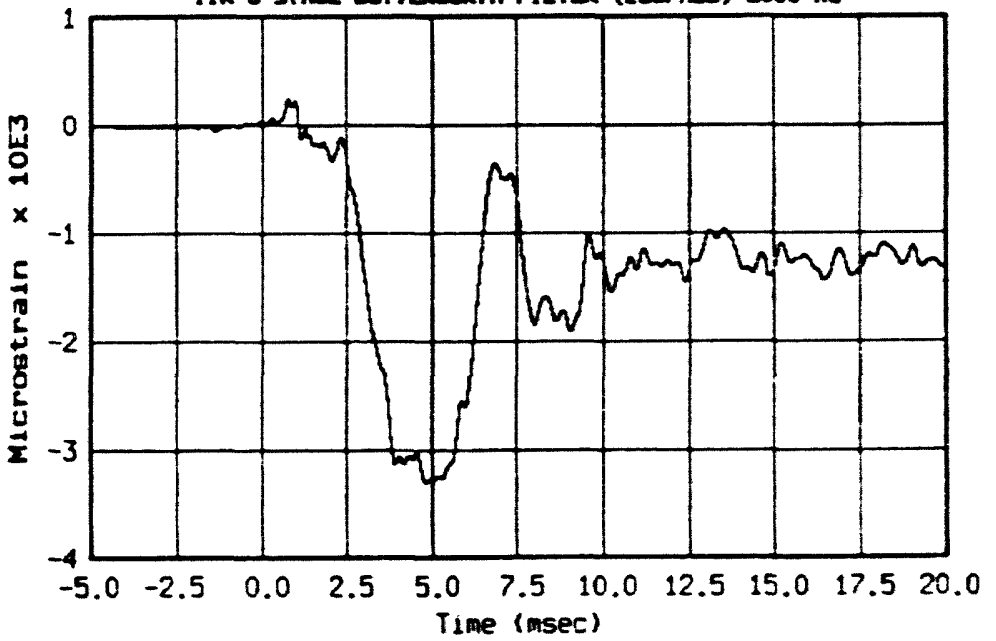




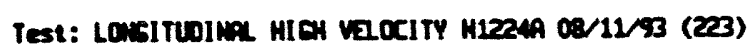
Session: Thu Aug 12 11:09:46 1993 Transtucer: 559 (secondwry) IIR 6-STRE EUTTEUORTH FILTER (LOMPES) $2000 \mathrm{~Hz}$

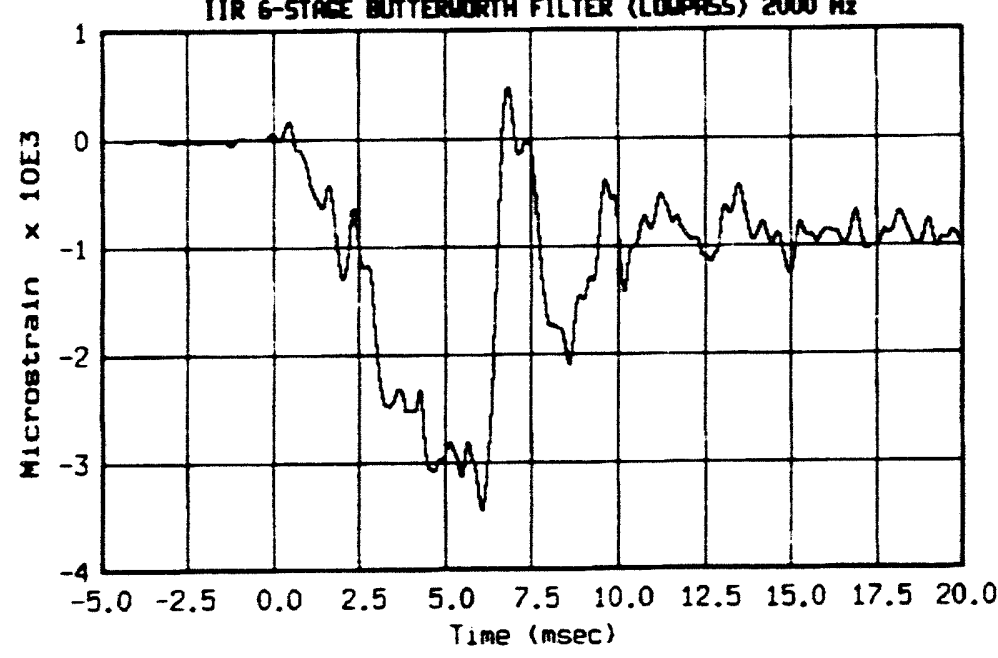

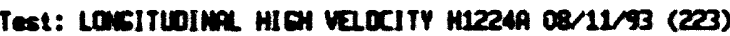
Session: Thu has 12 11:09:22 1993 Transducer: 5610 (secondery)

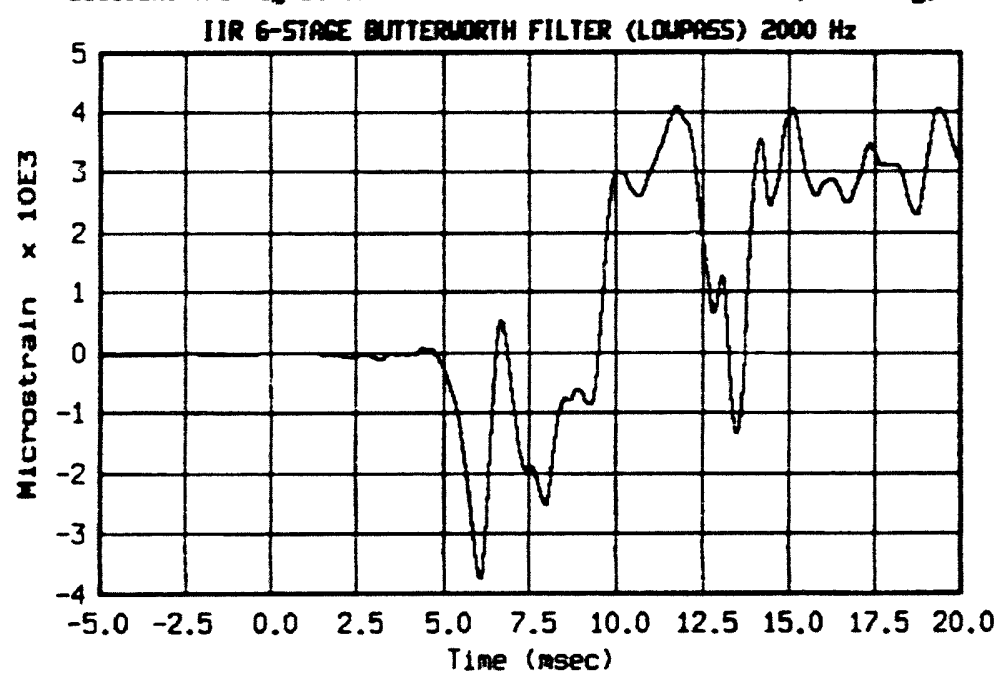

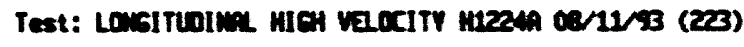
Session: Thu hus 12 11:10:00 1973 Irenetroer: 5511 (encondery)

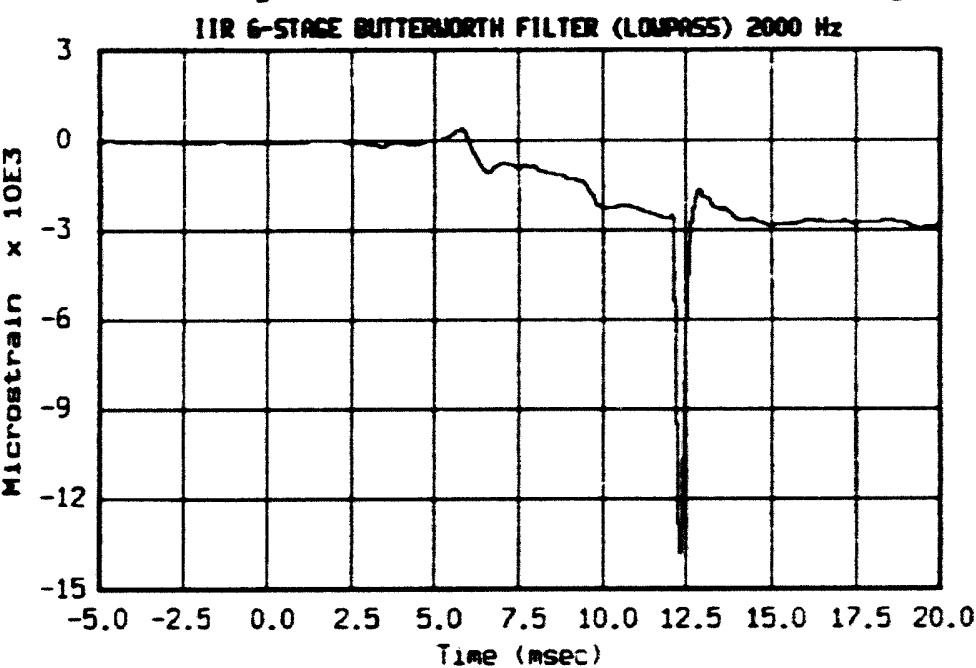

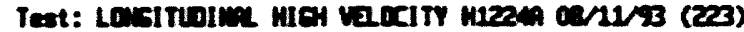
Sesslon: Thu has 12 11:10:07 1993 Tranedvoer: 5012 (meandery)

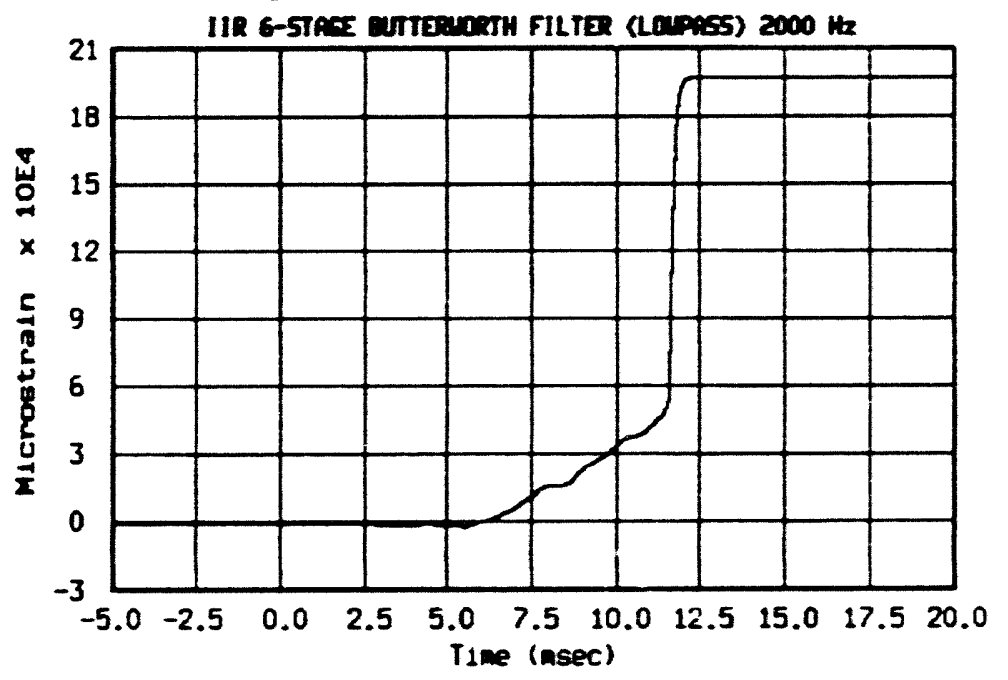


Test: LoxitwoIn HIGH VeCCITY H1224h 08/12/93 (223) Session: Thu Aug 12 11:10:15 1993 Transtucer: 5613 (secondary)

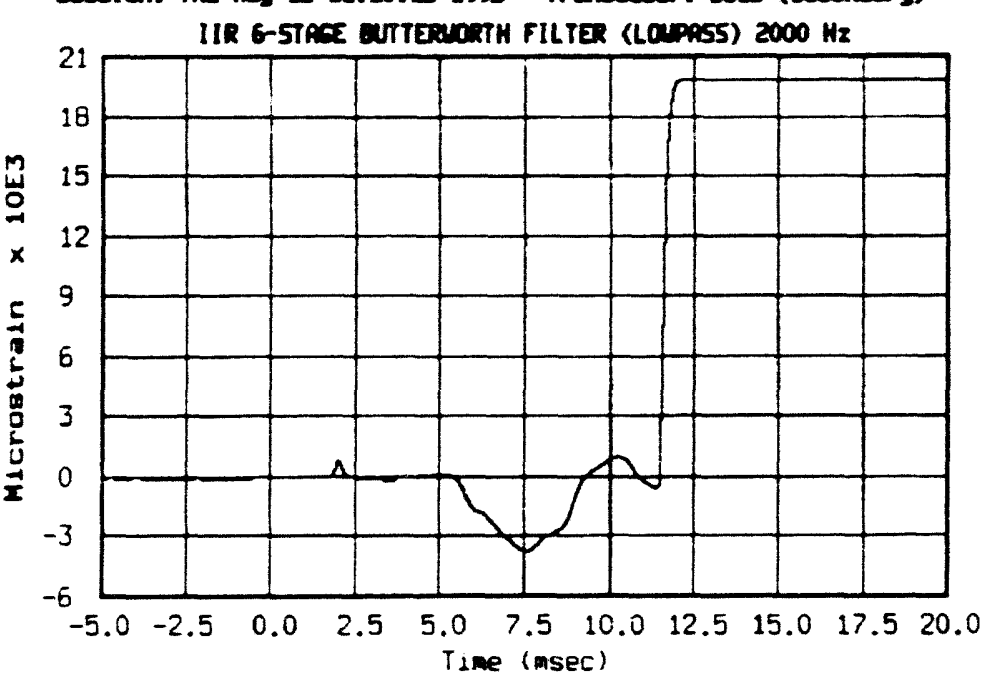

$\overline{8}$

Test: LOSITWOINAL HIEH VEOCITY HI224A De/12/93 (223) Session: Thu fug 12 11:10:21 1993 Trensodecer: 5614 (secondery)

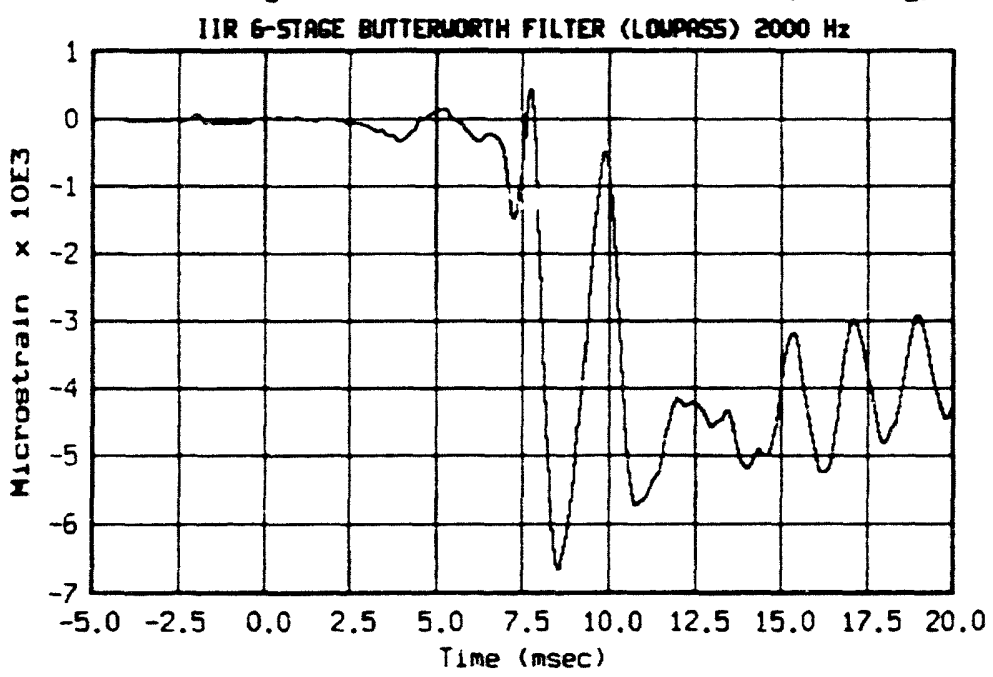

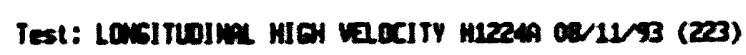

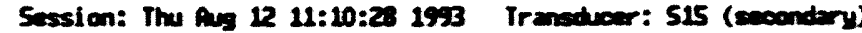

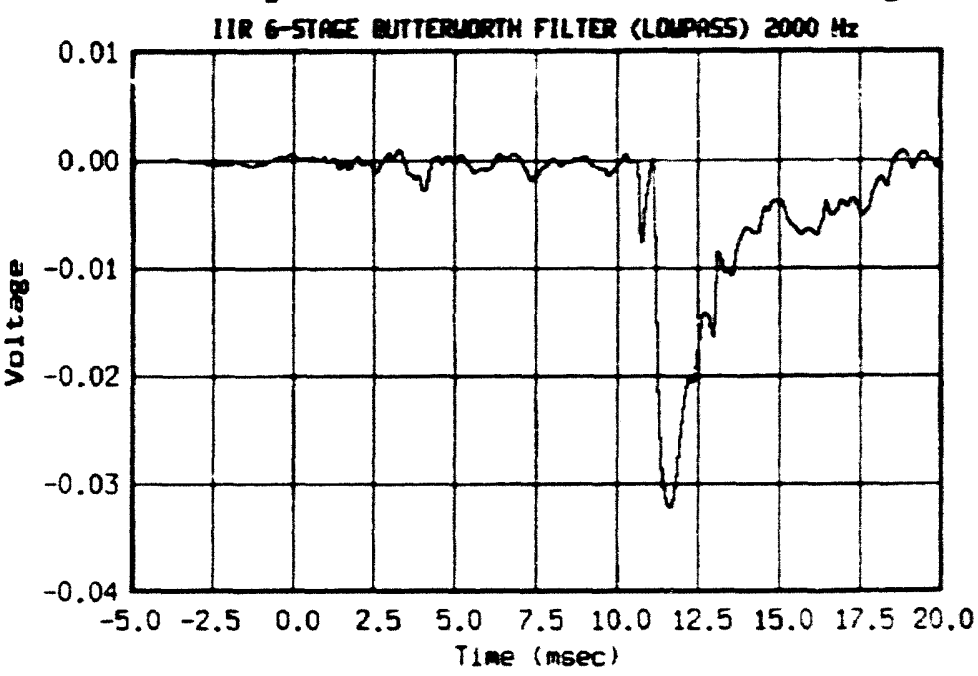

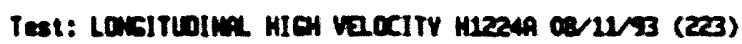
Session: Thu 12 11:10:35 1993 Transtoer: 516 (secondery)

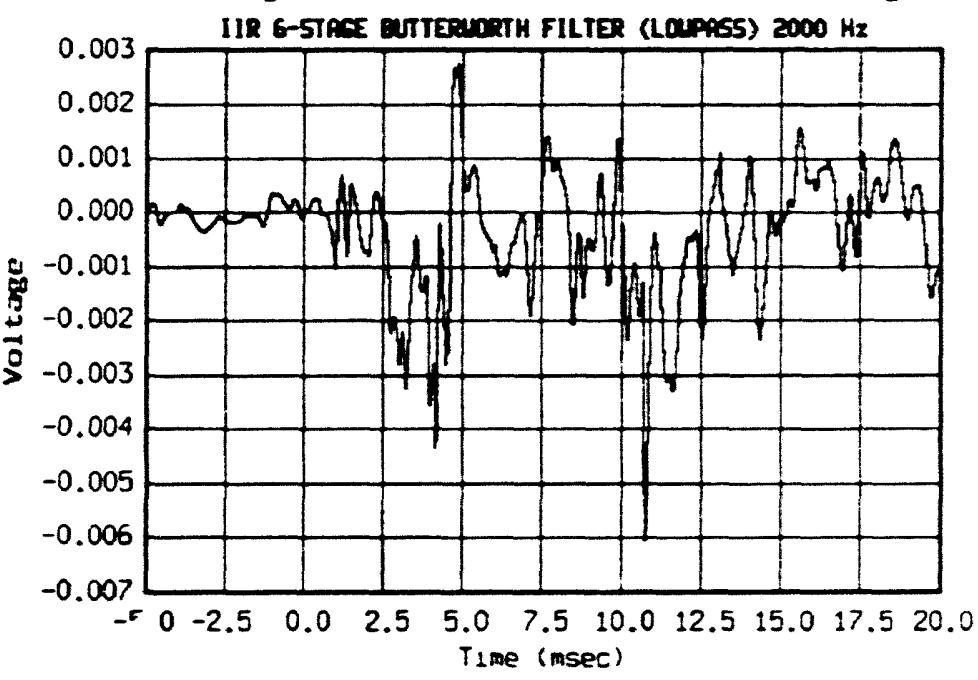



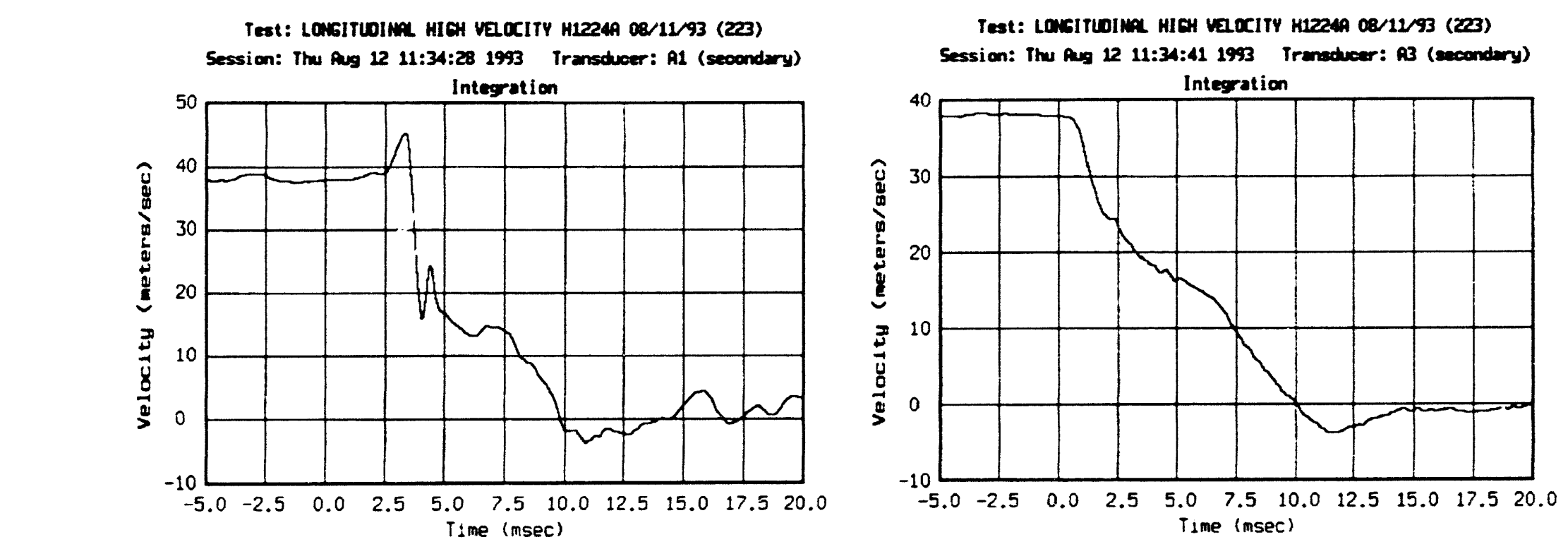

Test: LOKITUOINA HIEH VEIOCITY HI2249 08/12/93 (223) Session: Thu fus 12 11:34:33 1993 Transwicer: AR (seocondary)

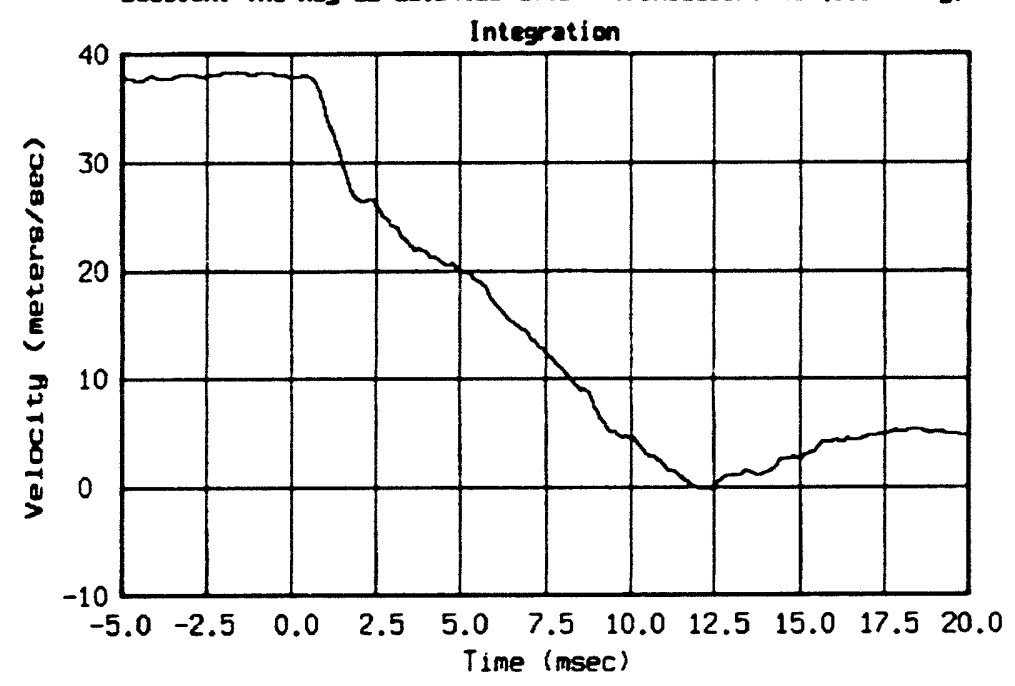

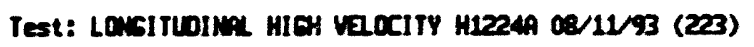
Session: Thu Aug 12 11:31:44 1993 Iransodver: MA (secondery)

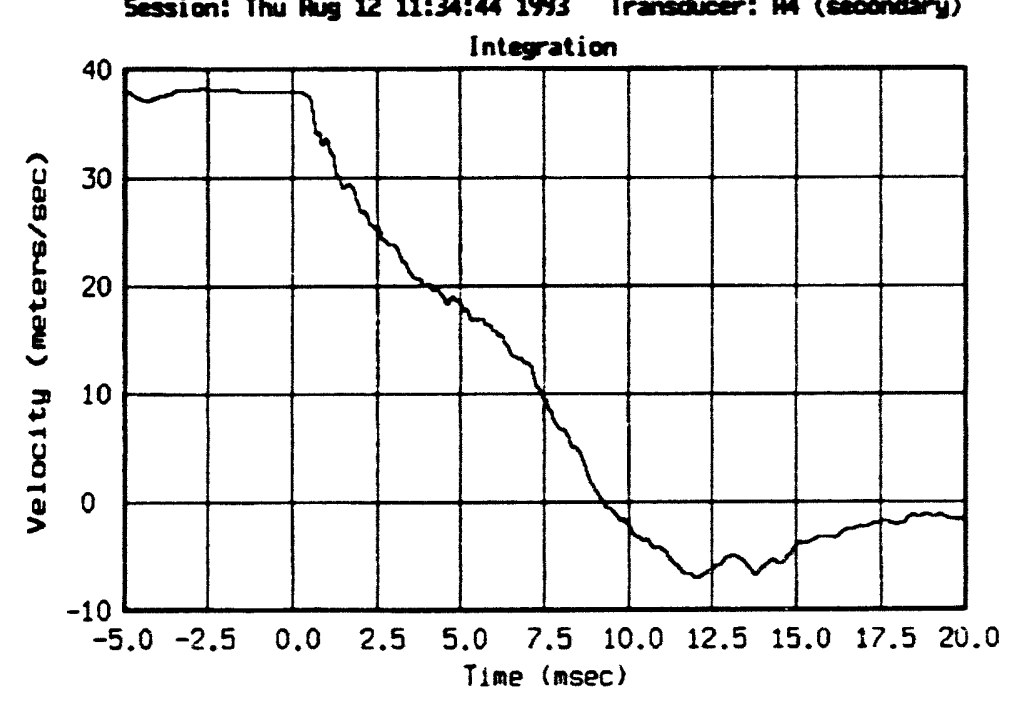


Test: LowsITDINA HIGH VelocITY H1224h Oe/11/93 (223) Session: Thu Aug 12 11:34:52 1993 Transducer: PS (secondary)

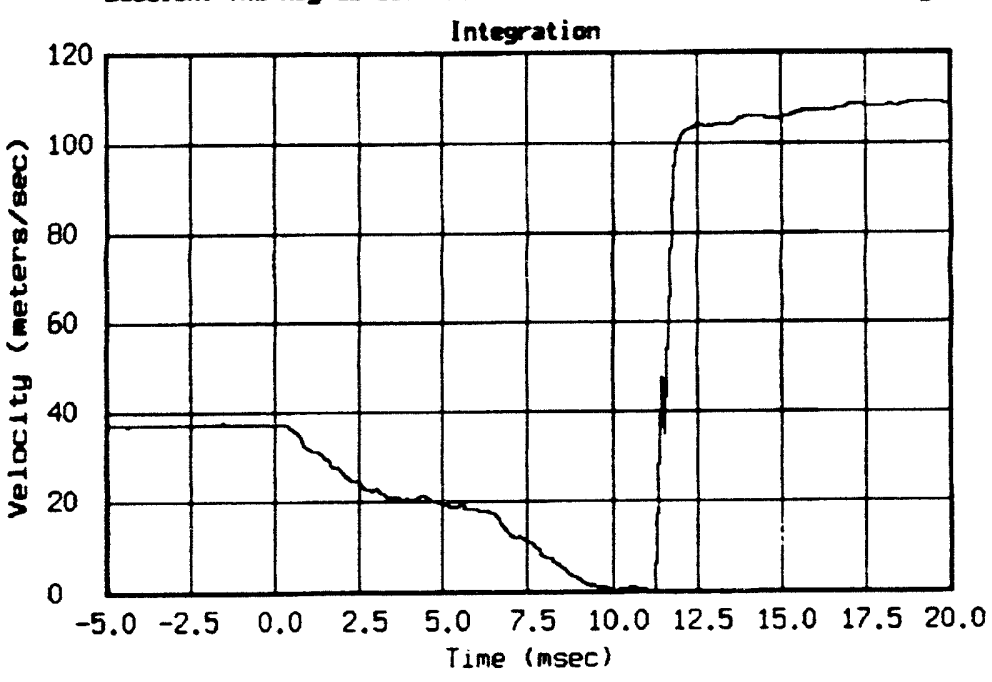

$\overrightarrow{\mathrm{N}}$

Test: LOWGITUIML HICH VaxcITY H1224A 08/12/93 (223) Session: Thu fug 12 11:34:58 1993 Transcheer: A6 (secondary)

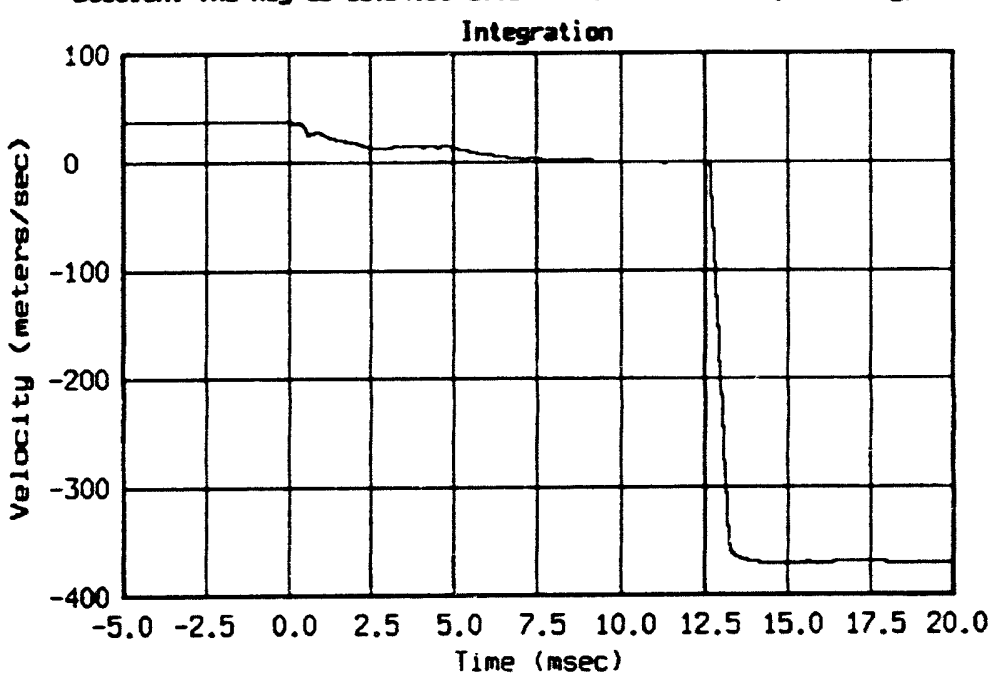

Test: Lovituoliph HIGH Vacity H1224A 08/11/93 (223) Session: Thu Aug 12 11:35:06 1993 Transdveer: A7 (sucondary)

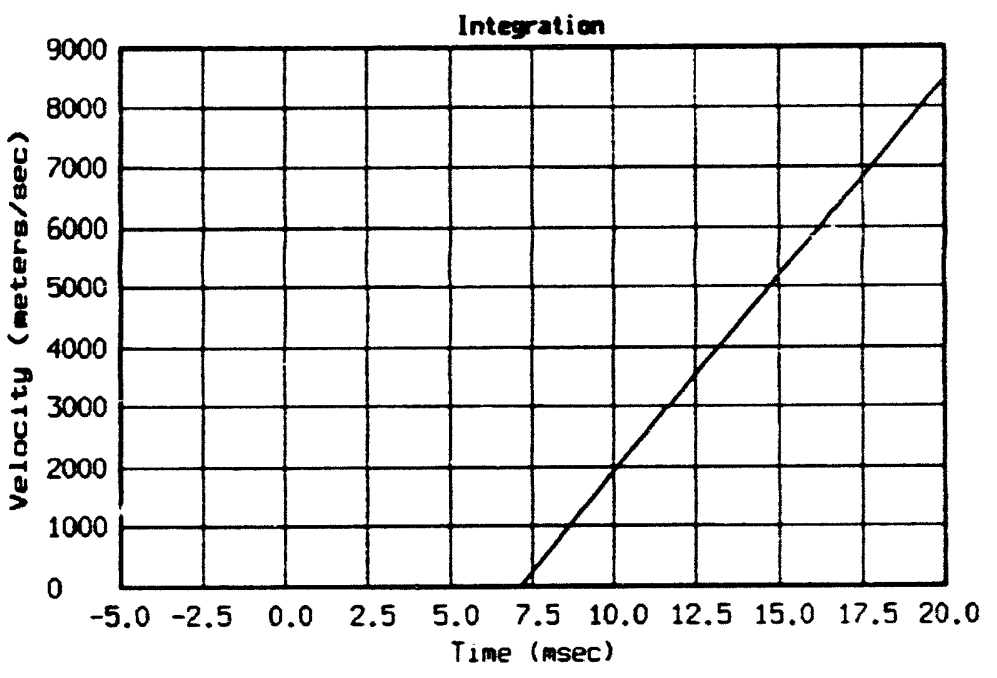

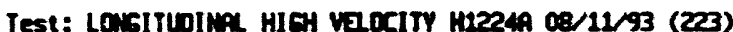
Session: Thu Aug 12 11:35:11 1993 Transducer: PB (secondary)

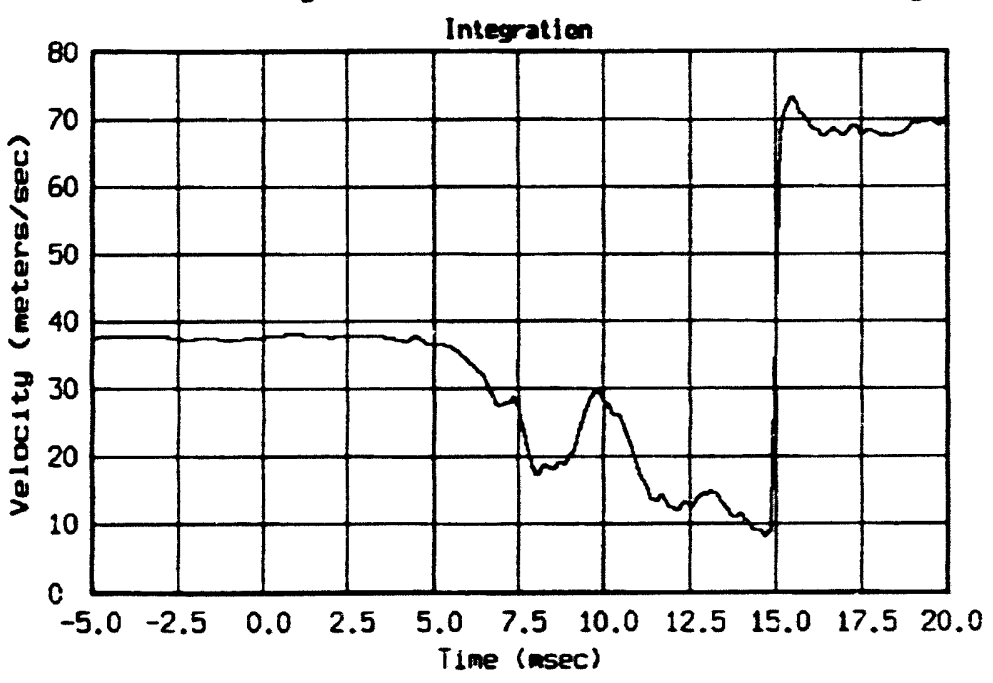


Test: LOWSITLIIRL HIGH VELOCITY H1224A 08/11/93 (223) Session: Thu fug 12 11:35:18 1993 Transducer: A9 (secondary)

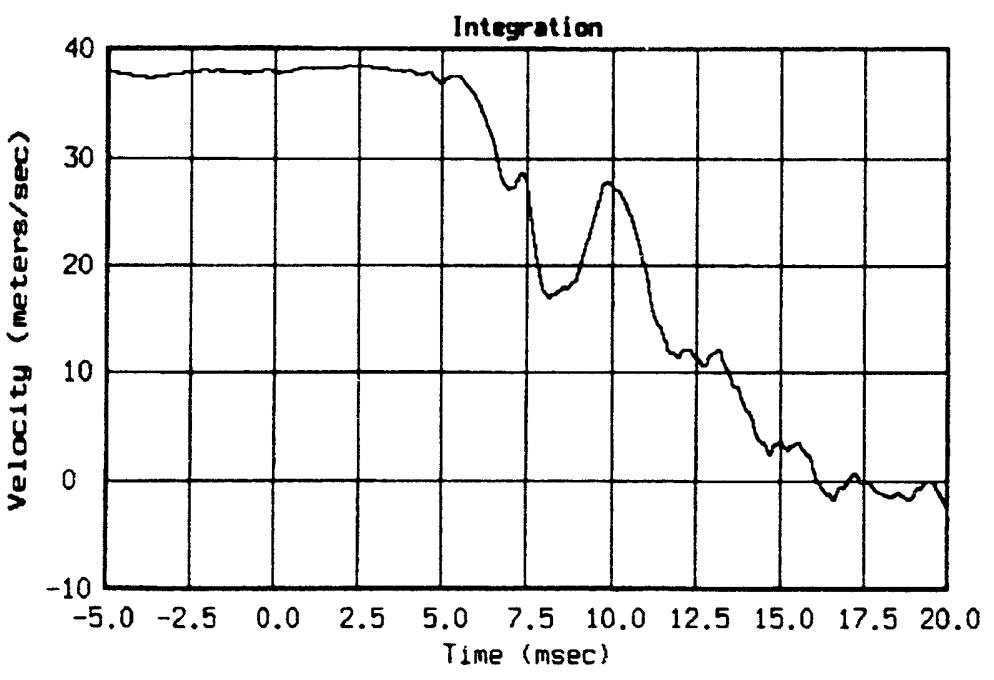

অิ

Test: LONGITLINA HIEH VEOCITY H1224A 08/11/93 (223) Session: Thu Aug 12 11:35:23 1993 Transducer: A10 (secondary)

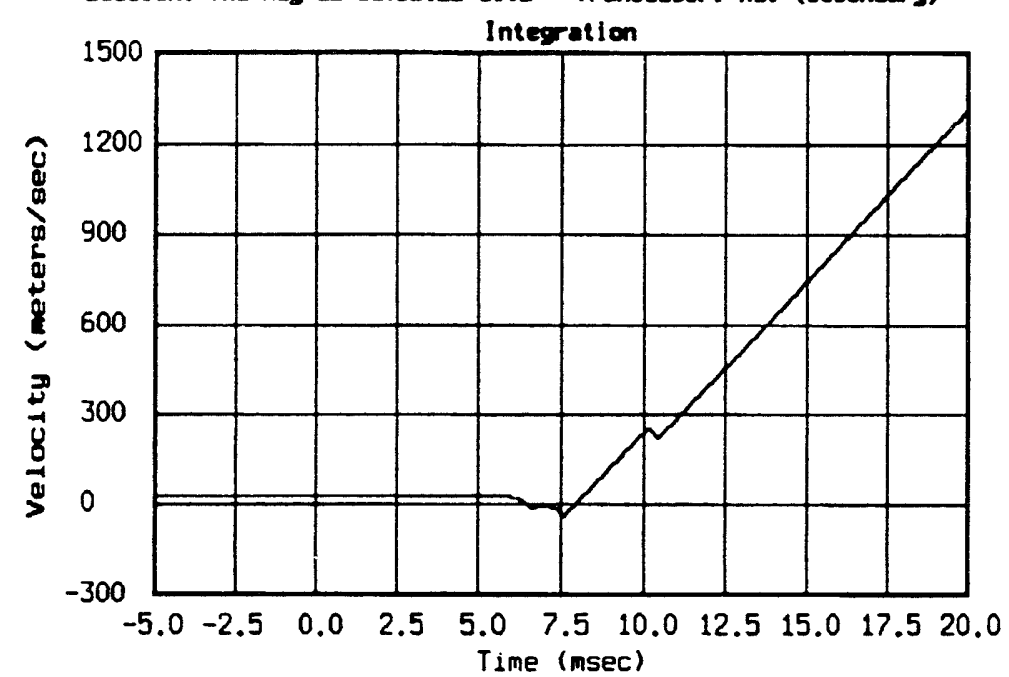

Test: LONSITUDINAL HICH VELCCITY H1224A 08/12/93 (223) Session: Thu Aug 12 11:35:30 1993 Transducer: A11 (secondary)

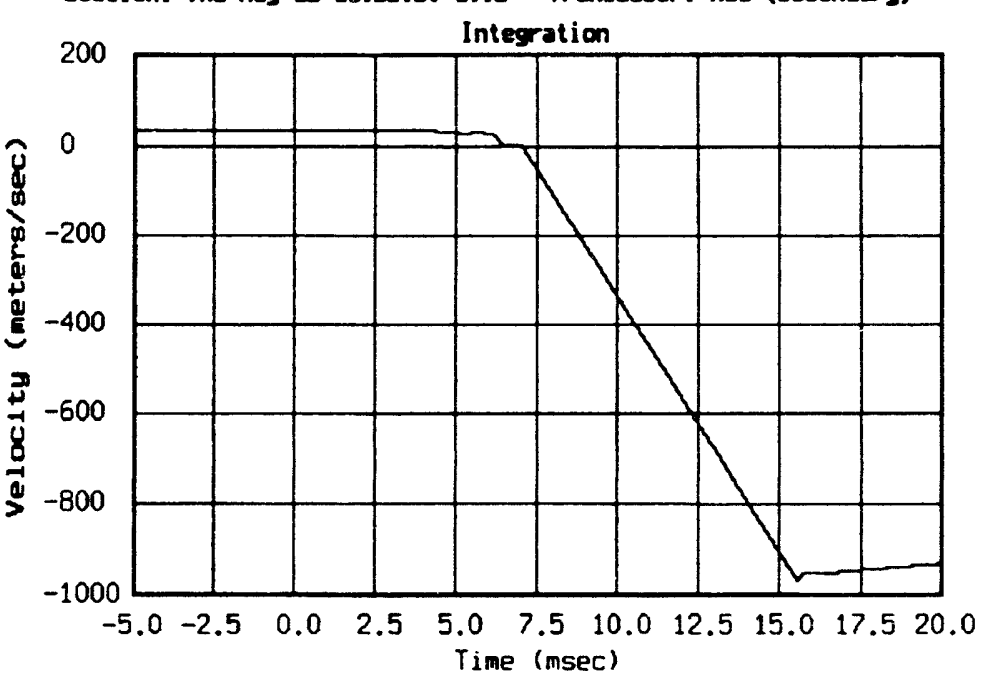


Teat: LOWSITOINA HIEH VeOCITY H1224A OR/11/93 (223) Seasion: Und Aug 25 14:54:51 1993 Transtucer: A1 (seocndory)

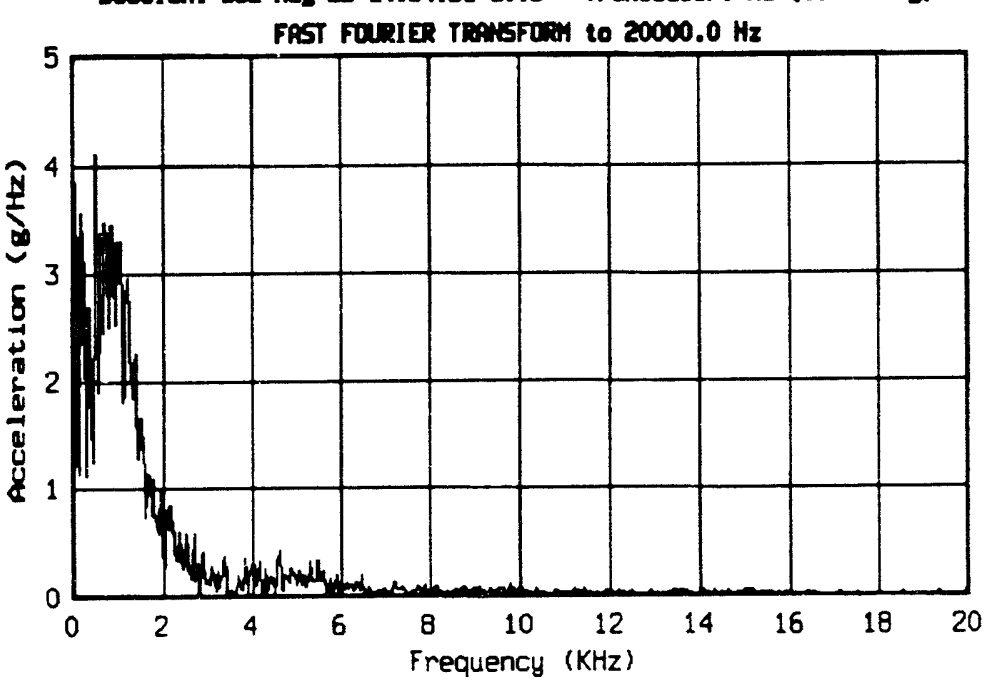

Test: LONGITUIMP HIGH VELOCITY H1224A 08/11/93 (223) Session: Led Rug 25 14:54:59 1993 Transctucer: R2 (secondary) FAST FOURIER TRANSFORM to $20000.0 \mathrm{~Hz}$

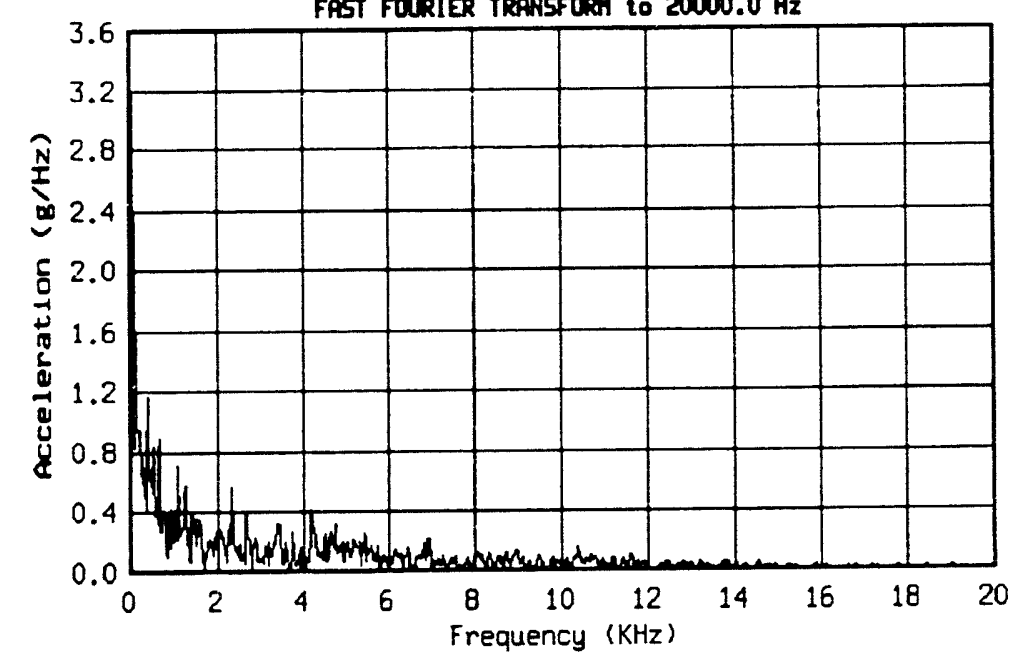



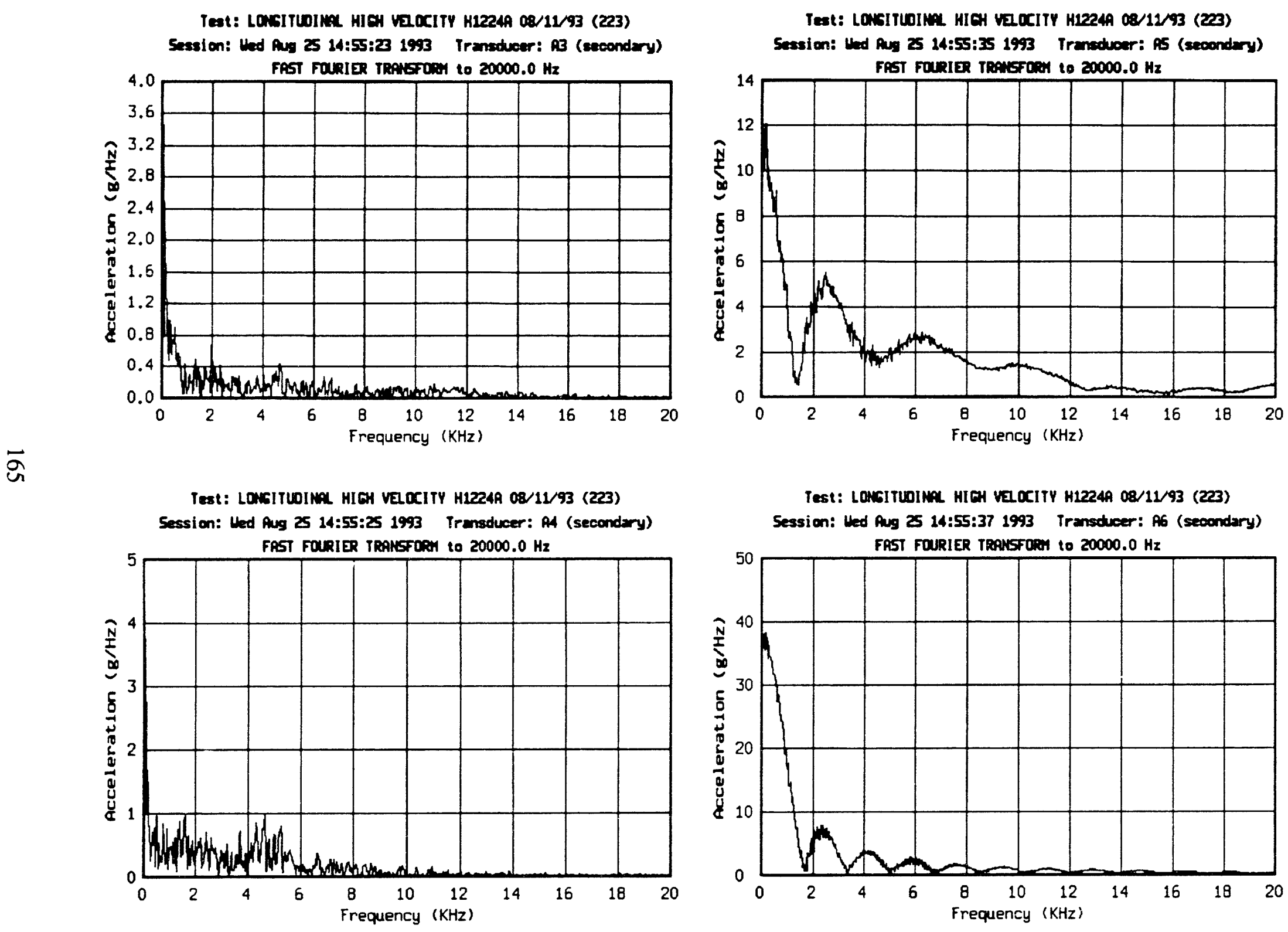

(203)

Test: LOKGITUDINAL HIGH VElOCITY H12244 08/11/93 (223) Session: thed Aug 25 14:55:37 1993 Transducer: A6 (secondary)

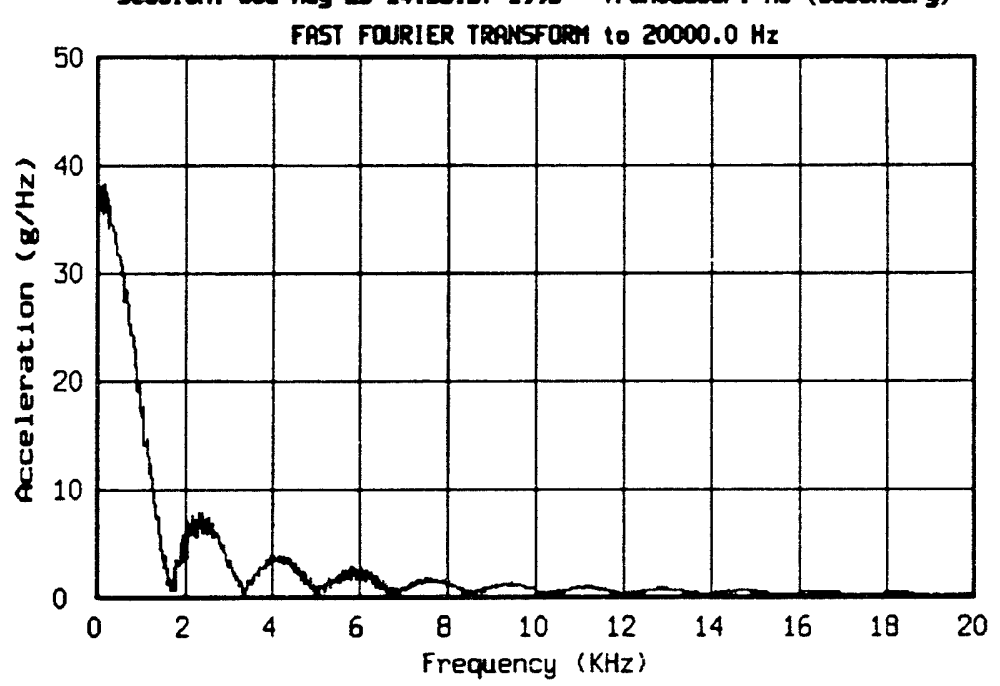




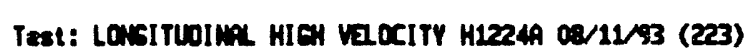

Session: Led Aug 25 14:55:46 1993 Trmaduow: AT (secondary) FRST FOURIER TRAUSTOOM to $20000.0 \mathrm{~Hz}$

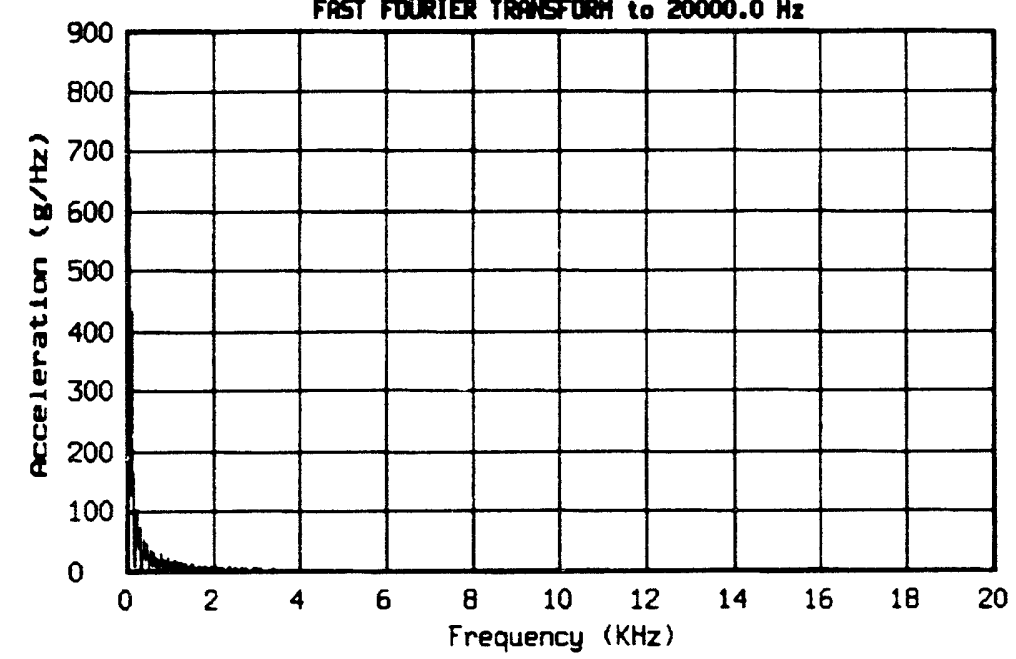

$\bar{\Omega}$

Test: LONGITUDINP HIGH VEOCITY H1224A 08/11/93 (223) Session: led Aug 25 14:55:49 1993 Transducer: AB (secondary) FAST FOURIER TRANSFOPH to $20000.0 \mathrm{~Hz}$

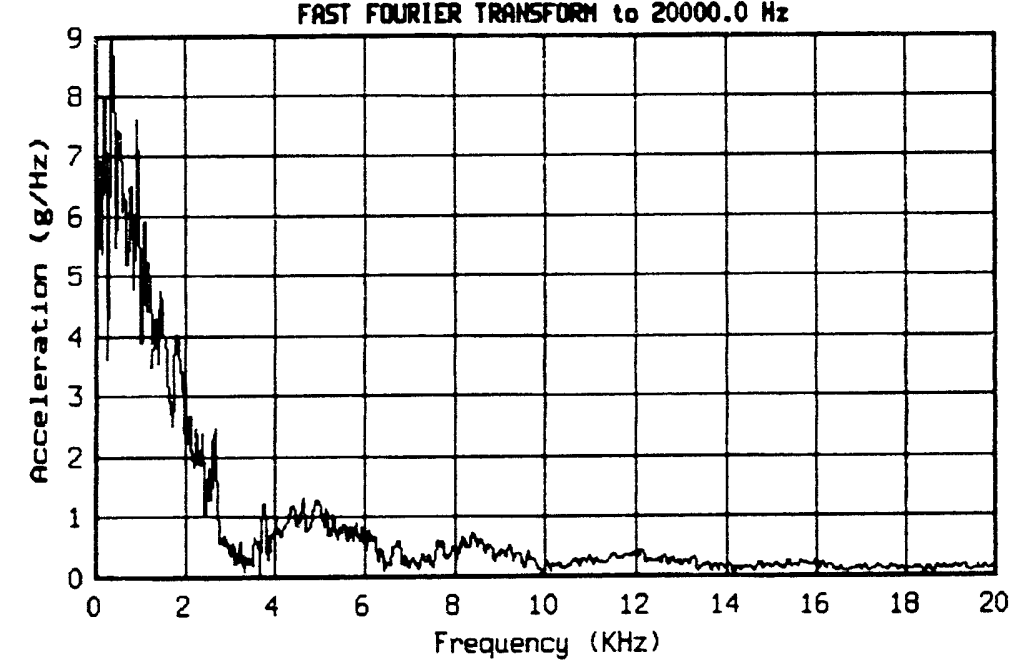

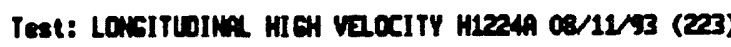
Seasion: thed Aug 25 14:55:59 1993 Tranodwoer: A9 (secondory) FRST FORIER TRONSTOEN to 20000.0 $\mathrm{Hz}$

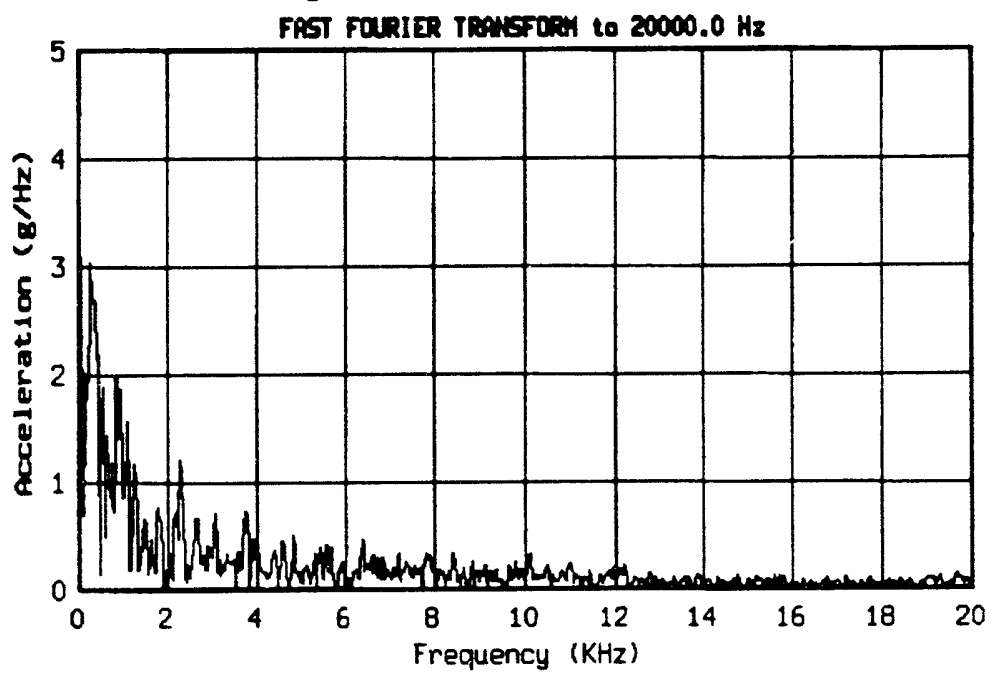

Test: LONGITUDIML HICH VELCITY HI224A 08/11/93 (223) Session: Led Aug Z2 14:56:04 1993 Trundwcer: A10 (secondary) FAST FOURIER TRAUSFORM to $20000.0 \mathrm{~Hz}$

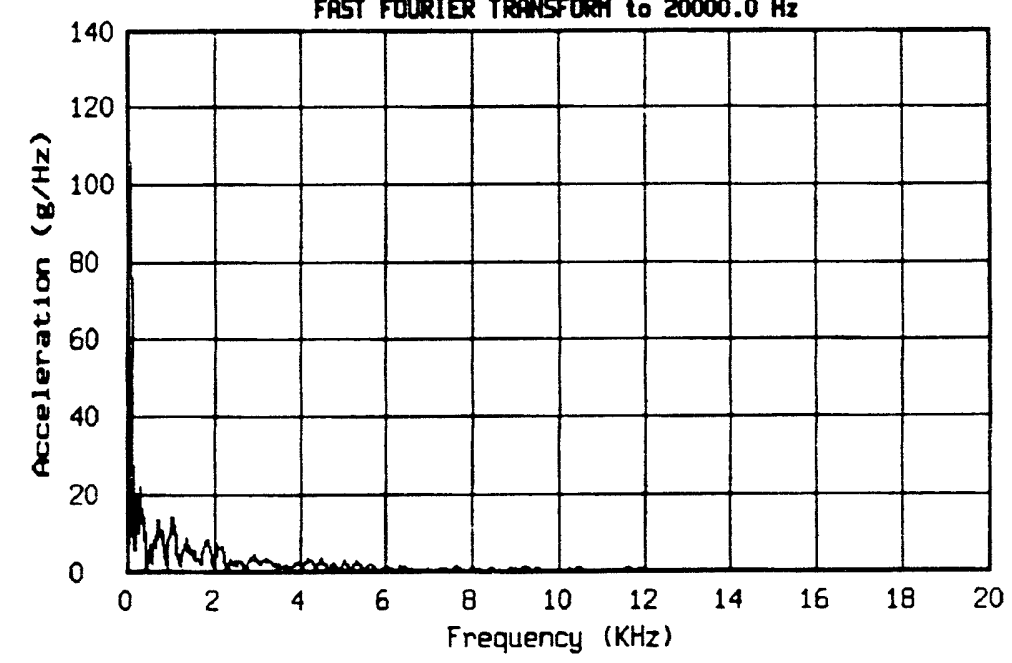


Teat: LONSITDINAL HICH VEOCITY H12249 08/11/93 (223) Seasion: led Pug 25 14:56:11 1993 Trensducer: A11 (secondary) FAST FOURIER TRANSTOMA to $20000.0 \mathrm{~Hz}$

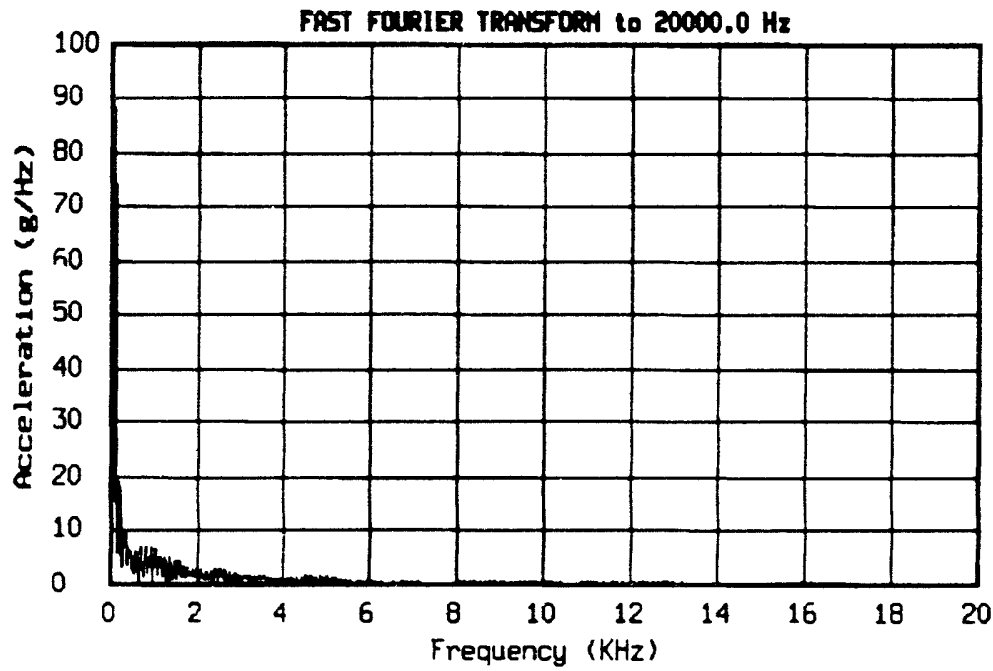

5

Test: LONGITLIIML HIGH VELOCITY HI224A 08/11/93 (223) Session: Led Aug 25 14:56:16 1993 Transducer: A13 (secondary) FAST FOURIER IRRASFORM to $20000.0 \mathrm{~Hz}$

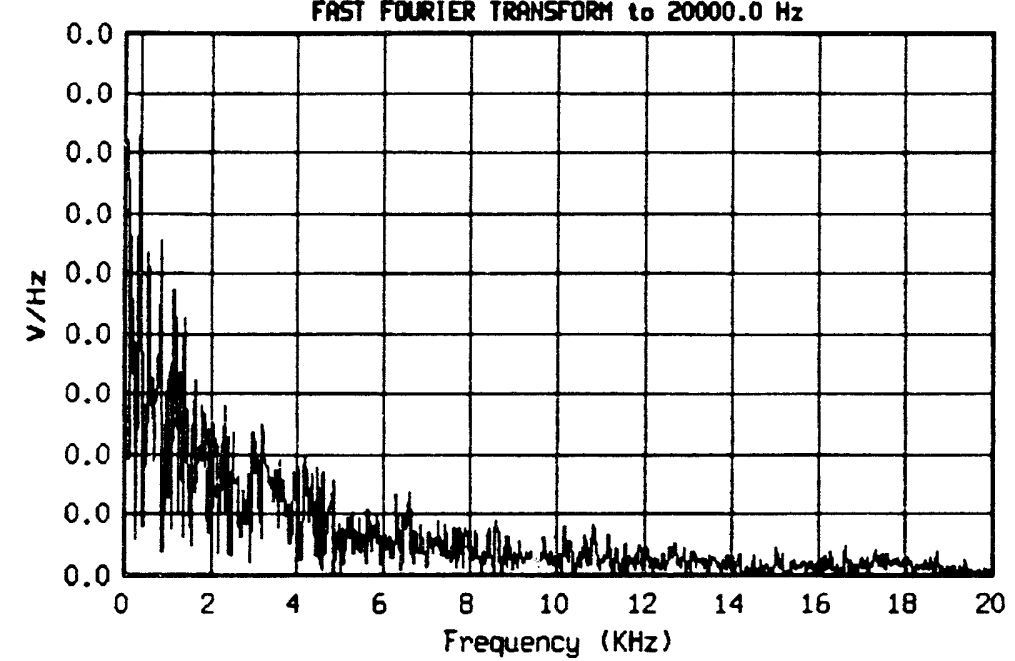

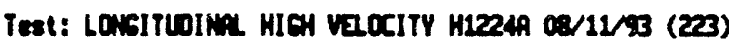
Session: thed Aug 25 14:56:27 1993 Traneducer: 561 (secondary) FRST FOARIER TROASTOOH to 20000.0 $\mathrm{Hz}$

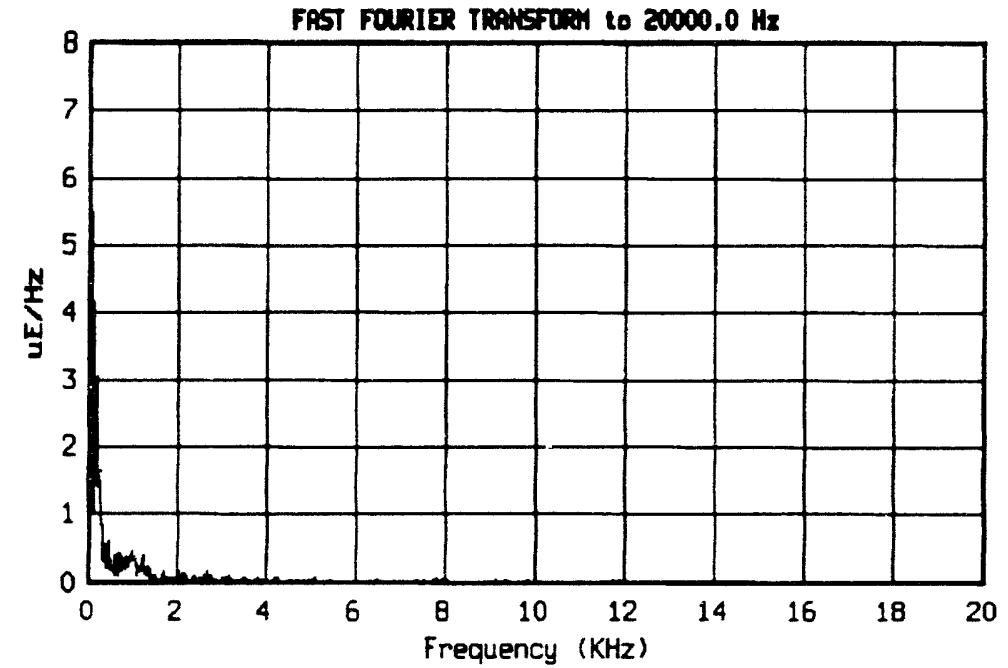

Test: LOHSITLIMAL HICH VEOCITY H1224A 08/11/93 (223) 5ession: Led Aug 25 14:56:33 1993 Transducer: 502 (secondary) FRST FORIER IRANSFORA to $20000.0 \mathrm{~Hz}$

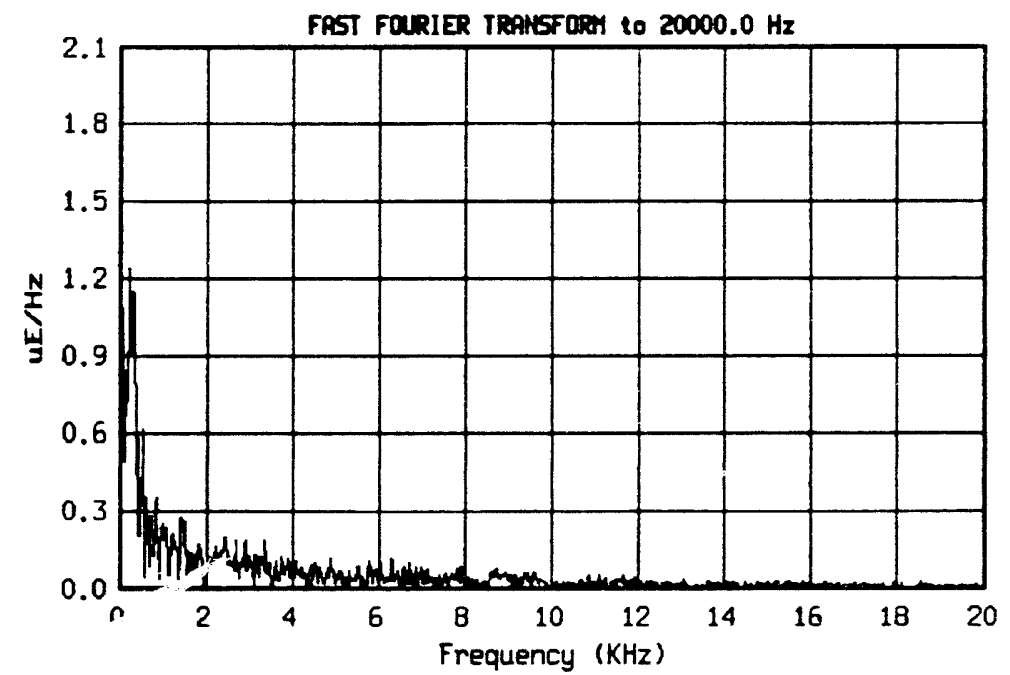




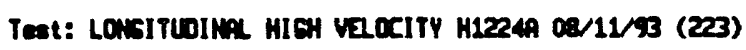
Session: Led Aug 25 14:56:41 1993 Transducer: 553 (secondwry)

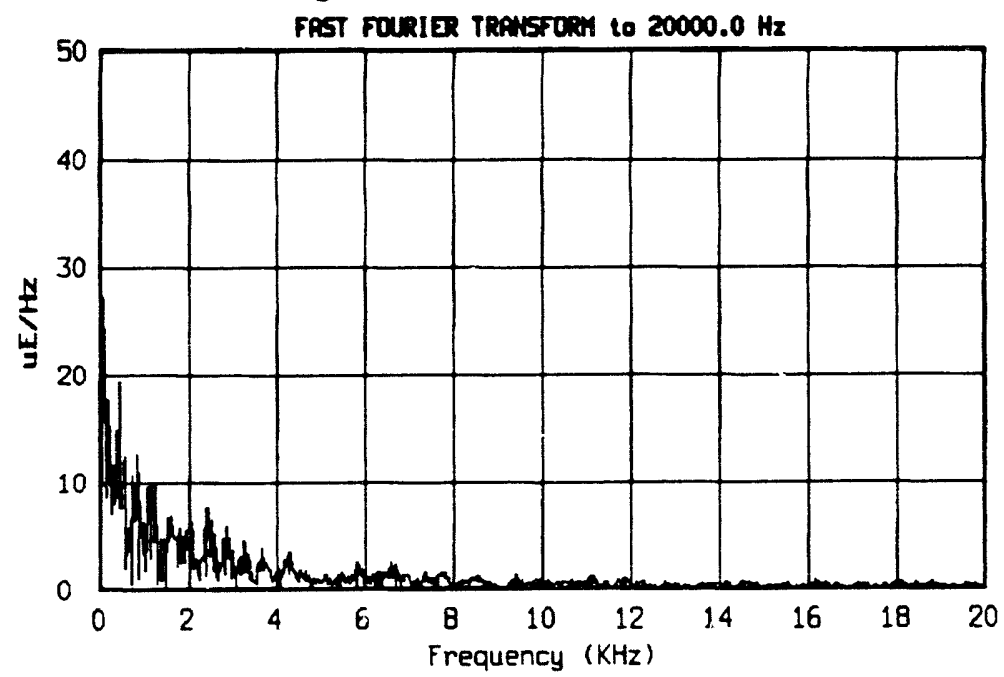

$\bar{\infty}$

Test: LONGITUDINPL HIGH VELOCITY H1224A 08/11/93 (223) Session: thed Aug 25 14:56:46 1993 Transolucer: S64 (secondary) FAST FOURIER TRANSFOPM to $20000.0 \mathrm{~Hz}$

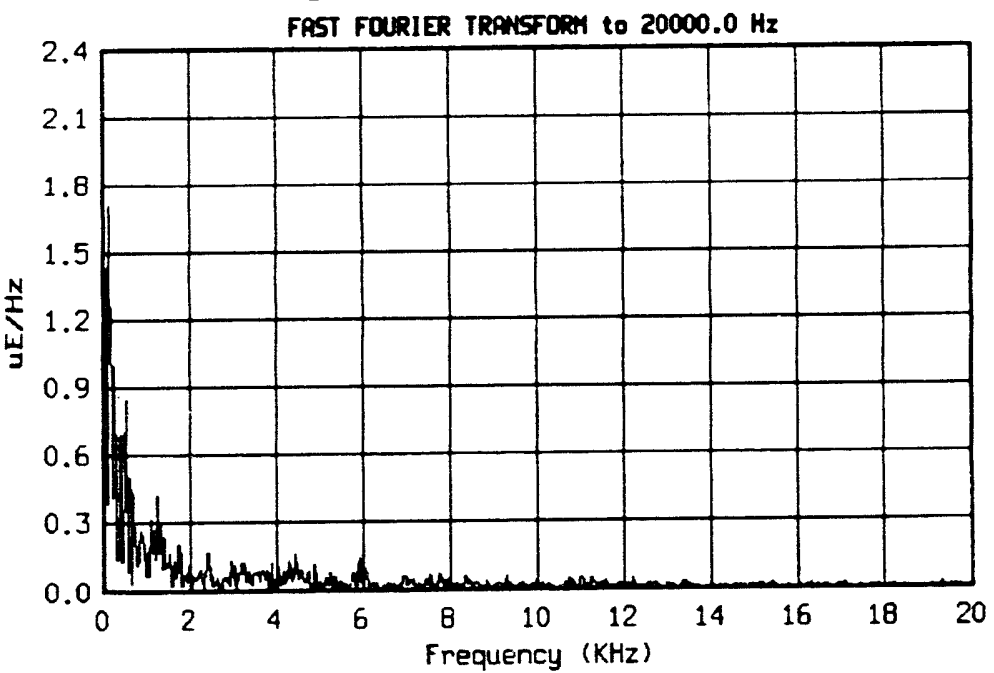

Teat: Lovitunin HICH VבoCITY M12249 08/11/93 (203)

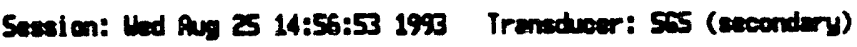
FRST FORIER TRAUSFOM to $20000.0 \mathrm{~Hz}$

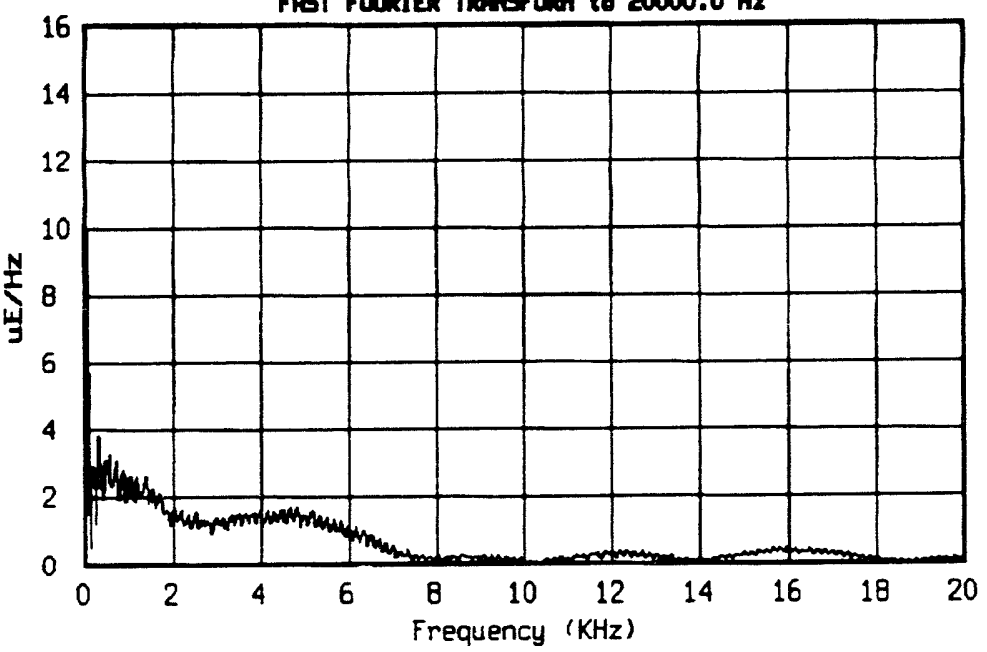

Test: LONSITLDINA HICH VeOCITY H12249 08/11/93 (223) Session: Led Aug 25 14:56:57 1993 Transdwoer: 566 (seccondary) FAST FOURIER TRPASFORH to $20000.0 \mathrm{~Hz}$

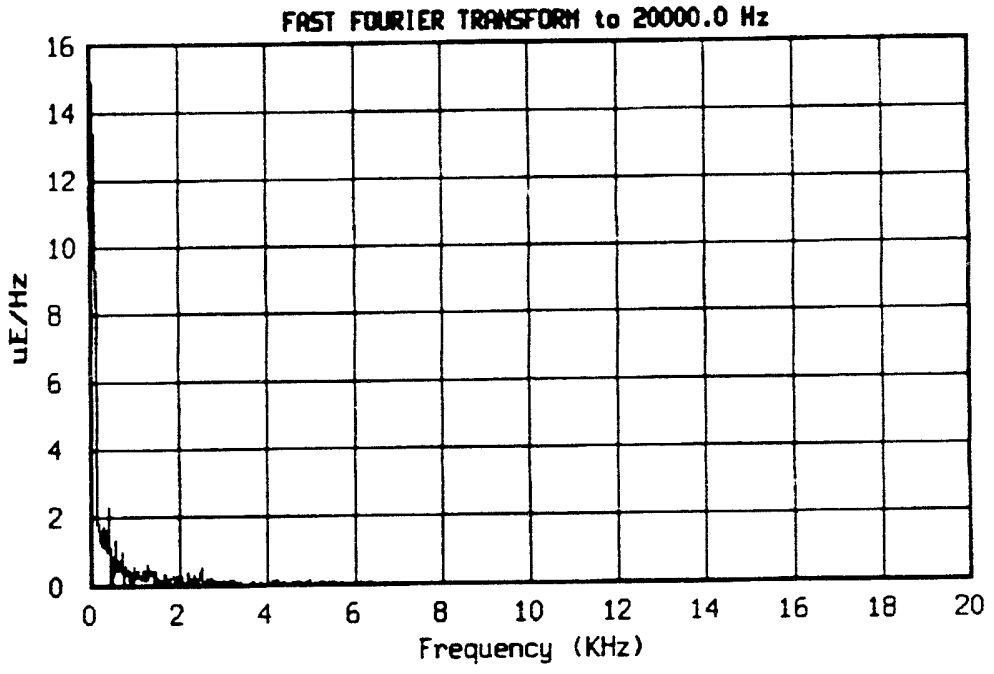




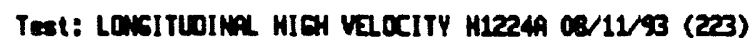
Session: led Aug 25 14:57:03 1993 Transituoer: 567 (secondary) FAST FOURIER TRAYSFODM to $20000.0 \mathrm{~Hz}$

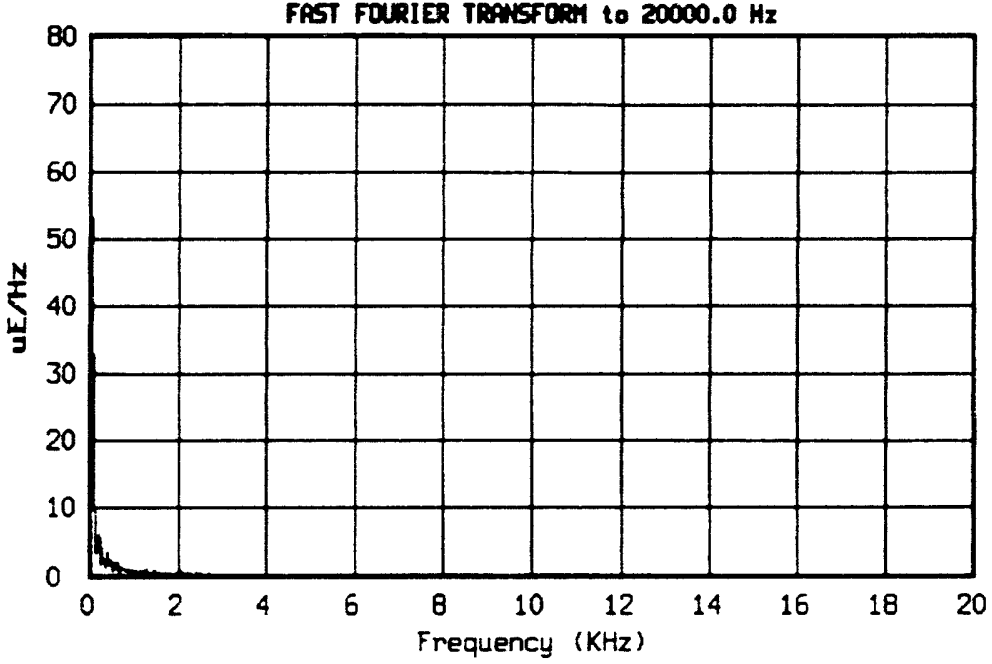

$\overrightarrow{8}$

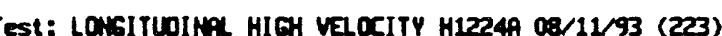
Session: Led Aug 25 14:57:08 1993 Transducer: 568 (secondary) FAST FOURIER TRANSTORM to $20000.0 \mathrm{~Hz}$

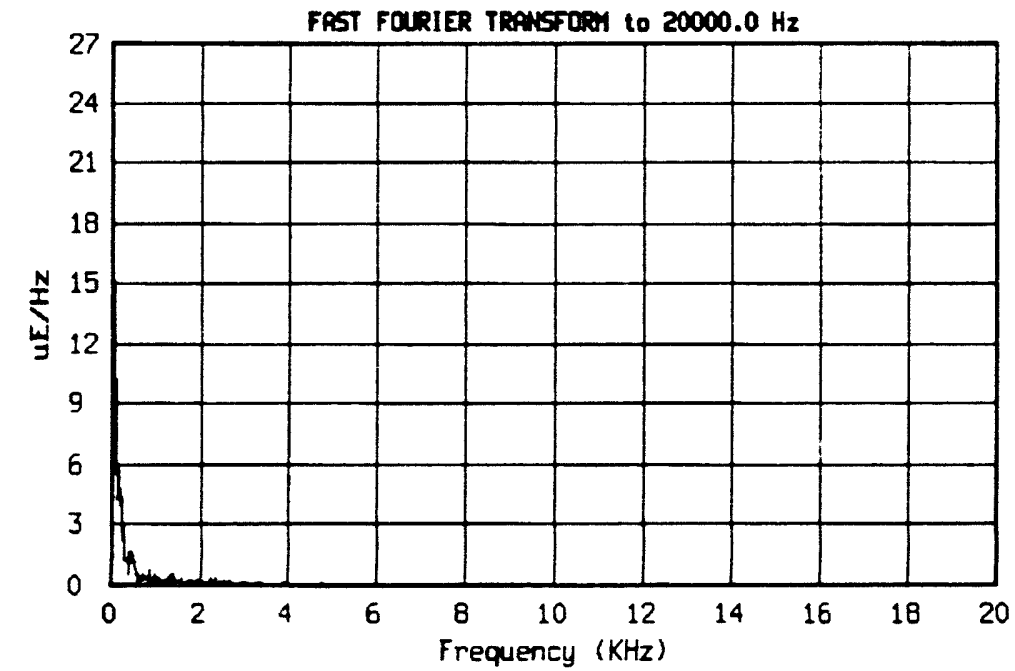

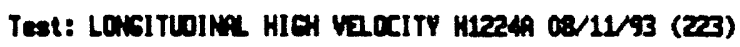

Session: led fug Z5 14:57:14 1993 Transtwoer: 559 (seoondary) FAST FURIER TRANSTOAN to $20000.0 \mathrm{~Hz}$

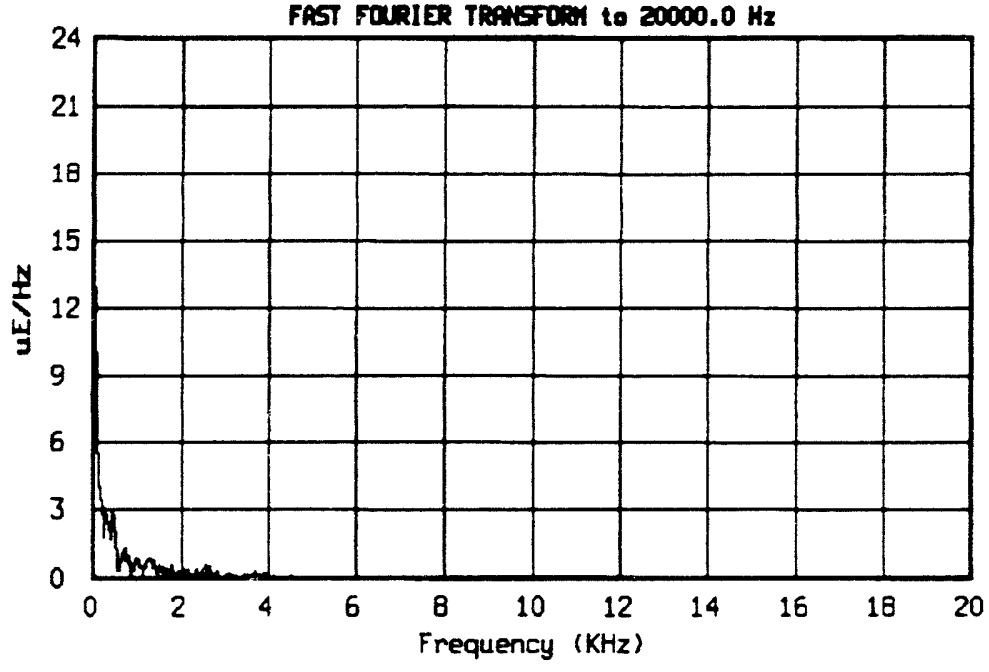

Test: LOGITUDINAL HIGH VeOCITY H1224A 08/11/93 (223) Session: Led Aug 25 14:57:21 1993 Transducer: 5610 (secondary)

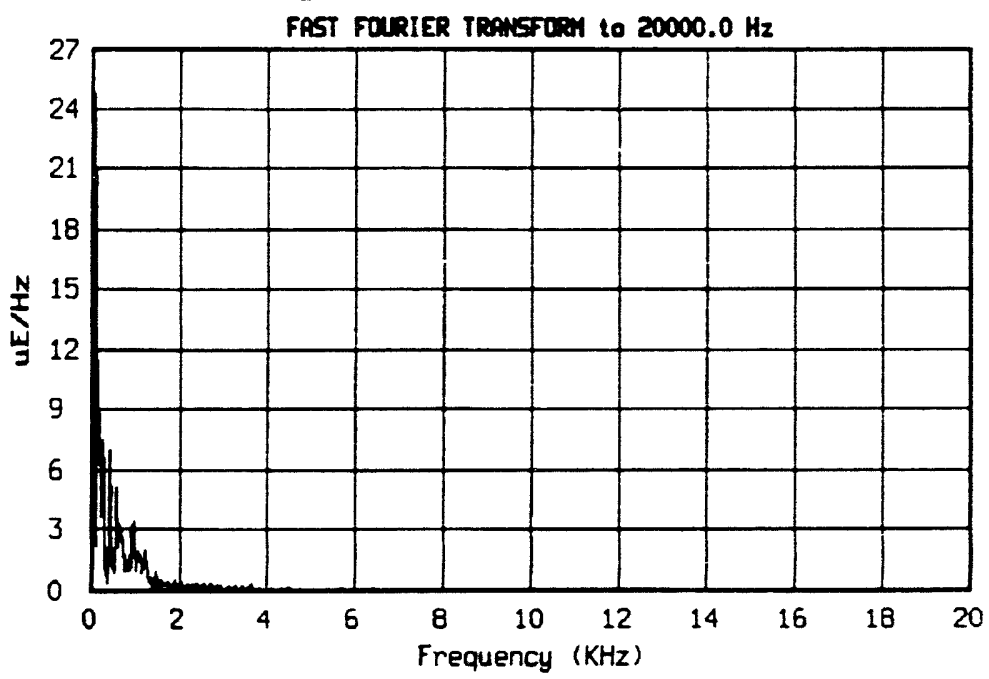


Teat: LONSITUIM HICH VEOCITY H12249 08/11/93 (223) Session: led Aug 25 14:57:31 1993 Transtued: 5511 (sacondary) FAST FOURIDR TRANSFOMN to $20000.0 \mathrm{~Hz}$

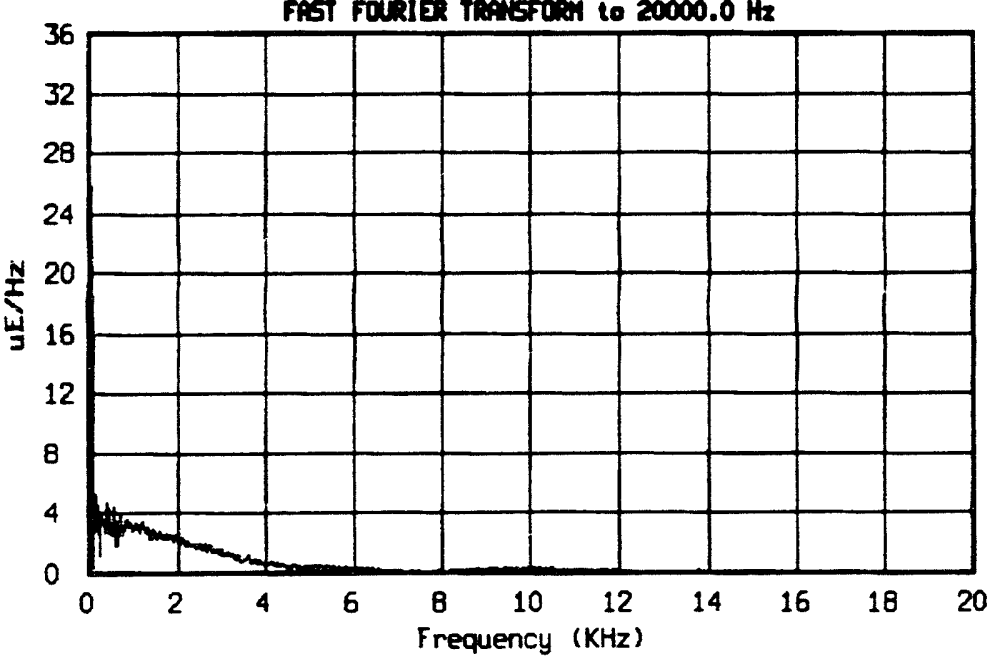

Test: LOWGITUDIMA HIGH VEOCITY H12249 08/11/93 (223) Session: led Aug Z5 14:57:32 1993 Transducer: 5612 (secondary)

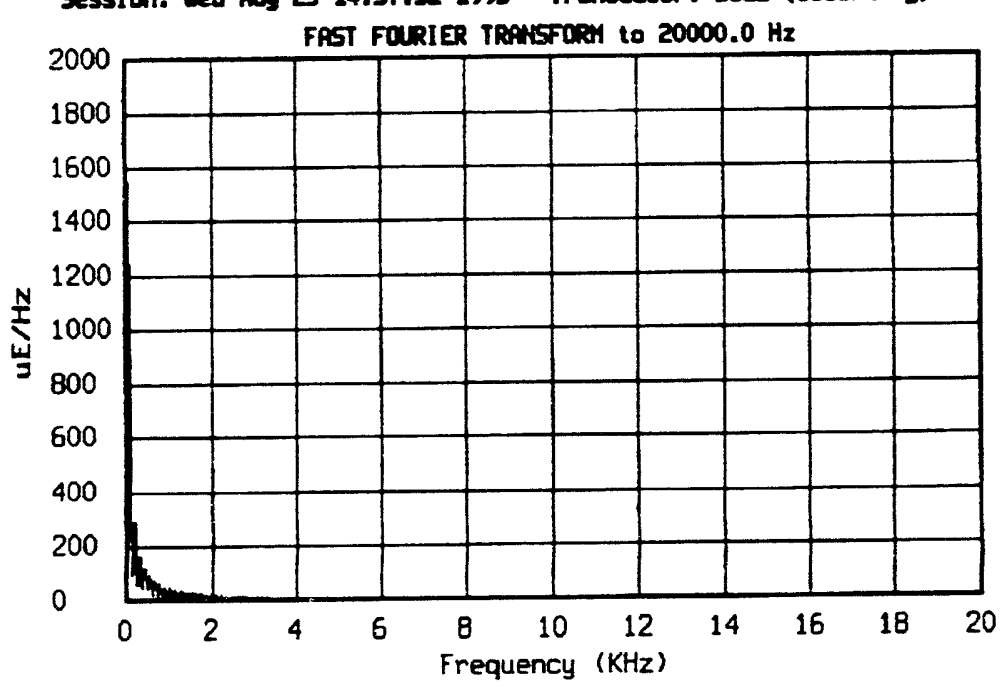

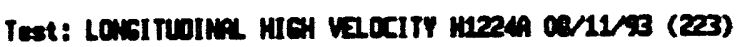

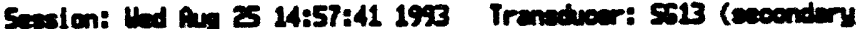

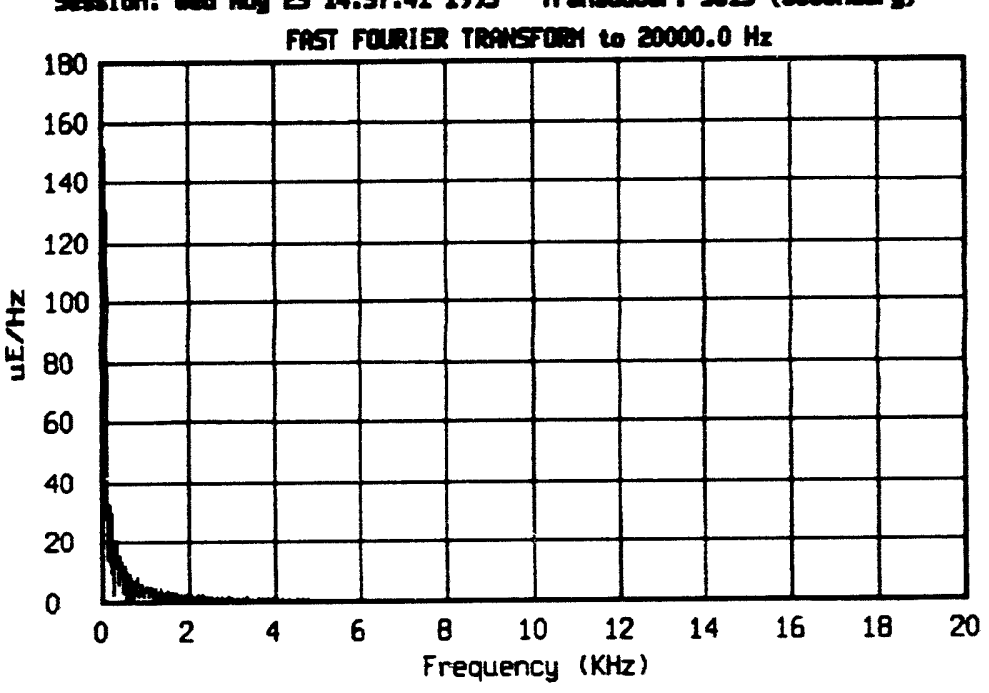

Test: LOWGITUIMLL HICH VECCITY M1224h 08/11/93 (223) Session: Ued Pug 25 14:57:12 1993 Transdveer: 5514 (secondery) FAST FOURIER TRAUSFORM to $20000.0 \mathrm{~Hz}$

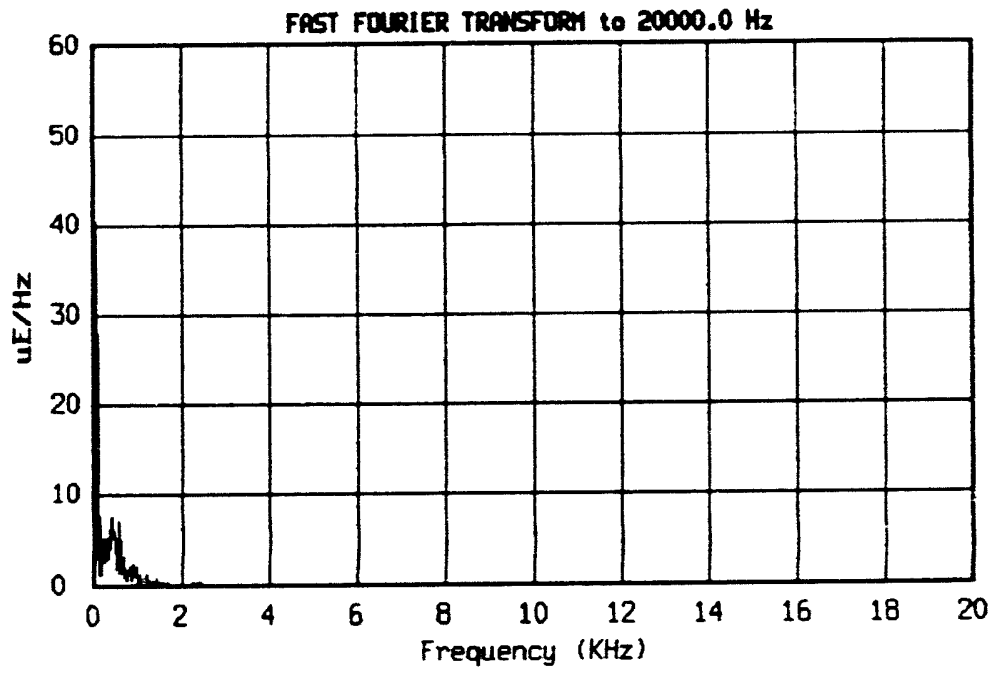




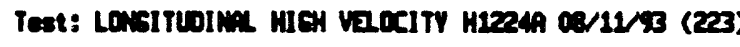

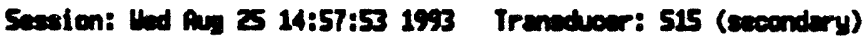

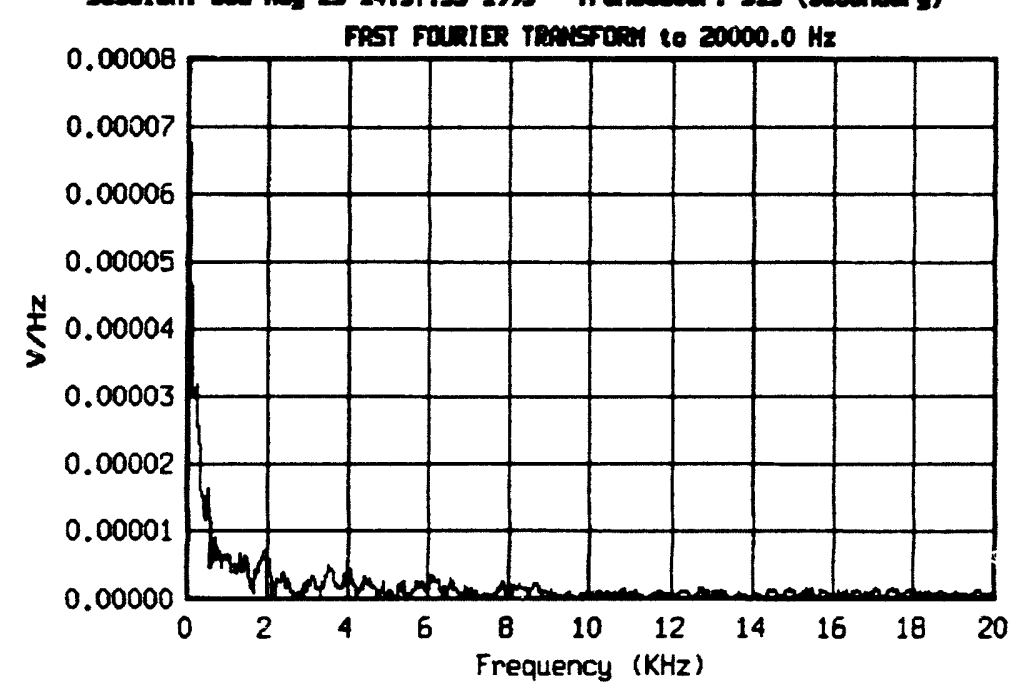

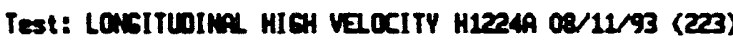

Session: led Aug 25 14:57:54 1993 Transtucer: 516 (secondary)

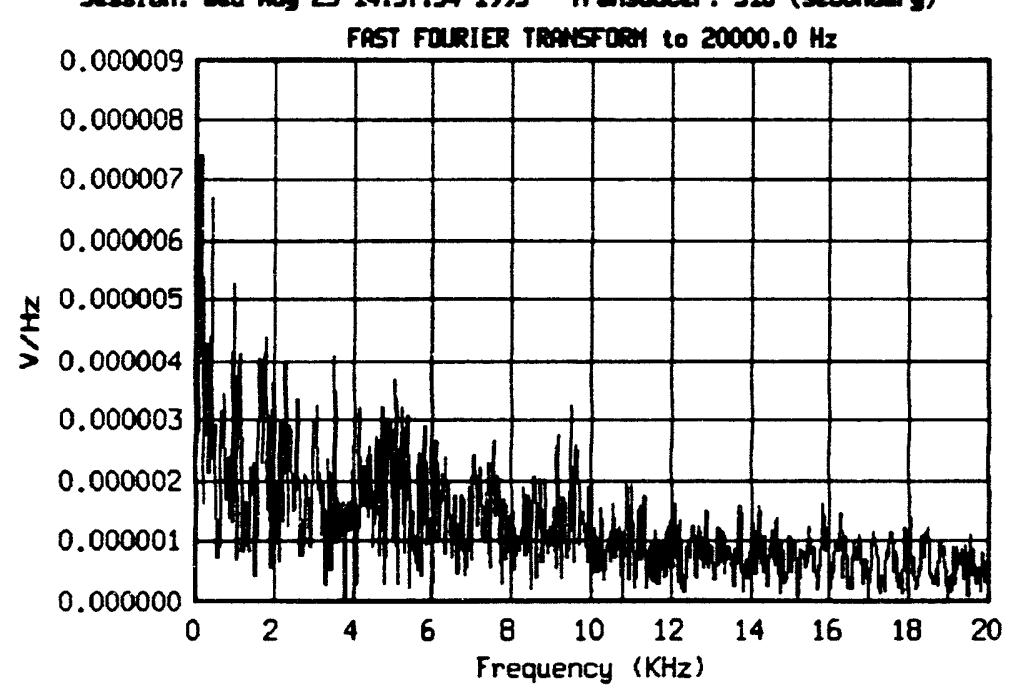




\section{Appendix D. HHV Accelerometer and Strain Gage Data: Raw, Filtered, and Reduced}

The following pages show raw (unfiltered) acceleration and strain gage data for the Horizontal High-Velocity (HHV) impact test. Following this raw data are plots of filtered data (using a low-pass Butterworth 6-stage filter) with cutoff frequencies of $250 \mathrm{~Hz}$ and $2,000 \mathrm{~Hz}$. Integrated acceleration data, yielding velocity versus time plots, are presented to analyze kinetic energy values during the test. And finally, Fast Fourier Transforms (FFTs) for each raw data channel are included to analyze acceleration and strain amplitudes in the frequency domain. 
Teat: MarizONTA HIGH VEOCITY M1224A 08/12/93 (224) Session: Thu Aug 12 15:19:23 1993 Trameducer: A1 (secondary)

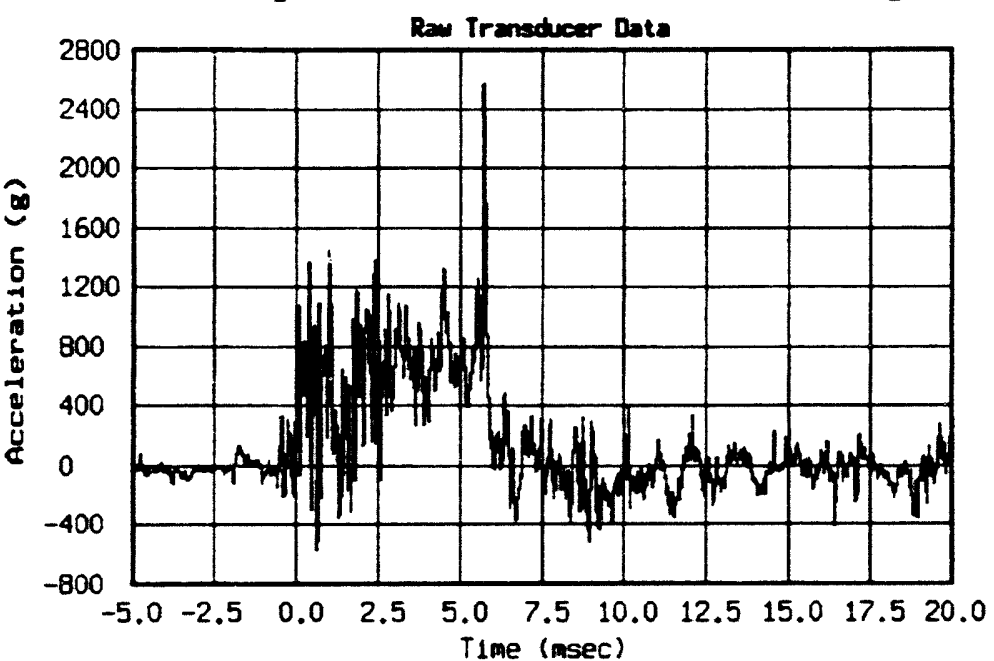

$\bar{\omega}$

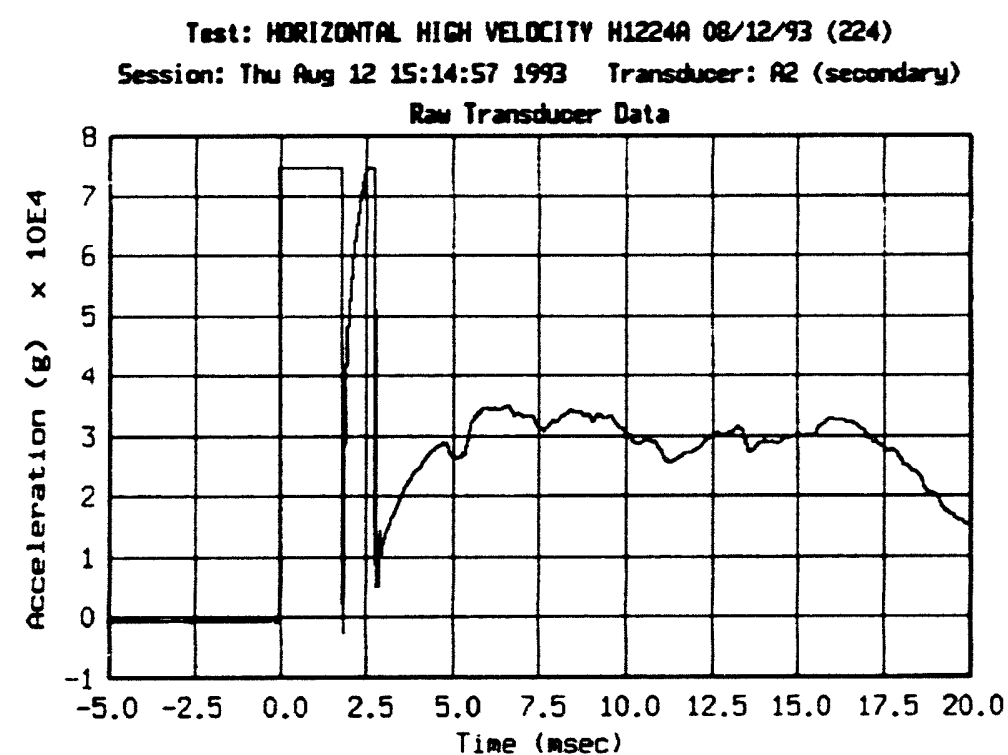

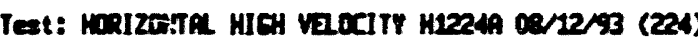
Sexsion: Thu Pug 12 15:15:02 1993 Tranedvoer: PB (secondary)

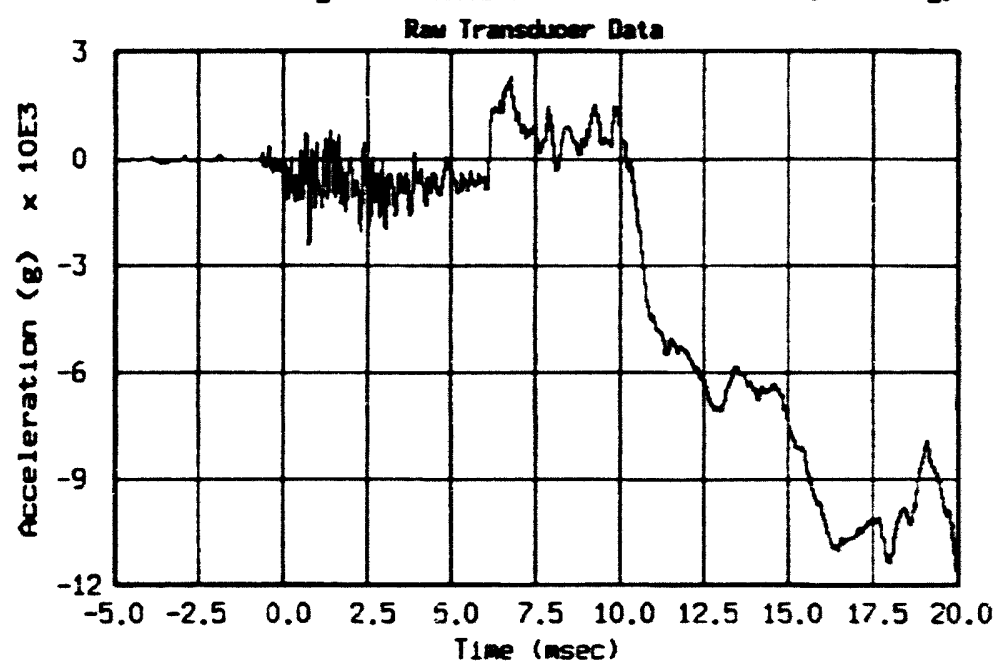

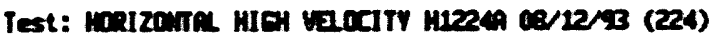

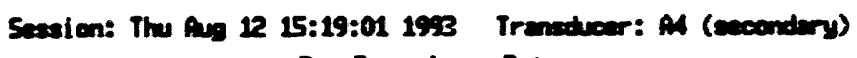

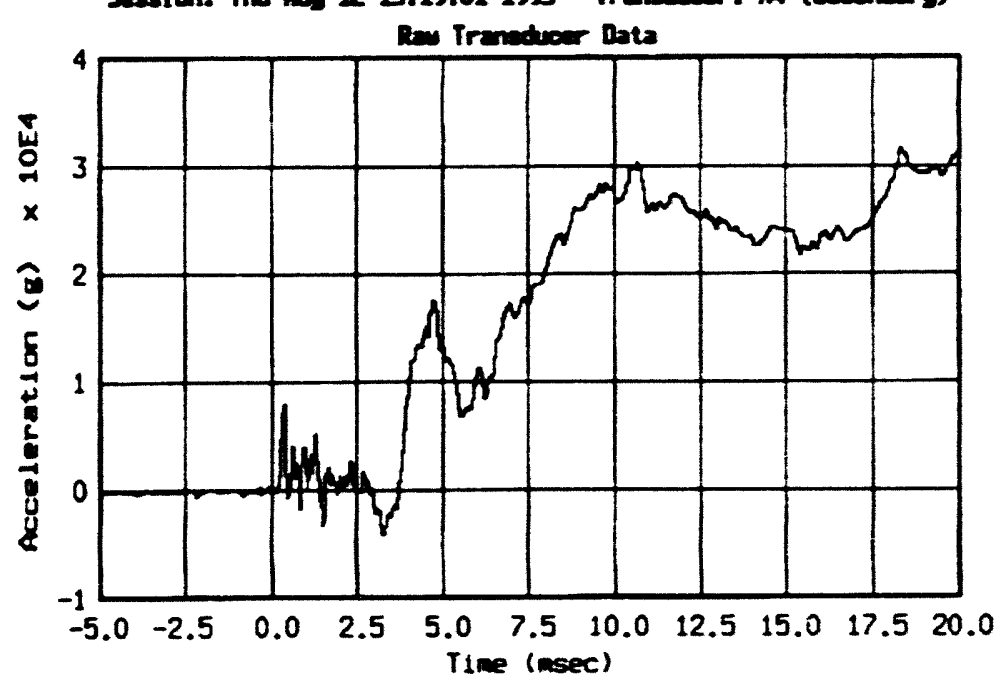



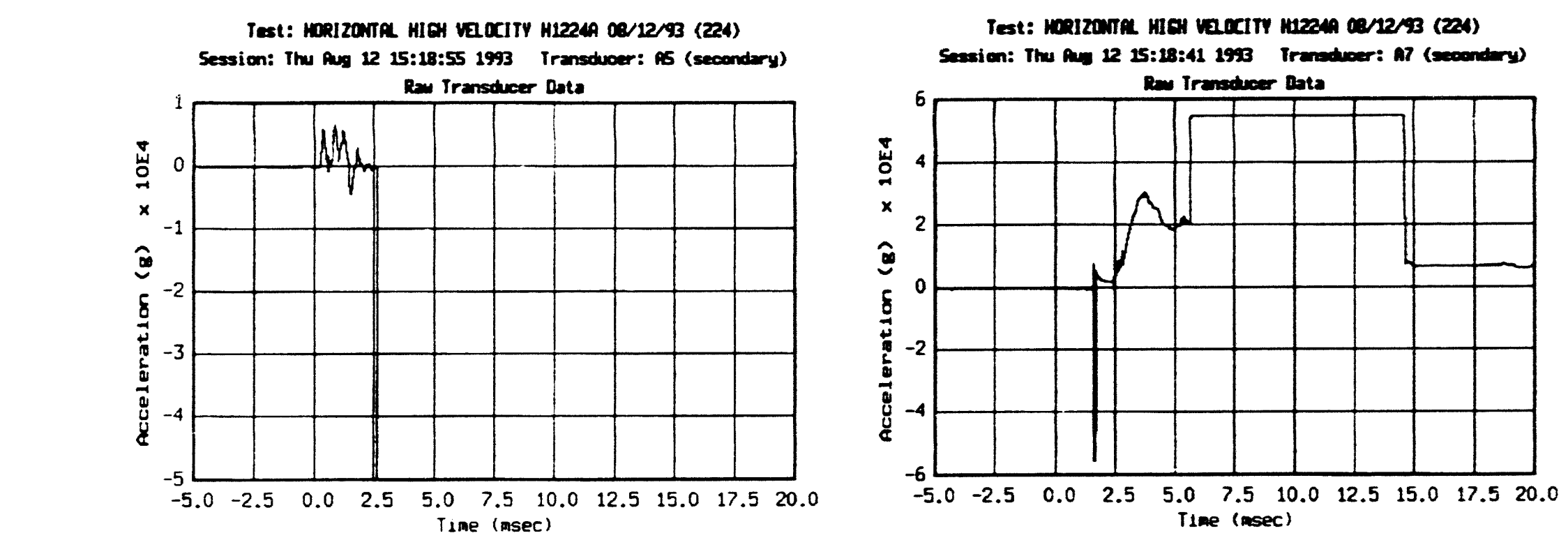

Test: HORIZOMTR HICH VIJOCITY HI224A 08/22/93 (224) Session: Thu fug 12 15:18:49 1993 Transodveer: F6 (encondery)
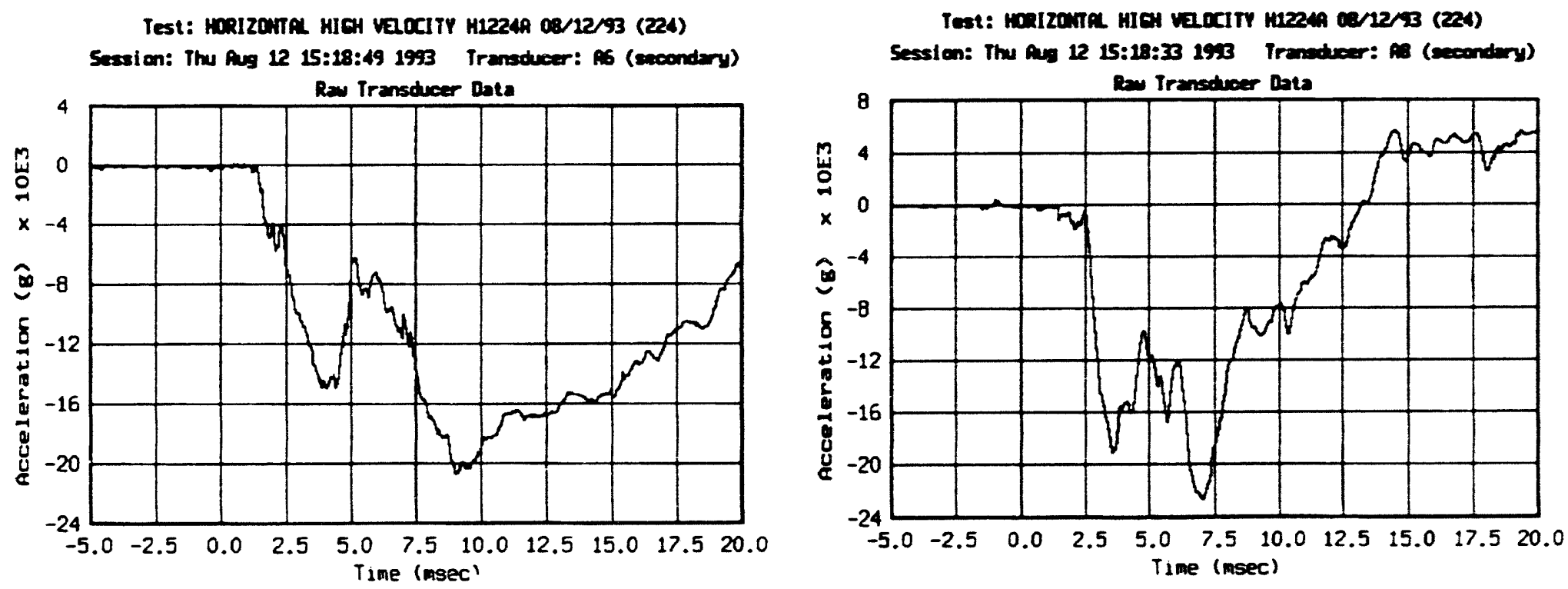


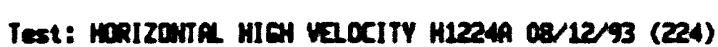
Session: Thu Aug 12 15:15:23 1993 Transcluoer: A9 (secondary)

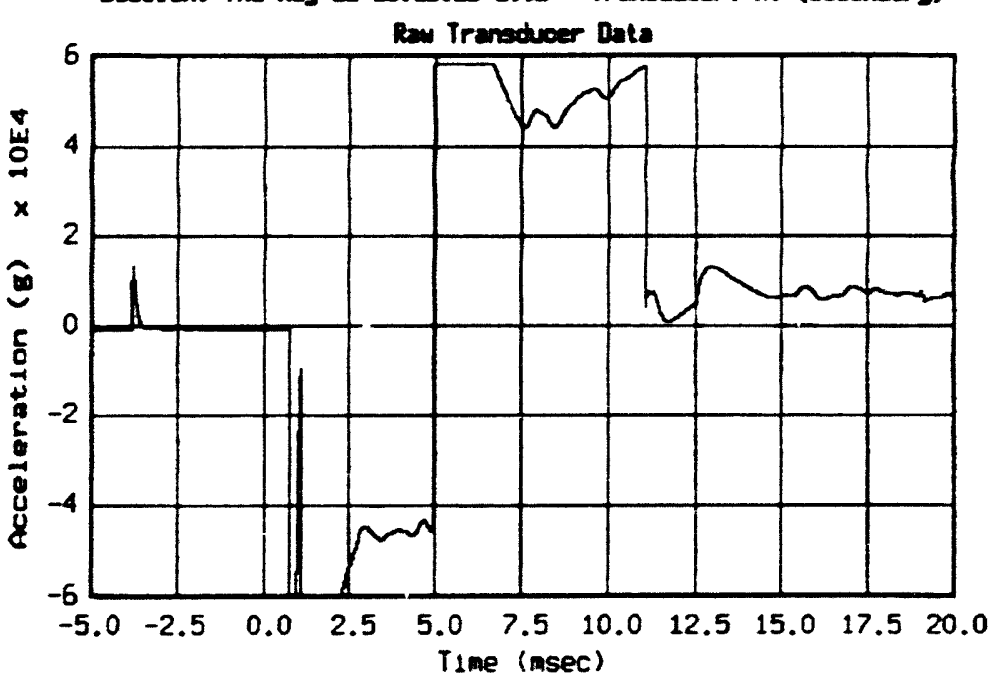

ฟ

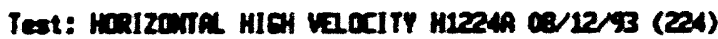
Sescelen: Thu Aug 12 15:15:24 1993 Transduoer: A10 (secondery)

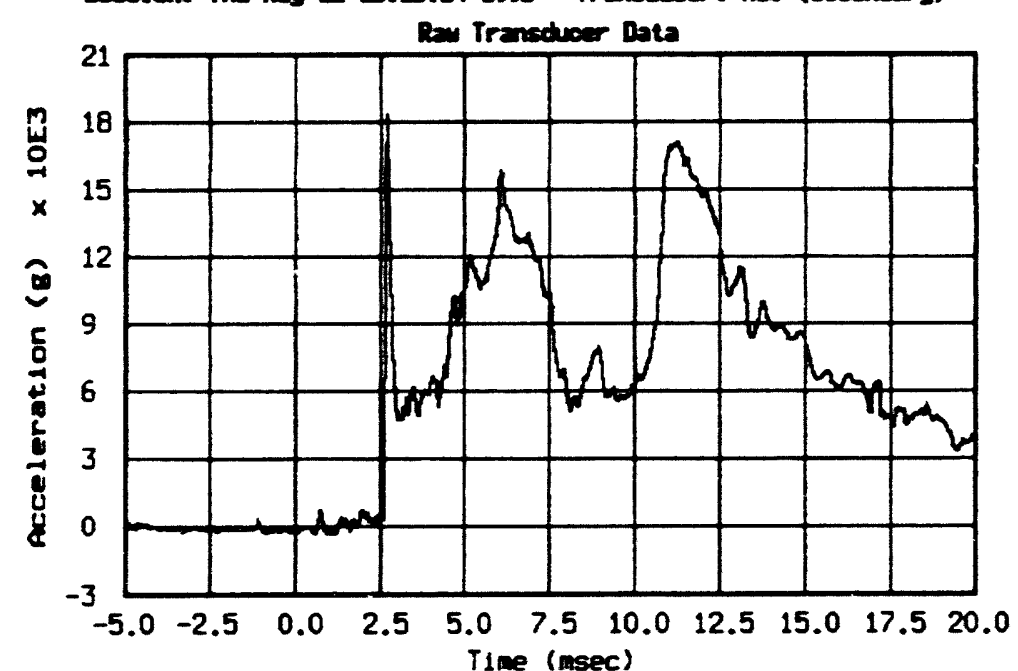

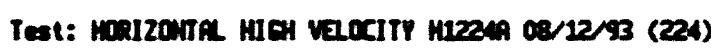
Session: Thu Aug 22 15:15:38 1993 Transtwoer: A11 (secondery)

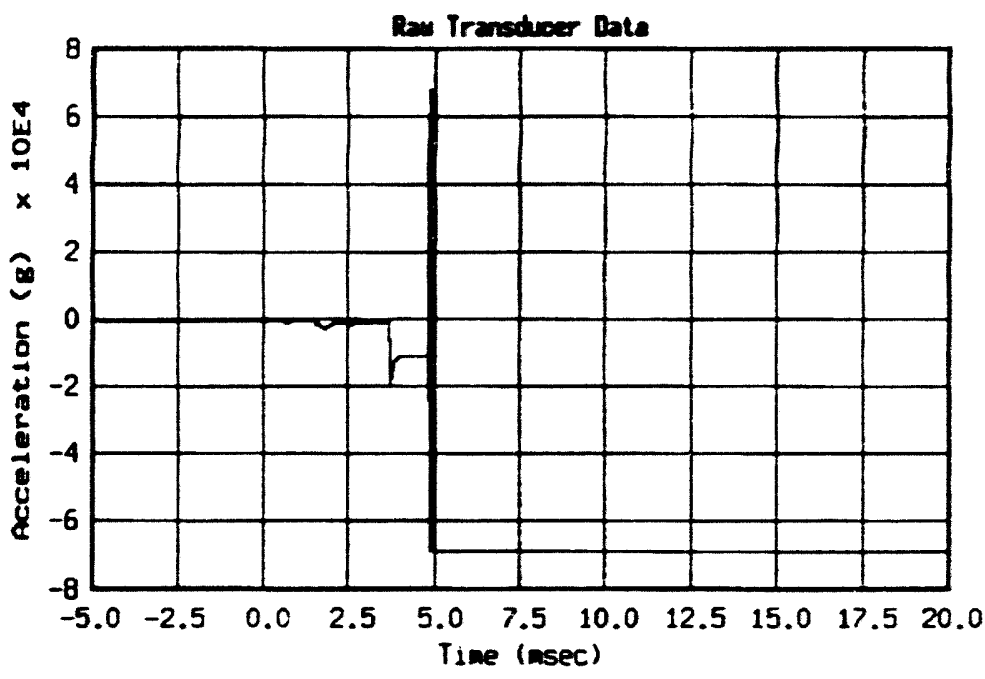

Test: Morizonf HIeH vacciry h12249 08/2/93 (224)

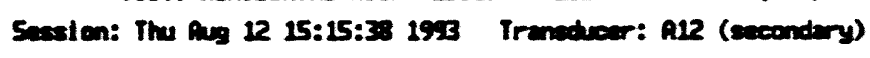

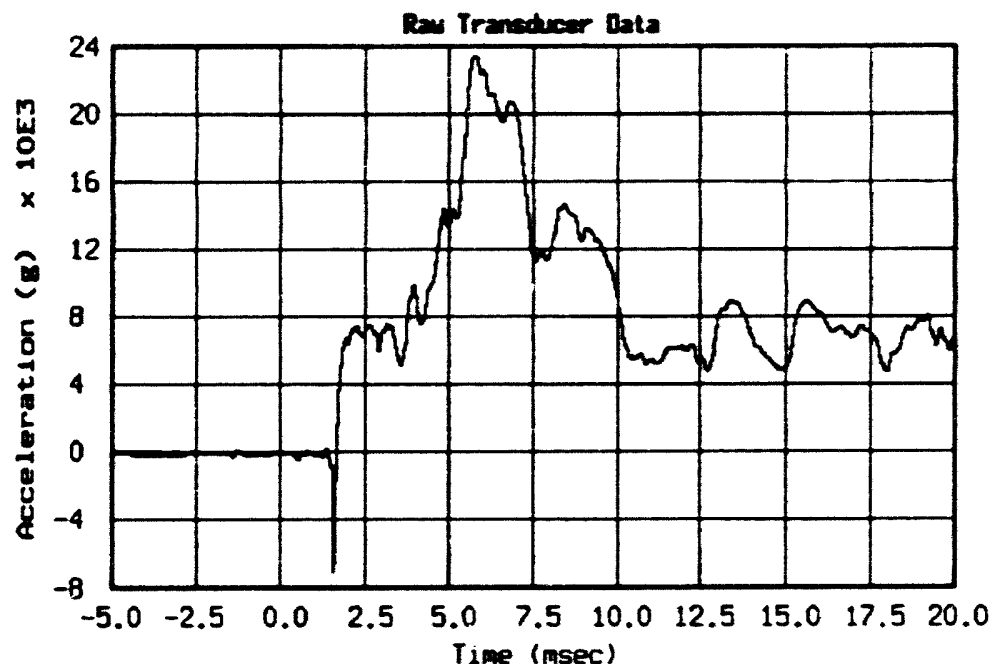


Test: moRizONTA HIA Vaccity H1224A OQ/12/93 (224) 5ession: Thu fug 12 15:15:51 1993 Trunsducer: A13 (secondary)

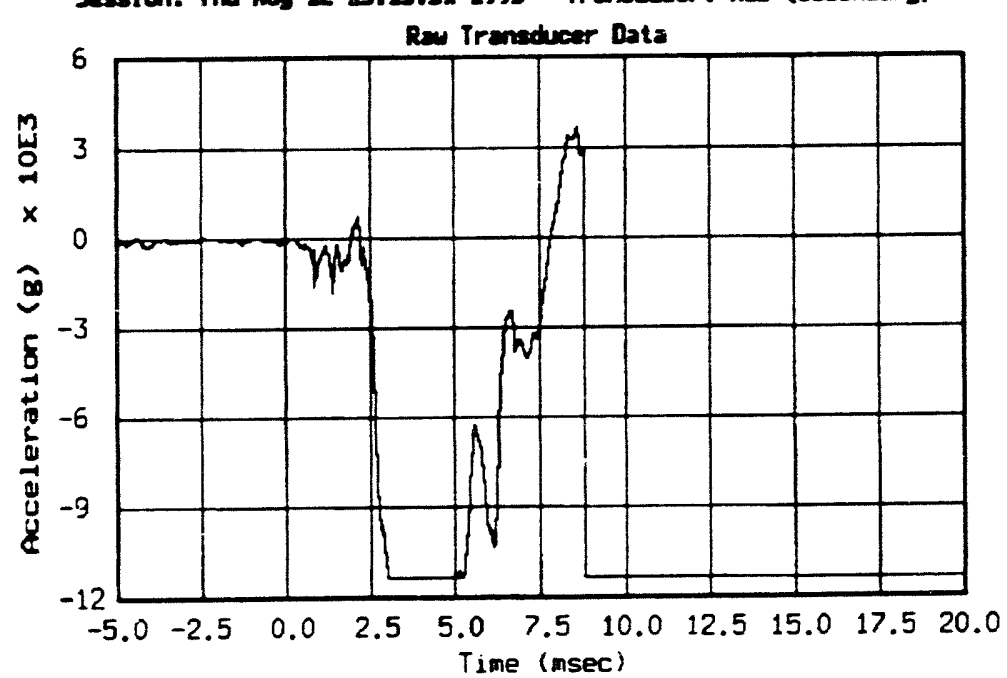

Test: HORIZONTAL HICH VelOCITY H1224A OQ/12/93 (224) Session: Thu Aug 12 15:15:22 1993 Transducer: A15 (secondary)

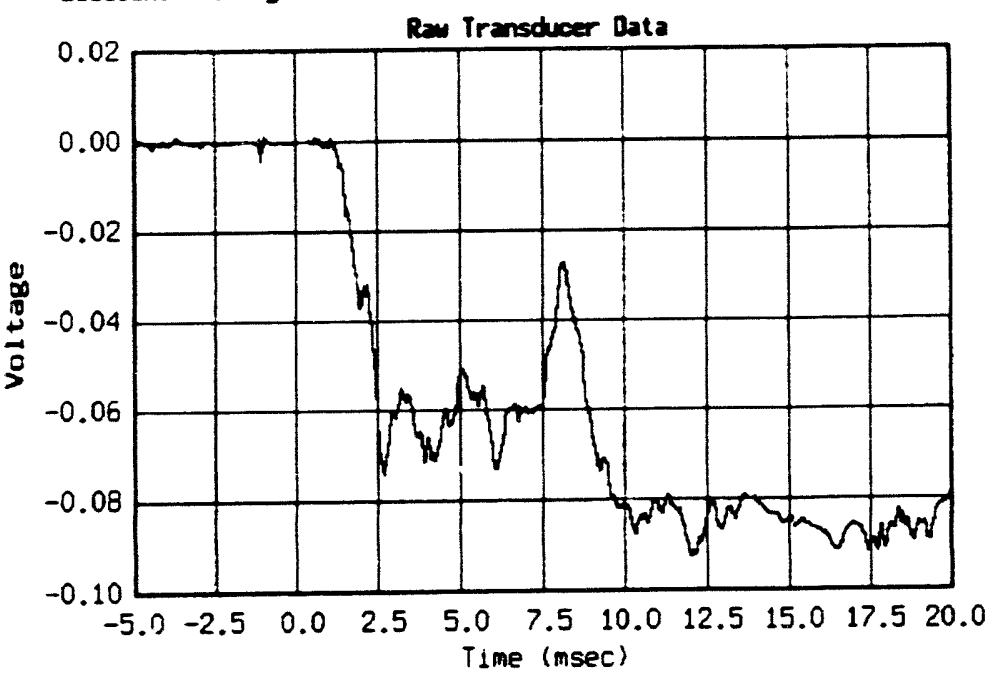

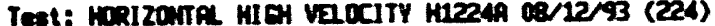
Seasion: The the 12 15:16:05 1993 Transducer: 551 (secondary)

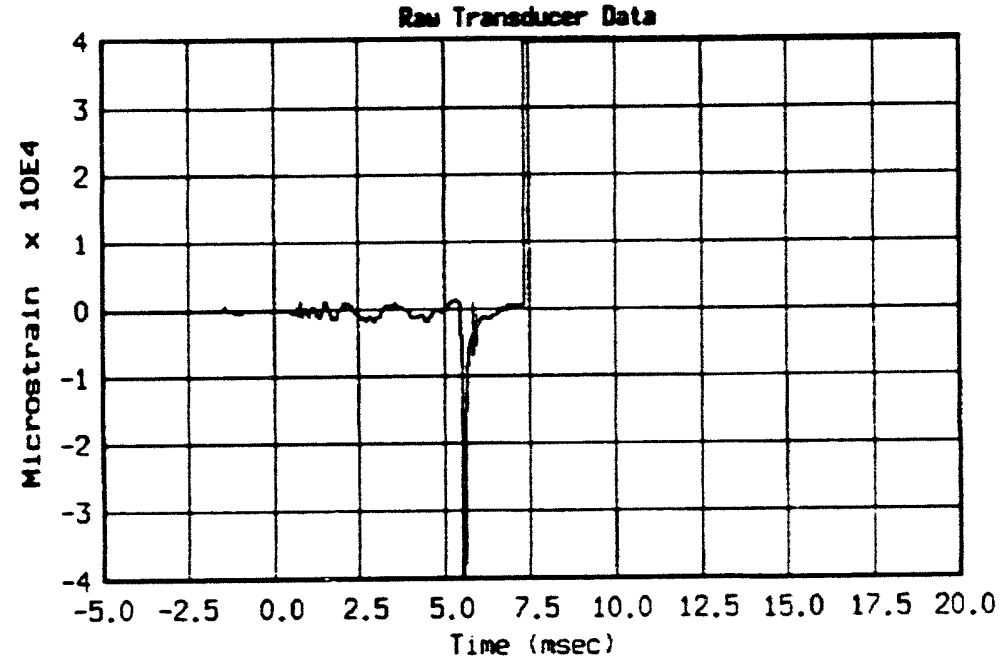

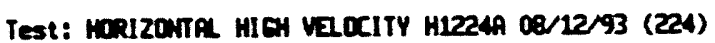
Session: Thu Aug 12 15:16:04 1993 Transducer: Se2 (secondary) Run Transedecer Data

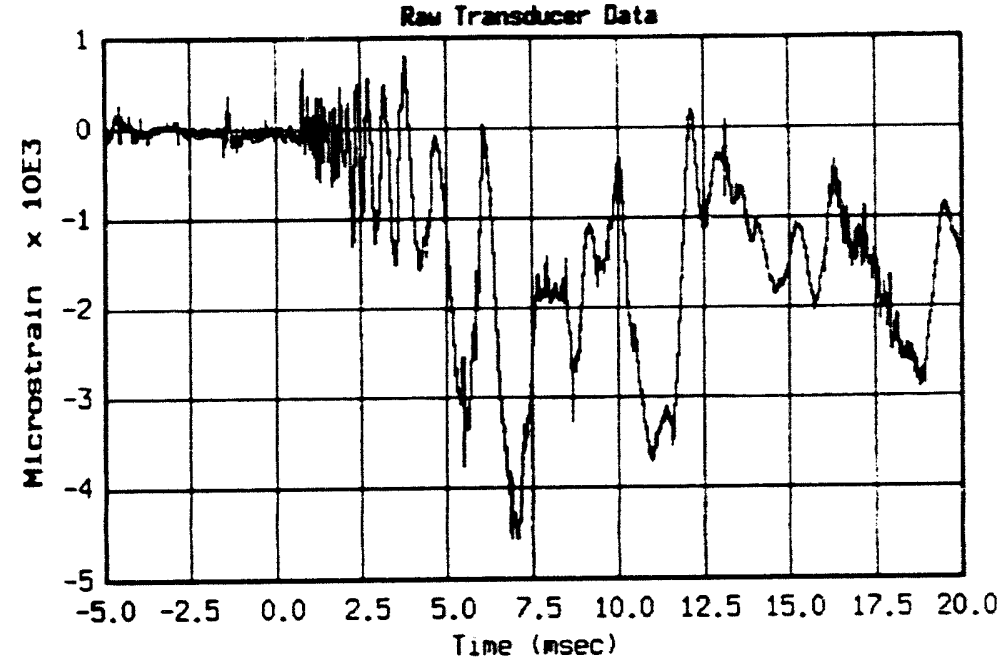



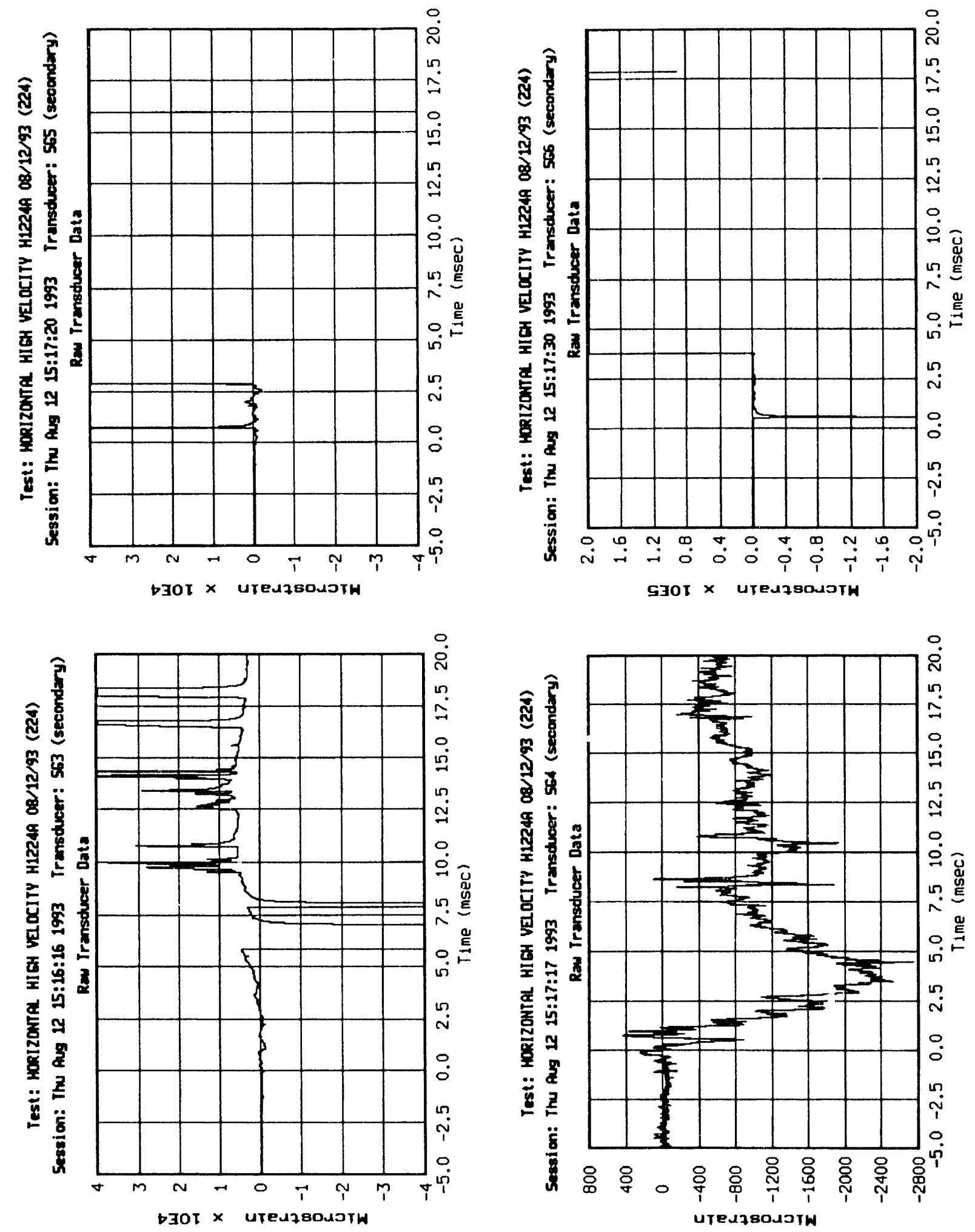
Test: HoRIZONTL HICH VIOCITY H12249 08/12/93 (224) Session: Thu Aug 12 15:17:34 1993 Transcucer: S67 (secendary)

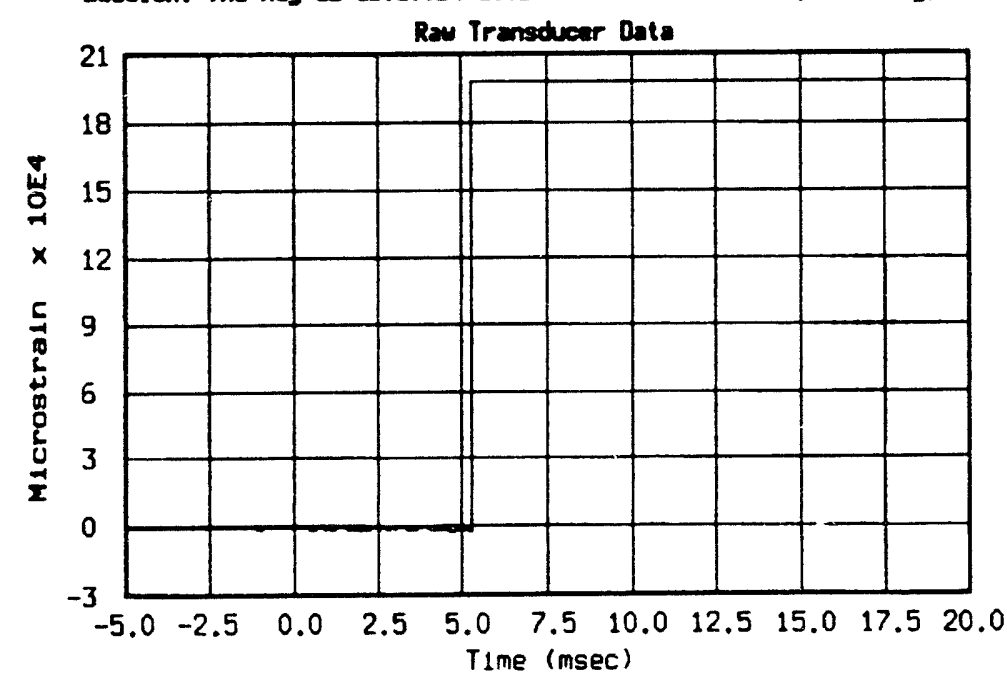

$\vec{\infty}$

Test: HoRIZONTR HIEH VelocITY H1224A 08/12/93 (224) Session: Thu Aug 12 15:17:42 1993 Transdveer: 568 (secondary)

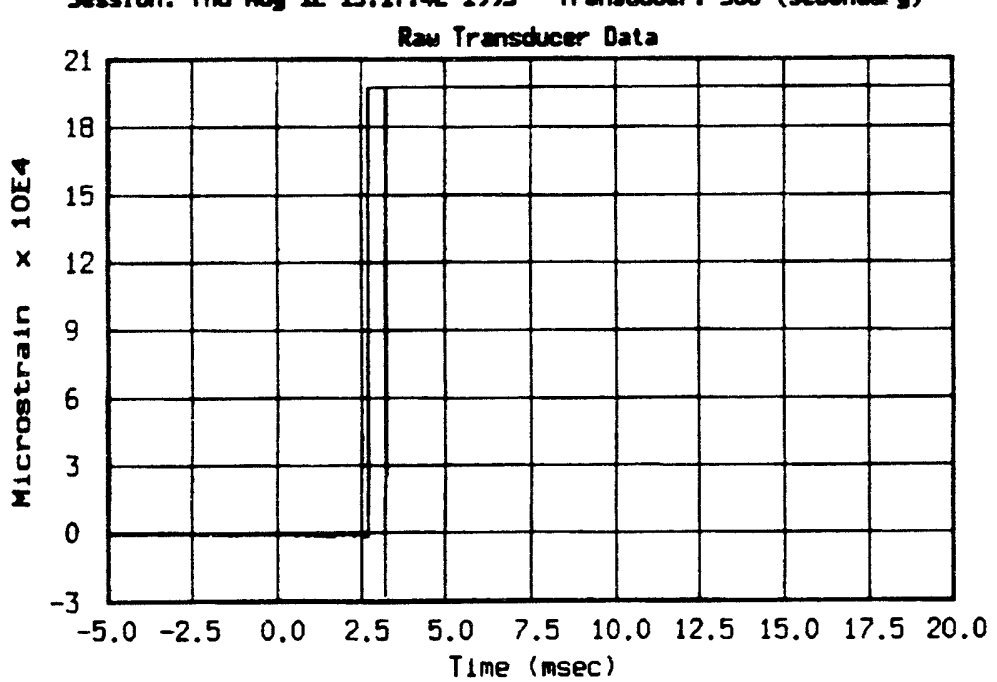

Test: MORIZONAL HIGH VHOCITY H1224A 08/12/93 (224) Session: Thu Aug 12 15:18:20 1993 Transducer: 569 (secondary)

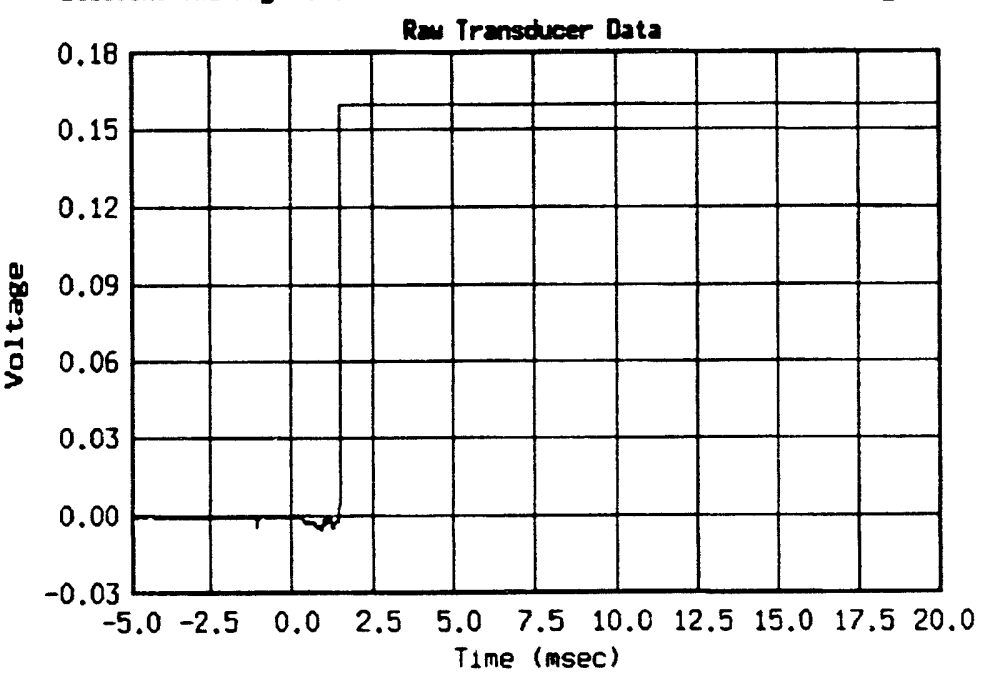

Test: HORIZONTR HIGH VIOCITY H1224A 08/12/93 (224) Session: Thu Aug 12 15:18:25 1993 Transchucer: 5610 (secondary)

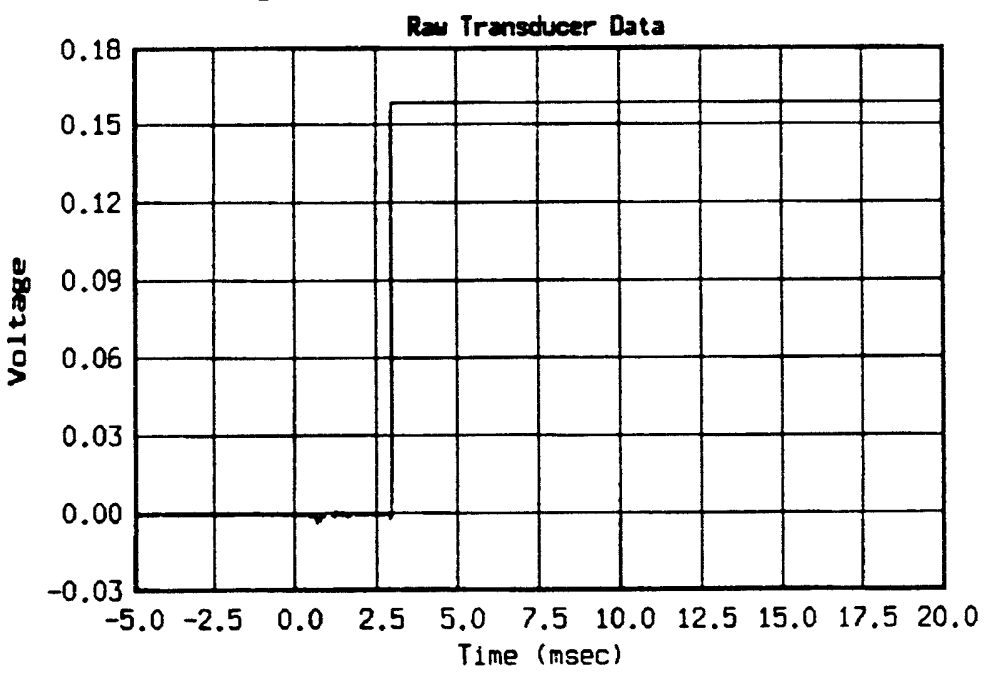


Test: MORIZONTAL HICH VEDCITY H1224A 08/12/93 (224) Session: Thu Aug 12 15:25:16 1993 Transducer: A1 (secondary)

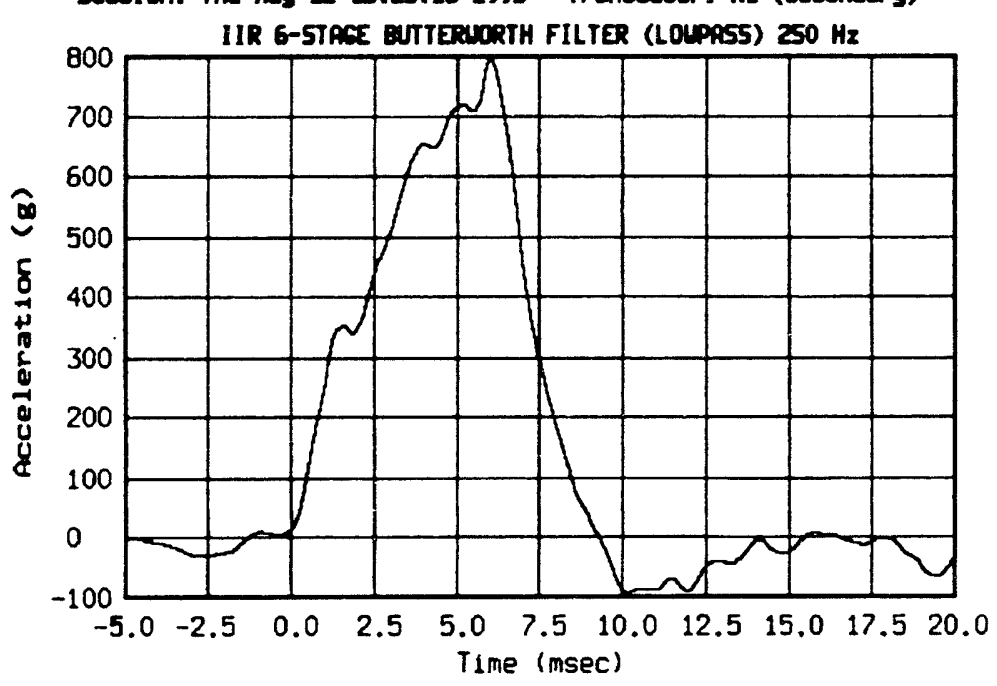

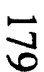

Test: HORIZONTL HIOH VEOCITY H12249 08/12/93 (224)

Session: Thu Pug 12 15:25:18 1993 Transicucer: R2 (secondary)

IIR 6-STAGE EUTTERIDRTH FILTER (LOPASS) $250 \mathrm{~Hz}$

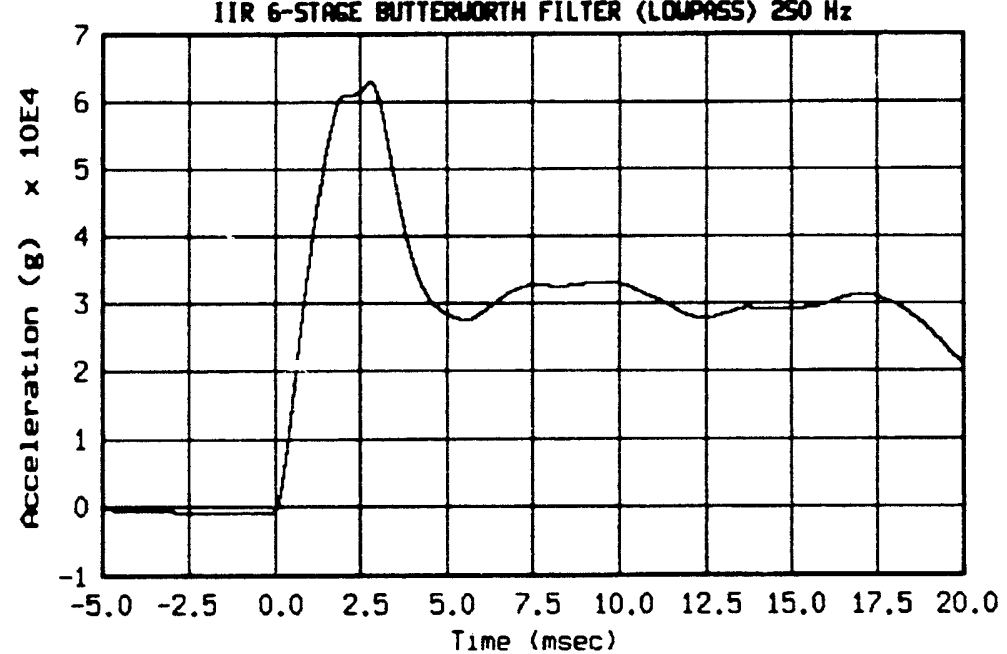

Test: HoRI20NA HIGH VELOCITY H1224A 08/12/93 (224)

Session: Thu Pug 12 15:25:29 1993 Iransducer: A3 (secondary)

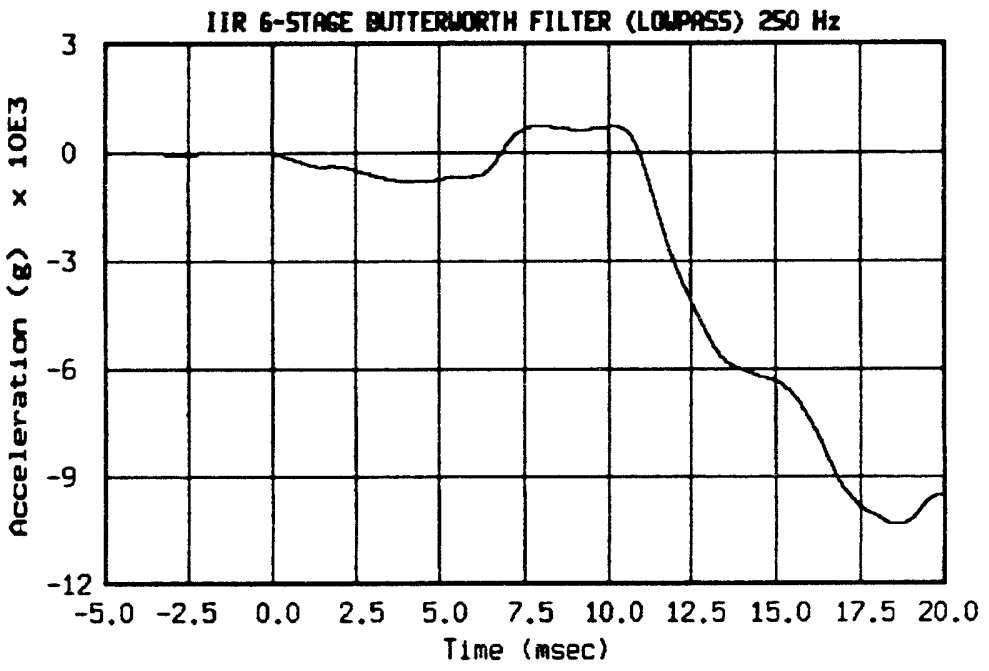

Test: MBRIZONTR HICH VEIOCITY H1224A 08/12/93 (224) Session: Thu Aug 12 15:25:32 1993 Transducer: A4 (secondiry) IIR G-STAGE EUTTERUCRTH FILTER (LAPAS5) $250 \mathrm{~Hz}$

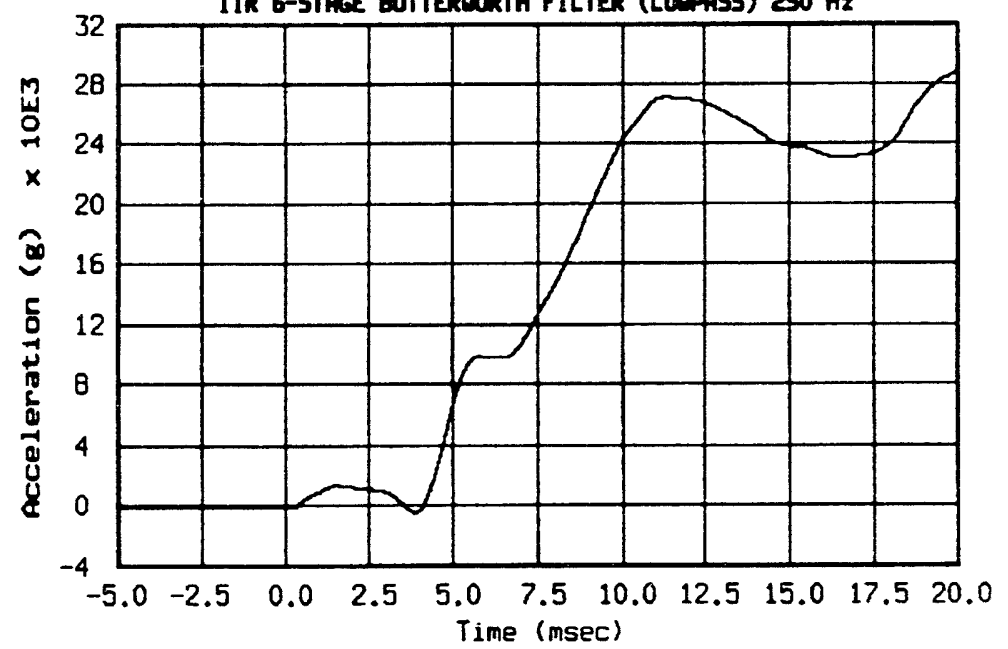



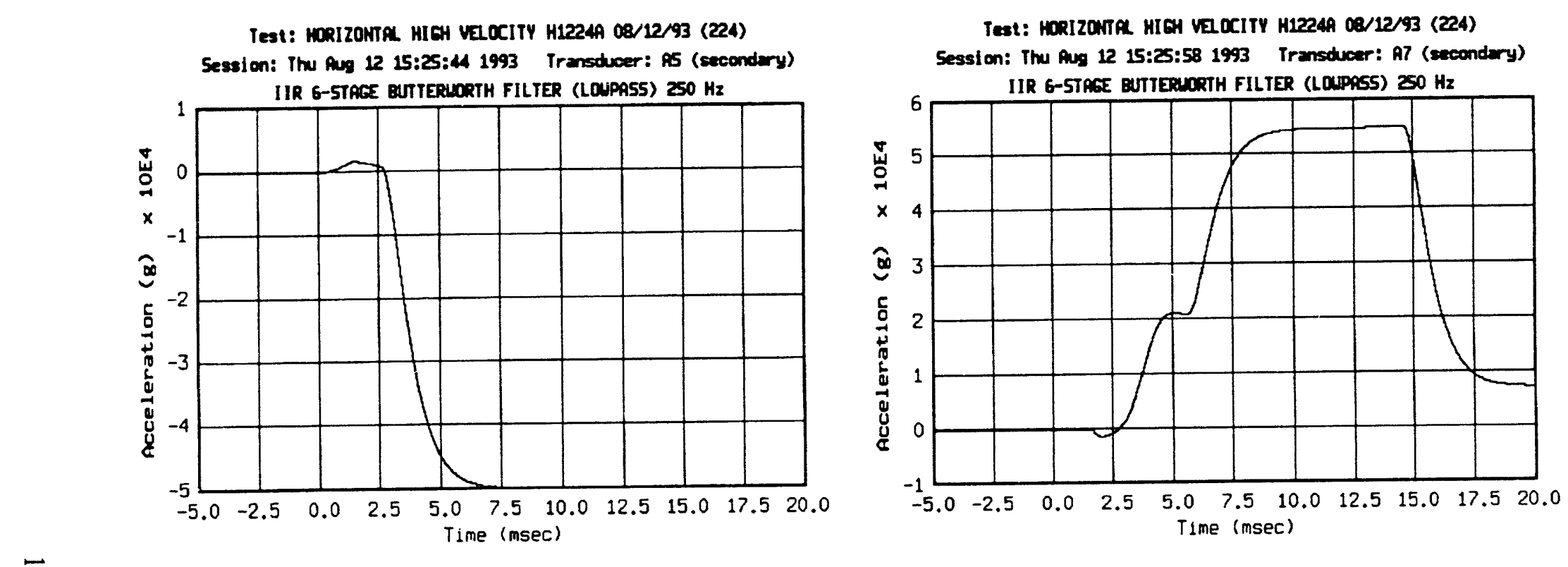

$\vec{\infty}$

Test: HORIZONTA HIGH VELOCITY HI224A 08/12/93 (224)

Session: Thu Aug 12 15:25:48 1993 Transducer: A6 (secondary)

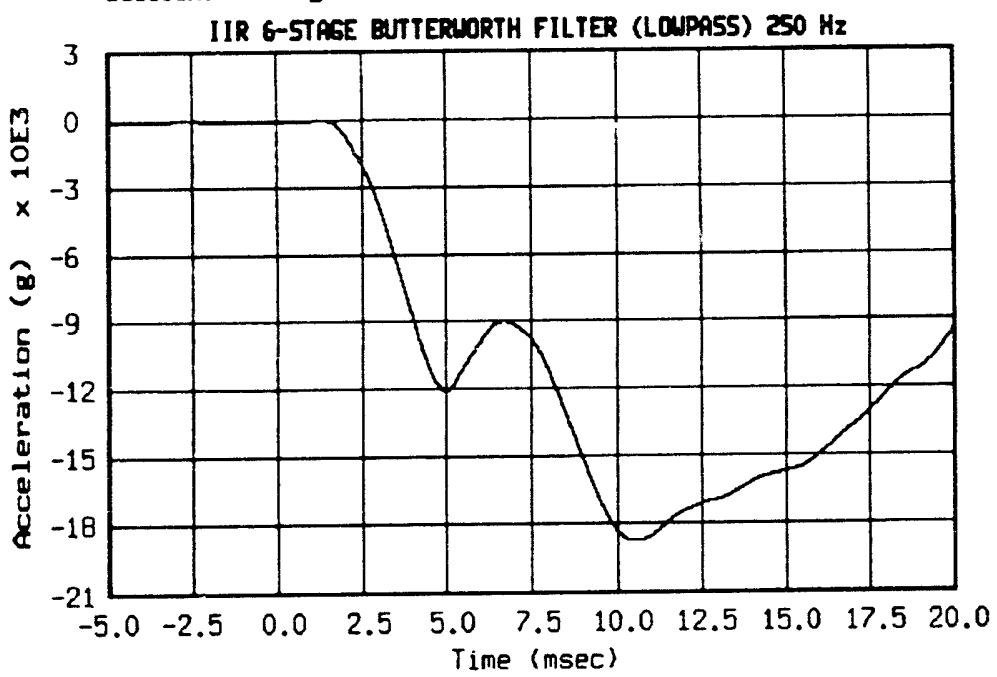

Test: HORIZOWTA. HIEH VELOCITY HI224A 08/12/93 (224)

Session: Thu Aug 12 15:26:02 1993 Transducer: AB (secondary)

IIR 6-STAGE BUTTERLORTH FILTER (LOLPAS5) $250 \mathrm{~Hz}$

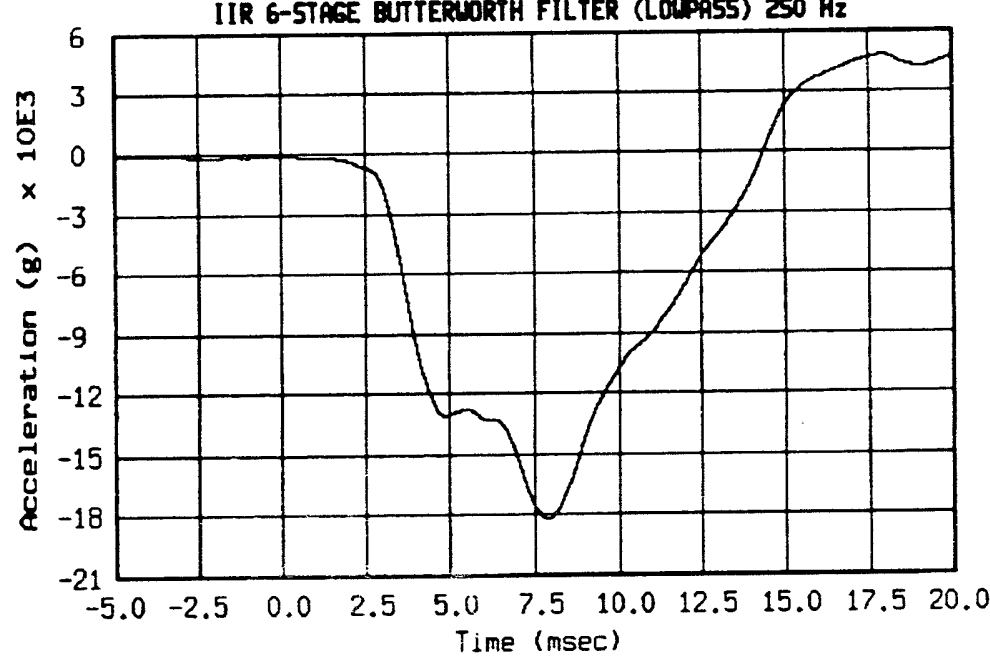



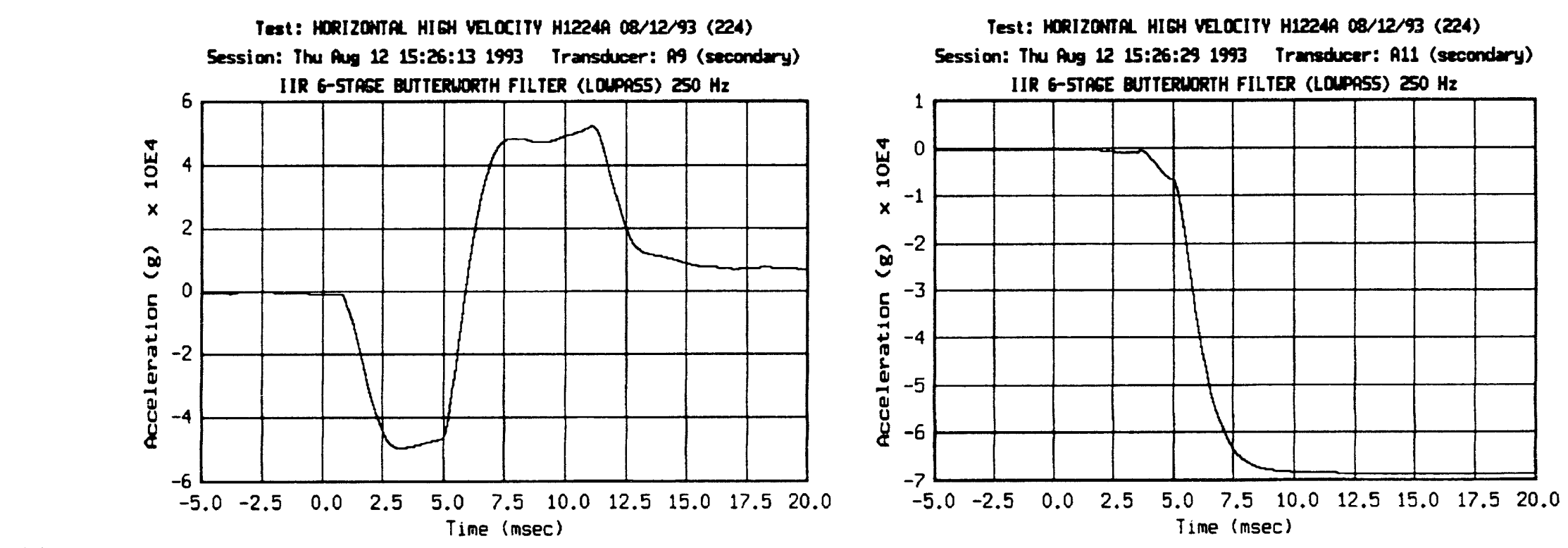

Test: HORIZONTR. HIGH VELOCITY H1224A 08/12/93 (224) Session: Thu fug 12 15:26:20 1993 Transducer: A10 (secondary)

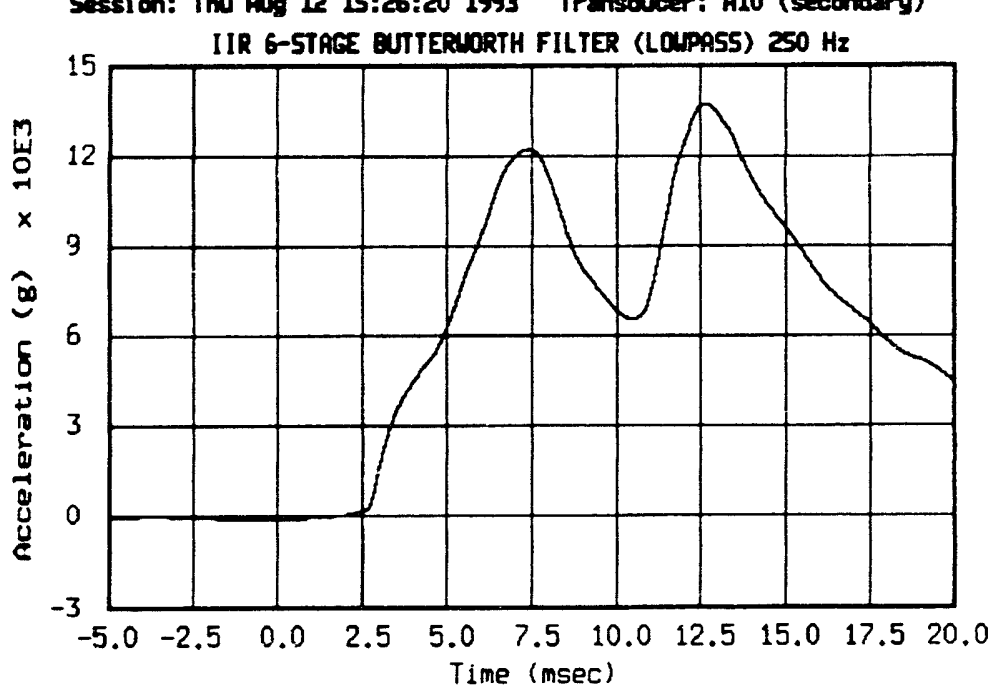

Test: HORIZOWTA HIGH VEIOCITY HI224A 08/12/93 (224) Session: Thu Aug 12 15:26:35 1993 Transtwoer: A12 (secondary)

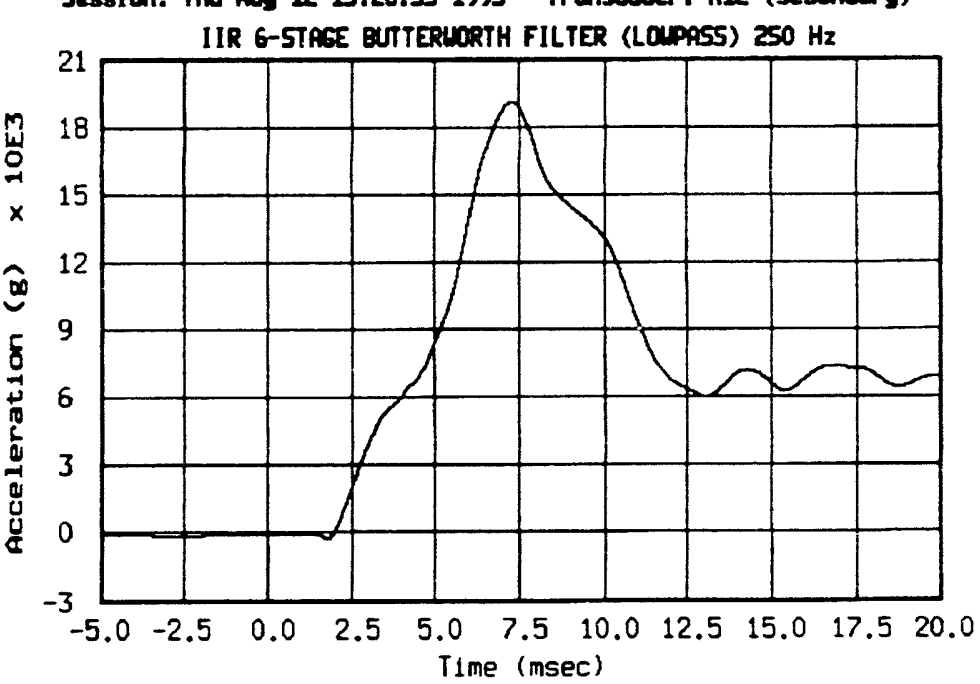


Test: HoRIZONTAL HICH VבOCITY H1224A 08/12/93 (224) Session: Thu fug 12 15:26:4 1993 Transodver: A13 (secondary)

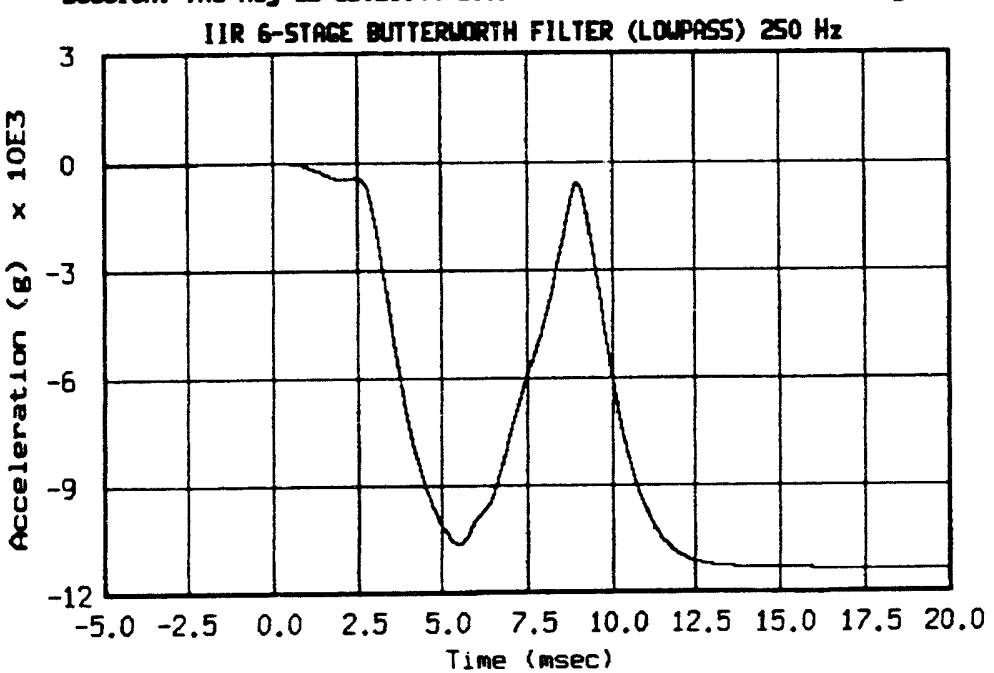

$\vec{N}$

Test: HORIZONTR HICH VEIOCITY H1224A 08/12/93 (224) Session: Thu Aug 12 15:26:50 1993 Transducer: A15 (secondary)

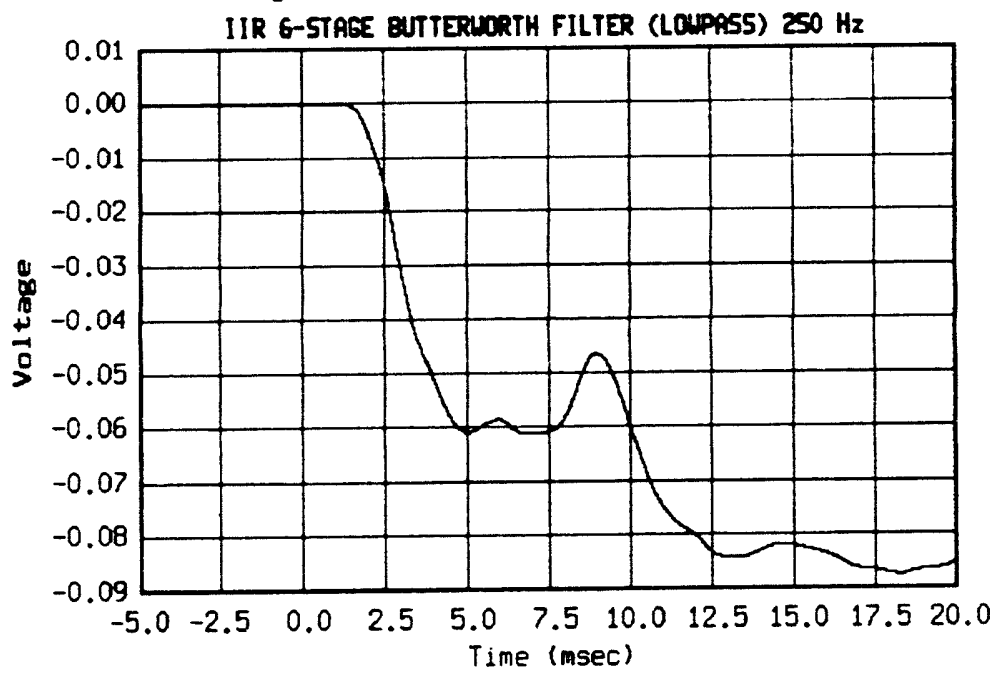

Test: MoplzONT HIGH VघOCITY H12249 08/12/93 (224) Session: Thu Aur 12 15:26:58 1993 Transducer: 561 (secondary) IIR 6-5TAGE BUTTERUORTH FILTER (LOAPES5) $250 \mathrm{~Hz}$

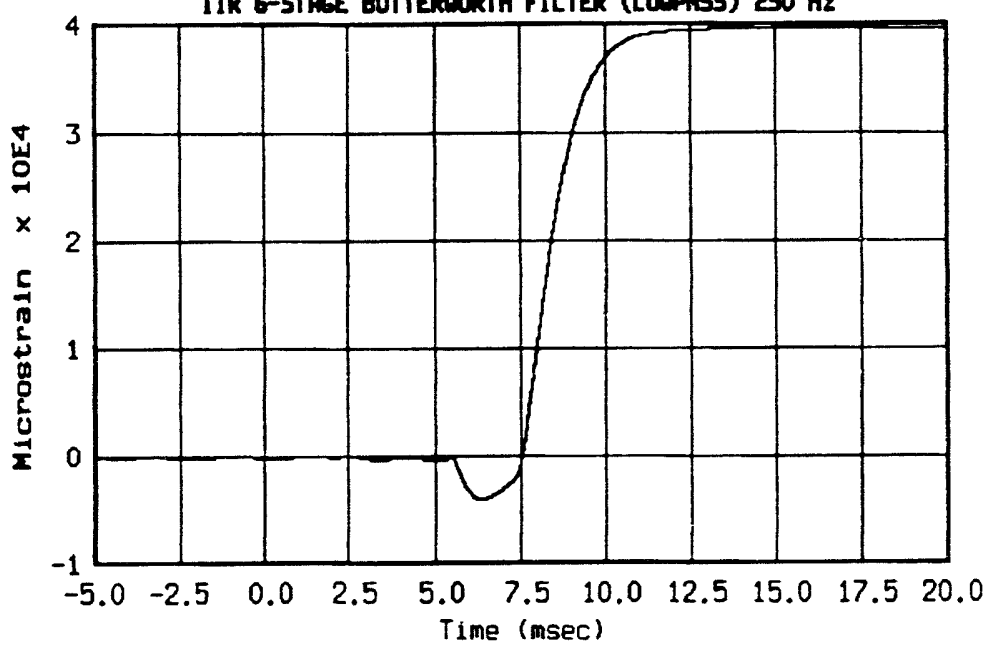

Test: HORIZONTR HICH VEOCITY H1224A 08/12/93 (224) Session: Thu fug 12 15:27:04 1993 Transducer: SE2 (secondary)

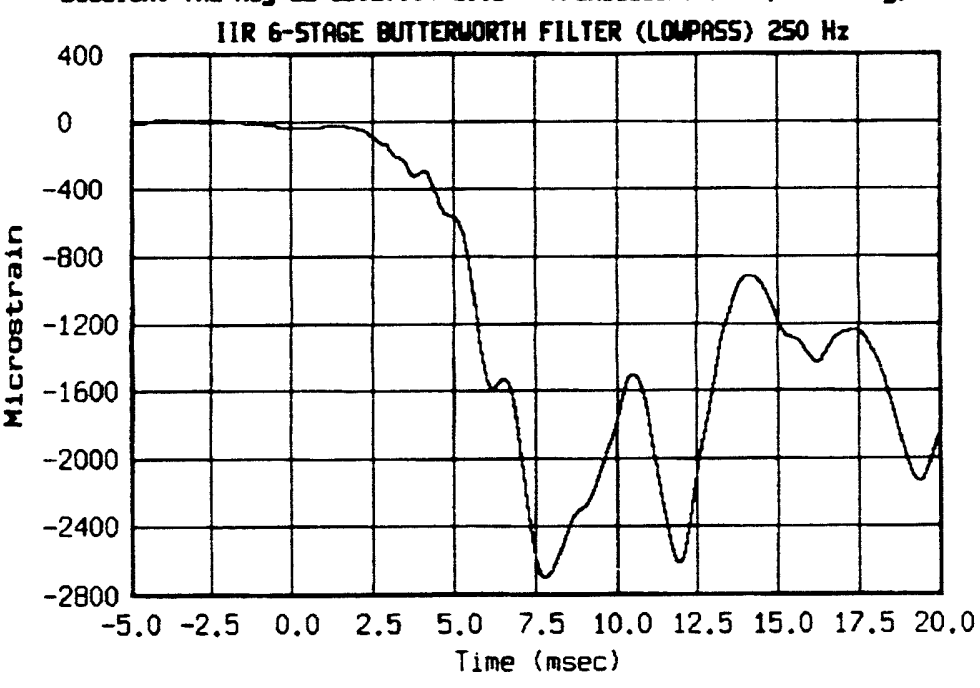


Test: HORIZONTAL HICH VEOCITY H1224h 08/12/93 (224) Session: Thu Aug 12 15:27:10 1993 Transducer: 563 (secondary) IIR 6-STAGE BUTTERLORTH FILTER (LOMPASS) $250 \mathrm{~Hz}$

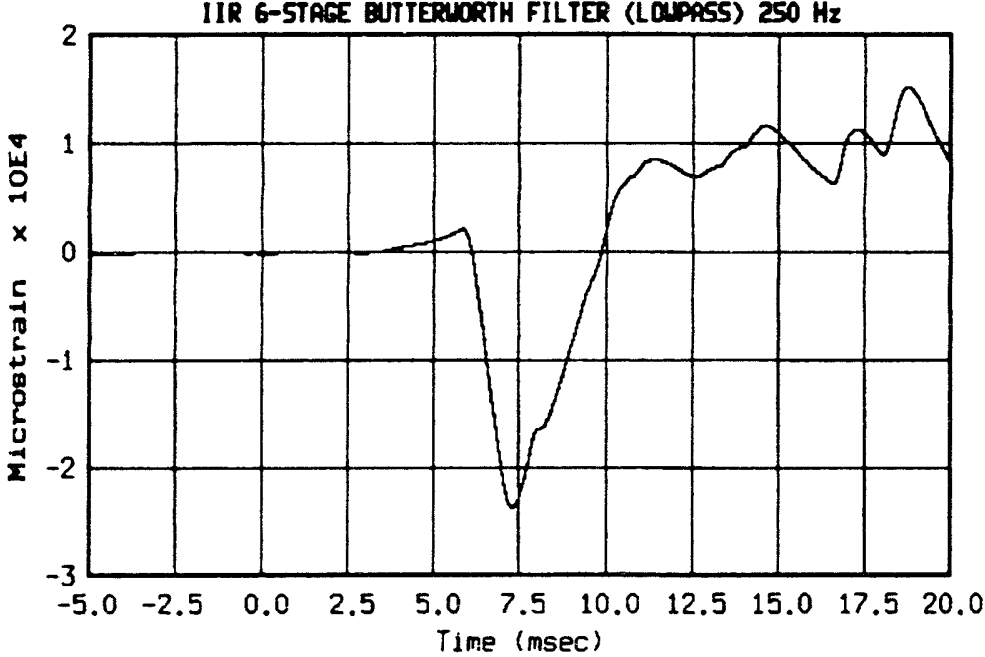

$\bar{\omega}$

Test: HORIZONTR. HIGH VELOCITY H1224A OS/12/93 (224)

Session: Thu Aug 12 15:27:16 1993 Transducer: S64 (secondary)

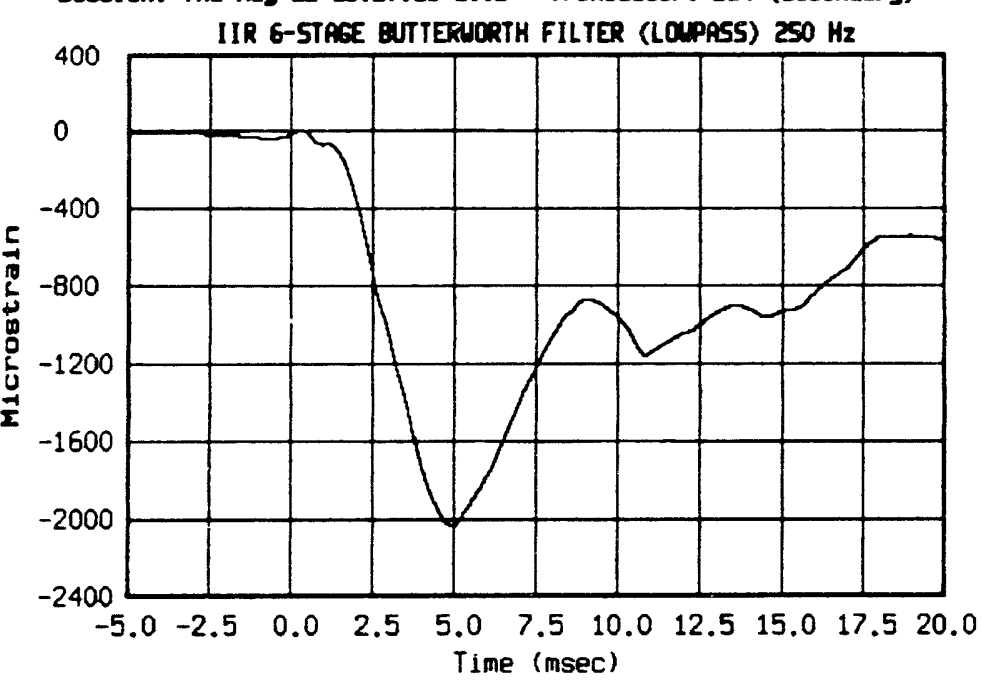

Test: hoRIZOWRL HIGH VEOCITY H12249 08/12/93 (224) Session: Thu Aug 12 15:27:22 1993 Transducer: 565 (secondary) IIR 6-STAEE EUTTERUDRTH FILTER (LOAPASS) $250 \mathrm{~Hz}$

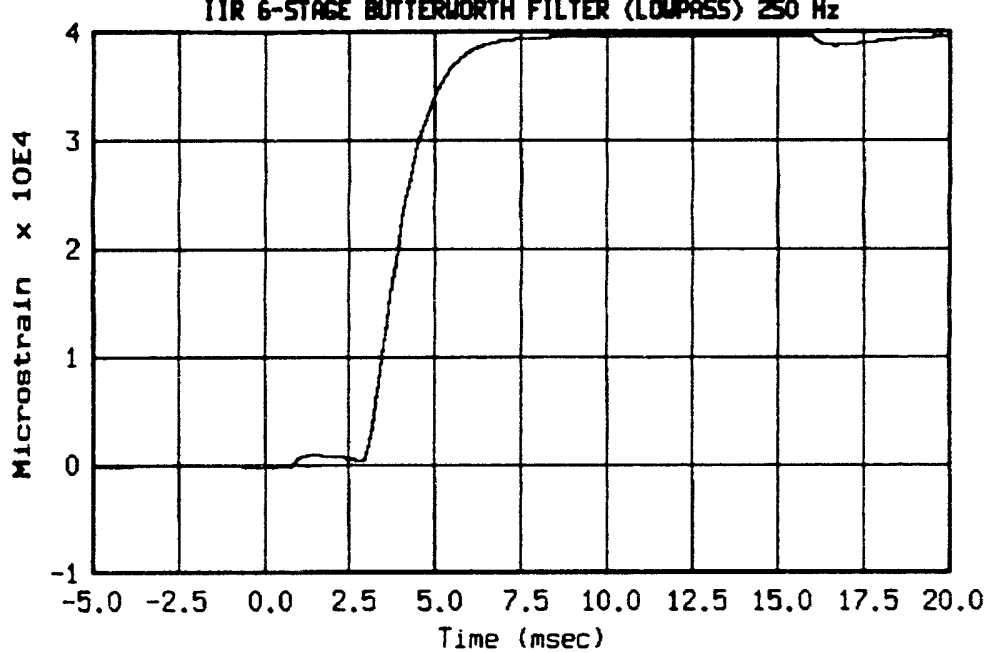

Test: HORIzONAL HIGH VElOCITY H12249 08/12/93 (224)

5ession: Thu Aug 12 15:27:27 1993 Transducer: 566 (secondary) IIR 6-STACE EUTTERIORTH FILTER (LOPASS) $250 \mathrm{~Hz}$

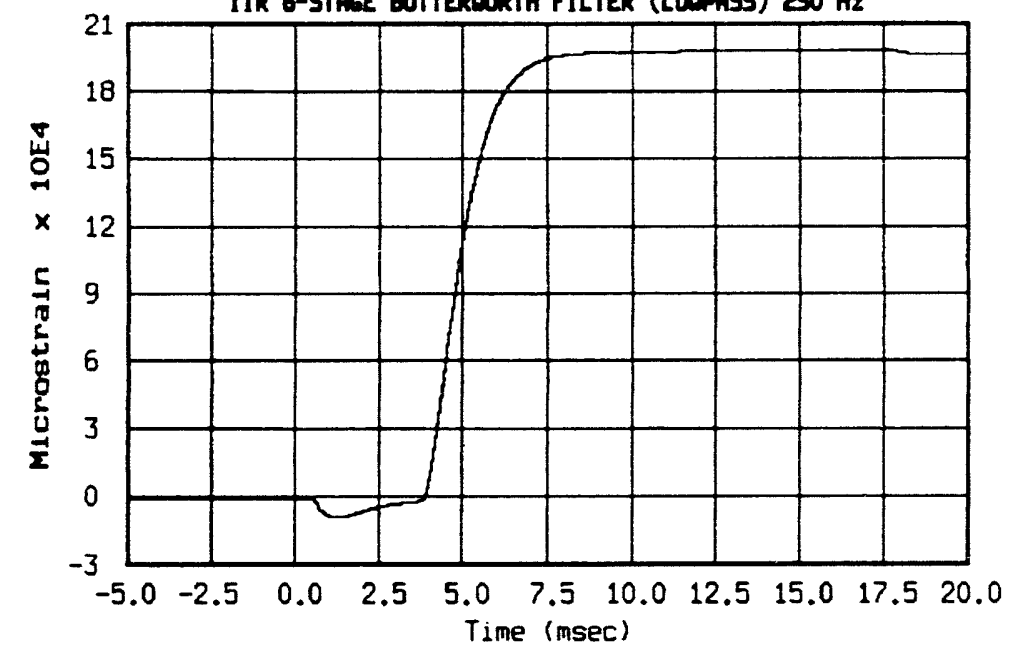


Test: MoRIZOMAL HIGH VEOCITY H12249 08/12/93 (224) Session: Thu fug 12 15:27:36 1993 Transtuoer: 567 (secondary)

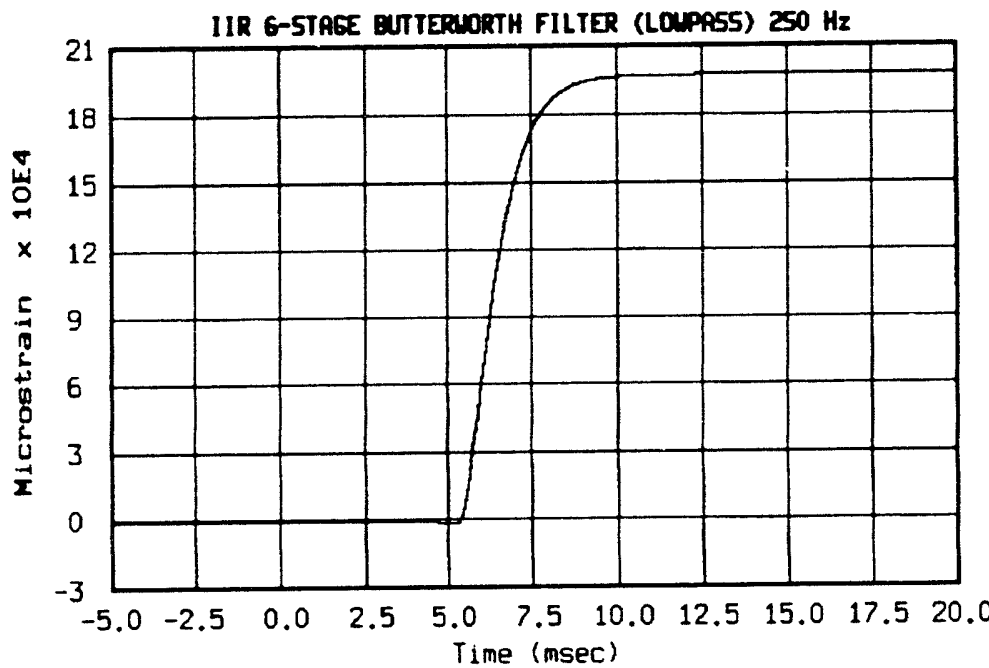

Test: HORIZONTAL HICH VELCITY H1224A 08/12/93 (224) Session: Thu Aug 12 15:27:43 1993 Transducer: 568 (secondary)

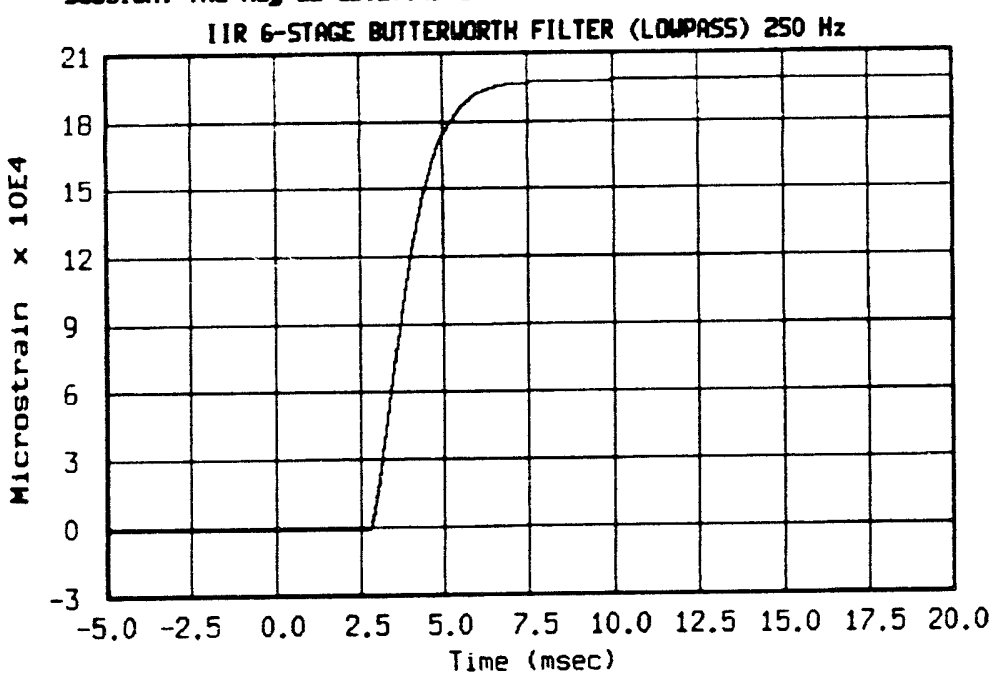

Test: HORIZONTA HICH VבOCITY H1224A 08/12/93 (224) Session: Thu fug 12 15:27:51 1993 Tranducer: 569 (secondary) IIR G-STRCE EUTTERUORTH FILTER (LOLPASS) $250 \mathrm{~Hz}$

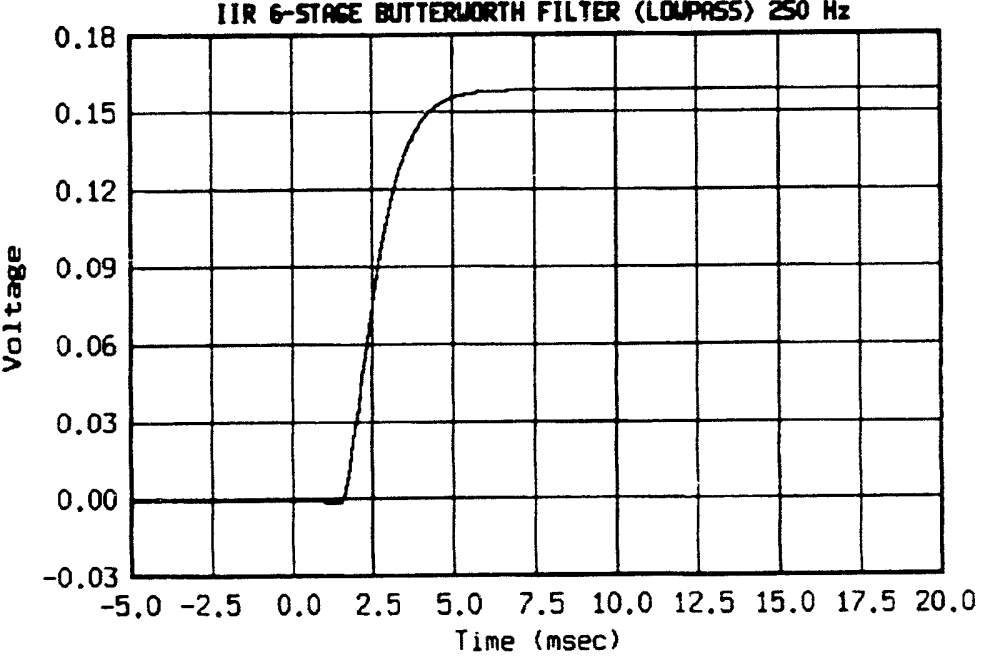

Test: HORIZONTA HIGH VElOCITY H1224A 08/12/93 (224) Session: Thu Pug 12 15:27:56 1993 Trunsotucer: 5610 (secondery)

IIR 6-STAGE BUTTERUORTH FILTER (LQUPASS) $250 \mathrm{~Hz}$

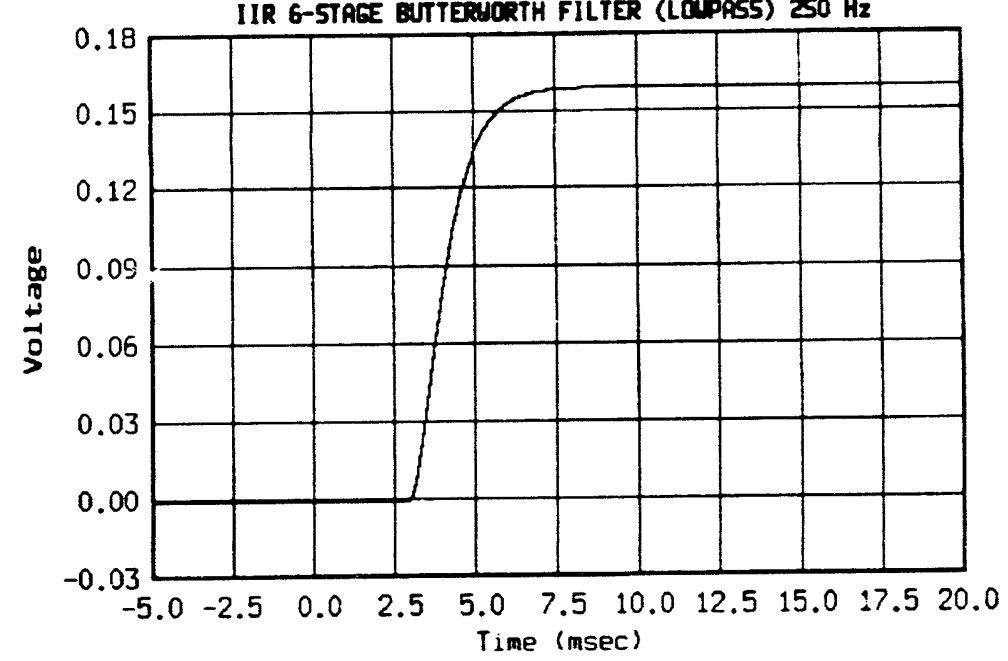


Test: HORIZONALL HIEH VELOCITY H1224A 08/12/93 (22d) Session: Thu Aug 12 15:28:10 1993 Transtucer: A1 (secondary)

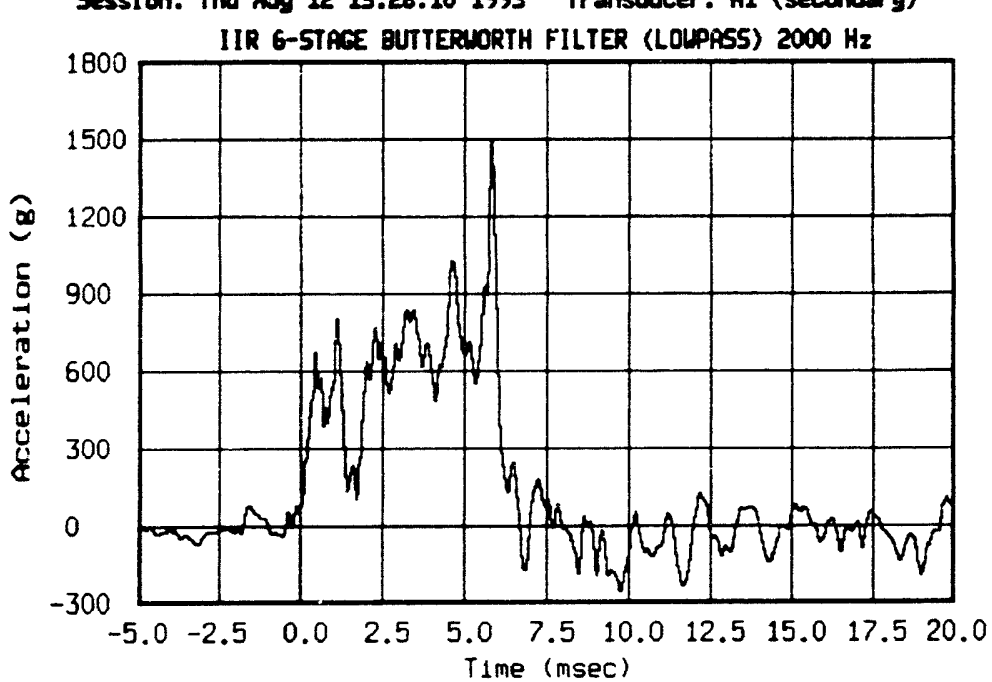

$\underset{\infty}{\leftrightarrow}$

Test: HORIZONTA HIEH VEOCITY H12249 08/12/93 (224) Session: Thu Aug 12 15:28:04 1993 Transducer: $R 2$ (secondary)

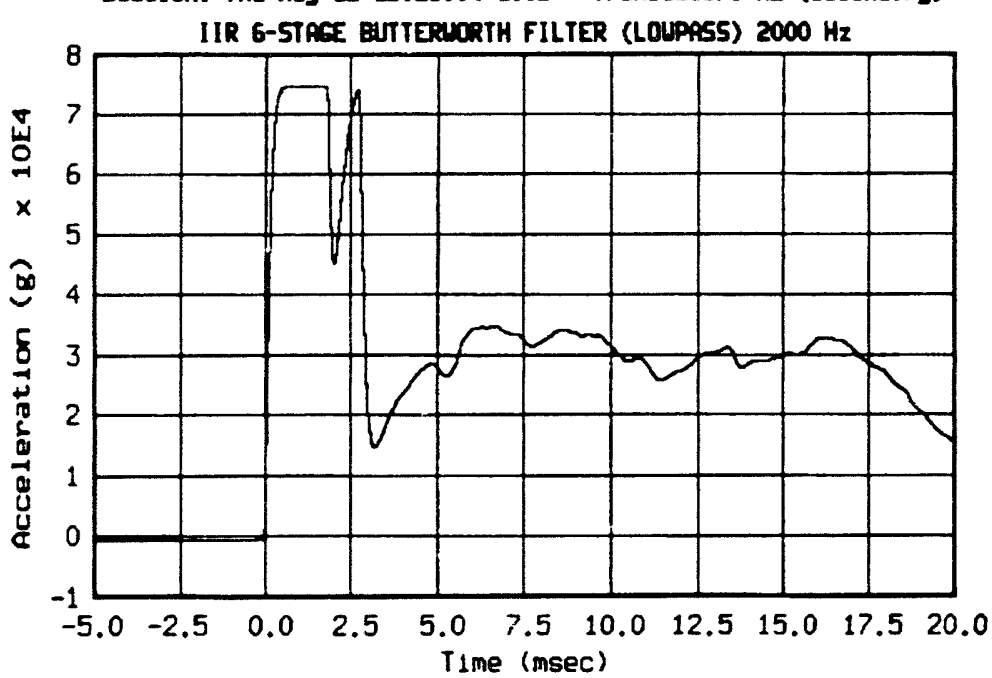

Test: HORIZONTR HIEH VELCCITY H1224A 08/12/93 (224) Session: Thu Aug 12 15:28:27 1993 Transducer: $A 3$ (secondary) IIR G-STACE BUTTERUORTH FILTER (LOUPASS) $2000 \mathrm{~Hz}$

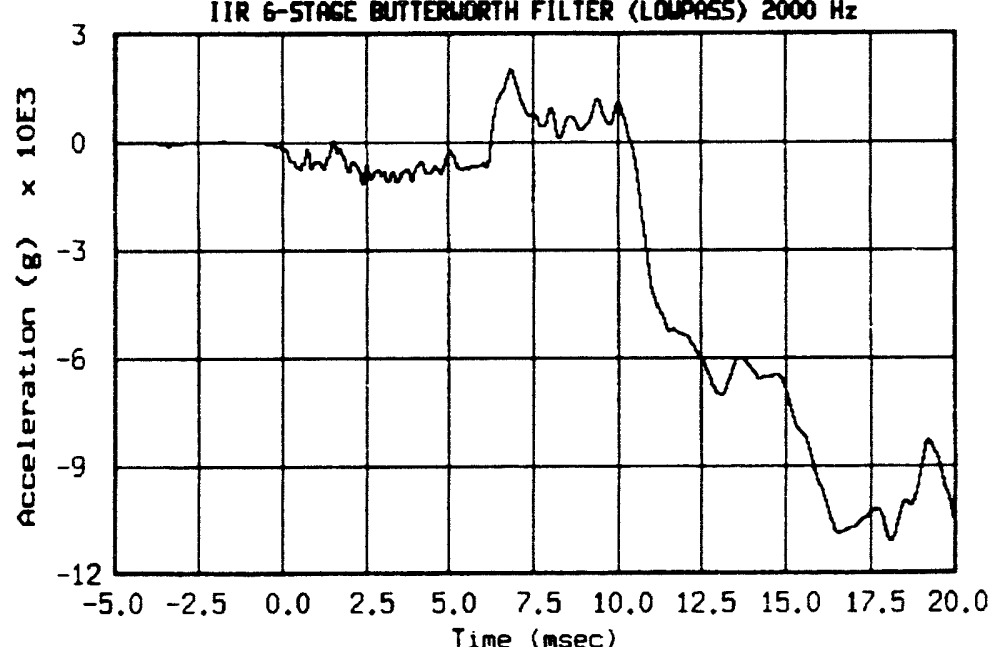

Test: HORIZONTL HICH VEocITY H. 249 08/22/93 (224) Session: Thu Aug 12 15:28:21 1993 Transdweer: A4 (secondary) IIR 6-5TAEE BUTTERUORTH FILTER (LOUPASS) $2000 \mathrm{~Hz}$

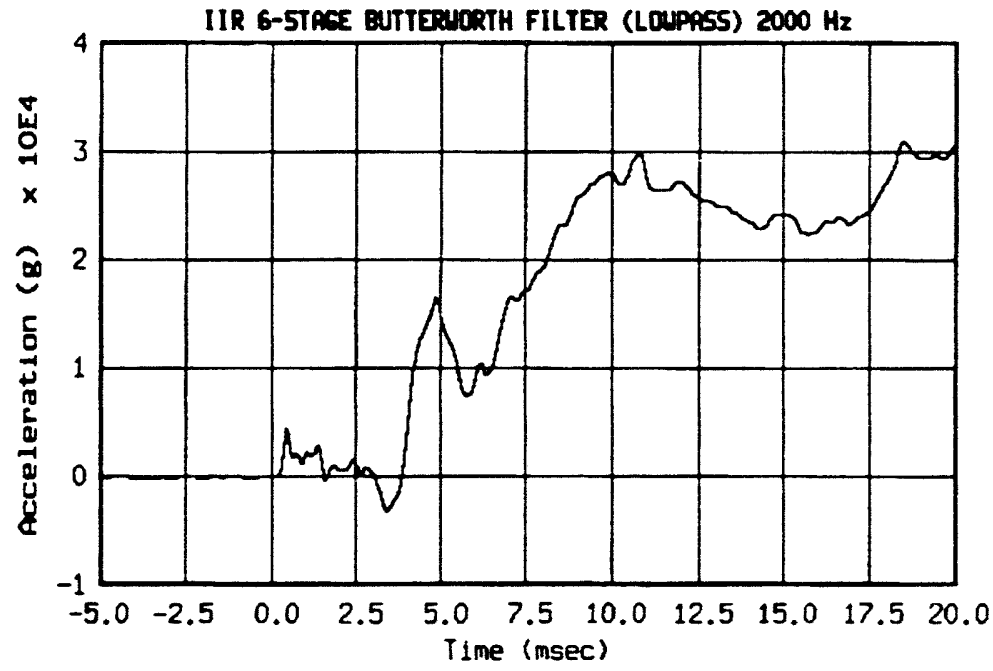



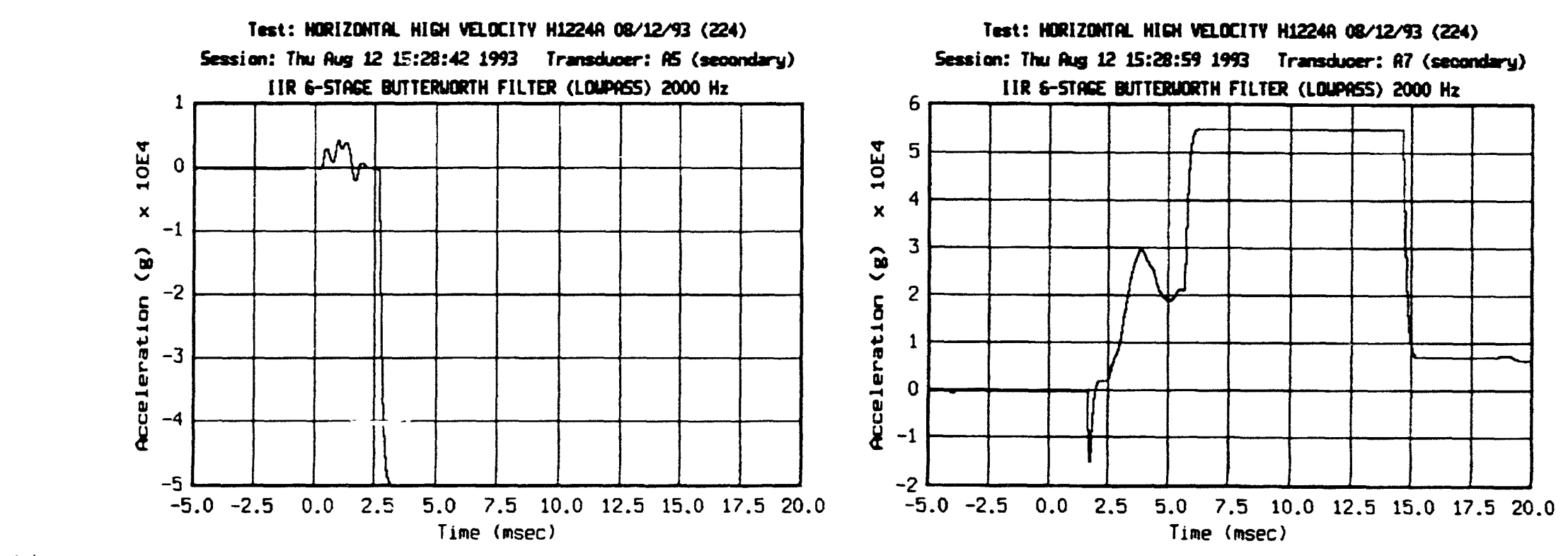

$\infty$

Test: HORIZONTA HIEH VELOCITY HI2249 08/12/93 (254)

Session: Thu Rug 12 15:23:36 1993 Tremsodveer: A6 (secondery) IIR G-STACE BUTTERAORTH FILTER (LOAPPSS) $2000 \mathrm{~Hz}$
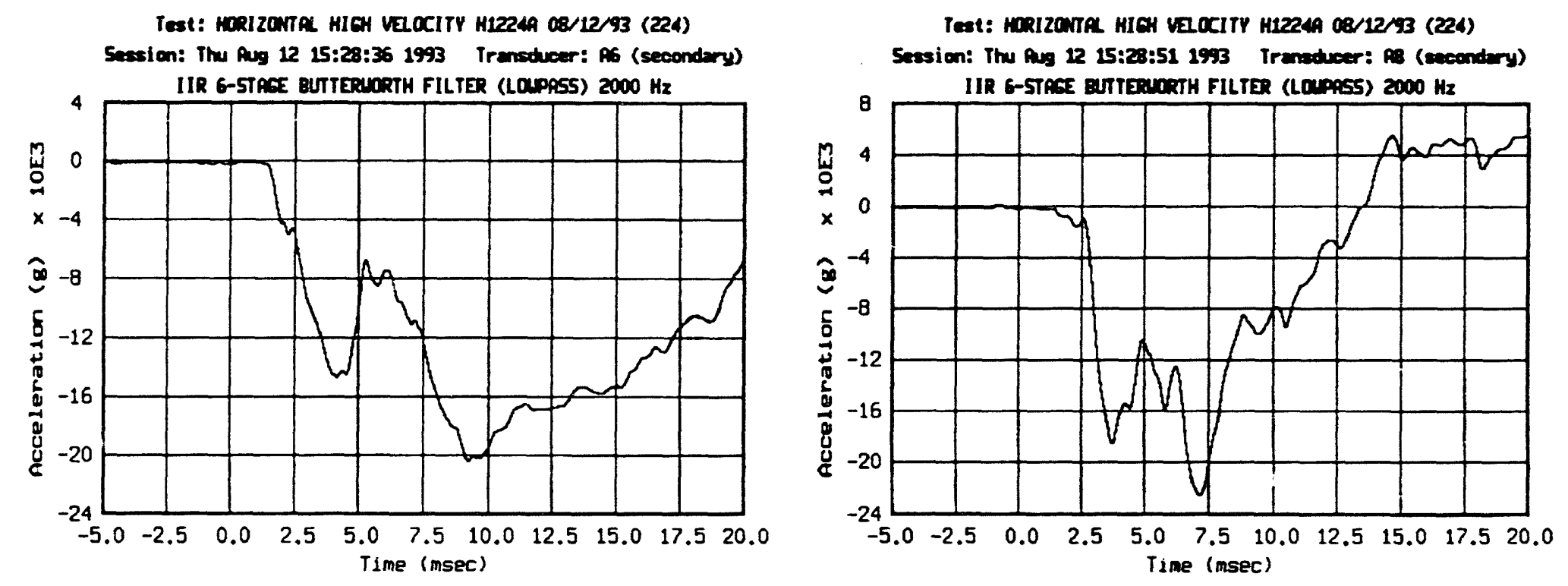

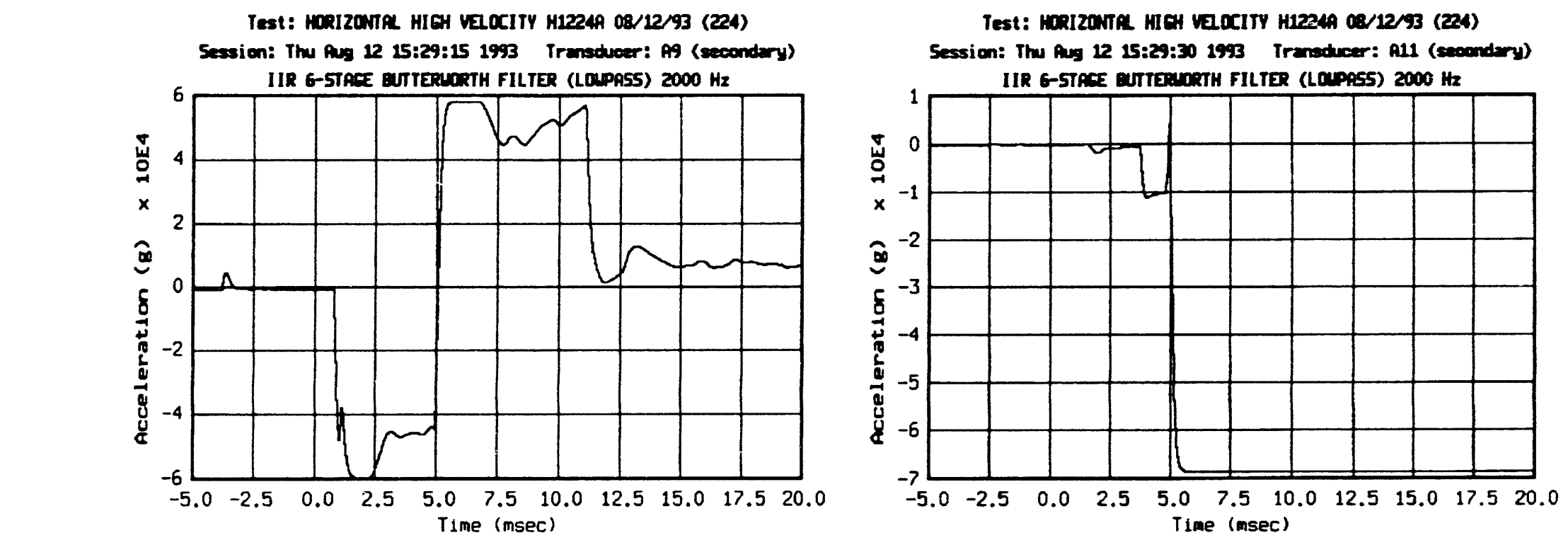

Teat: HORIZONTL HIDH VECCITY H12249 08/12/93 (224) 5ession: Thu Aug 12 15:29:09 1993 Tranoducer: A10 (secondery)

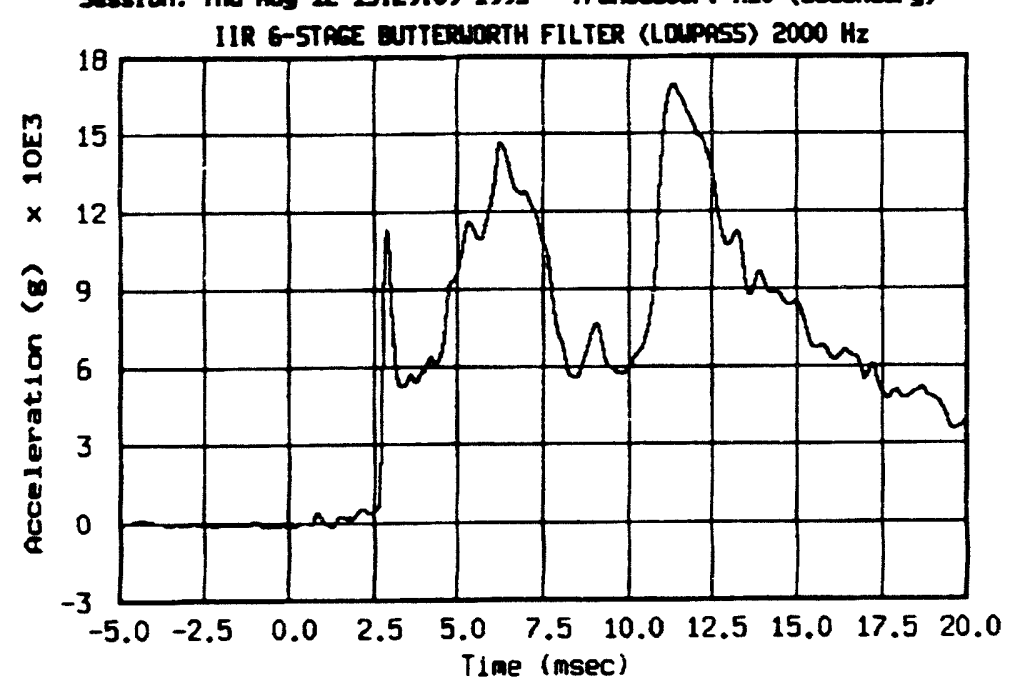

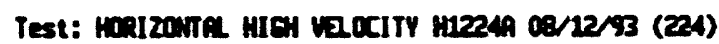
Session: Thu Aug 12 15:29:23 19:3 Transdvoer: A12 (secondery)

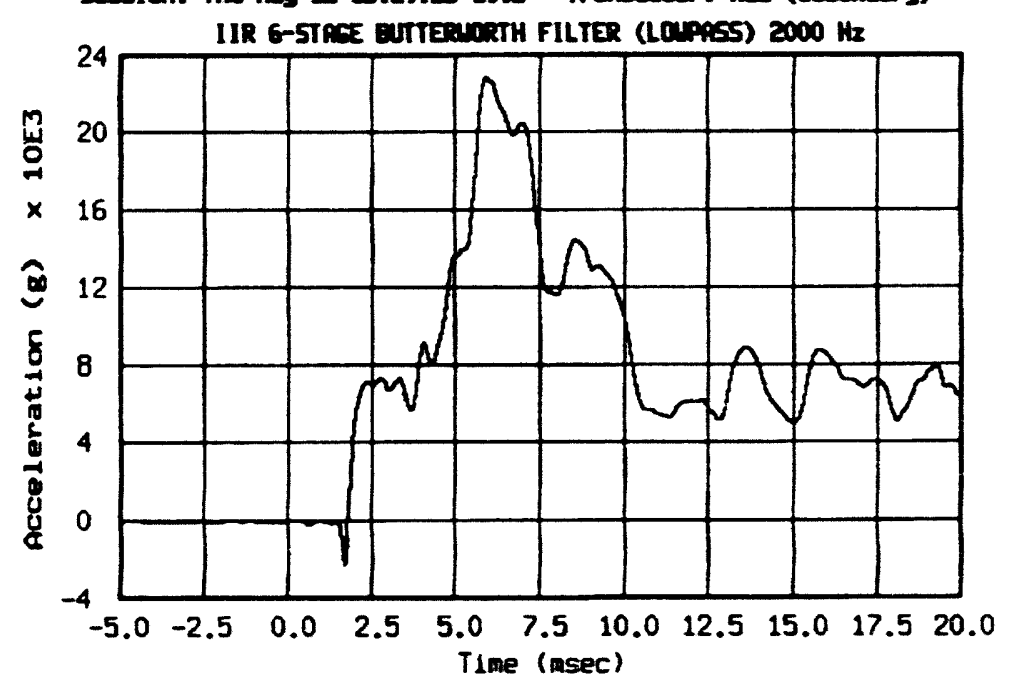


Test: HoRIZONTA HICH VeI0CITY H1224A 08/12/93 (224) Session: Thu hug 12 15:29:44 1993 Transdvoer: A13 (secondary) IIR S-STAGE BUTERUORTH FILTER (LOUPASS) $2000 \mathrm{~Hz}$

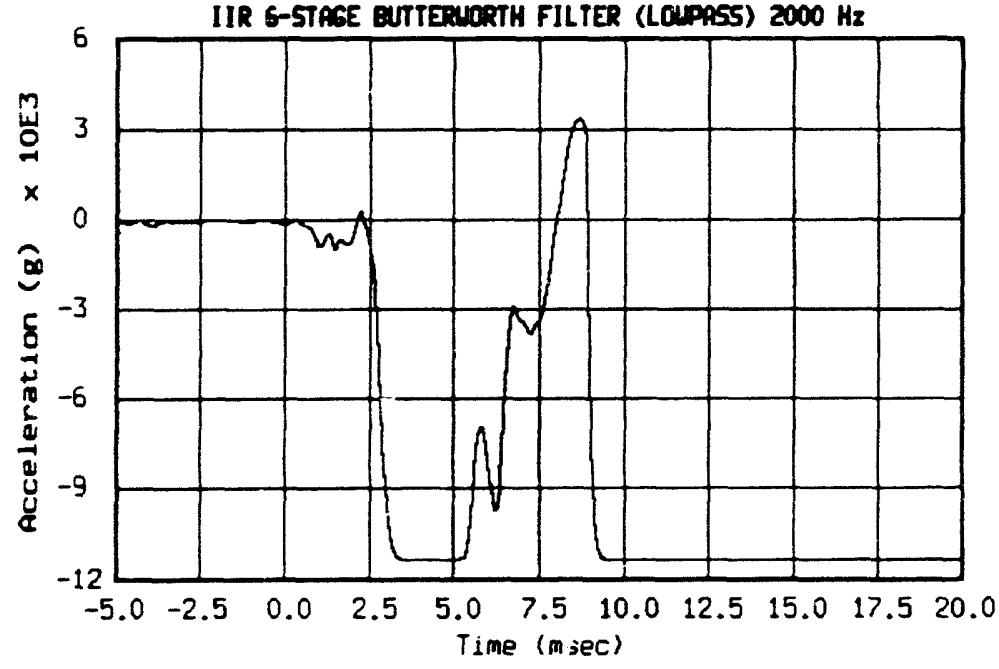

$\vec{\infty}$

Teat: HORIZONA HICH VeIOCITY H1224A 08/12/93 (224) Session: Thu fug 12 15:29:37 1993 Transducer: A15 (secondary)

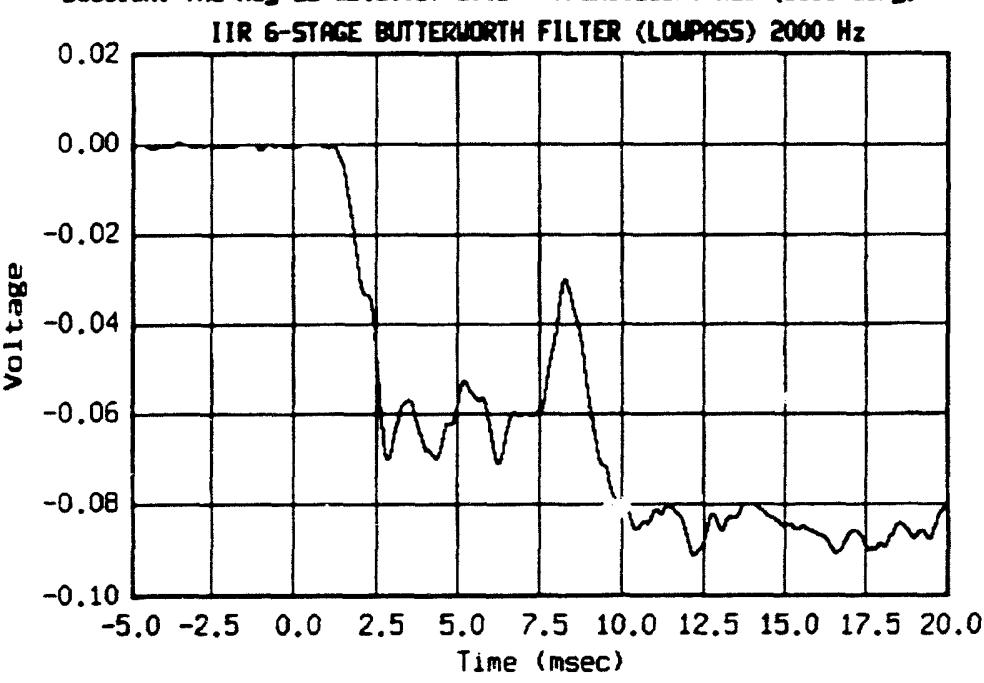

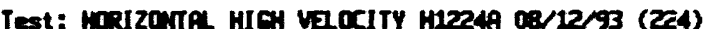
Session: Thu Pug 12 15:29:57 1993 Transducer: 551 (secondary) IR G-STMCE BUTTEDOORTH FILTER (LOLPGS5) $2000 \mathrm{~Hz}$

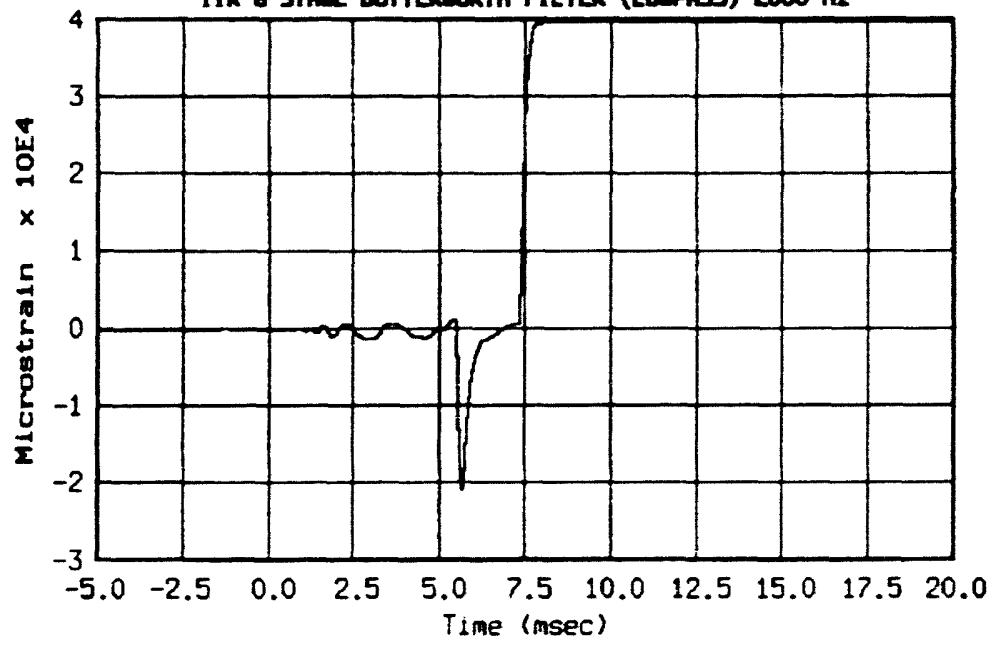

Test: HoRIzONTAL HICH Velocity H1224 08/12/93 (224) Session: Thu Aug 12 15:29:52 1993 Trenedveer: 502 (secondary) IIR G-STREE BUTTEUARTH FILTER (LOPPSSS) $2000 \mathrm{~Hz}$

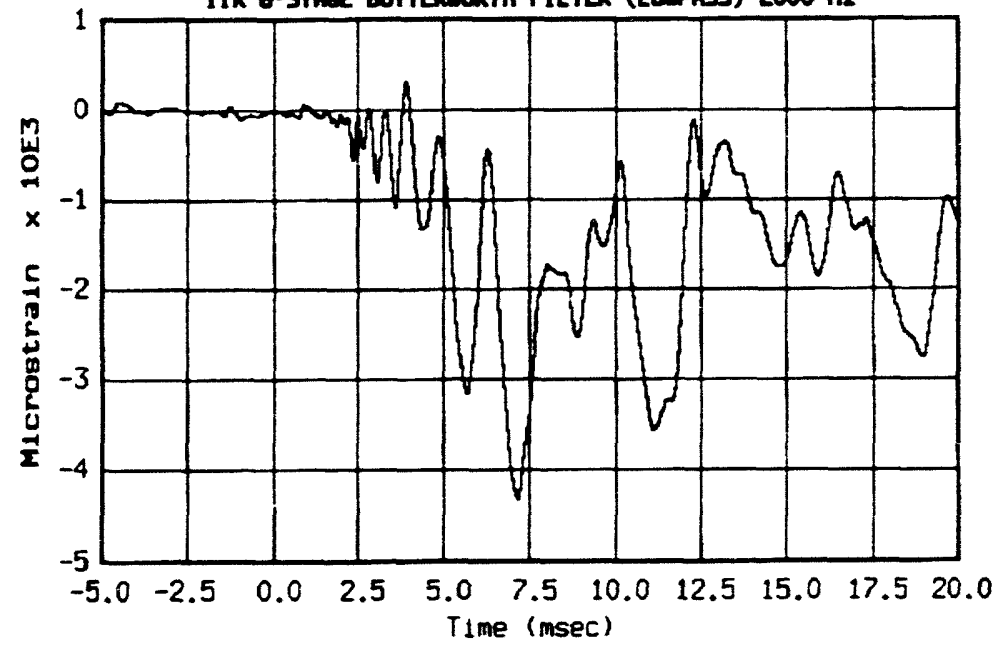


Test: MORIZONTAL HIEH VEOCITY H1224A 00/12/93 (224) Session: The fug 12 15:30:10 1993 Transcucer: 563 (secondary)

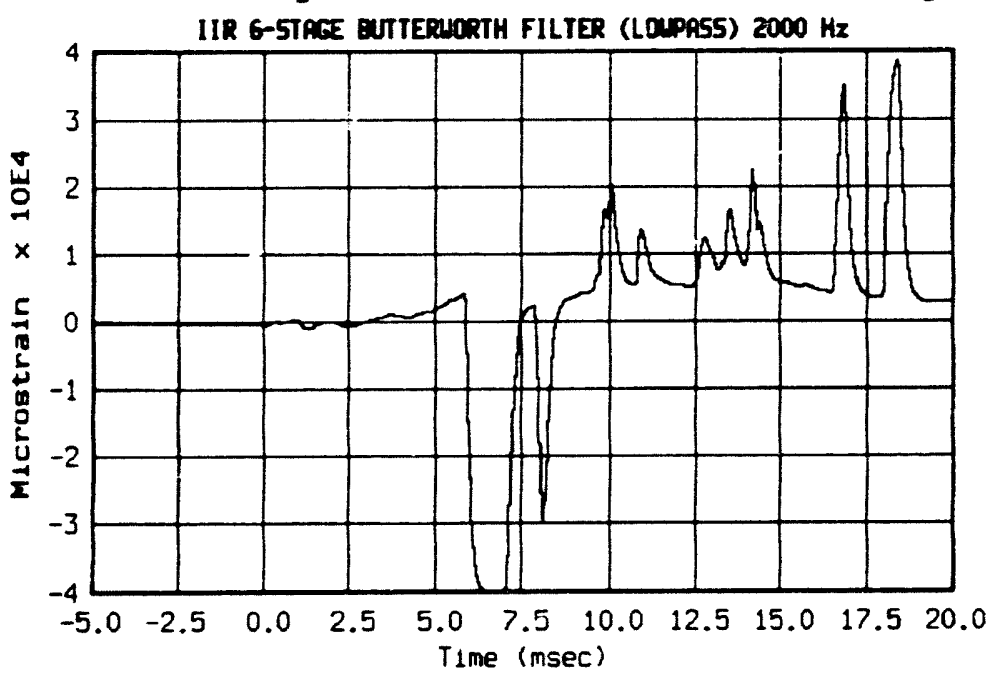

递

Test: HORIzOTTR HIEH VEOCITY H1224A D8/12/93 (224) Session: Thu Aug 12 15:30:04 1993 Transducer: 564 (secondary)

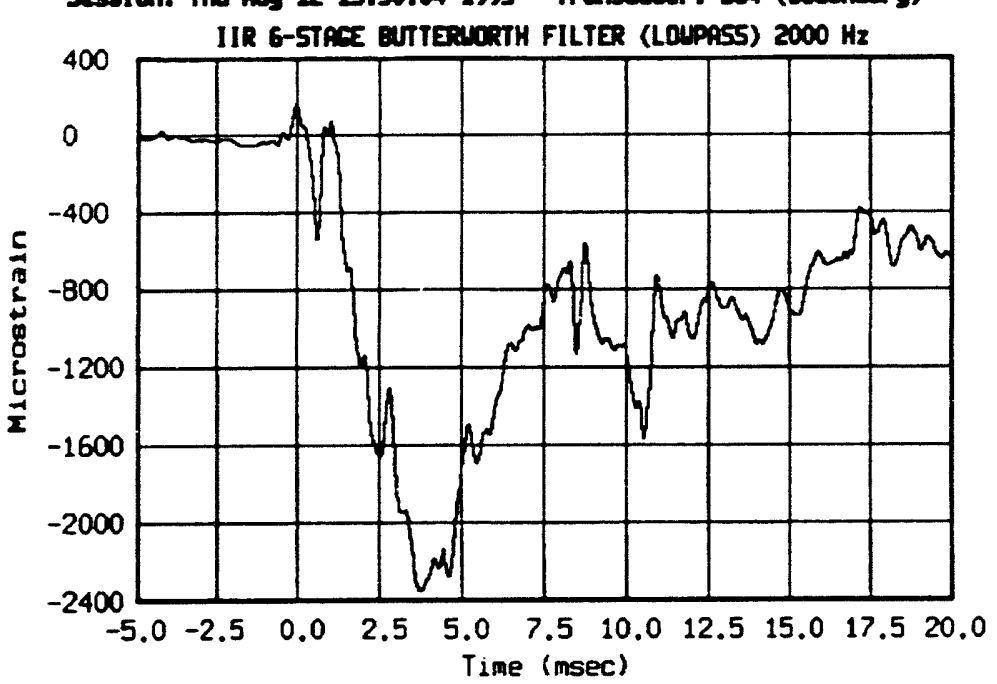

Test: MORIzOMAL HIOH VEOCITY HI224A 08/12/93 (224) Sesaion: Thu Aug 12 15:30:25 1993 Trunschcer: 555 (secondory) IIR 6-STACE EUTEEUDRTH FILTER (LOPASS) $2000 \mathrm{~Hz}$

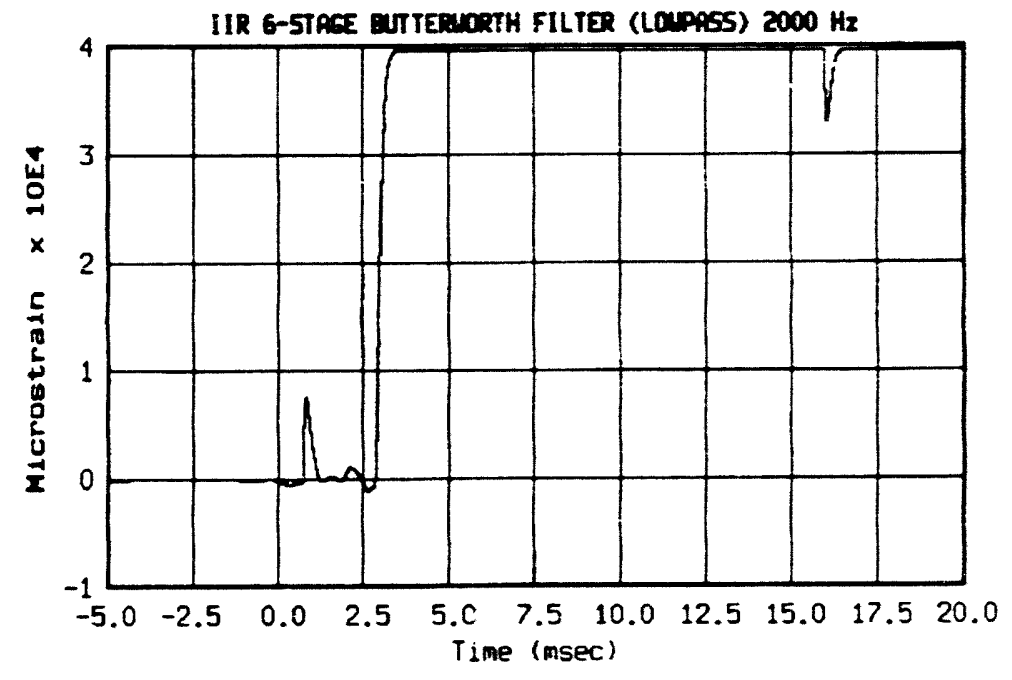

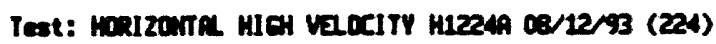
Sesalon: Thu Aug 12 15:30:17 1993 Transtucer: 556 (sacondary)

IIR G-STASE BUTERUCRTH FILTER (LOPPGS) $2000 \mathrm{~Hz}$

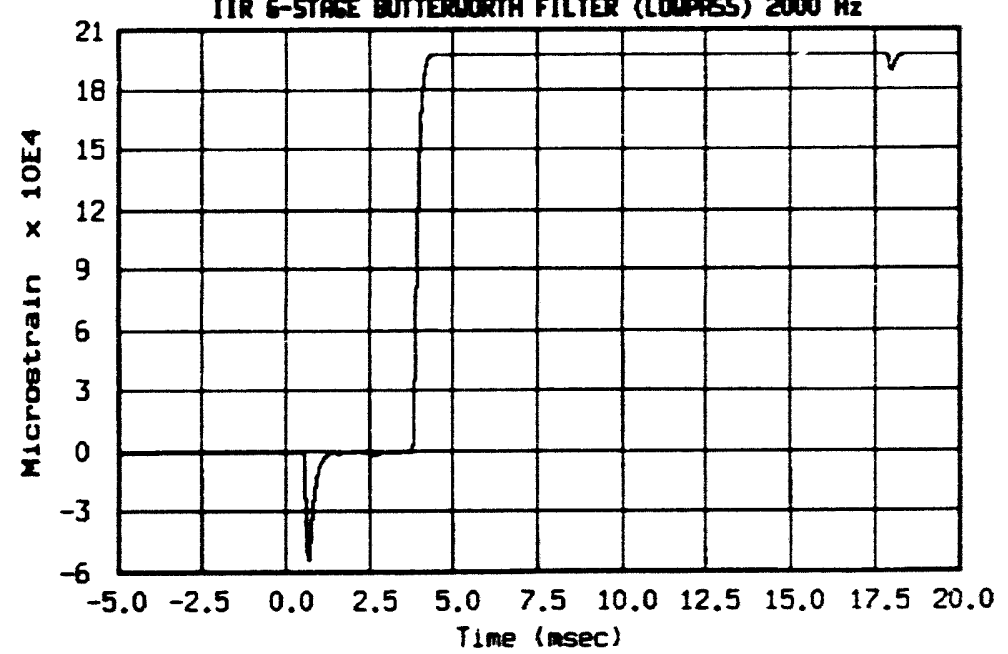


Test: HolizONTA HIGH VecClTY H12249 08/12/9s (224) Session: Thu hug 12 15:30:39 1993 Transodvar: 567 (secondary)

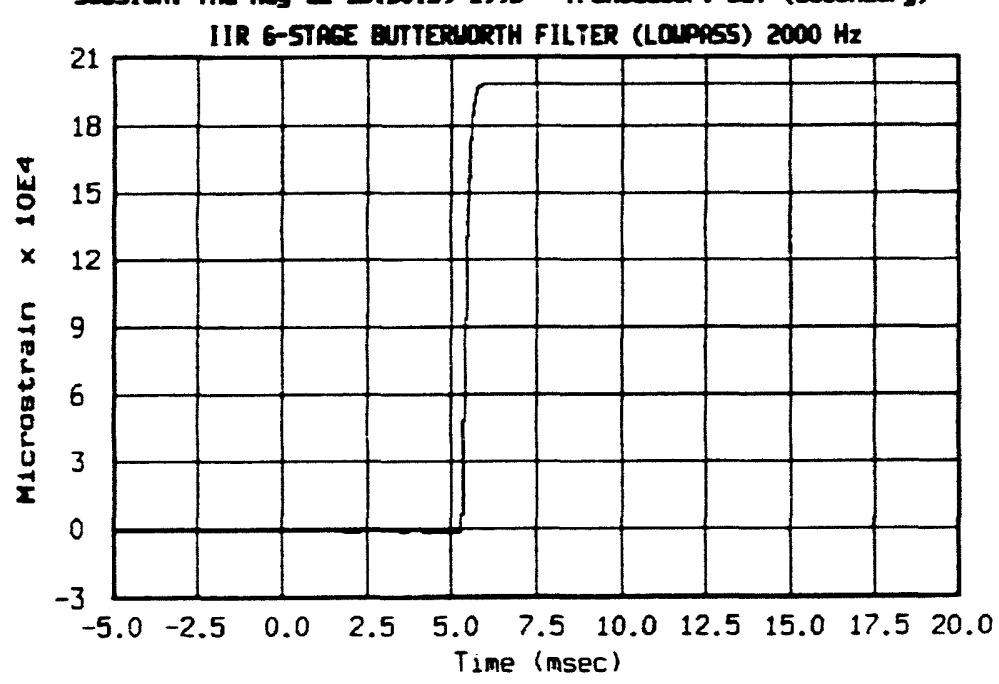

Iest: HORIZONTA HIGH VezocITY H12244 08/12/93 (224) Session: The Aug 12 15:30:32 1993 Trunsdvoer: 588 (secondary)

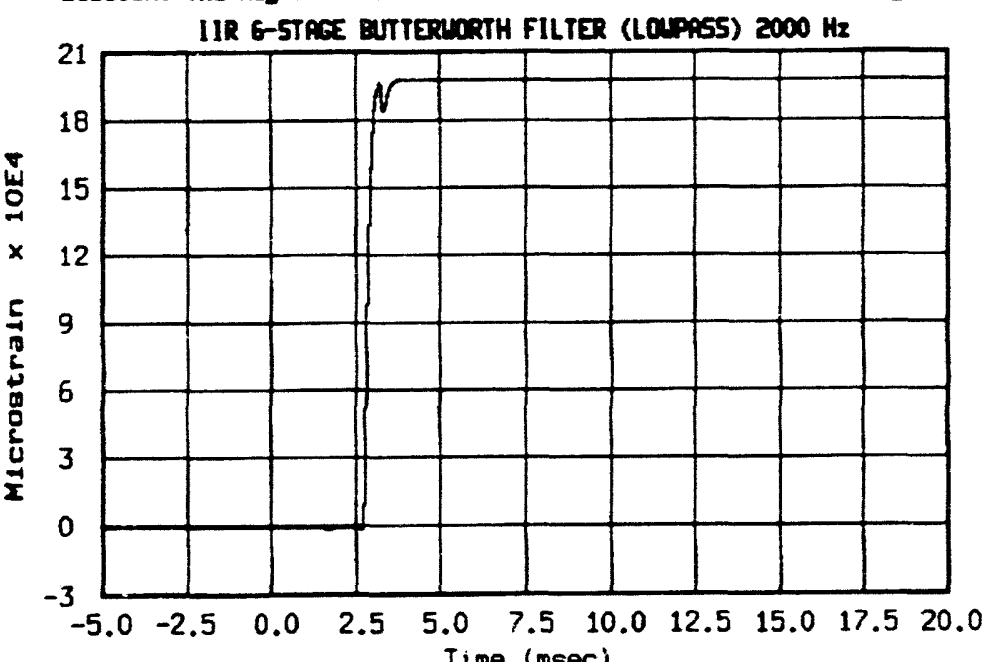

Test: Modzonth HIBH VeoclTY Mt224A 02/2/93 (224) 5ession: Thu Aug 12 15:30:52 1993 Transtwcer: 569 (secondery)

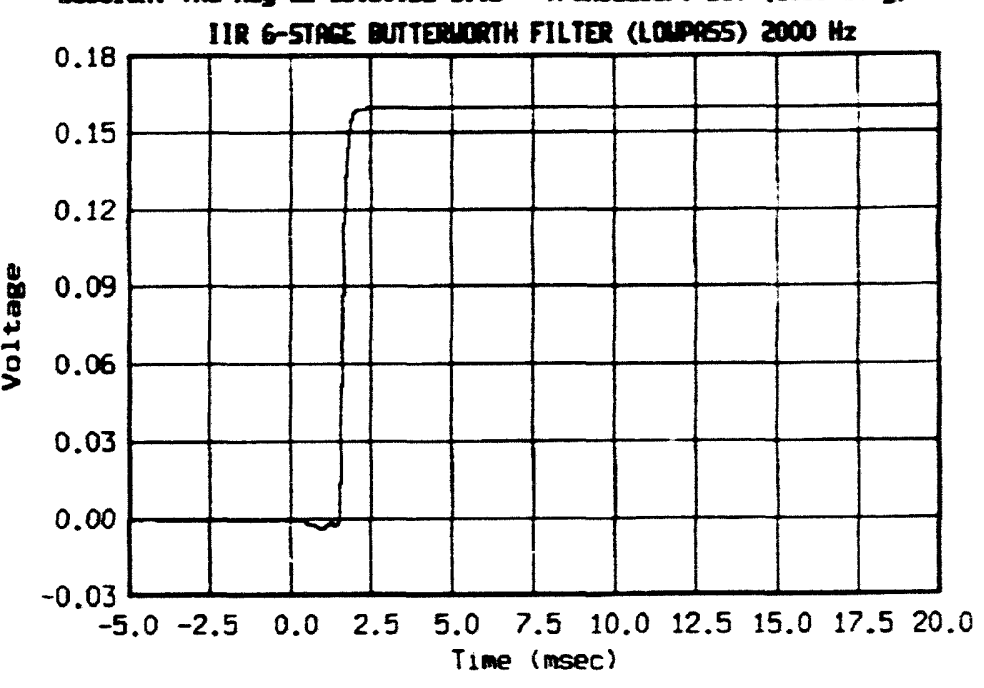

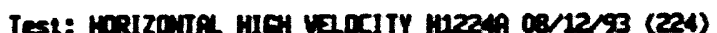
Session: Thu Aug 12 15:30:45 1993 Trmedveer: S510 (secondary)

IIR 6-STRCE EUTTEURRTH FILTER (LOUPASS) $2000 \mathrm{~Hz}$

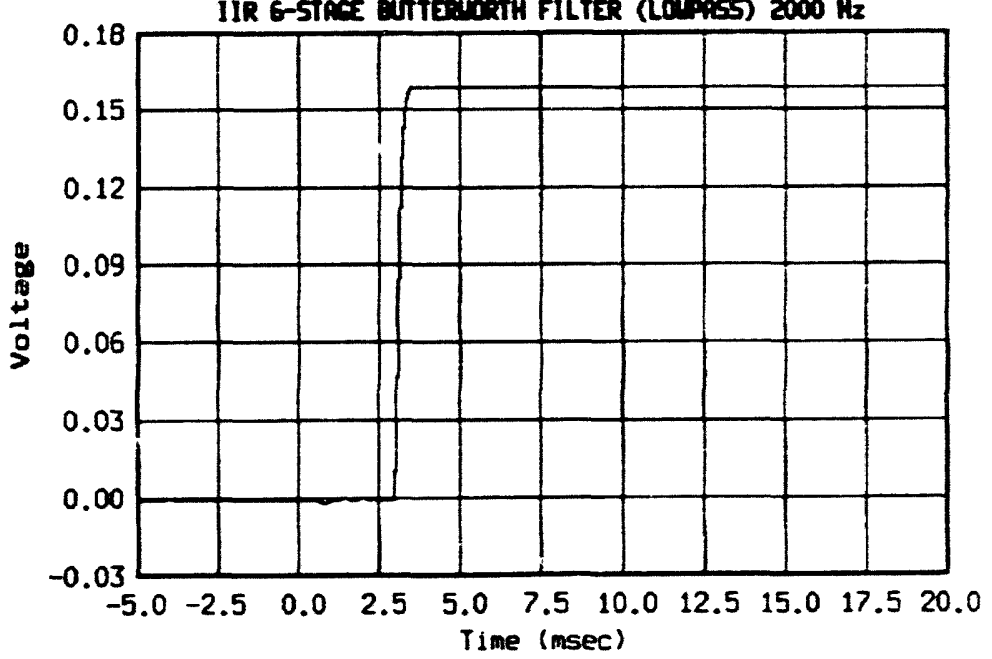



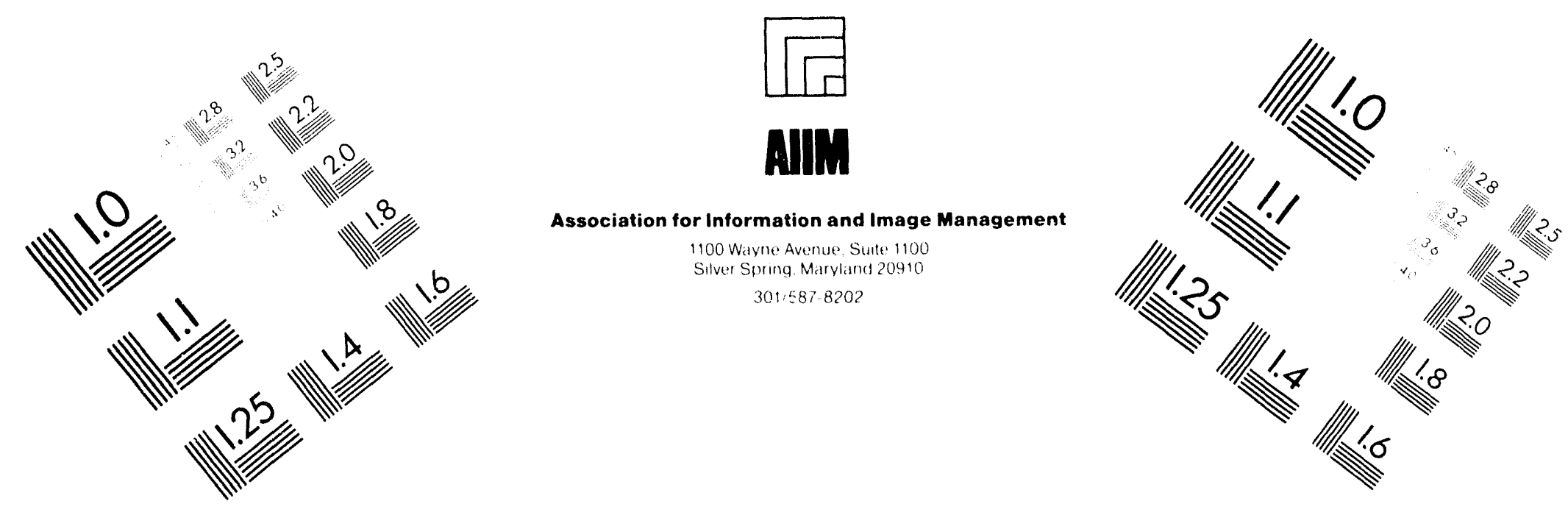

\section{Centimeter}

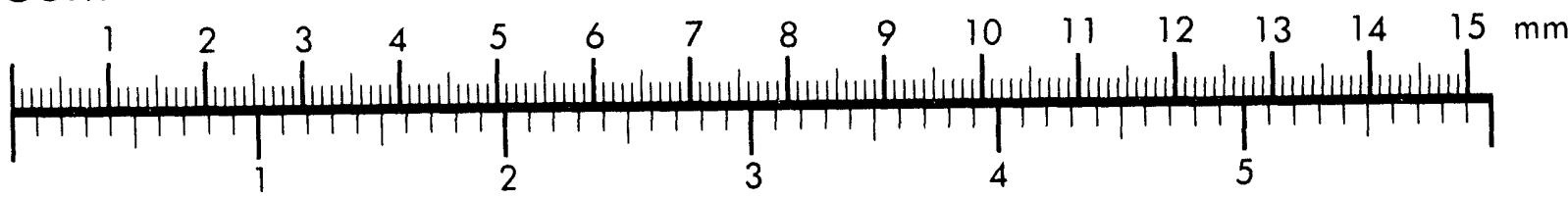

Inches
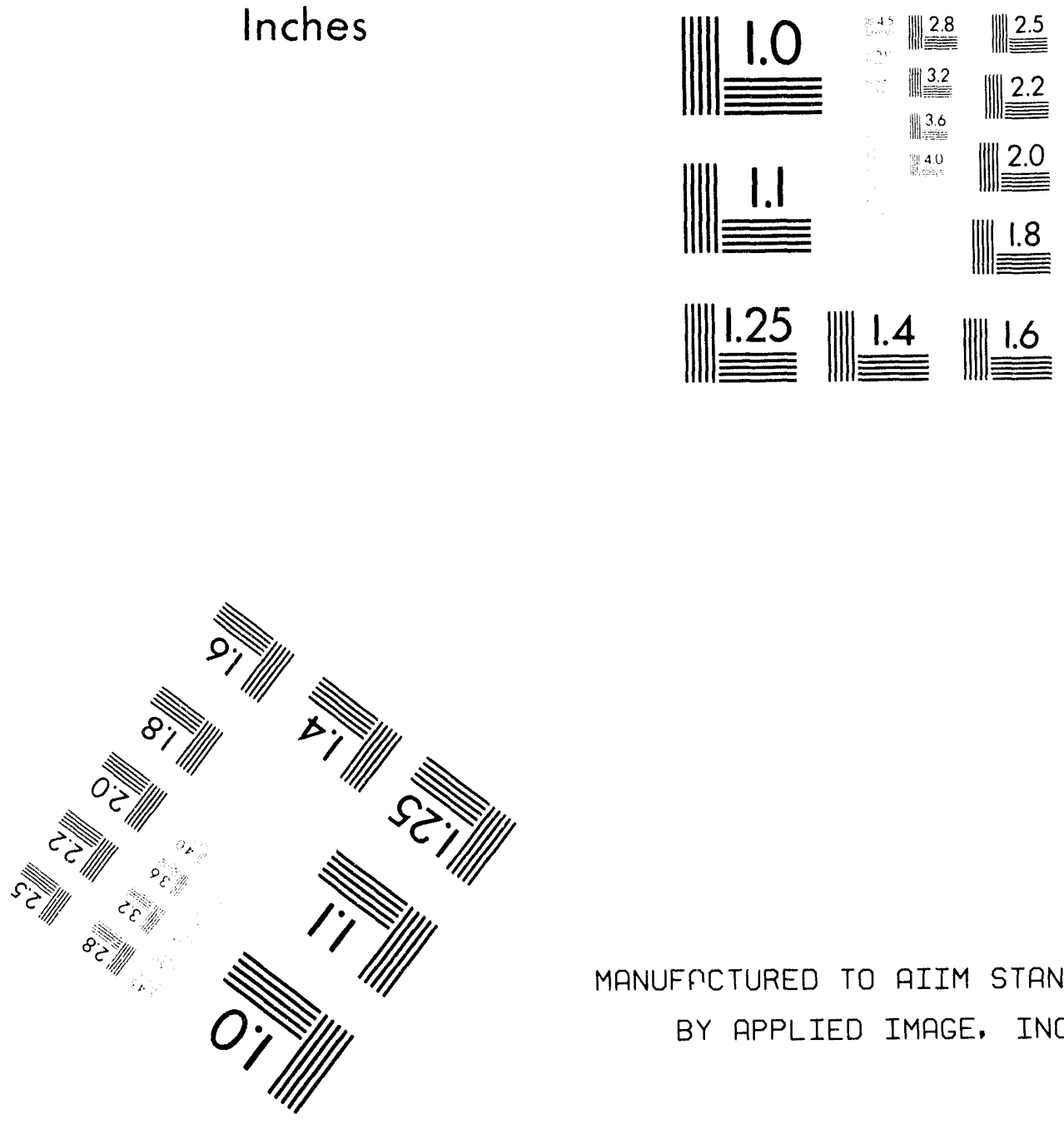

MANUFPCTURED TO AIIM STANDARDS

BY APPLIED IMAGE, INC.

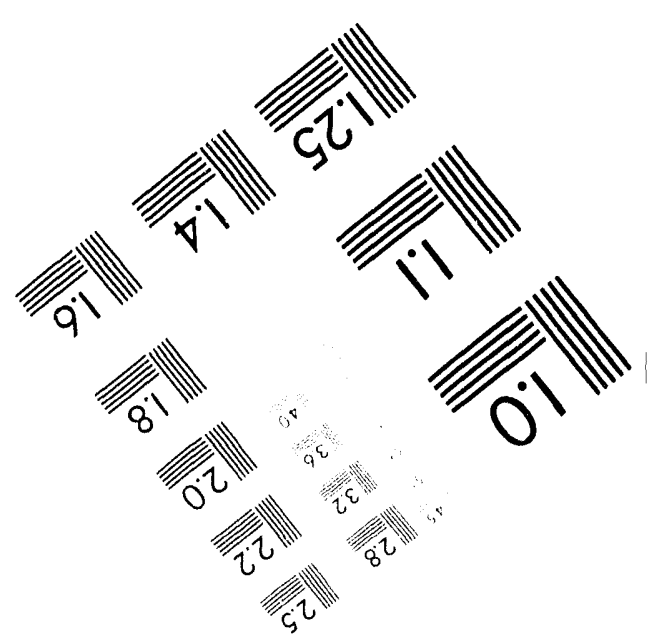



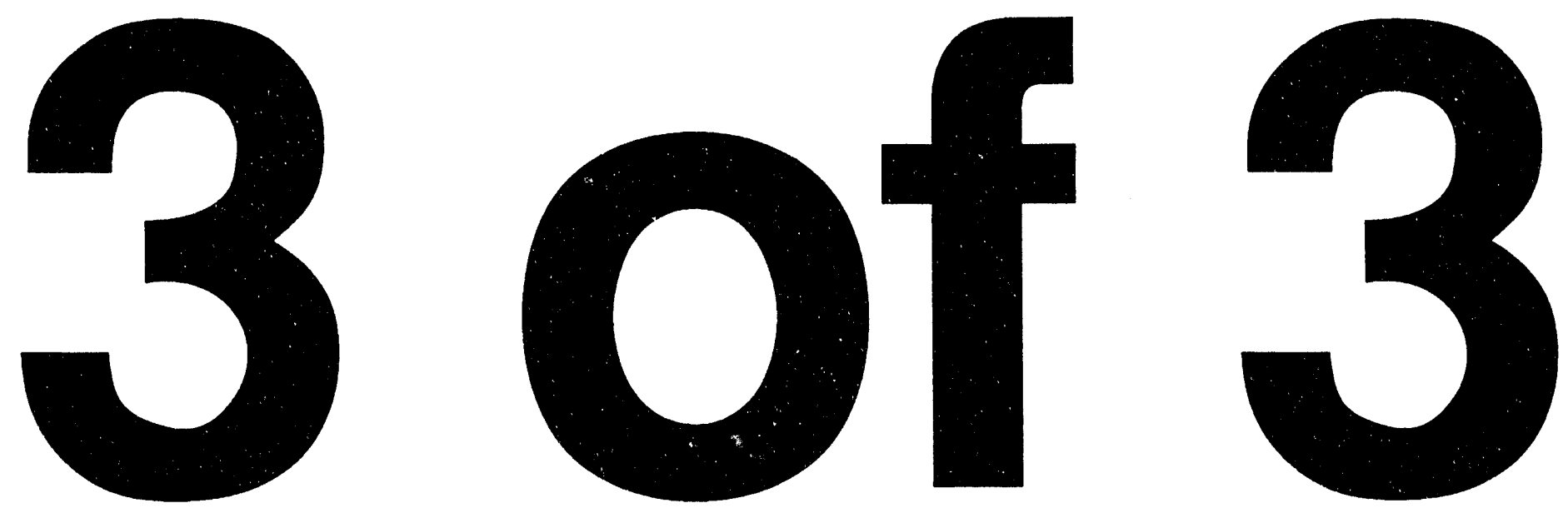
Test: HoRIZONTAL HIGH VELOCITY H1224A 08/12/93 (224) Session: Thu tug 26 09:56:37 1993 Transducer: A1 (secondary)

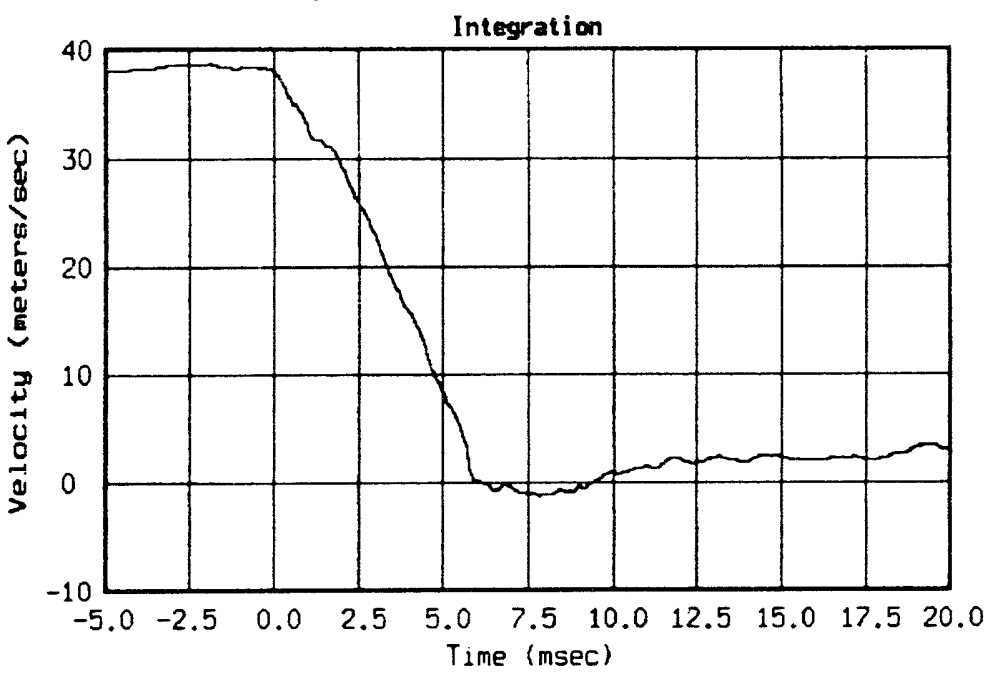

$\vec{b}$

Test: HORIZONAL HIGH VEOCITY H1224h O8/12/93 (224) Session: Thu Aug 26 09:56:41 1993 Trensodver! PR (scoondary)

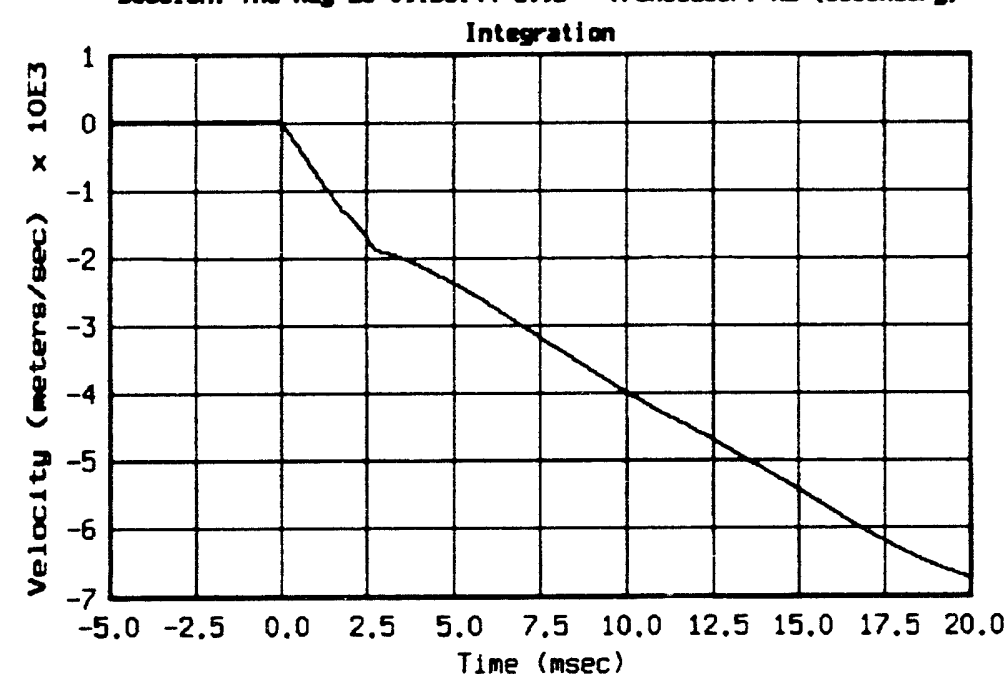

Test: HORI2OHTA HIGH VElOCITY H1224A 08/12/93 (224) Session: Thu Aug 26 10:08:11 1993 Transducer: A3 (secondary)

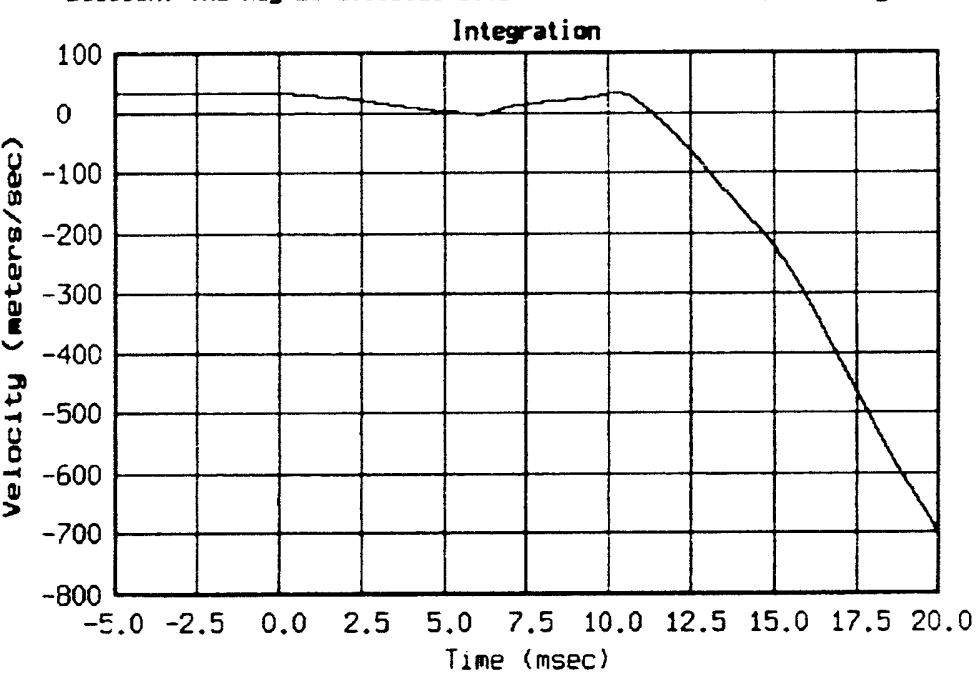

Test: HORizONA HICH VelocITY H12249 08/12/93 (224) Seasion: Thu Aug 26 09:56:57 1993 Transtuoer: M (secondry) Integration

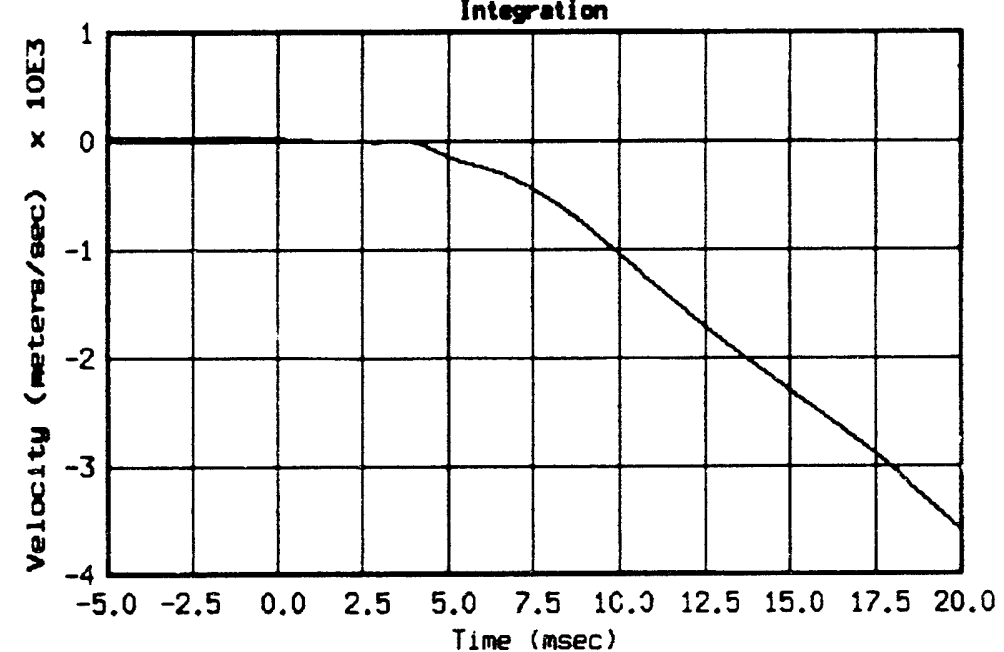


Test: HPIZONTA HIGH VEOCITY H1224A 08/12/93 (224) Session: Thu Aug 26 10:11:17 1993 Transducer: AS (secondery)

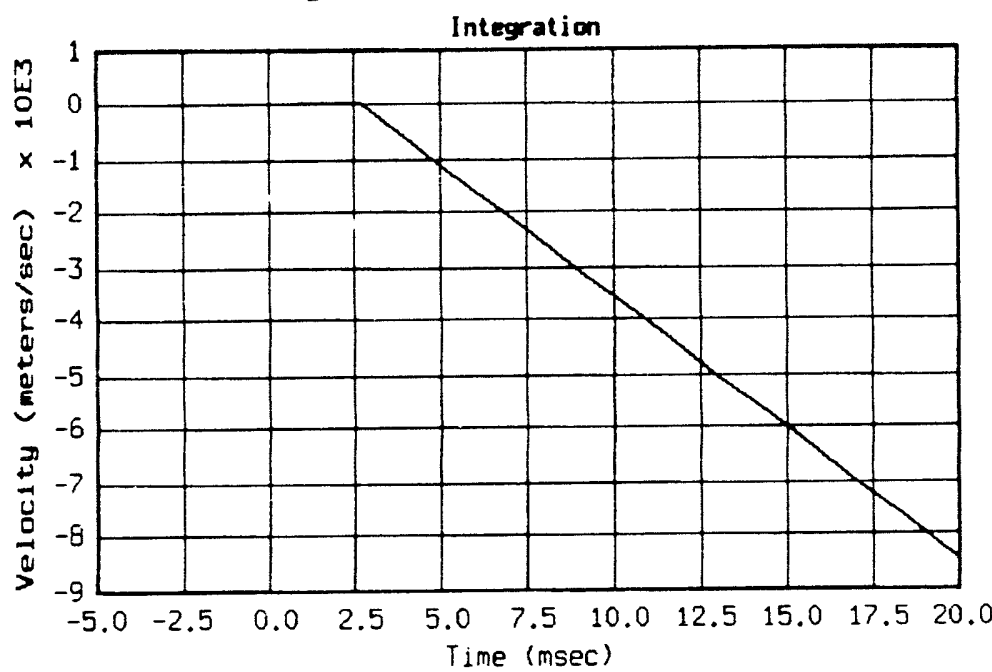

定

Test: HORIZONTAL HICH VEOCITY H1224A 08/12/93 (224) Session: Thu Aug 26 10:18:33 1993 Trunstuoer: A6 (secondery)

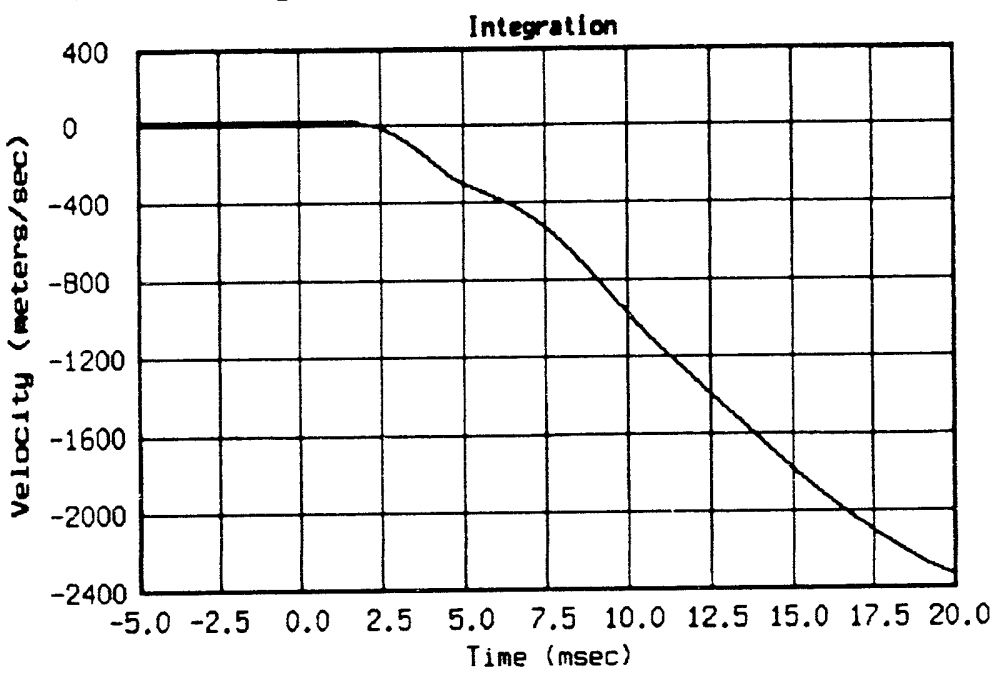

Test: HORIZONTR HIGH VEIOCITY H1224A 08/12/93 (224) Session: Thu fug 26 09:57:09 1993 Transducer: A7 (secondary)

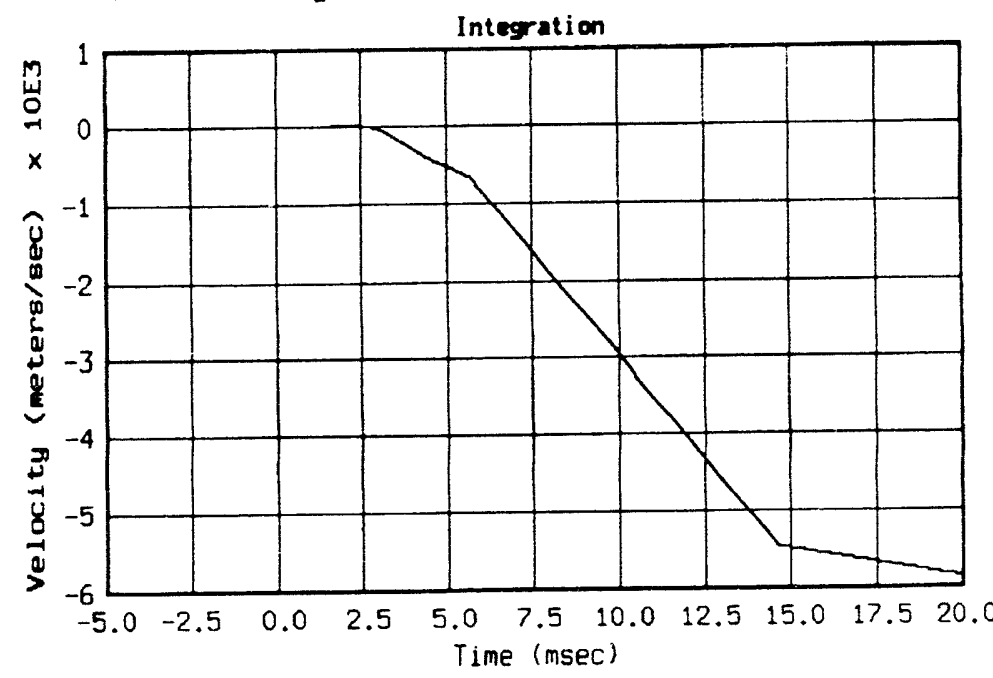

Test: HORIZONTAL HIGH VELOCITY HI224A 08/12/93 (224) Session: Thu Aug 26 10:11:25 1993 Transducer: A8 (secondary)

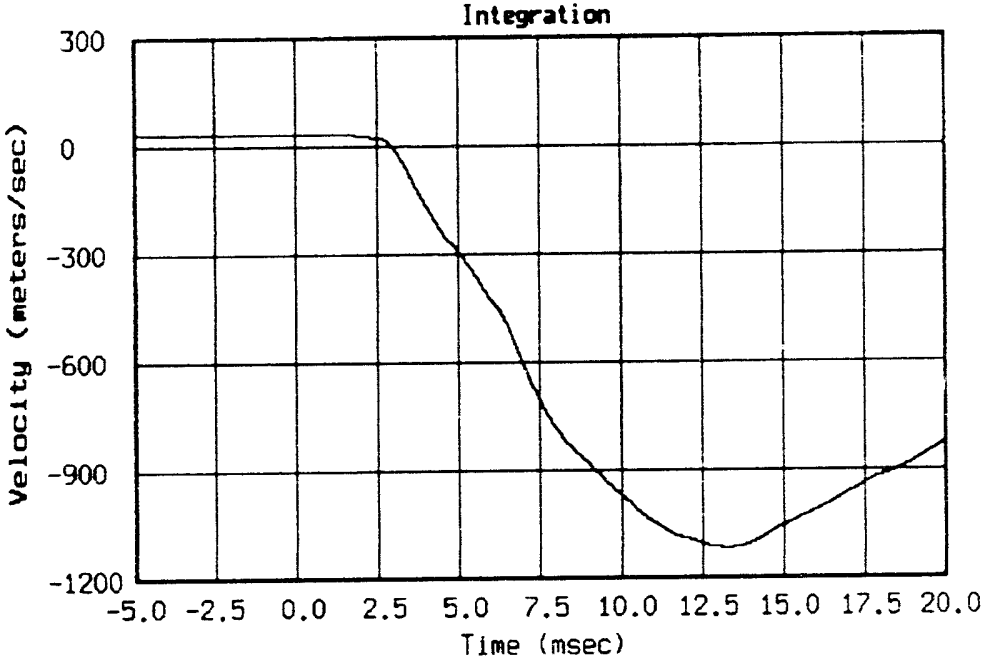


Test: HORIZONTA. HIGH VELOCITY H1224A 08/12/93 (224)

Session: Thu Aug 26 09:57:23 1993 Transducer: A9 (secondary)

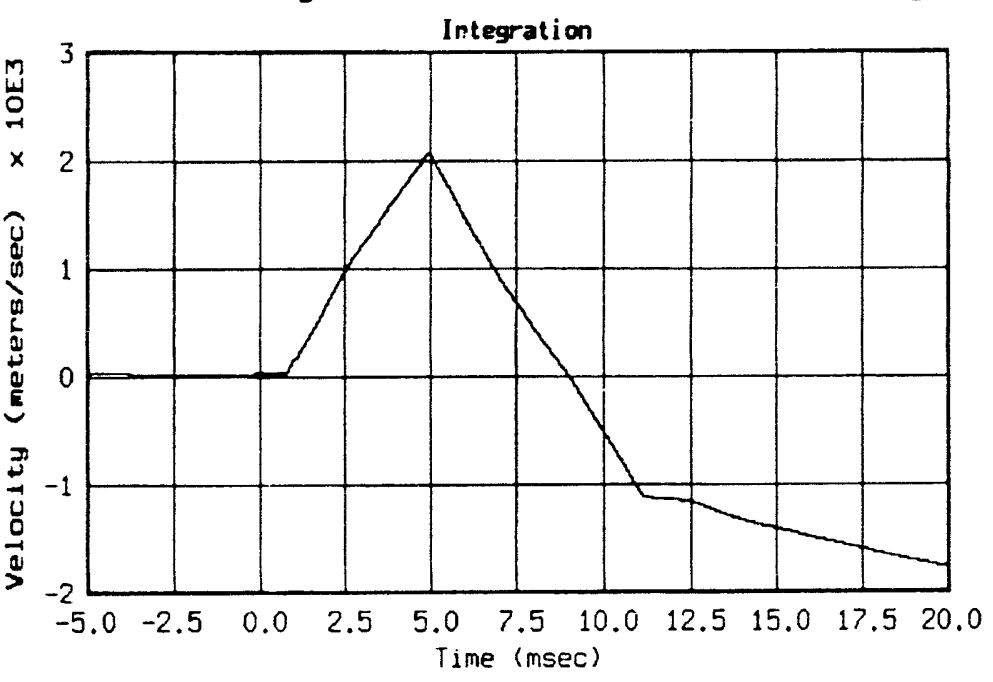

Test: hoRIzONTA HICH Veaclity H1224A 08/12/93 (224) Session: Thu Pug 26 09:57:36 1993 Transduoer: A10 (secondary)

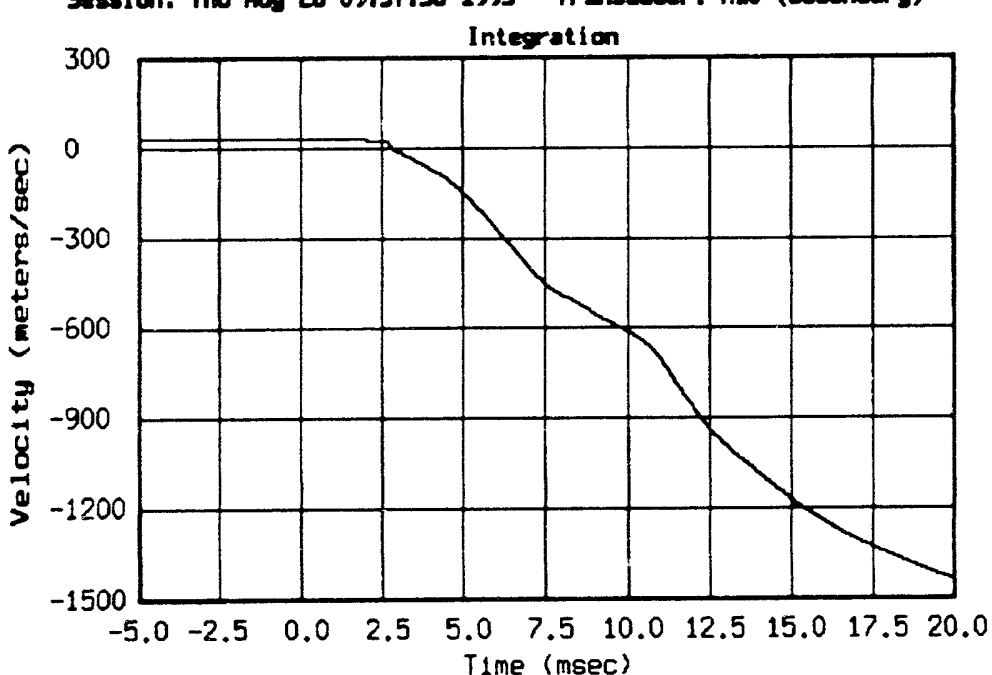

Test: HOR:ZONTA HIEH VEIOCITY H1224A 08/12/93 (224) Session: Thu Aug 26 10:19:33 1993 Transducer: A11 (secondary)

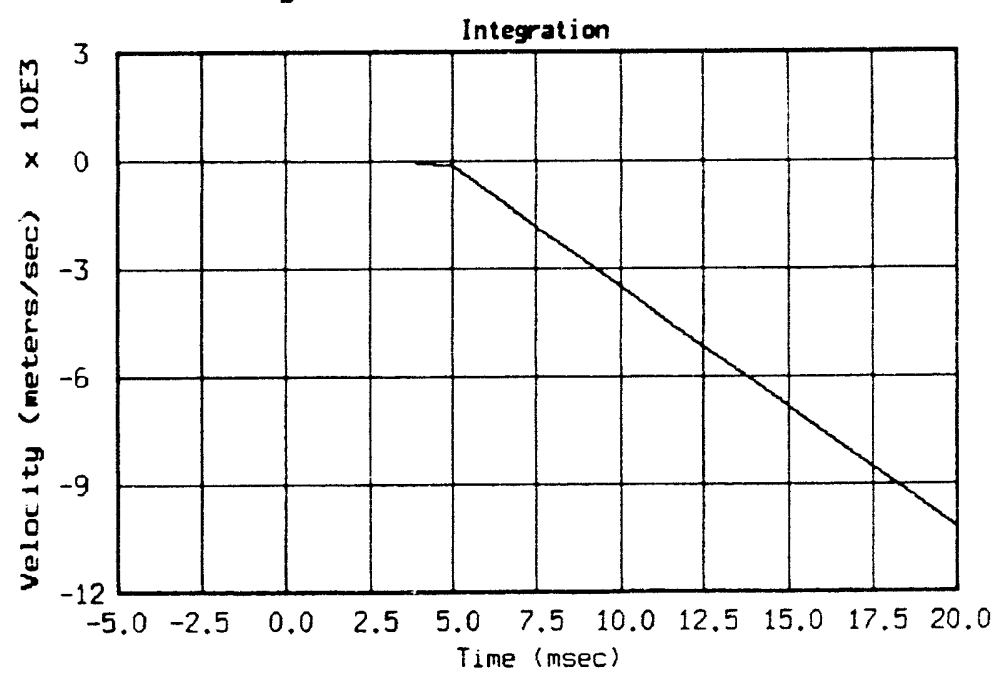

Test: HORIZONTA HICH VEOCITY H1224A 08/12/93 (224) 5ession: Thu fug 25 09:57:49 1993 Transduoer: A12 (secondary)

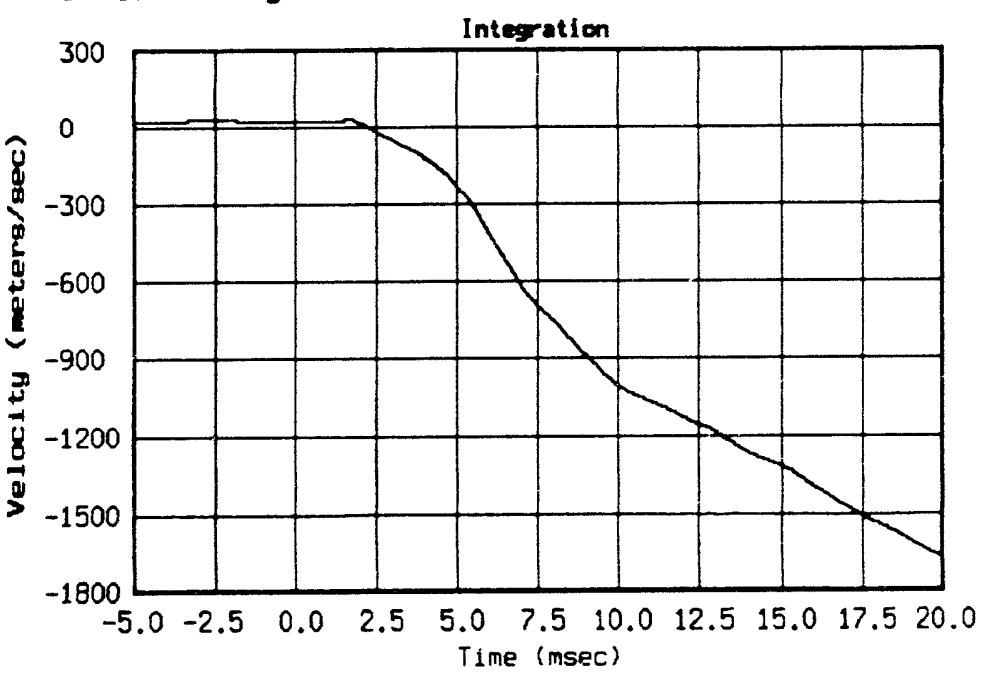


Test: MaRIZONTR HICH VZOCITY H12249 08/12/93 (224) Session: Thu Aug 26 10:19:43 1993 Transdwoer: A13 (secondery)

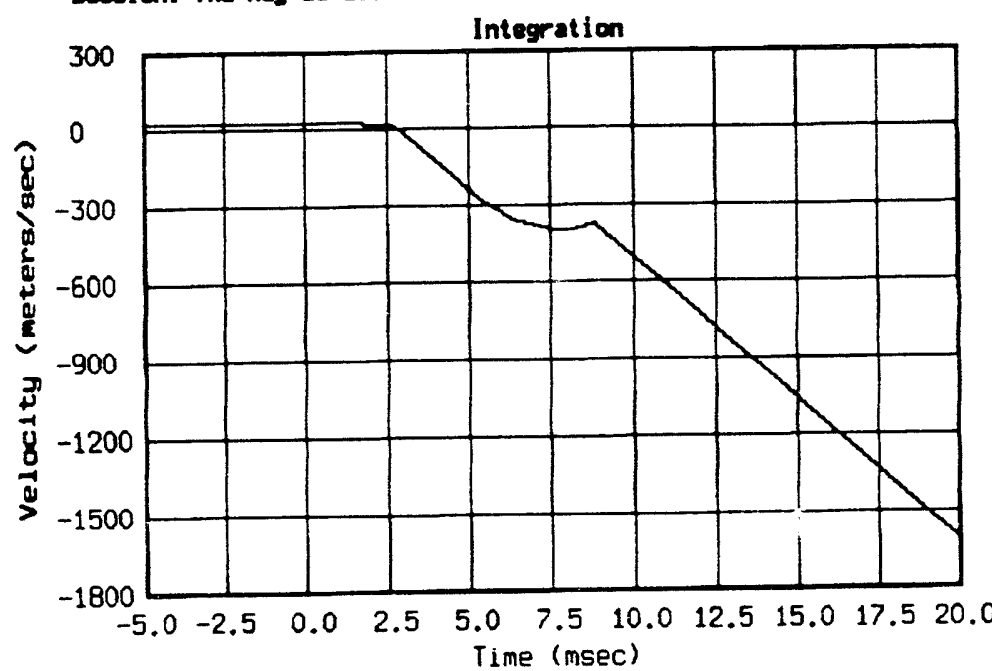

TESt: HDRIZONAL HIGH VELOCITY H1224A 08/12/93 (224) Session: Hed fug 25 13:48:35 1993 Transoducer: A1 (secondary) FAST FOURIER TRANSFORH to $20000.0 \mathrm{~Hz}$

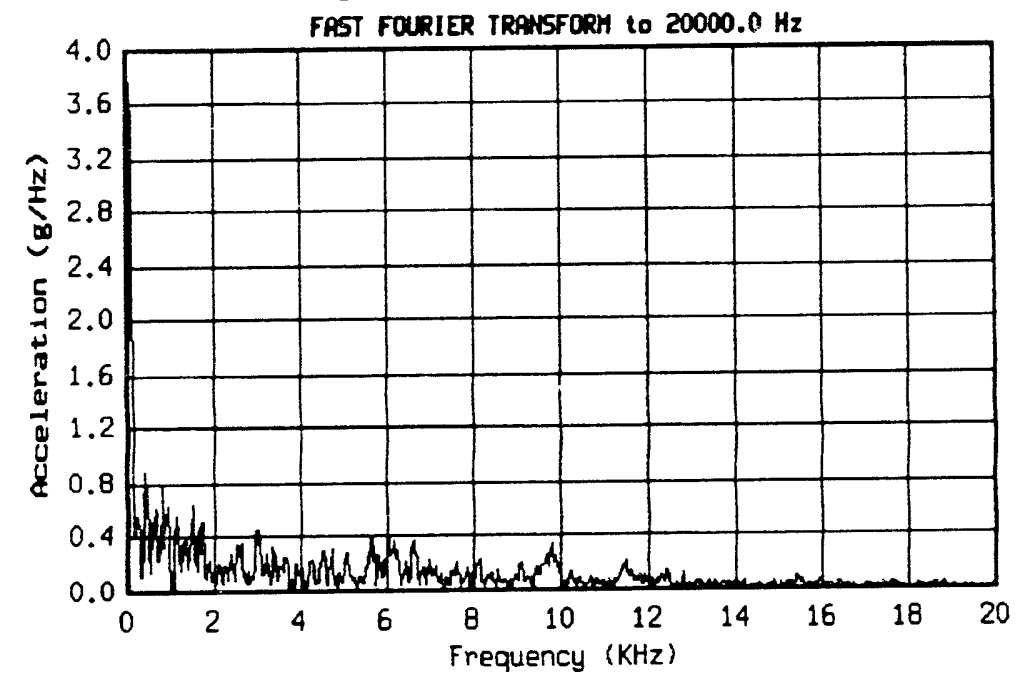

Teat: HoRIZONRL HIBH VelOCITY H1224A 08/2/93 (224) Session: Ued Ang 25 13:48:41 1993 Truneducer: P2 (sceondary) FAST FOURIER TROHSFORH to $20000.0 \mathrm{~Hz}$

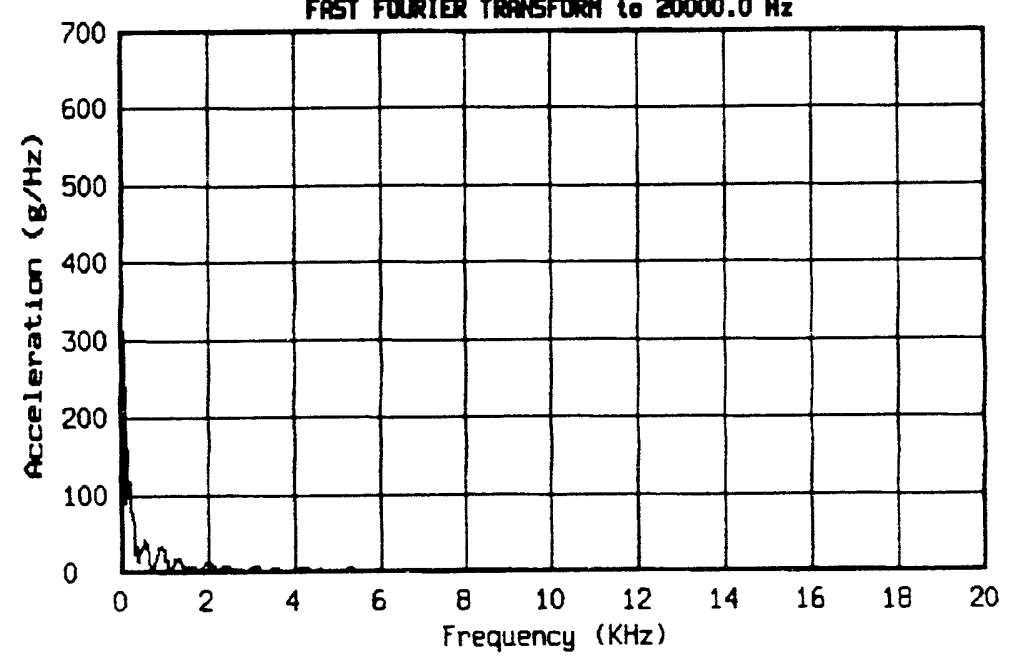

Test: HORIZONTAL HIG VEOCITY H12249 08/12/93 (224) Session: thed Pug 25 13:48:45 1993 Transducer: $A 3$ (secondary)

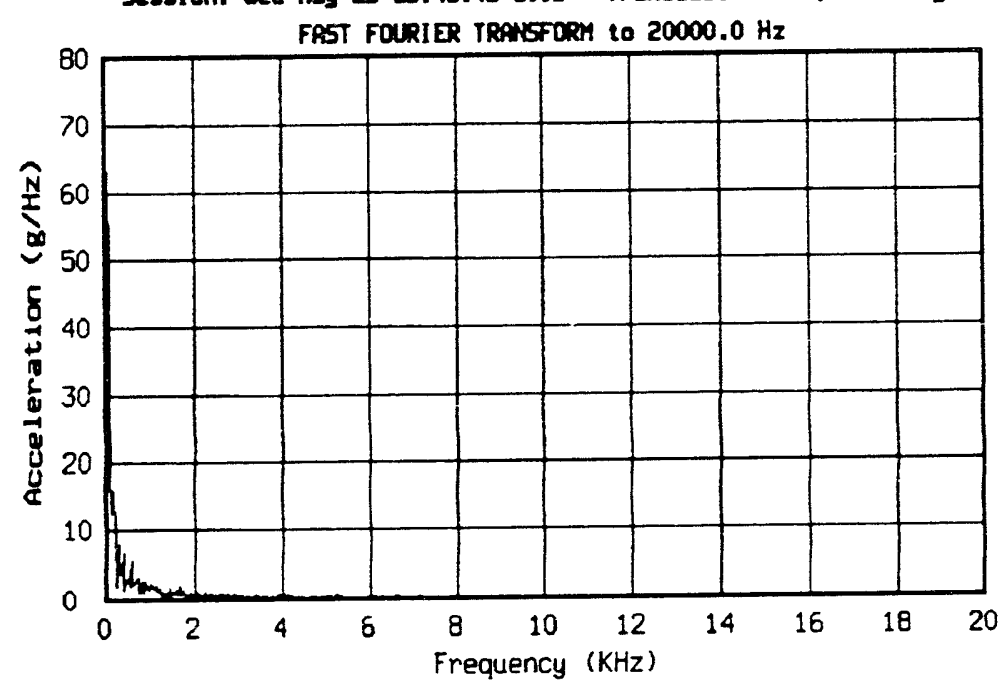


Test: hoRIZONTh HICH VEOCITY H12249 08/12/93 (224) Session: thed Aug 25 13:48:52 1993 Transedvoer: A4 (secondery)

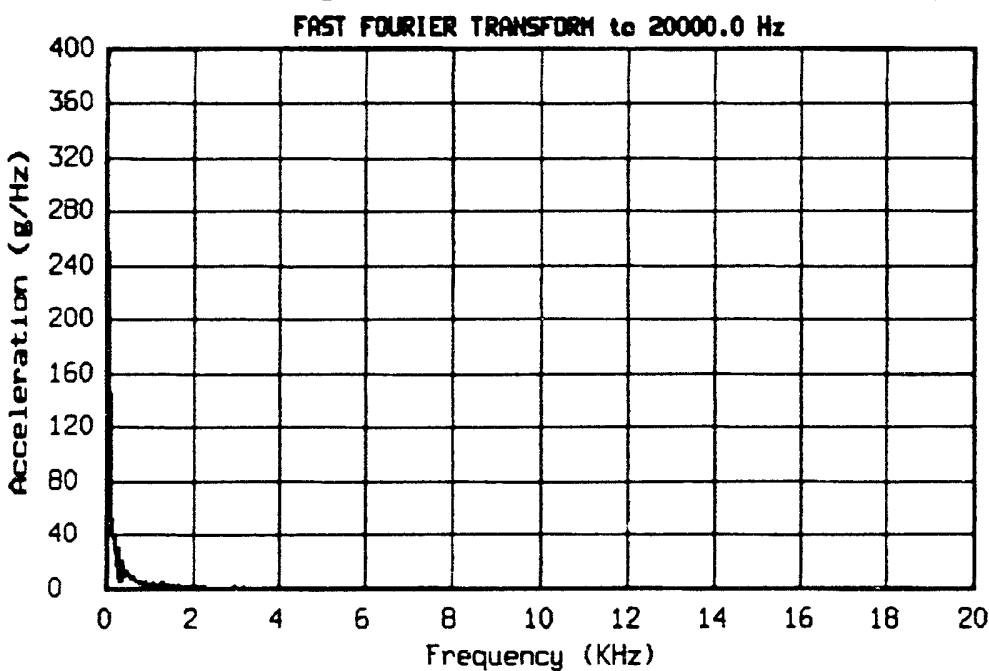

范

Test: HORIZONAL HIGH VELOCITY H1224A 08/12/93 (224)

Session: Led Rug 25 13:48:58 1993 Transducer: A5 (secondary) FAST FOURIER TRANSFORM to $20000.0 \mathrm{~Hz}$

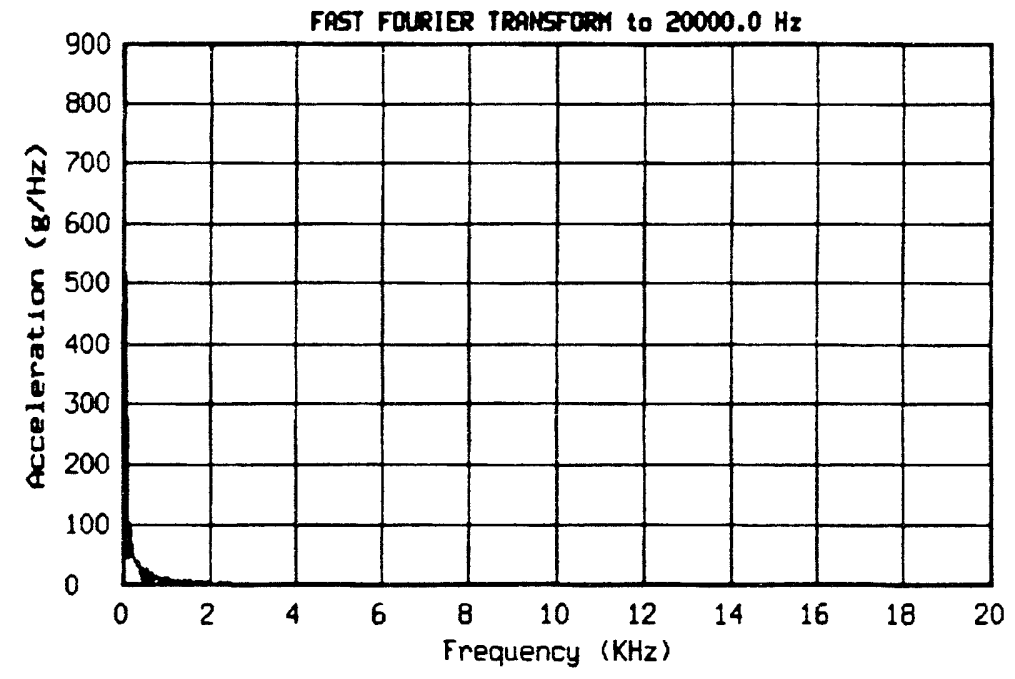

Teat: HORIZONTAL HIAH VEOCITY H1224A 08/12/93 (224) Sexsion: thed Aug ZS 13:49:06 1993 Traneducer: AT (secondary) FAST FOURIER TRAUSFOAH to $20000.0 \mathrm{~Hz}$

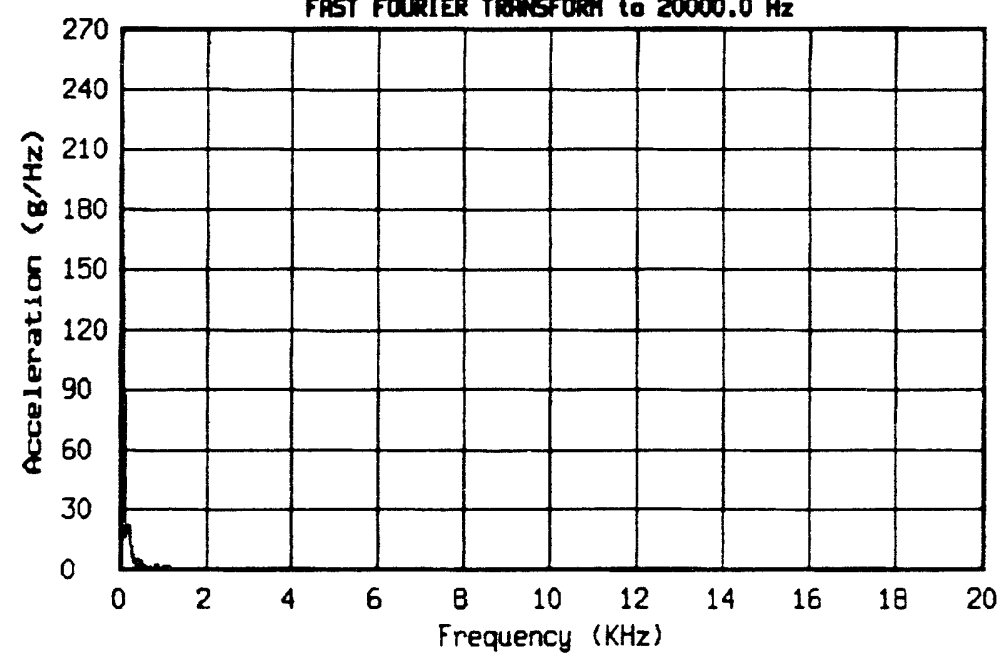

Test: HORIZONTA HICH VEOCITY H1224A 08/12/93 (224) Session: Led Aug 25 13:49:10 1993 Trunsducer: A7 (secondary) FRST FOURIER TRANSFOPA to $20000.0 \mathrm{~Hz}$

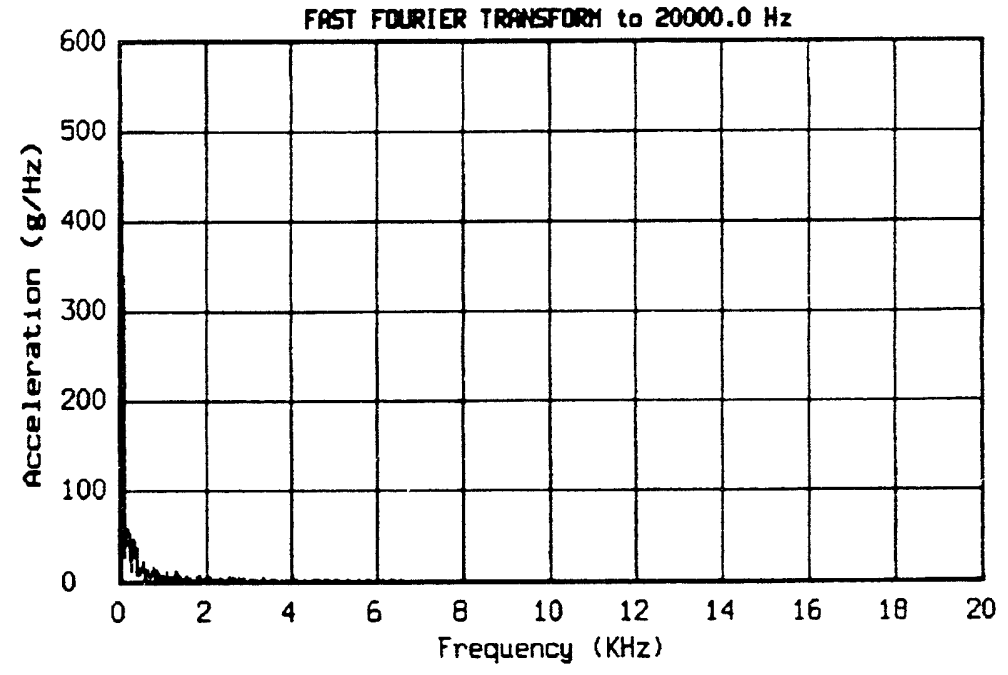


Test: HORIZONTA HIOH VEOCITY H1224A 08/12/93 (224) Session: thed Rug 25 13:49:18 1993 Traneducer: AB (accondary) FAST FORIER TREASFOQM to $20000.0 \mathrm{~Hz}$

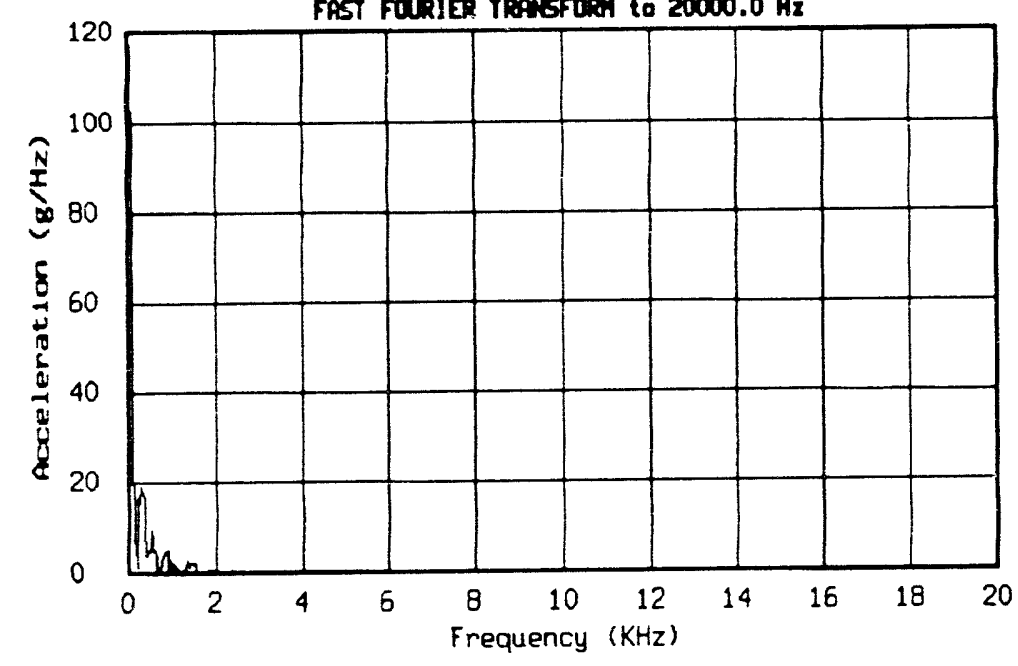

๘

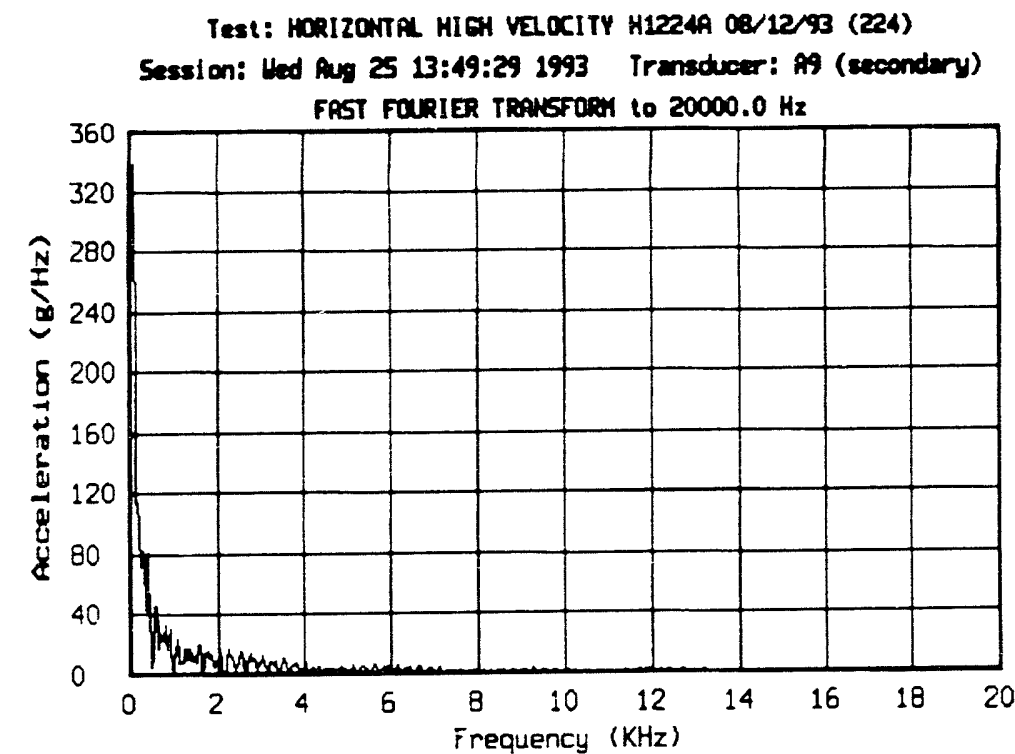

Test: HORIZONA HIGH VELCITY H1224A 08/12/93 (224) Session: thed Aug 25 13:49:22 1993 Transducer: A10 (secondary) FAST FOURIER TRANSFOOM to $20000.0 \mathrm{~Hz}$

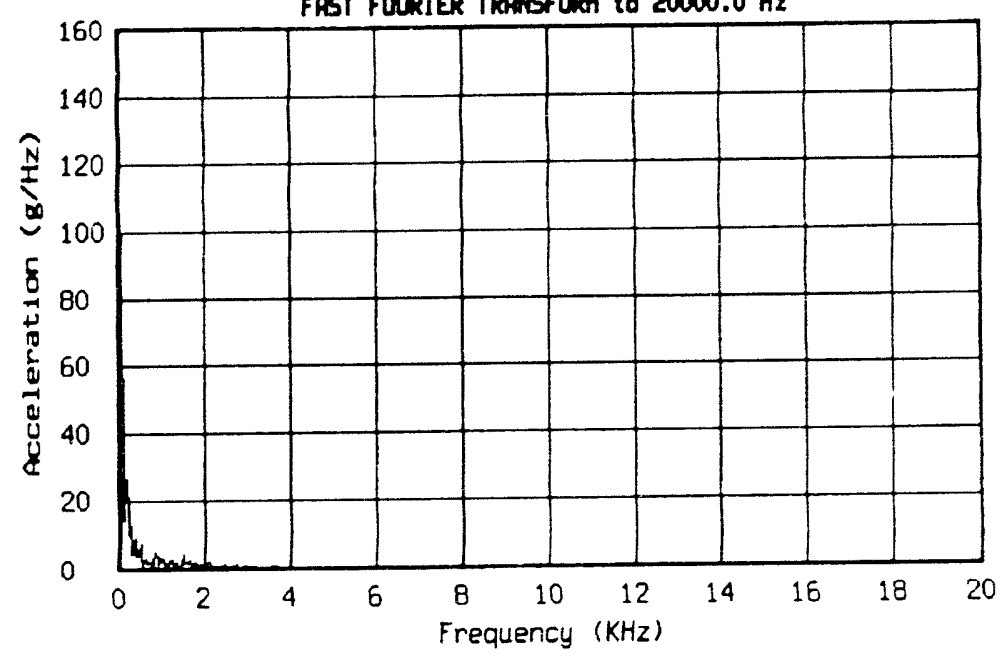

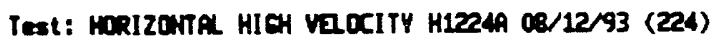
Session: led fun 25 13:49:44 1993 Trmeduoer: A11 (eccondary)

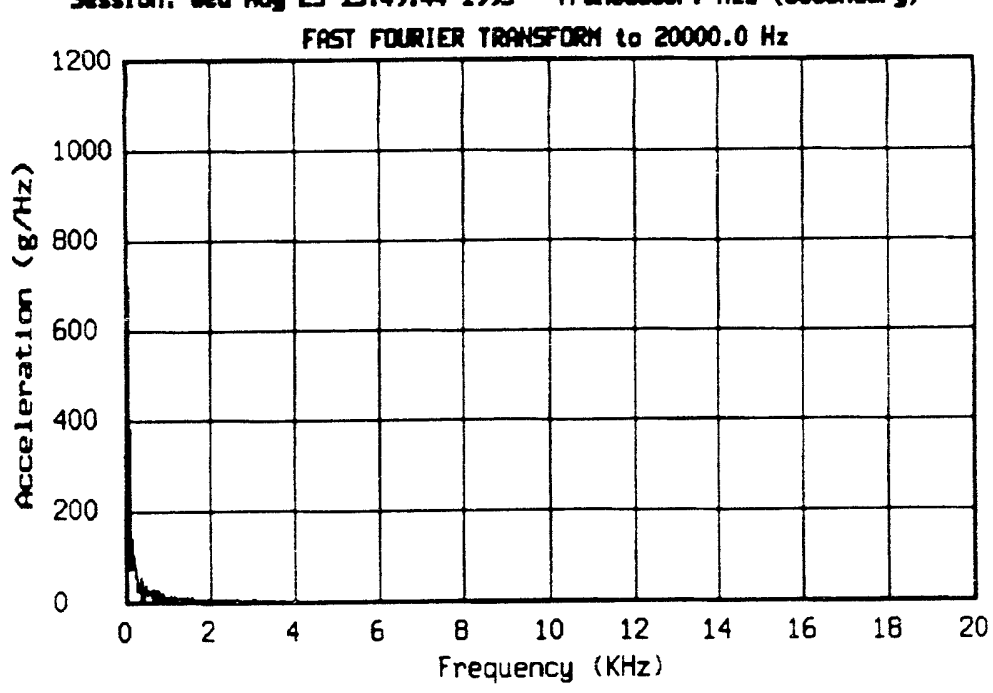


Test: HORIZONTAL HIGH VELOCITY H12244 08/12/93 (224)

Session: Led Aug 25 13:49:36 1993 Transotucer: A12 (secondary) FAST FOURIER TRAHSFORY to $20000.0 \mathrm{~Hz}$

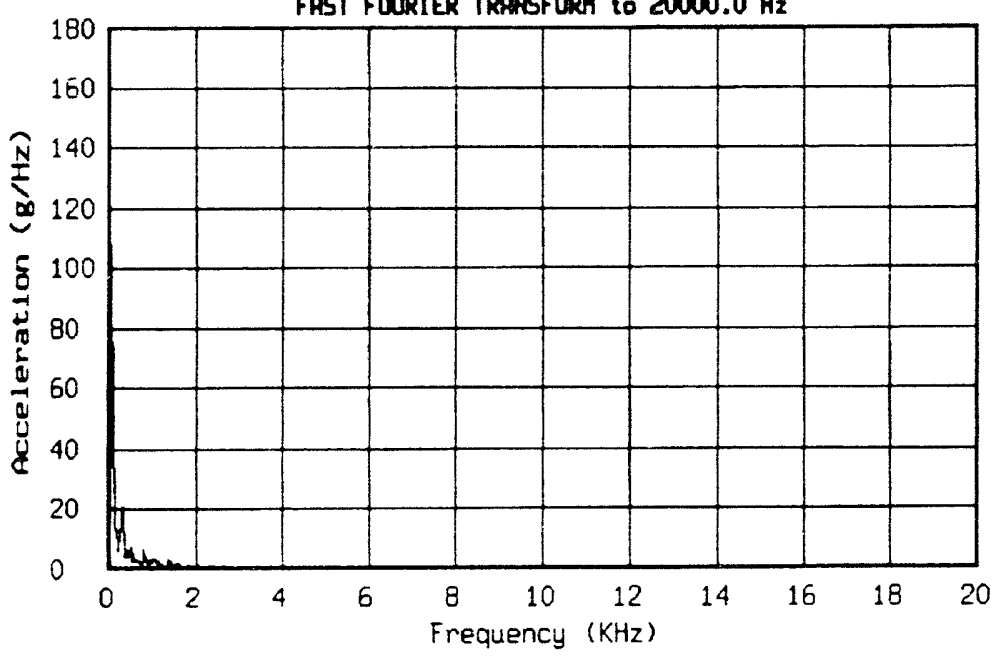

Test: HORIZONTAL HIGH VEOCITY H1224A 08/12/93 (224) Session: thed Aug 25 13:49:57 1993 Transducer: A13 (secondary) FAST FOURIER TRANSFORH to $20000.0 \mathrm{~Hz}$

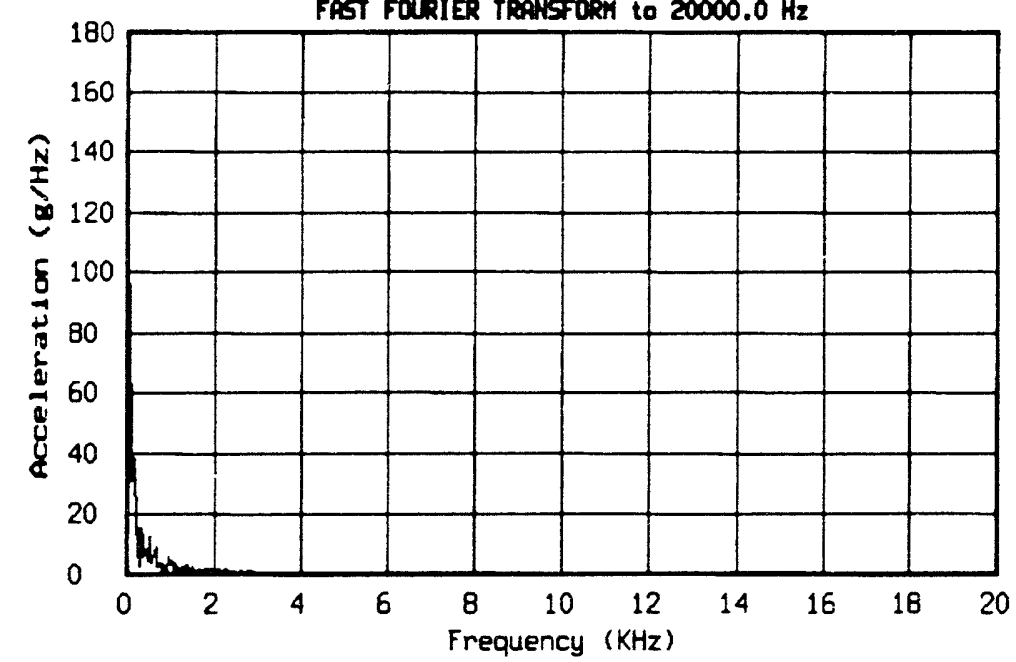

Test: HORIzONTR HICH VEOCITY H12249 08/12/93 (224) Session: Hed Aug 25 13:49:50 1993 Transolucer: A15 (secondary)

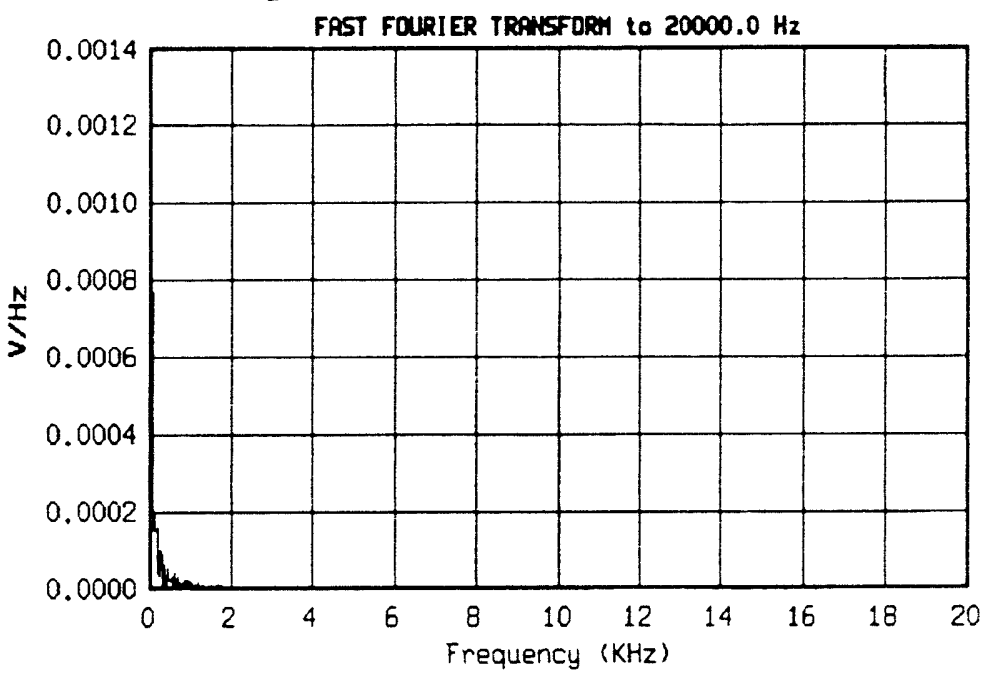

Test: HORIZONTL HIEH VEOCITY H1224A 08/12/93 (224) Session: lud Aus 25 13:50:09 1993 Tranaducer: S61 (secondary) FAST FOURIER TROASFOPA to $20000.0 \mathrm{~Hz}$

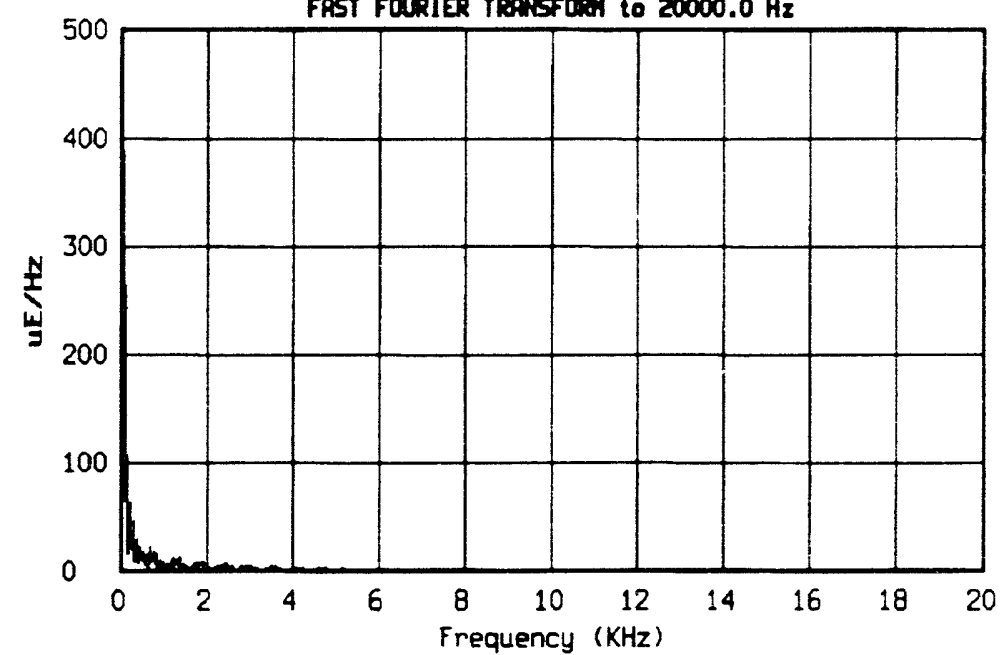


Test: HORIZONTL HIGH VEDCITY H1224A 08/12/93 (224) Session: Ued Aug 25 13:50:03 1993 Transicucer: 562 (secondary) FRST FOURIER TRANSFORM to $20000.0 \mathrm{~Hz}$

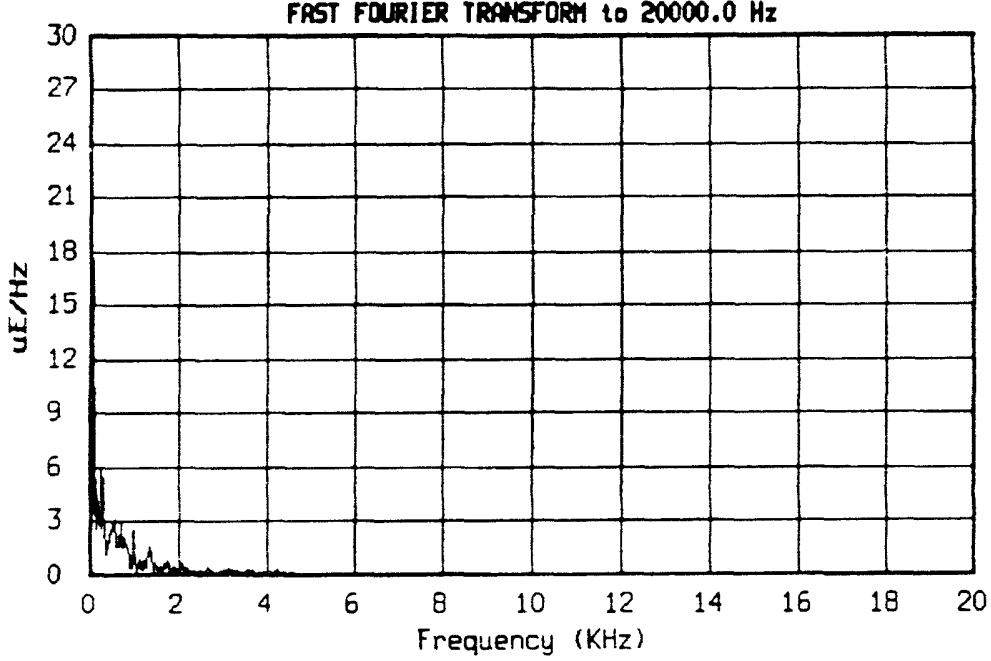

$\vec{\varnothing}$

Test: HORIZONTL HIEH VEDCCITY H1224A 08/12/93 (224)

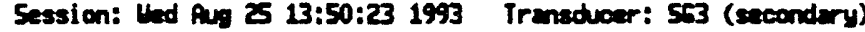
FRST FURIER TRESFORM to $20000.0 \mathrm{~Hz}$

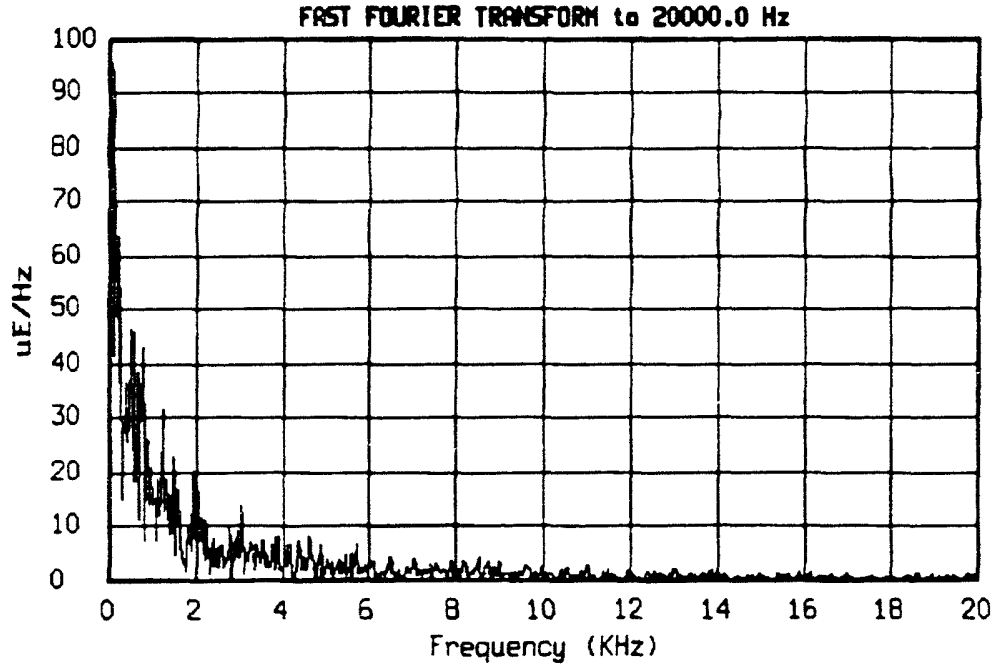

Test: HOSIZONTA HICH VEOCITY H1224A 08/12/93 (224) Session: lhed Aug 25 13:50:15 1993 Transduoer: 564 (secondary) FPST FOURIER TRAYSFORM to $20000.0 \mathrm{~Hz}$

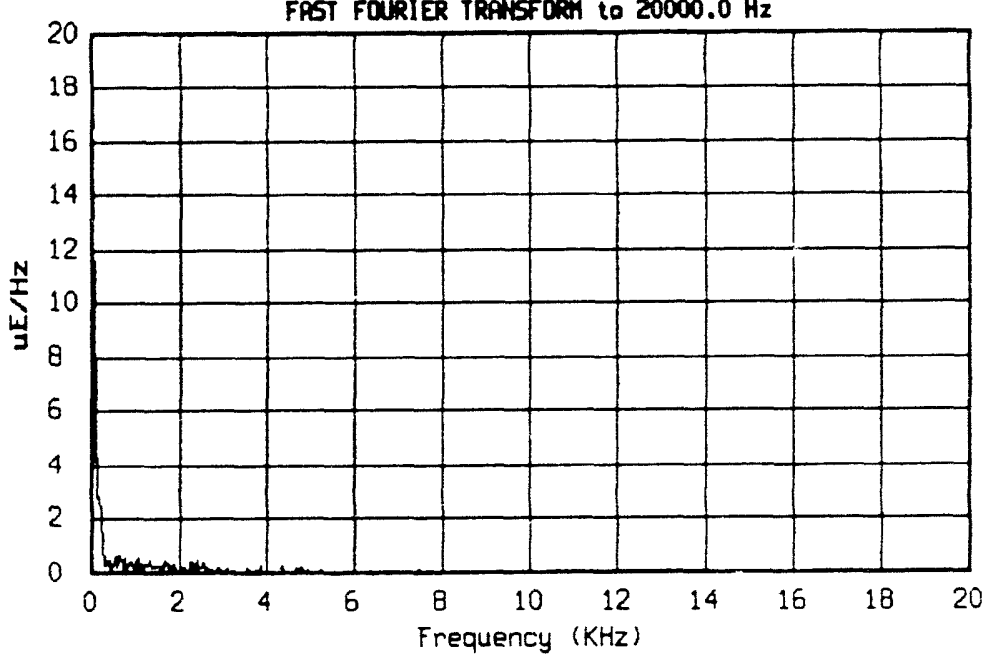

Test: HerIzOMAL HICH VaCCITY H1224h 08/12/93 (224) Session: thed Aug 25 13:50:10 1993 Transdwoer: 555 (secoondary) FRST FOURIER IRANSFORY to $20000.0 \mathrm{~Hz}$

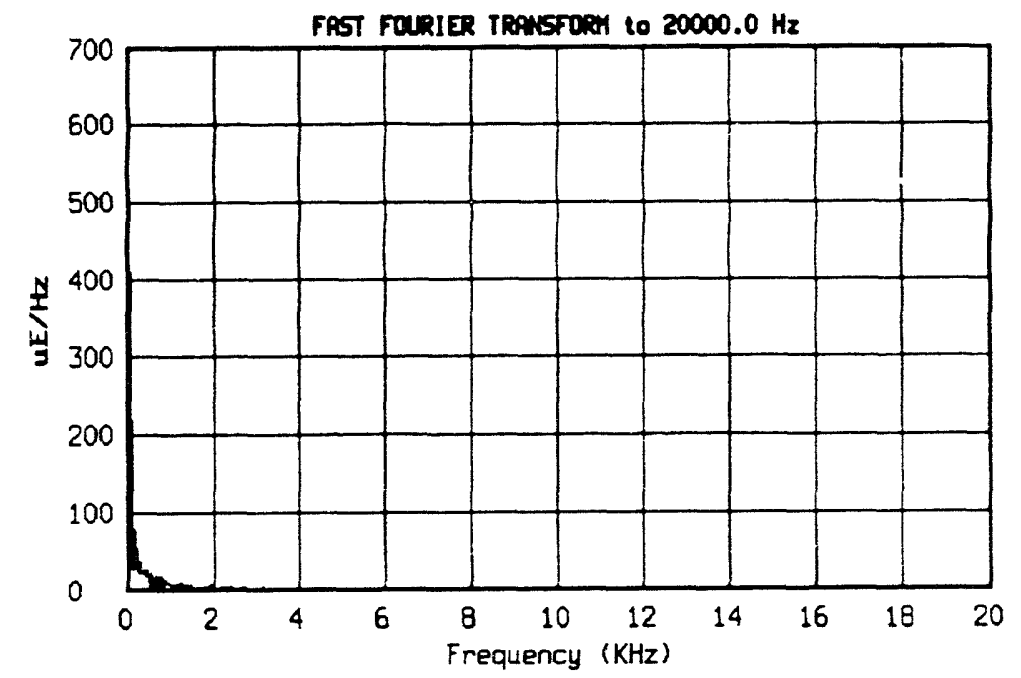


Test: HORIZONAA HIGH VELCCITY H1224A 08/12/93 (224) Session: thed Ang 25 13:50:31 1993 Transchoer: 566 (secondary)

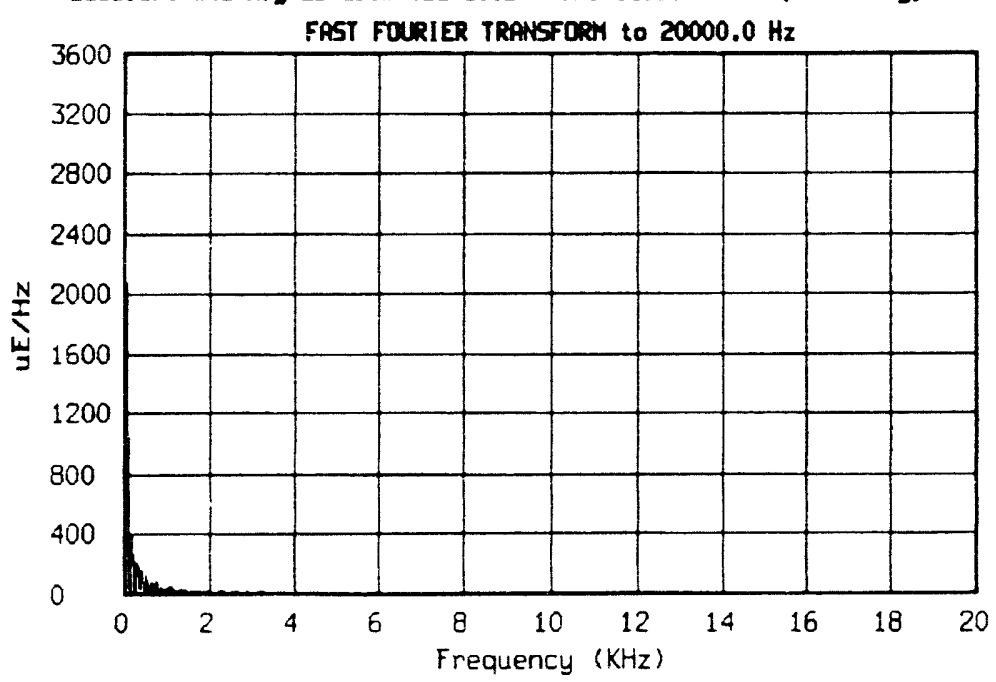

Test: HORIZONTA HIFH VELOCITY H1224A 08/12/93 (224) Session: thed Pug 25 13:50:53 1993 Iranedwoer: 567 (steocondary)

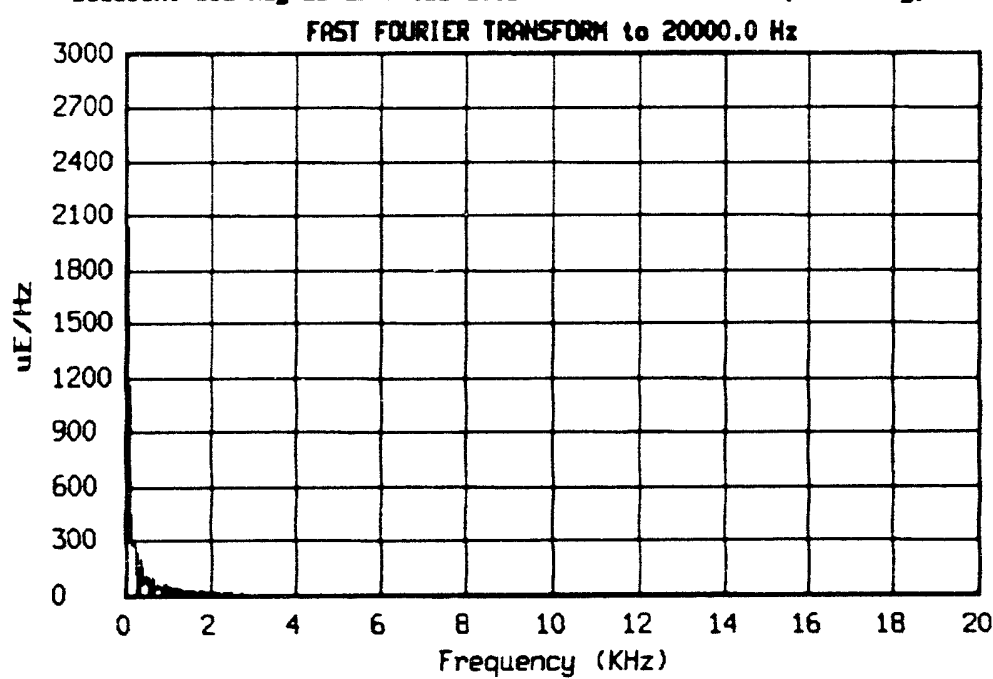

Test: HORI2ONTAL HIGH VEDCCITY H1224A 08/12/93 (224) Session: Led Aug 25 13:50:46 1993 Transaceer: 568 (secondary) FRST FOURIER TRANSFORY to $20000.0 \mathrm{~Hz}$

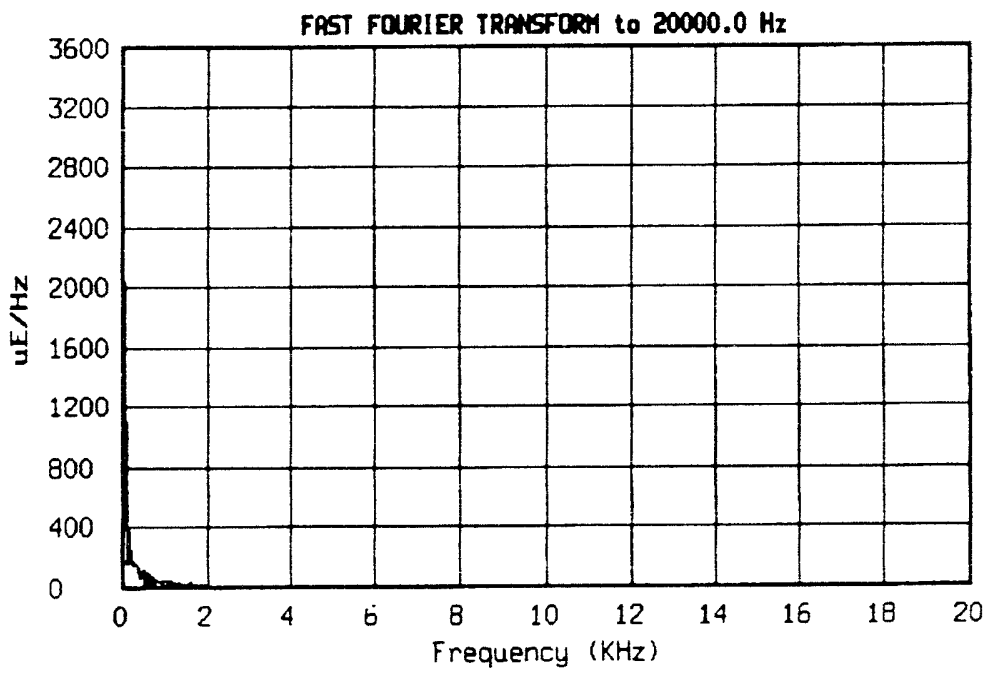

Test: HORIzONTA HICH velOCITY H1224A 08/12/93 (224) Session: thed AVg ZS 13:51:08 1993 Traneducer: 559 (secondary)

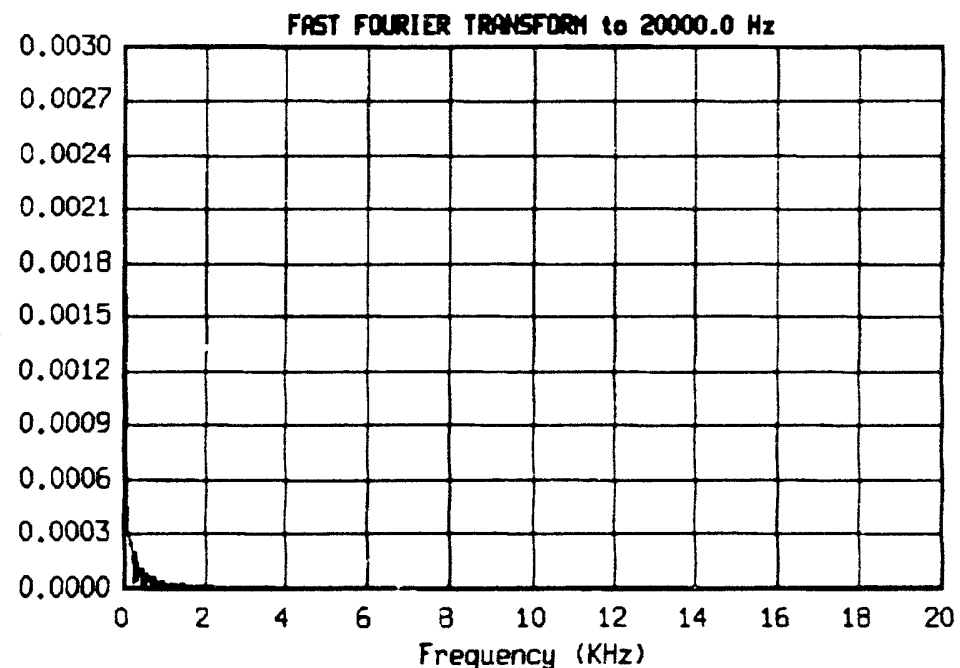


Test: HORIZONTA HIGH VElOCITY H1224A 08/12/93 (224) Session: Led Aug 25 13:51:01 1993 Transducer: 5610 (secondary)

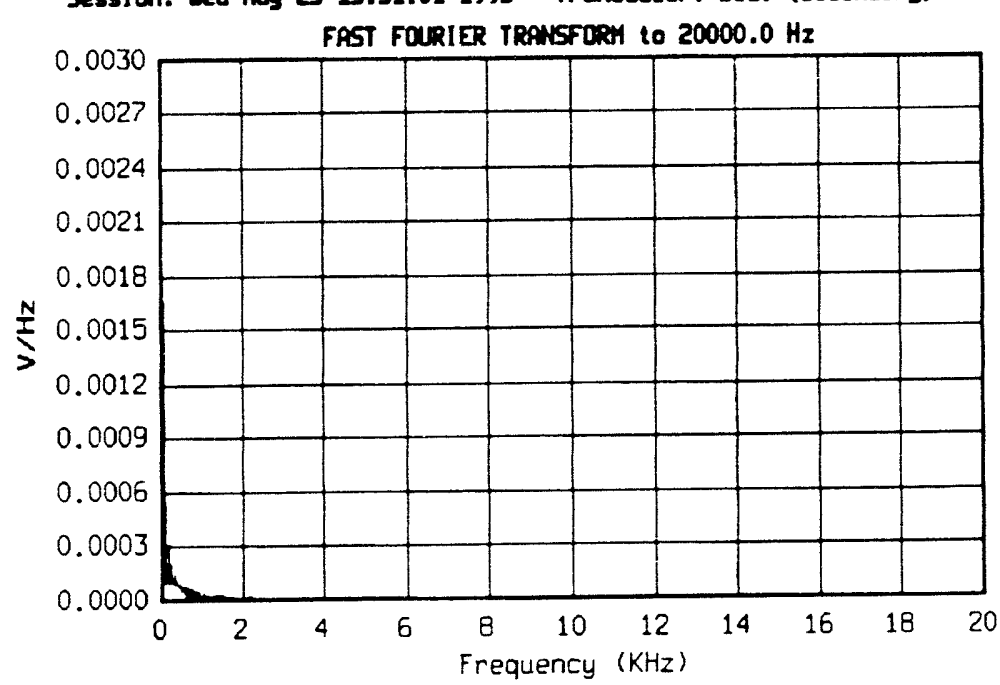




\section{Appendix E. Inspection Data}

The following tables present pre- and post-test H1224A container body, inner container, and $\mathrm{RV}$ and fore and aft cover inspection data at measurement locations designated in Figures 3.1, 3.2, and 3.3.

Table E 1.1: LLV H1224A Container Body Inspection Data

\begin{tabular}{|c|c|c|c|c|c|c|}
\hline \multirow{2}{*}{$\begin{array}{l}\text { Measurement } \\
\text { Designation }\end{array}$} & \multicolumn{2}{|c|}{ Pre-Test } & \multicolumn{2}{|c|}{ Post-Test } & \multicolumn{2}{|c|}{ Measurement Change } \\
\hline & $(\mathrm{mm})$ & (in.) & $(\mathrm{mm})$ & (in.) & $(\mathrm{mm})$ & (in.) \\
\hline OD $0,0^{\circ}$ & 825.70 & 32.508 & 825.09 & 32.484 & 0.61 & 0.024 \\
\hline OD $0,45^{\circ}$ & 822.83 & 32.395 & 822.50 & 32.382 & 0.33 & 0.013 \\
\hline $\mathrm{OD} 0,90^{\circ}$ & 821.77 & 32.353 & 821.41 & 32.339 & 0.36 & 0.014 \\
\hline OD $0,135^{\circ}$ & 824.08 & 32.444 & 823.72 & 32.430 & 0.36 & 0.014 \\
\hline OD $1,0^{\circ}$ & 824.61 & 32.465 & 824.38 & 32.456 & 0.23 & 0.009 \\
\hline OD $1,45^{\circ}$ & 823.24 & 32.411 & 823.14 & 32.407 & 0.10 & 0.004 \\
\hline OD $1,90^{\circ}$ & 821.77 & 32.353 & 821.72 & 32.351 & 0.05 & 0.002 \\
\hline OD $1,135^{\circ}$ & 824.33 & 32.454 & 824.18 & 32.448 & 0.15 & 0.006 \\
\hline $\mathrm{OD} 20,0^{\circ}$ & 822.33 & 32.375 & 824.33 & 32.454 & -2.01 & -0.079 \\
\hline OD $20,45^{\circ}$ & 822.15 & 32.368 & 823.98 & 32.440 & -1.83 & -0.072 \\
\hline OD $20,90^{\circ}$ & 822.91 & 32.398 & 822.96 & 32.400 & -0.05 & -0.002 \\
\hline OD $20,135^{\circ}$ & 824.79 & 32.472 & 821.16 & 32.329 & 3.63 & 0.143 \\
\hline OD $21,0^{\circ}$ & 851.84 & 33.537 & 855.68 & 33.688 & -3.84 & -0.151 \\
\hline OD $21,45^{\circ}$ & 852.42 & 33.560 & 854.68 & 33.649 & -2.26 & -0.089 \\
\hline OD $21,90^{\circ}$ & 853.67 & 33.609 & 853.49 & 33.602 & 0.18 & 0.007 \\
\hline $\mathrm{OD} 21,135^{\circ}$ & 855.68 & 33.688 & 852.96 & 33.581 & 2.72 & 0.107 \\
\hline $\mathrm{OD} 22,0^{\circ}$ & 822.12 & 32.367 & 824.97 & 32.479 & -2.84 & -0.112 \\
\hline OD $22,45^{\circ}$ & 821.72 & 32.351 & 823.90 & 32.437 & -2.18 & -0.086 \\
\hline OD $22,90^{\circ}$ & 822.91 & 32.398 & 822.81 & 32.394 & 0.10 & 0.004 \\
\hline
\end{tabular}


Tahle E 1.1: LLV H1224A Container Body Inspection Data

\begin{tabular}{|c|c|c|c|c|c|c|}
\hline \multirow{2}{*}{$\begin{array}{l}\text { Measurement } \\
\text { Designation }\end{array}$} & \multicolumn{2}{|c|}{ Pre-Test } & \multicolumn{2}{|c|}{ Post-Test } & \multicolumn{2}{|c|}{ Measurement Change } \\
\hline & $(\mathrm{mm})$ & (in.) & $(\mathrm{mm})$ & (in.) & $(\mathrm{mm})$ & (in.) \\
\hline OD $22,135^{\circ}$ & 824.94 & 32.478 & 821.69 & 32.350 & 3.25 & 0.128 \\
\hline OD $24,0^{\circ}$ & 820.60 & 32.307 & 824.15 & 32.447 & -3.56 & -0.140 \\
\hline OD $24,45^{\circ}$ & 821.66 & 32.349 & 824.41 & 32.457 & -2.74 & -0.108 \\
\hline OD $24,90^{\circ}$ & 823.24 & 32.411 & 821.92 & 32.359 & 1.32 & 0.052 \\
\hline OD $24,135^{\circ}$ & 825.32 & 32.493 & 822.63 & 32.387 & 2.69 & 0.106 \\
\hline OD $25,0^{\circ}$ & 820.80 & 32.315 & 824.15 & 32.447 & -3.35 & -0.132 \\
\hline OD $25,45^{\circ}$ & 821.05 & 32.325 & 823.77 & 32.432 & -2.72 & -0.107 \\
\hline OD $25,90^{\circ}$ & 822.91 & 32.398 & 821.31 & 32.335 & 1.60 & 0.063 \\
\hline $\mathrm{OD} 25,135^{\circ}$ & 824.64 & 32.466 & 822.05 & 32.364 & 2.59 & 0.102 \\
\hline OD $26,0^{\circ}$ & 912.47 & 35.924 & 913.43 & 35.962 & -0.97 & -0.038 \\
\hline OD $26,45^{\circ}$ & 911.12 & 35.871 & 911.96 & 35.904 & -0.84 & -0.033 \\
\hline OD $26,90^{\circ}$ & 909.22 & 35.796 & 908.20 & 35.756 & 1.02 & 0.040 \\
\hline OD $26,135^{\circ}$ & 912.44 & 35.923 & 910.92 & 35.863 & 1.52 & 0.060 \\
\hline OD $27,0^{\circ}$ & 822.83 & 32.395 & 823.85 & 32.435 & -1.02 & -0.040 \\
\hline OD $27,45^{\circ}$ & 820.09 & 32.287 & 822.15 & 32.368 & -2.06 & -0.081 \\
\hline OD $27,90^{\circ}$ & 818.77 & 32.235 & 816.81 & 32.158 & 1.96 & 0.077 \\
\hline OD $27,135^{\circ}$ & 821.49 & 32.342 & 821.11 & 32.327 & 0.38 & 0.015 \\
\hline $\mathrm{OD} 28,0^{\circ}$ & 813.97 & 32.046 & 814.27 & 32.058 & -0.30 & -0.012 \\
\hline $\mathrm{OD} 28,45^{\circ}$ & 811.38 & 31.944 & 813.82 & 32.040 & -2.44 & -0.096 \\
\hline OD $28,90^{\circ}$ & 809.42 & 31.867 & 806.02 & 31.733 & 3.40 & 0.134 \\
\hline OD $28,135^{\circ}$ & 812.55 & 31.990 & 813.33 & 32.021 & -0.79 & -0.031 \\
\hline OD $37.75,0^{\circ}$ & 812.80 & 32.000 & 810.39 & 31.905 & 2.41 & 0.095 \\
\hline OD $37.75,45^{\circ}$ & 812.34 & 31.982 & 819.20 & 32.252 & -6.86 & -0.270 \\
\hline OD $37.75,90^{\circ}$ & 807.34 & 31.785 & 790.12 & 31.107 & 17.22 & 0.678 \\
\hline
\end{tabular}


Table E 1.1: LLV H1224A Container Body Inspection Data

\begin{tabular}{|c|c|c|c|c|c|c|}
\hline \multirow{2}{*}{$\begin{array}{l}\text { Measurement } \\
\text { Designation }\end{array}$} & \multicolumn{2}{|c|}{ Pre-Test } & \multicolumn{2}{|c|}{ Post-Test } & \multicolumn{2}{|c|}{ Measurement Change } \\
\hline & $(\mathrm{mm})$ & (in.) & $(\mathrm{mm})$ & (in.) & $(\mathrm{mm})$ & (in.) \\
\hline OD $37.75,135^{\circ}$ & 814.43 & 32.064 & 823.59 & 32.425 & -9.17 & -0.361 \\
\hline OD $38.75,0^{\circ}$ & 812.80 & 32.000 & 808.94 & 31.848 & 3.86 & 0.152 \\
\hline OD $38.75,45^{\circ}$ & 811.61 & 31.953 & 818.54 & 32.226 & -6.93 & -0.273 \\
\hline OD $38.75,90^{\circ}$ & 806.83 & 31.765 & 788.19 & 31.031 & 18.64 & 0.734 \\
\hline OD $38.75,135^{\circ}$ & 814.48 & 32.066 & 823.59 & 32.425 & -9.12 & -0.359 \\
\hline OD $39.75,0^{\circ}$ & 843.71 & 33.217 & 852.32 & 33.556 & -8.61 & -0.339 \\
\hline OD $39.75,45^{\circ}$ & 843.36 & 33.203 & 855.88 & 33.696 & -12.52 & -0.493 \\
\hline OD $39.75,90^{\circ}$ & 838.89 & 33.027 & 832.71 & 32.784 & 6.17 & 0.243 \\
\hline OD $39.75,135^{\circ}$ & 845.24 & 33.277 & 860.83 & 33.891 & -15.60 & -0.614 \\
\hline OD $40.75,0^{\circ}$ & 812.67 & 31.995 & 817.98 & 32.204 & -5.31 & -0.209 \\
\hline $\mathrm{OD} 40.75,45^{\circ}$ & 811.81 & 31.961 & 814.02 & 32.048 & -2.21 & -0.087 \\
\hline OD $40.75,90^{\circ}$ & 806.53 & 31.753 & 789.71 & 31.091 & 16.81 & 0.662 \\
\hline OD $40.75,135^{\circ}$ & 814.15 & 32.053 & 821.00 & 32.323 & -6.86 & -0.270 \\
\hline OD $41.75,0^{\circ}$ & 812.16 & 31.975 & 818.74 & 32.234 & -6.58 & -0.259 \\
\hline OD $41.75,45^{\circ}$ & 812.77 & 31.999 & 815.70 & 32.114 & -2.92 & -0.115 \\
\hline OD $41.75,90^{\circ}$ & 807.21 & 31.780 & 792.40 & 31.197 & 14.81 & 0.583 \\
\hline OD $41.75,135^{\circ}$ & 814.55 & 32.069 & 821.08 & 32.326 & -6.53 & -0.257 \\
\hline OD $50.5,0^{\circ}$ & 811.10 & 31.933 & 814.17 & 32.054 & -3.07 & -0.121 \\
\hline OD $50.5,45^{\circ}$ & 811.76 & 31.959 & 808.35 & 31.825 & 3.40 & 0.134 \\
\hline OD $50.5,90^{\circ}$ & 811.53 & 31.950 & 798.30 & 31.429 & 13.23 & 0.521 \\
\hline OD $50.5,135^{\circ}$ & 813.05 & 32.010 & 811.68 & 31.956 & 1.37 & 0.054 \\
\hline OD $51.5,0^{\circ}$ & 815.90 & 32.122 & 813.03 & 32.009 & 2.87 & 0.113 \\
\hline OD $51.5,45^{\circ}$ & 817.30 & 32.177 & 815.75 & 32.116 & 1.55 & 0.061 \\
\hline OD $51.5,90^{\circ}$ & 815.82 & 32.119 & 803.73 & 31.643 & 12.09 & 0.476 \\
\hline
\end{tabular}


Table E 1.1: LLV H1224A Container Body Inspection Data

\begin{tabular}{|c|c|c|c|c|c|c|}
\hline \multirow{2}{*}{$\begin{array}{l}\text { Measurement } \\
\text { Designation }\end{array}$} & \multicolumn{2}{|c|}{ Pre-Test } & \multicolumn{2}{|c|}{ Post-Test } & \multicolumn{2}{|c|}{ Measurement Change } \\
\hline & $(\mathrm{mm})$ & (in.) & $(\mathrm{mm})$ & (in.) & $(\mathrm{mm})$ & (in.) \\
\hline OD $51.5,135^{\circ}$ & 817.32 & 32.178 & 816.36 & 32.140 & 0.97 & 0.038 \\
\hline OD $52.5,0^{\circ}$ & 815.52 & 32.107 & 809.07 & 31.853 & 6.45 & 0.254 \\
\hline OD $52.5,45^{\circ}$ & 816.99 & 32.165 & 809.57 & 31.873 & 7.42 & 0.292 \\
\hline OD $52.5,90^{\circ}$ & 816.31 & 32.138 & 809.73 & 31.879 & 6.58 & 0.259 \\
\hline OD $52.5,135^{\circ}$ & 817.19 & 32.173 & 811.56 & 31.951 & 5.64 & 0.222 \\
\hline $\mathrm{L} 1,0^{\circ}$ & 1459.13 & 57.446 & 1428.04 & 56.222 & 31.09 & 1.224 \\
\hline $\mathrm{L} 1,45^{\circ}$ & 1460.68 & 57.507 & 1431.16 & 56.345 & 29.51 & 1.162 \\
\hline $\mathrm{L} 1,90^{\circ}$ & 1460.73 & 57.509 & 1442.03 & 56.773 & 18.69 & 0.736 \\
\hline $\mathrm{L} 1,135^{\circ}$ & 1460.53 & 57.501 & 1455.06 & 57.286 & 5.46 & 0.215 \\
\hline $\mathrm{L} 1,180^{\circ}$ & 1459.81 & 57.473 & 1463.70 & 57.626 & -3.89 & -0.153 \\
\hline $\mathrm{L} 1,225^{\circ}$ & 1459.92 & 57.477 & 1461.69 & 57.547 & -1.78 & -0.070 \\
\hline $\mathrm{L} 1,270^{\circ}$ & 1457.93 & 57.399 & 1449.40 & 57.063 & 8.53 & 0.336 \\
\hline $\mathrm{L} 1,315^{\circ}$ & 1458.47 & 57.420 & 1436.22 & 56.544 & 22.25 & 0.876 \\
\hline $\mathrm{L} 2,0^{\circ}$ & 1344.17 & 52.920 & 1320.50 & 51.988 & 23.67 & 0.932 \\
\hline $\mathrm{L} 2,45^{\circ}$ & 1344.78 & 52.944 & 1317.12 & 51.855 & 27.66 & 1.089 \\
\hline $\mathrm{L} 2,90^{\circ}$ & 1345.54 & 52.974 & 1326.29 & 52.216 & 19.25 & 0.758 \\
\hline $\mathrm{L} 2,135^{\circ}$ & 1344.19 & 52.921 & 1339.90 & 52.752 & 4.29 & 0.169 \\
\hline $\mathrm{L} 2,180^{\circ}$ & 1344.30 & 52.925 & 1346.83 & 53.025 & -2.54 & -0.100 \\
\hline $\mathrm{L} 2,225^{\circ}$ & 1342.95 & 52.872 & 1342.49 & 52.854 & 0.46 & 0.018 \\
\hline $\mathrm{L} 2,270^{\circ}$ & 1342.26 & 52.845 & 1332.53 & 52.462 & 9.73 & 0.383 \\
\hline $\mathrm{L} 2,315^{\circ}$ & 1343.18 & 52.881 & 1322.58 & 52.070 & 20.60 & 0.811 \\
\hline
\end{tabular}


Table E 1.2: LLV Inner Container Inspection Data

\begin{tabular}{|c|c|c|c|c|c|c|}
\hline \multirow{2}{*}{$\begin{array}{l}\text { Measurement } \\
\text { Designation }\end{array}$} & \multicolumn{2}{|c|}{ Pre-Test } & \multicolumn{2}{|c|}{ Post-Test } & \multicolumn{2}{|c|}{ Measurement Change } \\
\hline & $(\mathrm{mm})$ & (in.) & $(\mathrm{mm})$ & (in.) & $(\mathrm{mm})$ & (in.) \\
\hline $\mathrm{OD} 0,0^{\circ}$ & 519.18 & 20.440 & 519.81 & 20.465 & -0.64 & -0.025 \\
\hline OD $0,60^{\circ}$ & 514.48 & 20.255 & 513.08 & 20.200 & 1.40 & 0.055 \\
\hline $\mathrm{OD} 0,120^{\circ}$ & 519.43 & 20.450 & 520.07 & 20.475 & -0.64 & -0.025 \\
\hline OD $11.38,0^{\circ}$ & 518.87 & 20.428 & 518.69 & 20.421 & 0.18 & 0.007 \\
\hline OD $11.38,60^{\circ}$ & 513.46 & 20.215 & 513.46 & 20.215 & 0.00 & 0.000 \\
\hline OD $11.38,120^{\circ}$ & 519.10 & 20.437 & 519.23 & 20.442 & -0.13 & -0.005 \\
\hline OD $17.38,0^{\circ}$ & 519.53 & 20.454 & 514.38 & 20.251 & 5.16 & 0.203 \\
\hline OD $17.38,60^{\circ}$ & 516.10 & 20.319 & 516.89 & 20.350 & -0.79 & -0.031 \\
\hline OD $17.38,120^{\circ}$ & 519.35 & 20.447 & 523.67 & 20.617 & -4.32 & -0.170 \\
\hline OD $23.38,0^{\circ}$ & 518.29 & 20.405 & 517.40 & 20.370 & 0.89 & 0.035 \\
\hline OD $23.38,60^{\circ}$ & 514.83 & 20.269 & 517.02 & 20.355 & -2.18 & -0.086 \\
\hline OD $23.38,120^{\circ}$ & 518.21 & 20.402 & 516.13 & 20.320 & 2.08 & 0.082 \\
\hline OD $38.75,0^{\circ}$ & 517.55 & 20.376 & 516.64 & 20.340 & 0.91 & 0.036 \\
\hline OD $38.75,60^{\circ}$ & 517.83 & 20.387 & 519.51 & 20.453 & -1.68 & -0.066 \\
\hline OD $38.75,120^{\circ}$ & 517.19 & 20.362 & 515.62 & 20.300 & 1.57 & 0.062 \\
\hline $\mathrm{L} 1,0^{\circ}$ & 987.02 & 38.859 & 987.45 & 38.876 & -0.43 & -0.017 \\
\hline $\mathrm{L} 1,60^{\circ}$ & 987.42 & 38.875 & 1002.59 & 39.472 & -15.16 & -0.597 \\
\hline $\mathrm{L} 1,120^{\circ}$ & 987.42 & 38.875 & 988.34 & 38.911 & -0.91 & -0.036 \\
\hline $\mathrm{L} 1,180^{\circ}$ & 987.15 & 38.864 & 989.43 & 38.954 & -2.29 & -0.090 \\
\hline $\mathrm{L} 1,240^{\circ}$ & 986.82 & 38.851 & 1002.16 & 39.455 & -15.34 & -0.604 \\
\hline $\mathrm{L} 1,300^{\circ}$ & 986.76 & 38.849 & 989.86 & 38.971 & -3.10 & -0.122 \\
\hline
\end{tabular}


Table E 1.3: LLV RV, Fore, and Aft Cover Inspection Data

\begin{tabular}{|c|c|c|c|c|c|c|}
\hline \multirow{2}{*}{$\begin{array}{l}\text { Measurement } \\
\text { Designation }\end{array}$} & \multicolumn{2}{|c|}{ Pre-Test } & \multicolumn{2}{|c|}{ Post-Test } & \multicolumn{2}{|c|}{ Measurement Change } \\
\hline & $(\mathrm{mm})$ & (in.) & $(\mathrm{mm})$ & (in.) & $(\mathrm{mm})$ & (in.) \\
\hline$\overline{\mathrm{OD} \mathrm{A}}, 0^{\circ}$ & 500.71 & 19.713 & 500.68 & 19.712 & 0.03 & 0.001 \\
\hline $\mathrm{OD} \mathrm{A}, 60^{\circ}$ & 500.68 & 19.712 & 500.63 & 19.710 & 0.05 & 0.002 \\
\hline $\mathrm{OD} \mathrm{A}, 120^{\circ}$ & 500.91 & 19.721 & 500.89 & 19.720 & 0.03 & 0.001 \\
\hline ID B, $0^{\circ}$ & 426.52 & 16.792 & 426.59 & 16.795 & -0.08 & -0.003 \\
\hline $\mathrm{ID} \mathrm{B}, 60^{\circ}$ & 426.49 & 16.791 & 426.39 & 16.787 & 0.10 & 0.004 \\
\hline $\mathrm{ID} \mathrm{B}, 120^{\circ}$ & 426.59 & 16.795 & 426.72 & 16.800 & -0.13 & -0.005 \\
\hline ID C, $0^{\circ}$ & 490.58 & 19.314 & 490.55 & 19.313 & 0.03 & 0.001 \\
\hline ID C, $60^{\circ}$ & 491.03 & 19.332 & 491.08 & 19.334 & -0.05 & -0.002 \\
\hline $\mathrm{ID} \mathrm{C}, 120^{\circ}$ & 491.19 & 19.338 & 491.21 & 19.339 & -0.03 & -0.001 \\
\hline $\mathrm{L} 2,0^{\circ}$ & 236.30 & 9.303 & 236.19 & 9.299 & 0.10 & 0.004 \\
\hline $\mathrm{L} 2,60^{\circ}$ & 236.19 & 9.299 & 236.02 & 9.292 & 0.18 & 0.007 \\
\hline $\mathrm{L} 2,120^{\circ}$ & 235.84 & 9.285 & 235.79 & 9.283 & 0.05 & 0.002 \\
\hline $\mathrm{L} 2,180^{\circ}$ & 235.76 & 9.282 & 235.74 & 9.281 & 0.03 & 0.001 \\
\hline $\mathrm{L} 2,240^{\circ}$ & 235.84 & 9.285 & 235.76 & 9.282 & 0.08 & 0.003 \\
\hline $\mathrm{L} 2,300^{\circ}$ & 235.94 & 9.289 & 235.89 & 9.287 & 0.05 & 0.002 \\
\hline $\mathrm{OD} \mathrm{B}, 0^{\circ}$ & 431.55 & 16.990 & 431.50 & 16.988 & 0.05 & 0.002 \\
\hline OD B, $60^{\circ}$ & 431.55 & 16.990 & 431.65 & 16.994 & -0.10 & -0.004 \\
\hline $\mathrm{OD} \mathrm{B}, 120^{\circ}$ & 431.62 & 16.993 & 431.62 & 16.993 & 0.00 & 0.000 \\
\hline ID D, $0^{\circ}$ & 165.76 & 6.526 & 165.71 & 6.524 & 0.05 & 0.002 \\
\hline $\mathrm{ID} \mathrm{D}, 60^{\circ}$ & 165.76 & 6.526 & 165.79 & 6.527 & -0.03 & -0.001 \\
\hline $\mathrm{ID} \mathrm{D}, 120^{\circ}$ & 165.76 & 6.526 & 165.76 & 6.526 & 0.00 & 0.000 \\
\hline $\mathrm{L} 1,0^{\circ}$ & 883.51 & 34.784 & 872.79 & 34.362 & 10.72 & 0.422 \\
\hline $\mathrm{L} 1,60^{\circ}$ & 883.41 & 34.780 & 872.64 & 34.356 & 10.77 & 0.424 \\
\hline
\end{tabular}


Table E 1.3: LLV RV, Fore, and Aft Cover Inspection Data

\begin{tabular}{|l|l|l|l|l|l|l|}
\hline \multirow{2}{*}{$\begin{array}{c}\text { Measurement } \\
\text { Designation }\end{array}$} & \multicolumn{2}{|c|}{ Pre-Test } & \multicolumn{2}{c|}{ Post-Test } & \multicolumn{2}{c|}{ Measurement Change } \\
\cline { 2 - 7 } & $(\mathrm{mm})$ & $(\mathrm{in})$. & $(\mathrm{mm})$ & $(\mathrm{in})$. & \multicolumn{1}{c|}{$(\mathrm{mm})$} & \multicolumn{1}{c|}{ (in.) } \\
\hline \hline $\mathrm{L} 1,120^{\circ}$ & 883.46 & 34.782 & 872.49 & 34.350 & 10.97 & 0.432 \\
\hline $\mathrm{L} 1,180^{\circ}$ & 883.36 & 34.778 & 872.31 & 34.343 & 11.05 & 0.435 \\
\hline $\mathrm{L} 1,240^{\circ}$ & 883.36 & 34.778 & 872.54 & 34.352 & 10.82 & 0.426 \\
\hline $\mathrm{L} 1,300^{\circ}$ & 883.41 & 34.780 & 872.67 & 34.357 & 10.74 & 0.423 \\
\hline OD D, $0^{\circ}$ & 171.25 & 6.742 & 171.30 & 6.744 & -0.05 & -0.002 \\
\hline OD D, $60^{\circ}$ & 171.25 & 6.742 & 171.27 & 6.743 & -0.03 & -0.001 \\
\hline OD D, $120^{\circ}$ & 171.25 & 6.742 & 171.25 & 6.742 & 0.00 & 0.000 \\
\hline OD E, $0^{\circ}$ & 482.35 & 18.990 & 482.60 & 19.000 & -0.25 & -0.010 \\
\hline OD E, $60^{\circ}$ & 482.35 & 18.990 & 481.41 & 18.953 & 0.94 & 0.037 \\
\hline OD E, $120^{\circ}$ & 482.35 & 18.990 & 481.51 & 18.957 & 0.84 & 0.033 \\
\hline
\end{tabular}

Table E 2.1: HLV H1224A Container Body Inspection Data

\begin{tabular}{|c|c|c|c|c|c|c|}
\hline \multirow{2}{*}{$\begin{array}{l}\text { Measurement } \\
\text { Designation }\end{array}$} & \multicolumn{2}{|c|}{ Pre-Test } & \multicolumn{2}{|c|}{ Post-Test } & \multicolumn{2}{|c|}{ Measurement Change } \\
\hline & $(\mathrm{mm})$ & (in.) & $(\mathrm{mm})$ & (in.) & $(\mathrm{mm})$ & (in.) \\
\hline $\mathrm{OD} 0,0^{\circ}$ & 822.60 & 32.386 & 807.21 & 31.780 & 15.39 & 0.606 \\
\hline $\mathrm{OD} 0,45^{\circ}$ & 822.83 & 32.395 & 823.65 & 32.427 & -0.81 & -0.032 \\
\hline OD $0,90^{\circ}$ & 818.34 & 32.218 & 816.46 & 32.144 & 1.88 & 0.074 \\
\hline $\mathrm{OD} 0,135^{\circ}$ & 824.69 & 32.468 & 825.27 & 32.491 & -0.58 & -0.023 \\
\hline OD $1,0^{\circ}$ & 822.86 & 32.396 & 808.51 & 31.831 & 14.35 & 0.565 \\
\hline OD $1,45^{\circ}$ & 823.49 & 32.421 & 824.99 & 32.480 & -1.50 & -0.059 \\
\hline OD $1,90^{\circ}$ & 819.91 & 32.280 & 819.76 & 32.274 & 0.15 & 0.006 \\
\hline OD $1,135^{\circ}$ & 825.27 & 32.491 & 825.88 & 32.515 & -0.61 & -0.024 \\
\hline $\mathrm{OD} 20,0^{\circ}$ & 822.20 & 32.370 & 773.28 & 30.444 & 48.92 & 1.926 \\
\hline
\end{tabular}


Table E 2.1: HLV H1224A Container Body Inspection Data

\begin{tabular}{|c|c|c|c|c|c|c|}
\hline \multirow{2}{*}{$\begin{array}{l}\text { Measurement } \\
\text { Designation }\end{array}$} & \multicolumn{2}{|c|}{ Pre-Test } & \multicolumn{2}{|c|}{ Post-Test } & \multicolumn{2}{|c|}{ Measurement Change } \\
\hline & $(\mathrm{mm})$ & (in.) & $(\mathrm{mm})$ & (in.) & $(\mathrm{mm})$ & (in.) \\
\hline OD $20,45^{\circ}$ & 823.49 & 32.421 & 827.35 & 32.573 & -3.86 & -0.152 \\
\hline OD $20,90^{\circ}$ & 823.75 & 32.431 & 854.61 & 33.646 & -30.86 & -1.215 \\
\hline OD $20,135^{\circ}$ & 825.60 & 32.504 & 826.54 & 32.541 & -0.94 & -0.037 \\
\hline OD $21,0^{\circ}$ & 853.85 & 33.616 & 799.95 & 31.494 & 53.90 & 2.122 \\
\hline OD $21,45^{\circ}$ & 854.41 & 33.638 & 857.99 & 33.779 & -3.58 & -0.141 \\
\hline OD $21,90^{\circ}$ & 855.60 & 33.685 & 887.12 & 34.926 & -31.52 & -1.241 \\
\hline OD $21,135^{\circ}$ & 856.26 & 33.711 & 856.69 & 33.728 & -0.43 & -0.017 \\
\hline OD $22,0^{\circ}$ & 822.50 & 32.382 & 760.55 & 29.943 & 61.95 & 2.439 \\
\hline OD $22,45^{\circ}$ & 822.88 & 32.397 & 827.07 & 32.562 & -4.19 & -0.165 \\
\hline OD $22,90^{\circ}$ & 824.97 & 32.479 & 859.46 & 33.837 & -34.49 & -1.358 \\
\hline OD $22,135^{\circ}$ & 825.14 & 32.486 & 826.34 & 32.533 & -1.19 & -0.047 \\
\hline OD $24,0^{\circ}$ & 822.02 & 32.363 & 748.69 & 29.476 & 73.33 & 2.887 \\
\hline OD $24,45^{\circ}$ & 822.22 & 32.371 & 826.31 & 32.532 & -4.09 & -0.161 \\
\hline OD $24,90^{\circ}$ & 824.43 & 32.458 & 862.89 & 33.972 & -38.46 & -1.514 \\
\hline OD $24,135^{\circ}$ & 823.72 & 32.430 & 824.18 & 32.448 & -0.46 & -0.018 \\
\hline OD $25,0^{\circ}$ & 820.93 & 32.320 & 738.66 & 29.081 & 82.27 & 3.239 \\
\hline OD $25,45^{\circ}$ & 821.64 & 32.348 & 825.40 & 32.496 & -3.76 & -0.148 \\
\hline OD $25,90^{\circ}$ & 823.87 & 32.436 & 863.30 & 33.988 & -39.42 & -1.552 \\
\hline OD $25,135^{\circ}$ & 823.19 & 32.409 & 823.24 & 32.411 & -0.05 & -0.002 \\
\hline OD $26,0^{\circ}$ & 910.59 & 35.850 & 833.70 & 32.823 & 76.89 & 3.027 \\
\hline OD $26,45^{\circ}$ & 913.21 & 35.953 & 914.22 & 35.993 & -1.02 & -0.040 \\
\hline OD $26,90^{\circ}$ & 912.75 & 35.935 & 960.30 & 37.807 & -47.55 & -1.872 \\
\hline OD $26,135^{\circ}$ & 912.80 & 35.937 & 911.99 & 35.905 & 0.81 & 0.032 \\
\hline OD $27,0^{\circ}$ & 819.15 & 32.250 & 739.04 & 29.096 & 80.11 & 3.154 \\
\hline
\end{tabular}


Table E 2.1: HLV H1224A Container Body Inspection Data

\begin{tabular}{|c|c|c|c|c|c|c|}
\hline \multirow{2}{*}{$\begin{array}{l}\text { Measurement } \\
\text { Designation }\end{array}$} & \multicolumn{2}{|c|}{ Pre-Test } & \multicolumn{2}{|c|}{ Post-Test } & \multicolumn{2}{|c|}{ Measurement Change } \\
\hline & $(\mathrm{mm})$ & (in.) & $(\mathrm{mm})$ & (in.) & $(\mathrm{mm})$ & (in.) \\
\hline OD $27,45^{\circ}$ & 822.60 & 32.386 & 828.67 & 32.625 & -6.07 & -0.239 \\
\hline OD $27,90^{\circ}$ & 822.12 & 32.367 & 960.22 & 37.804 & -138.10 & -5.437 \\
\hline OD $27,135^{\circ}$ & 821.41 & 32.339 & 821.77 & 32.353 & -0.36 & -0.014 \\
\hline OD $28,0^{\circ}$ & 810.46 & 31.908 & 734.97 & 28.936 & 75.49 & 2.972 \\
\hline OD $28,45^{\circ}$ & 811.99 & 31.968 & 817.80 & 32.197 & -5.82 & -0.229 \\
\hline OD $28,90^{\circ}$ & 813.61 & 32.032 & 858.90 & 33.815 & -45.29 & -1.783 \\
\hline OD $28,135^{\circ}$ & 811.81 & 31.961 & 813.51 & 32.028 & -1.70 & -0.067 \\
\hline OD $37.75,0^{\circ}$ & 812.90 & 32.004 & 778.13 & 30.635 & 34.77 & 1.369 \\
\hline OD $37.75,45^{\circ}$ & 811.91 & 31.965 & 815.64 & 32.112 & -3.73 & -0.147 \\
\hline OD $37.75,90^{\circ}$ & 812.22 & 31.977 & 838.50 & 33.012 & -26.29 & -1.035 \\
\hline OD $37.75,135^{\circ}$ & 812.80 & 32.000 & 811.76 & 31.959 & 1.04 & 0.041 \\
\hline OD $38.75,0^{\circ}$ & 812.52 & 31.989 & 77948 & 30.688 & 33.05 & 1.301 \\
\hline OD $38.75,45^{\circ}$ & 810.84 & 31.923 & 814.20 & 32.055 & -3.35 & -0.132 \\
\hline OD $38.75,90^{\circ}$ & 811.71 & 31.957 & 835.94 & 32.911 & -24.23 & -0.954 \\
\hline OD $38.75,135^{\circ}$ & 812.27 & 31.979 & 811.25 & 31.939 & 1.02 & 0.040 \\
\hline OD $39.75,0^{\circ}$ & 841.76 & 33.140 & 808.74 & 31.840 & 33.02 & 1.300 \\
\hline OD $39.75,45^{\circ}$ & 842.65 & 33.175 & 819.15 & 32.250 & 23.50 & 0.925 \\
\hline OD $39.75,90^{\circ}$ & 842.77 & 33.180 & 865.23 & 34.064 & -22.45 & -0.884 \\
\hline OD $39.75,135^{\circ}$ & 843.84 & 33.222 & 842.01 & 33.150 & 1.83 & 0.072 \\
\hline $\mathrm{OD} 40.75,0^{\circ}$ & 809.65 & 31.876 & 786.00 & 30.945 & 23.65 & 0.931 \\
\hline OD $40.75,45^{\circ}$ & 811.73 & 31.958 & 813.69 & 32.035 & -1.96 & -0.077 \\
\hline OD $40.75,90^{\circ}$ & 810.59 & 31.913 & 830.68 & 32.704 & -20.09 & -0.791 \\
\hline OD $40.75,135^{\circ}$ & 812.80 & 32.000 & 811.73 & 31.958 & 1.07 & 0.042 \\
\hline $\mathrm{OD} 41.75,0^{\circ}$ & 809.73 & 31.879 & 788.87 & 31.058 & 20.85 & 0.821 \\
\hline
\end{tabular}


Table E 2.1: HLV H1224A Container Body Inspection Data

\begin{tabular}{|c|c|c|c|c|c|c|}
\hline \multirow{2}{*}{$\begin{array}{l}\text { Measurement } \\
\text { Designation }\end{array}$} & \multicolumn{2}{|c|}{ Pre-Test } & \multicolumn{2}{|c|}{ Post-Test } & \multicolumn{2}{|c|}{ Measurement Change } \\
\hline & $(\mathrm{mm})$ & (in.) & $(\mathrm{mm})$ & (in.) & $(\mathrm{mm})$ & (in.) \\
\hline OD $41.75,45^{\circ}$ & 814.71 & 32.075 & 814.65 & 32.073 & 0.05 & 0.002 \\
\hline OD $41.75,90^{\circ}$ & 810.59 & 31.913 & 830.07 & 32.680 & -19.48 & -0.767 \\
\hline OD $41.75,135^{\circ}$ & 813.41 & 32.024 & 812.50 & 31.988 & 0.91 & 0.036 \\
\hline OD $50.5,0^{\circ}$ & 807.72 & 31.800 & 802.56 & 31.597 & 5.16 & 0.203 \\
\hline OD $50.5,45^{\circ}$ & 812.34 & 31.982 & 813.05 & 32.010 & -0.71 & -0.028 \\
\hline OD $50.5,90^{\circ}$ & 812.34 & 31.982 & 817.52 & 32.186 & -5.18 & -0.204 \\
\hline OD $50.5,135^{\circ}$ & 811.20 & 31.937 & 810.84 & 31.923 & 0.36 & 0.014 \\
\hline OD $51.5,0^{\circ}$ & 813.23 & 32.017 & 809.88 & 31.885 & 3.35 & 0.132 \\
\hline OD $51.5,45^{\circ}$ & 817.40 & 32.181 & 818.77 & 32.235 & -1.37 & -0.054 \\
\hline OD $51.5,90^{\circ}$ & 816.97 & 32.164 & 819.99 & 32.283 & -3.02 & -0.119 \\
\hline OD $51.5,135^{\circ}$ & 816.74 & 32.155 & 816.38 & 32.141 & 0.36 & 0.014 \\
\hline OD $52.5,0^{\circ}$ & 815.01 & 32.087 & 811.94 & 31.966 & 3.07 & 0.121 \\
\hline OD $52.5,45^{\circ}$ & 830.71 & 32.705 & 831.85 & 32.750 & -1.14 & -0.045 \\
\hline OD $52.5,90^{\circ}$ & 817.88 & 32.210 & 819.38 & 32.259 & -1.50 & -0.059 \\
\hline OD $52.5,135^{\circ}$ & 817.14 & 32.171 & 816.99 & 32.165 & 0.15 & 0.006 \\
\hline $\mathrm{L} 1,180^{\circ}$ & 1455.88 & 57.318 & 1468.27 & 57.806 & -12.40 & -0.488 \\
\hline $\mathrm{L} 1,0^{\circ}$ & 1457.96 & 57.400 & 1460.58 & 57.503 & -2.62 & -0.103 \\
\hline $\mathrm{L} 1,45^{\circ}$ & 1458.34 & 57.415 & 1463.80 & 57.630 & -5.46 & -0.215 \\
\hline $\mathrm{L} 1,90^{\circ}$ & 1458.82 & 57.434 & 1470.74 & 57.903 & -11.91 & -0.469 \\
\hline $\mathrm{L} 1,135^{\circ}$ & 1457.60 & 57.386 & 1470.38 & 57.889 & -12.78 & -0.503 \\
\hline $\mathrm{L} 1,0^{\circ}$ & 1457.96 & 57.400 & 1460.58 & 57.503 & -2.62 & -0.103 \\
\hline $\mathrm{L} 1,180^{\circ}$ & 1455.88 & 57.318 & 1468.27 & 57.806 & -12.40 & -0.488 \\
\hline $\mathrm{L} 1,225^{\circ}$ & 1455.32 & 57.296 & 1472.36 & 57.967 & -17.04 & -0.671 \\
\hline $\mathrm{L} 1,270^{\circ}$ & 1455.34 & 57.297 & 1472.13 & 57.958 & -16.79 & -0.661 \\
\hline
\end{tabular}


Table E 2.1: HLV H1224A Container Body Inspection Data

\begin{tabular}{|l|c|c|c|c|c|c|}
\hline \multirow{2}{*}{$\begin{array}{c}\text { Measurement } \\
\text { Designation }\end{array}$} & \multicolumn{2}{|c|}{ Pre-Test } & \multicolumn{2}{c|}{ Post-Test } & \multicolumn{2}{c|}{ Measurement Change } \\
\cline { 2 - 7 } & $(\mathrm{mm})$ & (in.) & $(\mathrm{mm})$ & $(\mathrm{in})$. & $(\mathrm{mm})$ & (in.) \\
\hline \hline $\mathrm{L} 1,315^{\circ}$ & 1455.75 & 57.313 & 1464.54 & 57.659 & -8.79 & -0.346 \\
\hline $\mathrm{L} 2,0^{\circ}$ & 1340.71 & 52.784 & 1336.14 & 52.604 & 4.57 & 0.180 \\
\hline $\mathrm{L} 2,45^{\circ}$ & 1340.76 & 52.786 & 1344.60 & 52.937 & -3.84 & -0.151 \\
\hline $\mathrm{L} 2,90^{\circ}$ & 1342.92 & 52.871 & 1354.76 & 53.337 & -11.84 & -0.466 \\
\hline $\mathrm{L} 2,135^{\circ}$ & 1339.93 & 52.753 & 1351.15 & 53.195 & -11.23 & -0.442 \\
\hline $\mathrm{L} 2,180^{\circ}$ & 1338.05 & 52.679 & 1346.10 & 52.996 & -8.05 & -0.317 \\
\hline $\mathrm{L} 2,225^{\circ}$ & 1337.77 & 52.668 & 1349.38 & 53.125 & -11.61 & -0.457 \\
\hline $\mathrm{L} 2,270^{\circ}$ & 1339.47 & 52.735 & 1353.24 & 53.277 & -13.77 & -0.542 \\
\hline $\mathrm{L} 2,315^{\circ}$ & 1337.61 & 52.662 & 1344.52 & 52.934 & -6.91 & -0.272 \\
\hline
\end{tabular}

Table E 2.2: HLV Inner Container Inspection Data

\begin{tabular}{|c|c|c|c|c|c|c|}
\hline \multirow{2}{*}{$\begin{array}{l}\text { Measurement } \\
\text { Designation }\end{array}$} & \multicolumn{2}{|c|}{ Pre-Test } & \multicolumn{2}{|c|}{ Post-Test } & \multicolumn{2}{|c|}{ Measurement Change } \\
\hline & $(\mathrm{mm})$ & (in.) & $(\mathrm{mm})$ & (in.) & $(\mathrm{mm})$ & (in.) \\
\hline $\mathrm{OD} 0,0^{\circ}$ & 513.08 & 20.200 & 521.44 & 20.529 & -8.36 & -0.329 \\
\hline OD $0,60^{\circ}$ & 512.24 & 20.167 & 520.88 & 20.507 & -8.64 & -0.340 \\
\hline OD $0,120^{\circ}$ & 530.76 & 20.896 & 506.25 & 19.931 & 24.51 & 0.965 \\
\hline OD $11.38,0^{\circ}$ & 514.02 & 20.237 & 519.05 & 20.435 & -5.03 & -0.198 \\
\hline OD $11.38,60^{\circ}$ & 513.94 & 20.234 & 509.04 & 20.041 & 4.90 & 0.193 \\
\hline OD $11.38,120^{\circ}$ & 526.52 & 20.729 & 511.73 & 20.147 & 14.78 & 0.582 \\
\hline OD $17.38,0^{\circ}$ & 515.70 & 20.303 & 521.36 & 20.526 & -5.66 & -0.223 \\
\hline OD $17.38,60^{\circ}$ & 516.15 & 20.321 & 521.21 & 20.520 & -5.05 & -0.199 \\
\hline OD $17.38,120^{\circ}$ & 526.59 & 20.732 & 491.67 & 19.357 & 34.92 & 1.375 \\
\hline OD 23.38, $0^{\circ}$ & 516.03 & 20.316 & 525.86 & 20.703 & -9.83 & -0.387 \\
\hline
\end{tabular}


Table E 2.2: HLV Inner Container Inspection Data

\begin{tabular}{|l|l|l|l|l|l|l|}
\hline \multirow{2}{*}{$\begin{array}{c}\text { Measurement } \\
\text { Designation }\end{array}$} & \multicolumn{2}{|c|}{ Pre-Test } & \multicolumn{2}{c|}{ Post-Test } & \multicolumn{2}{c|}{ Measurement Change } \\
\cline { 2 - 7 } & $(\mathrm{mm})$ & $(\mathrm{in})$. & $(\mathrm{mm})$ & $(\mathrm{in})$. & $(\mathrm{mm})$ & \multicolumn{1}{c|}{ (in.) } \\
\hline \hline OD 23.38, 60 & 516.61 & 20.339 & 525.88 & 20.704 & -9.27 & -0.365 \\
\hline OD 23.38, 120 & 523.27 & 20.601 & 499.29 & 19.657 & 23.98 & 0.944 \\
\hline OD 38.75, $0^{\circ}$ & 517.22 & 20.363 & 517.53 & 20.375 & -0.30 & -0.012 \\
\hline OD 38.75, 60 & 517.98 & 20.393 & 518.19 & 20.401 & -0.20 & -0.008 \\
\hline OD 38.75, 120 & 519.68 & 20.460 & 517.07 & 20.357 & 2.62 & 0.103 \\
\hline $\mathrm{L} 1,0^{\circ}$ & 987.37 & 38.873 & 986.66 & 38.845 & 0.71 & 0.028 \\
\hline $\mathrm{L} 1,60^{\circ}$ & 987.17 & 38.865 & 986.49 & 38.838 & 0.69 & 0.027 \\
\hline $\mathrm{L} 1,120^{\circ}$ & 985.88 & 38.814 & 982.90 & 38.697 & 2.97 & 0.117 \\
\hline $\mathrm{L} 1,180^{\circ}$ & 986.43 & 38.836 & 986.49 & 38.838 & -0.05 & -0.002 \\
\hline $\mathrm{L} 1,240^{\circ}$ & 986.71 & 38.847 & 986.08 & 38.822 & 0.64 & 0.025 \\
\hline $\mathrm{L} 1,300^{\circ}$ & 986.82 & 38.851 & 986.76 & 38.849 & 0.05 & 0.002 \\
\hline
\end{tabular}

Table E 2.3: HLV RV, Fore, and Aft Cover Inspection Data

\begin{tabular}{|l|c|c|c|c|c|c|}
\hline \multirow{2}{*}{$\begin{array}{c}\text { Measurement } \\
\text { Designation }\end{array}$} & \multicolumn{2}{|c|}{ Pre-Test } & \multicolumn{2}{c|}{ Post-Test } & \multicolumn{2}{c|}{ Measurement Change } \\
\cline { 2 - 7 } & $(\mathrm{mm})$ & $($ in. $)$ & $(\mathrm{mm})$ & $(\mathrm{in})$. & $(\mathrm{mm})$ & \multicolumn{1}{c|}{ (in.) } \\
\hline \hline OD A, $0^{\circ}$ & 502.29 & 19.775 & 502.87 & 19.798 & -0.58 & -0.023 \\
\hline OD A, $60^{\circ}$ & 502.34 & 19.777 & 500.48 & 19.704 & 1.85 & 0.073 \\
\hline OD A, $120^{\circ}$ & 502.21 & 19.772 & 502.97 & 19.802 & -0.76 & -0.030 \\
\hline ID B, $0^{\circ}$ & 502.87 & 19.798 & 426.54 & 16.793 & 76.33 & 3.005 \\
\hline ID B, $60^{\circ}$ & 502.89 & 19.799 & 425.45 & 16.750 & 77.44 & 3.049 \\
\hline ID B, $120^{\circ}$ & 502.89 & 19.799 & 428.09 & 16.854 & 74.80 & 2.945 \\
\hline ID C, $0^{\circ}$ & 490.60 & 19.315 & 492.07 & 19.373 & -1.47 & -0.058 \\
\hline ID C, $60^{\circ}$ & 490.30 & 19.303 & 486.64 & 19.159 & 3.66 & 0.144 \\
\hline
\end{tabular}


Table E 2.3: HLV RV, Fore, and Aft Cover Inspection Data

\begin{tabular}{|c|c|c|c|c|c|c|}
\hline \multirow{2}{*}{$\begin{array}{l}\text { Measurement } \\
\text { Designation }\end{array}$} & \multicolumn{2}{|c|}{ Pre-Test } & \multicolumn{2}{|c|}{ Post-Test } & \multicolumn{2}{|c|}{ Measurement Change } \\
\hline & $(\mathrm{mm})$ & (in.) & $(\mathrm{mm})$ & (in.) & $(\mathrm{mm})$ & (in.) \\
\hline ID C, $120^{\circ}$ & 490.86 & 19.325 & 492.56 & 19.392 & -1.70 & -0.067 \\
\hline $\mathrm{L} 2,0^{\circ}$ & 234.90 & 9.248 & 225.37 & 8.873 & 9.52 & 0.375 \\
\hline $\mathrm{L} 2,60^{\circ}$ & 235.36 & 9.266 & 226.34 & 8.911 & 9.02 & 0.355 \\
\hline $\mathrm{L} 2,120^{\circ}$ & 235.43 & 9.269 & 225.63 & 8.883 & 9.80 & 0.386 \\
\hline $\mathrm{L} 2,180^{\circ}$ & 235.31 & 9.264 & 225.86 & 8.892 & 9.45 & 0.372 \\
\hline $\mathrm{L} 2,240^{\circ}$ & 234.92 & 9.249 & 225.63 & 8.883 & 9.30 & 0.366 \\
\hline $\mathrm{L} 2,300^{\circ}$ & 234.62 & 9.237 & 224.92 & 8.855 & 9.70 & 0.382 \\
\hline $\mathrm{OD} \mathrm{B}, 0^{\circ}$ & 431.29 & 16.980 & 431.80 & 17.000 & -0.51 & -0.020 \\
\hline $\mathrm{OD} \mathrm{B}, 60^{\circ}$ & 431.67 & 16.995 & 430.15 & 16.935 & 1.52 & 0.060 \\
\hline $\mathrm{OD} \mathrm{B}, 120^{\circ}$ & 431.95 & 17.006 & 431.95 & 17.006 & 0.00 & 0.000 \\
\hline ID D, $0^{\circ}$ & 165.86 & 6.530 & 155.65 & 6.128 & 10.21 & 0.402 \\
\hline ID $D, 60^{\circ}$ & 165.86 & 6.530 & 155.70 & 6.130 & 10.16 & 0.400 \\
\hline ID D, $120^{\circ}$ & 165.86 & 6.530 & 155.70 & 6.130 & 10.16 & 0.400 \\
\hline $\mathrm{L} 1,0^{\circ}$ & 883.39 & 34.779 & 883.51 & 34.784 & -0.13 & -0.005 \\
\hline $\mathrm{L} 1,60^{\circ}$ & 883.36 & 34.778 & 883.82 & 34.796 & -0.46 & -0.018 \\
\hline $\mathrm{L} 1,120^{\circ}$ & 883.26 & 34.774 & 883.87 & 34.798 & -0.61 & -0.024 \\
\hline $\mathrm{L} 1,180^{\circ}$ & 883.28 & 34.775 & 883.64 & 34.789 & -0.36 & -0.014 \\
\hline $\mathrm{L} 1,240^{\circ}$ & 883.31 & 34.776 & 883.39 & 34.779 & -0.08 & -0.003 \\
\hline $\mathrm{L} 1,300^{\circ}$ & 883.34 & 34.777 & 883.28 & 34.775 & 0.05 & 0.002 \\
\hline OD D, $0^{\circ}$ & 171.32 & 6.745 & 171.22 & 6.741 & 0.10 & 0.004 \\
\hline $\mathrm{OD} \mathrm{D}, 60^{\circ}$ & 171.32 & 6.745 & 171.20 & 6.740 & 0.13 & 0.005 \\
\hline $\mathrm{OD} \mathrm{D}, 120^{\circ}$ & 171.32 & 6.745 & 171.22 & 6.741 & 0.10 & 0.004 \\
\hline $\mathrm{OD} \mathrm{E}, 0^{\circ}$ & 482.40 & 18.992 & 482.45 & 18.994 & -0.05 & -0.002 \\
\hline OD E, $60^{\circ}$ & 482.37 & 18.991 & 482.37 & 18.991 & 0.00 & 0.000 \\
\hline
\end{tabular}


Table E 2.3: HLV RV, Fore, and Aft Cover Inspection Data

\begin{tabular}{|c|c|c|c|c|c|c|}
\hline \multirow{2}{*}{$\begin{array}{c}\text { Measurement } \\
\text { Designation }\end{array}$} & \multicolumn{2}{|c|}{ Pre-Test } & \multicolumn{2}{c|}{ Post-Test } & \multicolumn{2}{c|}{ Measurement Change } \\
\cline { 2 - 7 } & $(\mathrm{mm})$ & (in.) & $(\mathrm{mm})$ & (in.) & $(\mathrm{mm})$ & (in.) \\
\hline \hline OD E, $120^{\circ}$ & 482.40 & 18.992 & 482.40 & 18.992 & 0.00 & 0.000 \\
\hline
\end{tabular}

Table E 3.1: LHV H1224A Container Body Inspection Data

\begin{tabular}{|c|c|c|c|c|c|c|}
\hline \multirow{2}{*}{$\begin{array}{l}\text { Measurement } \\
\text { Designation }\end{array}$} & \multicolumn{2}{|c|}{ Pre-Test } & \multicolumn{2}{|c|}{ Post-Test } & \multicolumn{2}{|c|}{ Measurement Change } \\
\hline & $(\mathrm{mm})$ & (in.) & $(\mathrm{mm})$ & (in.) & $(\mathrm{mm})$ & (in.) \\
\hline $\mathrm{OD} 0,0^{\circ}$ & 821.69 & 32.350 & 820.70 & 32.311 & 0.99 & 0.039 \\
\hline $\mathrm{OD} 0,45^{\circ}$ & 820.95 & 32.321 & 819.56 & 32.266 & 1.40 & 0.055 \\
\hline OD $0,90^{\circ}$ & 821.11 & 32.327 & 819.86 & 32.278 & 1.24 & 0.049 \\
\hline $\mathrm{OD} 0,135^{\circ}$ & 821.28 & 32.334 & 818.16 & 32.211 & 3.12 & 0.123 \\
\hline OD $1,0^{\circ}$ & 822.30 & 32.374 & 821.72 & 32.351 & 0.58 & 0.023 \\
\hline OD $1,45^{\circ}$ & 821.54 & 32.344 & 819.81 & 32.276 & 1.73 & 0.068 \\
\hline OD $1,90^{\circ}$ & 822.88 & 32.397 & 821.66 & 32.349 & 1.22 & 0.048 \\
\hline OD $1,135^{\circ}$ & 821.84 & 32.356 & 815.34 & 32.100 & 6.50 & 0.256 \\
\hline $\mathrm{OD} 20,0^{\circ}$ & 819.20 & 32.252 & 831.14 & 32.722 & -11.94 & -0.470 \\
\hline OD $20,45^{\circ}$ & 819.45 & 32.262 & 802.26 & 31.585 & 17.20 & 0.677 \\
\hline OD $20,90^{\circ}$ & 821.87 & 32.357 & 831.85 & 32.750 & -9.98 & -0.393 \\
\hline OD $20,135^{\circ}$ & 819.05 & 32.246 & 807.62 & 31.796 & 11.43 & 0.450 \\
\hline OD $21,0^{\circ}$ & 843.43 & 33.206 & 860.76 & 33.888 & -17.32 & -0.682 \\
\hline OD $21,45^{\circ}$ & 843.81 & 33.221 & 836.68 & 32.940 & 7.14 & 0.281 \\
\hline OD $21,90^{\circ}$ & 845.36 & 33.282 & 836.42 & 32.930 & 8.94 & 0.352 \\
\hline OD $21,135^{\circ}$ & 843.13 & 33.194 & 813.69 & 32.035 & 29.44 & 1.159 \\
\hline OD $22,0^{\circ}$ & 819.20 & 32.252 & 827.71 & 32.587 & -8.51 & -0.335 \\
\hline OD $22,45^{\circ}$ & 818.97 & 32.243 & 802.87 & 31.609 & 16.10 & 0.634 \\
\hline
\end{tabular}


Table E 3.1: LHV H1224A Container Body Inspection Data

\begin{tabular}{|c|c|c|c|c|c|c|}
\hline \multirow{2}{*}{$\begin{array}{l}\text { Measurement } \\
\text { Designation }\end{array}$} & \multicolumn{2}{|c|}{ Pre-Test } & \multicolumn{2}{|c|}{ Post-Test } & \multicolumn{2}{|c|}{ Measurement Change } \\
\hline & $(\mathrm{mm})$ & (in.) & $(\mathrm{mm})$ & (in.) & $(\mathrm{mm})$ & (in.) \\
\hline OD $22,90^{\circ}$ & 819.99 & 32.283 & 830.61 & 32.701 & -10.62 & -0.418 \\
\hline OD $22,135^{\circ}$ & 818.18 & 32.212 & 803.99 & 31.653 & 14.20 & 0.559 \\
\hline $\mathrm{OD} 24,0^{\circ}$ & 821.82 & 32.355 & 826.19 & 32.527 & -4.37 & -0.172 \\
\hline OD $24,45^{\circ}$ & 822.43 & 32.379 & 812.24 & 31.978 & 10.19 & 0.401 \\
\hline OD $24,90^{\circ}$ & 823.16 & 32.408 & 828.29 & 32.610 & -5.13 & -0.202 \\
\hline OD $24,135^{\circ}$ & 821.99 & 32.362 & 816.15 & 32.132 & 5.84 & 0.230 \\
\hline OD $25,0^{\circ}$ & 821.79 & 32.354 & 823.65 & 32.427 & -1.85 & -0.073 \\
\hline OD $25,45^{\circ}$ & 822.53 & 32.383 & 814.20 & 32.055 & 8.33 & 0.328 \\
\hline OD $25,90^{\circ}$ & 822.96 & 32.400 & 825.70 & 32.508 & -2.74 & -0.108 \\
\hline OD $25,135^{\circ}$ & 822.10 & 32.366 & 818.29 & 32.216 & 3.81 & 0.150 \\
\hline OD $26,0^{\circ}$ & 910.74 & 35.856 & 912.67 & 35.932 & -1.93 & -0.076 \\
\hline OD $26,45^{\circ}$ & 911.96 & 35.904 & 913.56 & 35.967 & -1.60 & -0.063 \\
\hline OD $26,90^{\circ}$ & 909.40 & 35.803 & 911.00 & 35.866 & -1.60 & -0.063 \\
\hline OD $26,135^{\circ}$ & 909.45 & 35.805 & 903.76 & 35.581 & 5.69 & 0.224 \\
\hline OD $27,0^{\circ}$ & 820.67 & 32.310 & 818.11 & 32.209 & 2.57 & 0.101 \\
\hline OD $27,45^{\circ}$ & 822.96 & 32.400 & 825.35 & 32.494 & -2.39 & -0.094 \\
\hline OD $27,90^{\circ}$ & 819.28 & 32.255 & 815.92 & 32.123 & 3.35 & 0.132 \\
\hline OD $27,135^{\circ}$ & 819.56 & 32.266 & 815.67 & 32.113 & 3.89 & 0.153 \\
\hline OD $28,0^{\circ}$ & 810.79 & 31.921 & 805.48 & 31.712 & 5.31 & 0.209 \\
\hline OD $28,45^{\circ}$ & 81.5 .09 & 32.090 & 820.17 & 32.290 & -5.08 & -0.200 \\
\hline OD $28,90^{\circ}$ & 810.26 & 31.900 & 803.91 & 31.650 & 6.35 & 0.250 \\
\hline OD $28,135^{\circ}$ & 810.64 & 31.915 & 809.07 & 31.853 & 1.57 & 0.062 \\
\hline OD $37.75,0^{\circ}$ & 809.37 & 31.865 & 752.47 & 29.625 & 56.90 & 2.240 \\
\hline OD $37.75,45^{\circ}$ & 815.11 & 32.091 & 843.38 & 33.204 & -28.27 & -1.113 \\
\hline
\end{tabular}


Table E 3.1: LHV H1224A Container Body Inspection Data

\begin{tabular}{|c|c|c|c|c|c|c|}
\hline \multirow{2}{*}{$\begin{array}{l}\text { Measurement } \\
\text { Designation }\end{array}$} & \multicolumn{2}{|c|}{ Pre-Test } & \multicolumn{2}{|c|}{ Post-Test } & \multicolumn{2}{|c|}{ Measurement Change } \\
\hline & $(\mathrm{mm})$ & (in.) & $(\mathrm{mm})$ & (in.) & $(\mathrm{mm})$ & (in.) \\
\hline OD $37.75,90^{\circ}$ & 806.83 & 31.765 & 763.47 & 30.058 & 43.36 & 1.707 \\
\hline OD $37.75,135^{\circ}$ & 812.62 & 31.993 & 835.79 & 32.905 & -23.16 & -0.912 \\
\hline OD $38.75,0^{\circ}$ & 807.06 & 31.774 & 752.40 & 29.622 & 54.66 & 2.152 \\
\hline OD $38.75,45^{\circ}$ & 813.00 & 32.008 & 837.74 & 32.982 & -24.74 & -0.974 \\
\hline OD $38.75,90^{\circ}$ & 803.73 & 31.643 & 759.56 & 29.904 & 44.17 & 1.739 \\
\hline OD $38.75,135^{\circ}$ & 810.54 & 31.911 & 832.28 & 32.767 & -21.74 & -0.856 \\
\hline OD $39.75,0^{\circ}$ & 830.86 & 32.711 & 819.33 & 32.257 & 11.53 & 0.454 \\
\hline OD $39.75,45^{\circ}$ & 836.47 & 32.932 & 874.27 & 34.420 & -37.80 & -1.488 \\
\hline OD $39.75,90^{\circ}$ & 827.43 & 32.576 & 785.44 & 30.923 & 41.99 & 1.653 \\
\hline OD $39.75,135^{\circ}$ & 834.59 & 32.858 & 879.53 & 34.627 & -44.93 & -1.769 \\
\hline $\mathrm{OD} 40.75,0^{\circ}$ & 806.73 & 31.761 & 780.41 & 30.725 & 26.31 & 1.036 \\
\hline OD $40.75,45^{\circ}$ & 812.75 & 31.998 & 805.43 & 31.710 & 7.32 & 0.288 \\
\hline OD $40.75,90^{\circ}$ & 802.03 & 31.576 & 697.23 & 27.450 & 104.80 & 4.126 \\
\hline $\mathrm{OD} 40.75,135^{\circ}$ & 811.73 & 31.958 & 829.26 & 32.648 & -17.53 & -0.690 \\
\hline OD $41.75,0^{\circ}$ & 807.97 & 31.810 & 793.80 & 31.252 & 14.17 & 0.558 \\
\hline OD $41.75,45^{\circ}$ & 814.71 & 32.075 & 819.53 & 32.265 & -4.83 & -0.190 \\
\hline OD $41.75,90^{\circ}$ & 803.78 & 31.645 & 704.09 & 27.720 & 99.69 & 3.925 \\
\hline OD $41.75,135^{\circ}$ & 814.17 & 32.054 & 835.94 & 32.911 & -21.77 & -0.857 \\
\hline OD $50.5,0^{\circ}$ & 811.83 & 31.962 & 809.27 & 31.861 & 2.57 & 0.101 \\
\hline OD $50.5,45^{\circ}$ & 813.84 & 32.041 & 818.79 & 32.236 & -4.95 & -0.195 \\
\hline OD $50.5,90^{\circ}$ & 808.10 & 31.815 & 780.54 & 30.730 & 27.56 & 1.085 \\
\hline OD $50.5,135^{\circ}$ & 813.38 & 32.023 & 813.74 & 32.037 & -0.36 & -0.014 \\
\hline OD $51.5,0^{\circ}$ & 815.57 & 32.109 & 814.53 & 32.068 & 1.04 & 0.041 \\
\hline OD $51.5,45^{\circ}$ & 817.17 & 32.172 & 815.95 & 32.124 & 1.22 & 0.048 \\
\hline
\end{tabular}


Table E 3.1: LHV H1224A Container Body Inspection Data

\begin{tabular}{|c|c|c|c|c|c|c|}
\hline \multirow{2}{*}{$\begin{array}{l}\text { Measurement } \\
\text { Designation }\end{array}$} & \multicolumn{2}{|c|}{ Pre-Test } & \multicolumn{2}{|c|}{ Post-Test } & \multicolumn{2}{|c|}{ Measurement Change } \\
\hline & $(\mathrm{mm})$ & (in.) & $(\mathrm{mm})$ & (in.) & $(\mathrm{mm})$ & (in.) \\
\hline OD $51.5,90^{\circ}$ & 813.74 & 32.037 & 813.31 & 32.020 & 0.43 & 0.017 \\
\hline OD $51.5,135^{\circ}$ & 817.40 & 32.181 & 818.39 & 32.220 & -0.99 & -0.039 \\
\hline OD $52.5,0^{\circ}$ & 816.15 & 32.132 & 815.70 & 32.114 & 0.46 & 0.018 \\
\hline OD $52.5,45^{\circ}$ & 829.69 & 32.665 & 814.17 & 32.054 & 15.52 & 0.611 \\
\hline OD $52.5,90^{\circ}$ & 816.61 & 32.150 & 830.50 & 32.697 & -13.89 & -0.547 \\
\hline OD $52.5,135^{\circ}$ & 817.98 & 32.204 & 812.04 & 31.970 & 5.94 & 0.234 \\
\hline $\mathrm{L} 1,0^{\circ}$ & 1454.76 & 57.274 & 1314.20 & 51.740 & 140.56 & 5.534 \\
\hline $\mathrm{L} 1,45^{\circ}$ & 1455.45 & 57.301 & 1326.39 & 52.220 & 129.06 & 5.081 \\
\hline $\mathrm{L} 1,90^{\circ}$ & 1454.12 & 57.249 & 1322.96 & 52.085 & 131.17 & 5.164 \\
\hline $\mathrm{L} 1,135^{\circ}$ & 1455.65 & 57.309 & 1303.96 & 51.337 & 151.69 & 5.972 \\
\hline $\mathrm{L} 1,180^{\circ}$ & 1455.24 & 57.293 & 1286.31 & 50.642 & 168.94 & 6.651 \\
\hline $\mathrm{L} 1,225^{\circ}$ & 1456.56 & 57.345 & 1274.95 & 50.195 & 181.61 & 7.150 \\
\hline $\mathrm{L} 1,270^{\circ}$ & 1455.85 & 57.317 & 1277.82 & 50.308 & 178.03 & 7.009 \\
\hline $\mathrm{L} 1,315^{\circ}$ & 1455.85 & 57.317 & 1294.77 & 50.975 & 161.09 & 6.342 \\
\hline $\mathrm{L} 2,0^{\circ}$ & 1340.38 & 52.771 & $*$ & * & N/A & N/A \\
\hline $\mathrm{L} 2,45^{\circ}$ & 1340.43 & 52.773 & * & $*$ & N/A & N/A \\
\hline $\mathrm{L} 2,90^{\circ}$ & 1339.21 & 52.725 & $*$ & $*$ & N/A & N/A \\
\hline $\mathrm{L} 2,135^{\circ}$ & 1340.28 & 52.767 & * & $*$ & N/A & N/A \\
\hline $\mathrm{L} 2,180^{\circ}$ & 1340.21 & 52.764 & * & * & N/A & N/A \\
\hline $\mathrm{L} 2,225^{\circ}$ & 1339.80 & 52.748 & $*$ & $*$ & N/A & N/A \\
\hline $\mathrm{L} 2,270^{\circ}$ & 1339.34 & 52.730 & * & * & N/A & N/A \\
\hline $\mathrm{L} 2,315^{\mathrm{c}}$ & 1339.27 & 52.727 & $*$ & $*$ & N/A & N/A \\
\hline
\end{tabular}

* Part destroyed during test and measurement not possible. 
Table E 3.2: LHV Inner Container Inspection Data

\begin{tabular}{|c|c|c|c|c|c|c|}
\hline \multirow{2}{*}{$\begin{array}{c}\text { Measurement } \\
\text { Designation }\end{array}$} & \multicolumn{2}{|c|}{ Pre-Test } & \multicolumn{2}{|c|}{ Post-Test } & \multicolumn{2}{|c|}{ Measurement Change } \\
\hline & $(\mathrm{mm})$ & (in.) & $(\mathrm{mm})$ & (in.) & $(\mathrm{mm})$ & (in.) \\
\hline $\mathrm{OD} 0,0^{\circ}$ & 520.47 & 20.491 & 528.68 & 20.814 & -8.20 & -0.323 \\
\hline OD $0,60^{\circ}$ & 517.50 & 20.374 & 514.48 & 20.255 & 3.02 & 0.119 \\
\hline OD $0,120^{\circ}$ & 516.81 & 20.347 & 508.48 & 20.019 & 8.33 & 0.328 \\
\hline OD $11.38,0^{\circ}$ & 518.90 & 20.429 & 492.02 & 19.371 & 26.87 & 1.058 \\
\hline OD $11.38,60^{\circ}$ & 517.68 & 20.381 & 521.64 & 20.537 & -3.96 & -0.156 \\
\hline OD $11.38,120^{\circ}$ & 517.42 & 20.371 & 532.13 & 20.950 & -14.71 & -0.579 \\
\hline OD $17.38,0^{\circ}$ & 520.17 & 20.479 & 449.71 & 17.705 & 70.46 & 2.774 \\
\hline OD $17.38,60^{\circ}$ & 518.13 & 20.399 & 673.35 & 26.510 & -155.22 & -6.111 \\
\hline OD $17.38,120^{\circ}$ & 517.98 & 20.393 & 712.47 & 28.050 & -194.49 & -7.657 \\
\hline OD $23.38,0^{\circ}$ & 519.68 & 20.460 & 588.21 & 23.158 & -68.53 & -2.698 \\
\hline OD $23.38,60^{\circ}$ & 517.45 & 20.372 & 477.52 & 18.800 & 39.93 & 1.572 \\
\hline OD $23.38,120^{\circ}$ & 517.60 & 20.378 & 479.96 & 18.896 & 37.64 & 1.482 \\
\hline OD $38.75,0^{\circ}$ & 519.48 & 20.452 & 531.22 & 20.914 & -11.73 & -0.462 \\
\hline OD $38.75,60^{\circ}$ & 517.14 & 20.360 & 514.73 & 20.265 & 2.41 & 0.095 \\
\hline OD $38.75,120^{\circ}$ & 517.78 & 20.385 & 509.52 & 20.060 & 8.26 & 0.325 \\
\hline $\mathrm{L} 1,0^{\circ}$ & 987.42 & 38.875 & 896.52 & 35.296 & 90.91 & 3.579 \\
\hline $\mathrm{L} 1,60^{\circ}$ & 987.93 & 38.895 & 879.91 & 34.642 & 108.03 & 4.253 \\
\hline $\mathrm{L} 1,120^{\circ}$ & 988.14 & 38.903 & 842.09 & 33.153 & 146.05 & 5.750 \\
\hline $\mathrm{L} 1,180^{\circ}$ & 987.12 & 38.863 & 814.65 & 32.073 & 172.47 & 6.790 \\
\hline $\mathrm{L} 1,240^{\circ}$ & 986.92 & 38.855 & 821.59 & 32.346 & 165.33 & 6.509 \\
\hline $\mathrm{L} 1,300^{\circ}$ & 986.97 & 38.857 & 873.30 & 34.382 & 113.67 & 4.475 \\
\hline
\end{tabular}


Table E 3.3: LHV RV, Fore, and Aft Cover Inspection Data

\begin{tabular}{|c|c|c|c|c|c|c|}
\hline \multirow{2}{*}{$\begin{array}{l}\text { Measurement } \\
\text { Designation }\end{array}$} & \multicolumn{2}{|c|}{ Pre-Test } & \multicolumn{2}{|c|}{ Post-Test } & \multicolumn{2}{|c|}{ Measurement Change } \\
\hline & $(\mathrm{mm})$ & (in.) & $(\mathrm{mm})$ & (in.) & $(\mathrm{mm})$ & (in.) \\
\hline$\overline{\mathrm{OD} \mathrm{A}}, 0^{\circ}$ & 500.68 & 19.712 & 500.63 & 19.710 & 0.05 & 0.002 \\
\hline $\mathrm{OD} \mathrm{A}, 60^{\circ}$ & 500.63 & 19.710 & 500.91 & 19.721 & -0.28 & -0.011 \\
\hline $\mathrm{OD} \mathrm{A}, 120^{\circ}$ & 500.89 & 19.720 & 500.94 & 19.722 & -0.05 & -0.002 \\
\hline ID B, $0^{\circ}$ & 426.59 & 16.795 & 426.47 & 16.790 & 0.13 & 0.005 \\
\hline $\mathrm{ID} \mathrm{B}, 60^{\circ}$ & 426.39 & 16.787 & 426.67 & 16.798 & -0.28 & -0.011 \\
\hline $\mathrm{ID} \mathrm{B}, 120^{\circ}$ & 426.72 & 16.800 & 426.59 & 16.795 & 0.13 & 0.005 \\
\hline ID C, $0^{\circ}$ & 490.55 & 19.313 & 490.27 & 19.302 & 0.28 & 0.011 \\
\hline $\mathrm{D} \mathrm{C}, 60^{\circ}$ & 491.08 & 19.334 & 491.13 & 19.336 & -0.05 & -0.002 \\
\hline ID C, $120^{\circ}$ & 491.21 & 19.339 & 490.86 & 19.325 & 0.36 & 0.014 \\
\hline $\mathrm{L} 2,0^{\circ}$ & 236.19 & 9.299 & 234.39 & 9.228 & 1.80 & 0.071 \\
\hline $\mathrm{L} 2,60^{\circ}$ & 236.02 & 9.292 & 235.99 & 9.291 & 0.03 & 0.001 \\
\hline $\mathrm{L} 2,120^{\circ}$ & 235.79 & 9.283 & 235.89 & 9.287 & -0.10 & -0.004 \\
\hline $\mathrm{L} 2,180^{\circ}$ & 235.74 & 9.281 & 234.29 & 9.224 & 1.45 & 0.057 \\
\hline $\mathrm{L} 2,240^{\circ}$ & 235.76 & 9.282 & 232.59 & 9.157 & 3.17 & 0.125 \\
\hline $\mathrm{L} 2,300^{\circ}$ & 235.89 & 9.287 & 232.56 & 9.156 & 3.33 & 0.131 \\
\hline $\mathrm{OD} \mathrm{B}, 0^{\circ}$ & 431.50 & 16.988 & 431.83 & 17.001 & -0.33 & -0.013 \\
\hline $\mathrm{OD} \mathrm{B}, 60^{\circ}$ & 431.65 & 16.994 & 431.47 & 16.987 & 0.18 & 0.007 \\
\hline $\mathrm{OD} \mathrm{B}, 120^{\circ}$ & 431.62 & 16.993 & 431.80 & 17.000 & -0.18 & -0.007 \\
\hline $\mathrm{ID} \mathrm{D}, 0^{\circ}$ & 165.71 & 6.524 & * & $*$ & N/A & N/A \\
\hline $\mathrm{ID} \mathrm{D}, 60^{\circ}$ & 165.79 & 6.527 & $*$ & $*$ & N/A & N/A \\
\hline $\mathrm{ID} \mathrm{D}, 120^{\circ}$ & 165.76 & 6.526 & $*$ & $*$ & N/A & N/A \\
\hline $\mathrm{L} 1,0^{\circ}$ & 840.92 & 33.107 & $*$ & $*$ & N/A & N/A \\
\hline $\mathrm{L} 1,60^{\circ}$ & 840.89 & 33.106 & * & * & N/A & N/A \\
\hline
\end{tabular}


Table E 3.3: LHV RV, Fore, and Aft Cover Inspection Data

\begin{tabular}{|l|l|l|l|l|l|l|}
\hline \multirow{2}{*}{$\begin{array}{c}\text { Measurement } \\
\text { Designation }\end{array}$} & \multicolumn{2}{|c|}{ Pre-Test } & \multicolumn{2}{c|}{ Post-Test } & \multicolumn{2}{c|}{ Measurement Change } \\
\cline { 2 - 7 } & $(\mathrm{mm})$ & (in.) & \multicolumn{1}{c|}{$(\mathrm{mm})$} & (in.) & \multicolumn{1}{c|}{$(\mathrm{mm})$} & \multicolumn{1}{c|}{ (in.) } \\
\hline \hline $\mathrm{L} 1,120^{\circ}$ & 840.92 & 33.107 & $*$ & $*$ & N/A & N/A \\
\hline $\mathrm{L} 1,180^{\circ}$ & 840.94 & 33.108 & $*$ & $*$ & N/A & N/A \\
\hline $\mathrm{L} 1,240^{\circ}$ & 840.94 & 33.108 & $*$ & $*$ & N/A & N/A \\
\hline L1, $300^{\circ}$ & 840.92 & 33.107 & $*$ & $*$ & N/A & N/A \\
\hline OD D, $0^{\circ}$ & 171.30 & 6.744 & 173.33 & 6.824 & -2.03 & -0.080 \\
\hline OD D, $60^{\circ}$ & 171.27 & 6.743 & 171.81 & 6.764 & -0.53 & -0.021 \\
\hline OD D, $120^{\circ}$ & 171.25 & 6.742 & 171.96 & 6.770 & -0.71 & -0.028 \\
\hline OD E, $0^{\circ}$ & 482.60 & 19.000 & 499.44 & 19.663 & -16.84 & -0.663 \\
\hline OD E, $60^{\circ}$ & 481.41 & 18.953 & 442.57 & 17.424 & 38.84 & 1.529 \\
\hline OD E, $120^{\circ}$ & 481.51 & 18.957 & 465.79 & 18.338 & 15.72 & 0.619 \\
\hline
\end{tabular}

* Part destroyed during test and measurement not possible.

Table E 4.1: HHV H1224A Container Body Inspection Data

\begin{tabular}{|c|c|c|c|c|c|c|}
\hline \multirow{2}{*}{$\begin{array}{l}\text { Measurement } \\
\text { Designation }\end{array}$} & \multicolumn{2}{|c|}{ Pre-Test } & \multicolumn{2}{|c|}{ Post-Test } & \multicolumn{2}{|c|}{ Measurement Change } \\
\hline & $(\mathrm{mm})$ & (in.) & $(\mathrm{mm})$ & (in.) & $(\mathrm{mm})$ & (in.) \\
\hline $\mathrm{OD} 0,0^{\circ}$ & 822.63 & 32.387 & 786.33 & 30.958 & 36.30 & 1.429 \\
\hline $\mathrm{OD} 0,45^{\circ}$ & 824.18 & 32.448 & 842.01 & 33.150 & -17.83 & -0.702 \\
\hline OD $0,90^{\circ}$ & 821.64 & 32.348 & 818.13 & 32.210 & 3.51 & 0.138 \\
\hline $\mathrm{OD} 0,135^{\circ}$ & 823.19 & 32.409 & 815.04 & 32.088 & 8.15 & 0.321 \\
\hline OD $1,0^{\circ}$ & 825.70 & 32.508 & 780.36 & 30.723 & 45.34 & 1.785 \\
\hline OD $1,45^{\circ}$ & 826.82 & 32.552 & 838.48 & 33.011 & -11.66 & -0.459 \\
\hline OD $1,90^{\circ}$ & 823.70 & 32.429 & 822.99 & 32.401 & 0.71 & 0.028 \\
\hline OD $1,135^{\circ}$ & 823.06 & 32.404 & 809.14 & 31.856 & 13.92 & 0.548 \\
\hline
\end{tabular}


Table E 4.1: HHV H1224A Container Body Inspection Data

\begin{tabular}{|c|c|c|c|c|c|c|}
\hline \multirow{2}{*}{$\begin{array}{l}\text { Measurement } \\
\text { Designation }\end{array}$} & \multicolumn{2}{|c|}{ Pre-Test } & \multicolumn{2}{|c|}{ Post-Test } & \multicolumn{2}{|c|}{ Measurement Change } \\
\hline & $(\mathrm{mm})$ & (in.) & $(\mathrm{mm})$ & (in.) & $(\mathrm{mm})$ & (in.) \\
\hline OD $20,0^{\circ}$ & 823.87 & 32.436 & 650.70 & 25.618 & 173.18 & 6.818 \\
\hline OD $20,45^{\circ}$ & 825.68 & 32.507 & 820.93 & 32.320 & 4.75 & 0.187 \\
\hline OD $20,90^{\circ}$ & 823.24 & 32.411 & 945.21 & 37.213 & -121.97 & -4.802 \\
\hline OD $20,135^{\circ}$ & 822.02 & 32.363 & 797.64 & 31.403 & 24.38 & 0.960 \\
\hline OD $21,0^{\circ}$ & 856.56 & 33.723 & 676.50 & 26.634 & 180.06 & 7.089 \\
\hline OD $21,45^{\circ}$ & 858.27 & 33.790 & 858.24 & 33.789 & 0.03 & 0.001 \\
\hline OD $21,90^{\circ}$ & 854.74 & 33.651 & 981.89 & 38.657 & -127.15 & -5.006 \\
\hline OD $21,135^{\circ}$ & 853.74 & 33.612 & 825.58 & 32.503 & 28.17 & 1.109 \\
\hline OD $22,0^{\circ}$ & 824.31 & 32.453 & 629.72 & 24.792 & 194.59 & 7.661 \\
\hline OD $22,45^{\circ}$ & 827.00 & 32.559 & 813.89 & 32.043 & 13.11 & 0.516 \\
\hline OD $22,90^{\circ}$ & 823.93 & 32.438 & 965.76 & 38.022 & -141.83 & -5.584 \\
\hline OD $22,135^{\circ}$ & 822.66 & 32.388 & 791.92 & 31.178 & 30.73 & 1.210 \\
\hline OD $24,0^{\circ}$ & 823.21 & 32.410 & 614.12 & 24.178 & 209.09 & 8.232 \\
\hline OD $24,45^{\circ}$ & 826.26 & 32.530 & 807.59 & 31.795 & 18.67 & 0.735 \\
\hline OD $24,90^{\circ}$ & 823.24 & 32.411 & 982.09 & 38.665 & -158.85 & -6.254 \\
\hline OD $24,135^{\circ}$ & 822.53 & 32.383 & 782.70 & 30.815 & 39.83 & 1.568 \\
\hline OD $25,0^{\circ}$ & 822.96 & 32.400 & 597.61 & 23.528 & 225.35 & 8.872 \\
\hline OD $25,45^{\circ}$ & 825.45 & 32.498 & 798.78 & 31.448 & 26.67 & 1.050 \\
\hline OD $25,90^{\circ}$ & 822.33 & 32.375 & 980.03 & 38.584 & -157.71 & -6.209 \\
\hline OD $25,135^{\circ}$ & 822.07 & 32.365 & 779.42 & 30.686 & 42.65 & 1.679 \\
\hline OD $26,0^{\circ}$ & 908.51 & 35.768 & 682.96 & 26.888 & 225.55 & 8.880 \\
\hline OD $26,45^{\circ}$ & 910.44 & 35.844 & 782.70 & 30.815 & 127.74 & 5.029 \\
\hline OD $26,90^{\circ}$ & 909.78 & 35.818 & 1059.05 & 41.695 & -149.28 & -5.877 \\
\hline OD $26,135^{\circ}$ & 907.49 & 35.728 & 907.03 & 35.710 & 0.46 & 0.018 \\
\hline
\end{tabular}


Table E 4.1: HHV H1224A Container Body Inspection Data

\begin{tabular}{|c|c|c|c|c|c|c|}
\hline \multirow{2}{*}{$\begin{array}{l}\text { Measurement } \\
\text { Designation }\end{array}$} & \multicolumn{2}{|c|}{ Pre-Test } & \multicolumn{2}{|c|}{ Post-Test } & \multicolumn{2}{|c|}{ Measurement Change } \\
\hline & $(\mathrm{mm})$ & (in.) & $(\mathrm{mm})$ & (in.) & $(\mathrm{mm})$ & (in.) \\
\hline OD $27,0^{\circ}$ & 819.81 & 32.276 & 585.09 & 23.035 & 234.72 & 9.241 \\
\hline OD $27,45^{\circ}$ & 821.87 & 32.357 & 747.67 & 29.436 & 74.19 & 2.921 \\
\hline OD $27,90^{\circ}$ & 820.55 & 32.305 & 978.53 & 38.525 & -157.99 & -6.220 \\
\hline OD $27,135^{\circ}$ & 818.54 & 32.226 & 828.42 & 32.615 & -9.88 & -0.389 \\
\hline OD $28,0^{\circ}$ & 810.39 & 31.905 & 591.41 & 23.284 & 218.97 & 8.621 \\
\hline OD $28,45^{\circ}$ & 813.51 & 32.028 & 745.95 & 29.368 & 67.56 & 2.660 \\
\hline OD $28,90^{\circ}$ & 810.92 & 31.926 & 968.32 & 38.123 & -157.40 & -6.197 \\
\hline OD $28,135^{\circ}$ & 814.22 & 32.056 & 818.59 & 32.228 & -4.37 & -0.172 \\
\hline OL $37.75,0^{\circ}$ & 809.60 & 31.874 & 634.90 & 24.996 & 174.70 & 6.878 \\
\hline OD $37.75,45^{\circ}$ & 811.68 & 31.956 & 775.28 & 30.523 & 36.40 & 1.433 \\
\hline OD $37.75,90^{\circ}$ & 806.86 & 31.766 & 951.56 & 37.463 & -144.70 & -5.697 \\
\hline OD $37.75,135^{\circ}$ & 816.89 & 32.161 & 809.83 & 31.883 & 7.06 & 0.278 \\
\hline OD $38.75,0^{\circ}$ & 808.05 & 31.813 & 634.52 & 24.981 & 173.53 & 6.832 \\
\hline OD $38.75,45^{\circ}$ & 808.43 & 31.828 & 775.67 & 30.538 & 32.77 & 1.290 \\
\hline OD $38.75,90^{\circ}$ & 804.24 & 31.663 & 947.62 & 37.308 & -143.38 & -5.645 \\
\hline OD $38.75,135^{\circ}$ & 816.33 & 32.139 & 806.15 & 31.738 & 10.19 & 0.401 \\
\hline OD $39.75,0^{\circ}$ & 833.27 & 32.806 & 649.63 & 25.576 & 183.64 & 7.230 \\
\hline OD $39.75,45^{\circ}$ & 832.36 & 32.770 & 798.53 & 31.438 & 33.83 & 1.332 \\
\hline OD $39.75,90^{\circ}$ & 829.23 & 32.647 & 961.97 & 37.873 & -132.74 & -5.226 \\
\hline OD $39.75,135^{\circ}$ & 833.70 & 32.823 & 834.59 & 32.858 & -0.89 & -0.035 \\
\hline OD $40.75,0^{\circ}$ & 309.02 & 31.851 & 641.25 & 25.246 & 167.77 & 6.605 \\
\hline OD $40.75,45^{\circ}$ & 809.57 & 31.873 & 787.10 & 30.988 & 22.48 & 0.885 \\
\hline OD $40.75,90^{\circ}$ & 803.22 & 31.623 & 938.48 & 36.948 & -135.26 & -5.325 \\
\hline OD $40.75,135^{\circ}$ & 816.81 & 32.158 & 806.78 & 31.763 & 10.03 & 0.395 \\
\hline
\end{tabular}


Table E 4.1: HHV H1224A Container Body Inspection Data

\begin{tabular}{|c|c|c|c|c|c|c|}
\hline \multirow{2}{*}{$\begin{array}{l}\text { Measurement } \\
\text { Designation }\end{array}$} & \multicolumn{2}{|c|}{ Pre-Test } & \multicolumn{2}{|c|}{ Post-Test } & \multicolumn{2}{|c|}{ Measurement Change } \\
\hline & $(\mathrm{mm})$ & (in.) & $(\mathrm{mm})$ & (in.) & $(\mathrm{mm})$ & (in.) \\
\hline OD $41.75,0^{\circ}$ & 810.77 & 31.920 & 644.80 & 25.386 & 165.96 & 6.534 \\
\hline OD $41.75,45^{\circ}$ & 812.24 & 31.978 & 791.54 & 31.163 & 20.70 & 0.815 \\
\hline OD $41.75,90^{\circ}$ & 805.51 & 31.713 & 935.94 & 36.848 & -130.43 & -5.135 \\
\hline OD $41.75,135^{\circ}$ & 818.24 & 32.214 & 808.69 & 31.838 & 9.55 & 0.376 \\
\hline OD $50.5,0^{\circ}$ & 811.61 & 31.953 & 614.32 & 24.186 & 197.28 & 7.767 \\
\hline OD $50.5,45^{\circ}$ & 812.42 & 31.985 & 809.96 & 31.888 & 2.46 & 0.097 \\
\hline OD $50.5,90^{\circ}$ & 807.82 & 31.804 & 851.87 & 33.538 & -44.04 & -1.734 \\
\hline OD $50.5,135^{\circ}$ & 817.24 & 32.175 & 806.70 & 31.760 & 10.54 & 0.415 \\
\hline OD $51.5,0^{\circ}$ & 816.13 & 32.131 & 762.00 & 30.000 & 54.13 & 2.131 \\
\hline OD $51.5,45^{\circ}$ & 817.17 & 32.172 & * & * & N/A & N/A \\
\hline OD $51.5,90^{\circ}$ & 815.01 & 32.087 & 833.45 & 32.813 & -18.44 & -0.726 \\
\hline OD $51.5,135^{\circ}$ & 825.32 & 32.493 & * & * & N/A & N/A \\
\hline OD $52.5,0^{\circ}$ & 816.66 & 32.152 & 764.54 & 30.100 & 52.12 & 2.052 \\
\hline OD $52.5,45^{\circ}$ & 831.09 & 32.720 & * & * & N/A & N/A \\
\hline OD $52.5,90^{\circ}$ & 817.91 & 32.201 & 828.04 & 32.600 & -10.13 & -0.399 \\
\hline OD $52.5,135^{\circ}$ & 825.32 & 32.493 & * & * & N/A & N/A \\
\hline $\mathrm{L} 1,0^{\circ}$ & 1458.04 & 57.403 & $*$ & $*$ & N/A & N/A \\
\hline $\mathrm{L} 1,45^{\circ}$ & 1454.76 & 57.274 & * & * & N/A & N/A \\
\hline $\mathrm{L} 1,90^{\circ}$ & 1454.89 & 57.279 & $*$ & $*$ & N/A & N/A \\
\hline $\mathrm{L} 1,135^{\circ}$ & 1456.18 & 57.330 & $*$ & * & $\mathrm{N} / \mathrm{A}$ & N/A \\
\hline $\mathrm{L} 1,180^{\circ}$ & 1457.55 & 57.384 & $*$ & $*$ & N/A & N/A \\
\hline $\mathrm{L} 1,225^{\circ}$ & 1457.88 & 57.397 & $*$ & $*$ & N/A & N/A \\
\hline $\mathrm{L} 1,270^{\circ}$ & 1457.58 & 57.385 & $*$ & * & N/A & N/A \\
\hline $\mathrm{L} 1,315^{\circ}$ & 1458.52 & 57.422 & * & * & N/A & N/A \\
\hline
\end{tabular}


Table E 4.1: HHV H1224A Container Body Inspection Data

\begin{tabular}{|l|c|l|l|l|l|l|}
\hline \multirow{2}{*}{$\begin{array}{c}\text { Measurement } \\
\text { Designation }\end{array}$} & \multicolumn{2}{|c|}{ Pre-Test } & \multicolumn{2}{c|}{ Post-Test } & \multicolumn{2}{c|}{ Measurement Change } \\
\cline { 2 - 7 } & $(\mathrm{mm})$ & $(\mathrm{in})$. & $(\mathrm{mm})$ & $(\mathrm{in})$. & \multicolumn{1}{c|}{$(\mathrm{mm})$} & \multicolumn{1}{c|}{ (in.) } \\
\hline \hline $\mathrm{L} 2,0^{\circ}$ & 1343.10 & 52.878 & $*$ & $*$ & N/A & N/A \\
\hline $\mathrm{L} 2,45^{\circ}$ & 1338.61 & 52.701 & $*$ & $*$ & N/A & N/A \\
\hline $\mathrm{L} 2,90^{\circ}$ & 1338.58 & 52.700 & $*$ & $*$ & N/A & N/A \\
\hline $\mathrm{L} 2,135^{\circ}$ & 1340.31 & 52.768 & $*$ & $*$ & N/A & N/A \\
\hline $\mathrm{L} 2,180^{\circ}$ & 1342.06 & 52.837 & $*$ & $*$ & N/A & N/A \\
\hline $\mathrm{L} 2,225^{\circ}$ & 1341.09 & 52.799 & $*$ & $*$ & N/A & N/A \\
\hline $\mathrm{L} 2,270^{\circ}$ & 1341.35 & 52.809 & $*$ & $*$ & N/A & N/A \\
\hline $\mathrm{L} 2,315^{\circ}$ & 1341.70 & 52.823 & $*$ & $*$ & N/A & N/A \\
\hline
\end{tabular}

* Part destroyed during test and measurement not possible.

Table E 4.2: HHV Inner Container Inspection Data

\begin{tabular}{|l|l|l|l|l|l|l|}
\hline \multirow{2}{*}{$\begin{array}{c}\text { Measurement } \\
\text { Designation }\end{array}$} & \multicolumn{2}{|c|}{ Pre-Test } & \multicolumn{2}{c|}{ Post-Test } & \multicolumn{2}{c|}{ Measurement Change } \\
\cline { 2 - 7 } & $(\mathrm{mm})$ & $(\mathrm{in})$. & $(\mathrm{mm})$ & $(\mathrm{in})$. & \multicolumn{1}{c|}{$(\mathrm{mm})$} & \multicolumn{1}{c|}{$(\mathrm{in})}$. \\
\hline \hline OD 0, $0^{\circ}$ & 520.83 & 20.505 & 527.51 & 20.768 & -6.68 & -0.263 \\
\hline OD 0,60 & 517.53 & 20.375 & 528.32 & 20.800 & -10.80 & -0.425 \\
\hline OD 0, 120 & 517.63 & 20.379 & 513.97 & 20.235 & 3.66 & 0.144 \\
\hline OD 11.38, $0^{\circ}$ & 518.57 & 20.416 & 470.05 & 18.506 & 48.51 & 1.910 \\
\hline OD 11.38, 60 & 517.42 & 20.371 & 528.35 & 20.801 & -10.92 & -0.430 \\
\hline OD 11.38, 120 & 517.58 & 20.377 & 539.39 & 21.236 & -21.82 & -0.859 \\
\hline OD 17.38, $0^{\circ}$ & 520.22 & 20.481 & 400.53 & 15.769 & 119.68 & 4.712 \\
\hline OD 17.38, 60 & 518.08 & 20.397 & 507.90 & 19.996 & 10.19 & 0.401 \\
\hline OD 17.38, 120 & 518.24 & 20.403 & 506.91 & 19.957 & 11.33 & 0.446 \\
\hline OD 23.38, $0^{\circ}$ & 519.05 & 20.435 & 469.52 & 18.485 & 49.53 & 1.950 \\
\hline
\end{tabular}


Table E 4.2: HHV Inner Container Inspection Data

\begin{tabular}{|c|c|c|c|c|c|c|}
\hline \multirow{2}{*}{$\begin{array}{l}\text { Measurement } \\
\text { Designation }\end{array}$} & \multicolumn{2}{|c|}{ Pre-Test } & \multicolumn{2}{|c|}{ Post-Test } & \multicolumn{2}{|c|}{ Measurement Change } \\
\hline & $(\mathrm{mm})$ & (in.) & $(\mathrm{mm})$ & (in.) & $(\mathrm{mm})$ & (in.) \\
\hline OD $23.38,60^{\circ}$ & 517.17 & 20.361 & 465.66 & 18.333 & 51.51 & 2.028 \\
\hline OD 23.38, $120^{\circ}$ & 517.09 & 20.358 & $5(2.21$ & 19.772 & 14.88 & 0.586 \\
\hline OD 38.75, $0^{\circ}$ & 518.74 & 20.423 & 483.46 & 19.034 & 35.28 & 1.389 \\
\hline OD $38.75,60^{\circ}$ & 517.53 & 20.375 & 595.58 & 23.448 & .78 .05 & -3.073 \\
\hline OD $38.75,120^{\circ}$ & 517.63 & 20.379 & 531.24 & 20.915 & -13.61 & -0.536 \\
\hline $\mathrm{L} 1,0^{\circ}$ & 986.23 & 38.828 & 982.68 & 38.688 & 3.56 & 0.140 \\
\hline $\mathrm{L} 1,60^{\circ}$ & 986.71 & 38.847 & 974.72 & 38.375 & 11.99 & 0.472 \\
\hline $\mathrm{L} 1,120^{\circ}$ & 987.12 & 38.863 & 971.55 & 38.250 & 15.57 & 0.613 \\
\hline $\mathrm{L} 1,180^{\circ}$ & 987.15 & 38.864 & 960.45 & 37.813 & 26.70 & 1.051 \\
\hline $\mathrm{L} 1,240^{\circ}$ & 987.04 & 38.860 & 966.80 & 38.063 & 20.24 & 0.797 \\
\hline $\mathrm{L} 1,300^{\circ}$ & 987.04 & 38.860 & 979.50 & 38.563 & 7.54 & 0.297 \\
\hline
\end{tabular}

Table E 4.3: HHV RV, Fore, and Aft Cover Inspection Data

\begin{tabular}{|l|l|l|l|l|l|l|}
\hline \multirow{2}{*}{$\begin{array}{c}\text { Measurement } \\
\text { Designation }\end{array}$} & \multicolumn{2}{|c|}{ Pre-Test } & \multicolumn{2}{c|}{ Post-Test } & \multicolumn{2}{c|}{ Measurement Change } \\
\cline { 2 - 7 } & $(\mathrm{mm})$ & $(\mathrm{in})$. & $(\mathrm{mm})$ & $(\mathrm{in})$. & \multicolumn{1}{c|}{$(\mathrm{mm})$} & \multicolumn{1}{c|}{ (in.) } \\
\hline \hline OD A, $0^{\circ}$ & 502.72 & 19.792 & $*$ & $*$ & N/A & N/A \\
\hline OD A, $60^{\circ}$ & 502.92 & 19.800 & 508.97 & 20.038 & -6.05 & -0.238 \\
\hline OD A, $120^{\circ}$ & 502.56 & 19.786 & 507.11 & 19.965 & -4.55 & -0.179 \\
\hline ID B, $0^{\circ}$ & 426.21 & 16.780 & 345.44 & 13.600 & 80.77 & 3.180 \\
\hline ID B, $60^{\circ}$ & 426.26 & 16.782 & 441.96 & 17.400 & -15.70 & -0.618 \\
\hline ID B, $120^{\circ}$ & 426.36 & 16.786 & 462.28 & 18.200 & -35.92 & -1.414 \\
\hline ID C, $0^{\circ}$ & 490.88 & 19.326 & 454.18 & 17.881 & 36.70 & 1.445 \\
\hline ID C, $60^{\circ}$ & 490.68 & 19.318 & 520.85 & 20.506 & -30.18 & -1.188 \\
\hline
\end{tabular}


Table E 4.3: HHV RV, Fore, and Aft Cover Inspection Data

\begin{tabular}{|c|c|c|c|c|c|c|}
\hline \multirow{2}{*}{$\begin{array}{l}\text { Measurement } \\
\text { Designation }\end{array}$} & \multicolumn{2}{|c|}{ Pre-Test } & \multicolumn{2}{|c|}{ Post-Test } & \multicolumn{2}{|c|}{ Measurement Change } \\
\hline & $(\mathrm{mm})$ & (in.) & $(\mathrm{mm})$ & (in.) & $(\mathrm{mm})$ & (in.) \\
\hline ID C, $120^{\circ}$ & 490.32 & 19.304 & 514.60 & 20.260 & -24.28 & -0.956 \\
\hline $\mathrm{L} 2,0^{\circ}$ & 234.87 & 9.247 & 227.20 & 8.945 & 7.67 & 0.302 \\
\hline $\mathrm{L} 2,60^{\circ}$ & 235.25 & 9.262 & 210.31 & 8.280 & 24.94 & 0.982 \\
\hline $\mathrm{L} 2,120^{\circ}$ & 235.48 & 9.271 & 226.70 & 8.925 & 8.79 & 0.346 \\
\hline $\mathrm{L} 2,180^{\circ}$ & 235.25 & 9.262 & 224.41 & 8.835 & 10.85 & 0.427 \\
\hline $\mathrm{L} 2,240^{\circ}$ & 234.87 & 9.247 & 224.16 & 8.825 & 10.72 & 0.422 \\
\hline $\mathrm{L} 2,300^{\circ}$ & 234.62 & 9.237 & 227.08 & 8.940 & 7.54 & 0.297 \\
\hline $\mathrm{OD} \mathrm{B}, 0^{\circ}$ & 431.55 & 16.990 & * & * & N/A & N/A \\
\hline OD B, $60^{\circ}$ & 431.50 & 16.988 & 433.43 & 17.064 & -1.93 & -0.076 \\
\hline $\mathrm{OD} \mathrm{B}, 120^{\circ}$ & 431.32 & 16.981 & 432.54 & 17.029 & -1.22 & -0.048 \\
\hline ID D, $0^{\circ}$ & 165.74 & 6.525 & 166.47 & 6.554 & -0.74 & -0.029 \\
\hline ID D, $60^{\circ}$ & 165.74 & 6.525 & 169.95 & 6.691 & -4.22 & -0.166 \\
\hline $\mathrm{ID} \mathrm{D}, 120^{\circ}$ & 165.74 & 6.525 & 170.21 & 6.701 & -4.47 & -0.176 \\
\hline $\mathrm{L} 1,0^{\circ}$ & 840.77 & 33.101 & * & * & N/A & N/A \\
\hline $\mathrm{L} 1,60^{\circ}$ & 840.74 & 33.100 & 846.33 & 33.320 & -5.59 & -0.22 \\
\hline $\mathrm{L} 1,120^{\circ}$ & 840.74 & 33.100 & 841.07 & 33.113 & -0.033 & -0.013 \\
\hline $\mathrm{L} 1,180^{\circ}$ & 840.79 & 33.102 & * & * & N/A & N/A \\
\hline $\mathrm{Ll}, 240^{\circ}$ & 840.79 & 33.102 & 838.99 & 33.031 & 1.80 & 0.071 \\
\hline $\mathrm{L} 1,300^{\circ}$ & 840.74 & 33.100 & 842.54 & 33.171 & -1.80 & -0.071 \\
\hline OD D, $0^{\circ}$ & 171.20 & 6.740 & 170.87 & 6.727 & 0.33 & 0.013 \\
\hline OD D, $60^{\circ}$ & 171.20 & 6.740 & 171.40 & 6.748 & -0.20 & -0.008 \\
\hline $\mathrm{OD} \mathrm{D}, 120^{\circ}$ & 171.17 & 6.739 & 171.45 & 6.750 & -0.28 & -0.011 \\
\hline $\mathrm{OD} \mathrm{E}, 0^{\circ}$ & 482.88 & 19.011 & 470.41 & 18.520 & 12.47 & 0.491 \\
\hline $\mathrm{OD} \mathrm{E}, 60^{\circ}$ & 482.85 & 19.010 & 483.29 & 19.027 & -0.43 & -0.017 \\
\hline
\end{tabular}


Table E 4.3: HHV RV, Fore, and Aft Cover Inspection Data

\begin{tabular}{|l|c|c|c|c|c|c|}
\hline \multirow{2}{*}{$\begin{array}{c}\text { Measurement } \\
\text { Designation }\end{array}$} & \multicolumn{2}{|c|}{ Pre-Test } & \multicolumn{2}{c|}{ Post-Test } & \multicolumn{2}{c|}{ Measurement Change } \\
\cline { 2 - 8 } & $(\mathrm{mm})$ & (in.) & $(\mathrm{mm})$ & $($ in. $)$ & $(\mathrm{mm})$ & (in.) \\
\hline \hline OD E, $120^{\circ}$ & 482.85 & 19.010 & 483.41 & 19.032 & -0.56 & -0.022 \\
\hline
\end{tabular}

* Part destroyed during test and measurement not possible. 


\section{Distribution List}

No. of

Copies

1 Director, Defense Nuclear Agency

ATTN: CSTI

6801 Telegraph Road

Alexandria, VA 22310-3398

1 Director, Defense Nuclear Agency

ATTN: Kenneth Stein

6801 Telegraph Road

Alexandria, VA 22310-3398

1 Director, Defense Nuclear Agency

ATTN: Martin Fuentes

6801 Telegraph Road

Alexandria, VA 22310-3398

1 Weidlinger Associates

ATTN: J. Isenberg and H. Levine

4410 El Camino Real, Suite 110

Los Altos, CA 94022

1 Logicon RDA

ATTN: Steve Woodford

6940 South Kings Highway, Suite 210

Alexandria, VA 22310

1 Director, Defense Nuclear Agency

ATTN: Wayne Andrews

6801 Telegraph Road

Alexandria, VA 22310-3398

1 Director, Defense Nuclear Agency

ATTN: Jack Deplitch

6801 Telegraph Road

Alexandria, VA 22310-3398

1 DASAIC

816 State Street

P.O. Drawer QQ

Santa Barbara, CA 93102

1 U. S. Department of Energy

Albuquerque Operations Office

Albuquerque Headquarters

Attn: H. T. Season

R. O. Gergen

P. O. Box 5400

Albuquerque, NM 87115

1 Defense Technical Information Center Cameron Station

Alexandria, VA 22304-6145 
Internal Distribution:

No. of

Copies

$\begin{array}{rll}1 & \text { MS } 0631 & \text { R. L. Schwoebel, 12300 } \\ 1 & \text { MS } 0490 & \text { P. E. D'Antonio, 12324 } \\ 1 & \text { MS } 0491 & \text { R. E. Smith, 12333 } \\ 1 & \text { MS 0491 } & \text { C. G. Shirley, 12333 } \\ 1 & \text { MS } 0490 & \text { NSIC File SGD-8d2a|Container Testingl } \\ 1 & \text { MS } 0479 & \text { D. C. Tipton, 5151 } \\ 1 & \text { MS } 0479 & \text { R. E. Davis, 5151 } \\ 1 & \text { MS } 0479 & \text { M. L. Kargel, 5151 } \\ 1 & \text { MS } 0724 & \text { D. L. Hartley, 6000 } \\ 1 & \text { MS } 0405 & \text { T. R. Jones, 6411 } \\ 1 & \text { MS } 0726 & \text { J. B. Woodard, 6600 } \\ 1 & \text { MS } 0726 & \text { L. E. Martin, 6600 } \\ 1 & \text { MS } 0715 & \text { R. E. Luna, 6603 } \\ & & \text { Attn: TTC Master File } \\ 15 & \text { MS } 0715 & \text { TTC Library, 6603 } \\ 1 & \text { MS } 0718 & \text { H. R. Yoshimura, 6641 } \\ 1 & \text { MS } 0718 & \text { J. D. Whitlow, 6641 } \\ 1 & \text { MS } 0717 & \text { G. F. Hohnstreiter, 6642 } \\ 1 & \text { MS } 0717 & \text { D. J. Ammerman, 6642 } \\ 1 & \text { MS } 0717 & \text { M. Arviso, 6642 } \\ 1 & \text { MS } 0717 & \text { J. G. Bobbe, 6642 } \\ 15 & \text { MS } 0717 & \text { D. C. Harding, 6642 } \\ 1 & \text { MS } 0717 & \text { J. D. Pierce, 6642 } \\ 1 & \text { MS } 0717 & \text { W. L. Uncapher, 6642 } \\ 1 & \text { MS } 0716 & \text { M. C. Brady, 6643 } \\ 1 & \text { MS } 0716 & \text { D. R. Stenberg, 6643 } \\ 5 & \text { MS } 0899 & \text { Technical Library, 7141 } \\ 1 & \text { MS } 0619 & \text { Technical Publications, 7151 } \\ 1 & \text { MS } 9018 & \text { Central Technical Files, 8523-2 } \\ 10 & \text { MS } 0100 & \text { Document Processing for DOE/OSTI, 7613-2 }\end{array}$



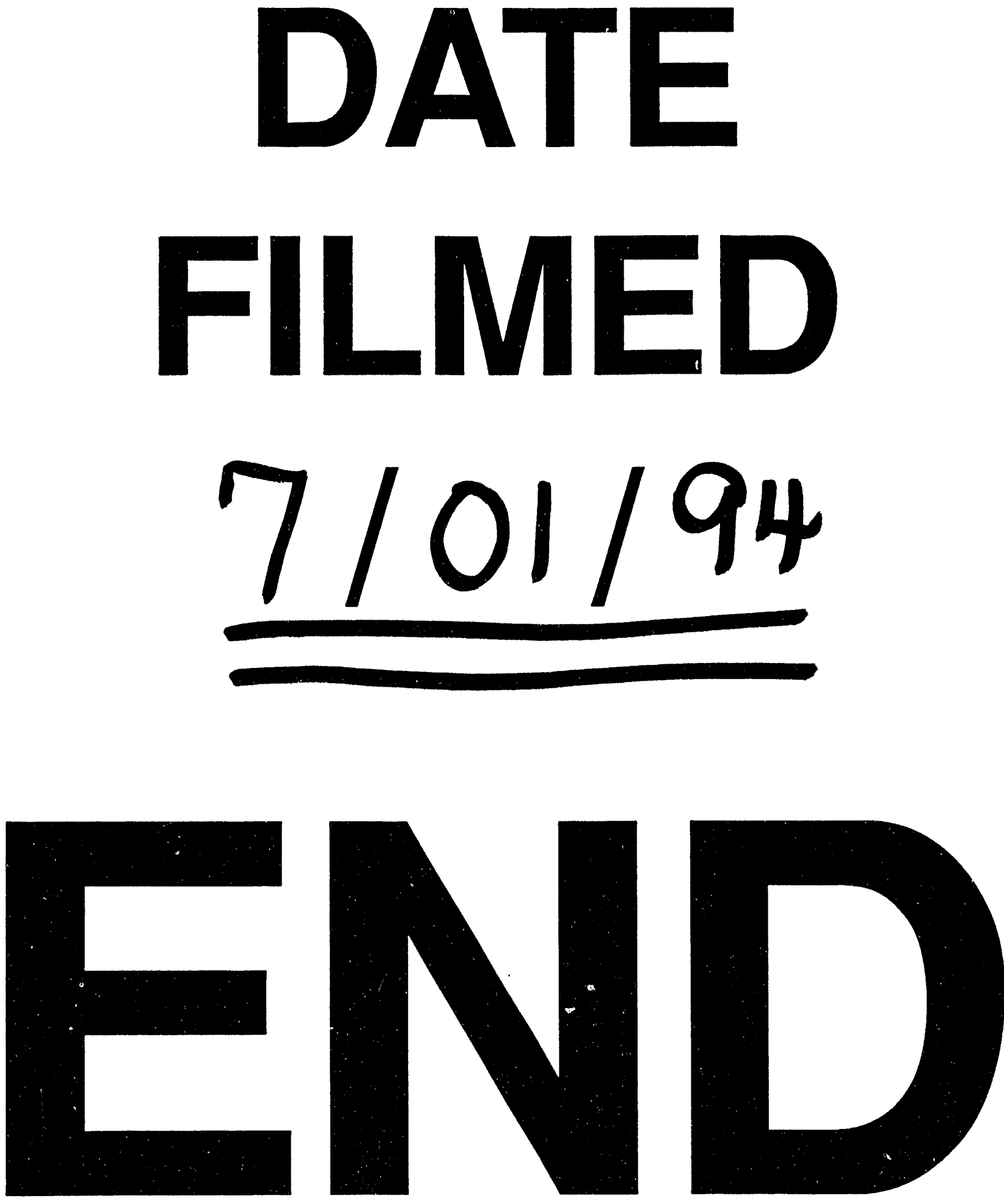
